\title{
Estudio de la prospección del uso de la fibra de tucumã-i (Astrocaryum acaule) para el desarrollo de productos semi-industriales
}

Tesis Doctoral

Karla Mazarelo Maciel Pacheco

Director: Prof. Dr. D. Bernabé Hernandis Ortuño

Valencia, 2012 



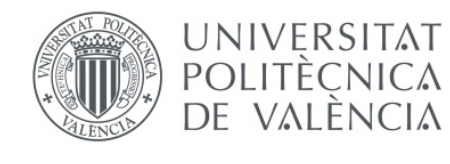

\author{
Universitat Politècnica de València \\ Escuela Técnica Superior de Ingeniería del Diseño \\ Departamento de Ingeniería Gráfica
}

\title{
Estudio de la prospección del uso de la fibra de tucumã-i (Astrocaryum acaule) para el desarrollo de productos semi-industriales \\ Programa de Doctorado: Diseño, Fabricación y Gestión de Proyectos Industriales
}



Tesis realizada bajo la dirección del profesor Dr. D. Bernabé Hernandis Ortuño en la Escuela Técnica Superior de Ingeniería del Diseño, a través del Departamento de Ingeniería Gráfica, de la Universitat Politècnica de València, y que para la obtención del grado de doctora presenta D. ${ }^{a}$ Karla Mazarelo Maciel Pacheco. 



\section{Dedicatoria}

A Dios que ilumina mi pensamiento y me da fortaleza.

A la memoria de mi Madre, desde donde te encuentres...

¡Este triunfo es para ti!

A mi esposo Almir de Souza Pacheco, una persona esplendida, a quién quiero mucho y deseo estar siempre a su lado.

A toda mi familia. 



\section{Agradecimientos}

En estas líneas quisiera manifestar de forma explícita mi agradecimiento a todas aquellas personas que directa e indirectamente han contribuido a la culminación de esta Tesis.

En primer lugar, y de forma sincera, profunda y afectuosa, a mi Director de Tesis, Dr. Bernabé Hernandis Ortuño, cuyo apoyo constante, motivación, paciencia, dedicación y sugerencias han sido fundamentales y determinantes para el desarrollo y finalización de este trabajo de investigación.

A mis compañeros de doctorado: Susana Paixão-Barradas, a quien considero una amiga y un apoyo en el desarrollo de la tesis, en la transferencia de información valiosa y, sobretodo en el trabajo realizado conjuntamente. A los amigos: Andrea Medina Gómez, John Jairo Cardozo Vásquez, Nélida Yaneth Ramírez Triana, José Rafael González Díaz, Elingth Simoné Rosales Marquina y Maurício Guerrero por su amistad, apoyo y confianza en los períodos más arduos y que me motivaron en la recuperación de la fuerza para seguir adelante en la culminación de este trabajo.

A Begoña Agudo por su paciencia, voluntad y colaboración en el análisis de los datos estadísticos.

Al Programa de Becas Euro Brazilian Windows - EBW, a través de la Universidad del Porto (UV), por concederme la oportunidad de cursar un doctorado en el área del Diseño en Europa.

Al equipo de la Oficina de Acción Internacional de la UPV, en especial a D. ${ }^{a}$ Begoña Lluzar Julian, $D^{a}$ Maria José Oltra y $D^{a}$ Geraldine Bustamante Reyes por su atenciosa disponibilidad en ayudar a los becarios del Programa EBW de Brasil. A mi compañero de beca Daniel Castro por toda ayuda dada en los momentos de dificuldades, principalmente cuanto a los procedimientos solicitados por el Programa de Becas para envio de documentaciones.

A Universidad Federal de Amazonas (UFAM), sobre todo al ex Director de la Facultad de Tecnología (FT), Prof. Dr. Waltair Vieira Machado y al Prof. Dr. Nelson Kuwahara por impulsarme el hecho de realizar estudios en otro país y al Departamento de Design \& Expressão Gráfica (DEG) por permitir a la calificación y a la formación de su equipo docente, visando la práctica de una mejor enseñanza y preparación académica de sus estudiantes.

A mis amigos de Brasil, especialmente a Rose Autran por ayudarme con preciosas orientaciones para venir a estudiar y vivir en Valencia, así como por presentarme a otra gran amiga Fernanda Parente que es como una hermana y que me ha dado un gran soporte durante esos años de estudios en el 
doctorado. Extendo el mismo sentimiento a sus padres, Valdenei y Fernando Parente, por su cariño y ayuda (transmitidos a mí y a mi esposo Almir), durante toda nuestra estancia en Valencia y, principalmente, por hacernos sentir como si fuéramos miembros de su familia. A vosotros mi eterna gratitud.

A todo mis compañeros diseñadores e investigadores de INPA (Dra. Claudete Catanhede, Ires Paula Miranda y Maria de Jesus Varejão), que se me enviarón sus positivas vibraciones para la conclusión de este trabajo, desde Manaus, a todo momento.

A mis ex alumnos Sharlene Melanie y Denis Solano por la ayuda para la obtención de informaciones importantes a esta investigación, desde Manaus/Amazonas/Brasil.

A todos los miembros de la comunidad indígena Tukano, en especial, a Maria das Dores y a Maria Gorete Fonseca, por la transferencia de conocimiento, respeto y confianza que se han despositados en mí. Hechos éstos, que me han motivado a la búsqueda de mayores informaciones con respecto a la fibra de tucumã-i (Astrocaryum acaule), con la intención de valorarla y divulgarla a como recurso natural de la Amazonía con potencial para el desarrollo de nuevos productos.

Quisiera reconocer todo el apoyo y cariño de mi padre José Nogueira Maciel, mis padrinos Antonio y Evangelina Gama y mis hermanos Marcos y Marcel.

A mi amable e incansable tía Leila Ferreira - a quién, con sus consejos, pujanza y dedicación me ha dado mucha fortaleza durante estos años de estudios lejos de mi tierra.

A mis primos, sobrinos y tíos por todo su cariño, oraciones e incentivo.

A mi amado esposo Almir de Souza Pacheco - a quién es mi puerto seguro y mi vida! Por toda su paciencia, cariño y ayuda en los momentos dificiles. iTE $\mathrm{AMO}$ !

A Dios y la Virgen María por estar siempre presentes en mi vida, dándome fortaleza, salud, paz de espíritu y perseverancia para alcanzar mis sueños como ser humano y profesional.

¡Muchísimas Gracias!

Muito obrigada! 
Estudio de la prospección del uso de la fibra de tucumã-i (Astrocaryum acaule) para el desarrollo de productos semi-industriales

"Algo sólo es imposible hasta que alguien lo duda y acaba probando lo contrario." Albert Einstein 



\section{Resumen}

La fibra de tucumã-i (Astrocaryum acaule) es un recurso natural vegetal de la Amazonía brasileña, poco explotado y conocido. Se caracteriza por su producción sostenible y la posibilidad de generar diversas tipologías de productos: textiles, elementos domésticos y/o decorativos. Sin embargo, no existen datos con respecto a su aplicación en productos mediante el uso de procesos de fabricación avanzados de tipo semi-industrial. Los pocos registros existentes, que describen las prácticas desarrolladas con esta fibra, se remiten al ámbito empírico y artesanal. La investigación realizada en esta tesis se basa en diversos estudios sobre la opinión de los expertos, diseñadores y consumidores, así como sobre la influencia de los aspectos relevantes a considerar desde sus diferentes puntos de vista y de la valoración que hacen de los atributos del diseño y su trazabilidad hasta la generación final de productos. Mediante compendio de artículos se presentan las diferentes aportaciones en forma de publicaciones en actas de congresos y revistas de investigación, en la que podemos destacar el estudio de mercado realizado desde la perspectiva del soporte técnico-científico del diseño, pudiéndose validar los atributos de innovación y diferenciación ofrecidos por la fibra, justificando su posible adaptación a una técnica más evolucionada y estudiando la viabilidad sobre nuevas formas de uso. El estudio correspondiente al empleo de la fibra natural de tucumã-i (Astrocaryum acaule) para el desarrollo de productos semi-industriales, utilizó el ámbito del diseño y herramientas habituales en sus procesos de investigación para la obtención de información que identificara los posibles caminos a seguir, análisis de la problemática, búsqueda de oportunidades y detección de limitaciones en el contexto investigado, siempre con el objeto de considerar aquellos aspectos importantes y competitivos que posibiliten el alcance de nuevos mercados, en áreas correlacionadas y afines. También se detecta mediante el uso de la metodología sistémica la problemática en cuanto a la implementación de las propuestas de inserción de procesos semi-industriales desde las comunidades que explotan los recursos naturales. Cabe destacar los diferentes proyectos de investigación que se inician en Brasil a partir de los resultados de las publicaciones de los artículos generados en esta tesis.

\section{Palabras clave:}

Fibra natural Amazónica, Estudio de mercado, Proceso semi-industrial, Diseño de producto, Sistémica.

\section{Líneas de investigación:}

Diseño, Gestión y Fabricación de Proyectos Industriales vinculados al uso de las fibras naturales amazónicas. 



\begin{abstract}
The tucumã-i fibre (Astrocaryum acaule) is a natural plant of the Brazilian Amazon untapped and a little bit known. It is characterized by sustainable production and the ability to generate various types of products: textiles, household items and / or decorative. However, no data regarding its application in products using advanced manufacturing semi-industrial processes. The few existing records that describe the practices developed with this fiber are referred to the empirical scope and craft. This research is based on several studies on expert opinion, designers and consumers, as well as the influence of the relevant aspects to be considered from different points of view and their assessment of the attributes of design and their traceability to the final generation of products. Through a compendium of articles by the different contributions are presented in the form of publications in conference proceedings and journals, in which we highlight the market study from the perspective of technical and scientific support of the design, being able to validate the attributes of innovation and differentiation offered by fiber, justifying their possible adaptation to a more advanced technique and studying the feasibility of new forms of use. The study for using of the natural fiber of tucuman-i (Astrocaryum acaule) for the development of semi-industrial products, used the area of design and standard tools in their research process to obtain information to identify possible paths to follow, analyzing problems, finding opportunities and detection of limits in context investigated, always with the purpose of considering those important and competitive aspects that facilitate the reach of new markets and related areas. It's also examined, by using the systemic methodology, the problem related to putting into practice the proposal for inclusion of semi-industrial processes in this context, from the communities that use natural resources. It's worth noting the various research projects that begin in Brazil from the results of the publications of the articles produced in this work.
\end{abstract}

\title{
Keywords:
}

Natural fiber of Amazonian, Research market, Semi-industrial process, Product design, Systemic.

Research lines:

Design, Management and Manufacturing of Industrial Projects linked to using of natural fibers Amazon. 



\section{Resum}

La fibra de tucumã-i (Astrocaryum acaule) és un recurs natural vegetal de l'Amazònia brasilera, poc explotat i conegut. Es caracteritza per la seva producció sostenible $\mathrm{i}$ la possibilitat de generar diverses tipologies de productes: tèxtils, elements domèstics i/o decoratius. No obstant això, no hi ha dades respecte a la seva aplicació en productes mitjançant l'ús de processos de fabricació avançats de tipus semi-industrial. Els pocs registres existents, que descriuen les pràctiques desenvolupades amb aquesta fibra, es remeten a l'àmbit empíric i artesanal. La investigació realitzada en aquesta tesi es basa en diversos estudis sobre l'opinió dels experts, dissenyadors i consumidors, així com sobre la influència dels aspectes rellevants a considerar des dels seus diferents punts de vista i de la valoració que fan dels atributs del disseny i la seva traçabilitat fins a la generació final de productes. Mitjançant un compendi d'articles, es presenten les diferents aportacions en forma de publicacions en actes de congressos i revistes d'investigació, en la qual podem destacar l'estudi de mercat realitzat des de la perspectiva del suport tècnic-científic del disseny, podent validar els atributs d'innovació $\mathrm{i}$ diferenciació oferts per la fibra, justificant la seva possible adaptació a una tècnica més evolucionada i estudiant la viabilitat sobre noves formes d'ús. L'estudi corresponent a l'ús de la fibra natural de tucumã-i (Astrocaryum acaule) per al desenvolupament de productes semi-industrials, va utilitzar l'àmbit del disseny $i$ eines habituals en els seus processos de recerca per a l'obtenció d'informació que identifiqués els possibles camins a seguir, anàlisi de la problemàtica, recerca d'oportunitats i detecció de limitacions en el context investigat, sempre amb l'objecte de considerar aquells aspectes importants $\mathrm{i}$ competitius que possibilitin l'abast de nous mercats, en àrees correlacionades $i$ afins. També es detecta mitjançant l'ús de la metodologia sistèmica la problemàtica pel que fa a la implementació de les propostes d'inserció de processos semi-industrials des de les comunitats que exploten els recursos naturals. Cal destacar els diferents projectes de recerca que s'inicien al Brasil a partir dels resultats de les publicacions dels articles generats en aquesta tesi.

\section{Paraules clau:}

Fibra natural Amazònica, Estudi de mercat, Procés semi-industrial, Disseny de producte, Sistèmica.

\section{Línies de recerca:}

Disseny, Gestió i Fabricació de Projectes Industrials vinculats a l'ús de les fibres naturals amazòniques. 



\section{Resumo}

A fibra de tucumã-i (Astrocaryum acaule) é um recurso natural vegetal da Amazônia brasileira, pouco explorado e conhecido. Caracteriza-se por sua produção sustentável e pela possibilidade de gerar diversos tipos de produtos: têxteis, utensílios domésticos e/ou decorativos. No entanto, não existem de dados registrados quanto a sua aplicação em produtos mediante o uso de processos de fabricação avançados de caráter semi-industrial. Os poucos registros existentes, que descrevem as práticas desenvolvidas com esta fibra, se remetem ao âmbito empírico e artesanal. A investigação, ora realizada nesta tese tem como base diversos estudos sobre a opinião de experts, designers e consumidores, assim como sobre a influência dos aspectos relevantes a considerar desde seus diferentes pontos de vista e de valoração que fazem dos atributos do design e sua relação de decisões até a geração final de produtos. Mediante a um compêndio de artigos, são apresentadas as diferentes contribuições em forma de publicações em atas de congressos e revistas de investigação, na qual se pode destacar o estudo de mercado realizado desde a perspectiva do suporte técnico-científico do design, validando-se os atributos de inovação e diferencial oferecidos pela fibra, justificando-se sua possível adaptação a uma técnica mais evoluída e estudando a sua viabilidade para novas formas de uso. 0 estudo correspondente ao emprego da fibra natural de tucumã-i (Astrocaryum acaule) para o desenvolvimento de produtos semi-industriais, utilizou o campo do design e ferramentas habituais nos seus processos de investigação para a obtenção de informação que identificam os possíveis caminhos a seguir, análise da problemática, pesquisa de oportunidades e detecção de limitações no contexto investigado, sempre com o intuito de considerar aqueles aspectos importantes e competitivos que possibilitem o alcance de novos mercados, em áreas correlacionadas e afins. Também se examina mediante o uso da metodologia sistêmica a problemática relacionada à por em prática a proposta de inserção de processos semi-industriais desde as comunidades que utilizam os recursos naturais. Cabe destacar os diferentes projetos de investigação que se iniciam no Brasil a partir dos resultados das publicações dos artigos produzidos neste trabalho.

\section{Palavras chave:}

Fibra natural Amazônica, Estudo de mercado, Processo semi-industrial, Design de produto, Sistêmica.

\section{Linhas de investigação:}

Design, Gestão e Fabricação de Projetos Industriais vinculados à utilização das fibras naturais amazônicas. 



\section{Tesis por compendio de publicaciones}

La tesis es un trabajo de creación inédita, una investigación rigurosa, un trabajo de producción científica, marco inicial de la especialidad de un investigador (Pujol, 1992). Constituyéndose en una fuente de información que refleja el logro en su propio campo del saber, estando directamente relacionado con la búsqueda y a la transmisión del conocimiento a través de la información documentada, donde es de gran importancia la recopilación y al análisis de datos para el origen de la producción científica.

Con el ritmo actual de la transmisión del conocimiento, las Universidades y las Instituciones Profesionales y de Investigación de alto nivel han aceptado el papel de preparar a los futuros científicos y conceder el grado de Doctor a aquellos que demuestren ser capacitados para llevar a cabo investigaciones de alta calidad (Nascimento, 2000) y cuya producción científica sea una práctica habitual de la publicación de los resultados de las búsquedas que van surgiendo durante el desarrollo de las tesis doctorales, componiendo un trabajo original de investigación, que no siempre es totalmente inédito.

Basado en esta información, el Estudio de la prospección de la fibra natural amazónica de tucumã-i (Astrocaryum acaule) para el desarrollo de productos semi-industriales se presenta en forma de un documento estructurado por compendio de artículos previamente publicados, aceptados y en evaluación para publicación, guardando relación entre sí. Los artículos poseen calidad contrastada, demostrada por el potencial atribuido al tema del estudio en revistas, congresos y eventos de naturaleza centrada en los aspectos de: diseño, enseñanza, gestión, desarrollo y fabricación de productos, así como en base al prestigio de la publicación en que han sido insertados.

La presentación del documento, en esta especificidad, buscó estar de acuerdo con las normativas de estudio establecidas por el Programa de Doctorado en Diseño, Fabricación y Gestión de Proyectos Industriales de la Escuela Técnica Superior de Ingeniería de Diseño - ETSID perteneciente a la Universitat Politècnica de València - UPV, de acuerdo con sus líneas de investigación, mediante la oportuna tramitación ofrecida dentro de su organización funcional y aprobación de la propuesta del Proyecto de Tesis por la dirección y la Comisión de Doctorado de esta Universidad. 



\section{Autorización del Director de Tesis para su presentación}

Dr. Bernabé Hernandis Ortuño como Director de la Tesis Doctoral: Estudio de la prospección de la fibra natural amazónica de tucumã-i (Astrocaryum acaule) para el desarrollo de productos semi-industriales, realizada en el Programa de Doctorado en Diseño, Fabricación y Gestión de Proyectos Industriales del Departamento de Ingeniería Gráfica de la Escuela Técnica Superior de Ingeniería del Diseño - ETSID de la Universitat Politècnica de València - UPV, Valencia/España, por la Doctoranda Doña Karla Mazarelo Maciel Pacheco, AUTORIZO la presentación de la citada Tesis Doctoral, desarrollada en la modalidad "Tesis por compendio de publicaciones", dado que el documento de investigación reúne las condiciones necesarias para su defensa.

En Valencia a de de 2012

EL DIRECTOR DE LA TESIS

Fdo:_ Dr. Bernabé Hernandis Ortuño 



\section{Tribunal de Evaluación}

\section{EL PRESIDENTE}

Fdo:_ Dr. Gabriel Songel González Universitat Politècnica de València- UPV/ ESPAÑA

\section{LA SECRETÁRIA}

Fdo:_ Dra. Susana Paixão Barradas Universitat Politècnica de València- UPV/ESPAÑA

LOS VOCALES TITULARES

Fdo:_ Dra. Ruth León Morán Universidad de Los Andres - ULA/VENEZUELA

Fdo:_ Dr. Ismael Quintanilla Pardo Universitat de València- UV/ESPAÑA

Fdo:_ Dr. José Luís Navarro Lizandra Universitat Jaume I de Castelló - ESPAÑA 



\section{Índice}

1. Introducción............................................................45

1.1. Motivación de la investigación.........................................45

1.2. Contextualización del tema............................................46

1.3. Problema identificado ...............................................48

1.4. Objetivos de la investigación .........................................50

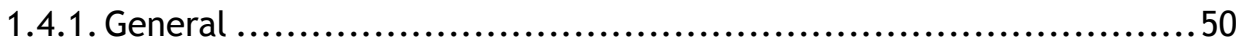

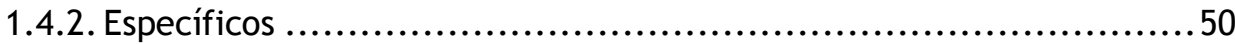

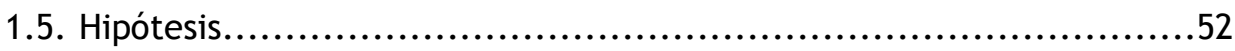

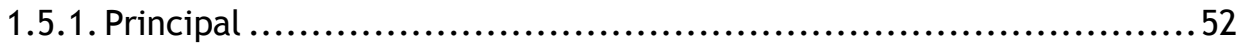

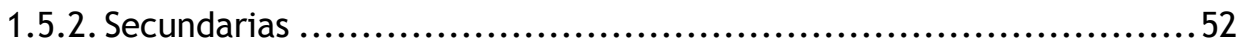

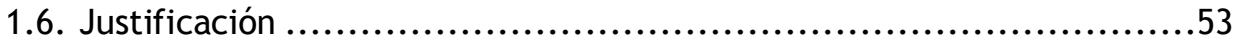

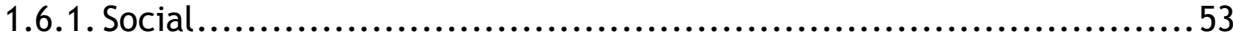

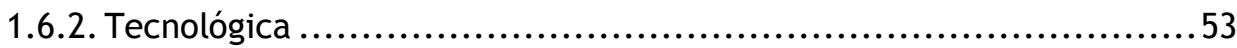

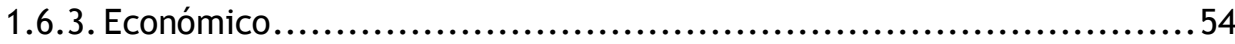

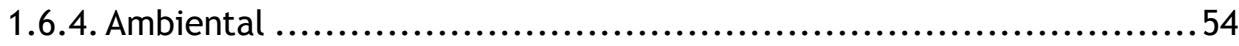

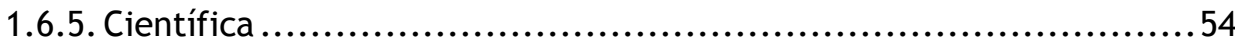

1.7. Delimitación de la investigación ......................................55

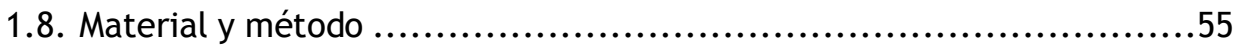

1.8.1. Tipo de la investigación ............................................55

1.8.2. Tipo y diseño general del estudio ..................................56

1.8.3. Universo de estudio, selección y tamaño de muestra....................57

1.8.4. Procedimientos para la captación de datos, instrumentos a utilizar y métodos para el control y calidad de estos. ................................57

a. Dinámica de grupo focal................................................ 58

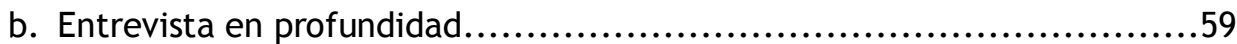

c. Encuesta a la población objetivo .....................................60 
Estudio de la prospección del uso de la fibra de tucumã-i (Astrocaryum acaule) para el desarrollo de productos semi-industriales

d. Procedimientos para garantizar los aspectos éticos de las investigaciones con sujetos humanos ..................................................62

1.8.5. Análisis y validación de los resultados ...............................63

a. Método DAFO para el grupo focal y la entrevista en profundidad ..........63

b. Modelo del Diseño concurrente para la sistematización de las informaciones pertinentes a la aplicación del objeto de estudio para el desarrollo de productos semi-industriales

c. Aplicación del Statistical Package for the Social Sciences (SPSS) para el estudio y análisis de los datos estadísticos................................65

1.8.6. Estructura planeada para el desarrollo de los artículos para la producción de la tesis por compendio de publicaciones.......................66

1.9. Estructura de la tesis................................................71

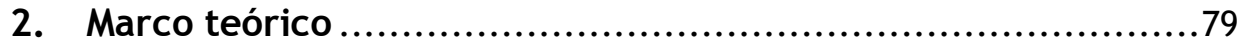

2.1. El uso de las fibras vegetales para el desarrollo de productos ............79

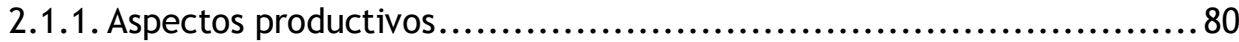

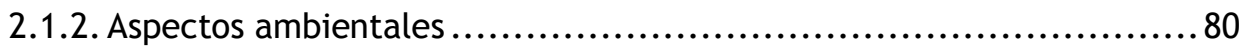

2.1.3. Aspectos sociales ................................................. 80

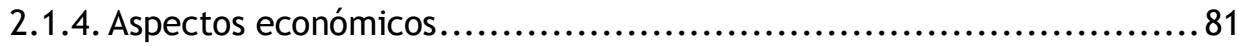

2.1.5. Aspectos mercadológicos .......................................... 81

2.2. La busca por nuevas fibras naturales para la innovación y competitividad

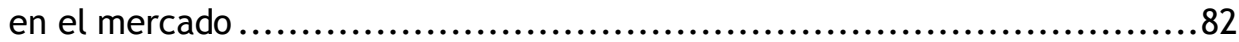

2.3. La fibra natural de tucumã-i (Astrocaryum acaule) .......................83

2.3.1. Aspectos socio-cultural y eco sostenible ............................. 85

2.3.2. Aspecto productivo y proceso tecnológico aplicados a la fibra............86

2.3.3. Propiedades tecnológicas comparadas a otras fibras similares...........86 86

2.3.4. Situación del mercado ............................................ 88

2.4. La posibilidad de nuevas tecnologías y transferencia de conocimiento para la mejora del proceso de transformación de las fibras naturales para el desarrollo de productos ........................................................ 89

2.4.1. Procesos tecnológicos ............................................. 90

2.4.2. Transferencia de conocimiento .................................... 91 
2.4.3. Del aspecto artesanal al semi-industrial............................. 92

2.5. El diseño como factor estratégico para la sistematización de informaciones sobre el uso de la fibra natural de tucumã-i (Astrocaryum acaule) para la gestión, desarrollo y fabricación de productos semi-

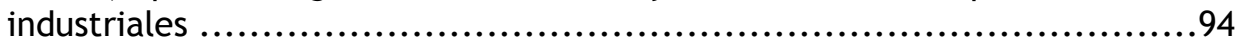

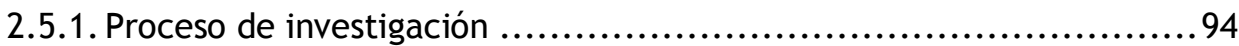

a. Identificación de las oportunidades y límites del producto para su inserción en el mercado ............................................................95

b. Estudio de mercado (consulta de opiniones/ expertos/ consumidor) .......95

c. Identificación de los atributos necesarios para diseño del producto ........96

d. Sistematización de los datos..........................................97

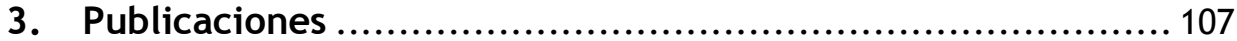

3.1. Artículo 1 - Análisis del posicionamiento del diseño cuanto al uso semiindustrial de la fibra amazónica de tucumã-i (Astrocaryum acaule) para la fabricación de productos ............................................... 107

3.2. Artículo 2 - Análisis sobre el posicionamiento de los expertos cuanto al uso de la fibra natural amazónica tucumã-i (Astrocaryum acaule) para el desarrollo de productos semi-industriales 113

3.3. Artículo 3 - Atributos del diseño para el proceso de transformación y uso de la fibra natural amazónica de tucumã-i (Astrocaryum acaule) para el desarrollo de productos semi-industriales 139

3.4. Artículo 4 - Oportunidades y limitaciones del uso de la fibra natural de tucumã-i (Astrocaryum acaule) para la gestión y desarrollo de productos semiindustriales 157

3.5. Artículo 5 - Análisis de la apreciación de los consumidores sobre el uso semi-industrial de la fibra vegetal amazónica de tucumã-i (Astrocaryum acaule) para el desarrollo de productos: Un estudio de mercado 179

3.6. Artículo 6 - Fibra vegetal amazónica de tucumã-i (Astrocaryum acaule) para la aplicación textil: Un análisis de opiniones. 199

3.7. Artículo 7 - Atributos necesarios a la fabricación de productos semiindustriales a partir del uso de la fibra natural amazónica de tucumã-i (Astrocaryum acaule): Una segmentación de mercado 211

3.8. Artículo 8 - La importancia del diseño sistémico para la competitividad de la fibra natural Amazónica de tucumã-i (Astrocaryum acaule) en el desarrollo 
Estudio de la prospección del uso de la fibra de tucumã-i (Astrocaryum acaule) para el desarrollo de productos semi-industriales

semi-industrial de productos: Un estudio de caso para la categoría del vestuario ............................................................ 231

3.9. Artículo 9 - Variables esenciales y aspectos del diseño considerados importantes al uso y beneficio de la fibra natural amazónica de tucumã-i (Astrocaryum acaule) para su aplicación textil

3.10. Artículo 10 - Viabilidad técnica de la fibra de tucumã-i (Astrocaryum acaule) para la producción textil ......................................... 261

3.11. Artículo 11 - Procedimientos para la obtención de tintes vegetales de la Amazonía para su aplicación en productos industriales 265

3.12. Artículo 12 - Diseño mediante el uso de materiales naturales: análisis de los atributos esenciales al desarrollo de nuevos productos ................... 271

3.13. Capítulo de libro - La enseñanza del diseño en la utilización de los recursos naturales para la aplicación en productos industriales.............. 277

3.14. Proyecto de innovación tecnológica - Intervención del diseño en el proceso de beneficio de la fibra natural de tucumã-i (Astrocaryum acaule) para el desarrollo de productos - Proyecto elaborado para el Nucleó de Innovación Tecnológica (NIT) de la Universidad Federal de Amazonas - UFAM / Manaus - Amazonas - Brasil. .............................................. 289

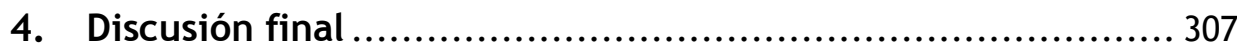

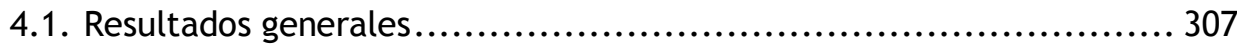

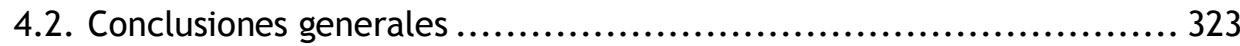

4.3. Futuras líneas de investigación.......................................... 325

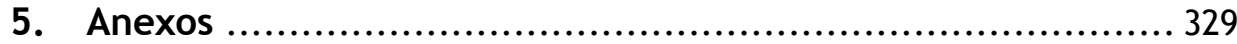

5.1. Anexo I: Cuestionarios utilizados - Cuestionario para expertos .......... 329

5.2. Anexo II: Cuestionarios utilizados - Cuestionario para Consumidor ..... 332

5.3. Anexo III: Consentimientos Informativos - expertos ..................... 336

5.4. Anexo IV: Consentimientos Informativos - consumidor .................. 339

5.5. Anexo V: Informaciones a los expertos ............................. 342

5.6. Anexo VI: Informaciones a los consumidores ........................... 351

5.7. Anexo VII: Aceptación publicaciones .................................... 353

5.8. Anexo VIII: Justificante de la aprobación del Comité Ética.............. 377

5.9. Anexo IX: Carta de aceptación de los autores........................... 379 


\section{Listado de Figuras}

\section{Introducción}

Figura 1. Productos artesanales hechos con la fibra de tucumã-i (Astrocaryum acaule) Fuente: de la autora (2012)

Figura 2. Ubicación de la fibra en el estado de Amazonas (región norte de Brasil) / producción y manejo ejercidos por las comunidades productoras de forma sostenible. Fuente: de la autora (2012).

Figura 3. Ejemplos de productos artesanales fabricados con la fibra. Fuente: de la autora (2012) ..........................................................49

Figura 4. Temas abordados por la encuesta ................................62

Figura 5. Matriz DAFO ..................................................64

Figura 6. Representación gráfica del modelado, Hernandis (2003).............65

Figura 7. Cuadro con los objetivos y sus sub-objetivos de la tesis - Parte 1 (disponible para consulta en los ANEXOS).................................67

Figura 8. Cuadro con los objetivos y sus sub-objetivos de la tesis - Parte 2 (disponible para consulta en los ANEXOS). .68

Figura 9. Cuadro con los objetivos y sus sub-objetivos de la tesis - Parte 3 (disponible para consulta en los ANEXOS). .69

Figura 10. Cuadro con los objetivos y sus sub-objetivos de la tesis - Parte 4 (disponible para consulta en los ANEXOS)..................................70

\section{Marco Teórico}

Figura 11 - Palmera en momento joven; B - palmera un poco más evolucionada; C - palmera adulta y en su hábito de crecimiento por sí solo; D - tipo de hoja pinnada y folletos agrupados en diferentes planos. Fuente: Miranda \& Rabelo (2008). .83

Figura 12. Distribución de la fibra de tucumã-i (Astrocaryum acaule) en Amazonas/Brasil. Fuente: Souza (2004) ......................................84

Figura 13. A - ovillo de hilo de tucumã-i (Astrocaryum acaule). Fuente: (Tear com fibra de tucum, cestos trançados de arumrã, 2011); B - "Hilo de la

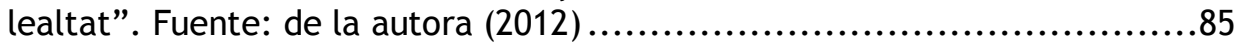

\section{Artículo 1}

A1_Figura 1. Fibra de tucumã-i (Astrocaryum acaule) e sua área de localização no estado do Amazonas................................................... 108 
Estudio de la prospección del uso de la fibra de tucumã-i (Astrocaryum acaule) para el desarrollo de productos semi-industriales

A1_Figura 2. Exemplos de produtos artesanais fabricados com a fibra amazônica de tucumã-i (Astrocaryum acaule) .............................. 108

A1_Figura 3. Técnica Focus group realizada com profissionais do design na UPV/Espanha. 110

\section{Artículo 2}

A2_Figura 1. Palmeira, folhas, fibra de tucumã-i (Astrocaryum acaule) e a sua área de localização na Amazônia brasileira................................... 118

A2_Figura 2. Alguns dos produtos artesanais desenvolvidos com a fibra de tucumã-i (Astrocaryum acaule). ........................................... 119

A2_Figura 3. Médias apresentadas aos aspectos de Inovação (mais evidenciado) e Modernidade (menos evidenciado)......................... 126

A2_Figura 4. Médias de valores apresentadas às variáveis, mais e menos, evidenciadas pelos entrevistados........................................ 129

A2_Figura 5. Médias de valores apresentadas às vantagens, mais e menos, evidenciadas pelos entrevistados....................................... 130

A2_Figura 6. Médias de valores apresentadas às características tecnológicas, mais e menos, evidenciadas.

A2_Figura 7. Médias de valores apresentadas aos critérios para certificação, mais e menos, evidenciados.

132

A2_Figura 8. Médias de valores apresentadas às categorias de uso, mais e menos, evidenciadas.

Artículo 3

A3_Figura 1. A - Ejemplo de la selección de la palmera para la realización de la extracción de la fibra; B - Extracción hecha de forma manual, a partir de las ramas de la palmera; $C$ - Ramas unificadas y amarradas para el transporte hasta las comunidades artesanales. 142

A3_Figura 2. A - Pequeña cantidad de ramas seleccionadas para proceder con la producción del hilado; B - Proceso de hilatura hecho con una de las ramas seleccionadas; C - Ejemplo de un hilo producido a partir de las ramas de tucumã-i (Astrocaryum acaule). Fuente: de los autores..................... 143

A3_Figura 3. A - Ramas desfibradas y organizadas en montículos para el lavado; $\quad$ B - Lavado manual de las fibras con agua y limón; C - Secado de las fibras al sol. Fuente: de los autores. 143 
A3_Figura 4. A - A partir de un montaje de las fibras lavadas es seleccionada una tira; B - La tira seleccionada es estirada y partida por la mitad; C Después de la división, la tira se transforma en dos tiras más que son retiradas del resto de la fibra; D - Las fibras son puestas en la pierna de la artesana para el inicio de la creación de hilos de tacum; E - Inicio de la formación del hilo; F - Entrelazamiento de las tiras hasta generar una línea continua; G Resultado del entrelazamiento de las fibras en forma de hilo; $\mathrm{H}$ - Ovillo a partir de los hilos de tucum. Fuente: de los autores. 144

A3_Figura 5. A- Hilos de tucum que van a ser utilizados para el telar; B- Hilos introducidos en el telar manual para la confección del tejido; C - Ajustes de los hilos para proceder con el tejido; D, E y F - Producción del tejido con textura más gruesa en un telar vertical de mayor tamaño. Fuente: de los

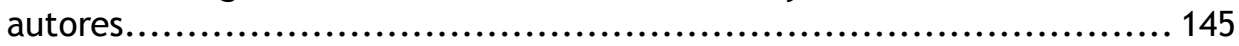

A3_Figura 6. A- Telar hecho con fibras in natura de tucum; B- Entrelazado de las fibras para la transformación del tejido; C- Tejido plano confeccionado con las fibras de tucum. Fuente: de los autores.

A3_Figura 7. A, B , C, D, E, F y G - Ejemplos de algunos de los productos artesanales elaborados a partir de la fibra de tucumã-i (Astrocaryum acaule). Fuente: de los autores.

A3_Figura 8. A, B, C y D. Piezas de vestuario elaboradas a partir de experiementos hechos con tejidos de tucumã-i (Astrocaryum acaule). Fuente: de los autores. 146

\section{Artículo 4}

A4_Figura 1. Fibra de tucumã-i (Astrocaryum acaule) da Amazônia .......... 159 A4_Figura 2. Palmeira, folhas, fibra e área de localização do objeto de estudo.................................................................. 160

A4_Figura 3. Fibra de tucumã-i (Astrocaryum acaule) transformada em produto artesanal....................................................... 162

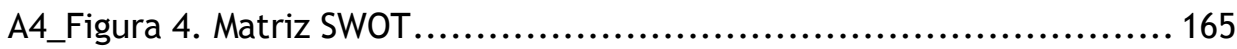

A4_Figura 5. Opiniões consideradas pelos Designers de produto sobre o objeto de estudo............................................................. 167

A4_Figura 6. Opiniões consideradas pelos Especialistas de áreas correlacionadas ao tema estudado. ...................................... 169

A4_Figura 7. Análise SWOT para identificar as oportunidades e limitações do

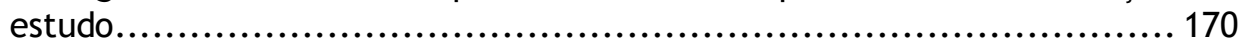


Estudio de la prospección del uso de la fibra de tucumã-i (Astrocaryum acaule) para el desarrollo de productos semi-industriales

A4_Figura 8. Codificação e cruzamento das informações estruturadas a partir da matriz SWOT........................................................ 172

\section{Artículo 5}

A5_Figura 1. Palmeira de tucumã-i (Astrocaryum acaule) e a sua área de localização no estado do Amazonas. ......................................... 183

A5_Figura 2. Fibra, fio, tecidos e alguns produtos de tucumã-i (Astrocaryum acaule) 184

\section{Artículo 6}

A6_Figura 1. A - Fibra de tucumã-i (Astrocaryum acaule) in natura; B transformada em fio e; C - em forma de novelo e linhas. .................... 201

A6_Figura 2. A - Fibra de tucumã-i (Astrocaryum acaule) processada em fios para o desenvolvimento de produtos; B - Fibra aplicada em vestuário C - Fibra aplicada em tecido decorativa; D - Fibra aplicada em acessórios; E - Fibra simulada para aplicação em têxteis para estofamento de veículos. .......... 202

\section{Artículo 7}

A7_Figura 1. Palmeira amazônica Astrocaryum acaule e a sua fibra adaptada à fabricação de produto (tecido). Fonte: dos Autores. ........................ 214

A7_Figura 2. Alguns produtos desenvolvidos e comercializados com a fibra de tucumã-i (Astrocaryum acaule). Fonte: dos Autores. ........................ 214

\section{Artículo 8}

A8_Figura 1. Fibra de tucumã-i (Astrocaryum acaule)....................... 235

A8_Figura 2. Ejemplos de productos desarrollados con la fibra............... 235

A8_Figura 3. Modelo de diseño concurrente.............................. 237

A8_Figura 4. Fases observadas en la confección de la blusa (Sistema de estudio)................................................................ 239

A8_Figura 5. Modelo de diseño concurrente aplicado al tema en estudio. .. 241

Artículo 9

A9_Figura 1. Resultado da sondagem de opiniões feita com designers de produto e especialistas de áreas relacionadas ao tema de estudo. .......... 250 A9_Figura 2. Pesquisa de opinião realizada com os consumidores. ........... 251 A9_Figura 3. Opinião do consumidor: categoria de uso e tipo de produto... 251 A9_Figura 4. Objeto de análise - blusa de tucumã-i (Astrocaryum acaule). . 252 
A9_Figura 5. Etapas de fiação e confecção de tecido.......................... 253

A9_Figura 6. Sistema exterior e variável de entrada do sistema. ............ 253

A9_Figura 7. Objetivos do sistema de estudo. .............................. 254

A9_Figura 8. Subsistemas formal, funcional e ergonómico. .................. 255

A9_Figura 9. Processo de atuação das variáveis de ação e informação nos sistemas fundamentais do estudo........................................ 256

A9_Figura 10. Variáveis essenciais do sistema. ............................ 257

\section{Artículo 10}

A10_Figure 1. A, B e C - Technology assessment of tucumã-i fiber (Source: author's archives).

A10_Figure 2. A, B e C - Adaptation of the tucumã-i fiber for cords (Source: author's archives).

A10_Figure 3. A, B - Design of the prototypes; C, D - Production and finishing of the fabric of tucumã-i (Source: author's archives). 263

A10_Figure 4. Properties identified in the tucumã-i fiber (Source: Adapted from MACIEL, 2007). 263

A10_Figure 5. A e B - Clothes made with the tucumã-i fiber (Source: author's archives) 263

\section{Artículo 11}

A11_Figure 1. Seeds of urucum in their natural state and then diluted and mixed with a natural oil. (Source: SANTOS, 2002).

A11_Figure 2. Urucum's natural dye application in the arumã fiber. (Source: SANTOS, 2002). 267

A11_Figure 3. Tucumã fiber boiled with the crajiru's leaves and getting the red tinge. (Source: SANTOS, 2002). 268

A11_Figure 4. Colors obtained by vegetable dyes of Amazon. (Source: authors' file). 268

A11_Figure 5. Textile pieces manufactured with tucumã fiber and dyed with vegetable dyes Amazon. (Source: authors' file). 269

Artículo 12

A12_Figure 1. Natural Stone, processed into products.

A12_Figure 2. Natural fiber, processed into handcraft product. 
Estudio de la prospección del uso de la fibra de tucumã-i (Astrocaryum acaule) para el desarrollo de productos semi-industriales

\section{Capítulo Libro}

Cap_Lib_Figura 1. Interação da atividade projetual em relação a: contexto, pessoas e produtos. Fonte: autores. ...................................... 279

Cap_Lib_Figura 2. Modelo conceitual para a concepção de produto pelo processo de investigação do design. Fonte: Adaptado de Norman (2002).... 281

Cap_Lib_Figura 3. Fases da investigação do design para um sistema de estudo, focado em recursos naturais. Fonte: Adaptado de Bonsiepe (1984), Bonfim (1995), Munari (1983) e Asimov (1962). 282

\section{Proyecto de Innovación Tecnológica}

PIT_Figura 1. Representação gráfica do modelo de Design Concorrente (HERNANDIS, 2003)..................................................... 296

\section{Discusión Final}

Figura 14. Posicionamiento de los especialistas de diseño. Fuente: de la

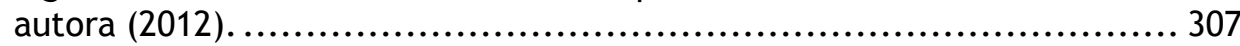

Figura 15. Posicionamiento de los expertos. Fuente: de la autora (2012). .. 308

Figura 16. Oportunidades y limitaciones del estudio. Fuente: de la autora (2012) 310

Figura 17. Posicionamiento de mercado. Fuente: de la autora (2012). 311

Figura 18. Categoria de uso y tipo de producto elegidos por los consumidores. Fuente: de la autora (2012). .............................................. 312

Figura 19. Grupos caracterizados. Fuente: de la autora (2012).............. 313

Figura 20. Atributos del diseño señalados. Fuente: de la autora (2012). ... 314

Figura 21. Informaciones del sistema exterior. Fuente: de la autora (2012).316 Figura 22. Objetivos del sistema en estudio. Fuente: de la autora (2012)... 316

Figura 23. Subsistemas del sistema de estudio. Fuente: de la autora (2012). 317

Figura 24. Representación del proceso de interacción de las variables de acción y de información en el sistema de estudio. Fuente: Hernandis (2003). 


\section{Listado de tablas}

\section{Introducción}

Tabla 1. Grupo Focal - Estructura y Procedimiento ............................58

Tabla 2. Entrevista en profundidad - Expertos ................................59

\section{Marco Teórico}

Tabla 3. Propiedades del objeto de estudio comparadas a otras fibras

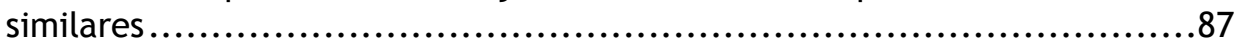

\section{Artículo 1}

A1_Tabela 1. Aspectos considerados importantes pelos designers 110

\section{Artículo 2}

A2_Tabela 1. Caracterização da amostra - Nac. dos profissionais entrevistados 122

A2_Tabela 2. Caracterização da amostra - Áreas de atuação profissional ... 123

A2_Tabela 3. Caracterização da amostra - Local de atuação dos entrevistados 123

A2_Tabela 4.Caracterização da amostra - Perfil dos locais de atuação dos entrevistados.... 124

A2_Tabela 5. Nível de apreciação do uso das fibras vegetais para a fabricação

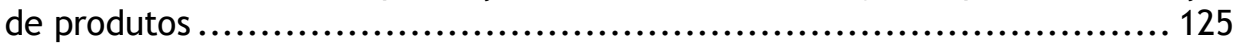

A2_Tabela 6. Valores atribuídos aos produtos feitos com fibras vegetais.... 125

A2_Tabela 7. Valores associados aos produtos de qualidade 125

A2_Tabela 8. Nível de aprovação da inserção de novas fibras vegetais no mercado de produtos 126

A2_Tabela 9. Grau de aceitação da fibra de tucumã-i (Astrocaryum acaule) para o desenvolvimento de produtos.

A2_Tabela 10. Nível de credibilidade - processo de transformação semiindustrial da fibra. 128

A2_Tabela 11. Variáveis importantes - processo de transformação semiindustrial da fibra de tucumã-i (Astrocaryum acaule) ....................... 128

A2_Tabela 12. Vantagens fibra de tucumã-i (Astrocaryum acaule) com o processo de transformação semi-industrial 
Estudio de la prospección del uso de la fibra de tucumã-i (Astrocaryum acaule) para el desarrollo de productos semi-industriales

A2_Tabela 13. Características tecnológicas importantes ao uso da fibra .... 130

A2_Tabela 14. Critérios para certificação dos produtos semi-industriais feitos com a fibra............................................................ 132

A2_Tabela 15. Categorias de uso a aplicação semi-industrial da fibra ....... 133

\section{Artículo 3}

A3_Tabla 1. Variables importantes en el proceso de transformación semiindustrial de la fibra de tucumã-i (Astrocaryum acaule) ..................... 149

A3_Tabla 2. Ventajas de la fibra de tucumã-i (Astrocaryum acaule) en el proceso de transformación semi-industrial ................................ 150

A3_Tabla 3. Aspectos formales............................................ 151

A3_Tabla 4. Aspectos funcionales ........................................... 152

A3_Tabla 5. Aspectos ergonómicos....................................... 152

\section{Artículo 4}

A4_Tabela 1. Adaptação da fibra de tucumã-i (Astrocaryum acaule) por processo artesanal....................................................... 160

A4_Tabela 2. Propriedades tecnológicas identificadas na fibra de tucumã-i (Astrocaryum acaule) .................................................. 162

A4_Tabela 3. Mensuração dos fatores estudados ............................ 166

A4_Tabela 4. Identificação das oportunidades para o estudo .................. 173

A4_Tabela 5. Identificação das limitações para o estudo ....................... 173

\section{Artículo 5}

A5_Tabela 1. Propriedades tecnológicas da fibra de tucumã-i (Astrocaryum acaule) compatíveis à produção têxtil.................................... 184

A5_Tabela 2. Nível de apreciação do uso das fibras vegetais para o desenvolvimento de produtos ............................................ 189

A5_Tabela 3. Nível de consumo de produtos desenvolvidos com fibras vegetais 190

A5_Tabela 4. Razão atribuída ao uso de produtos feitos com as fibras vegetais 190

A5_Tabela 5. Valoração atribuída ao uso de produtos feitos com as fibras vegetais. 191 
A5_Tabela 6. Razão atribuída ao uso de produtos feitos com as fibras vegetais 192

A5_Tabela 7. Nível de aceitação do uso das fibras vegetais para o desenvolvimento de produtos 193

A5_Tabela 8. Aspectos considerados importantes para o uso semi-industrial do objeto de estudo 194

\section{Artículo 6}

A6_Tabela 1. Categoria Selecionada Pelos Entrevistados 204

A6_Tabela 2. Produto escolhido para a aplicação semi-industrial da fibra de tucumã-i (Astrocaryum Acaule) 204

A6_Tabela 3. Características organolépticas denominadas pelos consumidores 205

A6_Tabela 4. Características mecânicas denominadas pelos consumidores . 205

A6_Tabela 5. Características físico-químicas denominadas pelos consumidores 206

A6_Tabela 6. Aspectos tecnológicos e de certificação do produto considerados pelos consumidores................................................... 206

A6_Tabela 7. Perfil dos consumidores em relação à categoria de uso ........ 208

\section{Artículo 7}

A7_Tabela 1. Aglomeração hierárquica formada com até de seis grupos distintos

A7_Tabela 2. Amostra Selecionada. 218

A7_Tabela 3. Posicionamento da amostra em relação aos atributos formais do produto 219

A7_Tabela 4. Posicionamento da amostra em relação aos atributos funcionais do produto 220

A7_Tabela 5. Posicionamento da amostra em relação aos atributos ergonômicos do produto. 221

A7_Tabela 6. Perfil do grupo de consumidores em função das variáveis de classificação 223

A7_Tabela 7. Perfil do grupo de consumidores em relação à idade 224

A7_Tabela 8. Perfil do grupo de consumidores em relação à escolaridade .. 224 
Estudio de la prospección del uso de la fibra de tucumã-i (Astrocaryum acaule) para el desarrollo de productos semi-industriales

A7_Tabela 9. Apreciação do uso de fibras vegetais para o desenvolvimento de

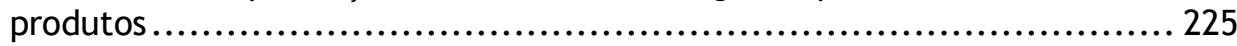

A7_Tabela 10. Grau de satisfação dos produtos desenvolvimento com fibras

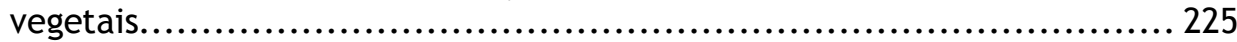

A7_Tabela 11. Consumo de produtos desenvolvimento com fibras vegetais. 226 A7_Tabela 12. Razões para consumir produtos desenvolvimento com fibras vegetais.................................................................. 227

\section{Artículo 12}

A12_Table 1. Illustrative Table - Attributes / Case Studies.................... 274 


\section{Listado de Cuadros}

\section{Proyecto de Innovación Tecnológica}

Quadro 1. Ações a serem realizadas pelo projeto ............................ 297

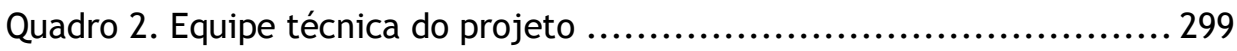

Quadro 3. Cronograma provisório do projeto............................. 300

Quadro 4. Planilha de material e serviço................................... 301

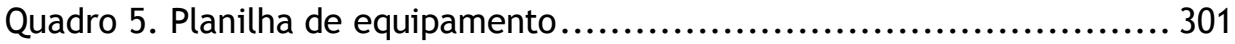

Quadro 6. Planilha de diárias............................................. 302

Quadro 7. Planilha de passagens.......................................... 302

Quadro 8. Planilha de bolsas............................................ 302 

Capítulo 1 - Introducción 



\section{Introducción}

\subsection{Motivación de la investigación}

Con la finalidad de mejorar la visibilidad de las fibras naturales y crear una conciencia sobre la importancia del uso de esas materias primas para los productores, la industria, el mercado, los consumidores y el medio ambiente, la Asamblea General de las Naciones Unidas (ONU) declaró el año 2009 como el Año Internacional de las Fibras Naturales y sus usos (Organización de las Naciones Unidas, 2009). A partir de este evento, se estableció algunos objetivos, que sirven de orientación, para conducir las actividades y proyectos que involucran ésta tipología de recursos naturales como por ejemplo:

- Crear conciencia y estimular la demanda de fibras naturales;

- Alentar a las respuestas políticas adecuadas por los gobiernos a los problemas que enfrentan las industrias de fibras naturales;

- Promover una efectiva y duradera colaboración internacional entre las distintas industrias de fibras naturales;

- Promover la eficiencia y la sostenibilidad de las industrias de fibras naturales.

La importancia de las fibras naturales se hace patente en función de los 35 millones de toneladas de fibras procedentes de una amplia variedad de plantas y animales utilizadas para suplir las necesidades humanas básicas, sobre todo relacionadas con el vestir y el cobijo, desarrollados tradicionalmente en todas las culturas (Macía, 2006). Las ventajas en relación al uso de otros tipos de materiales se producen debido a su bajo costo, alta resistencia, buenas propiedades mecánicas y térmicas, la reducción del desgaste de las máquinas, facilidad de separación, la resistencia a la tracción, la durabilidad, la degradación y la reutilización para el puesto (Finkler, Scapini, Freire, Zattera, \& Zeni, 2005). En función de estos aspectos, la industria de productos, sobre todo en lo que se refiere a la producción textil, es una de las mayores consumidoras de fibras naturales (Oliveira, 2000), volviéndose importante para la decisiva participación de los interlocutores sociales, económicos, culturales y ambientales en el proceso de conocimiento y uso de estos recursos naturales al alcance de nuevos mercados y con beneficios para sus consumidores potenciales.

Basado en ello, esta tesis presenta un estudio sobre una fibra natural perteneciente a la amazonia brasileña, considerada por el campo científico poco explotada y sin muchos datos registrados sobre su uso en la fabricación de productos, principalmente en una escala de aplicación evolucionada, 
Estudio de la prospección del uso de la fibra de tucumã-i (Astrocaryum acaule) para el desarrollo de productos semi-industriales

donde se pueda considerar sus propiedades tecnológicas, la perspectiva del mercado en cuanto a posibles usos, el tipo de artículo a ser confeccionado y los atributos del diseño de producto para optimizar su gestión, desarrollo y fabricación final.

Por tanto, la investigación tiene la ocasión de obtener datos más actualizados sobre la fibra de tucumã-i (Astrocaryum acaule) considerada en este contexto un nueva materia prima, de forma que se favorezca su inserción en el mercado de productos más competitivos, se aprecien sus características intrínsecas, se posibiliten nuevos tipos de aplicaciones y procesos, combinando tecnología y ciencia, como apoyo al rendimiento funcional y bienestar del producto final como beneficio de los potenciales consumidores.

Otra motivación considerada para la realización de este trabajo es la posibilidad de ampliar y promover usos más innovadores (Organización de las Naciones Unidas, 2009), visando la concepción y/o rediseño de productos para el alcance de nuevos mercados, una vez que la fibra corresponde positivamente a los criterios tecnológicos para la utilización textil, de acuerdo con las normativas establecidas por ASTM (Annual Book of Astm Standart) y ABNT (Associação Brasileira de Normas Técnicas).

Esta tesis no se propone el desarrollo de un producto específico, sino validar la propuesta del uso de la fibra de tucumã-i (Astrocaryum acaule) para el desarrollo de productos semi-industriales, respaldando la investigación con el documento científico por compendio de publicaciones referentes a los objetivos a ser alcanzados a lo largo de todo su proceso de posible producción.

\subsection{Contextualización del tema}

Desde que algunos investigadores comenzaron a explorar, investigar y difundir las fibras naturales como una opción para satisfacer las necesidades básicas del hombre, se observa que tal propósito va más allá de las funciones iniciales, llegando en la actualidad a una amplia gama de aplicaciones en el mercado de productos (Figueiras, 2008). El interés renovado para el uso comercial de las fibras naturales las llevó a un proceso de investigación, a nivel mundial, para producir una serie de productos en base al uso de fibras vegetales (Olesen, 1997). Las ventajas de utilización de las fibras naturales con respecto a otros tipos de materiales para el desarrollo de productos incluyen: bajo costo, alta durabilidad, buenas propiedades tecnológicas, bajo consumo energía y del tiempo, la biodegradabilidad, entre otros (Houston \& Holbery, 2006). Con esas posibilidades, las fibras vegetales se vuelvan as posibles opciones de ingresos para promover la seguridad alimentaria, la erradicación de la pobreza y la consecución de ciertos alcances de algunos 
objetivos del milenio para el desarrollo humano (Organización de las Naciones Unidas, 2009).

En este contexto, Brasil es considerado como un país rico en fibras naturales, con una diversidad muy amplia. En su territorio se concentra la mayor y más potente diversidad biológica del planeta, la selva amazónica (Capobianco, 2001). Debido a la inmensa cantidad de plantas leñosas y fibrosas frecuentes en la Amazonia, hay una gran oportunidad para el descubrimiento de fibras naturales con deseables propiedades tecnológicas (Marinelli, Monteiro, Ambrósio, Brancifort, Kobayashi, \& Nobre, 2008). Por tanto, la biodiversidad del ecosistema de la Amazonia puede ser considerada como la mayor potencia natural del mundo contemporáneo, y una fuente de recursos materiales para el estudio científico y para incursión en la bio-industria (Pletsch, 1998).

La variedad de flora tropical de la Amazonia y el conocimiento popular del uso de las fibras vegetales, sugiere la posibilidad de transformación de estas materias primas en plantas cultivadas para el desarrollo de productos con denominación de origen, que puede tornarse en expresiones sociales, culturales, medioambientales, tecnológicas y económicas para la región.

Los productos extraídos pueden constituir importantes fuentes de ingresos para los pueblos nativos y se deben reforzar las iniciativas para el fortalecimiento y amplitud de los mercados de estos nuevos productos (Schwartzman, 2004). Considerando éste principio, la fibra natural amazónica de tucumã-i (Astrocaryum acaule) está siendo señalada como una buena opción para el desarrollo de nuevos productos (Maciel, 2007).

Las características morfológicas, sociales, económicas y sostenibles observadas durante el proceso de producción de la fibra, atribuyen condiciones favorables a su proceso de adaptación y aplicación en serie, lo que puede contribuir a conseguir nuevos mercados. Sin embargo, es importante observar que por tratarse de una materia prima trabajada artesanalmente, se considera que su adaptación a los procesos industriales lleva gran dificultad, lo que implica la necesidad de investigar los pasos a seguir y así como los criterios específicos para su transformación, la que permite que sea considerada para una evolución apropiada desde el proceso artesanal al semi-industrial. Este intento puede imponer un paso inicial en el camino de su futura utilización en la industria de los productos. Tal propósito hace que el diseño participe en el proceso como factor clave en el análisis del objeto de estudio, buscando orientar las posibles vías de acción para vislumbrar los problemas y las oportunidades existentes en la solución y verificación de una alternativa de aplicación de la fibra en estudio. 
Estudio de la prospección del uso de la fibra de tucumã-i (Astrocaryum acaule) para el desarrollo de productos semi-industriales

Los beneficios de esta investigación se fundamentan por tanto en el análisis de los factores que puedan involucrar desde el estudio de antecedentes, la posibilidad de una nueva forma de uso para la aplicación de la fibra de tucumã-i (Astrocaryum acaule), las consideraciones de las opiniones de profesionales y expertos, el posicionamiento del mercado - a través de lo que piensan los consumidores potenciales, y la sistematización de datos obtenidos a lo largo de la investigación con objeto de poder auxiliar acciones futuras, más eficaces, favoreciendo el estudio de elementos que necesitan más atención en un proceso de transición tecnológica - desde el estado artesanal al semi-industrial - para estudiar y describir las etapas de uso de la materia prima y, consecuentemente, la gestión, desarrollo y fabricación de productos más competitivos al alcance de nuevos mercados. Al mismo tiempo se pretende contribuir en la realización de un registro científico sobre el estudio de la prospección del uso de la fibra natural amazónica de tucumã-i (Astrocaryum acaule) para el desarrollo de productos semi-industriales.

\subsection{Problema identificado}

En el sector de las fibras naturales, proveniente de la explotación de palmeras amazónicas, se encuentra la fibra de tucumã-i (Figura 1), también conocida como tucum, originada a partir de los géneros: Astrocaryum sp y/o Bactris sp. Esta fibra se considera como uno de los recursos vegetales más utilizados en la cadena de productos artesanales (Souza, 2004).
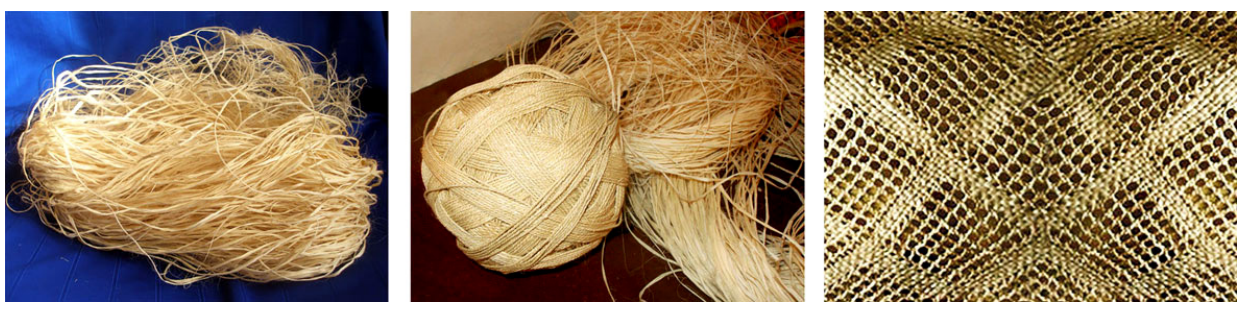

Figura 1. Productos artesanales hechos con la fibra de tucumã-i (Astrocaryum acaule) Fuente: de la autora (2012).

Se encuentra ubicada principalmente en el Alto Río Negro, al norte de Brasil, estado de Amazonas (Figura 2), donde se produce y maneja de forma sostenible por las comunidades productoras pertenecientes a la zona; considerándose como los mayores consumidores y conocedores de esta fibra (Maciel, 2007). 

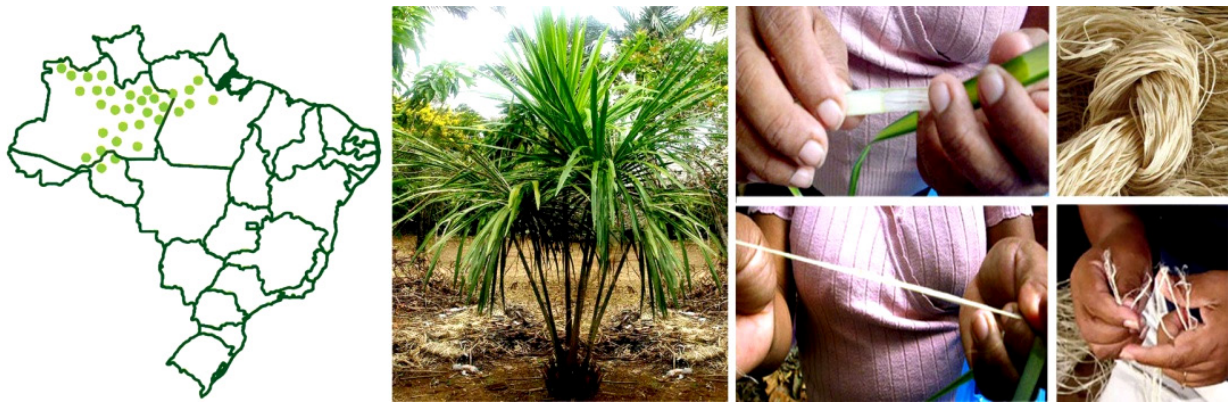

Figura 2. Ubicación de la fibra en el estado de Amazonas (región norte de Brasil) / producción y manejo ejercidos por las comunidades productoras de forma sostenible. Fuente: de la autora (2012).

La comercialización de la fibra de tucumã-i (Astrocaryum acaule) se realiza mediante la compra y venta de la fibra en su estado natural o ya convertido en productos artesanales (Figura 3).
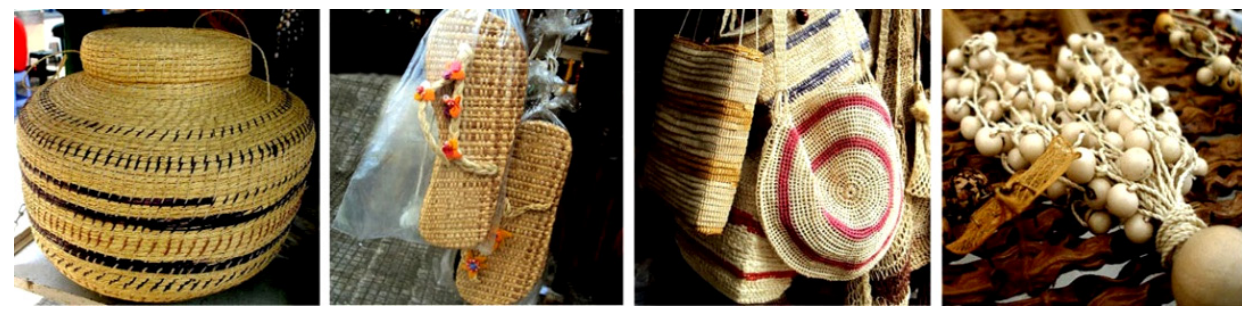

Figura 3. Ejemplos de productos artesanales fabricados con la fibra. Fuente: de la autora (2012)

Esta actividad se lleva a cabo en centros comerciales, ferias y eventos culturales. Los mercados principales alcanzados con las ventas de estos productos son: la capital de Amazonas (Manaus), algunos estados de Brasil y algunos países de América del Norte, América del Sur y Europa (Menezes, Pinheiro, Guazzell, \& Martins, 2005). Los aspectos sostenibles, la materia prima de calidad, las condiciones socio-culturales, la demanda del mercado y el resultado de su uso en productos artesanales están atrayendo la atención de muchos turistas, ONG (Organizaciones No Gubernamentales) y empresas del segmento industrial. Sin embargo, el desarrollo de productos a partir de la fibra es considerado de naturaleza empírica - sin criterio o auxilio técnicocientífico para respaldar su debida aplicación para esta finalidad, comprometiendo muchas veces la esencia de la materia prima. Además, si se pretende adaptar un proceso más avanzado como el semi-industrial a un 
recurso natural, explotado específicamente de forma artesanal que implicará un estudio más profundo. En esta situación se considera que su adaptación a un sistema semi-industrial, conlleva gran dificultad siendo necesarios una mayor recopilación y análisis de datos, con objeto de orientar su utilización bajo esta perspectiva. Por tanto, estando el mercado de las fibras naturales aplicadas en productos, sometido a las normativas y patrones para la determinación del grado de desempeño de la materia prima, de acuerdo con la función y utilidad que le serán exigidas, es fundamental evaluar las etapas necesarias en su proceso de adaptación (transformación) desde la concepción hasta la generación del producto final. De igual manera, surgen las siguientes cuestiones con respecto al objeto y a la propuesta en estudio:

¿Puede la fibra de tucumã-i (Astrocaryum acaule) ser utilizada para el desarrollo de productos?

¿Cuál es el grado de aceptación de esta fibra para el desarrollo de productos?

¿En qué categoría de uso podría ser insertada?

¿Qué tipos de productos podrían ser fabricados a partir de ella?

¿Cuáles son los aspectos tecnológicos que deben ser considerados más importantes en el proceso de transformación de la fibra en producto?

¿Cómo se podrá adaptar mejor la fibra para su aplicación en productos semiindustriales?

Sobre estos aspectos y partiendo del principio de que todo producto antes de ser lanzado al mercado, debe ser sometido a un estudio de evaluación para garantizar su funcionalidad y posible aplicación semi-industrial. Tendremos en cuenta los siguientes objetivos:

\subsection{Objetivos de la investigación}

\subsubsection{General}

Estudiar la prospección del uso de la fibra natural de tucumã-i (Astrocaryum acaule) para el desarrollo de productos semi-industriales

\subsubsection{Específicos}

A - Identificar las oportunidades y limitaciones del estudio propuesto mediante especialistas del diseño y expertos en áreas relacionadas al tema;

A.1 - Análisis del posicionamiento del diseño cuanto al uso semiindustrial de la fibra amazónica de tucumã-i (Astrocaryum acaule) para la fabricación de productos; 
A.2 - Análisis sobre el posicionamiento de los expertos cuanto al uso de la fibra natural amazónica tucumã-i (Astrocaryum acaule) para el desarrollo de productos semi-industriales;

A.3 - Observación de los Atributos del diseño para el proceso de transformación y uso de la fibra natural amazónica de tucumã-i (Astrocaryum acaule) para el desarrollo de productos semi-industriales

A.4 - Análisis comparativa de las informaciones y opiniones obtenidas, a partir del punto de vista de diseñadores y expertos consultados.

B - Observar el posicionamiento del mercado (consumidor) con respecto al objetivo principal del estudio, identificando la categoría de uso, el tipo de producto y los atributos del diseño considerados importantes para la aplicación de la fibra en el contexto abordado;

B.1 - Análisis de la apreciación de los consumidores sobre el uso semiindustrial de la fibra vegetal amazónica de tucumã-i (Astrocaryum acaule) para el desarrollo de productos: Un estudio de mercado

B.2 - Fibra vegetal amazónica de tucumã-i (Astrocaryum acaule) para la aplicación textil: Un análisis de opiniones;

B.3 - Estudio sobre Atributos necesarios para la fabricación de productos semi-industriales a partir del uso de la fibra natural amazónica de tucumã-i (Astrocaryum acaule): Una segmentación de mercado.

C - Analizar la posibilidad del uso de la fibra de tucumã-i (Astrocaryum acaule) para el desarrollo de productos semi-industriales, a partir del estudio de un caso que se basa en la aplicación artesanal de la materia prima para el desarrollo de prendas de vestir;

C.1 - La importancia del diseño sistémico para la competitividad de la fibra natural Amazónica de tucumã-i (Astrocaryum acaule) en el desarrollo semi-industrial de productos: Un estudio de caso para la categoría del vestuario.

C.2 - Identificación de las variables esenciales y de los aspectos del diseño, considerados importantes, para el beneficio de la fibra natural amazónica de tucumã-i (Astrocaryum acaule) y su aplicación textil. 
D - Generar información complementaria (contribuciones) para la valoración, y registro científico del tema estudiado.

D.1 - Estudio sobre Viabilidad técnica de la fibra de tucumã-i (Astrocaryum acaule) para la producción textil;

D.2 - Procedimientos para obtener tintes vegetales amazónicos para la aplicación de productos industriales;

D.3 - La enseñanza del diseño en la utilización de los recursos naturales para la aplicación en productos industriales;

D.4 - Diseño mediante el uso de materiales naturales: análisis de los atributos esenciales al desarrollo de nuevos productos;

D.5 - Análisis sobre la Intervención del diseño para la gestión, desarrollo y fabricación de productos a partir del uso de fibras vegetales amazónicas.

\subsection{Hipótesis}

\subsubsection{Principal}

La información obtenida mediante de éste estudio, puede confirmar posibilidades de aplicación, reducir las incertidumbres, sistematizar los datos y facilitar el correcto dimensionamiento del uso de la fibra natural amazónica de tucumã-i (Astrocaryum acaule) para la gestión, desarrollo y fabricación de productos semi-industriales.

\subsubsection{Secundarias}

H1 - El conocimiento sobre las debilidades, amenazas, fortalezas y oportunidades de un producto determinan su perspectiva de mercado;

H2 - La información sobre el gusto, uso, nuevos materiales, procesos para la fabricación, aspectos técnicos, de innovación, de diferencia y eco sostenibles que se evalúan en la compra de un producto;

H3 - Los atributos de diseño influyen en la percepción de calidad de los consumidores de productos desarrollados con fibras naturales, así como en la transformación de materias primas en productos y bienes de consumo, considerando el vínculo entre conocimiento y producción;

H4 - La transformación de un recurso natural en producto, puede evidenciar en éste las expresiones sociales, culturales, medioambientales, tecnológicas y económicas y favorecer la transferencia de conocimiento; 
H5 - La producción científica generada de acuerdo a los objetivos establecidos en este estudio y desarrollada mediante los principios de una tesis por compendio de publicaciones, garantiza una mejor evaluación de los datos por parte de revistas indexadas, congresos, eventos científicos, entre otros, con objeto de validarlos y registrarlos como resultados de investigaciones de alta calidad, tornándolos referencia para estudios futuros.

\subsection{Justificación}

\subsubsection{Social}

Introducir la fibra de tucumã-i (Astrocaryum acaule) en el mercado de productos, conociendo sus formas de aplicación y sistematizando sus etapas de transición para el desarrollo de productos, podrá agregar más valor a la materia prima, ofreciendo mayores cualidades a los productos desarrollados. Cuanto al papel de las comunidades productoras, éste estará evidenciado y valorado a través del saber y del uso de las tecnologías tradicionales, así como también vinculado a los valores de mercado, patrones contemporáneos y nuevas necesidades en favor del alcance de un proceso más sofisticado que integra nuevos elementos al complexo universo de la producción artesanal, de modo a favorecer el objeto de estudio y, principalmente, a divulgar su identidad cultural. Trabajar el perfeccionamiento de pequeños negocios significa crear un ambiente favorable para que estos se desarrollen, y es con base en la dimensión del ambiente que participa fuertemente los aspectos culturales y tradicionales de las comunidades involucradas. Además, los resultados del estudio podrán fornecer informaciones que posibiliten la generación de ingresos adicionales para las comunidades locales, la mejora de aspectos sociales y la oferta de más productos con denominación de origen.

\subsubsection{Tecnológica}

Las ventajas que la utilización de las fibras naturales posee, como materia prima en comparación con otros tipos de materiales, se deben a su bajo coste, alta resistencia, buenas propiedades mecánicas y térmicas, reducción del desgaste de las máquinas, facilidad de separación, buena resistencia a la tracción, durabilidad, degradación y posibilidad de reutilización. Además el proceso semi-industrial que puede ser atribuido al uso de la fibra de tucumã-i (Astrocaryum acaule) para el desarrollo de productos, tendrá relación a las posibles formas de protección establecidas por la legislación brasileña de la Propiedad Intelectual, que protege y respalda a las indicaciones geográficas (IG), indicaciones de procedencia (IP) y la denominación de origen (DO) de los productos o servicios con características naturales y humanas. 


\subsubsection{Económica}

La producción y el procesamiento de la fibra de tucumã-i (Astrocaryum acaule) son de gran importancia económica, para la subsistencia y de seguridad alimentaria de las comunidades productoras en la amazonia brasileña. Sobre este aspecto, el conocimiento adecuado de la materia prima podrá hacer de ella un producto conducente a la calidad de vida, generación de ingresos, desarrollo local y divulgación del estado de Amazonas, como gran productor de la fibra en la región norte de Brasil, teniendo en cuenta que la fibra presenta aspectos favorables en el mercado de productos y, con eso, se podrá estimular más su cultivo, generar más empleos para los productores agrícolas y al mismo tiempo contribuir para que se realicen otros estudios en este sentido, siendo auto-suficiente para el alcance de nuevos mercados, en Brasil o en el comercio internacional.

\subsubsection{Ambiental}

Cuando se opta por el uso de las fibras naturales para el desarrollo de productos, se sugiere el consumo de una materia prima renovable por excelencia y que al final de su ciclo de vida se vuelve $100 \%$ biodegradable. Con respecto a la fibra de tucumã-i (Astrocaryum acaule), su proceso de obtención involucra todo un cuidado que comienza desde la recolección, pasa por la extracción y se consolida en el corte. Este procedimiento realizado con las hojas de una palmera amazónica, tiene como base la reposición natural de las hojas en un período corto de tres meses, poco después de ser correctamente recogidas. Estos procedimientos no perjudican el medio ambiente, y sí, vienen en evento los principios eco-sostenibles que enfocan las preocupaciones globales.

\subsubsection{Científica}

El género Astrocaryum acaule, no posee un gran conocimiento al respecto de su aplicación en el desarrollo de productos, sobre todo con respecto a intentos de fabricación en serie, se puede mediante este estudio ofrecer posibilidades de aplicaciones que van más allá de las prácticas artesanales. La temática abordada pretende identificar las variables de acción y las etapas necesarias para auxiliar el proceso en la transición del producto y del paso artesanal al semi-industrial, sistematizando los datos obtenidos a través de la investigación con objeto de posterior auxilio a la gestión, desarrollo y fabricación de nuevos productos, generando una nueva forma de aplicabilidad para la fibra y, consecuentemente, un registro inédito e innovador al campo científico en este ámbito. 


\subsection{Delimitación de la investigación}

El estudio se centra en la recolección y producción de datos en lo que se refiere a la prospección de uso de la fibra natural amazónica de tucumã-i (Astrocaryum acaule) para el desarrollo de productos semi-industriales de acuerdo con su comportamiento cuanto a los siguientes aspectos:

- Material $\rightarrow$ tomando como base una materia prima amazónica y el contexto que involucra su utilización en la fabricación de productos.

- Uso comercial $\rightarrow$ verificando el posicionamiento del mercado, sobre todo con respecto a lo qué piensan los consumidores potenciales en cuenta al uso de esta materia prima para la fabricación de productos semi-industriales, así como qué uso es adecuada y qué tipo de producto es conveniente desarrollar a partir de ésta materia prima.

- Proceso Tecnológico $\rightarrow$ Se pretende observar las posibilidades de transformación y evolución de un recurso natural utilizado de forma artesanal y en evolución al proceso semi-industrial;

- Científico $\rightarrow$ produciendo y registrando datos pertinentes a las posibilidades del uso semi-industrial de la fibra para la gestión, desarrollo y fabricación de nuevos productos.

\subsection{Material y método}

\subsubsection{Tipo de la investigación}

La investigación es cualitativa y cuantitativa, exploratoria, descriptiva y explicativa dentro de un marco teórico que proporciona un enfoque conceptual sobre el tema propuesto (Gil, 2002).

Los aspectos de la investigación cualitativa servirán para obtener las percepciones de la gente sobre los problemas sociales y hechos en relación al estado actual del fenómeno en estudio y / o para describir la naturaleza de las condiciones existentes en una situación (Trochim, 2002).

Así, para examinar las cuestiones desde el punto de vista empírico y compararlo con un panorama teórico de los datos recogidos de la realidad, el estudio pretende presentar un modelo de funcionamiento - que muestra una recopilación de datos precedidos por una investigación bibliográfica y documental, entrevista de enfoque, entrevista en profundidad y análisis comparativo y de significación de las variables identificadas (Marconi \& Lakatos, 2006). 
Estudio de la prospección del uso de la fibra de tucumã-i (Astrocaryum acaule) para el desarrollo de productos semi-industriales

Los datos cuantitativos permiten examinar la información recogida de manera científica, o más específicamente en forma numérica y estudiar con ayuda de herramientas estadísticas, observando donde se inicia el problema, en qué dirección va y qué tipo de incidencia existe entre sus elementos. Son respuestas que podrán obtener y representar por medio de un modelo numérico lineal, exponencial o similar (Blaxter, Hughes, \& Tight, 2002).

El estudio estadístico podrá determinar la fuerza de asociación o correlación entre variables, la generalización y objetivación de los resultados a través de una muestra representativa para hacer inferencia a una población de la cual la muestra procede. El análisis al respecto de la asociación o correlación de estas variables, pretende hacer una inferencia causal que explique por qué las cosas suceden o no de una forma determinada.

\subsubsection{Tipo y diseño general del estudio}

El proceso de esta investigación científica involucra a una serie de actividades sucesivas y organizadas que deben ser consecuentes con los objetivos del tema propuesto y que constituyen los pasos y pruebas a efectuar así como las técnicas a utilizar para recolección y el análisis de datos. Trabajaremos por tanto mediante investigación bibliográfica y toma de datos en trabajos de campo.

El trabajo bibliográfico, recurre a las fuentes secundarias: libros, revistas, etc. Los trabajos de campo inciden en la realidad a los primeros aportados por los instrumentos que se han diseñado para recogerlos, entre estos tenemos:

- Diseño de encuestas $\rightarrow$ siendo este un procedimiento exclusivo de las ciencias sociales, donde se parte de la premisa de que si queremos conocer algo sobre el comportamiento de las personas, lo mejor es preguntarlo directamente a ellas. Es importante en este diseño determinar la validez de muestreo.

- Diseño estadístico $\rightarrow$ que efectúa mediciones para determinar los valores de una variable o de un grupo de variables. Consiste en el estudio cuantitativo o evaluación numérica de hechos colectivos.

- Diseño de casos $\rightarrow$ realiza un estudio exhaustivo de uno o muy pocos objetos de investigación, lo cual permite conocer en forma amplia y detallada a los mismos. Este procedimiento consiste, por lo tanto, en estudiar cualquier unidad de un sistema, para estar en condiciones de conocer algunos problemas generales del mismo.

- Diseño experimental $\rightarrow$ cuando a través de un experimento se pretende llegar a la causa de un fenómeno. Su esencia es la de someter el objeto de 
estudio a la influencia de ciertas variables en condiciones controladas y conocidas por el investigador.

\subsubsection{Universo de estudio, selección y tamaño de muestra}

La muestra de la investigación pretende abordar 3 grupos distintos:

- Grupo $1 \rightarrow$ serán seleccionados 13 especialistas en diseño - estudiantes de doctorado en Diseño, Fabricación y Gestión de Proyectos Industriales de la Universidad Politécnica de Valencia (UPV/España) para participar de una entrevista de enfoque (Focus Group), con el intuito de identificar las etapas necesarias al proceso de investigación en diseño para el tema propuesto.

- Grupo $2 \rightarrow$ serán seleccionados 11 expertos pertenecientes a los respectivos ámbitos: Ingeniería Textil, Ingeniería Industrial, Ingeniería de Producción, Ingeniería Química, Ingeniería Forestal, Medio Ambiente, Economía, Diseño y Mercado de Productos, para participar de una entrevista en profundidad para la observación de las consideraciones sobre el uso de la fibra de tucumã-i (Astrocaryum acaule) en productos semi-industriales.

La investigación se realiza en la Escuela Técnica de Ingeniería del Diseño ETSID de la Universidad Politécnica de Valencia, en la sede de la ciudad de Valencia (España). Se ha optado por elegir profesionales brasileños vinculados con Intuiciones de Enseñanza o de Investigación Tecnológica con experiencia en el tema abordado y que están ubicados en Brasil, Portugal y España.

- Grupo $3 \rightarrow$ Está constituido por 408 personas - conocedoras de productos desarrollados a partir de fibras naturales, ubicados en Brasil - más específicamente en el estado de Amazonas (Región Norte del país), que participan de una encuesta a consumidores con el objetivo de verificar el grado de aceptación del uso de la fibra natural amazónica de tucumã-i (Astrocaryum acaule) para el desarrollo de productos semi-industrial. Así como también, identificar la categoría y tipo de producto para la aplicación del objeto de estudio.

\subsubsection{Procedimientos para la captación de datos, instrumentos a utilizar y métodos para el control y calidad de estos.}

Los procedimientos que serán utilizados para la recolección de información contemplan: dinámica de grupo focal, entrevista en profundidad y encuesta a población. Por lo tanto, los instrumentos elegidos para recopilar las informaciones son: guía de moderador del grupo focal, guía de entrevista, cuestionario y guía de análisis de contenido. Cada una de las actividades tendrá un método específico para proceder con la recopilación de los datos, así como para controlar y validar la calidad de estos. A saber: 


\section{a. Dinámica de grupo focal}

La dinámica de grupo focal es una herramienta de investigación cualitativa que consiste en la grabación de un grupo de discusión y la transcripción detallada de las respuestas y de las opiniones, tiene una duración de una o dos horas, y es dirigida por un moderador. La técnica proporciona un foro para recabar ideas y comentarios. La gran ventaja de la actividad es la producción de conocimientos (Krueger \& Casey, 2000).

Las discusiones suelen ser grabadas por audio y/o vídeo para garantizar un registro preciso de las interacciones y permitir la identificación de las respuestas. El tamaño de la muestra es pequeña, de 6 a 12 personas; no permite las pruebas o generalizaciones estadísticas, sino más bien una exploración de los temas seleccionados sin forzar las ideas preconcebidas de sus áreas de conocimiento (Clifton \& Handy, 2001).

Por tanto, la captación de opiniones e ideas al respecto del estudio de la fibra natural Amazónica de tucumã-i (Astrocaryum acaule) para su aplicación en productos por procesos semi-industriales, será elaborada en una sesión de focus group con 13 participantes especialistas en diseño, se realiza en la Universidad Politécnica de Valencia, en la sede de la ciudad de Valencia, España, con una duración de 01h 30min, donde la información será grabada en cinta de audiotape, audiovideo y documentada por escrito.

Un moderador comandará la actividad, basándose en una guía con información sobre el tema de discusión, presentará la propuesta de estudio, los objetivos, las justificaciones y la estructura planeada para la sesión; igualmente, ilustrará el tema con varias citas y los posibles aspectos relacionados al contexto del objeto investigado.

Los especialistas en diseño participan activamente del proceso de discusión, teniendo en cuenta las fortalezas y debilidades del objeto en estudio. Así, los pasos considerados esenciales para la estructuración de la investigación serán descritos por los miembros de la sesión. Al final de la actividad, todas las informaciones serán grabadas y redactadas para su posterior aprobación por los participantes. La Tabla 1 muestra la estructura y el procedimiento adoptados para la práctica de grupo focal aplicada para este estudio.

Tabla 1. Grupo Focal - Estructura y Procedimiento

\begin{tabular}{ll}
\hline Elementos & Dinámica de Grupo \\
\hline Formato & $\rightarrow$ Sesión de Grupo \\
Tamaño & $\rightarrow 13$ participantes \\
Duración & $\rightarrow 1 \mathrm{~h}$ a $1: 30 \mathrm{~h}$ \\
Número de sesión & $\rightarrow 1$ sesión \\
Participantes & $\rightarrow$ Especialistas en Diseño \\
\hline
\end{tabular}




\begin{tabular}{ll}
\hline Forma de datos & $\rightarrow$ Conversación \\
Recopilación de datos & $\rightarrow$ Audiotape; \\
& $\rightarrow$ Audiovideo; \\
& $\rightarrow$ Transcribir \\
Moderador & $\rightarrow$ Profesional de Diseño \\
& $\rightarrow$ Flexible, pero centrado en el tema $;$ \\
& $\rightarrow$ Usa guía de entrevista \\
Formatos de Comunicación & $\rightarrow$ Citas seleccionadas; \\
& $\rightarrow$ El análisis de temas frecuentes \\
Información producida & $\rightarrow$ Redacción y presentación de datos para la \\
& aprobación de los participantes \\
\hline
\end{tabular}

\section{b. Entrevista en profundidad}

La entrevista en profundidad es también una técnica de investigación cualitativa que implica la realización entrevistas individuales intensivas, con un pequeño número de encuestados para explorar sus puntos de vista sobre una idea, programa o situación (Boyce \& Neale, 2006). Es considerada como una fuente de información no estructurada y directa, que se realiza con cada persona (Malhotra, 2006).

Para este estudio, la entrevista ha sido estructurada en base a las informaciones consideradas pertinentes por el focus group. Para tanto, es importante atribuir tiempo y atención al planeamiento de la entrevista, a la selección de los participantes (profesionales relacionados con el tema para el debate) y la preparación de preguntas específicas.

La entrevista en profundidad se llevó a cabo mediante la participación de 11 expertos (Tabla 2) pertenecientes a las áreas: Textil, Ingeniería Industrial, Medio Ambiente, Diseño y Productos de Mercado.

Tabla 2. Entrevista en profundidad - Expertos

\begin{tabular}{lll}
\hline Expertos & Formación & Actuación Profesional en: \\
\hline Experto 1 & Ingeniería Química & Ingeniería Textil \\
Experto 2 & Diseño Industrial & Diseño de Productos \\
Experto 3 & Ingeniería Forestal & Productos Forestales \\
Experto 4 & Ciencias Económicas & Mercado y Productos \\
Experto 5 & Ingeniería de Producción & Ingeniería de Producción \\
Experto 6 & Diseño Industrial & Diseño \\
\hline
\end{tabular}


Estudio de la prospección del uso de la fibra de tucumã-i (Astrocaryum acaule) para el desarrollo de productos semi-industriales

\begin{tabular}{lll}
\hline Experto 7 & Ingeniería Química & Química/ Textil \\
Experto 8 & Diseño Industrial & Diseño /Textil \\
Experto 9 & Ingeniería Química & Ingeniería Química \\
Experto 10 & Diseño Industrial & Diseño de Productos \\
Experto 11 & Ciencias Económicas & Mercado y Productos \\
\hline
\end{tabular}

Como se trata de una investigación direccionada al estudio de una fibra natural específica de la Amazonia brasileña, para su aplicación en productos mediante la utilización de procesos semi-industriales, y dado que el estudio se ha realizado en la Escuela Técnica Superior de Ingeniería del Diseño - ETSID de la Universitat Politècnica de València, en la sede de la ciudad de Valencia/España, se optó por elegir algunos profesionales ubicados en Brasil, Portugal y España - todos con experiencia en el tema abordado. De esta manera, los cuestionarios y el consentimiento escrito se prepararon y enviaron a los entrevistados mediante correo electrónico, donde se adjuntó una nota explicativa sobre la naturaleza e importancia de la investigación.

\section{c. Encuesta a la población objetivo}

La encuesta es una técnica de recogida de información por medio de preguntas escritas organizadas en un cuestionario impreso. Se trata de un proceso interrogativo que delimita su valor científico en las reglas de procedimiento. Se utiliza para conocer lo que opina la gente sobre una situación o problema que lo involucra. Es también empleada para investigar hechos o fenómenos de forma general y no particular (Montemayor, Velia, Treviño, \& Gorena, 2002).

En este contexto, donde la encuesta se considera como un sondeo de opinión, es primordial realizar un estudio acerca del grado de aceptación la fibra de tucumã-i (Astrocaryum acaule) para el desarrollo de productos semiindustriales. Para tanto, la aplicación de una encuesta dirigida a consumidores de productos hechos con fibras naturales, sobre todo las fibras naturales vegetales, podrá demonstrar el nivel de opinión del usuario con respecto al tema de investigación propuesto, así como también identificar las variables que contemplen los aspectos de las propiedades tecnológicas, categorías y tipos de productos que podrán ser desarrollados a partir de la fibra natural amazónica en estudio.

El método a aplicar en la encuesta es de tipo probabilístico, estratificado, aleatorio simple sistemático que puede dar la misma precisión de estimación acerca de la población que en un muestreo aleatorio simple cuando los 
elementos en la población están distribuidos al azar (Lohr, 2000), premisa que se cumplirá dado a que el muestreo corresponde a un muestreo probabilístico.

Por lo tanto, se pretende aplicar la encuesta a personas de nacionalidad brasileña, ubicadas principalmente en la ciudad de Manaus - estado de Amazonas (región norte de Brasil) - área de concentración, producción y comercialización del objeto de estudio. Pero no irá impedir la participación de personas pertenecientes a otras ubicaciones de Brasil, una vez que el cuestionario será enviado por mail y contestado por internet.

El tamaño de la muestra se determinará bajo los siguientes supuestos: M.A.S. (Muestreo Aleatorio Simple), para Estimador de Proporción, Nivel de Confianza de $95 \%$ y Varianza Máxima $(\mathrm{p}=\mathrm{q}=0,5)$ donde la expresión que relaciona el error con el tamaño de la muestra es la siguiente:

$$
e=z^{\prime} \sqrt{\frac{N-n}{N}}, \sqrt{\frac{s^{2}}{n}} \text { (Martínez \& Martínez, 2006) }
$$

Dónde:

e : error muestra

$z$ : coeficiente de confianza (para un 95\% de confianza)

$\mathrm{s}^{2}$ : Varianza máxima

El cálculo de tamaño de la muestra para el caso de proporciones se realizará mediante la siguiente ecuación:

$$
n=\frac{N z^{2} p q}{z^{2}(N-1)+z^{2} p q}
$$

Siendo $\mathrm{n}$ el tamaño muestral, $\mathrm{N}$ el tamaño de la población, $\mathrm{z}$ el error muestral, $\mathrm{p}$ el valor de probabilidad binomial correspondiente a la proporción de personas que cumplen con el atributo de interés y q la proporción de personas que no cumplen con el atributo de interés (Levy \& Lemeshow, 1999; Lohr, 2000; Vivanco, 2005; Martínez \& Martínez, 2006). En este caso se asume $\mathrm{p}=\mathrm{q}=0,5$. La evaluación y grado de aceptación de los usuarios es uno de los aspectos centrales para conocer en qué medida dichos objetivos son logrados. Por esto, la unidad principal de análisis es el individuo para el uso y satisfacción con la aplicación de la fibra natural amazónica de tucumã-i (Astrocaryum acaule) en productos semi-industriales. La encuesta presentará en su estructura, preguntas de respuesta abierta, preguntas para selección múltiple de respuestas y preguntas de respuesta jerarquizada. Todas serán 
Estudio de la prospección del uso de la fibra de tucumã-i (Astrocaryum acaule) para el desarrollo de productos semi-industriales

formuladas con bases en los siguientes temas correlacionados abajo (Figura 4):

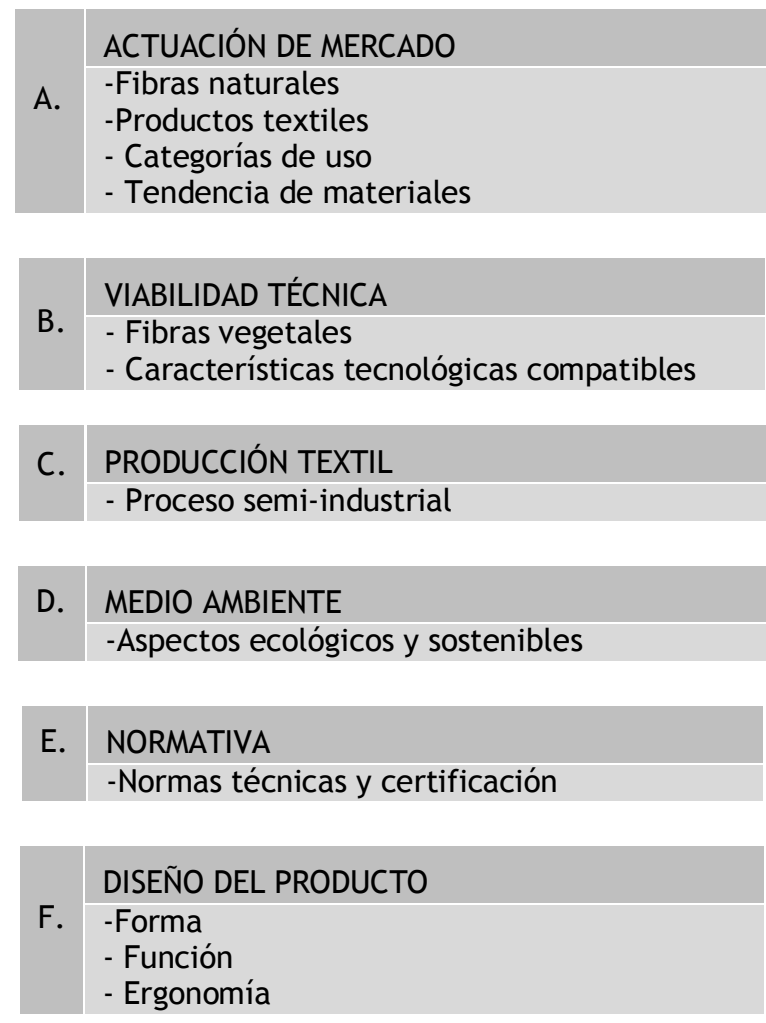

Figura 4. Temas abordados por la encuesta

d. Procedimientos para garantizar los aspectos éticos de las investigaciones con sujetos humanos

Los estudios de opinión y de mercado se apoyan en la colaboración voluntaria de las personas y en la confianza de que son realizados con toda honestidad y objetividad, sin que las personas entrevistadas sean importunadas o sufran molestias de cualquier índole. Ambos emplean la recolección y el análisis de la información a través de muestreo, de cuestionarios y otras técnicas apropiadas.

Los procedimientos para la investigación deben, igualmente, ser realizados conforme a los principios de la competencia leal, tal como son generalmente comprendidos y aceptados y según estándares técnicos de alto nivel. Los 
investigadores de mercado y de opinión deben estar dispuestos siempre a comunicar las informaciones necesarias que permitan comprobar la calidad de sus trabajos y la validez de los resultados.

El público, en general, o cualquier otra parte interesada, tiene derecho a que se le garantice que todo estudio de mercado es realizado en estricta conformidad con las disposiciones del Código Internacional de la Asociación Europea de Estudios de Opinión y Mercado (ESOMAR9 de 1976), en cuanto a la protección de su privacidad, son respetados.

Sobre este contexto, se pretende en esta investigación:

- Trabajar mediante el anonimato de los entrevistados cumpliendo la norma del artículo 2 del Código de ética que enfatiza el siguiente $\rightarrow$ Ninguna información que pueda servir para identificar a las personas entrevistadas, sea directa o indirectamente, debe ser divulgada a nadie, a excepción del personal de investigación perteneciente a la organización del investigador que necesita de esta información para la realización y el control de las entrevistas, tratamiento de los datos, etc.

- Considerar los derechos de los entrevistados, conforme artículo $6 \rightarrow$ Todas las precauciones razonables deben ser tomadas a fin de asegurarse que la persona entrevistada y sus familiares no sufrirán ninguna incomodidad o molestia a consecuencia de la entrevista. La persona entrevistada debe estar informada del objeto de la encuesta cuando, por no estarlo, se arriesga a facilitar informaciones que podrían perjudicarlo.

- Presentar los resultados de un estudio, de acuerdo con el artículo $33 \rightarrow \mathrm{El}$ investigador debe hacer una clara distinción entre los resultados propiamente dichos y la interpretación de los mismos, así como de sus recomendaciones sea en forma de informe escrito, de exposición oral, o en cualquier otra forma.

\subsubsection{Análisis y validación de los resultados}

Para proceder con los análisis y validación de las informaciones obtenidas a partir de las técnicas, presentadas anteriormente, se pretende aplicar los siguientes métodos y herramientas de trabajo:

\section{a. Método DAFO para el grupo focal y la entrevista en profundidad}

El análisis DAFO es una herramienta de apoyo importante para la toma de decisiones y se utiliza a menudo como un medio para analizar el entorno interno y externo de una organización o un producto (Kotler, 1998). La información obtenida puede ser sistemáticamente representada en una matriz 
(Ulgen \& Mirze, 2004), o en diferentes combinaciones de los cuatro factores de la matriz (Dincer, 2004) y puede ayudar a determinar las estrategias a largo plazo. El resultado del análisis DAFO puede generar una simple enumeración o un examen cualitativo de los factores internos y externos a considerar cuando se estudian objetos (Kangas, Kurtila, Kajanus, \& Kangas, 2003).

El escenario para la identificación de oportunidades y limitaciones del estudio de la fibra de tucumã-i (Astrocaryum acaule) para su aplicación en productos a través de un proceso semi-industrial, se establecerá de acuerdo con el método DAFO (Figura 5), que hará un análisis del entorno externo que incluye el universo del objeto de estudio identificando así las oportunidades y amenazas. Luego el mismo procedimiento será utilizado para observar el ambiente interno que rodea las fortalezas y debilidades en la fibra de tucumã-i (Astrocaryum acaule) de acuerdo con los objetivos planteados en la investigación, validando las informaciones obtenidas por las técnicas anteriormente aplicadas.

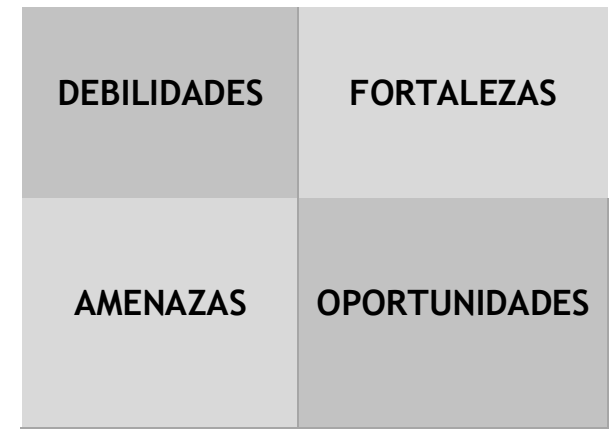

Figura 5. Matriz DAFO

b. Modelo del Diseño concurrente para la sistematización de las informaciones pertinentes a la aplicación del objeto de estudio para el desarrollo de productos semi-industriales

El modelado de sistemas utilizado se basa en el modelo de Ashby y se desarrolló en la Escuela de Investigación Operativa y Sistemas de Valencia (España). Hay varios modelos basados en el desarrollo de Ashby, pero el elegido por esa escuela fue el modelo español para la formulación de objetivos. El modelo de diseño concurrente es una variante del sistema de modelado utilizada para el desarrollo de productos industriales (Hernandis, 2003). 
El uso de este modelo (Figura 6) se justifica por la posibilidad de examinar las variables necesarias para el diseño, a través del análisis de los aspectos formales, funcionales y ergonómicos del objeto en estudio, y a partir de esta información, obtener los parámetros de referencia para la construcción de una estructura modular dirigida al diseño de productos semi-industriales que podrán ser desarrollados a partir de la fibra de tucumã-i (Astrocaryum acaule) de acuerdo con los objetivos planteados por esta investigación. La figura 9 muestra una representación gráfica del modelo.

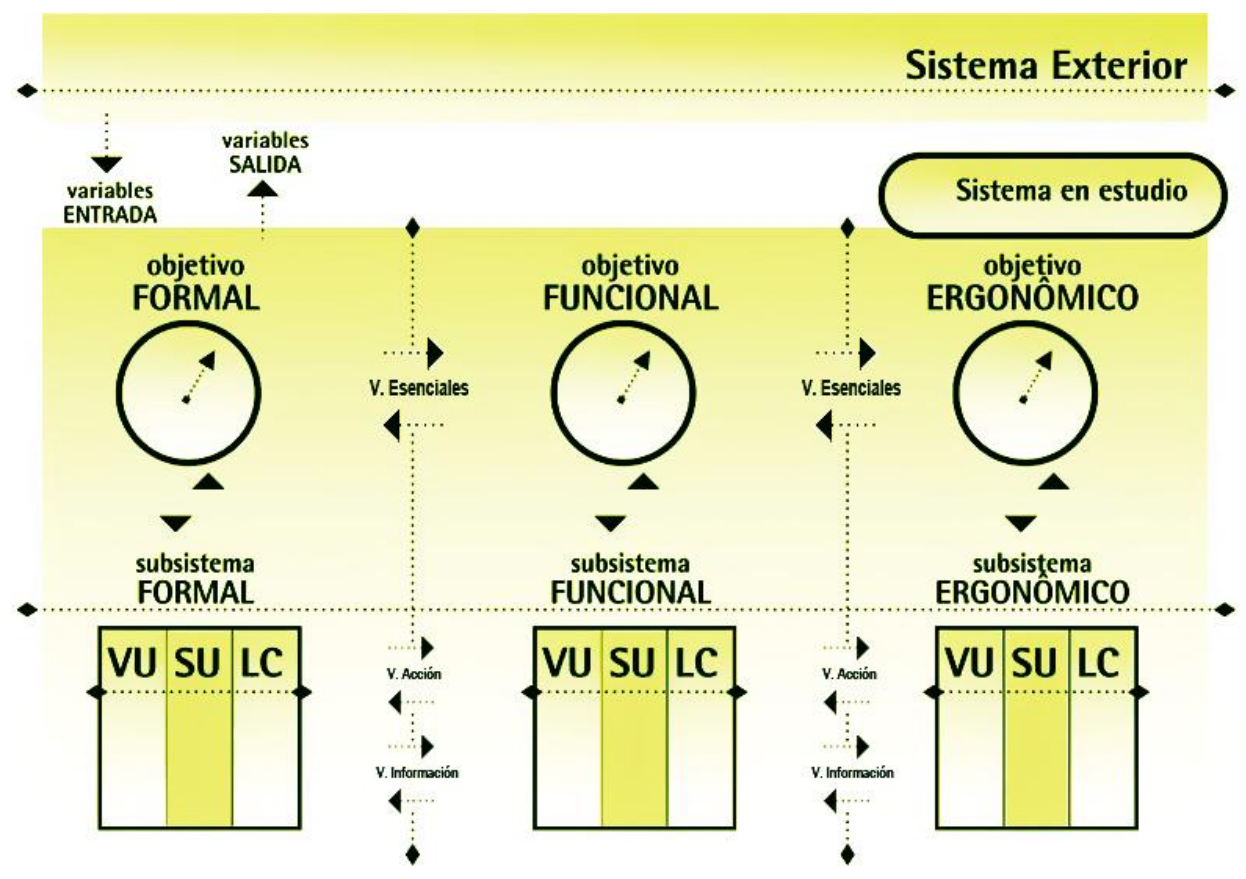

Figura 6. Representación gráfica del modelado, Hernandis (2003).

c. Aplicación del Statistical Package for the Social Sciences (SPSS) para el estudio y análisis de los datos estadísticos

SPSS es un poderoso sistema de análisis estadístico y de gestión de datos. Una herramienta capacitada para trabajar con bases de datos de gran tamaño, pudiendo se llevar a cabo análisis útiles de sus datos de forma práctica y sencilla, haciendo la recodificación de las variables y registros según las necesidades del usuario, consistiendo en un módulo base y módulos anexos actualizados constantemente y trabajados a través de procedimientos 
estadísticos (Martínez A. G., 2005) específicos y compatibles al contexto de los datos que se desea obtener en esta investigación, que son entre éstos:

- La clasificación de los datos $\rightarrow$ que permite realizar agrupaciones de observaciones o de variables (cluster analysis) mediante tres algoritmos distintos.

- Análisis por tablas $\rightarrow$ que permite al usuario dar un formato especial a las salidas de los datos para su uso posterior.

\section{- Tendencias}

- Identificación de las categorías de informaciones $\rightarrow$ que permite realizar análisis multivariante de variables normalmente categorías. También se pueden usar variables métricas siempre que se realice el proceso de recodificación adecuado de las mismas.

- Análisis Conjunto $\rightarrow$ que permite realizar el análisis de datos recogidos para este tipo específico de pruebas estadísticas.

- Análisis de Valores Perdidos $\rightarrow$ que permite una regresión simple basada en imputaciones sobre los valores ausentes.

- Validación de Datos $\rightarrow$ que permite al usuario realizar revisiones lógicas de la información contenida en un fichero y obtener reportes de los valores considerados atípicos. Es similar al uso de sintaxis o scripts para realizar revisiones de los ficheros. De la misma forma que estos mecanismos es posterior a la digitalización de los datos.

\subsubsection{Estructura planeada para el desarrollo de los artículos para la producción de la tesis por compendio de publicaciones}

La producción de los artículos que forman parte del documento de investigación desarrollado de acuerdo con la modalidad "Tesis por compendio de publicaciones" está basada en el siguiente cuadro de actividades abajo identificado (Figuras 7, 8, 9 y 10). 


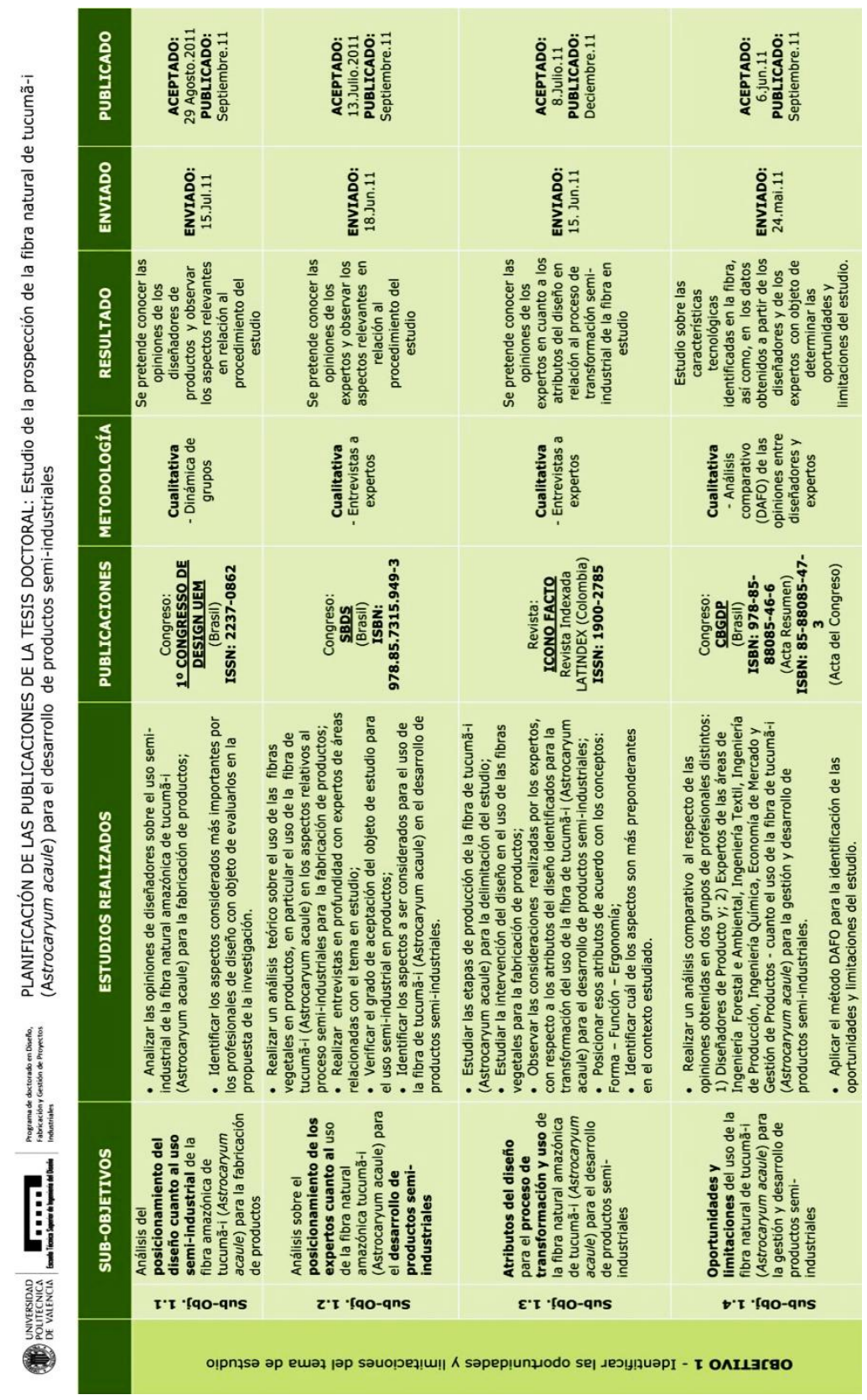

Figura 7. Cuadro con los objetivos y sus sub-objetivos de la tesis - Parte 1 (disponible para consulta en los ANEXOS). 


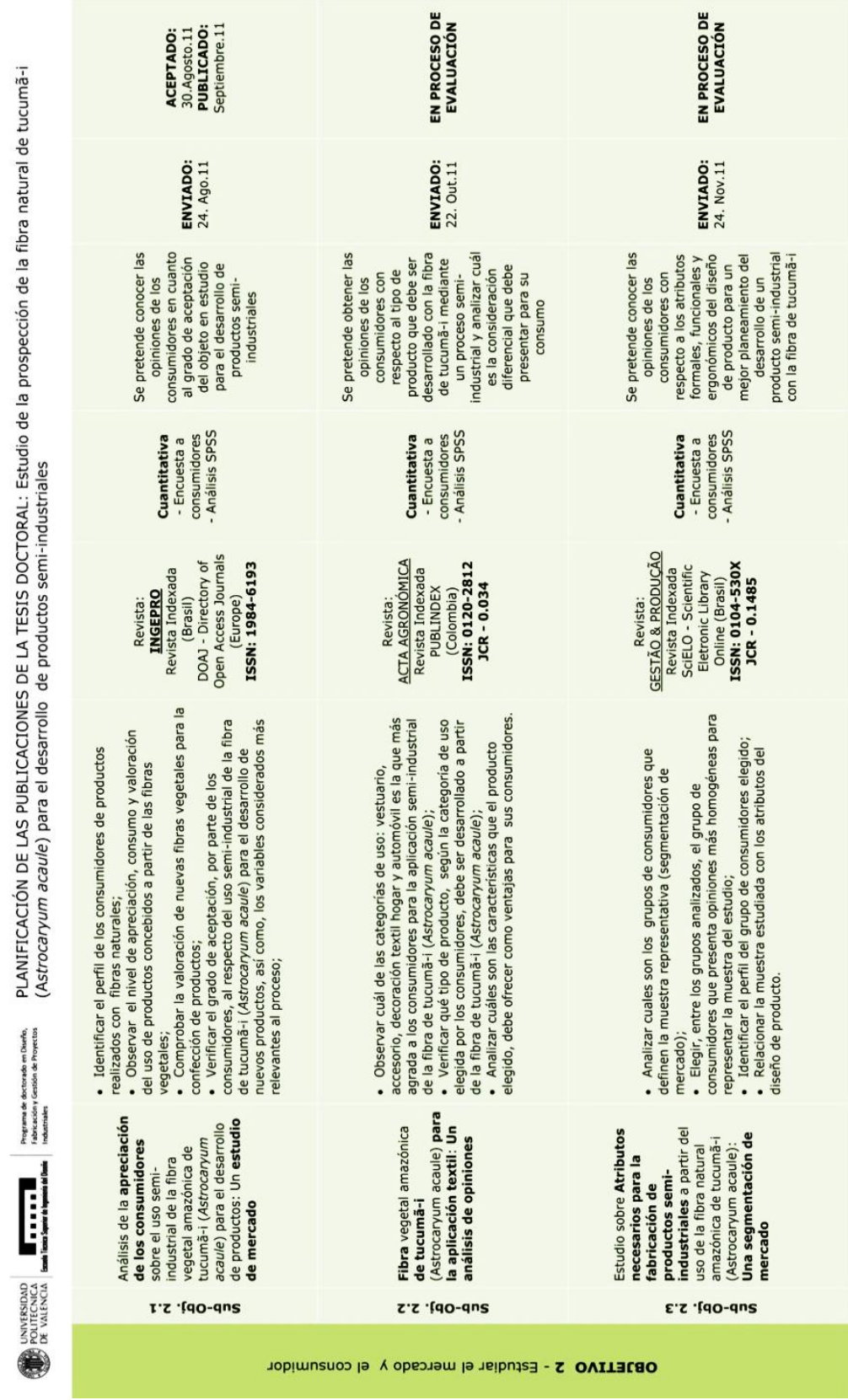

Figura 8. Cuadro con los objetivos y sus sub-objetivos de la tesis - Parte 2 (disponible para consulta en los ANEXOS). 


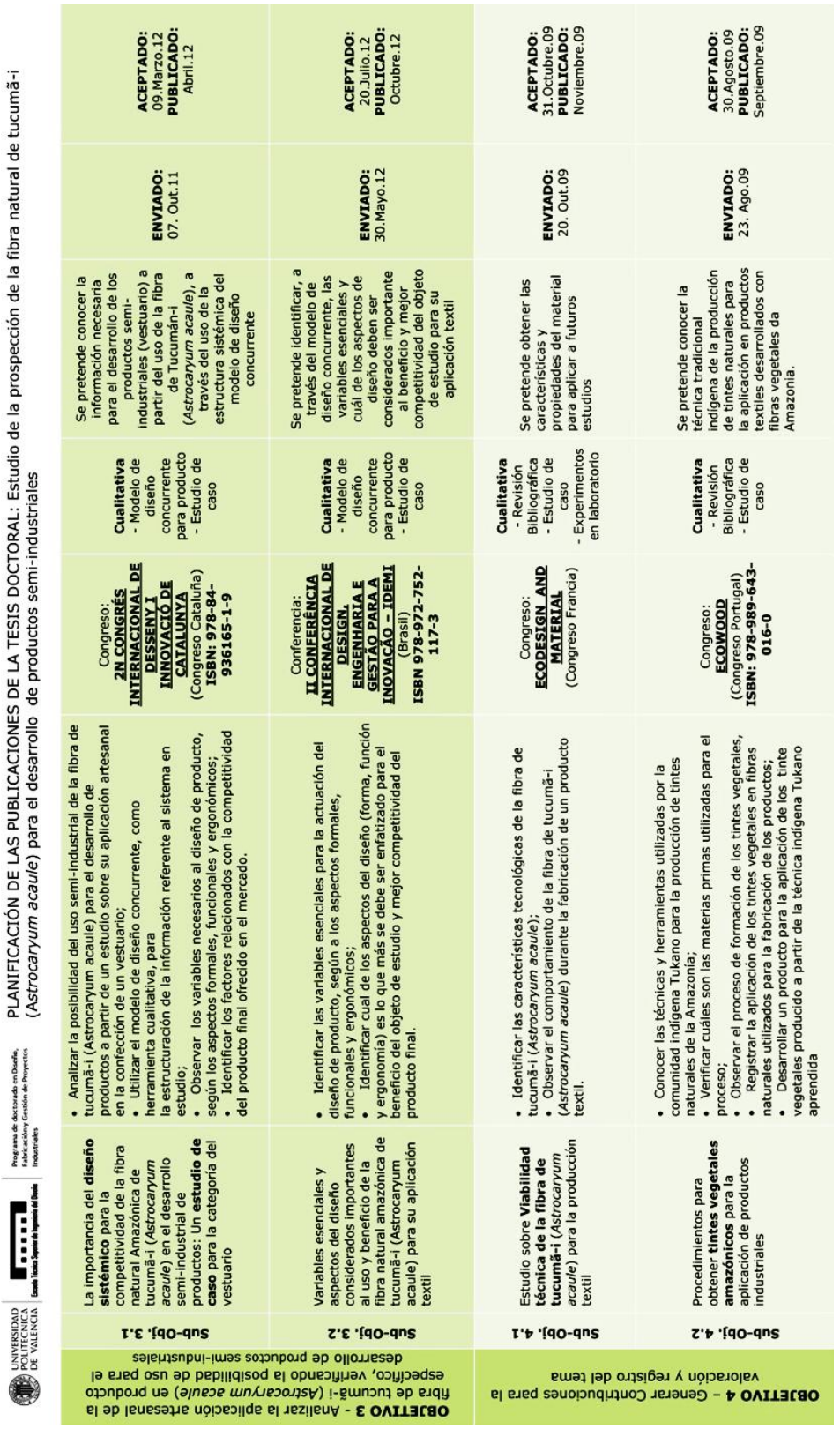

Figura 9. Cuadro con los objetivos y sus sub-objetivos de la tesis - Parte 3 (disponible para consulta en los ANEXOS). 


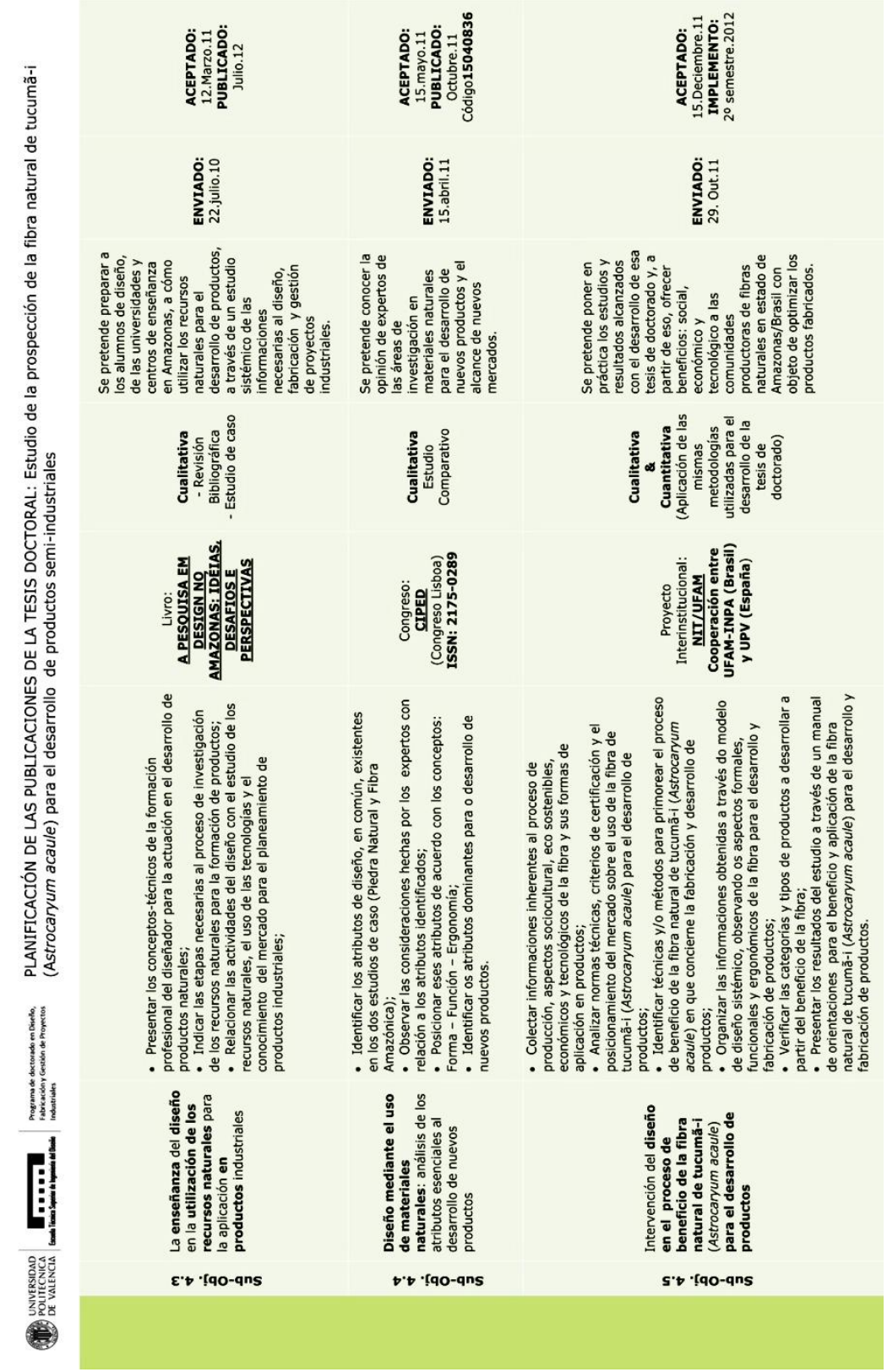

Figura 10. Cuadro con los objetivos y sus sub-objetivos de la tesis - Parte 4 (disponible para consulta en los ANEXOS). 


\subsection{Estructura de la tesis}

El trabajo está dividido en 4 capítulos. El capítulo 1 presenta una introducción, donde son abordados los ítems relacionados con: la motivación del estudio; la contextualización del tema; la identificación del problema; los objetivos de la tesis; las hipótesis; la justificación - centrada en los factores social, tecnológico, económico, ambiental y científico; la delimitación del estudio - basada en los aspectos que involucran: el tipo de material (materia prima amazónica), la opinión de mercado (uso comercial), la posibilidad de transformación (proceso tecnológico semi-industrial) y el registro científico a partir de los objetivos alcanzados; los materiales y métodos utilizados para el alcance de los objetivos propuestos, los procedimientos adoptados, los instrumentos aplicados para la recolección de datos, los demostrativos y los análisis desarrollados para la obtención de los resultados esperados y; por último, la estructura la tesis.

En el capítulo 2 presenta el estado del arte, posicionado de acuerdo con las siguientes informaciones: fibras naturales - describiendo el escenario de uso para el desarrollo de productos y observando de forma general los aspectos productivos, ambientales, sociales, económicos, mercadológicos; otra cuestión averiguada se trata de la búsqueda de nuevas fibras naturales para la innovación y competitividad en el mercado; en seguida, el capítulo examina la fibra natural amazónica de tucumã-i (Astrocaryum acaule), su origen, los aspectos socio-cultural, sostenible, productivo, comercial y su posicionamiento en relación a las propiedades tecnológicas comparadas a otras fibras similares, al proceso tecnológico y en cuanto al precio/costo de la fabricación de productos. Después de un abordaje más direccionado al contexto de las fibras naturales; el capítulo aborda la viabilidad de nuevas tecnologías y transferencia de conocimiento para la mejora del proceso de transformación de las fibras naturales para el desarrollo de productos y con eso, los procesos tecnológicos, el cambio de informaciones y la posible transición del aspecto artesanal al semi-industrial. Por otra parte, el capítulo 2 posee información sobre la utilización del diseño como factor estratégico para la sistematización de informaciones sobre el uso de la fibra natural de tucumã-i (Astrocaryum acaule) para la gestión, desarrollo y fabricación de productos semi-industriales, situando el proceso investigativo, en cuál son observadas: las oportunidades y límites del producto para su inserción en el mercado; el proceso para el estudio de mercado (consulta de opiniones/ expertos/ consumidor); identificación de los atributos necesario al diseño del producto y la sistematización de los datos.

En el capítulo 3 se presentan, en orden secuencial, los artículos previamente publicados, aceptados y en proceso de evaluación para su publicación y que 
Estudio de la prospección del uso de la fibra de tucumã-i (Astrocaryum acaule) para el desarrollo de productos semi-industriales

guardan relación entre sí. Todos fueron trabajados de acuerdo con los objetivos determinados para el desarrollo del estudio y en conformidad con la estructura establecida para la producción de los artículos.

Por fin, el capítulo 4 presenta la discusión final con una síntesis de los resultados alcanzados en función de los objetivos propuestos, así como las respuestas obtenidas para suplir el problema identificado en el objeto de estudio, las conclusiones generadas y algunas recomendaciones consideradas necesarias para el fortalecimiento de la investigación, permitiendo e incentivando la realización de nuevos estudios y posibilitando futuras líneas de investigación. 


\section{Referencias}

ABNT - Associação Brasileira de Normas Técnicas. (1999). Ensaios de Proficiência por Comparações Interlaboratoriais - ABNT: 43-1.1999. São Paulo - SP: ABNT.

ASTM - Annual Book of Astm Standart. (1984). ASTM - Annual Book of Astm Standart. Pennsylvania: Wood.

Blaxter, L., Hughes, C., \& Tight, M. (2002). Cómo se hace una investigación. Barcelona: Gedisa.

Boyce, C., \& Neale, P. (2006). http://www.pathfind.org/site/DocServer/. Acesso em 05 de Octubre de 2010, disponivel em Conducting In-Depth Interview: a guide for designing and conducting In-Depth Interviews for evaluation input. Pathfinder International Tool Series, monitoring and evaluation - 2. USA.

Capobianco, J. P. (2001). Dossiê Mata Atlântica 2001: Projeto Monitoramento Participativo da Mata Atlântica. São Paulo: Rede de ONGs da Mata Atlântica.

Clifton, K. J., \& Handy, S. L. (2001). Qualitative Methods in Travel Behaviour Research. . International Conference on Transport Survey Quality and Innovation. South Africa.: Kruger National Park.

Dincer, O. (2004). Strategy Management and Organization Policy. Istanbul: Beta Publication.

Figueiras, A. (2008). A importância de fibras e fios no design de têxteis destinados à prática desportiva. Rio de Janeiro: PUC-Rio/Brasil.

Finkler, M., Scapini, P., Freire, E., Zattera, A. J., \& Zeni, M. (2005). Compósitos de HDPE com resíduos de fibras têxteis $I$. Caracterização mecânica. São Paulo: Polímeros.

Gil, A. C. (2002). Como elaborar projetos de pesquisa. São Paulo: Atlas.

Hernandis, B. (2003). Tesis Doctoral: Desarrollo de una metodología sistémica para el diseño de productos industriales. Valencia - España: Universidad Politécnica de Valencia - UPV.

Holbery, J., \& Houston, D. (2006). Natural-fibre-reinforced polymer composites in automotive applications. . Journal of the Minerals, Metals and Materials Society , 58: 80-86.

Kangas, J., Kurtila, M., Kajanus, M., \& Kangas, A. (2003). Evaluating the management strategies of a forestland estate-the S-O-S approach. Journal of Environmental Management , 69, 349-358. 
Kotler, P. (1998). Marketing Management: Analysis, Planning, Implementation and Control. New Jersey: Prentice- Hall.

Krueger, R. A., \& Casey, M. A. (2000). Focus groups: A practical guide for applied research. . California: Thousand Oaks, Calif.: SAGE Publications.

Levy, P., \& Lemeshow, S. (1999). Sampling of Populations: Methods and Applications. New York: Wiley.

Lohr, S. (2000). Muestreo, diseño y análisis. México: Ed. Thomson.

Macía, M. (2006). Las plantas de fibra. Botánica Económica de los Andes. La Paz - Bolivia.: Centrales Editores: M. Moraes R., B. Øllgaard, L. P. Kvist, F. Borchsenius \& H. Balslev. Universidad Mayor de San Andrés.

Maciel, K. M. (17 de Agosto de 2007). http:// www.ppgcifa.ufam.edu.br/dissertacao.html. Acesso em 24 de Maio de 2008, disponível em Programa de Pós-graduação em Ciências Florestais e Ambientais da Universidade Federal do Amazonas.

Malhotra, N. K. (2006). Pesquisa de marketing. Porto Alegre - Brasil: Bookman.

Marconi, M. A., \& Lakatos, E. M. (2006). Fundamentos de metodologia cientifica. . São Paulo: Atlas.

Marinelli, A. L., Monteiro, M., Ambrósio, J. D., Brancifort, M. C., Kobayashi, M., \& Nobre, A. D. (2008). Desenvolvimento de compósitos poliméricos com fibras vegetais naturais da biodiversidade: uma contribuição para a sustentabilidade amazônica. . Polímeros Ciência e Tecnologia , 18(2):92-99.

Martínez, A. G. (2005). SPSS para todos. Bogotá, Colombia: bonaventuriana.

Martínez, J. A., \& Martínez, L. (2006). El Factor de Imprecisión sobre la Escala de Medida (FIEM) en la estimación de medias en un muestreo aleatorio simple. Investigación y Márketing , 92, 66-70.

Menezes, M. R., Pinheiro, R., Guazzell, A. C., \& Martins, F. (2005). Cadeia produtiva das fibras vegetais extrativistas no estado do Amazonas. . Manaus AM.: Governo do Estado do Amazonas: SDS. Série Técnica. Meio Ambiente e Desenvolvimento Sustentável.

Montemayor, H., Velia, M., Treviño, M. C., \& Gorena, Y. G. (2002). Guía para la investigación documental. México: Trillas.

Olesen, A. B. (1997). Karakterisering af Plantefibre (Characterization of Plant Fibres: Plant Fibre Laboratory. Report No.1, 39 p. 
Oliveira, M. H. (2000). Principais Matérias-primas utilizadas na indústria têxtil. . São Paulo: Setorial de Bens de Consumo Não-Duráveis do BNDES. .

Organización de las Naciones Unidas. (2009). http://www.naturalfibres2009.org/es/aifn/index.html. Acesso em 02 de Octubre de 2009, disponível em International Year of Natural Fibres: http://www.naturalfibres2009.org

Pletsch, M. (1998). Compostos naturais biologicamente ativos. Biotecnologia, Ciência e Desenvolvimento - Scielo , v. 4, p. 12-15.

Schwartzman, S. (2004). Mercado para produtos extrativistas da Amazônia brasileira. In ARNT, A. R. O destino da floresta. Reservas extrativistas e desenvolvimento sustentável na Amazônia. Rio de Janeiro - RJ: Relume Dumará.

Souza, H. M. (2004). Palmeiras brasileiras e exóticas cultivadas. São Paulo: Nova Odessa - Instituto Platarum.

Trochim, W. M. (2002). http://trochim.human.cornell.edu/kb/index.htm . Acesso em 15 de Octubre de 2010, disponível em The Research Methods Knowledge Base.

Ulgen, H., \& Mirze, S. K. (2004). Strategic Management. Istanbul: Literatur Publication.

Vivanco, M. (2005). Muestreo Estadístico. Diseño y Aplicaciones. . Santiago de Chile: Editorial Universitaria. 

Capítulo 2 - Marco teórico 



\section{Marco teórico}

\subsection{El uso de las fibras vegetales para el desarrollo de productos}

La preferencia por utilizar las fibras vegetales en el desarrollo de productos se justifica debido a la existencia de ventajas productivas (disponibilidad, bajos costos de adquisición y facilidad de procesamiento), físicas (baja densidad, características de aislamiento y resistencia estructural, etc.), bioquímicas (inocuidad, biodegradabilidad), entre otras (Holbery \& Houston, 2006). Las ventajas productivas, fisicotérmicas, ambientales y bioquímicas de las fibras naturales propician su utilización como una alternativa para impulsar el uso racional de los recursos naturales y la preserva ambiental (Cadena \& Silvera, 2002). Así mismo y según FAO (2004), las fibras naturales se aplican, por lo general, en una gran variedad de productos y de muchas formas, entre las cuales figuran el uso como relleno o refuerzo, aislamiento, el uso como elemento estructural, y también teniendo en cuenta en consideración como productos desechables o duraderos, a saber:

- hilos y textiles; cuerdas, bramantes y redes;

- telas no tejidas, tejidos;

- productos de papel y cartón;

- embalajes;

- materiales de edificios y construcciones, tableros de fibra, aislamiento, geotextiles y;

- compuestos y piezas para automoción.

La demanda de productos desarrollados con fibras naturales aparece en el consumidor y despierta el interés en producción como resultado de la potencialidad del negocio, sobretodo porque éstas materias primas están en el centro del movimiento impulsado por la eco-moda o "material sostenible" que se focaliza en las preocupaciones globales: por el medio ambiente y por el bienestar de los productores y consumidores. Además, la utilización de esta categoría de fibras para el desarrollo de productos toma como objetivo crear objetos de uso que sean sostenibles en cada etapa de su ciclo de vida, desde su producción hasta su eliminación adoptando prácticas de "comercio justo" que ofrecen precios más favorables para los productores y protege a los trabajadores (Organización de las Naciones Unidas, 2009). 


\subsubsection{Aspectos productivos}

La producción de fibras naturales, tanto vegetales como animales sigue siendo muy importante hoy en día, en plena era de la tecnología, por la importancia fundamental que tienen en el conjunto de toda la oferta de fibras (FAO, 2004). Su producción supone una importante fuente de ingresos: se trata de un sector que genera para los agricultores de todo el mundo unos 29.000 millones de euros anuales (Vargasa \& Quispeb, 2009).

Los productores y fabricantes afrontan el reto de crear y mantener los mercados en los que puedan competir con eficacia contra las fibras sintéticas. Esto ha significado definir y promover nichos de mercado, donde las ventajas naturales les permiten competir con eficacia contra las fibras sintéticas, se requieren investigación básica y desarrollo para facilitar el uso de las fibras naturales en aplicaciones nuevas (Natural Fibres, 2009).

\subsubsection{Aspectos ambientales}

Actualmente, las fibras naturales, se han convertido en material de estudio y adquiriendo gran importancia como consecuencia de la crisis del petróleo, de las nuevas reglamentaciones ambientales, del desarrollo sostenible, de los productos verdes y de la reducción del gasto energético (Forero, 2007). La creciente conciencia de los aspectos ecológicos en la producción y el consumo de materias primas han liderado las tendencias para el uso sostenible de los recursos naturales (Van Dam, Van Vilsteren, Zomers, Shannon, \& Hamilton, 1994). El mayor uso de las fibras naturales en la fabricación de productos o como nicho de mercados, con un mínimo impacto ambiental, requiere el conocimiento de sus propiedades básicas, y a nivel internacional podemos observar un gradual interés por parte del consumidor para adquirir productos de los que conozca su origen, así como la forma en que fueron producidos, también que no dañen su salud y que garanticen que no contaminarán el planeta, siendo así denominados productos "sustentables" (INTI, 2009).

\subsubsection{Aspectos sociales}

En muchos países considerados en vías de desarrollo o no tan adelantados, los beneficios procedentes de la venta y exportación de las fibras naturales contribuyen considerablemente a los ingresos y por ende a la seguridad alimentaria de los agricultores pobres así como los trabajadores de las industrias de las fibras (Organización de las Naciones Unidas, 2009).

Para algunos países las fibras naturales tienen una importancia económica fundamental a nivel nacional, por ejemplo, el algodón en algunos países del África occidental, el yute en Bangladesh y el sisal en la República Unida de 
Tanzanía. En otros casos, estas fibras tienen menor relevancia a nivel nacional, pero tienen una importancia considerable a escala local, como sucede con el yute en Bengala occidental (India), o el algodón y el sisal en el noreste del Brasil (Natural Fibres, 2009).

\subsubsection{Aspectos económicos}

El valor económico de las fibras es especialmente elevado en los países en vías de desarrollo, donde puede alcanzar en algunos casos hasta la mitad de las exportaciones. Por lo tanto la seguridad alimentaria de millones de personas depende de las fibras naturales (Vargasa \& Quispeb, 2009).

El consumidor valora por tanto la nueva funcionalidad de los productos de última generación desarrollados con las fibras naturales, así como considera las propiedades únicas de éstas a partir de polímeros naturales puros o en composición con otras materias primas pues consideran que se obtienen de esta manera productos con características de confort, tacto y aspecto extraordinarios, así como también competitivos desde el punto de vista comercial por los altos precios que alcanzan en el mercado (INTI, 2009).

\subsubsection{Aspectos mercadológicos}

Los mercados especializados en los cultivos de fibras naturales se han mantenido con gran consideración. Asimismo están surgiendo una serie de nuevos mercados, como por ejemplo compuestos de fibra reforzados en la industria del automóvil, materiales de construcción y geotextiles biodegradables, convirtiéndose la imagen ecológica de las fibras celulósicas en fuerza impulsora de la innovación y el desarrollo (Natural Fibres, 2009).

Las tendencias de los mercados internacionales apuntan hacia la consolidación de los mercados verdes. La demanda a nivel mundial de este tipo de productos está creciendo a tasas del $20 \%$ y $30 \%$, esto es a un ritmo de crecimiento superior al de los productos tradicionales, razón por la cual se presenta una gran oportunidad para países en desarrollo como Brasil, que se considera un país rico en fibras naturales y posee la mayor y más potente diversidad biológica del planeta, la selva amazónica (Capobianco, 2001). Así siendo, los productos extraídos de este modo pueden constituir importantes fuentes de ingresos para los pueblos nativos y por tanto se deben reforzar las iniciativas para el fortalecimiento y amplitud de los mercados de estos nuevos productos (Schwartzman, 2004). 


\subsection{La busca por nuevas fibras naturales para la innovación y competitividad en el mercado}

El desarrollo de nuevos materiales a partir de nuevos procesos crea una nueva demanda para los materiales tradicionales mejorando su competitividad (OCDE, 1994). Así, la denominación "nuevos materiales", específicamente en este estudio, se refiere a todos aquellos que resultan como una mejora o nueva aplicación de un material ya existente, o como un desarrollo enteramente nuevo, como respuesta a la necesidad de materiales mejores para aplicaciones en distinta categorías de uso y tipos de productos, tomando como base algunos principios considerados importantes (Castillo \& Burbano, 2005), a saber:

- Proteger el medio ambiente;

- Incrementar la competitividad en el mercado;

- Poner en valor los aspectos tecnológicos presentados por los recursos naturales;

- Generar beneficios socios económicos y culturales;

- Observar las posibilidades de transformación de la materia prima a través del uso de nuevas tecnologías;

- Suplir la necesidad del consumidor

Con respecto a la busca de nuevas fibras naturales para su innovación y competitividad en el mercado, las investigaciones destacan propiedades específicas orientadas a lograr la eficiencia global de los procesos. Se incide así en aspectos como la resistencia a las altas temperaturas, la resistencia mecánica, la resistencia a la corrosión, así como una mayor eficiencia energética, a la par de reducciones en la densidad y en peso, o bien, capacidades conductoras ampliadas, texturas, etc. (Holbery \& Houston, 2006).

En este contexto, la fibra de tucumã-i (Astrocaryum acaule) es un recurso vegetal de la Amazonía brasileña, poco explotado y conocido, pero se caracteriza por su producción sostenible y adaptabilidad a diferentes tipologías de productos como los textiles domésticos o decorativos; sin embargo, no se identifican en el universo científico datos relevantes con respecto a su aplicación en el mercado industrial. Se observa que los pocos registros existentes que describen las prácticas desarrolladas con la fibra, son del ámbito empírico y de prácticas artesanales (Pacheco, Ortuño, Miranda, Nascimento, \& Pacheco, 2011). Por lo tanto, se cree que estudios científicos pueden validar los atributos de innovación y de diferenciación ofrecidos por la fibra para el desarrollo de productos que van más allá de la producción artesanal (Artículos 1, 2, 3, 4, 5, 6, 7, 8 y 9), ofreciendo benefícios no sólo para el mercado, como también para sus comunidades productoras, localidad de procedencia y consumidores potenciales. 


\subsection{La fibra natural de tucumã-i (Astrocaryum acaule)}

De acuerdo con estudios realizados por Miranda I. P. (2001), la fibra vegetal proveniente de la espécie Astrocaryum del género acaule se trata de una palmera con tallo subterráneo. Hojas con una variación numérica de 5 a 12 . Tamaño de las hojas varía de 1,7 a 4,0 m de longitud; número de pinnas 55 a 100 por lado, regularmente agrupados y dispuestos en diferentes planos. Inflorescencia intercalada, fruto ovoide a sub-globoso suave, que mide $4,4 \mathrm{x}$ $3,2 \mathrm{~cm}$ de diámetro, de color amarillo a anaranjado cuando está madura. La palmera Astrocaryum acaule (Figura 1), posee como nombre populares: tucumã-i, tucumã-i da terra firme, tucumã-i da várzea.
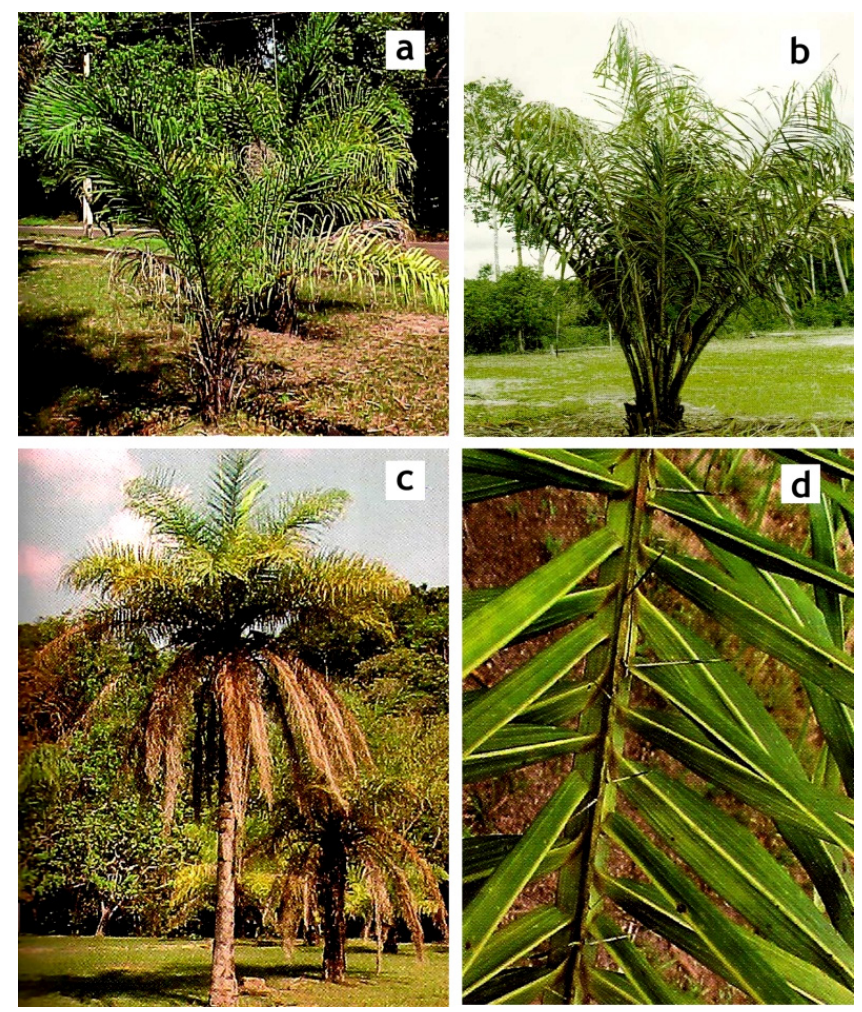

Figura 11 - Palmera en momento joven; B - palmera un poco más evolucionada; C - palmera adulta y en su hábito de crecimiento por sí solo; D - tipo de hoja pinnada y folletos agrupados en diferentes planos. Fuente: Miranda \& Rabelo (2008). 
De acuerdo con su ecología y hábitat: crece bien en áreas abiertas, pastizales, afloramientos rocosos, bosques perturbados, orillas de ríos, arroyos y caminos, y a menudo aparece en los suelos con mal drenaje de arena de poca elevación. Esta palma no es común en el bosque.

Sus formas de uso son: la pulpa del fruto es comestible y se utiliza como cebo para los peces. La cubierta de la semilla es dura y lo suficientemente rígida para ser utilizada en la artesanía. Las hojas contienen fibra que puede ser aplicado a diversos fines.

Con respecto a su potencial industrial se destaca: la cubierta de la semilla posee gran potencial para la artesanía en la confección de collares, pulseras y anillos. Asimismo sus hojas, a través de la fibra, son muy utilizadas para la fabricación de tejidos, alfombras, toallas y otros artículos de la práctica textil, doméstica y decorativa.

La fibra de tucumã-i (Astrocaryum acaule), y en concreto su palmera, se distribuye geográficamente en las siguientes ubicaciones: Colombia (Guainía, Meta, Vaupés, Vichada); Venezuela (Amazonas, Bolívar); Guyanas y Brasil (Amazonas, Pará, Rondônia y Roraima). En el estado de Amazonas (Figura 2), la fibra es predominante en la región del Alto Río Negro y en las ciudades de Manaus, Alvarães, Humaitá, Nueva Aripuanã, Presidente Figueiredo, de Río Preto da Eva y Tefé.

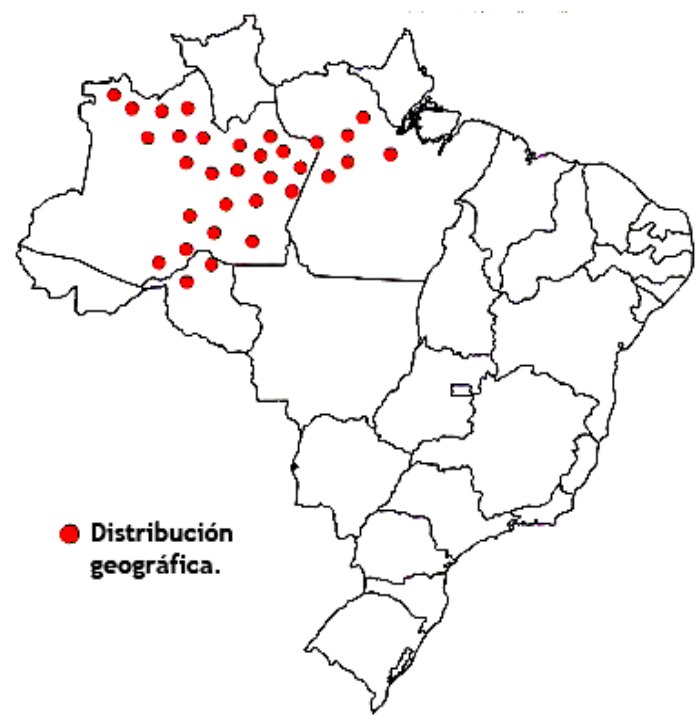

Figura 12. Distribución de la fibra de tucumã-i (Astrocaryum acaule) en Amazonas/Brasil. Fuente: Souza (2004) 
La producción anual de frutos por planta varía desde 202 hasta 404. Germinan con relativa facilidad y se ponen a germinar tan pronto como se cosecha. Una libra contiene alrededor de 104 semillas y 55 frutos. La siembra debe hacerse en suelo arenoso. Después de la germinación el crecimiento de las plantas es lento. De acuerdo con el universo simbólico de las diversas comunidades productoras amazónicas de la fibra de tucumã-i (Astrocaryum acaule), el hilo de esta materia prima (Figura 3) se considera como "Hilo de Lealtad", pues tiene una estructura muy resistente y nunca se rompe (Tucum: A arte de fiação da fibra dessa palmeira constitui-se numa técnica ancestral herdada dos povos indígenas, 2009 ).
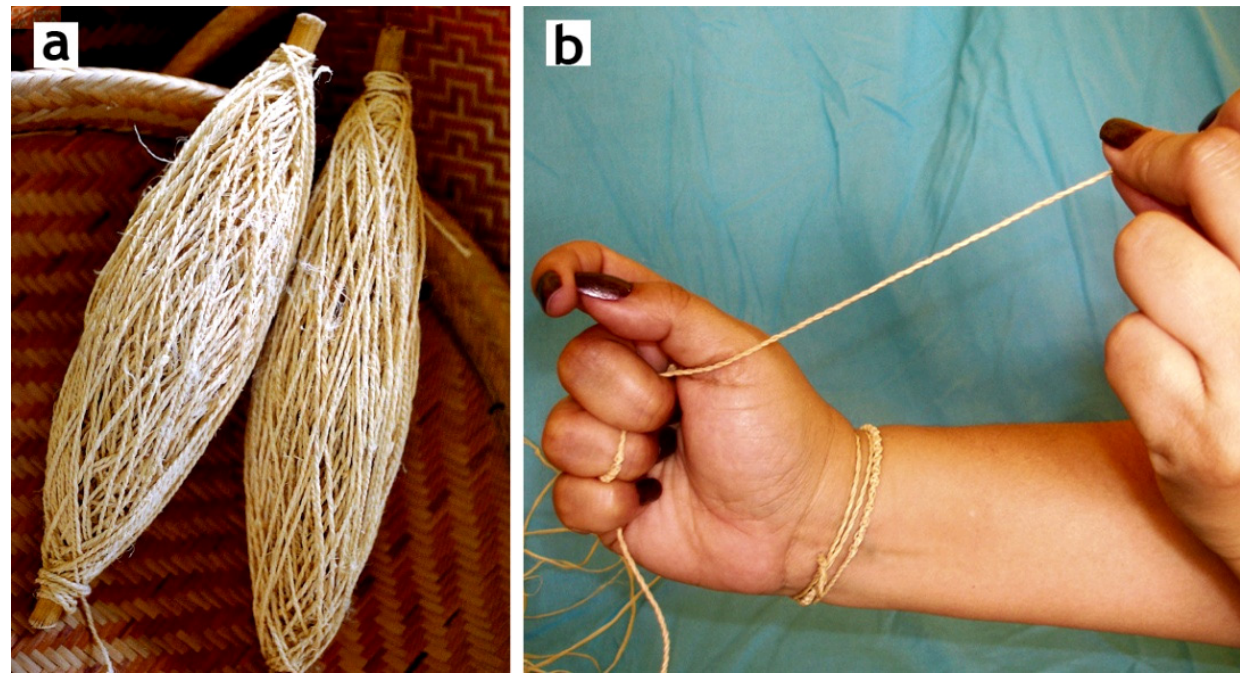

Figura 13. A - ovillo de hilo de tucumã-i (Astrocaryum acaule). Fuente: (Tear com fibra de tucum, cestos trançados de arumrã, 2011); B - "Hilo de la lealtat".

Fuente: de la autora (2012)

\subsubsection{Aspectos socio-cultural y eco sostenible}

Las comunidades productoras de la fibra de tucumã-i (Astrocaryum acaule) que viven en la región del Alto Río Negro presentan niveles de complejidad cultural muy variada y la historia de la formación muy diferente. En esta región hay un registro de una rica diversidad lingüística y el Nheengatú, Tukano y Baniwa son los idiomas principales de intercomunicación (Souza, 2008).

La producción de la fibra se da en función del tipo de aplicabilidad al ser atribuida al perfil cultural de cada comunidad. Hay comunidades productoras 
Estudio de la prospección del uso de la fibra de tucumã-i (Astrocaryum acaule) para el desarrollo de productos semi-industriales

que trabajan la materia prima para la fabricación de alfombras, otras para la confección de tejidos, otras para la composición de objetos decorativos y otras para usos domésticos (Barreto, 2007).

Las comunidades (generalmente constituidas por indígenas) dominan el medio ambiente y el desarrollo de tecnologías eficaces y se apropiadas para la extracción de la fibra. También son conocedores del uso y mantenimiento de los recursos naturales y las fuentes disponibles, tales como bosques, ríos, lagos, arroyos, etc. De esta manera, desarrollan una economía productiva de carácter sostenible, que se beneficia de generación de alimentos, medicinas, utensilios y herramientas.

\subsubsection{Aspecto productivo y proceso tecnológico aplicados a la fibra}

La producción sostenible de la fibra de tucumã-i (Astrocaryum acaule) garantiza las cualidades de la fibra a partir del momento de su cultivo. Es durante este proceso donde se define la función para la que va a ser utilizada la materia prima. Una vez que se recolecta la fibra, la comunidad determina su proceso de adaptación (artesanía) y su aplicación en los productos (Santos A. V., 2002).

Las etapas del proceso de producción de la fibra de tucumã-i (Astrocaryum acaule), siguen una determinada secuencia y se llevan a cabo por un procedimiento completamente manual, mediante el uso de instrumentos domésticos producidos en las propias comunidades, y de acuerdo a las siguientes etapas: selección de la planta, técnica de corte, lavado y secado, aplicación de tintes naturales, fijación del color, atado de las ramas, hilado y en última instancia, tejido de los hilos (Artículo 3)

\subsubsection{Propiedades tecnológicas comparadas a otras fibras similares}

La fibra de tucumã-i (Astrocaryum acaule) presenta características tecnológicas consideradas muy importantes para el desarrollo de productos y, sobretodo, para su proceso textil (Maciel K. M., 2008). Entre las propiedades identificadas está la buena resistencia atracción y la ausencia de componentes toxicos en su estructura (Artículo 8).

Cuando se le compara a otros productos vegetales similares, la fibra se destaca por exhibir características agradables con respecto a los aspectos físicos, químicos, mecánicos y organolépticos. De acuerdo con los datos identificados (Tabla 1) y correspondientes a estudios anteriores, la fibra demuestra ser un recurso natural con potencial para el desarrollo de productos fabricados en procesos más avanzados y no sólo aplicada mediante a la técnica artesanal. 
Tabla 3. Propiedades del objeto de estudio comparadas a otras fibras similares

\begin{tabular}{|c|c|c|c|c|c|c|c|}
\hline \multirow{2}{*}{$\begin{array}{l}\text { PROPIE } \\
\text { DADES }\end{array}$} & \multicolumn{7}{|c|}{ Cuadro comparativo - tucumã-i (Astrocaryum acaule) y fibras similares } \\
\hline & ALGODÓN ${ }^{1}$ & LINO $^{1}$ & RAMIO $^{1}$ & YUTE $^{2}$ & SISAL $^{2}$ & $\mathrm{COCO}^{3}$ & TUCUMÃ-I ${ }^{4}$ \\
\hline 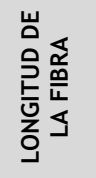 & De 3 a $4 \mathrm{~cm}$ & Hasta $70 \mathrm{~cm}$ & $\begin{array}{l}\text { cerca de los } \\
190 \mathrm{~cm}\end{array}$ & De 100 a $400 \mathrm{~cm}$ & $\begin{array}{l}\text { Cerca de los } \\
100 \mathrm{~cm}\end{array}$ & $\begin{array}{c}\text { Entre } 10 \mathrm{y} \\
35 \mathrm{~cm}\end{array}$ & Hasta $100 \mathrm{~cm}$ \\
\hline 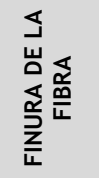 & $\begin{array}{c}\text { De } 20 \text { a } 40 \\
\text { mm }\end{array}$ & $\begin{array}{l}\text { Única, } \\
\text { irregular, } \\
\text { delgada }\end{array}$ & $\begin{array}{c}\text { Fibra sencilla } \\
\text { de } 2 \text { a } 6 \mathrm{~cm}\end{array}$ & De 2 a $2,5 \mathrm{~cm}$ & $\begin{array}{l}\text { Es una fibra } \\
\text { gruesa }\end{array}$ & $\begin{array}{c}\text { De } 0.05 \mathrm{a} \\
0.4 \mathrm{~mm}\end{array}$ & $\begin{array}{c}\text { De } 0.07 \text { a } 0.6 \\
\mathrm{~mm}\end{array}$ \\
\hline 옹 & $\begin{array}{l}\text { Desde el } \\
\text { blanco hasta } \\
\text { el pardo }\end{array}$ & Amarilla & $\begin{array}{l}\text { Blanca, } \\
\text { ligeramente } \\
\text { cenizo y } \\
\text { plateado. }\end{array}$ & $\begin{array}{c}\text { Blanca y } \\
\text { oscurecen con el } \\
\text { tiempo }\end{array}$ & $\begin{array}{l}\text { Blanco } \\
\text { cremoso }\end{array}$ & $\begin{array}{l}\text { Marrón } \\
\text { claro a } \\
\text { oscuro }\end{array}$ & $\begin{array}{l}\text { Amarilla con } \\
\text { un brillo } \\
\text { sedoso }\end{array}$ \\
\hline 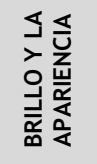 & Suave y lisa & $\begin{array}{l}\text { Suave y } \\
\text { sedosa }\end{array}$ & $\begin{array}{l}\text { Fina con alto } \\
\text { brillo }\end{array}$ & $\begin{array}{l}\text { Agradable y } \\
\text { blanda. }\end{array}$ & $\begin{array}{l}\text { Hermosa y } \\
\text { lustrosa }\end{array}$ & $\begin{array}{l}\text { Un poca } \\
\text { áspera }\end{array}$ & Suave y lisa \\
\hline 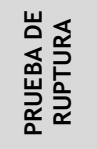 & $\begin{array}{c}\text { Alta } \\
\text { resistencia }\end{array}$ & $\begin{array}{l}\text { Resistente. } \\
\text { Con sonidos } \\
\text { claro y largo }\end{array}$ & $\begin{array}{l}\text { Fisuras } \\
\text { transversales } \\
\text { de la fibra } \\
\text { que hacen } \\
\text { frágil }\end{array}$ & Sin información & $\begin{array}{l}\text { Presenta una } \\
\text { alta } \\
\text { resistencia a } \\
\text { la ruptura }\end{array}$ & $\begin{array}{l}\text { Presenta } \\
\text { una buena } \\
\text { resistencia }\end{array}$ & $\begin{array}{l}\text { Buena } \\
\text { resistencia }\end{array}$ \\
\hline 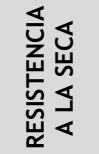 & $\begin{array}{l}\text { Seca } \\
\text { fácilmente y } \\
\text { es muy } \\
\text { resistente }\end{array}$ & $\begin{array}{l}\text { Muy alto en } \\
\text { fibra de } 35 \text { a } \\
60 \text { kilómetros }\end{array}$ & $\begin{array}{c}\text { Muy alta } \\
\text { hasta } 31 \% \text { de } \\
\text { su peso en } \\
\text { seco }\end{array}$ & $\begin{array}{l}\text { Muy alta } 2.3 \% \text { de } \\
\text { su peso en seco }\end{array}$ & $\begin{array}{c}\text { Sin } \\
\text { información }\end{array}$ & $\underset{\text { información }}{\text { Sin }}$ & $\begin{array}{c}\text { Resistente y } \\
\text { fácil de secar }\end{array}$ \\
\hline 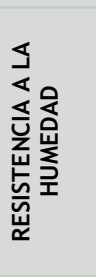 & $\begin{array}{l}\text { La fibra } \\
\text { absorbe } 8.0 \\
\text { a } 8.5 \% \text { de la } \\
\text { humedad del } \\
\text { aire cuando } \\
\text { el clima es } \\
\text { normal, el } \\
32 \% \text { cuando } \\
\text { la humedad } \\
\text { relativa en } \\
100 \% \text {. }\end{array}$ & Muy alta & Muy alta & $\begin{array}{c}\text { En clima normal } \\
\text { la fibra absorbe } \\
\text { de } 12.5 \% \text { a } \\
14.0 \% \text { de } \\
\text { humedad }\end{array}$ & $\begin{array}{l}\text { No absorbe } \\
\text { humedad } \\
\text { fácilmente }\end{array}$ & $\begin{array}{c}\text { Sin } \\
\text { información }\end{array}$ & $\begin{array}{c}\text { La fibra } \\
\text { absorbe de } \\
11,82 \% \text { a } \\
11,59 \% \text { de la } \\
\text { humedad }\end{array}$ \\
\hline
\end{tabular}


Estudio de la prospección del uso de la fibra de tucumã-i (Astrocaryum acaule) para el desarrollo de productos semi-industriales

\begin{tabular}{|c|c|c|c|c|c|c|c|}
\hline 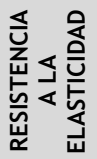 & $\begin{array}{c}\text { Suficiente } \\
\text { mayor que } \\
\text { la del lino y } \\
\text { menos que } \\
\text { la de la lana }\end{array}$ & Muy baja & $\begin{array}{c}\text { Baja } \\
\text { elasticidad }\end{array}$ & Sin información & $\begin{array}{l}\text { Poca } \\
\text { elasticidad }\end{array}$ & $\begin{array}{l}\text { Buena } \\
\text { elasticidad }\end{array}$ & $\begin{array}{l}\text { Buena } \\
\text { elasticidad }\end{array}$ \\
\hline 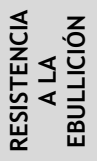 & $\begin{array}{l}\text { Resistente a } \\
\text { la ebullición }\end{array}$ & $\begin{array}{l}\text { Resistente a } \\
\text { la ebullición }\end{array}$ & $\begin{array}{l}\text { Resistente a } \\
\text { la ebullición }\end{array}$ & $\begin{array}{l}\text { Resistente a la } \\
\text { ebullición }\end{array}$ & $\begin{array}{l}\text { Resistente a } \\
\text { la ebullición }\end{array}$ & $\begin{array}{l}\text { Resistente a } \\
\text { la ebullición }\end{array}$ & $\begin{array}{l}\text { Resistente a } \\
\text { la ebullición }\end{array}$ \\
\hline 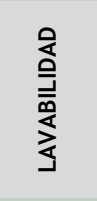 & $\begin{array}{l}\text { Fácilmente } \\
\text { lavable }\end{array}$ & $\begin{array}{l}\text { Fácilmente } \\
\text { lavable }\end{array}$ & $\begin{array}{l}\text { Optima, su } \\
\text { suciedad se } \\
\text { retira con } \\
\text { facilidad, y es } \\
\text { consistente a } \\
\text { la cocción }\end{array}$ & $\begin{array}{l}\text { Fácilmente } \\
\text { lavable }\end{array}$ & $\begin{array}{l}\text { Fácilmente } \\
\text { lavable }\end{array}$ & $\begin{array}{l}\text { Fácilmente } \\
\text { lavable }\end{array}$ & $\begin{array}{l}\text { Muy buena, } \\
\text { siendo } \\
\text { posible de } \\
\text { lavar con } \\
\text { agua y jabón } \\
\text { o por la } \\
\text { lavaje a la } \\
\text { seco }\end{array}$ \\
\hline 是 & $1.55 \mathrm{~g} / \mathrm{cm}^{3}$ & $1,48 \mathrm{~g} / \mathrm{cm}^{3}$ & $1,48 \mathrm{~g} / \mathrm{cm}^{3}$ & Sin información & $1,45 \mathrm{~g} / \mathrm{cm}^{3}$ & Muy baja & $1.52 \mathrm{~g} / \mathrm{cm}^{3}$ \\
\hline 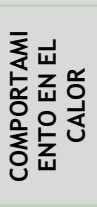 & $\begin{array}{c}\text { Calor } \\
\text { continuo de } \\
120^{\circ} \mathrm{C}, \\
\text { amarilla la } \\
\text { fibra a } 150^{\circ} \\
\text { C se } \\
\text { descompone }\end{array}$ & $\begin{array}{c}\text { Calor } \\
\text { continuo de } \\
120^{\circ} \mathrm{C}, \\
\text { amarillea la } \\
\text { fibra a } 150^{\circ} \\
\text { C se } \\
\text { descompone }\end{array}$ & $\begin{array}{c}\text { Calor } \\
\text { continuo de } \\
120^{\circ} \mathrm{C} \\
\text { provoca un } \\
\text { color amarillo } \\
\text { y perdida de } \\
\text { resistencia }\end{array}$ & $\begin{array}{l}\text { Presenta baja } \\
\text { conductividad } \\
\text { térmica }\end{array}$ & $\begin{array}{c}\text { Color } \\
\text { continuo a } \\
120 \mathrm{C} ; \\
\text { amarillo a } \\
180^{\circ} \mathrm{C} \text { se } \\
\text { descompone }\end{array}$ & $\begin{array}{c}\text { Sin } \\
\text { información }\end{array}$ & $\begin{array}{c}\text { Color } \\
\text { continuo a } \\
120 \text { grados } \\
\text { Celsius, } \\
\text { amarilla la } \\
\text { fibra a más } \\
\text { de } 200^{\circ} \mathrm{C} \text { se } \\
\text { descompone }\end{array}$ \\
\hline $\begin{array}{l}\text { 오 } \\
\text { 음 } \\
\text { ò }\end{array}$ & $\begin{array}{l}\text { Sin } \\
\text { componente } \\
\text { s tóxicos }\end{array}$ & $\begin{array}{l}\text { Sin } \\
\text { componentes } \\
\text { tóxicos }\end{array}$ & $\begin{array}{c}\text { Sin } \\
\text { componentes } \\
\text { tóxicos }\end{array}$ & $\begin{array}{l}\text { Sin } \\
\text { componentes } \\
\text { tóxicos }\end{array}$ & $\begin{array}{l}\text { Sin } \\
\text { componente } \\
\text { s tóxicos }\end{array}$ & $\begin{array}{l}\text { Sin } \\
\text { componente } \\
\text { s tóxicos }\end{array}$ & $\begin{array}{l}\text { Sin } \\
\text { componentes } \\
\text { tóxicos }\end{array}$ \\
\hline 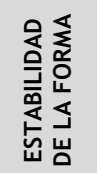 & $\begin{array}{c}\text { Reducida, } \\
\text { mayor que } \\
\text { la del lino y } \\
\text { menor que } \\
\text { la de lana y } \\
\text { la seda }\end{array}$ & $\begin{array}{l}\text { Inferior al } \\
\text { algodón }\end{array}$ & Reducida & $\begin{array}{l}\text { Inferior al } \\
\text { algodón }\end{array}$ & $\begin{array}{l}\text { Inadecuado } \\
\text { para textiles } \\
\text { o telas }\end{array}$ & $\begin{array}{l}\text { Inferior al } \\
\text { algodón }\end{array}$ & $\begin{array}{l}\text { Inferior al } \\
\text { algodón }\end{array}$ \\
\hline
\end{tabular}

Fuentes: ${ }^{1}$ (Oliveira M. H., 2000); ${ }^{2}$ (Marinelli, Monteiro, Ambrósio, Brancifort, Kobayashi, \& Nobre, 2008); ${ }^{3}$ (Natural Fibres, 2009); ${ }^{4}$ (Organización de las Naciones Unidas, 2009); ${ }^{5}$ (Maciel K. M., 2008).

\subsubsection{Situación del mercado}

El mercado de productos desarrollados con la fibra de tucumã-i (Astrocaryum acaule) en el estado de Amazonas no está completamente definido, ya que 
según el estudio realizado por Menezes, Pinheiro, Guazzell, \& Martins (2005), las fibras provenientes de palmas presentan dificultades como:

- Aspectos relacionados con la gestión y administración de proveedores de fibras de palma;

- Falta de apoyo a la producción y comercialización de la fibra;

- Capacidad limitada para comercializar productos y fibras;

- Falta de tecnología apropiada;

- Falta de estructura organizativa para la exposición de los productos.

Aunque presente los mismos problemas la fibra en estudio posee una buena aceptación por parte de los turistas y despierta gran interés en las empresas y tiendas de productos desarrollados con recursos naturales de la región amazónica, sobretodo en la ciudad de Manaus, pues allí la comercialización puede ser realizada a través de la compra y venta de la fibra en su estado natural o ya transformada en producto artesanal. Los puntos de negocio son los centros comerciales, ferias y eventos culturales. La calidad de la materia prima es tanta, que está siendo comercializada en un estado inicial como hilo en otros estados brasileños, así como en algunos países de América del Norte, América del Sur y Europa (Pacheco, Ortuño, \& Pacheco, 2011).

\subsection{La posibilidad de nuevas tecnologías y transferencia de conocimiento para la mejora del proceso de transformación de las fibras naturales para el desarrollo de productos}

Las nuevas tecnologías son actualmente un componente muy importante en el ámbito económico por su existencia casi omnipresente (November, 1994). Constituyen la parte fundamental de toda una revolución científicotecnológica que impacta el ámbito productivo, económico, político, social y cultural en el conjunto de actividades humanas.

En este contexto se relaciona la ciencia, la tecnología y la técnica en función de una secuencia dónde: la primera responde al deseo del hombre de conocer y buscar comprender racionalmente el mundo que lo rodea y los fenómenos relacionados con él; la segunda utiliza el método científico, comprende el saber sistematizado y en su proceder se maneja tanto a nivel práctico como conceptual, es decir, que abarca el hacer y su reflexión teórica; la tercera y última es el procedimiento o el conjunto de procedimientos que tienen como objetivo obtener un resultado determinado, ya sea en el campo de la ciencia, de la tecnología, de las artesanías o en otra actividad. Estos procedimientos no excluyen la creatividad como factor importante de la técnica (Boniscontro, y otros, 2005). 
Estudio de la prospección del uso de la fibra de tucumã-i (Astrocaryum acaule) para el desarrollo de productos semi-industriales

La fuerte competencia y la complejidad reinante en momentos donde la globalización tiene cada vez más auge, están marcando tendencias para que las organizaciones concentren sus esfuerzos en gestionar estratégicamente sus capacidades tecnológicas. De ahí que la experiencia de las organizaciones indica que la vía para alcanzar la capacidad de competir es a través de la tecnología e innovación, factor clave de la competitividad (U. \& A., 2005).

De acuerdo con Porter (1992), la tecnología e innovación ayudan a sistematizar las diferentes actividades de una organización, observando cómo éstas interactúan, analizando las fuentes de ventajas competitivas a través de las diferentes innovaciones como consecuencia del desarrollo de capacidades tecnológicas y, aún, permite a la organización diseñar, mejorar, transformar, innovar y reemplazar procesos o productos, para ofrecer constantemente al mercado ventajas diferenciales, creando nuevos productos o modificando los actuales, generando barreras a la competencia y así asegurar el éxito.

Estas informaciones también sirven como base para orientar el uso de nuevas tecnologías y/o para la transferencia del conocimiento, también como herramientas de apoyo para la mejora del proceso de transformación y aplicación de las fibras naturales para la fabricación de productos, ya que son de carácter revolucionario y pueden ofrecer oportunidades inéditas para aprender el desarrollo y alcanzar nuevos mercados.

\subsubsection{Procesos tecnológicos}

Desde una óptica económica, el desarrollo tecnológico fundamenta el camino seguido por la tecnología cuando se busca la rentabilidad, los beneficios de las inversiones y la eficiencia en el desarrollo de mercados (García-Vera, 2000).

El concepto de tecnología hoy dominante es una caricatura de lo que el concepto significa, porque tecnología es, ante todo, una forma de hacer cosas que implica a la vez un objetivo, un modo y un saber (Martínez, Lucio, \& Marín, 2008). Es, en su sentido más radical, una producción, un proceso que hace aparecer lo que no existía, que pone delante lo que falta (eso significa etimológicamente producir). De este modo, el proceso tecnológico se va a constituir de acuerdo con la dimensión social de la técnica, dónde ésta es aplicada en un contexto, también basado en un conocimiento, efectividad derivada de una idealidad (Heidegger, 1984).

Para la aplicación de una nueva técnica, que favorezca el uso de las fibra naturales para el desarrollo de productos, es necesario primero realizar un reconocimiento de las técnicas y saberes ancestrales utilizados para la elaboración de productos, en los cuales la materia prima está acostumbrada o 
destinada a ser manejada, y caracterizar sobre todo los factores intrínsecos e extrínsecos relacionados con ésta (Chedid, 2009).

En los factores intrínsecos se puede reconocer: la identidad cultural, la tradición en el oficio, la organización de los talleres y procesos (artesanales o industriales), la capacidad de inversión, los niveles tecnológicos, la ubicación geográfica de las comunidades y la dinámica comercial. Los factores extrínsecos posibilitan verificar los tipos de exigencias del mercado, la productividad y la competitividad local, las políticas de estado, etc.

\subsubsection{Transferencia de conocimiento}

A partir del reconocimiento de las técnicas y saberes ancestrales utilizados para la elaboración de productos, el paso siguiente será sistematizar las informaciones adquiridas, como apoyo al proceso tecnológico al ser elegido e implementado como ventajas del uso de las fibras naturales en la fabricación de produtos y, consecuentemente, para auxilar en la transferencia de conocimiento a los componentes involucrados en este contexto. Este último procedimento, es un concepto complejo, difuso y en transformación por las dificultades que entraña definirlo y proporcionar una explicación que contemple los principales elementos implicados en el proceso, dada la cantidad de factores concurrentes (Roessner, 2000).

Según Fernández, Castro, \& Conesa (2000), el término "transferencia de conocimiento", no sólo comprende los aspectos relacionados con el producto físico y conocimiento ligado al mismo sino que también permite incluir otros ámbitos del conocimiento (ciencias humanas, sociales, económicas,...) de gran utilidad socioeconómica, incluso relacionar el papel de las universidades y organismos de investigación a través de tres funciones clave: generación del conocimiento: mediante las actividades de I+D; transmisión del conocimiento mediante la formación y por último la publicación de los resultados y transferencia del conocimiento, para proporcionar soluciones a los problemas de las empresas o organizaciones. Todos ellos orientados a generar un fuerte componente de servicio hacia la colectividad, lo cual la transforma en un polo importante en las estrategias de desarrollo local y regional.

En este contexto, los estudios de los procesos y de los determinantes de la transferencia de tecnología y conocimiento se orientan preferentemente hacia las aplicaciones en la industria y desde las ciencias experimentales, las agrarias o las ingenierías (Martínez, Lucio, \& Marín, 2008).

Con respecto al uso de fibras naturales en el desarrollo de productos, sobre todo aquellas trabajadas de modo artesanal y que presentan aspectos tecnológicos compatibles para un proceso de aplicación más avanzado como 
Estudio de la prospección del uso de la fibra de tucumã-i (Astrocaryum acaule) para el desarrollo de productos semi-industriales

por ejemplo el semi-industrial, se hace necesario identificar cuáles son los elementos y principios esenciales para proceder con la organización y ejecución de la transición y aplicabilidad de la materia prima del aspecto artesanal al semi-industrial.

\subsubsection{Del aspecto artesanal al semi-industrial}

La disponibilidad de las fibras naturales, son la causa principal del desarrollo de artesanías en la mayoría de las sociedades en que esta actividad se reconoce, debido a que obedecen a ellas como la materia prima para una buena gama de productos artesanales de tipo utilitario y decorativo que elaboran (Contreras, 2007).

El modo de producción artesanal tradicional hecho con las fibras naturales consiste en un "proceso de transformación, que conlleva cambios en la naturaleza física del producto, lo que tiene gran relevancia en términos de valor agregado y dinámica" (Machado, 2002).

La actividad artesanal con fibras naturales es básicamente familiar; aunque no todos los miembros del hogar se dedican completamente al oficio, colaboran en su tiempo libre ya que todos saben tejer. Hecho que se comprueba en que para estos artesanos, el único costo de inversión lo constituye la pita o hilo de amarre (Quiñones A, 2003).

La disponibilidad permanente de materia prima conlleva a un proceso repetitivo de cultivo, recolección, transporte, selección, lavaje, secado, hilatura y tejeduría. Estas etapas son desarrolladas en las propias viviendas de los artesanos, dónde los talleres son de tecnología baja y adecuados de acuerdo con el espacio de trabajo (Contreras, 2007). Aún que presente condiciones limitadas se verifica que, según Gamboa (1995), la actividad artesanal ofrece un espacio de realización personal, en donde los artesanos comparten saberes, experiencias y sentimientos, al tiempo que se sienten productivos económicamente, se relajan y distraen su atención del quehacer doméstico y familiar.

Podemos decir por tanto que uno de los objetivos planteado es adaptar una fibra natural (con aspectos de manejo totalmente artesanal) a un proceso tecnológico más avanzado y moderno como el semi-industrial, que beneficie las comunidades productoras y posibilite el desarrollo de productos más competitivos al mercado. Siendo esto un reto que necesita comprender bien no sólo los aspectos físicos, químico y mecánicos de la materia prima, sino también toda la estructura organizacional artesanal antes aplicada a ésta, de modo que se pueda implementar una nueva técnica continua y automática 
centrada específicamente en la preparación de la materia para tórnala en un bien de consumo.

En verdad, éste procedimiento de transición no es brusco ya que en la práctica, la técnica semi-industrial busca establecer una unión entre el trabajo manual y el uso de maquinaria, en dónde el aspecto artesanal se aplica en algunas etapas del transcurso de producción (las cuales dan forma al producto) y el factor semi-industrial va actuar en otras tareas más específicas, calificando la materia prima y agilizando todo el proceso.

En este contexto, el diseño se vuelve una herramienta estratégica para establecer los métodos y los procesos de trabajo, dónde el perfeccionamiento de las técnicas y las materias primas aseguran el acceso a nuevos usos comerciales, volviendo los productos más competitivos y mejorando la respuesta a la demanda de los mercados (Foro Nacional de Artesanal - Grupo Impulsor de Diseño Artesanal 2010).

Por lo tanto, tomando como base estas consideraciones y unificándolas en torno a los aspectos del diseño (en cuanto proyecto e instrumento facilitador que orienta a la creación y al desarrollo de los productos) se percibe que para proceder con la transición de un proceso artesanal para un semi-industrial, es necesario:

- elegir el objeto de estudio (fibra natural);

- elaborar un diagnóstico: socio-cultural, artesanal y de diseño, con base en un estudio de los antecedentes;

- identificar cuáles son las necesidades del grupo o comunidad de artesanos que utilizan fibras naturales para la fabricación de productos;

- analizar el posicionamiento del mercado en relación al uso de estas materias primas para el desarrollo de productos y la posibilidad de su adaptación mediante de otro tipo de proceso tecnológico;

- identificar el grado de la demanda para el consumo de este producto;

- contrastar las informaciones y capturar aquellas que servirán de soporte para la organización de un nuevo sistema de producción;

- planear una propuesta de proyecto;

- proponer bocetos, maquinaria, plantillas, moldes, etc.

- transferir conocimiento;

- verificar la capacitación técnica del grupo de artesanos en función del uso de una nueva tecnología;

- observar costes;

- evaluar los resultados obtenidos

Siendo los resultados positivos, será interesante crear nuevos usos para un producto anteriormente trabajado de forma tradicional; hacer un registro y un control interno para las instituciones que se encargan de la 
Estudio de la prospección del uso de la fibra de tucumã-i (Astrocaryum acaule) para el desarrollo de productos semi-industriales

comercialización y; fortalecer la asimilación de las nuevas técnicas para su producción, así como considerar la autonomía del grupo de trabajo en función del mercado al que sus productos estarán destinados.

\subsection{El diseño como factor estratégico para la sistematización de informaciones sobre el uso de la fibra natural de tucumã-i (Astrocaryum acaule) para la gestión, desarrollo y fabricación de productos semi-industriales}

El enfoque sistémico para el diseño de productos permite gestionar el conocimiento de manera sistematizada y utiliza el boceto como configuración sintética orientada a representar los atributos teóricos del producto según los objetivos planteados. Propone que mediante un modelo conceptual, un ejercicio de análisis del objeto a diseñar considerando tres subsistemas fundamentales; forma, función y ergonomía (Hernandis, 2003), que desde sus diversos aspectos y consideraciones dotarán al producto de atributos específicos y conceptuales que respondan a las demandas, impuestas por el contexto social. En este caso específico, el diseño se convierte en la sistematización de datos referentes al uso de una fibra natural amazónica para la gestión, desarrollo y fabricación de productos semi-industriales, dónde el diseño surge vinculado al proceso de investigación, observando el universo que involucra el objeto de estudio, participando como un elemento estratégico que orienta los posibles caminos de acción, comprende los problemas e identifica las oportunidades y limitaciones de la temática abordada (Miguel Fernández, 2005).

\subsubsection{Proceso de investigación}

La investigación es un proceso que mediante la aplicación del método científico, procura obtener información relevante y fidedigna para entender, verificar, corregir o aplicar el conocimiento (Tamayo y Tamayo, 2000), constituyéndose como una herramienta esencial en el ampliar, mejorar ó modificar los cambios necesarios en beneficio de la sociedad y del mismo individuo, mediante la construcción del conocimiento que se define como la esencia de la búsqueda de toda investigación que proponga aportar a la transformación de una realidad (Arenas, Carlosama, \& R., 2004).

A través del proceso de investigación el diseño es capaz de tomar decisiones estratégicas que permiten ir creando un plan de acción, un esbozo o bosquejo del desarrollo de todo proceso investigativo, organizando en conjunto todos los componentes (tema, justificación, problema, preguntas, objetivos, entre otros), y posibilitando al investigador comprender a partir de una 
representación organizada todo el proceso de aproximación al objeto de estudio (Valencia, 2011).

\section{a. Identificación de las oportunidades y límites del producto para su inserción en el mercado}

Mediante a un plan de acción establecido, el diseño adopta una postura determinada como "misión de negocio" (Ackoff, 1987), la cual utiliza como un método más sistemático de evaluar la posición estratégica de un producto o negocio es el análisis del SWOT donde se identifican las fuerzas, las debilidades, las oportunidades y las amenazas de la compañía, sobre todo en lo referente a la competición (Shrestha, Alavalapati, \& Kalmbacher, 2004).

La meta más usual del diseño estratégico, en este momento inicial de la investigación, es encontrar maneras de identificar las oportunidades y límites del producto para su inserción en el mercado, definir las direcciones principales donde éstas informaciones se pueden ser obtenidas, a través de expertos, clientes nuevos o por otras personas (Aalto University School of Art, 2010).

En esta etapa también es posible trabajar el propósito de la investigación para el desarrollo de:

- un producto existente - visando solamente el perfeccionamiento del proceso, concepto, fabricación o logística;

- un producto completamente nuevo - creando las innovaciones tecnológicas necesarias, basado en el estudio de mercado y combinando los resultados con las capacidades de producción y;

- un producto nuevo para clientes nuevos - investigando y planeando las estrategias de acuerdo con el segmento del mercado.

\section{b. Estudio de mercado (consulta de opiniones/ expertos/ consumidor)}

Antes de introducir un nuevo producto o servicio al mercado, es necesario llevar a cabo un estudio previo con el objeto de analizar las características del consumidor entre otros aspectos (Motta, Mattar, Barreto, \& Teixeira, 2007). El estudio de mercado es un proceso que refleja las necesidades, tendencias y perfil del mercado; así como la opinión, conducta y hábitos del consumidor, pudendo ser realizado mediante aplicación de encuestas (por correo, telefónica o personal), estadísticas, entrevistas y grupos focales (focus groups) (Gerencia y Negocios en HispanoAmérica, 2011).

Para orientar en esta práctica, existen varios tipos de investigación de mercado: cuantitativa, cualitativa, documental y de marketing. Cada una de 
Estudio de la prospección del uso de la fibra de tucumã-i (Astrocaryum acaule) para el desarrollo de productos semi-industriales

ellas arrojará diferentes resultados, dependiendo de las características y variables que se deseen estudiar. En el caso del diseño, aunque no sea su responsabilidad, es útil conocer la mecánica de la investigación de mercado y, a través de ésta, las informaciones resultantes para mejor definición de las acciones estratégicas que deberán ser adoptadas al diseño del producto (Torres, Cavalcante, \& Almeida, 2011).

\section{c. Identificación de los atributos necesarios para diseño del producto}

Un buen diseño, o un buen producto es aquel que cumple correctamente todas sus funciones, de tal manera que pasa totalmente desapercibido durante su uso (Potter, 1999). Desde la perspectiva del marketing, se dice que un producto es aceptado por el mercado cuando logra satisfacer las necesidades del consumidor y, según Hernandis \& Bonmatí (2008), es necesario comprobar que un producto representa un conjunto de atributos tangibles e intangibles desde el punto de vista del consumidor. Segun éstos autores, entre los posíbles atributos necesários para el diseño de producto están:

- Las propiedades físicas, químicas y técnicas del producto, que lo harán apto para determinadas funciones y usos;

- La calidad, valoración de los elementos que componen el objeto de estudio, en razón de los estándares que deben apreciar o medir las cualidades y permiten ser comparables con su competencia;

- Precio y/o valor de adquisición;

- El valor promocional y de imagen;

- El diseño, la forma y el tamaño que permiten, en mayor o menor grado, la identificación del producto o la empresa y, generalmente, configura la propia personalidad del mismo;

- Marca, nombres y expresiones gráficas que facilitan la identificación del producto y permiten su recuerdo asociado a uno u otro atributo;

- Servicio, conjunto de valores añadidos a un producto que nos permite poder marcar las diferencias respecto a los demás; hoy en día es lo que más valora el mercado, de ahí su desarrollo a través del denominado marketing de percepciones;

- Imagen del producto, opinión global que se crea en la mente del consumidor según la información recibida, directa o indirectamente, sobre el producto «en sí mismo».

Así siendo, el proceso de identificación de este tipo de atributos puede ser realizado a través de la aplicación de técnicas específicas como por ejemplo:

- Entrevistas al usuario o consumidor - mediante el pase de encuestas orientadas previamente. Esta técnica exige un tratamiento posterior de los datos obtenidos con objeto de "traducirlos" a términos técnicos; 
- Grupos expertos - quizás una de las maneras más efectivas y rápidas de obtener un análisis rápido del producto;

- Análisis de los usuarios líderes - esta técnica está orientada a la prospectiva, se trata de estudiar únicamente los usuarios que se encuentran al frente de los consumidores, aquellos que se adelantan a la mayoría de los gustos y necesidades existentes;

- Técnica Delphi - se trata de pasar encuestas a un grupo de personas determinadas, recoger los datos, analizarlos, modificar las encuestas en función de ello y volverla a pasar razonando con el grupo hasta llegar a una solución;

- Investigación contextual - es una mezcla entre las entrevistas al consumidor y la observación directa, que observa el comportamiento del consumidor ante el producto de forma directa, cómo lo usa, las funciones se cumplen correctamente.

Uno de los factores considerados más importante en el proceso de identificación de los atributos del diseño, es obtener información acerca de cómo es percibido el producto, en concreto, por parte del usuario en función del grado de cumplimiento de cada uno de los objetivos prefijados como forma, función y ergonomía, de los cuales se obtendrá un resultado (producto) concreto.

\section{d. Sistematización de los datos}

La sistematización de los datos hace referencia al ordenamiento y clasificación de datos e informaciones, estructurando de manera precisa categorías, relaciones, posibilitando la constitución de bases de datos organizados, etc. (Jara H., 2011). Éste tratamiento de la información, es un proceso de recuperación y apropiación de una práctica formativa determinada, que al relacionar sistémica e históricamente sus componentes teórico-prácticos, permite a los sujetos comprender y explicar los contextos, sentido, fundamentos, lógicas y aspectos problemáticos que presenta la experiencia, con el fin de transformar y cualificar la comprensión, experimentación y expresión de las propuestas educativas de carácter comunitario (Ghiso, 2001).

La principal ventaja de la sistematización de información es extraer aprendizajes y generar un nuevo conocimiento, de modo a aprender para compartir, de partir de una experiencia particular para obtener un conocimiento que sea útil en otros contextos (Fantova, 2003), entre los cuales están la gestión del conocimiento, que se utiliza un mecanismo continuo y tiene que ver fundamentalmente con los procesos de la comunicación, divulgando las informaciones (Fantova F. , 2001) y el diseño, como un elemento integrado del sistema, que tiene en cuenta todos los elementos del 
ciclo de vida del producto, desde el diseño conceptual, hasta su disponibilidad incluyendo calidad, costo y necesidades de los clientes. El diseño persigue un estudio sistemático, simultáneo, en el momento del desarrollo del producto, de las necesidades de mercado que va a cubrir, de los requisitos de calidad y costos, de los medios y métodos de fabricación, venta y servicio necesarios para garantizar la satisfacción del cliente.

Por lo tanto, la sistematización de los dados de la investigación pueden ser trabajados de acuerdo con los aspectos del diseño y de la gestión y orientados a través de modelos metodológicos basados en la teoría sistémica (Hernandis \& Iribarren, 2000), que contribuyen de manera específica al estudio de la problemática del diseño incidiendo en la innovación y /o evaluación estratégica, táctica y operativa de la empresa, así como ayudan a definir el desarrollo conceptual de productos industriales con análisis desde la forma, función y ergonomía (Hernandis \& Briede, 2009). En este aspecto, el uso de un modelo sistémico específico, como el modelo de diseño concurrente, se justifica por la posibilidad de examinar las variables necesarias para el diseño, de manera a dar vida, dinámica y actualizar a través de la retroalimentación de las informaciones $y$, consecuentemente, del feedback de todas las partes que componen el modelo, en el cual las variables se tornan responsables por analizar, comprobar y mantener todo el sistema activo y controlado (Hernandis, 2003).

Así, el pensamiento sistémico se constituirá en un instrumento adecuado para hacer frente a problemas de diversa índole y, sobre todo, a los problemas actuales, ya que la sistémica puede relacionar y sobrepasar las concepciones parciales y opuestas, supuestamente, de las ciencias, de la tecnología y de las humanidades, ayudando a gestionar todos los datos, informaciones y conocimientos durante el desarrollo de la actividad propuesta. Aportando soluciones consensuadas, mediante el uso de modelos que consideran los aspectos fundamentales del problema en estudio de manera ponderada $y$, representan gráficamente de manera esquemática, una realidad compleja. 


\section{Referencia}

Aalto University School of Art, D. a. (2010). Desarrollar un producto industrial. Recuperado el 05 de julio de 2010, de Aalto University School of Art, Design and Architecture: http://www.uiah.fi/projekti/metodi/230.htm

Ackoff, R. (1987). Mission statements. Planning Review , 25 (4).

Arenas, G. M., Carlosama, D. C., \& R., A. d. (2004). Importancia de una metodología de investigación y su relación con el diseño y elaboración de un proyecto investigativo de carácter social. Manizales - Colombia: Universidad Nacional de Colombia.

Barreto, P. D. (2007). A produção da fibra de tucum como alternativa econômica dos povos indígenas do Alto Rio Negro. Dissertação (Mestrado em Sociedade e Cultura da Amazônia). Manaus - AM - Brasil: Universidade Federal do Amazonas - UFAM.

Boniscontro, G., Franco, W., Malsam, L., Ramondetta, S., Rodríguez, G., Silva, H., y otros. (2005). La tecnologia - Ingeniería y Sociedad. Buenos Aires Argentina: Mundo UTN.

Cadena, C. G., \& Silvera, A. J. (2002). Estudio de la variación en la conductividad térmica de la cascarilla de arroz aglomerada con fibras vegetales. Ingeniería \& Desarrollo. Universidad del Norte , 12: 8-9.

Castillo, O. B., \& Burbano, N. C. (2005). Mercado y perspectivas de los nuevos materiaes para usos biomedicos en LatinoAmerica. Cauca - Colombia: Universidad del Cauca.

Chedid, J. A. (2009). Modelo de intervención para el mejoramiento de procesos artesanales, mediante la integracion: Estado - Univerdidad - Empresa - Sociedad. 7th Latin American and Caribbean Conference for Engineering and Technology. San Cristóbal, Venezuela: Latin American and Caribbean Conference for Engineering and Technology .

Contreras, A. M. (2007). Características de los sistemas de producción artesanal en enea (Typha latifolia) en las zonas rural y urbana del municipio de montería departamento de Córdoba . Bogotá - Colombia: Pontifica Universidad Javerina.

Fantova, F. (2001). La gestión de organizaciones no lucrativas. Herramientas para la intervención social. . Madrid - España: CCS.

Fantova, F. (2003). La sistematización como herramienta de gestión. Sistematización de experiencias de desarrollo humano. Bilbao - España: Universidad de Deusto. 
FAO. (2004). Consulta sobre fibras naturales. Roma: FAO - Organizaión de las Naciones Unidas para la Alimentación y Agricultura.

Fernández, I., Castro, E., \& Conesa, F. y. (2000). Las relaciones Universidadempresa: entre la transferencia de resultados y el aprendizaje regional. Revista Espacios , 21(2), 1-17.

Forero, R. A. (2007). Las fibras naturales en los materiales compuestos. Peru: Tecnología del plástico aplicaciones comerciales.

Foro Nacional de Artesanal - Grupo Impulsor de Diseño Artesanal. (2010). Manual de Diseño y Desarrollo de Productos Artesanales. México: Editorial Plaza y Valdés Editores.

Gamboa, C. I. (1995). La mujer y la agroindustria rural en América Latina. Serie de Estudios de Agroindustria Rural. . San José - Costa Rica: S.P.I. Reedición.

García-Vera, A. B. (2000). Tres temas tecnológicos para la formación del profesorado. Revista de Educación , 322, pp. 167-188.

Gerencia y Negocios en HispanoAmérica. (2011). Investigacion de mercado. Recuperado el 16 de agosto de 2011, de degerencia.com: http://www.degerencia.com/tema/investigacion_de_mercado\#articulos

Ghiso, A. (2001). Sistematización de experiencias en Educación popular. Memorias Foro: Los contextos actuales de la educación popular. Medellín: Memorias Foro.

Heidegger, M. (1984). La pregunta por la técnica. Conferencias y artículos Ediciones del Serbal , pp. 9-37.

Hernandis, B. (2003). Tesis Doctoral: Desarrollo de una metodología sistémica para el diseño de productos industriales. Valencia - España: Universidad Politécnica de Valencia - UPV.

Hernandis, B., \& Bonmatí, J. (16 de enero de 2008). El diseño coherente la correcta definición del producto - 1er Encuentro Interinstitucional de Diseño Industrial. Recuperado el 26 de febrero de 2010, de objetual.com: http://www.objetual.com/main.htm

Hernandis, B., \& Briede, J. C. (2009). An Educational Application for a Product Design and Engineering Systems using Integrated Conceptual Models. Ingeniare , v. 17, n. 3, pp. 432-442.

Hernandis, B., \& Iribarren, N. (2000). Diseño de nuevos productos: Una perspectiva sistémica. Valencia - España: Universidad Politécnica de Valencia. 
Holbery, J., \& Houston, D. (2006). Natural-fibre-reinforced polymer composites in automotive applications. . Journal of the Minerals, Metals and Materials Society , 58: 80-86.

INTI, I. N. (Junio de 2009). Textiles sustentables - El auge de las fibras nobles y el cuidado del medio ambiente. Recuperado el 05 de enero de 2011, de Instituto Nacional de Tecnología Industrial : http://www.inti.gob.ar/sabercomo/sc77/inti5.php

Jara H., O. (2011). Dilemas y desafios de la sistematización de experiencias. Seminario ASOCAM: Agricultura Sostenible Campesina de Montaña. Cochabamba - Bolivia: Intercooperation.

Machado, A. (2002). De la estructura agraria al sistema agroindustrial. Bogotá - Colombia: Universidad Nacional de Colombia.

Maciel, K. M. (2008). Estudo da viabilidade técnica da fibra do tucumã-i (Astrocaryum acaule) para a produção têxtil. XXVIII Encontro Nacional de Engenharia de Produção (ENEGEP). Rio de Janeiro - RJ.: Enegep.

Marinelli, A. L., Monteiro, M., Ambrósio, J. D., Brancifort, M. C., Kobayashi, M., \& Nobre, A. D. (2008). Desenvolvimento de compósitos poliméricos com fibras vegetais naturais da biodiversidade: uma contribuição para a sustentabilidade amazônica. . Polímeros Ciência e Tecnologia , 18(2):92-99.

Martínez, E. C., Lucio, I. F., \& Marín, M. P. (2008). La transferencia de conocimiento desde las humanidades: Posibilidades y características. ARBOR Ciencia, Pensamiento y Cultura , 619-636.

Menezes, M. R., Pinheiro, R., Guazzell, A. C., \& Martins, F. (2005). Cadeia produtiva das fibras vegetais extrativistas no estado do Amazonas. . Manaus AM.: Governo do Estado do Amazonas: SDS. Série Técnica. Meio Ambiente e Desenvolvimento Sustentável.

Miguel Fernández, E. d. (2005). Introducción a la Gestión (Managment). Valencia: Editorial de la UPV.

Miranda, I. P. (2001). Frutos e Palmeiras da Amazônia. Ministério da Ciência e Tecnologia (MCT). . Manaus - Amazonas - Bras: Instituto Nacional de Pesquisas da Amazônia (INPA).

Miranda, I. P., \& Rabelo, A. (2008). Guia de Identificação das palmeiras de Porto. . Trombetas/PA.: UFAM / INPA.

Motta, S. L., Mattar, F. N., Barreto, I. F., \& Teixeira, L. F. (2007). Processo de desenvolvimento e lançamento de novos produtos em pequena empresa: Um estudo de caso. Revista de Administração USP - R.Adm , v.42, n.3, p.373-383. 
Natural Fibres. (2009). ¿ Por qué naturales? Recuperado el 09 de Mayo de 2009, de EL AÑO INTERNACIONAL DE LAS FIBRAS NATURALES 2009: www.naturalfibres2009.org

November, A. (1994). Nuevas tecnologías y transformaciones socioeconómicas. Manual de nuevas tecnologías. Madrid - España: Ediciones, IEPALA.

OCDE. (1994). Políticas nacionales de la ciencia y de la tecnología. México México: Mundi-prensa.

Organización de las Naciones Unidas. (2009). http://www.naturalfibres2009.org/es/aifn/index.html. Recuperado el 02 de Octubre de 2009, de International Year of Natural Fibres: http: / / www.naturalfibres2009.org

Pacheco, K. M., Ortuño, B. H., \& Pacheco, A. S. (2011). Análise do posicionamento de especialistas sobre o uso da fibra natural amazônica de tucumã-i (Astrocaryum acaule) para o desenvolvimento de produtos semiindustriais. Anais do III Simpósio Brasileiro de Design Sustentável (III SBDS) Proceedings of the 3rd International Symposium on Sustainable Design (ISSD). Pernambuco - RE: Editora Universitária UFPE.

Pacheco, K. M., Ortuño, B. H., Miranda, I. P., Nascimento, C. C., \& Pacheco, A. S. (2011). Oportunidades e limitações do uso da fibra natural de tucumã-i (Astrocaryum acaule) para a gestão e desenvolvimento de produtos semiindustriais. Anais do $8^{\circ}$ Congresso Brasileiro de Gestão de Desenvolvimento de Produto (CBGDP). (págs. 1-13). Porto Alegre - RS/ Brasil: UFRGS/FEEng.

Potter, N. (1999). Qué es un diseñador: objetos, lugares, mensajes. Barcelona - España: Paidós.

Quiñones A, A. C. (2003). Reflexiones en torno a la artesanía y el diseño en Colombia. Bogotá - Colombia: Ceja.

Roessner, J. D. (2000). "Technology transfer”,en Hill, C. (Ed.). Science and technology policy in the US. A time of change. Londo - UK: Longman.

Santos, A. V. (2002). Fibras vegetais para artesanato: Técnicas de produção de fibras de Arumã, Cipó Ambé e Tucumã. Manaus - AM - Brasil: Fundação Vitória Amazônica (FVA).

Schwartzman, S. (2004). Mercado para produtos extrativistas da Amazônia brasileira. In ARNT, A. R. O destino da floresta. Reservas extrativistas e desenvolvimento sustentável na Amazônia. Rio de Janeiro - RJ: Relume Dumará. 
Shrestha, R. K., Alavalapati, J. R., \& Kalmbacher, R. S. (2004). Exploring the potential for silvopasture adoption in south-central Florida: An application of SWOT-AHP method. Agricultural Systems , 81 (3): 185-199.

Souza, H. M. (2004). Palmeiras brasileiras e exóticas cultivadas. São Paulo: Nova Odessa - Instituto Platarum.

Souza, L. A. (2008). Desenvolvimento sustentável, cultura e alteridade: um estudo a partir das comunidades indígenas da Amazônia. Curitiba: Pontifícia Universidade Católica do Paraná.

Tamayo y Tamayo, M. (2000). El proceso de la investigación científica. México: Noriega Editores.

Tear com fibra de tucum, cestos trançados de arumrã. (29 de março de 2011). Recuperado el 10 de julio de 2011, de Instituto Socio Ambiental । triangulo.org.br:

http://pib.socioambiental.org/anexos/19455_20110329_121707.pdf

Torres, P., Cavalcante, A., \& Almeida, R. (2011). Pesquisa de mercado como base para o design de calçados femininos - Marketing como fonte de informação para projeto de design. VI Congresso Internacional de Pesquisa em Design (CIPED). Lisboa - Portugal: CIAUD - Centro de Investigação.

Tucum: $A$ arte de fiação da fibra dessa palmeira constitui-se numa técnica ancestral herdada dos povos indígenas. (2 de dezembro de 2009 ). Recuperado el 6 de octubre de 2010, de Industria Textil e do Vestuário - Textile Industry Ano IV: http://textileindustry.ning.com/profiles/blogs/tucuma-arte-defiacao-da-fibra

U., C., \& A., D. (2005). Modelo de gestión estratégica para el de capacidades tecnológicas. Compendium , v.8, n.015, pp.5-19.

Valencia, L. I. (2011). La lógica y la importancia del diseño de investigación. Revista Poiésis , 1-14.

Van Dam, J., Van Vilsteren, G., Zomers, F., Shannon, W., \& Hamilton, I. (1994). Industrial Fibre Crops: Increased Application of Domestically Produced Plant Fibres in Textiles, Pulp and Paper Production, and Composite Materials. ATO-DLO, Wag. Wageningen, The Netherlands.: ATO-DLO.

Vargasa, J., \& Quispeb, F. (2009). 2009 Año internacional de las fibras naturales, problemática y tecnología de irradiación. REVISTA DEL ENCUENTRO CIENTÍFICO INTERNACIONAL - ECI , 1-8. 

Capítulo 3 - Publicaciones 



\section{Publicaciones}

\subsection{Artículo 1 - Análisis del posicionamiento del diseño cuanto al uso semi-industrial de la fibra amazónica de tucumã-i (Astrocaryum acaule) para la fabricación de productos}

Esta producción científica ha sido desarrollada con la intención de obtener informaciones sobre qué piensan algunos de los profesionales del diseño con respecto a la temática abordada (Publicación en portugués). El artículo corresponde al sub-objetivo 1 del objetivo 1 de la tesis (Pags.67, 68,69 y 70).

Congreso: $1{ }^{\circ}$ Congresso de Design UEM

ISSN: 2237-0862

Enviado: 15.Julio.11 | Aceptado: 29.Agosto.11 | Publicado: Septiembre.11

Cita: Pacheco, K. M. M.; Ortuño, B. H.; Miranda, I. P. A. (2011). Análise do posicionamento do design quanto ao uso semi-industrial da fibra amazônica de tucumã-i (Astrocaryum acaule) para a fabricação de produtos. $1^{\circ}$ Congresso de Design UEM - $5^{\text {a }}$ Semana de Design UEM - Design brasileiro: cultura ou influência? - Universidade Estadual de Maringá - UEM. Campus Regional de Cianorte - Paraná/ Brasil.

Análise do posicionamento do design quanto ao uso semi-industrial da fibra amazônica de tucumã-i (Astrocaryum acaule) para a fabricação de produtos

PACHECO, Karla Mazarelo Maciel; Mestre, Universidade Federal do Amazonas UFAM, Manaus/Amazonas, karlamazarelo@hotmail.com; ORTUÑO, Bernabé Hernandis; Doutor, Universidade Politécnica de Valência - UPV, Valência/Espanha, bhernand@degi.upv.es; MIRANDA, Ires Paula de Andrade; Doutora, Instituto Nacional de Pesquisas da Amazônia - INPA, Manaus/Amazonas, ires@inpa.gov.br.

Design, Fibra vegetal amazônica, Processo semi-industrial e Fabricação de produtos

\section{Introdução}

A fibra de tucumã-i (Astrocaryum acaule) é um recurso vegetal proveniente de palmeira amazônica (Figura 1) que se destaca pela produção sustentável realizada por comunidades indígenas e caboclas localizadas no Alto Rio Negro, estado do Amazonas - região norte do Brasil (Souza, 2004). 

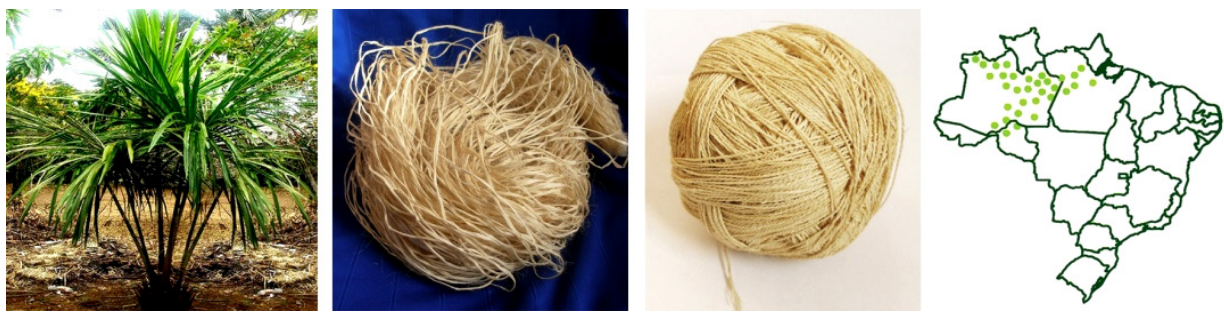

A1_Figura 1. Fibra de tucumã-i (Astrocaryum acaule) e sua área de localização no estado do Amazonas

A potencialidade econômica da matéria-prima encontra-se nas folhas (Miranda, 2001), com a extração de fibras de alta resistência, das quais são fabricados os produtos artesanais (Figura 2), como: doméstico e decorativo.
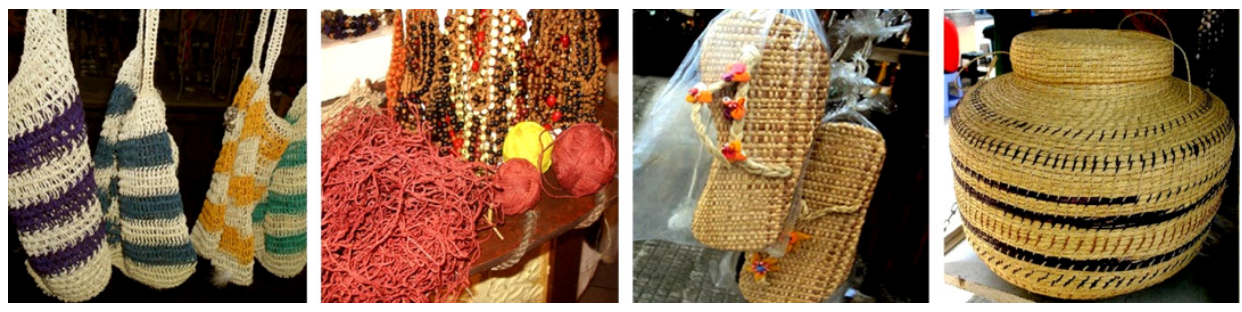

A1_Figura 2. Exemplos de produtos artesanais fabricados com a fibra amazônica de tucumã-i (Astrocaryum acaule)

A qualidade da matéria-prima, os aspectos sócio-culturais e a demanda de mercado são fatores considerados como um diferencial positivo à fibra, o que tem chamado a atenção de turistas, ONGs (Organizações NãoGovernamentais), Institutos de Investigação Tecnológica e Empresas do ramo industrial (Menezes, 2005). Além disso, a fibra apresenta dados observados e comparados com outros produtos similares - conforme critérios para a produção têxtil estabelecido pelo Instituto de Pesos e Medidas de São Paulo (IPEM/SP), que a consideram compatível à fabricação de tecidos naturais, inclusive, com valores próximos aos identificados na fibra de algodão e, ainda, com um número de informações significativo quanto aos atributos relacionados às suas características tecnológicas (Maciel, 2008).

Assim, as oportunidades para ampliar a variedade de produtos e melhorar os processos para aplicação da fibra só aumentam. No entanto, promover um produto artesanal - mesmo com aspectos tecnológicos favoráveis para o uso têxtil, a um nível de qualidade mais elevado e que satisfaça as expectativas dos consumidores e do mercado, sem que comprometa a essência do vegetal, 
a identidade cultural e o conhecimento de seus produtores - requer uma atenção maior, principalmente, quanto ao emprego da tecnologia adequada. Neste caso, compreende-se que seria algo muito brusco adaptar a fibra a um processo diretamente industrial. Desta forma, como sugestão inicial, um estudo sobre a sua prospecção para o uso semi-industrial destinado à fabricação de produtos, poderá ser uma ponte entre os conhecimentos artesanais e industriais de forma a contribuir para a evolução da matériaprima, a aprimorar as suas etapas de produção através de ferramentas e métodos não rudimentares, e ainda, a auxiliar para a padronização de uma linha de gestão e fabricação de produtos.

Portanto, produzir informações científicas que justifiquem o uso semiindustrial da fibra natural amazônica de tucumã-i (Astrocaryum acaule) para a fabricação de produtos, baseadas no posicionamento de alguns profissionais do design, é o ponto-chave para este artigo, no qual são propostos os seguintes objetivos:

- Analisar a opinião de designers sobre o uso semi-industrial da fibra natural amazônica de tucumã-i (Astrocaryum acaule) para a fabricação de produtos; e

- Identificar os aspectos considerados, pelos profissionais, como os mais importantes para dar continuidade à proposta da investigação.

\section{Material e métodos}

O estudo apresenta uma abordagem qualitativa, com objetivos de caráter exploratório e descritivo (Gil, 2002). A estrutura do conteúdo contempla uma pesquisa do tipo bibliográfica e documental, ratificada um estudo de caso específico - correlacionado aos processos de inovação e de estratégia (Yin, 2001). Para o presente artigo, que é parte de um estudo maior, os dados foram obtidos a partir de referências que discutem a temática e através da aplicação da técnica qualitativa Focus Group, com o intuito de obter as percepções de um grupo de pessoas sobre questões, fatos sociais e status atual do objeto de estudo, gerando idéias, comentários e a produção de insights (Krueger \& Casey, 2000).

Considerando o caráter do estudo e seus objetivos, foram selecionados - de forma intencional, 13 profissionais do design (Figura 3), para a realização da dinâmica (Focus Group) na sede da Universidade Politécnica de Valencia UPV/Espanha. 

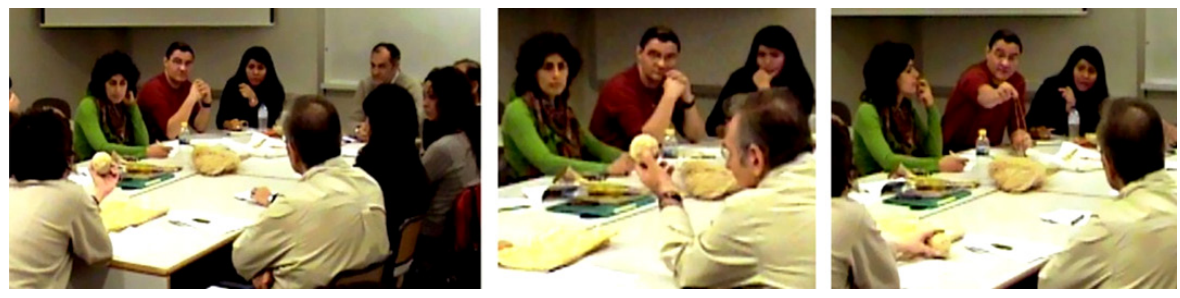

\section{A1_Figura 3. Técnica Focus group realizada com profissionais do design na UPV/Espanha.}

Para a execução desta proposta, foram analisadas as opiniões dos participantes com relação ao tema abordado e identificados os aspectos considerados importantes para o seu procedimento.

\section{Resultados e discussão}

Os designers consultados posicionaram-se favoráveis à proposta de investigação. Sendo assim, na tabela 1 podemos observar todos os aspectos considerados importantes e os parâmetros, por eles, determinados necessários à realização do estudo. As informações identificadas em $(J)$ representam as mais relevantes e, por conseguinte, as representadas em $(\mathrm{X})$ as de menor importância.

\section{A1_Tabela 1. Aspectos considerados importantes pelos designers}

\begin{tabular}{|c|c|c|c|}
\hline \multirow{26}{*}{ 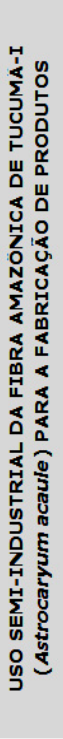 } & ASPECTOS & PARÂMETROS PARA O ESTUDO & $\begin{array}{l}\text { VALORAÇÃO } \\
X\end{array}$ \\
\hline & \multirow{9}{*}{ 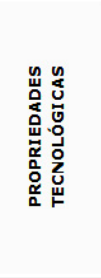 } & Resistência & $\sqrt{ }$ \\
\hline & & Elasticidade & $\mathrm{x}$ \\
\hline & & Toxicidade & $\sqrt{ }$ \\
\hline & & Umidade & $x$ \\
\hline & & Textura & $\mathrm{x}$ \\
\hline & & Lavagem & $\mathrm{x}$ \\
\hline & & Aparência & $\mathrm{x}$ \\
\hline & & Espessura & $\mathrm{x}$ \\
\hline & & Estabilidade da forma & $\sqrt{ }$ \\
\hline & \multirow{9}{*}{ 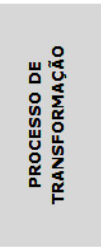 } & Origem da fibra & $\sqrt{ }$ \\
\hline & & Tipo de produção & $\sqrt{ }$ \\
\hline & & Características intrínsecas da fibra & $\sqrt{ }$ \\
\hline & & Normas de certificação & $\mathrm{x}$ \\
\hline & & Tipo de processo & $\sqrt{ }$ \\
\hline & & Tipo de maquinaria & $x$ \\
\hline & & Conhecimento técnico dos produtores & $x$ \\
\hline & & Transferência de tecnologia & $\sqrt{ }$ \\
\hline & & Fator socioambiental & $\sqrt{ }$ \\
\hline & \multirow{7}{*}{ 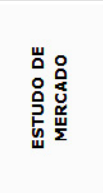 } & Opinião de Especialistas & $\sqrt{ }$ \\
\hline & & Opinião de Consumidores & $\sqrt{ }$ \\
\hline & & Apreciação / uso de fibras vegetais em produtos & $\sqrt{ }$ \\
\hline & & Aceitação/ uso da fibra de tucumã-i para produtos & $\sqrt{ }$ \\
\hline & & Categoria de uso e tipo de produtos & $\sqrt{ }$ \\
\hline & & Atributos do design de produto & $\sqrt{ }$ \\
\hline & & Preço do produto & $\sqrt{ }$ \\
\hline
\end{tabular}


De acordo com os aspectos considerados importantes pelos profissionais de design, os mais relevantes foram: Propriedades tecnológicas $\rightarrow$ Resistência, Toxidade e Estabilidade da forma; Processo de Transformação $\rightarrow$ Origem da fibra, Tipo de produção, Características intrínsecas da fibra, Tipo de processo, Transferência de tecnologia, Fator socioambiental; Estudo de Mercado $\rightarrow$ Opinião de especialistas e consumidores, Apreciação das fibras vegetais em produtos, Aceitação do uso da fibra de tucumã-i para produto, Categorias de uso e tipos de produtos, Atributos do design de produto e Preço.

\section{Conclusão}

Os dados apresentados nesse artigo contemplam sugestões de alguns profissionais do design para o planejamento de ações que facilitem o processo de adaptação da fibra de tucumã-i (Astrocaryum acaule) para o uso semiindustrial. 0 posicionamento favorável dos participantes considera alguns aspectos importantes para o procedimento do estudo, principalmente para aqueles apontados como os mais relevantes. Os designers ainda sugerem que a organização de todas essas informações, deve ser trabalhada de forma sistemática em prol do beneficiamento da matéria-prima e do alcance de resultados satisfatórios a partir do seu uso.

\section{Referências}

GIL, ANTONIO CARLOS. Como Elaborar Projetos de Pesquisa. Metodologia da Pesquisa. 4.ed. São Paulo: Atlas, 2002.

KRUEGER, RICHARD A. \& CASEY, M. A. Focus Groups. A Practical Guide for Applied Research. 3rd ed. Thousand Oaks, CA: Sage Publications, 2000.

MACIEL, K. M. F. Technical Viability of Tucumã-i Fibre (Astrocaryum acaule) for Production in Textile Industry. ECOWOOD 2008, 3rd International Conference \& Exhibition on Environmentally-compatible forest products. Univerdidade Fernado Pessoa. Oporto, Portugal, 2008.

MENEZES, M. R. et al. Cadeia produtiva das fibras vegetais extrativistas no estado do Amazonas. Governo do Estado do Amazonas - Manaus: SDS. Série Técnica. Meio Ambiente e Desenvolvimento Sustentável, 4.32p.; il., 2005.

MIRANDA, IRES PAULA DE ANDRADE. Frutos e Palmeiras da Amazônia. Ministério da Ciência e Tecnologia (MCT). Instituto Nacional de Pesquisas da Amazônia (INPA). Manaus - Amazonas - Brasil, 2001.

SOUZA, HERMES MOREIRA DE. et al. Palmeiras brasileiras e exóticas cultivadas. Nova Odessa. São Paulo: Instituto Platarum, 2004. 
Estudio de la prospección del uso de la fibra de tucumã-i (Astrocaryum acaule) para el desarrollo de productos semi-industriales

YIN, ROBERT K. Estudo de caso: planejamento e métodos. Tradução Daniel Grassi. 2.ed. Porto Alegre: Bookman, 2001. 


\subsection{Artículo 2 - Análisis sobre el posicionamiento de los expertos cuanto al uso de la fibra natural amazónica tucumã-i (Astrocaryum acaule) para el desarrollo de productos semi- industriales}

Esta producción científica ha sido desarrollada con la intención de obtener informaciones sobre qué piensan algunos expertos, de áreas relacionadas al tema abordado, uso el uso del objeto de estudio para el desarrollo de productos semi-industriales (Publicación en portugués). El artículo corresponde al sub-objetivo 2 del objetivo 1de la tesis (Pags.67, 68,69 y 70).

Congreso: III Simpósio Brasileiro de Design Sustentável (III SBDS) | Proceedings of the 3rd International Symposium on Sustainable Design (ISSD

ISBN: 978.85.7315.949-3

Enviado: 18.Junio.11 | Aceptado: 13.Julio.11 | Publicado: Septiembre.11

Cita: Pacheco, K. M. M.; Ortuño, B. H.; Pacheco, A. S. (2011). Análise do posicionamento de especialistas sobre o uso da fibra natural amazônica de tucumã-i (Astrocaryum acaule) para o desenvolvimento de produtos semiindustriais. Anais do III Simpósio Brasileiro de Design Sustentável (III SBDS) Proceedings of the 3rd International Symposium on Sustainable Design (ISSD). Editora Universitária - UFPE. Pernambuco - RE/Brasil.

Análise do posicionamento de especialistas sobre o uso da fibra natural amazônica de tucumã-i (Astrocaryum acaule) para o desenvolvimento de produtos semi-industriais

Positioning analysis of experts about using Amazon natural fiber of tucumã-i (Astrocaryum acaule) for the development of semi-industrial

Karla Mazarelo Pacheco ${ }^{1}$

Bernabé Hernandis Ortuño ${ }^{2}$

Almir de Souza Pacheco ${ }^{2}$

Palavras chave: Design; Produto; Fibra Natural da Amazônia.

Este artigo apresenta uma análise relativa às tomadas de decisões que o designer deve considerar com relação ao estudo da prospecção do uso da fibra natural amazônica tucumã-i (Astrocaryum acaule) para o desenvolvimento de produtos semi-industriais. 0 documento descreve as opiniões e ideias fornecidas por 11 especialistas de áreas correlacionadas ao referente estudo: Design de Produto; Engenharia de Produção; Engenharia Têxtil; Engenharia

\footnotetext{
1 Universidade Federal do Amazonas - UFAM/Brasil karlamazarelo@hotmail.com

2 Universidad Politécnica de Valencia - UPV/Espanha bhernand@degi.upv.es
} 
Estudio de la prospección del uso de la fibra de tucumã-i (Astrocaryum acaule) para el desarrollo de productos semi-industriales

Florestal e Ambiental; Engenharia Química; e Economia de Mercado e Produtos, todas coletadas através de uma entrevista em profundidade. Os dados foram analisados por meio de freqüências e calculo de medias. Como resultado, os profissionais entrevistados identificaram e relacionaram algumas oportunidades e limitações para o procedimento da investigação. Dos fatores primordiais destacados estão: o processo e o registro de evolução da fibra em questão - do estágio artesanal ao semi-industrial; o valor atribuído aos materiais naturais e com denominação de origem; as tecnologias modernas ao processo de transformação de matérias-primas; os benefícios sócio-ambientais e econômicos; a variedade das categorias de uso e de produtos no mercado de fibras naturais. Neste contexto o design poderá atuar como ferramenta estratégica para a transformação da fibra, qualidade dos processos e alcance de novos mercados.

Keywords: Design; Product; Amazon Natural Fiber

This article presents an analysis about decisions making that designer should consider in relation to the study of the use of natural Amazon fiber of tucumani (Astrocaryum acaule) for the development of semi-industrial products. The document describes opinions and ideas provided by 11 experts referring to the related areas of study: Product Design, Production Engineering, Textile Engineering, Forestry and Environmental Engineering, Chemical Engineering, and Economics Market and Products, all collected through an in-depth interview. Data were analyzed using frequencies and calculating averages. As a result, the professionals identified some opportunities and limitations for investigation. The principal factors highlighted are: the process of evolution and the record of such fiber - stage craft to the semi-industrial; the value attributed to natural materials and designation of origin, the modern technology to the process of transformation of raw materials and the benefits social- environmental and economic; the variety of use categories and products in the natural fibers market. In this context, the design will be as a strategic tool for the transformation of the fiber, in the quality of processes and for the reach new markets.

\section{Introdução}

As fibras naturais tem sido o foco principal de muitos pesquisadores nos últimos anos. A busca por novos materiais se apresenta como uma oportunidade única de encontrar soluções alternativas e inovadoras às áreas ainda não exploradas. O que significa avançar em direção ao sucesso, conquistando posições dominantes e promissoras (Reis Neto, 2003).

0 interesse por esses tipos de matérias-primas se dá em função de apresentarem baixa densidade, alto módulo específico, serem menos 
abrasivas aos equipamentos de processamento, quando comparadas com outros recursos - pois são renováveis, biodegradáveis e recicláveis, o que thes permite competir com outros materiais fósseis e industrializados (Leão, 1997).

Esses aspectos são considerados vantajosos ao mercado de produtos e ainda podem ser mais valorizados, uma vez que o avanço tecnológico tem mostrado que o uso de fibras naturais já não pode ficar limitado apenas às aplicações tradicionais (Oashi, 1998).

Neste contexto, busca-se atribuir uma atenção especial às fibras vegetais da Amazônia brasileira, região dotada de uma biodiversidade considerada como o maior potencial natural do mundo contemporâneo e que vem servindo de material para estudos científicos e insumos às bioindústrias (Pletsch, 1998).

Os produtos extrativistas amazônicos além de apresentarem características naturais qualitativas, também constituem fontes importantes de renda às populações florestais, que se tornam mais um motivo a reforçar as iniciativas de fortalecer e ampliar os mercados para novos produtos (Schwartzman, 2004).

Desta forma, pretende-se orientar à obtenção de informações e direciona o uso da fibra natural Amazônica de tucumã-i (Astrocaryum acaule) para o desenvolvimento de produtos semi-industrial, de acordo com o posicionamento de especialistas atuantes em áreas correlacionadas ao tema.

A fibra é identificada como um recurso vegetal, pouco explorado e conhecido, contudo se destaca pela produção sustentável e adaptação a diversos tipos de produtos de segmento decorativo e utilitário. Informações pertinentes ao seu uso no mercado industrial não são identificadas pelo universo científico. Os poucos registros observados descrevem práticas empíricas e artesanais (Maciel, 2007).

No entanto, estudos recentes, relatam que se trata de uma matéria-prima com características tecnológicas em potenciais, com compatibilidade de uso para o segmento têxtil, principalmente por apresentar boa resistência à tração e flexibilidade no desdobramento; índice nulo à reação tóxica; umidade e densidade satisfatórias, entre outras (Maciel, 2008).

Portanto, a proposta de analisar o universo do objeto de estudo para o uso semi-industrial, parte de princípios e informações relacionadas aos seus aspectos de produção e transformação - unicamente artesanal, que consideram ser algo muito brusco tentar adaptá-lo, nesse primeiro momento, diretamente ao processo industrial, sem que haja o apoio de experimentos técnicos, teóricos e práticos - registrados cientificamente para o devido 
Estudio de la prospección del uso de la fibra de tucumã-i (Astrocaryum acaule) para el desarrollo de productos semi-industriales

procedimento, uma vez que são indispensáveis às etapas de planejamento, gestão e desenvolvimento de produtos em alta escala.

Como trabalho científico que visa contemplar o uso semi-industrial da fibra de tucumã-i (Astrocaryum acaule) para o desenvolvimento de produtos, construir e sistematizar informações pertinentes com base no conhecimento de profissionais experientes, relatando as idéias e as sugestões para a melhor utilização dessa matéria-prima, valida as possíveis formas de transformação, inovação e aplicação diferenciada a serem oferecidas por ela.

Dessa forma, uma análise relativa às tomadas de decisões que o designer deve considerar com relação ao tema proposto, torna-se o ponto-chave desse artigo, que também contempla os seguintes objetivos:

Apresentar uma abordagem teórica sobre o uso das fibras vegetais em produtos, a fibra de tucumã-i (Astrocaryum acaule) e os aspectos semiindustriais para fabricação de produtos;

Aplicar uma entrevista em profundidade com especialistas de áreas correlacionadas ao tema em estudo;

Verificar o grau de aceitação do objeto de estudo para o uso semi-industrial em produtos;

Identificar os aspectos a serem considerados para o uso da fibra de tucumã-i (Astrocaryum acaule) ao desenvolvimento de produtos semi-industriais.

\section{0 uso das fibras vegetais para o desenvolvimento de produtos}

Desde que estudiosos passaram a explorar, investigar e divulgar as fibras naturais como opção para atender às necessidades básicas do homem, observar-se que tal propósito ultrapassa essas funções iniciais e chega à atualidade com uma gama variada para utilização no mercado de produtos (Figueiras, 2008).

O campo de emprego das fibras naturais é bastante amplo, abrangendo desde as aplicações clássicas na indústria têxtil até o reforço de matrizes poliméricas termoplásticas e termofixas (Nunes, Franca, \& Oliveira, 2009).

0 renovado interesse pelo uso industrial das fibras naturais levou-as a um processo de investigação mais elevado, a nível mundial, para a fabricação de uma série de produtos a partir das fibras vegetais (Olesen, 1997), por apresentarem vantagens com relação a outros tipos de materiais, como por exemplo: baixo custo, alta tenacidade, boas propriedades tecnológicas, redução de energia e tempo, biodegradabilidade, entre outros (Holbery \& Houston, 2006). 
As novas utilizações finais, das fibras celulósicas, demonstram ser tecnicamente viáveis e a consciência crescente dos aspectos ecológicos de suas produções e consumo tem sido uma líder para a tendência do uso sustentável dos recursos naturais (Van Dam, Van Vilsteren, Zomers, Shannon, \& Hamilton, 1994). Muitas delas têm sido aplicadas como matérias-primas para compor materiais novos como é o caso da juta, do sisal, do coco, do rami, do cânhamo, e outras, que além de estarem enquadradas nos ciclos ecológicos, apresentam um grande potencial comercial (Bledzki \& Gassan, 1999).

O maior emprego das fibras vegetais para a fabricação de produtos industriais, semi-industriais, e/ou produtos de nicho, com o mínimo impacto ambiental tem necessitado do conhecimento de suas propriedades básicas, implicando aos envolvidos na produção e crescimento das plantas, uma noção básica sobre o desempenho exercido por essas, cujo aproveitamento em escalas maiores exige desafios comerciais com força elevada ao incremento da cadeia produtiva que, para as culturas de fibras vegetais, divide-se em três elos principais: a produção agrícola, o processamento de fibras e utilização final (Van Dam J. E., 1999).

A sequência atribuída ao cultivo dessas matérias-primas, para a aplicação em produtos, requer um cuidado especial que não leve tal propósito à exaustão e, com isso, causar desequilíbrio e degradação ambiental, refletindo na carência dos recursos naturais, meios financeiros e talentos humanos que acarretem obstáculos ao crescimento econômico (Reis Neto, 2003).

O emprego das fibras vegetais deve ocorrer dentro dos limites físicos dos ecossistemas, considerando os aspectos intrínsecos do material, além de concentrar esforços no uso mais eficiente de energia e recursos, em processos de produção não poluentes, na redução de resíduos e emissões e no gerenciamento de riscos tecnológicos (Bortolanza, 1999).

\section{Fibra de tucumã-i (Astrocaryum acaule) da Amazônia brasileira}

Dados referentes ao gênero Astrocaryum, sobretudo a espécie acaule, estão a apontá-lo como um grande fornecedor de fibras naturais para a produção artesanal em abundância na Amazônia brasileira, mas especificamente na região norte do Brasil (Miranda, 2001).

É um produto natural proveniente de palmeira nativa, com caule subterrâneo predominante de terra firme ou de várzea, medindo entre 6 a 15 metros de altura. É notável por apresentar uma composição paisagística. Fornece frutos suculentos e aromáticos que, em tom alaranjado, se destacam no meio da coroa foliar (Miranda \& Rabelo, 2008). 
Estudio de la prospección del uso de la fibra de tucumã-i (Astrocaryum acaule) para el desarrollo de productos semi-industriales

A espécie possui um impacto visual muito forte, devido ao tamanho das folhagens e da coloração em tom verde escurecido. Suas potencialidades econômicas estão centradas nas folhas, com a extração de fibras de alta resistência (Miranda, 2001)

O tucum, também conhecido por tucumã-i (Astrocaryum acaule), está localizado em grande parte na região do Alto Rio Negro, estado do Amazonas (Figura 1), onde é produzido, cultivado e manuseado, de forma sustentável, por comunidades indígenas e caboclas, que por tradição são consideradas como as maiores conhecedoras e consumidoras dessa matéria-prima (Maciel, 2007).

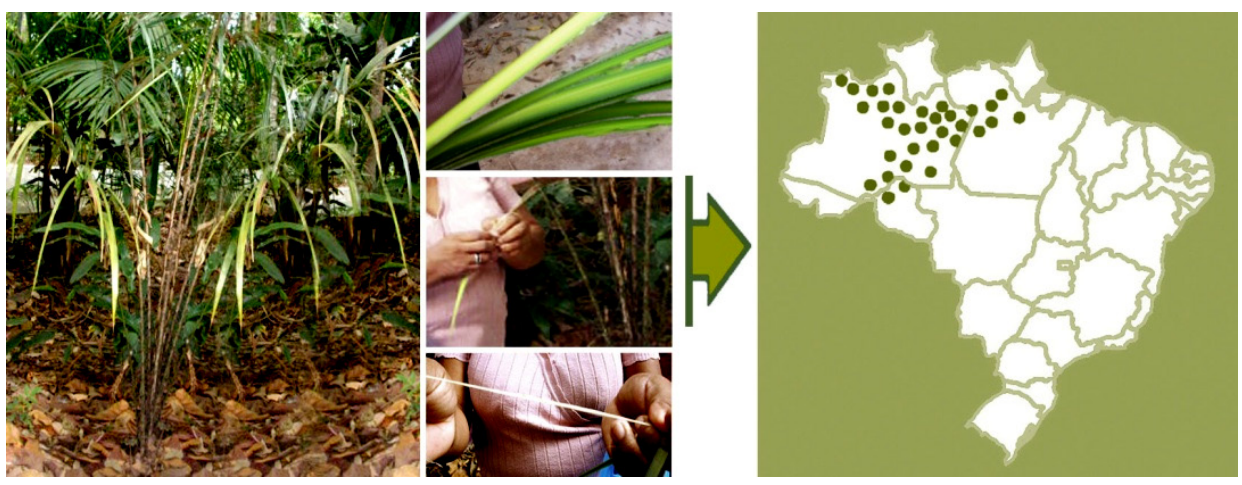

A2_Figura 1. Palmeira, folhas, fibra de tucumã-i (Astrocaryum acaule) e a sua área de localização na Amazônia brasileira.

A atividade extrativista feita na área mencionada demonstra ser a mais organizada e com maior grau de sofisticação técnica de produção florestal não madeireira da Amazônia. 0 uso sustentável das suas bases de recursos é feito pelas próprias comunidades indígenas e caboclas (Menezes, 2005).

A produção sustentável de tucumã-i (Astrocaryum acaule) valoriza a fibra desde o momento do seu cultivo, já determinando a função para a qual a matéria-prima será destinada e definida. 0 processo é totalmente manual (artesanal), dispondo apenas de instrumentos domésticos produzidos pelas próprias comunidades, contemplando: a escolha da planta, a técnica de corte, lavagem e secagem, aplicação de tingimento natural, fixação da cor, amarração das ramas, técnica de fiação e, por fim, a tecelagem dos fios (Santos, 2002).

0 método produtivo da fibra busca estar de acordo com as normas da Comissão Mundial sobre o meio ambiente, criada pela ONU, tentando fazer dela um recurso natural capaz de suprir as necessidades atuais sem 
comprometer as gerações futuras e, ainda, gerar emprego e melhores condições de vida para as suas comunidades produtoras (Maciel, 2008).

Dos produtos artesanais fabricados com a fibra de tucumã-i (Figura 2) destacam-se: tecidos, toalhas de mesa, mantas, cestos, bolsas, chapéus, pulseiras, colares, cintos, calçados e entre outros. A comercialização é feita através da compra ou venda da fibra no seu estado in natura ou, então, já transformada em produto artesanal. A atividade é exercida em centros comerciais, feiras e eventos culturais. Os principais mercados alcançados com a venda desse produto são a capital do estado do Amazonas - Manaus, alguns estados brasileiros e alguns países da América do Norte, América do Sul e Europa (Menezes, 2005).
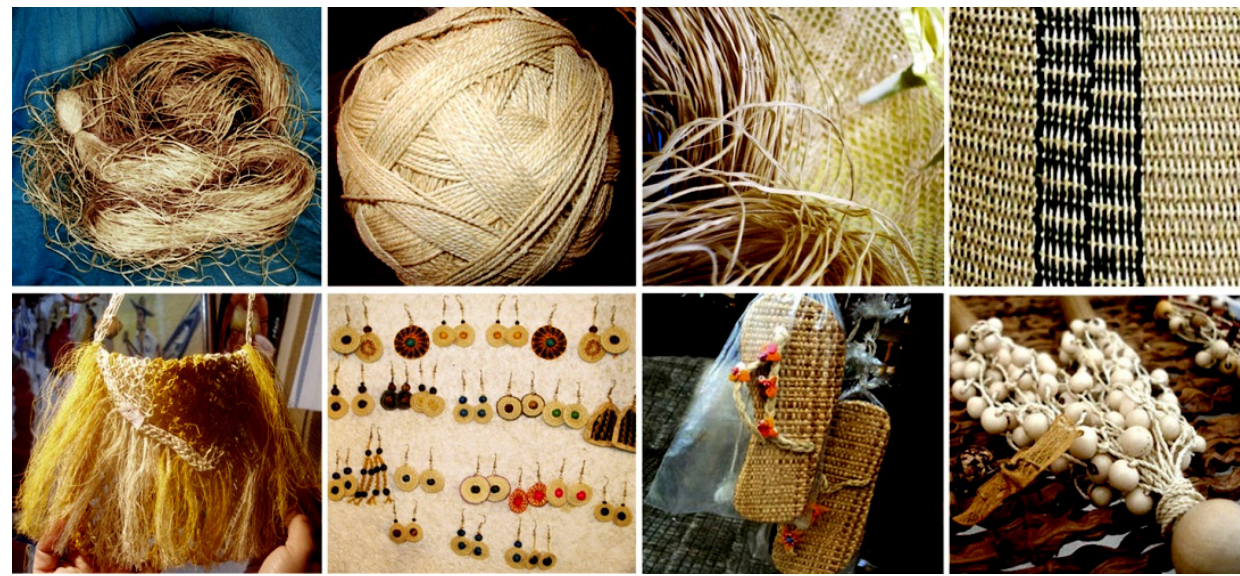

A2_Figura 2. Alguns dos produtos artesanais desenvolvidos com a fibra de tucumã-i (Astrocaryum acaule).

A questão sustentável, a qualidade da matéria-prima, os aspectos sócioculturais, a demanda de mercado e o resultado da sua aplicação em produtos artesanais estão chamando a atenção de muitos turistas, ONGs (Organizações Não-Governamentais) e empresas do segmento industrial.

No entanto, a produção e o consumo são bastante diferenciados no tempo e no espaço, devido existir uma difícil compreensão, por parte das comunidades, em atender certa ou até necessária adequação entre as exigências do mercado regional e as características tradicionais valorizadas pelas unidades produtoras (Cano, 1998).

Tal realidade corresponde a desafios e superação, em busca de inovações e qualidade dos produtos para a concorrência, sem temer dificuldades ou 
Estudio de la prospección del uso de la fibra de tucumã-i (Astrocaryum acaule) para el desarrollo de productos semi-industriales

fracassos, relacionando sua produção nas operações econômicas, na organização, na comercialização e na gestão necessária ao funcionamento de seu empreendimento (Barreto, 2007).

O desenvolvimento de novos produtos competitivos não é uma tarefa fácil, em função da exigência do mercado e do esforço contínuo de renovação para aqueles que se acostumou a produzir, o mesmo produto durante anos e que precisam oferecê-los como novos e criativos (Tassinari, 1995).

Portanto, sintetizar informações à tomada de decisões, solucionar problemas e querer cada vez mais dados relevantes para determinados fins, beneficiando o uso de novos materiais à fabricação dos produtos, à melhoria dos serviços e à mudança de um sistema mais eficaz na produção desses materiais possibilita criar produtos de sucesso, uma vez, que podem ser tão importantes (se não mais) para investir no projeto do processo de concepção, assim como na concepção do próprio produto (Buxton, 2007).

\section{Aspectos semi-industriais para a fabricação de produtos}

A procedência do processo semi-industrial, aplicado ao desenvolvimento de produtos, pode ser compreendida a partir de referencias feita sobre as transformações nos meios de fabricação (Revolução Industrial) ocorridas na Europa entre os séculos 18 e 19 (Cardoso, 2004), colaborado pelo surgimento do movimento Arts and Crafts, os quais contextualizavam o posicionamento de idéias sobre as produções industriais e artesanais (Pevsner, 2002), que:

Em um primeiro momento $\rightarrow$ o projeto e a execução de objetos de forma artesanal ou semi-industrial retratavam a recuperação dos valores produtivos tradicionais, buscando uma relação mais democrática entre os trabalhadores e um elevado padrão de qualidade de materiais e de acabamento (Cardoso, 2004); e

Em um segundo momento $\rightarrow$ a viabilização da comercialização de produtos de bom design, em grande quantidade, necessitavam de um ponto de equilíbrio que pudesse envolver o processo de mecanização (Fiell \& Fiell, 2001).

Em meio essas informações compreende-se que o progresso tecnológico tornava-se irreversível à criação de formas capazes de manter as tradicionais habilidades técnicas humanas em parceria às novas tecnologias de produção industrial, sugerindo novos conceitos educacionais para um novo tipo de desenhador que pudesse entender e explorar as particularidades das máquinas com arte e sensibilidade estética (Pevsner, 2002).

Para tanto, a participação do design surge atrelada à diferenciação dos produtos e otimização da produção, sendo vista como o cruzamento, a relação entre arte e ciência - a partir da integração das artes e ofícios, e também 
como arte popular no sentido da arte prática presente no cotidiano destinada ao homem na sociedade da cultura material e imaterial (Wollner, 2002).

Apesar de o design pertencer à esfera produtiva, ainda guarda relações de proximidade, referência e diálogo com a arte (Villas-Boas, 1998), uma vez que design é produção de cultura e de linguagem, porém um projeto não existe, isto é, não pode ser materializado sem a tecnologia. E antes da tecnologia ser aplicada, deve existir um projeto com conceito e propostas indicando a aplicação, a sistematização e a utilização das técnicas (Moura, 2003).

Relacionar o design ao processo de transição do estado artesanal ao industrial é envolver a consideração do grau de reprodutibilidade de um objeto e da qualidade seja do projeto, seja de sua execução (Cunha de Castro, 2009). E para o desenvolvimento semi-indutrial de produtos (com características artesanais) em série, essa relação e produção podem dispor da utilização de moldes e fôrmas, máquinas e equipamentos de reprodução, assim como, da colaboração de pessoas envolvidas e conhecedoras apenas de partes do processo (Mascêne, 2010).

A possibilidade de projetar pequenas séries diferenciadas para produção em ambientes tradicionais viabilizava, portanto, uma forma de design que interpretava a cultura contemporânea e local, partindo do contexto produtivo artesanal para dotá-lo de estratégia e método, tornando-se competitivo no âmbito do mercado e contribuindo na busca do desenvolvimento sustentável (Cunha de Castro, 2009).

\section{Materiais e Métodos}

A pesquisa é de caráter: descritivo-exploratória, utilizando técnicas quantitativas e qualitativas, ambas baseadas em marco teórico que possibilita uma aproximação conceitual sobre o tema abordado (Gil, 2002). 0 procedimento qualitativo foi adequado à obtenção das percepções dos participantes consultados sobre questões e fatos sociais relativos ao status atual do fenômeno estudado e para descrever a natureza das condições existentes sobre a situação (Trochim \& Donnelly, 2007).

A coleta de dados foi feita por pesquisa bibliográfica e documental, além disso, foi aplicada uma entrevista em profundidade com 11 especialistas, pertencentes às áreas de Design de Produto, Engenharia Florestal e Ambiental, Engenharia Têxtil, Engenharia de Produção, Engenharia Química, Economia de Mercado e Gestão Produtos. A intenção da aplicação dessa técnica foi de explorar o posicionamento e as perspectivas desses profissionais sobre a proposta do estudo. Tal método é considerado não-estruturado e direto de obter informações, sendo realizado com cada pessoa de forma individual (Malhotra, 2006). 
Estudio de la prospección del uso de la fibra de tucumã-i (Astrocaryum acaule) para el desarrollo de productos semi-industriales

Por ser um estudo a envolve uma fibra natural amazônica para o desenvolvimento de produtos semi-industriais, e estar em processo de investigação sobre a coordenação da Escola Técnica Superior de Engenharia do Design - ETSID da Universidade Politécnica de Valência - UPV/ Espanha, optouse por aplicar a entrevista com profissionais atuantes em Instituições de Ensino e Pesquisas Tecnológicas, Empresas e Universidades localizadas no Brasil (sobretudo região Norte), Portugal e Espanha.

0 procedimento foi realizado num prazo de três meses, considerando o tempo para aplicação das entrevistas e para as análises dos resultados, sendo iniciado no mês de agosto de 2010, através de um formulário preparado e enviado aos informantes, por correio eletrônico juntamente com uma nota, em anexo, explicando a natureza da pesquisa. 0 documento apresentou 24 questões, elaborado a partir de temas relevantes apontados na literatura.

Para a presente publicação, que é parte de um estudo maior, foram explorados os resultados de 10 questões do roteiro, em consonância com os objetivos do artigo, focalizando os seguintes aspectos: 1. Apreciação das fibras naturais vegetais para fabricação de produtos; 2 . Valores atribuídos aos produtos feitos com fibras vegetais; 3. Aprovação da inserção de novas fibras vegetais ao mercado de produtos; 4. Aceitação da fibra de tucumã-i (Astrocaryum acaule) para o uso semi-industrial em produtos; 5 . Credibilidade para o processo de transformação semi-industrial da fibra; 6. Variáveis consideradas importantes ao processo de transformação da fibra; 7. Vantagens a serem oferecidas pela fibra com o processo de transformação semi-industrial; 8. Características tecnológicas a serem consideradas ao uso da fibra; 9. Critérios para certificação dos produtos semi-industriais feitos com a fibra; e, 10. Categorias de uso para a aplicação semi-industrial da fibra.

Os dados quantitativos foram organizados e analisados a partir da distribuição de frequência e o cálculo de médias.

\section{Resultados}

A amostra analisada apresentou um número maior de profissionais residentes e trabalhando no Brasil (Tabela 1), enquanto os demais são especialistas de Portugal e Espanha.

A2_Tabela 1. Caracterização da amostra - Nac. dos profissionais entrevistados

\begin{tabular}{l|ll} 
Nacionalidade & Freqüência & Porcentagem \\
\hline Brasil & 7 & $63,6 \%$ \\
Portugal & 3 & $27,3 \%$
\end{tabular}




\begin{tabular}{l|lr} 
Espanha & 1 & $9,1 \%$ \\
TOTAL & 11 & $100 \%$ \\
\hline
\end{tabular}

Dos campos de atuação profissional (Tabela 2), a área de maior destaque, identificada na amostra, pertence ao 'design de produto'. Em seguida temos a 'engenharia têxtil' e a 'engenharia de produção'. As engenharias florestais e ambientais, química e economia de mercado e gestão produtos, contemplaram um número menor de profissionais colaboradores.

A2_Tabela 2. Caracterização da amostra - Áreas de atuação profissional

\begin{tabular}{l|ll} 
Atuação Profissional & Frequiência & Porcentagem \\
\hline Design & 4 & $36,4 \%$ \\
Eng. Têxtil & 2 & $18,2 \%$ \\
Eng.Produção & 2 & $18,2 \%$ \\
Eng. Florestal e & 1 & $9,1 \%$ \\
Ambiental & & \\
Eng.Química & 1 & $9,1 \%$ \\
Economia & 1 & $9,1 \%$ \\
TOTAL & 11 & $100 \%$
\end{tabular}

A maior parte dos entrevistados destaca os profissionais vinculados aos 'centros de investigação e desenvolvimento têxtil' (Tabela 3). Na sequência estão os 'institutos de pesquisa' e as 'empresas de atuação em design'. As universidades, centros de ensino e demais locais de atuação, formaram a menor parte constituída pelos participantes entrevistados.

A2_Tabela 3. Caracterização da amostra - Local de atuação dos entrevistados

\begin{tabular}{l|ll} 
Locais de atuação dos entrevistados & Freqüência & Porcentagem \\
\hline Centros de Invest. e Desenv. Têxtil & 4 & $36,4 \%$ \\
Institutos de pesquisa & 2 & $18,2 \%$ \\
Empresas de design & 2 & $18,2 \%$ \\
Universidades Federais & 1 & $9,1 \%$
\end{tabular}




\begin{tabular}{l|lr} 
Centros de Ensino & 1 & $9,1 \%$ \\
Outros & 1 & $9,1 \%$ \\
TOTAL & 11 & $100 \%$ \\
\hline
\end{tabular}

Dos perfis de trabalho apresentados pelos locais de atuação, os que 'estudos em design' demonstraram maior evidência (Tabela 4), seguidos pelos que trabalham com 'estudos de fibras têxteis' e 'gestão e fabricação de produtos'. Os demais recintos, por ter poucos representantes, não apresentaram uma ênfase muito elevada.

A2_Tabela 4.Caracterização da amostra - Perfil dos locais de atuação dos entrevistados

\begin{tabular}{l|ll} 
Perfis dos locais de atuação & Frequiência & Porcentagem \\
\hline Estudo em design & 4 & $36,4 \%$ \\
Estudo de fibras têxteis & 2 & $18,2 \%$ \\
Gestão e fabricação de produtos & 2 & $18,2 \%$ \\
Estudo e Uso dos Recursos Naturais & 1 & $9,1 \%$ \\
Estudo de Mercado \& Produtos & 1 & $9,1 \%$ \\
Outros & 1 & $9,1 \%$ \\
TOTAL & 11 & $100 \%$ \\
\hline
\end{tabular}

De acordo com os aspectos observados, com base nas 11 perguntas formuladas partir de temas relevantes apontados na literatura, os especialistas apresentaram os seguintes posicionamentos quanto a (o):

1. Apreciação das fibras vegetais para a fabricação de produtos

Todos os profissionais apresentaram um nível de apreciação bastante elevado $(100 \%)$, sendo favorável ao uso das fibras vegetais para o desenvolvimento de produtos (Tabela 5). 0 alto índice foi justificado em função dos valores atribuído aos materiais naturais: recursos renováveis com propriedades desejáveis para aplicação em produtos; menos abrasivos que as fibras artificiais; serem biodegradáveis; fonte de renda para promover a segurança alimentar de muitas comunidades produtoras, e entre outros aspectos. 
A2_Tabela 5. Nível de apreciação do uso das fibras vegetais para a fabricação de produtos

\begin{tabular}{ll|lc}
$\begin{array}{l}\text { Uso das fibras naturais em } \\
\text { produtos }\end{array}$ & Freqüência & Porcentagem \\
\hline Sim & 11 & $100 \%$ \\
Não & 0 & $0 \%$ \\
TOTAL & 11 & $100 \%$ \\
\hline
\end{tabular}

2. Valores atribuídos aos produtos feitos com fibras vegetais

A maioria dos entrevistados valorizou como muito importante (Tabela 6) os produtos feitos com fibras vegetais, devido apresentarem baixo custo tecnológico, serem eco-eficientes, diferenciados, variados, inovadores, resistentes e apresentarem conforto e qualidade aos seus consumidores.

A2_Tabela 6. Valores atribuídos aos produtos feitos com fibras vegetais

\begin{tabular}{l|ll} 
Valores & Freqüência & Porcentagem \\
\hline Pouco importante & 4 & $36,4 \%$ \\
Importante & 2 & $18,2 \%$ \\
Muito importante & 5 & $45,5 \%$ \\
Bastante importante & 0 & $0 \%$ \\
TOTAL & 11 & $100 \%$ \\
\hline
\end{tabular}

Sendo assim, dos atributos associados aos produtos, de qualidade, fabricados com as fibras vegetais, os entrevistados consideraram positivos ( com media > 2) - numa escala de 1 a 4 - onde 1 significa 'pouco importante' e 4 'bastante importante'(Tabela 7).

A2_Tabela 7. Valores associados aos produtos de qualidade

\begin{tabular}{l|l} 
Atributos & $\begin{array}{l}\text { Total } \\
\text { (Médias) }\end{array}$ \\
\hline Elegância & 2,73 \\
Origem da fibra & 3,45
\end{tabular}




\begin{tabular}{l|l} 
Tradição & 3,18 \\
Modernidade & 2,55 \\
Inovação & 3,55 \\
Variedade & 3,27 \\
\hline
\end{tabular}

Os especialistas avaliaram como atributos 'muito importantes' (media $>3$ ): em primeiro lugar a 'inovação', seguida pela 'origem da fibra', a 'variedade', e a 'tradição'. Como atributos importantes (media entre 2 e 3): a 'elegância' e a 'modernidade'. Sendo esse último um predicado que menos influenciaria aos produtos feitos com fibras vegetais. A figura 3 ilustra as medias de valores apresentadas para os aspectos, mais e menos, evidenciados pelos entrevistados nesse quesito.
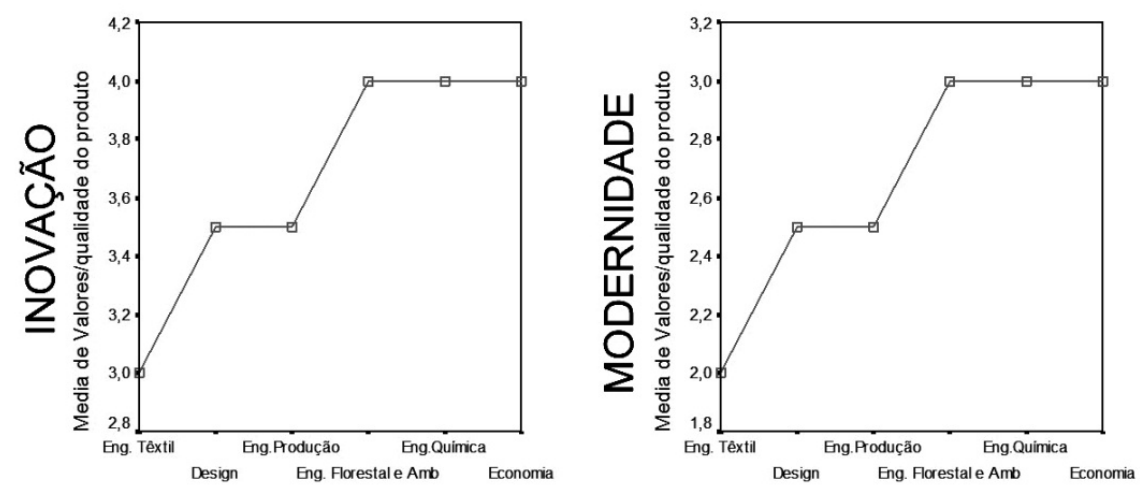

A2_Figura 3. Médias apresentadas aos aspectos de Inovação (mais evidenciado) e Modernidade (menos evidenciado).

3. Aprovação da inserção de novas fibras vegetais no mercado de produtos

Todos os especialistas mostraram-se favoráveis (100\%) a inserção de novas fibras vegetais no mercado de produtos (Tabela 8), devido ser matériasprimas competitivas para a fabricação de produtos inovadores e ao alcance de novos mercados.

A2_Tabela 8. Nível de aprovação da inserção de novas fibras vegetais no mercado de produtos

\begin{tabular}{l|ll} 
Inserção de novas fibras no mercado & Freqüência & Porcentagem
\end{tabular} 


\begin{tabular}{l|ll} 
Sim & 11 & $100 \%$ \\
Não & 0 & $0 \%$ \\
TOTAL & 11 & $100 \%$
\end{tabular}

4. Aceitação da fibra de tucumã-i (Astrocaryum acaule) para o uso semiindustrial em produtos

Os entrevistados foram unanimes $(100 \%)$ quanto à aceitação da fibra de tucumã-i (Astrocaryum acaule) para o uso semi-industrial em produtos (Tabela 9). Eles acreditam que a fibra apresenta boas vantagens com relação: ao seu processo produtivo; aos benefícios socio-econômicos que poderão gerar; as características tecnológicas já identificadas; a viabilidade para aplicação em produtos artesanais e; o forte valor da sua denominação de origem - matériaprima amazônica. 0 uso da fibra para desenvolver produtos, nessa categoria de processo, ainda, poderá propor novas categorias de produtos e, ainda, conquistar um bom posicionamento no mercado.

A2_Tabela 9. Grau de aceitação da fibra de tucumã-i (Astrocaryum acaule) para o desenvolvimento de produtos

\begin{tabular}{l|ll}
$\begin{array}{l}\text { Aceitação da fibra de tucumã-i } \\
\text { (Astrocaryum acaule) }\end{array}$ & Freqüência & Porcentagem \\
\hline Sim & 11 & $100 \%$ \\
Não & 0 & $0 \%$ \\
TOTAL & 11 & $100 \%$ \\
\hline
\end{tabular}

5. Credibilidade para processo de transformação semi-industrial da fibra

A maioria dos especialistas entrevistados, acreditam ser positivo (Tabela 10) o processo de transformação semi-industrial da fibra de tucumã-i (Astrocaryum acaule). Eles consideram que adaptar a fibra de modo a contribuir para a sua evolução - do estágio artesanal ao semi-industrial - poderá ser um grande marco para o ramo científico, uma vez que a espécie analisada não dispõe de muitos registros técnicos e experimentais nesse sentido e, ainda, apresentar novas formas para aplicação em produtos.

No entanto, ressaltam que o processo de transformação deve ser auxiliado a partir de um registro sistematizado das informações coletadas sobre os aspectos intrínsecos do objeto de estudo. 
Estudio de la prospección del uso de la fibra de tucumã-i (Astrocaryum acaule) para el desarrollo de productos semi-industriales

A2_Tabela 10. Nível de credibilidade - processo de transformação semi-industrial da fibra

Credibilidade - Processo de Frequiência Porcentagem transformação semi-industrial da fibra

\begin{tabular}{l|ll}
\hline Sim & 9 & $81,8 \%$ \\
Não & 2 & $18,2 \%$ \\
TOTAL & 11 & $100 \%$ \\
\hline
\end{tabular}

6. Variáveis consideradas importantes ao processo de transformação semi-industrial da fibra

Das variáveis consideradas importantes ao processo de transformação semiindustrial da fibra, as de maior representatividade foram as 'características Intrínsecas' (Tabela 11) da matéria-prima estudada. Os 'aspectos socioambientais' também receberam uma atenção especial, seguidos pela 'origem da fibra', 'tipo de processos/transformação dos materiais', 'normas para certificação' e por último, com importância não muito elevada, o 'tipo de produção/tecnologia'.

A2_Tabela 11. Variáveis importantes - processo de transformação semi-industrial da fibra de tucumã-i (Astrocaryum acaule)

\begin{tabular}{l|l} 
Variáveis & Total (Médias) \\
\hline Origem da fibra & 2,36 \\
Tipo de produção/tecnologia & 1,82 \\
Características intrínsecas da fibra & 3,36 \\
Normas para certificação & 2,27 \\
Tipo de processo/transformação dos materiais & 2,27 \\
Aspectos socio-ambientais & 2,55 \\
\hline
\end{tabular}

Mesmo sendo todas consideradas importantes (média > 1) pelos entrevistados, as variáveis, ainda assim, apresentaram valores diferenciados quanto ao grau de importância. Na escala de valoração: 1 significa 'pouco importante' e 4 'bastante importante'. A figura 4 ilustra as médias atribuídas às 'características intrínsecas da fibra' e ao 'tipo de produção e tecnologia' como as mais e menos evidenciadas para esse quesito. 

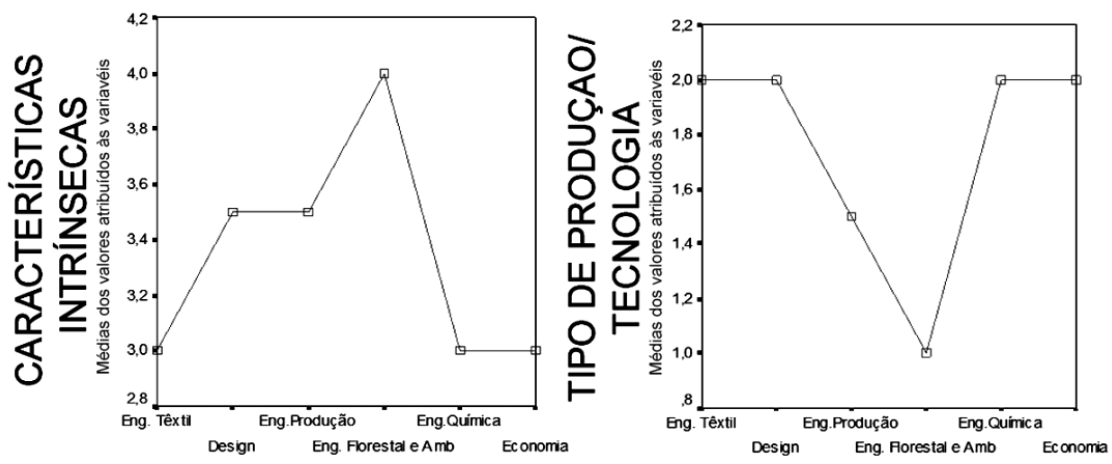

A2_Figura 4. Médias de valores apresentadas às variáveis, mais e menos, evidenciadas pelos entrevistados.

7. Vantagens a serem oferecidas pela fibra com o processo de transformação semi-industrial

A maior parte dos entrevistados avaliou que a transformação semi-industrial da fibra de tucumã-i (Astrocaryum acaule), poderá oferecer como vantagem principal o 'alcance de novos produtos', por a fibra apresentar um perfil característico ao mercado das fibras naturais - oferecendo aspectos sustentáveis e socio-culturais, demanda variada para a sua aplicação em produtos, até o momento por processo artesanal, e que tem despertado a atenção de consumidores. Outros aspectos favoráveis foram: a 'maior eficiência e competitividade', uma vez que apresenta um esquema de produção simples e empírico, mas que gera bons resultados; e 'mais qualidade aos produtos' - atribuindo melhor acabamento e novas formas de aplicação para o uso destes. Assim sendo, a maioria dos aspectos foram considerados positivos (com media > 2), numa escala de 1 a 4 - onde 1 significa 'pouco importante' e 4 'bastante importante' (Tabela 12).

A2_Tabela 12. Vantagens fibra de tucumã-i (Astrocaryum acaule) com o processo de transformação semi-industrial

\begin{tabular}{l|l} 
Variáveis & $\begin{array}{l}\text { Total } \\
\text { (Médias) }\end{array}$ \\
\hline Alcance de novos mercados & 3,36 \\
Maior eficiência e competitividade & 2,73 \\
Mais qualidade aos produtos & 2,45 \\
Redução de custos & 2,09 \\
Novas tecnologias & 2,09
\end{tabular}




\begin{tabular}{l|l} 
Aumento de produção & 2,00 \\
Maior controle do processo & 2,09 \\
Outras & 1,82 \\
\hline
\end{tabular}

Conforme os valores das medias apresentadas, o item 'alcance de novos mercados' continuou com o grau mais elevado, posicionado como 'muito importante'. O aspecto relacionado a 'outras' foi o elemento que menor demonstrou evidência (Figura 5).
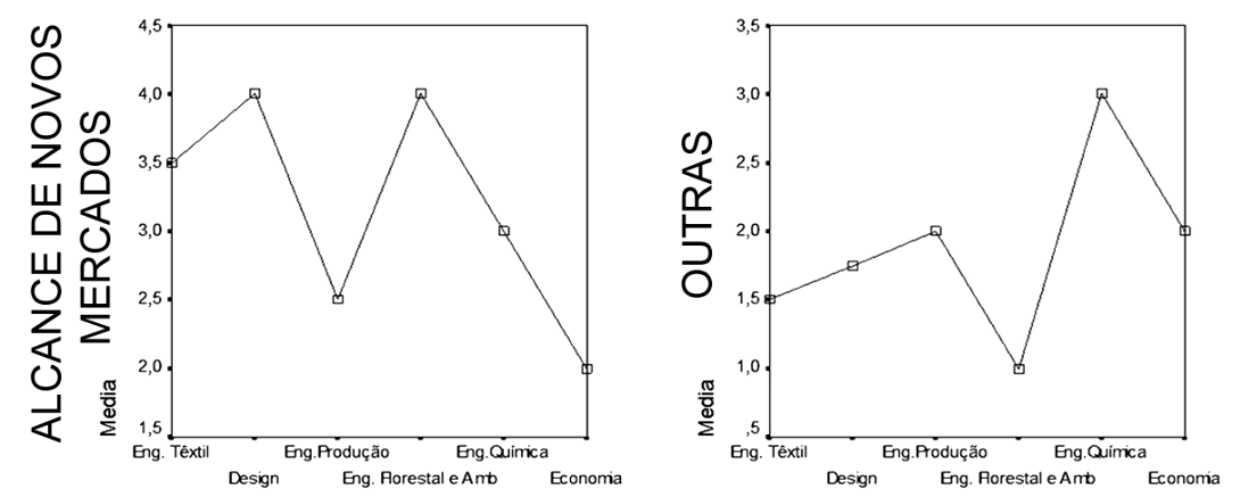

A2_Figura 5. Médias de valores apresentadas às vantagens, mais e menos, evidenciadas pelos entrevistados.

Características tecnológicas a serem consideradas ao uso da fibra

Os especialistas consideraram como 'importantes' todas as características tecnológicas apresentadas (com médias entre 2 e 3 ). No entanto, o fator com maior relevância, identificado, corresponde a 'resistência' (com media > 3) numa escala de 1 a 4 - onde 1 significa 'pouco importante' e 4 'bastante importante' (Tabela 13).

A preferência pela 'resistência' se dá em função das normas e certificações de parâmetro nacional e internacional, especificadas, exigidas e aplicadas às empresas que trabalham com fibras: naturais e não naturais aplicadas em produtos, sobretudo, na área têxtil.

A2_Tabela 13. Características tecnológicas importantes ao uso da fibra

\begin{tabular}{l|l} 
Características & $\begin{array}{l}\text { Total } \\
\text { (Médias) }\end{array}$ \\
\hline Suavidade & 2,64
\end{tabular}




\begin{tabular}{l|l} 
Resistência & 3,36 \\
Elasticidade & 2,27 \\
Toxidade & 2,91 \\
Ruptura & 2,73 \\
Cor & 2,55 \\
Textura/brilho & 2,36 \\
Lavagem & 2,18 \\
Aparência & 2,27 \\
Espessura & 2,55 \\
Estabilidade da forma & 2,36 \\
Outras & 2,55 \\
\hline
\end{tabular}

Assim como a 'resistência', outras propriedades também receberam médias com valores altos, como por exemplo: a 'toxidade', a 'ruptura' que contempla os requisitos de resistência, a 'suavidade', a 'cor' e a 'espessura'. A 'lavagem' foi o item menos valorado (Figura 6).
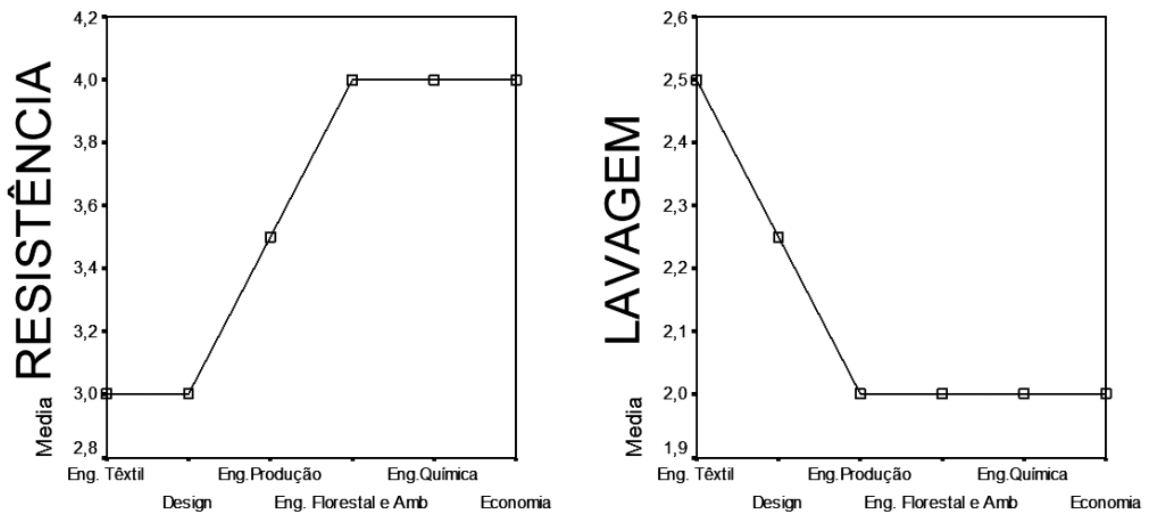

A2_Figura 6. Médias de valores apresentadas às características tecnológicas, mais e menos, evidenciadas.

8. Critérios para certificação dos produtos semi-industriais feitos com a fibra

Dos critérios para certificação dos produtos semi-industriais feitos com a fibra de tucumã-i (Astrocaryum acaule), a 'qualidade do material' foi o principal aspecto evidenciado pelos entrevistados (Tabela 14). A justificativa reforça que os benefícios oferecidos por um produto natural devem evidenciar desde a sua essência, passando pelo cultivo da matéria-prima, até a sua 
Estudio de la prospección del uso de la fibra de tucumã-i (Astrocaryum acaule) para el desarrollo de productos semi-industriales

customização e acabamento final, proporcionando a melhoria contínua da qualidade de seus artigos e serviços e, consequentemente, a maior satisfação aos clientes.

A2_Tabela 14. Critérios para certificação dos produtos semi-industriais feitos com a fibra

\begin{tabular}{l|l} 
Critérios & Total (Médias) \\
\hline Conforto & 3,09 \\
Segurança & 2,55 \\
Durabilidade & 2,36 \\
Qualidade do material & 3,36 \\
Aspecto biodegradável & 2,64 \\
Aspecto ecológico & 2,73 \\
Resistência & 2,64 \\
Outros & 2,27 \\
\hline
\end{tabular}

Os critérios foram conceituados como 'importantes' (médias entre 2 e 3 ) e 'muito importantes' (médias > 3). Com valores altos' também foram enfatizados: o 'conforto', o 'aspecto ecológico' e o 'aspecto biodegradável'. 0 critério 'outros', recebeu menos pontuação (Figura 7).
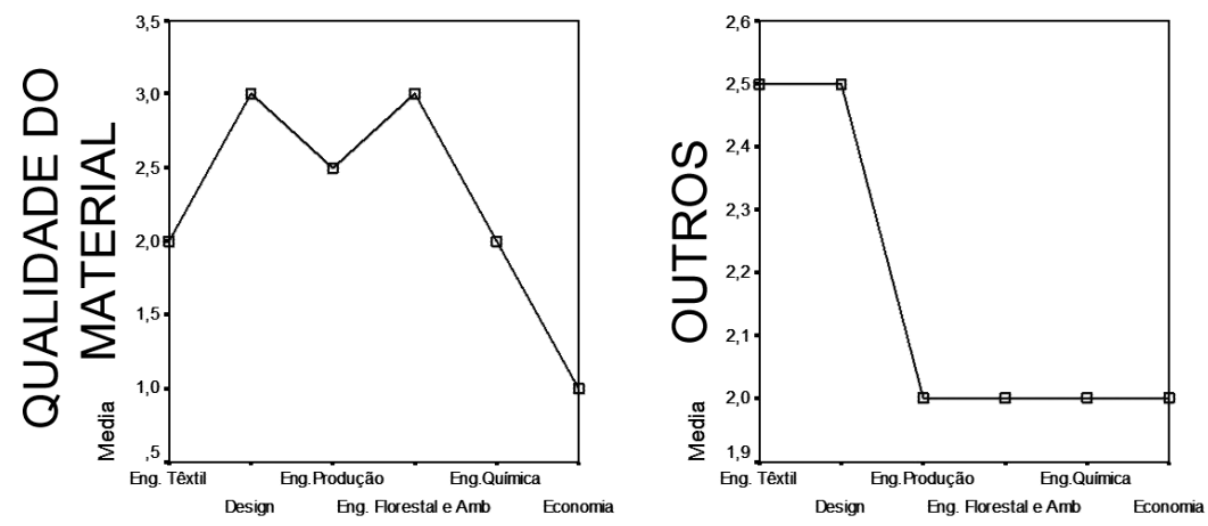

A2_Figura 7. Médias de valores apresentadas aos critérios para certificação, mais e menos, evidenciados. 
9. Categorias de uso para a aplicação semi-industrial da fibra.

De acordo com as categorias de uso apresentadas, os especialistas acreditam a linha de 'acessórios' é a mais propicia para o emprego semi-industrial da fibra de tucumã-i (Astrocaryum acaule), por ser uma tendência de produtos fáceis para fabricar, por dispor de tecnologias simples e eficientes para execução e, principalmente, por ser um possível instrumento de avaliação (como teste inicial) para os primeiros experimentos, em produtos, com o objeto de estudo. Após verificar o comportamento da fibra para esse segmento, outros aspectos poderão ser vistos e/ou revistos para uma melhor aplicação futura ou talvez mais avançada como a categoria 'têxtil/vestuário', que também foi citada e apresentou um bom nível de pontuação (Tabela 15).

A2_Tabela 15. Categorias de uso a aplicação semi-industrial da fibra

\begin{tabular}{l|l} 
Categorias de uso & $\begin{array}{l}\text { Total } \\
\text { (Médias) }\end{array}$ \\
\hline Acessórios & 3,20 \\
Decoração & 2,36 \\
Têxtil/Vestuário & 3,10 \\
Outras & 2,11 \\
\hline
\end{tabular}

Conforme os valores das médias apresentadas, a preferência dos entrevistados contemplou mais a categoria 'acessórios'. 0 item relacionado à 'outras' apresentou uma valoração menor (Figura 8).
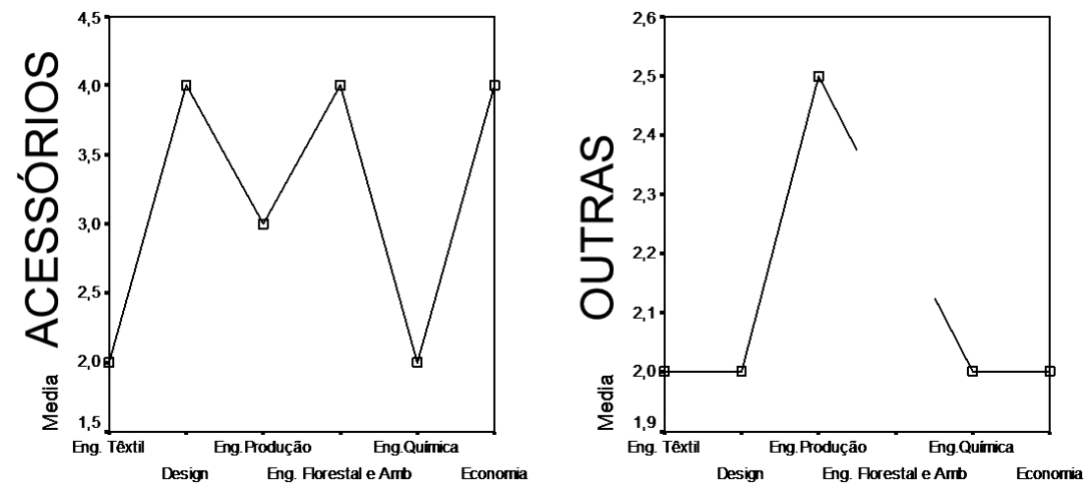

A2_Figura 8. Médias de valores apresentadas às categorias de uso, mais e menos, evidenciadas. 


\section{Conclusão}

Este artigo apresentou um levantamento de informações referentes a primeira etapa do estudo da prospecção do uso da fibra natural da Amazônia tucumã-i (Astrocaryum acaule) para o desenvolvimento de produtos semi-industriais. A partir de dados bibliográficos e outras investigações iniciais, feitas a respeito da fibra, foram observados alguns aspectos favoráveis a um planejamento de ações que facilitem o processo de transformação e adaptação a sua utilização semi-industrial. Além disso, a prática da entrevista em profundidade com especialistas de áreas correlatas ao tema de estudo, sinalizou boas oportunidades para esse procedimento e, ainda, contribuiu com a obtenção de informações que auxiliarão para o alcance dos objetivos propostos por essa investigação.

Os entrevistados interpretaram as informações fornecidas e responderam a cada uma das perguntas elaboradas considerando a realidade apresentada pela fibra de tucumã-i (Astrocaryum acaule) e todos os contextos atribuídos aos aspectos: social, tecnológico, econômico, ambiental e científico.

0 posicionamento dos profissionais entrevistados apresentou, de forma, unanime a aceitação da fibra como um novo recurso vegetal a ser inserido no mercado das fibras naturais. Também se puseram a favor do seu processo de transformação e adaptação semi-industrial, com o propósito de qualificar, tornar mais eficientes e competitivos os produtos, tanto já desenvolvidos a partir dela por processo artesanal, quanto para novas categorias de uso, além de poder alcançar novos mercados.

Eles enfatizam que as características tecnológicas e os critérios para certificação dos produtos são aspectos primordiais para a aplicação da fibra em qualquer categoria de produtos. É através deles que se validam os valores atribuídos aos materiais naturais e com denominação de origem, conferem o processo de transformação da matéria-prima em função da sua essência e tecnologias empregadas e observam o posicionamento desse processo de adaptação por meio dos fatores socio-ambientais e econômicos.

Sendo assim, os entrevistados observaram que a proposta do estudo tem como ponto de partida o processo de transformação da matéria-prima. Para tanto, um registro de informações que contemplem os seus aspectos intrínsecos, de modo a contribuir para a sua evolução - do estágio artesanal ao semiindustrial - torna-se importante para o campo científico, uma vez que a espécie analisada não dispõe de muitos registros técnicos e experimentais.

Outra sugestão é o apoio de uma ferramenta sistêmica que auxilie na estruturação dessas informações para um planejamento das ações mais 
eficazes à gestão e uso da fibra, uma vez que é um recurso natural novo, além de possibilitar a sua inserção no mercado de produtos.

Nesse contexto, os profissionais entrevistados acreditam que o design poderá participar como elemento de sistematização das informações, sendo uma ferramenta-chave para a elaboração estratégica, tomadas de decisões, ações e atribuição de todos esses valores para um melhor conhecimento, adaptação e utilização da fibra amazônica de tucumã-i (Astrocaryum acaule) em produtos semi-industriais.

\section{Agradecimento}

Os autores agradecem aos especialistas das áreas de Design de Produto, Engenharia Florestal e Ambiental, Engenharia Têxtil, Engenharia de Produção, Engenharia Química, Economia de Mercado e Gestão Produtos por suas contribuições para o desenvolvimento desta pesquisa.

\section{Referências}

Barreto, P. D. O. L. (2007). A produção da fibra de tucum como alternativa econômica dos povos indígenas do Alto Rio Negro. Dissertação (Mestrado em Sociedade e Cultura da Amazônia). Universidade Federal do Amazonas UFAM, Manaus - AM.

Bledzki, A. K., \& Gassan, J. (1999). Composites reinforced with cellulose based fibres. Progress in Polymer Science, 24, 221-274

Bortolanza, j. (199). Uma contribuição ao planejamento municipal que propicie o desenvolvimento sustentável - o uso de indicadores de saúde da população. Universidade Federal de Santa Catarina - UFSC, Florianópolis - SC.

Buxton, B. (2007). Sketching user experience - Getting the design right and the right design. San Francisco: Morgan Kaufman.

Cano, W. (1998). Introdução à Economia: uma abordagem crítica. 2 ed. UNESP, SP.

Cardoso, R.(2004). Uma introdução à história do design. Edgard Blücher, SP.

Cunha de Castro, M.L. A. (2009). Entre a arte a indústria: o artesanato em suas articulações com o design. Revista Espaço Acadêmico, Maringá: UEM, v 9 , n. 102.

Fiell, C.; Fiell, P. (2001). Design do século XX. Taschen. Lisboa/Portugal.

Filgueiras, A. (2008). A importância de fibras e fios no design de têxteis destinados à prática desportiva. Estudos em Design. PUC-Rio/Brasil. 
Estudio de la prospección del uso de la fibra de tucumã-i (Astrocaryum acaule) para el desarrollo de productos semi-industriales

Gil, A.C. (2002). Como elaborar projetos de pesquisa. 4.ed. São Paulo: Atlas. 176p.

Holbery, J. and Houston, D. (2006). Natural-fibre-reinforced polymer composites in automotive applications. Journal of the Minerals, Metals and Materials Society 58: 80-86.

Leão, A. L. (1997). Viabilidade técnica da produção de compósitos nãoestruturais à base de lignocelulósicos. Tese (Livre Docência em Recursos Naturais Renováveis). Universidade Estadual Paulista - UNESP. Botucatu - SP.

Maciel, K. M. F. (2007). Estudo da Viabilidade Técnica da Fibra de Tucumã-i (Astrocaryum acaule) para Produção de Tecido a ser utilizado na Indústria de Confecções. Dissertação (Mestrado em Ciências Florestais e Ambientais). Universidade Federal do Amazonas - UFAM. Manaus - AM.

Maciel, K. M. F. (2008). Technical Viability of Tucumã-i Fibre (Astrocaryum acaule) for Production in Textile Industry. ECOWOOD 2008, 3 rd International Conference \& Exhibition on Environmentally-compatible forest products. Univerdidade Fernado Pessoa. Oporto, Portugal.

Malhotra, Naresh K.(2006). Pesquisa de marketing. $4^{\mathrm{a} e d . ~ P o r t o ~ A l e g r e: ~}$ Bookman, RS.

Mascêne, D. C. (2010). Termo de referência: atuação do Sistema SEBRAE no artesanato. Brasília: SEBRAE, DF.

Menezes, M. R, Pinheiro, R, Guazzell, A. C. e Martins, F. (2005). Cadeia produtiva das fibras vegetais extrativistas no estado do Amazonas. Governo do Estado do Amazonas: SDS. Série Técnica. Meio Ambiente e Desenvolvimento Sustentável, Manaus - AM.

Miranda, I. P. A. (2001). Frutos e Palmeiras da Amazônia. Ministério da Ciência e Tecnologia (MCT). Instituto Nacional de Pesquisas da Amazônia (INPA). Manaus - AM.

Moura, M. (2003). O Design de Hipermídia. Tese Doutorado não publicada em Comunicação e Semiótica. Pontifícia Universidade Católica de São Paulo - SP.

Nunes, A. A., Franca, A. S., \& Oliveira, L .S. (2009). Activated carbons from waste biomass: an alternative use for biodiesel production solid residues. Bioresource Technology., (100) 1786-1792.

Olesen, A. B (1997). Karakterisering af Plantefibre (Characterization of Plant Fibres: Plant Fibre Laboratory, Report No.1, 39 p.

Oashi, M. C. G. (1998). Estudo da cadeia produtiva como subsídio da pesquisa e desenvolvimento do agronegócio do sisal na Paraíba. Tese (Doutorado de 
Engenharia de Produção). Universidade Federal de Santa Catarina - UFSC. Florianópolis - SC.

Pevsner, N. (2002). Os pioneiros do desenho moderno: de William Morris a Walter Gropius. 3. ed., Martins Fontes. São Paulo -SP.

Pletsch, M. (1998). Compostos naturais biologicamente ativos. Biotecnologia, Ciência e Desenvolvimento, Brasília - DF, v. 1, n. 4, p. 12-15.

Reis Neto, O. P. R. (2003). Fundamentos para a viabilização econômica da utilização de matérias-primas de fontes renováveis na fabricação de bens de consumo. Dissertação de Mestrado de Engenharia Mecânica. Universidade Estadual de Campinas - UEC, Faculdade de Engenharia Mecânica. Campinas SP.

Santos, A. V. (2002). Fibras vegetais para artesanato: Técnicas de produção de fibras de Arumã, Cipó Ambé e Tucumã. Fundação Vitória Amazônica (FVA), Manaus - AM.

Schwartzman, S. (2004). Mercado para produtos extrativistas da Amazônia brasileira. In ARNT, A. R. O destino da floresta. Reservas extrativistas e desenvolvimento sustentável na Amazônia. Relume Dumará, Rio de Janeiro RJ.

Sparke, Penny. (1999). El Diseño en el siglo XX: los pioneros del siglo. Blume, Barcelona.

Tassinari, A. M. I. (1995). Sociedades Indígenas: Introdução ao tema da diversidade cultural. A Temática indígena na escola: novos subsídios para professores de 1 e 2 graus. MEC/MARI/UNESCO, Brasília - DF.

Trochim, W. and Donnelly, J.P. (2007). The Research Methods Knowledge Base. 3rd edition. Thomson Publishing, Mason, $\mathrm{OH}$.

Van Dam, J.E.G., Van Vilsteren, G.E.T., Zomers, F.H.A., Shannon,W.B., Hamilton, I.T., (1994). Industrial Fibre Crops: Increased Application of Domestically Produced Plant Fibres in Textiles, Pulp and Paper Production, and Composite Materials. ATO-DLO, Wageningen, The Netherlands.

Van Dam, J.E.G. (1999). Optimisation of methods of fibre preparation from Agricultural Raw Materials. Agrotechnical Research Institute, Wageningen, The Netherlands.

Villas-Boas, A.(1998). O Que é e o Que Nunca foi Design Gráfico. 2AB, RJ.

Wollner, A. (2002). Textos Recentes e Escritos Históricos. Ed.Rosari, São Paulo. 



\subsection{Artículo 3 - Atributos del diseño para el proceso de transformación y uso de la fibra natural amazónica de tucumã-i (Astrocaryum acaule) para el desarrollo de productos semi- industriales}

Esta producción científica ha sido desarrollada con la intención de obtener informaciones sobre cuáles son los atributos del diseño considerados importantes para el proceso de transformación del objeto de estudio para el desarrollo de productos semi-industriales (Publicación en español). El artículo corresponde al sub-objetivo 3 del objetivo 1 de la tesis (Pags.67, 68,69 y 70).

Revista Icono Facto - Revista de la Escuela de Arquitectura y Diseño.

Indexada: LATINDEX

ISSN: 1900-2785

Enviado: 15.Junio.11 | Aceptado: 08.Julio.11 | Publicado: Deciembre.11

Cita: Pacheco, K. M. M.; Ortuño, B. H.; Miranda, I. P. A.; Paixão-Barradas, S. (2011). Atributos del diseño para el proceso de transformación y uso de la fibra natural amazónica de tucumã-i (Astrocaryum acaule) en el desarrollo de productos semi-industriales. Revista Icono Facto - Revista de la Escuela de Arquitectura y Diseño. Universidad Pontificia Bolivariana. Volumen 7, número 8 - Diciembre, Medellín - Colombia.

Atributos del diseño para el proceso de transformación y uso de la fibra natural amazónica de tucumã-i (Astrocaryum acaule) en el desarrollo de productos semi-industriales

Karla Mazarelo Maciel Pacheco: Maestra en Ciencias Forestales y Ambientales, diseñadora industrial y profesora de la Universidad Federal de Amazonas (UFAM) Manaus, Brasil. Actualmente participa en el Grupo de Investigación en Diseño Industrial y está estudiando el Doctorado en Diseño, Fabricación y Gestión de Proyectos Industriales de la Universidad Politécnica de Valencia (UPV), España. Correo electrónico: karlamazarelo@hotmail.com.

Bernabé Hernandis Ortuño: Doctor en Ingeniería Industrial, ingeniero industrial, profesor y director del programa del Doctorado en Diseño, Fabricación y Gestión de Proyectos Industriales de la Universidad Politécnica de Valencia (UPV), España. Correo electrónico: bhernand@degi.upv.es.

Ires Paula de Andrade Miranda. Doctora en Ciencias Biológicas del Instituto Nacional de Pesquisas de la Amazonía (INPA) y del Museo Nacional de Historia Natural de París (CNRS). Bióloga, especialista en Palmeras Nativas de la 
Estudio de la prospección del uso de la fibra de tucumã-i (Astrocaryum acaule) para el desarrollo de productos semi-industriales

Amazonía e investigadora titular del Instituto Nacional de Pesquisas de la Amazonía (INPA), Brasil. Correo electrónico: ires@inpa.gov.br.

Susana Paixão Pereira Mestre Barradas. Maestra en Diseño, Gestión y Desarrollo de Nuevos Productos, diseñadora industrial y profesora de la Universidad Politécnica de Valencia (UPV), España. Actualmente participa en el Grupo de Investigación en Diseño Industrial y está estudiando el Doctorado en Diseño, Fabricación y Gestión de Proyectos Industriales de la Universidad Politécnica de Valencia (UPV). Correo electrónico: supaipe@upvnet.upv.es.

\section{Resumen}

Considerando el diseño como una actividad proyectual para las soluciones originales de los productos, a partir de un análisis de los elementos relacionados con su función, el uso de los materiales, las diversas tecnologías, su productividad, los aspectos ambientales y de sostenibilidad, y mediante la conversión de valores a través de atributos mesurables en forma de innovaciones, el presente artículo presenta un análisis sobre los elementos técnico-conceptuales del diseño para la transformación y el uso de la fibra tucumã-i (Astrocaryum acaule), en el desarrollo de productos semiindustriales, conforme a la opinión de algunos especialistas en las áreas relacionadas con el tema. Los resultados resaltan la importancia de los aspectos formales, funcionales y ergonómicos (mostrándose prioritarios estos últimos) en la planificación de las acciones de nuevos recursos naturales en el mercado, y destacan la innovación y el diferencial ofrecido por ellos.

\section{Palabras clave}

Diseño, Fibra vegetal amazónica, Proceso semi-industrial, Producto, Atribución de valores.

\section{Introducción}

Entre las fibras naturales provenientes de las palmeras amazónicas encontramos la fibra de tucum, originada por los géneros Astrocaryum $s p$ y/o Bactris sp. Esta fibra es considerada uno de los recursos más empleados en la cadena de productos artesanales (Souza, 2004). El tucum originado por el género Astrocaryum de la especie acaule, también es conocido como tucumã-i y está localizado en gran parte en el Alto Rio Negro, región norte de Brasil, donde es producido de forma sostenible por las comunidades indígenas y mestizas, consideradas como las mayores conocedoras y consumidoras de la materia prima en aquella área (Maciel, 2008). La comercialización de este recurso natural es hecha a través de la compra y venta de la fibra en su estado natural, o ya transformada en producto artesanal. La actividad es 
realizada en centros comerciales, ferias y eventos culturales. Los principales mercados alcanzados con la venta de este producto son la capital del Estado de Amazonas (Manaos), algunos estados brasileros y algunos países de América del Norte, América del Sur y Europa (Menezes, Pinheiro, Guazzell, \& Martins, 2005).

Las características morfológicas, sociales, económicas y sostenibles observadas durante el proceso de producción artesanal, atribuyen a esa materia prima condiciones favorables para el proceso de adaptación y aplicación industrial, o semi-industrial. Además de eso, otras cualidades identificadas en la fibra, como las señaladas a continuación, posibilitan el alcance de nuevos mercados:

- Las variedades de uso para el seguimiento de productos domésticos y decorativos.

- La facilidad de plantación y cultivo en abundancia en el área de localización.

- Las características tecnológicas compatibles con la utilización textil.

- La producción sostenible.

- El proceso de adaptación simple y fácil de la fibra para el uso en productos.

En vista de lo anterior, este documento, que es parte de un estudio mayor, tiene como objetivo direccionar el análisis de los datos a través del posicionamiento de expertos pertenecientes a las áreas correlacionadas con el tema, para el estudio de la prospección del uso de la fibra de tucumã-i (Astrocaryum acaule) en el desarrollo de productos semi-industriales. De esta forma, son propuestos los siguientes objetivos:

- Presentar las etapas de producción de la fibra de tucumã-i (Astrocaryum acaule) para la delimitación del estudio.

- Abordar la interferencia del diseño sobre el uso de las fibras vegetales para la fabricación de productos.

- Observar las consideraciones hechas por los especialistas en relación con los atributos del diseño, identificados para la transformación y el uso de la fibra de tucumã-i (Astrocaryum acaule), en el desarrollo de productos semi-industriales.

- Posicionar esos atributos de acuerdo con los conceptos de forma, función y ergonomía.

- Identificar cuál de los conceptos es el más preponderante en el contexto estudiado. 
Estudio de la prospección del uso de la fibra de tucumã-i (Astrocaryum acaule) para el desarrollo de productos semi-industriales

\section{Proceso artesanal de la fibra de tucumã-i (Astrocaryum acaule) para el desarrollo de productos}

La producción sostenible hecha con la materia prima valoriza la fibra desde el momento de su cultivo. Es durante ese proceso que la función para la cual ella será destinada es definida. La recolección destaca todas las fases necesarias en el proceso de adaptación artesanal para la aplicación en productos (Santos, 2002). El procedimiento inicia con una plantación simple, sin la ayuda de ninguna tecnología. Todo el cultivo es hecho de forma artesanal con base en el conocimiento indígena, teniendo cuidado de no agredir la naturaleza. Después del cultivo, los productores esperan a que las palmeras alcancen su desarrollo para proceder con la recolección. Luego de que las palmeras comienzan a tener una buena estatura, los productores inician el proceso de selección, que es realizado cuando la palmera presenta una altura aproximada de dos metros, así como una buena apariencia, evidenciada en el tono verde oscuro de los follajes. La extracción se lleva a cabo poco después, en todas las ramas de la palma. El corte de la materia prima se calcula a ojo (área del conocimiento indígena), así se garantiza el crecimiento de esa misma rama tres meses después de que haya sido retirada. Después de la extracción de la materia prima, los productores recogen las ramas en las porciones unificadas y las amarran en los extremos para transportarlas hasta las comunidades con el fin de comenzar el trabajo del material. La figura 1 ilustra la escogencia, la extracción y la recolección de la fibra.
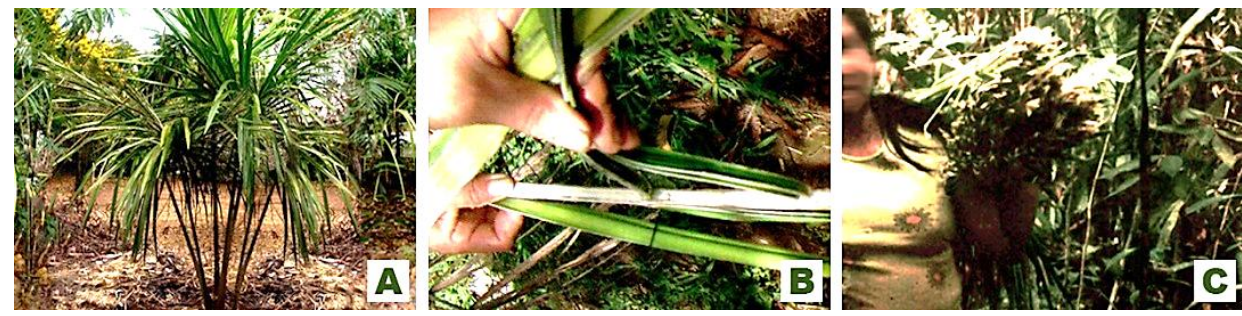

A3_Figura 1. A - Ejemplo de la selección de la palmera para la realización de la extracción de la fibra; B - Extracción hecha de forma manual, a partir de las ramas de la palmera; $\mathrm{C}$ - Ramas unificadas y amarradas para el transporte hasta las comunidades artesanales.

Después de la recolección y el transporte de las ramas, estas son entregadas a las comunidades responsables del proceso de hilatura de las fibras, realizado manualmente, una a una, conforme al espesor deseado (Figura 2). 

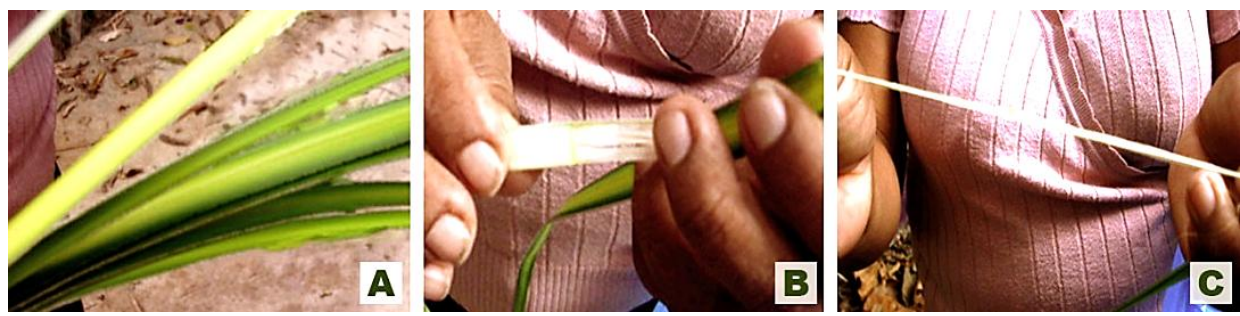

A3_Figura 2. A - Pequeña cantidad de ramas seleccionadas para proceder con la producción del hilado; B - Proceso de hilatura hecho con una de las ramas seleccionadas; C - Ejemplo de un hilo producido a partir de las ramas de tucumã-i (Astrocaryum acaule). Fuente: de los autores.

Las ramas desfibradas son organizadas en montículos. Pasan por un proceso de blanqueamiento y son lavadas a mano con agua y limón. Posteriormente, las ramas son extendidas en una vara de madera y permanecen allí durante tres días al sol para su secado natural. La figura 3 ilustra los montículos hechos con las ramas desfibradas y los procesos de lavado y secado de las fibras.
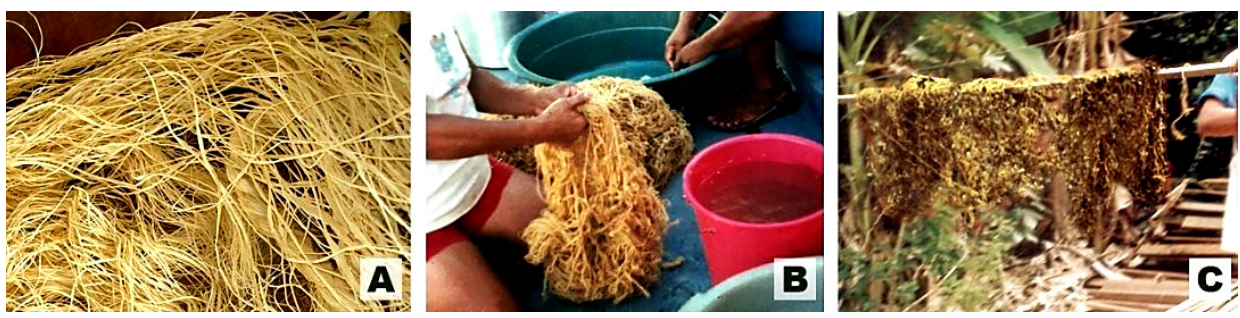

A3_Figura 3. A - Ramas desfibradas y organizadas en montículos para el lavado; B - Lavado manual de las fibras con agua y limón; C - Secado de las fibras al sol. Fuente: de los autores.

Durante la selección de las ramas, los artesanos también escogen algunas cantidades de fibras para teñirlas naturalmente, proceso realizado después del secado. Utilizan hojas y frutos de otros vegetales propios de la Amazonía que son idóneos para la producción de colorantes naturales, al ser aplicados a través de técnicas de hervido o de pintura manual.

Para que el teñido natural tenga un efecto perfecto y cualifique todavía más la estructura y la apariencia de las fibras, el mismo proceso es repetido dos o tres veces seguidas y al final de la última repetición son agregadas pequeñas porciones de sal para una mejor fijación de la coloración aplicada a la fibra. 
Estudio de la prospección del uso de la fibra de tucumã-i (Astrocaryum acaule) para el desarrollo de productos semi-industriales

Después de la fijación del color, las fibras pasan por más de un lavado y, consecuentemente, por más de un secado (Pacheco, 2010).

Concluida la etapa del secado, tanto las fibras in natura como aquellas que pasan por un teñido natural son llevadas al proceso de hilado, en el cual es seleccionada una tira entre la cantidad de fibras secas, para luego partirla por la mitad e iniciar la extracción de los hilos (Figura 4).

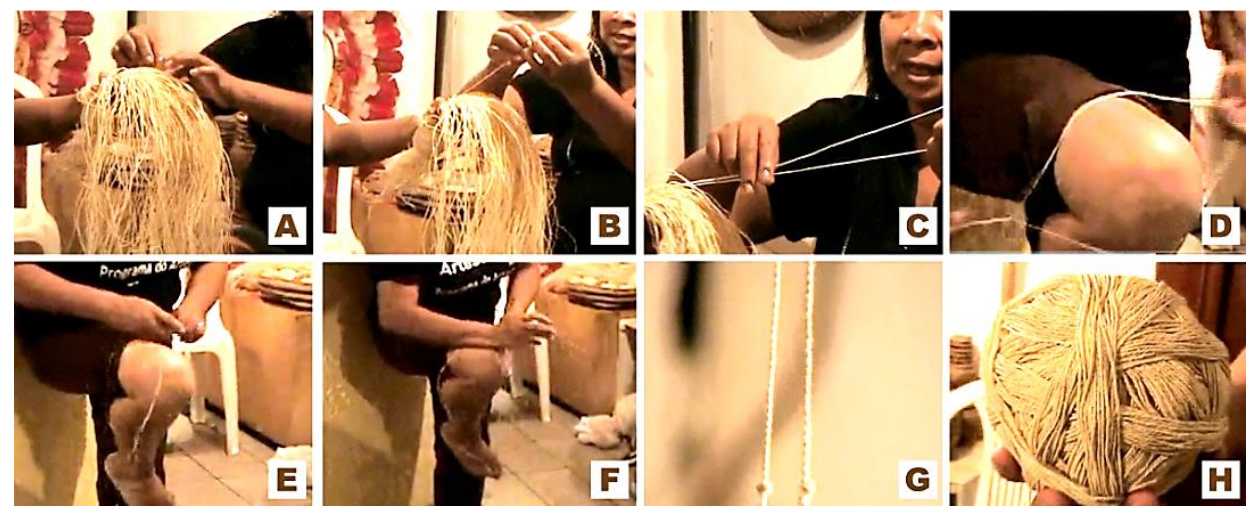

A3_Figura 4. A - A partir de un montaje de las fibras lavadas es seleccionada una tira; B - La tira seleccionada es estirada y partida por la mitad; C - Después de la división, la tira se transforma en dos tiras más que son retiradas del resto de la fibra; D - Las fibras son puestas en la pierna de la artesana para el inicio de la creación de hilos de tacum; E - Inicio de la formación del hilo; F - Entrelazamiento de las tiras hasta generar una línea continua; $\mathrm{G}$ - Resultado del entrelazamiento de las fibras en forma de hilo; $\mathrm{H}$ - Ovillo a partir de los hilos de tucum. Fuente: de los autores.

Como ilustra la figura 4, el hilo es hecho con dos unidades que se parten de la tira inicial originando dos tiras más, que apoyadas en la pierna del artesano son entrelazadas hasta generar una única línea, dando origen así al hilo de tucum. A partir de dos hilos son producidos los ovillos o madejas, tanto para la comercialización como para el tisaje.

Con los hilos producidos, la próxima etapa le compete al tisaje, que es hecho con dos conjuntos de hilos (trama y urdimbre). Ambos son entrelazados en un telar manual y van dando origen al tejido de tucum.

Cuando el objetivo es producir un tejido con textura más gruesa, se elabora en un telar vertical de mayor tamaño. En la figura 5 podemos ver el proceso de hilado mencionado. 

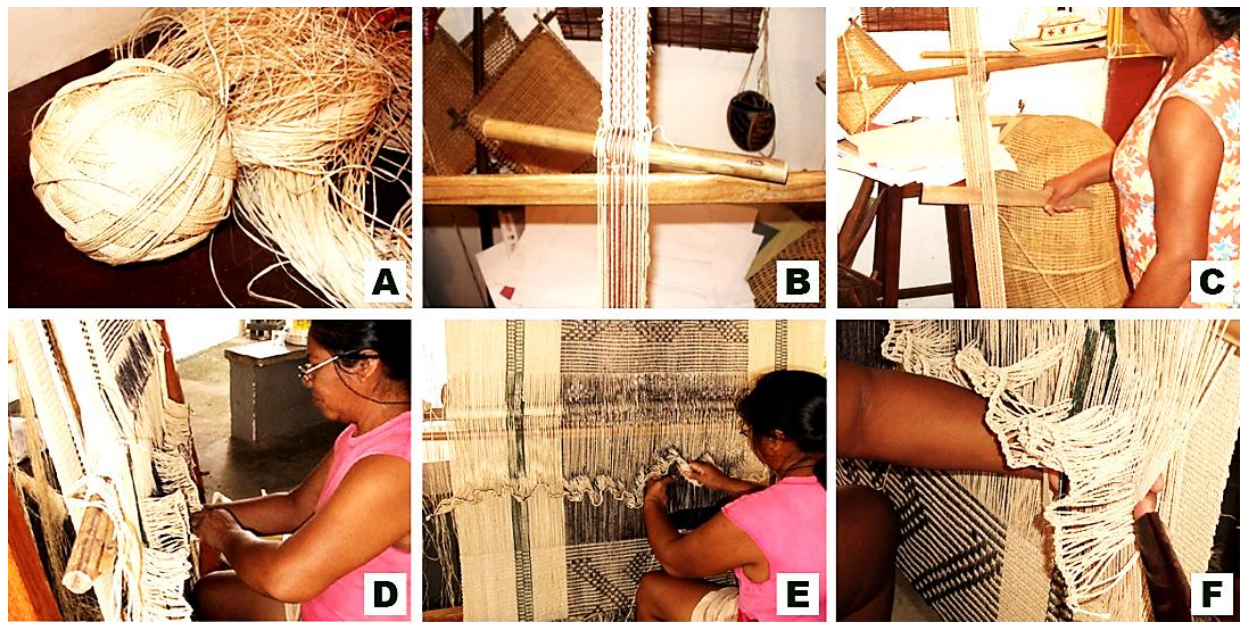

A3_Figura 5. A- Hilos de tucum que van a ser utilizados para el telar; B- Hilos introducidos en el telar manual para la confección del tejido; $\mathrm{C}$ - Ajustes de los hilos para proceder con el tejido; D, E y F - Producción del tejido con textura más gruesa en un telar vertical de mayor tamaño. Fuente: de los autores.

Hay ocasiones en que el tisaje también es realizado con las fibras in natura, sin que hayan pasado por la transformación de la fibra para el hilo. En las fibras destinadas a este tipo de tejido el proceso de preparación sigue hasta la fase de lavado y secado. Las fases de teñido, fijación del color y de transformación de la fibra en hilo no son ejecutadas. Por lo tanto, el tejido es hecho en un telar pequeño o a mano, entretejiendo las fibras y transformándolas en un tejido plano (Figura 6).
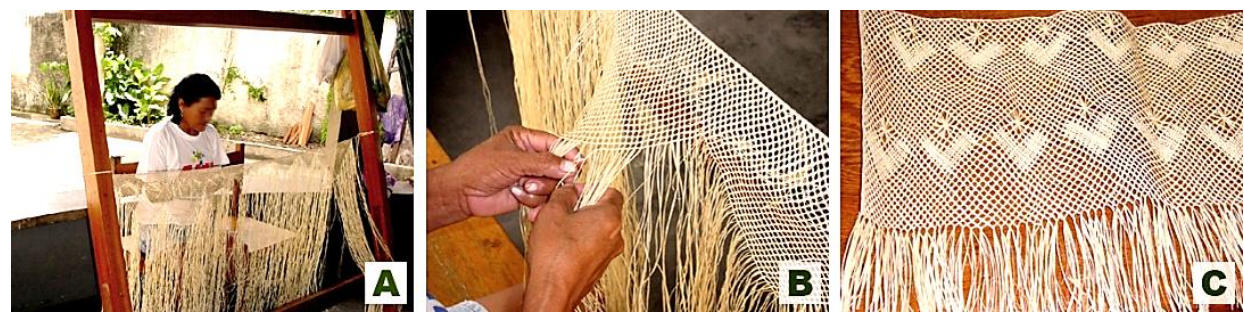

A3_Figura 6. A- Telar hecho con fibras in natura de tucum; B- Entrelazado de las fibras para la transformación del tejido; C- Tejido plano confeccionado con las fibras de tucum. Fuente: de los autores. 
Estudio de la prospección del uso de la fibra de tucumã-i (Astrocaryum acaule) para el desarrollo de productos semi-industriales

A partir de los tejidos producidos con la fibra de tucumã-i (Astrocaryum acaule) es desarrollada una gran variedad de productos, como tejidos, centros de mesa, mantas, cestos, bolsas, sombreros, pulseras, collares, cinturones, calzado, entre otros. (Figura 7).
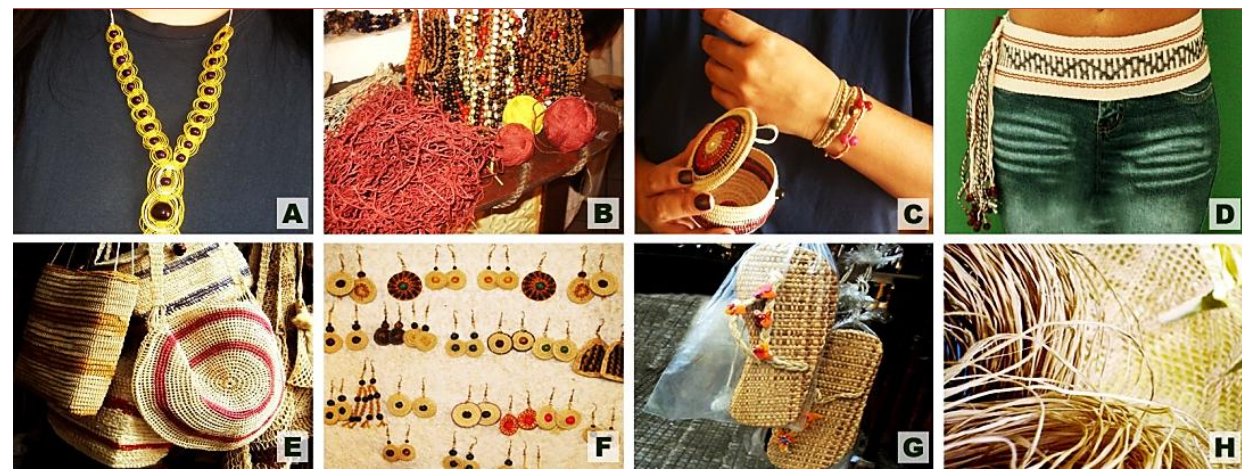

A3_Figura 7. A, B ,C, D, E, F y G - Ejemplos de algunos de los productos artesanales elaborados a partir de la fibra de tucumã-i (Astrocaryum acaule). Fuente: de los autores.

Además del anterior, hay también un experimento mayor que consiste en una prueba realizada con la fabricación del vestuario hecho con la fibra y con los tejidos confeccionados con la misma (Figura 8).
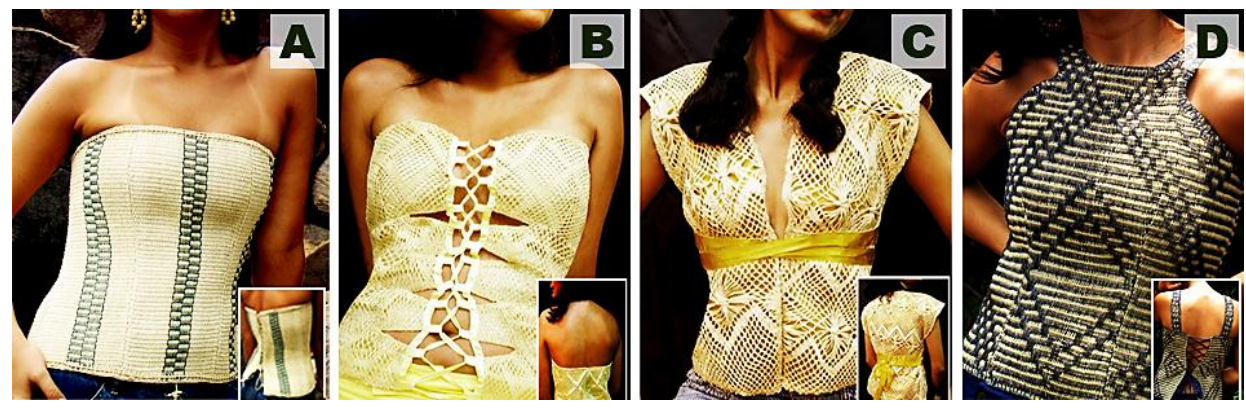

A3_Figura 8. A, B, C y D. Piezas de vestuario elaboradas a partir de experiementos hechos con tejidos de tucumã-i (Astrocaryum acaule). Fuente: de los autores.

Para este experimento, los aspectos morfológicos del vegetal y todas las etapas de su producción artesanal fueron considerados en el momento de la confección de los tejidos de tucum, los cuales hicieron que las piezas de vestuario confeccionadas resultasen en productos diferenciados e innovadores, algo que nunca antes se había practicado con las fibras de 
tucumã-i (Astrocaryum acaule). Por este motivo y también por la demanda de mercado y por las aplicaciones en productos artesanales, la materia prima viene llamando la atención de muchos turistas ONG (organizaciones no gubernamentales) y de empresas del sector industrial.

Es con base en estas informaciones que surge la idea de la realización de un estudio sobre la prospectiva de la transformación y del uso de la fibra de tucumã-i (Astrocaryum acaule) para el desarrollo de productos semiindustriales. Una vez se comprende la realidad de sus aspectos de producción y adaptación - únicamente artesanal -, se advierte que es un procedimiento muy brusco para intentar adaptarlo, en ese primer momento, a un estudio para el proceso industrial.

Por lo tanto, la investigación es, en este caso, una herramienta importante para la gestión y el desarrollo de nuevos productos competitivos, aunque aún no sea una tarea fácil debido al esfuerzo continuo de renovación que exige el mercado a aquellos que se acostumbran a producir los mismos productos durante años y que necesitan ofrecerlos como nuevos y creativos. Sin embargo, esta investigación ayuda a la producción de informaciones, a tomar decisiones, a solucionar problemas y a buscar cada vez más datos relevantes para determinados fines. De este modo, el trabajo se limita al proceso de transformación y uso de la fibra para el desarrollo de productos semiindustriales.

\section{Diseño y uso de materiales naturales en productos}

El trabajo de diseño en la transformación de la materia prima en productos y bienes de consumo se muestra como un punto intermedio entre el conocimiento y la producción. Es la directriz de las tendencias de consumo de la sociedad, superpone la función de producto a los aspectos tecnológico, económico y sociocultural; sobre todo, le compete al diseño la racionalización del proceso de producción, así como también la visualización de la eficacia productiva que se deriva del empleo de métodos científicos (Teixeira, Candido, \& Abreu, 2001).

La mejora de nuevas fibras vegetales para la aplicación en productos puede encontrar en el diseño una herramienta de ayuda para el uso de la materia. De esta manera, se pueden trabajar mejor los aspectos funcionales, formales, ergonómicos y tecnológicos del producto final, al tener como base las variables de estudio identificadas a lo largo del proceso. Así, el diseño va convirtiendo tales informaciones en atributos de valor identificado por el mercado y transformado en atributos físicos del producto, con miras a satisfacer necesidades como el confort, la durabilidad y, principalmente, la funcionalidad y el uso. 
Estudio de la prospección del uso de la fibra de tucumã-i (Astrocaryum acaule) para el desarrollo de productos semi-industriales

A medida que las fibras vegetales son utilizadas en productos industriales o semi-industriales, la búsqueda de nuevos nichos aumenta. De esta forma, las técnicas de procesamiento deben ser optimizadas, la mano de obra cualificada y los desafíos más que justificados para que las demandas de mercado, la economía de procesos y la tecnología que son esenciales en la utilización de esas fibras alcancen su pleno potencial.

La investigación sistemática en diseño puede demostrar que su resultado es un producto tangible de diseño. Ella es interactiva y solo puede ser eficaz si es un proceso constante que vuelve al problema, lo analiza nuevamente y sintetiza soluciones (Swann, 2002).

En este contexto, el levantamiento de las informaciones sintetizadas por el diseño podrá beneficiar el uso de nuevos materiales, la fabricación de los productos, la mejora de servicios y el cambio para un sistema más eficaz en la producción de estos. Crear productos de éxito es importante (si no lo más importante) para invertir en el proyecto del proceso de concepción del propio producto (Buxton, 2007).

En otras palabras, el éxito de los nuevos productos necesita de una planificación que esté directamente relacionada con conceptos y características que despierten una actitud diferente en el consumidor en lo concerniente al producto. Así, el resultado de la investigación en diseño pasa a existir como input, generando más informaciones, una vez que el diseño tangible traiga consigo valores intangibles que formen los conceptos del producto final (Santos F. A., 2000).

\section{Metodología}

La investigación fue de carácter descriptivo, exploratoria y explicativa; utilizó técnicas cuantitativas y cualitativas basadas en una investigación bibliográfica y documental (Gil, 2002). Para la recolección de datos fue aplicada en profundidad una entrevista a once especialistas de las áreas de diseño de producto, ingeniería forestal y ambiental, ingeniería textil, ingeniería de producción, ingeniería química, economía de mercado y gestión de productos.

La técnica exploró el posicionamiento y las perspectivas que los profesionales tenían sobre la propuesta del estudio; aquí la metodología no-estructurada se convierte en una herramienta directa para obtener informaciones y puede ser aplicada por cada persona de forma individual (Malhotra, 2006).

La técnica fue aplicada durante tres meses e inició en el mes de agosto de 2010, a través de un formulario preparado y enviado a los informantes por correo electrónico junto con una nota anexa que explicaba la naturaleza de la investigación. 
El documento presentó 24 preguntas y fue elaborado a partir de temas relevantes registrados en la literatura. Sin embargo, para esta publicación, fueron explorados los resultados de cinco preguntas del guión, en consonancia con los objetivos del artículo, focalizando los siguientes aspectos:

1. Variables consideradas importantes en el proceso de transformación semi-industrial de la fibra.

2. Ventajas ofrecidas por el proceso de transformación semi-industrial de la fibra.

3. Aspectos formales de la fibra considerados interesantes para el diseño de producto.

4. Aspectos funcionales de la fibra considerados interesantes para el diseño de producto.

5. Aspectos ergonómicos de la fibra considerados interesantes para el diseño de producto.

Todos los datos fueron organizados y analizados conforme a los resultados obtenidos con el cálculo de medias ponderadas.

\section{Resultados}

5.1 Variables consideradas importantes en el proceso de transformación semi-industrial de la fibra

Las características intrínsecas (tabla 1) de la materia prima, como el origen de la fibra, los aspectos productivos, las características tecnológicas, los beneficios sociales y económicos y el uso y la aplicación en productos, fueron consideradas las más importantes dentro del grupo de variables del proceso de transformación semi-industrial de la fibra.

A3_Tabla 1. Variables importantes en el proceso de transformación semi-industrial de la fibra de tucumã-i (Astrocaryum acaule)

\begin{tabular}{|l|l|}
\hline Variables & Medias \\
\hline Origen de la fibra & 2,36 \\
\hline Tipo de producción/tecnología & 1,82 \\
\hline Características intrínsecas de la fibra & 3,36 \\
\hline Normas para la certificación & 2,27 \\
\hline Tipo de proceso/transformación de materiales & 2,27 \\
\hline Aspectos socio ambientales & 2,55 \\
\hline
\end{tabular}

Los aspectos socio ambientales también recibieron una atención especial, seguidos por el origen de la fibra, el tipo de proceso/transformación de los 
Estudio de la prospección del uso de la fibra de tucumã-i (Astrocaryum acaule) para el desarrollo de productos semi-industriales

materiales, las normas para la certificación y por último, con importancia no muy elevada, el tipo de producción/tecnología. Al considerar todas las variables como positivas (media > 1), los valores presentados fueron diferenciados en cuanto al grado de importancia. En la escala de valoración 1 significa poco importante y 4 bastante importante.

\subsection{Ventajas ofrecidas en el proceso de transformación semi-industrial de la fibra}

La mayor parte de los entrevistados consideró que la transformación semiindustrial de la fibra de tucumã-i (Astrocaryum acaule) puede ofrecer como ventaja principal el alcance de nuevos mercados (Tabla 2).

A3_Tabla 2. Ventajas de la fibra de tucumã-i (Astrocaryum acaule) en el proceso de transformación semi-industrial

\begin{tabular}{|l|l|}
\hline Ventajas & Medias \\
\hline Alcance de nuevos mercados & 3,36 \\
\hline Mayor eficiencia y competitividad & 2,73 \\
\hline Más calidad a los productos & 2,45 \\
\hline Reducción de costos & 2,09 \\
\hline Nuevas tecnologías & 2,09 \\
\hline Aumento de producción & 2,00 \\
\hline Mayor control del proceso & 2,09 \\
\hline Otras & 1,82 \\
\hline
\end{tabular}

El ítem referido a los mercados recibió una puntuación mayor (media $>3$ ), siendo considerado muy importante porque la fibra presentó un perfil propio y característico para la participación en el mercado de las fibras naturales, ofreciendo aspectos sostenibles y socioculturales, demanda variada para su aplicación en productos y el interés por parte de nuevos consumidores. Además del alcance de nuevos mercados, otros aspectos también fueron considerados favorables: la mayor eficiencia y competitividad, toda vez que presentó un esquema de producción simple y empírico, pero que genera buenos resultados; y más calidad a los productos, atribuyendo mejor acabado y nuevas formas de aplicación para el uso de estos. La mejor puntuación identificada representa el tópico otras (media < 2) al no presentar una importancia elevada, toda vez que en una escala de 1 a 4,1 significa poco importante y 4 bastante importante.

\subsection{Aspectos formales considerados importantes en el diseño de producto}

Para los especialistas, todos los atributos presentados e identificados en la fibra de tucumã-i (Astrocaryum acaule) fueron considerados positivos (con 
media $=0>3)$, para su proceso de transformación y uso en productos. Sin embargo, entre los aspectos visuales observados, el acabado fue el tópico más destacado por los entrevistados (Tabla 3).

A3_Tabla 3. Aspectos formales

\begin{tabular}{|l|l|}
\hline Aspectos formales & Medias \\
\hline Estilo & 3,27 \\
\hline Color & 3,18 \\
\hline Textura & 3,27 \\
\hline Tendencia & 3,00 \\
\hline Armonía & 3,27 \\
\hline Acabado & 3,73 \\
\hline Originalidad & 3,55 \\
\hline
\end{tabular}

Según los especialistas el ítem con mayor valoración (media > 3), considerado como bastante importante, debe recibir una atención especial, sobre todo durante los procesos de separación, teñido y tejido de la fibra.

Ellos evidencian que el flujo del proceso de acabado debe ser establecido conforme al tipo de artículo y a las características que se pretenden obtener, pues resulta de una gama de operaciones que confieren confort, durabilidad y propiedades específicas al producto final. La normalización es otro punto que debe ser considerado para fortalecer los acabados, debe tornarse uno de los objetivos a ser planificados para el alcance de un buen acabado y cualificación de los productos desarrollados a partir de un tejido de tucum, por ejemplo. De los valores de medias presentados, la tendencia recibió la menor puntuación $\mathrm{y}$, aun así, continúa siendo considerada muy importante (media $=3$ ), en una escala de 1 a 4 , donde 1 significa poco importante y 4 bastante importante.

\subsection{Aspectos funcionales de la fibra considerados importantes en el diseño de producto:}

Según los profesionales entrevistados, el aspecto funcional atribuido al proceso de transformación de la fibra tiene la tarea de hacer aprovechables por el hombre las materias primas en la forma de materiales. El producto, durante tal proceso, acrecienta gradualmente su valor y llega al mercado incorporando en el precio la importancia ganada durante el curso.

Desde esta óptica, los cambios artesanales para los procesos semi-industriales pueden viabilizar un proceso creativo, sistematizando y poniendo a disposición la construcción de nuevos productos textiles a partir de un determinado tejido base, como el que es generado con la fibra de tucumã-i 
Estudio de la prospección del uso de la fibra de tucumã-i (Astrocaryum acaule) para el desarrollo de productos semi-industriales

(Astrocaryum acaule). Con base en esto, el ítem de mayor valoración, atribuido por los especialistas, fue la transformación (media $=3,45$ ) al ser considerado como muy importante (Tabla 4).

A3_Tabla 4. Aspectos funcionales

\begin{tabular}{|l|l|}
\hline Aspectos funcionales & Medias \\
\hline Tecnología & 3,18 \\
\hline Durabilidad & 3,00 \\
\hline Multifuncionalidad & 2,82 \\
\hline Adaptabilidad & 3,00 \\
\hline Transformación & 3,45 \\
\hline Conservación & 3,27 \\
\hline Uso & 3,18 \\
\hline
\end{tabular}

Los atributos de conservación, tecnología y uso también presentaron buenas puntuaciones. En general los factores funcionales fueron evaluados como positivos por los especialistas, por presentar valores de medidas $>2$, toda vez que en una escala de 1 a 4,1 significa poco importante y 4 bastante importante.

5.5 Aspectos ergonómicos considerados importantes en el diseño de producto

De los aspectos ergonómicos observados, los especialistas atribuyeron al confort (Tabla 5) la mayor importancia (valor de media = 3,91). La justificación se da en función de que los consumidores buscan cada vez más el confort y la practicidad en los productos hechos con fibras naturales.

A3_Tabla 5. Aspectos ergonómicos

\begin{tabular}{|l|l|}
\hline Aspectos ergonómicos & Medias \\
\hline Confort & 3,91 \\
\hline Seguridad & 3,82 \\
\hline Estructura del material & 3,50 \\
\hline Atributos al usuario & 3,50 \\
\hline Uso de la materia prima & 3,18 \\
\hline Innovación del producto & 2,82 \\
\hline Concepto del material & 3,30 \\
\hline
\end{tabular}

El confort es uno de los temas más importantes en la relación del producto con el usuario. En este sentido, especialmente, el proceso de transformación y uso de la fibra debe ser orientado a contribuir a la salud, al bienestar y a la calidad de vida de las personas, así como al uso y aplicación adecuada de los 
materiales naturales y a futuras adaptaciones a la confección de un producto final. Según los entrevistados, todos los aspectos ergonómicos fueron evaluados como positivos (valores de media > 2), en una escala de 1 a 4 , donde1 significa poco importante y 4 bastante importante. La innovación del producto fue la característica con la menor valoración atribuida (media = 2,82 ) y aun así conservó su valor de importancia para el tema analizado.

La preferencia de los especialistas por el aspecto ergonómico es perfectamente nítida. Ese concepto técnico-científico del diseño presentó mayor puntuación para la ejecución del proceso de transformación y el uso de la fibra de tucumã-i (Astrocaryum acaule) en el desarrollo de productos semiindustriales. Los profesionales entrevistados consideran que la ergonomía irá a reunir todos los atributos identificados y considerados positivos en las cinco cuestiones validadas en el cuestionario. De acuerdo con el punto de vista presentado, el concepto ergonómico puede orientar e integrar las informaciones relacionadas con los aspectos formales y funcionales del objeto de estudio, en pro de una planificación de las acciones más eficaces para la gestión y adaptación de ese nuevo recurso natural en el mercado de productos semi-industriales, validando de esta manera/de este modo la innovación y el diferencial por él ofrecidos.

\section{Conclusión}

El artículo presentó informaciones pertinentes en cuanto al proceso de transformación y uso de la fibra natural amazónica de tucumã-i (Astrocaryum acaule) en el desarrollo de productos semi-industriales. Fueron demostradas y comprendidas cada una de las etapas de producción artesanal de la fibra y con eso fue delimitado el tema propuesto de la investigación que se centralizó en las fases de obtención de la fibra y de hilado y tejido de la fibra.

En este contexto, se percibe que las comunidades productoras de la fibra de tucumã-i (Astrocaryum acaule) producen más para sobrevivir, más para vender en un mercado, y con eso sufren los problemas ligados a la modernización, a los factores de la innovación y la calidad de los productos. A pesar de eso, se permiten buscar una salida con la elaboración y/o procesamiento artesanal, con el fin de agregar valor a su producto, beneficiar la producción, desarrollar una mejor calidad de los productos y de la comercialización, así como generar ingresos partiendo de su identidad local.

Desde esa óptica, la interferencia del diseño en el uso de las fibras vegetales para la fabricación de productos hace de esa actividad proyectual una herramienta estratégica para la conversión de valores a través de atributos mesurables en forma de innovaciones, al relacionar con su función el uso de materiales, de múltiples tecnologías, del conocimiento sobre la productividad 
de estos, sobre los aspectos ambientales, de sostenibilidad, de la realidad del mercado y de las necesidades, gustos y preferencias de los consumidores. Con este fin, la recopilación de información sintetizada por el diseño podrá beneficiar al uso de la fibra de tucumã-i (Astrocaryum acaule) en la fabricación de los productos, a la mejora de servicios y al cambio hacia un sistema más eficaz en la producción del material.

En función de esto, el posicionamiento de especialistas con relación al tema abordado fue de vital importancia para orientar al diseño en la toma de decisiones y en la sistematización de informaciones. Las ideas y opiniones contemplaron los atributos necesarios para el proceso de transformación y uso de la fibra de tucumã-i (Astrocaryum acaule) en el desarrollo de productos semi-industriales, y fueron comprendidas a profundidad a través de la aplicación de una entrevista formulada a partir de 24 preguntas, de las cuales cinco cuestiones fueron trabajadas para elaborar este documento.

Las cuestiones fueron evaluadas conforme a los conceptos de forma, función y ergonomía, destacando como factores muy importantes para el proceso de transformación y uso de la fibra: 1 . Variable importante $\rightarrow$ las características intrínsecas de la materia prima; 2. Ventaja $\rightarrow$ el alcance de nuevos mercados; 3 . Aspectos formales del producto $\rightarrow$ o acabado del material; 4 . Aspectos funcionales del producto $\rightarrow$ la transformación, evolución de la fibra del estado artesanal al semi-industrial; y 5 . Aspectos ergonómicos del producto $\rightarrow$ o confort, relacionado con todos los aspectos sensoriales que son transmitidos a partir de la fibra.

Todos los atributos fueron considerados importantes para la investigación. Así mismo, las características conceptuales estructuradas en el ámbito ergonómico fueron dominantes. Los entrevistados consideran que ese aspecto del diseño puede reunir los demás atributos identificados para una mejor planificación de las acciones y una atribución de todos los valores en pro de un mejor conocimiento, adaptación y utilización de la fibra amazónica de tucumã-i (Astrocaryum acaule) en el desarrollo de productos semiindustriales.

\section{Referencias}

Buxton, B. (2007). Sketching user experience - Getting the design right and the right design.San Francisco: Morgan Kaufman.

Gil, A.C. (2002). Como elaborar projetos de pesquisa. 4.ed. São Paulo: Atlas. $176 p$.

Maciel, Karla Mazarelo Ferreira (2008). Technical Viability of Tucumã-i Fibre (Astrocaryum acaule) for Production in Textile Industry. Ecowood 2008, 3rd 
International Conference \& Exhibition on Environmentally-compatible forest products. Universidade Fernando Pessoa. Oporto, Portugal.

Pacheco, Karla Mazarelo Maciel (2010). Procedures for Obtaining Vegetable Dyes Amazon for Application in. Industrial Products. Ecowood 2010, 4th International Conference \& Exhibition on Environmentally-compatible forest products. Universidade Fernando Pessoa. Oporto, Portugal.

Malhotra, Naresh K.(2006). Pesquisa de marketing. $4^{a} e d$. Porto Alegre: Bookman, RS.

Menezes, M. R, Pinheiro, R, Guazzell, A. C. e Martins, F. (2005). Cadeia produtiva das fibras vegetais extrativistas no estado do Amazonas. Governo do Estado do Amazonas: SDS. Série Técnica. Meio Ambiente $e$ Desenvolvimento Sustentável, Manaus - AM.

Santos, F. Anthero dos.(2000). O Design como diferencial competitivo. Santa Catarina: Editora da Univale.

Santos, Aurelina Viana dos (2002). Fibras vegetais para artesanato: Técnicas de produção de fibras de Arumã, Cipó Ambé e Tucumã. Amazonas: Fundação Vitória Amazônica (FVA).

Souza, Hermes Moreira de. et al. (2004). Palmeiras brasileiras e exóticas cultivadas. Nova Odessa. São Paulo: Instituto Platarum.

Swann, Cal (2002). Action Research and the Practice of Design, Design Issues. Vol.18, No.2, 49- 61.

Teixeira, J.A; Candido, G.A \& Abreu, A.F. (2001). A Utilização dos Materiais no Design e a Competitividade da Indústria Moveleira da Região Metropolitana de Curitiba: um estudo de caso. Revista Produção - Scielo Brasil, v. 11 n. 1. São Paulo. 



\subsection{Artículo 4 - Oportunidades y limitaciones del uso de la fibra natural de tucumã-i (Astrocaryum acaule) para la gestión y desarrollo de productos semi-industriales}

Esta producción científica ha sido desarrollada con la intención de obtener informaciones sobre las oportunidades y limitaciones del uso del objeto de estudio para el desarrollo de productos semi-industriales, a partir de las opiniones registradas sobre qué piensan los diseñares y los expertos consultados (Publicación en portugués). El artículo corresponde al subobjetivo 4 del objetivo 1de la tesis (Pags.67, 68,69 y 70).

Congreso: $8^{\circ}$ Congresso Brasileiro de Gestão de Desenvolvimento de Produto

ISBN: 978-85-88085-46-6(Acta Resumes)

ISBN: 85-88085-47-3 (Acta Congreso)

Enviado: 24.Mayo.11 | Aceptado: 06.Junio.11 | Publicado: Septiembre.11

Cita: Pacheco, K. M. M.; Ortuño, B. H.; Miranda, I. P. A.; Nascimento, C. C.; Pacheco, A. S.(2011). Oportunidades e limitações do uso da fibra natural de tucumã-i (Astrocaryum acaule) para a gestão e desenvolvimento de produtos semi-industriais. Anais do $8^{\circ}$ Congresso Brasileiro de Gestão de Desenvolvimento de Produto (CBGDP). UFRGS/FEEng. Porto Alegre - RS/ Brasil.

Oportunidades e limitações do uso da fibra natural de tucumã-i (Astrocaryum acaule) para a gestão e desenvolvimento de produtos semiindustriais

Karla Mazarelo Maciel Pacheco a (karlamazarelo@hotmail.com); Bernabé Hernandis Ortuño b (bhernand@degi.upv.es); Ires Paula de Andrade Miranda c (ires@inpa.gov.br); Claudete Catanhede do Nascimento d (catanhed@inpa.gov.br); Almir de Souza Pacheco e (almirdesigner@gmail.com)

a Universidade Federal do Amazonas (UFAM), AM - BRASIL

b Universidade Politécnica de Valência (UPV), VALÊNCIA - ESPANHA

c Instituto Nacional de Pesquisas da Amazônia (INPA), AM - BRASIL

d Instituto Nacional de Pesquisas da Amazônia (INPA), AM - BRASIL

e Universidade Politécnica de Valência (UPV), VALÊNCIA - ESPANHA

\section{Resumo}

O artigo descreve uma análise comparativa, através do método SWOT, que relata as opiniões de dois grupos de profissionais distintos: 1- Designers de 
Estudio de la prospección del uso de la fibra de tucumã-i (Astrocaryum acaule) para el desarrollo de productos semi-industriales

produto; e 2 - Especialistas de áreas correlacionadas ao tema investigado, sobre o uso da fibra de tucumã-i (Astrocaryum acaule) para o desenvolvimento de produtos semi-industriais. Os resultados consideram três aspectos fundamentais ao seguimento do estudo: o processo de transformação da fibra deve ser o ponto de partida para o propósito da investigação; um estudo de mercado se faz necessário para identificar as possíveis categorias de uso e tipos de produtos à aplicação semi-industrial da fibra e; as informações coletadas e construídas, no decorrer da pesquisa, precisam estar organizadas e estruturadas com o auxílio de um método sistematizado, para um planejamento das ações mais eficaz à gestão e uso de novos recursos naturais ao mercado de produtos, validando a inovação e o diferencial, por eles, oferecidos.

Palavras-chave: Fibra Vegetal Amazônica, Design, Inovação, Gestão e Desenvolvimento de Produtos

\section{Introdução}

Devido à imensa quantidade de plantas lenhosas e fibrosas predominantes na Amazônia, existe uma grande possibilidade para a descoberta de fibras naturais com propriedades diversas desejáveis (Marinelli, Monteiro, Ambrósio, Brancifort, Kobayashi, \& Nobre, 2008).

A variedade da flora tropical Amazônica e o conhecimento da utilização popular, sobre as fibras vegetais, sugerem a possibilidade de transformação dessas matérias-primas em plantas cultiváveis para o desenvolvimento de produtos com denominação de origem e com expressão social, cultural, ambiental, tecnológica e econômica para a região. Desta forma, a biodiversidade do ecossistema amazônico é considerada como o maior potencial natural do mundo contemporâneo, servindo como material para estudo científico e insumo às bioindústrias (Pletsch, 1998).

O embasamento científico e experimentos observados, neste contexto, reforçam que os produtos extrativistas constituem fontes importantes de renda às populações florestais e que as iniciativas para fortalecer e ampliar os mercados para novos produtos devem ser reforçadas (Schwartzman, 2004).

Partindo desse princípio, o artigo apresenta o universo que contempla o objeto de estudo e faz uma analisa comparativa sobre o posicionamento de alguns profissionais e especialistas de áreas que trabalham com: pesquisa, gestão e desenvolvimento de produtos naturais - a respeito do uso da fibra de tucumã-i (Astrocaryum acaule) em produtos semi-industriais.

Com se trata de uma matéria-prima produzida e transformada de forma totalmente artesanal, considera-se algo muito brusco tentar adaptá-la, 
diretamente, ao processo industrial - sem que haja o apoio de experimentos teóricos e práticos registrados cientificamente, que contemplem a sua realizada de uso e produção, uma vez que esses tipos de informações se tornam indispensáveis às etapas de planejamento da gestão e desenvolvimento de produtos em alta escala. Sendo assim, a intenção é identificar as oportunidades e limitações do uso semi-industrial que esta matéria-prima poderá oferecer, em função das necessidades de mercado, tipos de produtos, dos benefícios às comunidades produtoras, do respeito ao meio ambiente e das precisões do público consumidor. Para tanto, o referente estudo propõem o seguinte objetivo:

- Realizar uma análise comparativa, através do método SWOT, sobre as opiniões registradas em dois grupos de profissionais distintos: 1) Designers de Produto e; 2) Especialistas das áreas de Engenharia Florestal e Ambiental, Engenharia Têxtil, Engenharia de Produção, Engenharia Química, Economia de Mercado e Gestão Produtos - a respeito do uso da fibra de tucumã-i (Astrocaryum acaule) para a gestão e desenvolvimento de produtos semiindustriais.

\section{0 objeto de estudo}

A fibra de tucumã-i (Astrocaryum acaule) é um recurso vegetal da Amazônia brasileira (Figura 1), pouco explorado e conhecido. No entanto, se destaca pela produção sustentável e adaptação a diversos tipos de produtos de segmentos: domésticos, decorativos e têxteis (Souza, 2004).
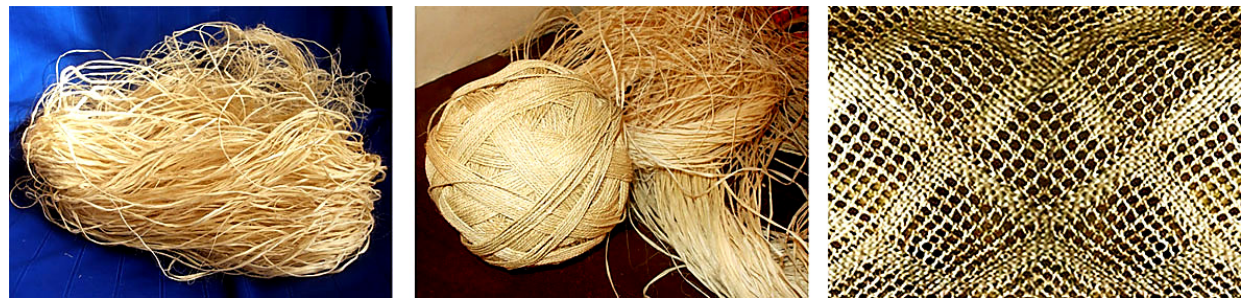

A4_Figura 1. Fibra de tucumã-i (Astrocaryum acaule) da Amazônia

Trata-se de um produto natural proveniente de palmeira nativa, com caule subterrâneo predominante de terra firme ou de várzea, medindo entre 6 a 15 metros de altura. É notável por apresentar uma composição paisagística. Fornece frutos suculentos e aromáticos que, em tom alaranjado, se destacam no meio da coroa foliar (Miranda \& Rabelo, 2008).

Essa espécie (Figura 2) possui um impacto visual muito forte, devido ao tamanho das folhagens e da coloração em tom verde escurecido. Suas 
Estudio de la prospección del uso de la fibra de tucumã-i (Astrocaryum acaule) para el desarrollo de productos semi-industriales

potencialidades econômicas estão centradas nas folhas, com a extração de fibras de alta resistência, conforme cita Miranda (2001) e está localizada, em grande parte, na região do Alto Rio Negro, norte do Brasil, onde é cultivada por comunidades indígenas e caboclas, consideradas como as maiores conhecedoras e consumidoras dessa matéria-prima (Maciel, 2007).
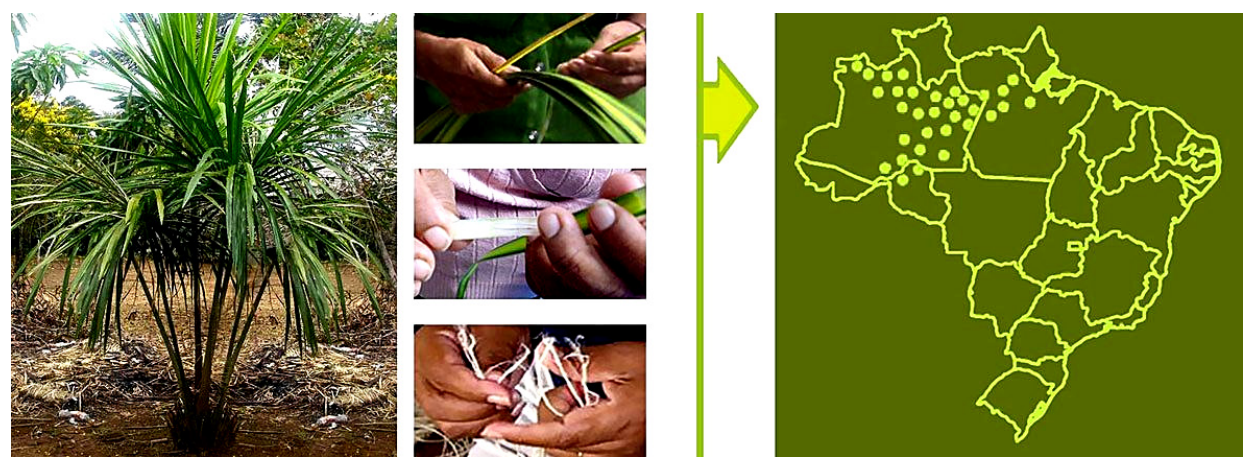

A4_Figura 2. Palmeira, folhas, fibra e área de localização do objeto de estudo.

A produção sustentável de tucumã-i (Astrocaryum acaule) valoriza a fibra desde o momento do seu cultivo. É durante esse processo que a função para a qual a matéria-prima será destinada, é definida. A coleta da fibra destaca todas as fases necessárias ao seu processo de adaptação artesanal, para a aplicação em produtos (Santos A. V., 2002). As etapas seguem uma sequência e são realizadas de forma totalmente manual, dispondo apenas de instrumentos domésticos produzidos pelas próprias comunidades.

O passo-a-passo contempla: a escolha da planta, a técnica de corte, lavagem e secagem, aplicação de tingimento natural, fixação da cor, amarração das ramas, técnica de fiação e, por fim, a tecelagem dos fios (Tabela 1).

A4_Tabela 1. Adaptação da fibra de tucumã-i (Astrocaryum acaule) por processo artesanal

\begin{tabular}{ll}
\hline Etapas & Descrição \\
\hline Escolha & As comunidades produtoras da fibra observam a palmeira mais \\
& $\begin{array}{l}\text { adequada para a retirada da rama (verifica-se por tamanho e } \\
\text { aparência). }\end{array}$ \\
Corte & o cocedimento é feito na parte onde começam as ramas da palmeira. \\
& conhecimento indígena) de modo a garantir o crescimento, dessa \\
& mesma rama, num período de três meses após a sua retirada.
\end{tabular}


Lavagem As ramas passam por um processo de clareamento. São lavadas, à mão, apenas com água e limão.

Secagem Nessa fase, as ramas são estendidas num varal feito com madeira e permanecem ali durante três dias ao sol.

Tingimento Processo realizado após a secagem. Utiliza folhas e frutos, de outros vegetais da Amazônia, que são próprios para a produção de corantes naturais. A aplicação do tingimento é feita através das técnicas de fervura ou de pintura manual.

Fixação da 0 tingimento é repetido por duas ou três vezes seguidas e ao final da cor sua última repetição, são acrescentadas pequenas porções de sal para melhor fixação da coloração aplicada à fibra.

Amarração Após o período da secagem, as ramas são recolhidas e juntas em porções pequenas. Cada porção de ramas unificada tem a sua extremidade amarrada em forma de nó.

Fiação As ramas agrupadas em porções são desfiadas manualmente, uma a uma, conforme a espessura desejada. A criação do fio é feita entre duas tiras da rama, apoiadas às pernas do artesão, que são entrelaçadas até gerar uma única linha. Dos fios, originados pelas ramas da palmeira de tucumã-i, são feitos os novelos.

Tecelagem A tecelagem é feita com dois conjuntos de fios (urdidura e trama), ambos são entrelaçados em um tear manual e vão dando origem ao tecido de tucumã-i. Quando o objetivo é produzir um tecido com textura mais grossa, a tecelagem é executada num tear vertical, de tamanho maior.

Vale ressaltar que a produção da fibra apresenta-se de acordo com as normas da Comissão Mundial sobre o meio ambiente, criada pela ONU, podendo ser considerada como um recurso natural capaz de suprir as necessidades atuais sem comprometer as gerações futuras e, também, de gerar emprego e melhores condições de vida para as suas comunidades produtoras. Todas as etapas vão agregando valores específicos às fibras produzidas pelo tucumã-i, permitindo com que a sua utilização se torne uma das principais fontes de renda sustentáveis da região Amazônica.

A comercialização do tucumã-i (Astrocaryum acaule) é feita através da compra ou venda da fibra no seu estado in natura ou, então, já transformada em produto artesanal (Figura 3). A atividade é exercida em centros comerciais, feiras e eventos culturais. Os principais mercados alcançados com a venda desse produto são a capital do estado do Amazonas - Manaus, alguns estados brasileiros e alguns países da América do Norte, América do Sul e Europa (Menezes, Pinheiro, Guazzell, \& Martins, 2005). 

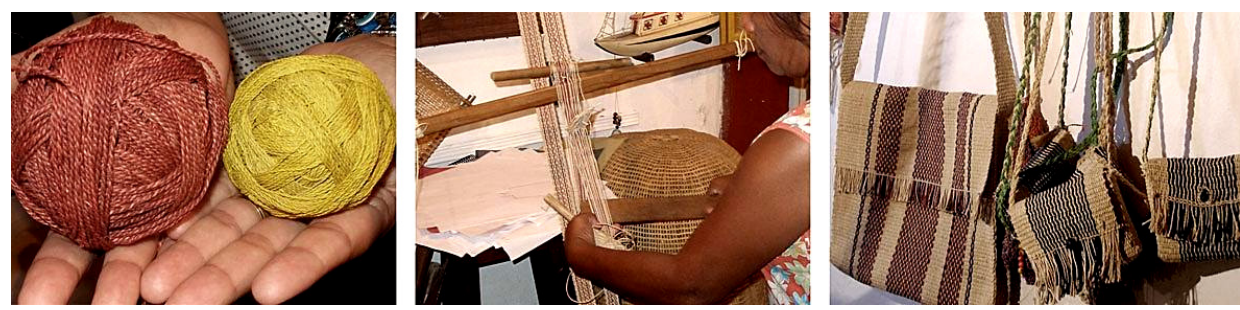

A4_Figura 3. Fibra de tucumã-i (Astrocaryum acaule) transformada em produto artesanal.

Uma pesquisa recente sobre a viabilidade técnica da fibra de tucumã-i (Astrocaryum acaule) para produção têxtil, afirma que esse recurso natural amazônico ainda é considerado novo aos olhos da ciência e, principalmente, para o mercado de produtos industriais. No entanto, o registro confirma a existência de propriedades tecnológicas compatíveis à sua utilização para o segmento industrial têxtil (Maciel, 2007).

Testes laboratoriais (Tabela 2), realizados com amostras da fibra, registram que certas características organolépticas, físicas, químicas e mecânicas apresentam-se de acordo com as normas técnicas estabelecidas por órgãos nacionais e internacionais como: ASTM (Annual Standart Trade Materials) $\rightarrow$ ASTM 1413-76; COPANT (Comissão Panamericana de Normas Técnica) $\rightarrow$ NBR 13774:1997e; ABNT (Associação Brasileira de Normas Técnicas) $\rightarrow$ NBR 13374/1995 e ABNT: 43-1/1999.

A4_Tabela 2. Propriedades tecnológicas identificadas na fibra de tucumã-i (Astrocaryum acaule)

\begin{tabular}{ll}
\hline Propriedades & \multicolumn{1}{c}{ Diagnósticos } \\
\hline Organolépticas & $\rightarrow$ Cheiro e gosto indistintos; \\
& $\rightarrow$ Textura lisa, macia e alinhada \\
& em direção às pontas; \\
& $\rightarrow$ Aparência com brilho natural e \\
& tom amarelado.
\end{tabular}


Químicas

$\rightarrow$ Índice nulo para reação tóxica;

$\rightarrow$ Presença de heterosídeos

cianogênicos;

$\rightarrow$ Ausência de fungos

Físicas

Mecânicas

$\rightarrow$ Teor de umidade dentro do padrão desejável. Variando entre $11,82 \%$ e $11,59 \%$;

$\rightarrow$ Densidade satisfatória com resultado igual a $1.49 \mathrm{~g} / \mathrm{cm}^{3}$;

$\rightarrow$ Fibra com ondulações e espessuras resistentes aos processos de tingimentos naturais ou de coloração artificial.

$\rightarrow$ Boa flexibilidade nos testes de manuseio e desdobramento da fibra, não apresenta casos de rompimentos bruscos na sua estrutura;

$\rightarrow$ Resistente a lavagem a seco ou a base de água e sabão;

$\rightarrow$ Resistente ao calor (máximo a $200^{\circ} \mathrm{C}$ );

$\rightarrow$ Resistente à tração com variação em média de $18 \mathrm{~kg} / \mathrm{cm} 2$
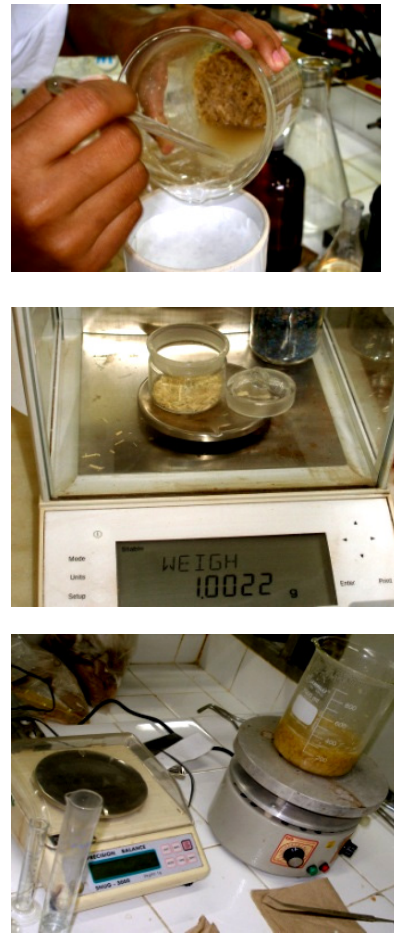

Além dessas propriedades tecnológicas identificadas, existe também uma análise sobre a confecção de um tecido a partir desta fibra, na qual os aspectos morfológicos do vegetal e todas as etapas de sua produção foram considerados positivos durante todo o processo realizado, resultando em um produto diferenciado e inovador (Maciel, 2007).

Com relação aos aspectos econômicos, a fibra de tucumã-i (Astrocaryum acaule) está vinculada a uma atividade produtiva organizada, especialmente, a partir do parentesco entre os membros das suas comunidades produtoras, uma vez que a economia empregada na região do Alto Rio Negro, frequentemente, possui uma característica de exploração dos recursos naturais que envolvem as especializações artesanais de cada grupo familiar (Athias, 1990).

Sua coleta extrativa, voltada para o uso e consumo, é autossustentada e não predatória. Ocorre em todo o seu potencial quando as pessoas se organizam e 
Estudio de la prospección del uso de la fibra de tucumã-i (Astrocaryum acaule) para el desarrollo de productos semi-industriales

executam a prática, utilizando fatores de produção e benefícios intermediários a fim de produzir bens e serviços, mediante uma técnica de produção pré-estabelecida e exercida pelas chamadas unidades produtoras.

No entanto, Cano (1998) afirma que a produção e o consumo são bastante diferenciados no tempo e no espaço, devido existir uma difícil compreensão, por parte das comunidades, em atender certa ou até necessária adequação entre as exigências do mercado regional e as características tradicionais valorizadas pelas unidades produtoras. Dessa forma, as atividades econômicas dos grupos étnicos do Alto Rio Negro estão organizadas, parcialmente, sobe influência das relações comerciais consagradas no mundo "civilizado". No entanto, as comunidades produtoras, possuem uma relação estabelecida com a natureza a qual não pode nunca ser confundida com uma atividade meramente técnica, prática e econômica (Tassinari, 1995).Apesar da busca pela valorização da natureza e o conhecimento tradicional da transformação da fibra em produto, as comunidades teme que suas atividades extrativas possam, em função do alcance de novas economias e benefícios locais, desvirtuar a essência do produto original, fabricado artesanalmente, deformando valores e tradição e deturpando a percepção de identidade cultural.

No entanto, sabem que tudo isso corresponde a desafios e superação, em busca de inovações e qualidade de seus produtos para a concorrência, sem temer dificuldades ou fracassos, relacionando sua produção nas operações econômicas, organização, comercialização e gestão necessárias ao funcionamento de seu empreendimento (Barreto, 2007).

A pesquisa é, nesse caso, uma ferramenta importante à relação política, econômica, sociocultural, tecnológica e ambiental, pois a gestão e o desenvolvimento de novos produtos competitivos não é uma tarefa fácil, devido a exigência do mercado de um esforço contínuo de renovação para aqueles que se acostumaram a produzir, os mesmos produto durante anos e que precisam oferecê-los como novos e criativos. No entanto, ela auxilia à produção de informações, à tomar decisões, à solucionar problemas e à querer cada vez mais dados relevantes para determinados fins.

\section{Materiais e Métodos}

Esse estudo está delineado por uma pesquisa qualitativa, classificada como: exploratória, descritiva e explicativa baseada em marco teórico que possibilita uma aproximação conceitual sobre o tema abordado (Gil, 2002).

O caráter qualitativo adequa-se à obtenção de percepções e opiniões das pessoas, sobre questões e fatos sociais sobre o status atual do fenômeno estudado e /ou para descrever a natureza das condições existentes em uma 
situação (Trochim W. M., 2002). Portanto, para a análise dos fatos, sob o ponto de vista empírico e confrontá-lo a uma visão teórica a respeito dos dados coletados da realidade, o trabalho proporciona um modelo operativo apresentando uma coleta de dados procedida por pesquisa bibliográfica e documental.

O método SWOT foi escolhido para a coleta de dados, identificação das oportunidades e possibilidades de solução para o problema detectado. A ferramenta possibilita a categorização dos fatores como sendo internos (pontos fortes e fracos) e externos (oportunidades e ameaças) em relação a uma determinada decisão, e como tal permite-lhes a comparação das oportunidades e ameaças com as fraquezas e pontos fortes do produto (Shrestha, Alavalapati, \& Kalmbacher, 2004). Nessa etapa da investigação, foi observado o posicionamento de alguns profissionais, pertencentes a 2 categorias de grupos distintos, que expressaram suas opiniões e sugestões com relação à gestão e uso da fibra vegetal da Amazônia de tucumã-i (Astrocaryum acaule) para o desenvolvimento de produtos semi-industriais, informações estas registradas através das técnicas: focus group e entrevista em profundidade, aplicadas a uma fase anterior do estudo. Assim, os dados coletados foram transcritos e submetidos à análise qualitativa.

0 processo de identificação das oportunidades e limitações do objeto de estudo, partiu de uma estrutura criada para análise qualitativa de dados com base conceitual no método SWOT (Figura 4).

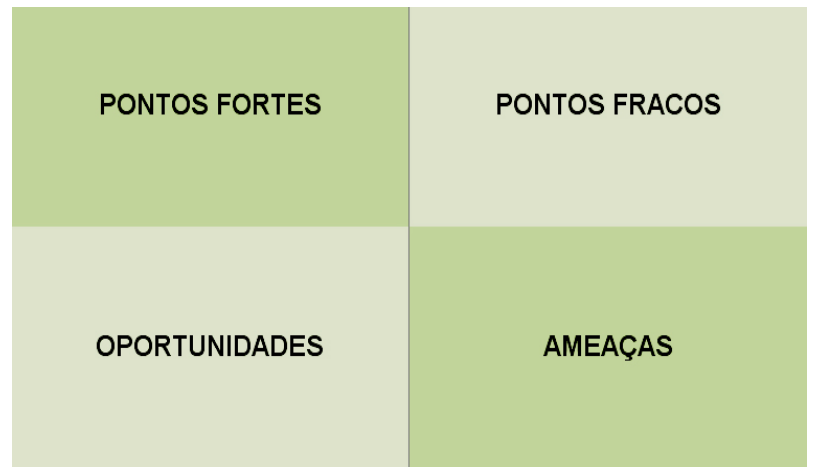

\section{A4_Figura 4. Matriz SWOT}

A análise de SWOT é uma ferramenta de suporte importante para a tomada de decisão e é frequentemente usada como forma de analisar os ambientes internos e externos de uma organização ou de um produto (Kotler, 1998). Para Ulgen \& Mirze (2004), as informações obtidas podem ser sistematicamente, 
Estudio de la prospección del uso de la fibra de tucumã-i (Astrocaryum acaule) para el desarrollo de productos semi-industriales

representadas numa matriz, ou então em diferentes combinações dos quatro fatores da matriz e segundo Dincer (2004), podem ajudar na determinação das estratégias para o longo prazo. 0 resultado também pode gerar uma mera listagem ou um exame qualitativo dos fatores internos e externos a serem considerados ao objeto estudado (Kangas, Kurtila, Kajanus, \& Kangas, 2003).

A análise SWOT, aplicada nesse estudo, foi desenvolvida a partir das informações obtidas nas técnicas de grupo focal e entrevista em profundidade. Uma apreciação sobre o ambiente externo que contempla o universo do objeto de estudo identificou as oportunidades e ameaças. Em seguida, o mesmo procedimento foi feito para observar o ambiente interno que envolve os aspectos fortes e fracos sobre a fibra de tucumã-i (Astrocaryum acaule).

As informações observadas em cada ambiente (externo e interno) foram listadas até cinco variáveis isoladas para cada predominância quadrante da matriz de SWOT, estabelecendo, assim, as oportunidades e limitações para o procedimento da investigação. Ainda com base na análise de SWOT, para verificar quais variáveis deverão ter uma atenção mais especial ao prosseguimento da pesquisa, o processo de identificação realizou um cruzamento entre as informações do ambiente externo e interno. Para tanto, foram ponderadas cada uma das variáveis propostas, definiu-se a pontuação por relevância (Tabela 3). As pontuações mensuradas como as mais altas, representaram as principais tendências das áreas de interesse ao estudo proposto, conforme o posicionamento resultante do grupo focal e entrevista em profundidade.

A4_Tabela 3. Mensuração dos fatores estudados

\begin{tabular}{cc}
\hline Valores & Parâmetros \\
\hline 1 & Baixo \\
2 & Médio \\
3 & Alto \\
\hline
\end{tabular}

\section{Resultados}

As oportunidades e limitações do objeto de estudo, foram identificadas a partir de uma seleção de informações obtidas através das opiniões fornecidas pelos 2 grupos distintos de profissionais. Em um primeiro momento, dos dados registrados e observados no grupo 1, foram destacados que:

Grupo 1 - Por parte dos Designers de Produto existe duas ressalvas a serem consideradas pela investigação sobre o uso da fibra natural amazônica de tucumã-i (Astrocaryum acaule) para a gestão e desenvolvimento de produtos semi-industriais (Figura 5): 

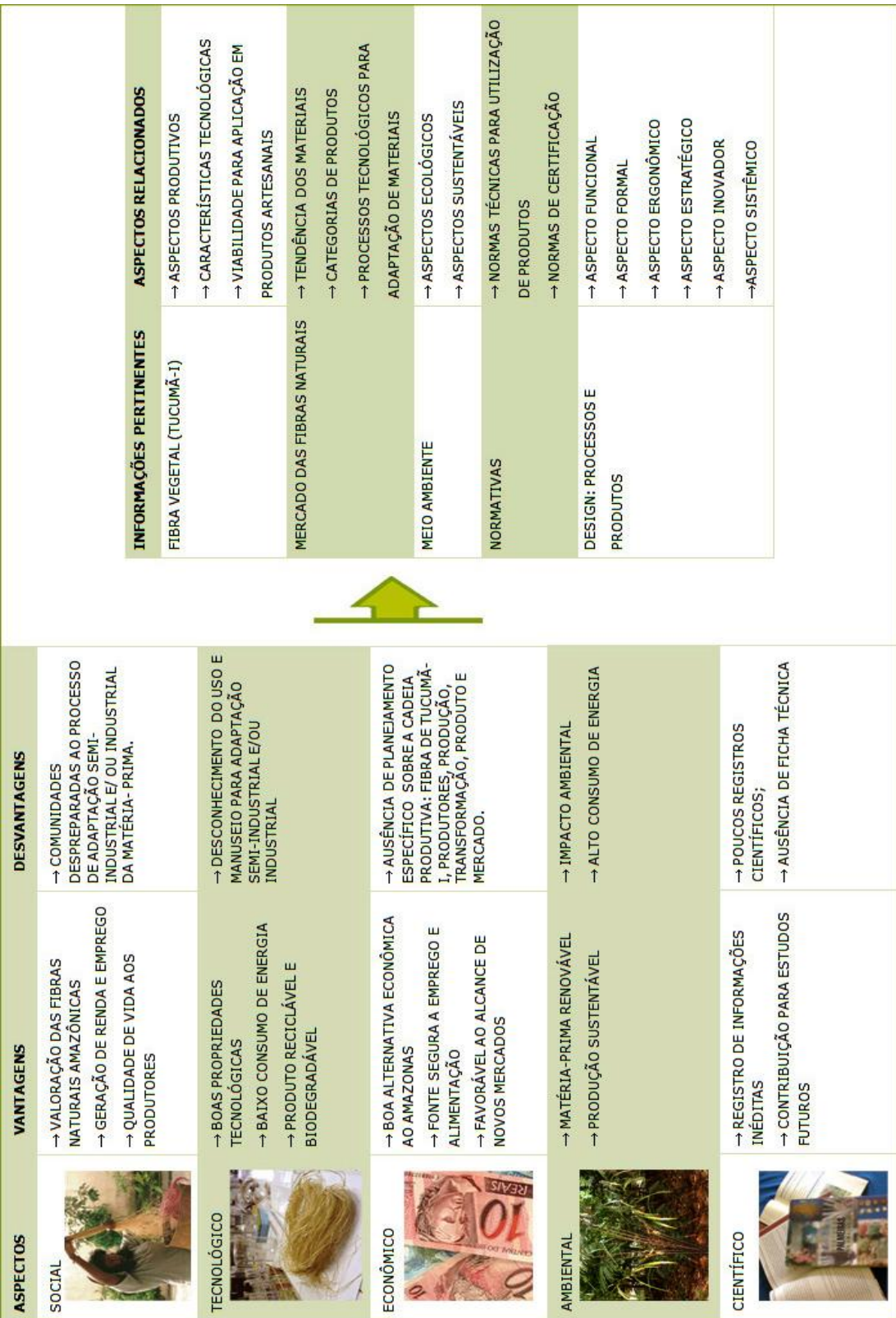

A4_Figura 5. Opiniões consideradas pelos Designers de produto sobre o objeto de estudo. 
Estudio de la prospección del uso de la fibra de tucumã-i (Astrocaryum acaule) para el desarrollo de productos semi-industriales

Posicionamento 1- contempla as vantagens e desvantagens relacionadas aos aspectos sociais, tecnológicos, econômicos, ambientais e científicos identificados como necessários à pesquisa; e

Posicionamento 2- apresenta os atributos classificados como positivos no universo da fibra analisada, de acordo com as informações avaliadas sobre os aspectos apreciados pelo ponto de vista anterior.

As informações construídas nas duas observações, trabalhadas de forma sistematizada - em função do processo de transformação da fibra à gestão e uso semi-industrial, conclui o raciocínio do grupo. Dos dados gerados e avaliados pelo grupo seguinte, foram obtidas as seguintes informações:

Grupo 2 - De acordo com os especialistas de Engenharia Florestal e Ambiental, Engenharia Têxtil, Engenharia de Produção, Engenharia Química, Economia de Mercado e Gestão Produtos, torna-se importante construir e registrar o conhecimento sobre a fibra de tucumã-i (Astrocaryum acaule) com base nos mesmos aspectos observados pelo grupo anterior.

No entanto, o grupo 2 apresentou ideias mais direcionadas ao processo de transformação da fibra, ponderando os aspectos: político, social, econômico, cultural, tecnológico e científico. Evidenciou também, como captação para este processo, os valores atribuídos às fibras naturais como o aspecto de inovação e as variedades de uso e aplicação em produtos.

Foi dado destaque à importante do registro de informações sobre a fibra para o acompanhamento da sua evolução, ou seja, a transição do estágio artesanal ao semi-industrial, uma vez que o objeto de estudo é carente de informações científicas nesse sentido.

Além disso, os especialistas apontaram outros pré-requisitos (Figura 6), os quais relacionaram o objeto de estudo com: mercado de atuação; meio ambiente; normativas e; concepção e planejamento de produto.

Vale ressaltar que: ao item mercado de atuação, foi sugerido um estudo de opinião dos consumidores quanto às categorias e tipos de produtos, relacionando sua forma e; à concepção e planejamento do produto - a tarefa foi atribuída ao design em função de ser uma atividade projetual. 


\begin{tabular}{|c|c|c|}
\hline PONTOS AVALIADOS & VANTAGENS & DESVANTAGENS \\
\hline FIBRA VEGETAL TUCUMÃ-I & $\begin{array}{l}\rightarrow \text { ORIGEM DA FIBRA } \\
\rightarrow \text { PROCESSO PRODUTIVO } \\
\rightarrow \text { BENEFÍCIO SOCIALE } \\
\text { ECONÔMICO }\end{array}$ & $\begin{array}{l}\rightarrow \text { DADOS CIENTIIFICOS } \\
\text { INSUFICIENTES } \\
\rightarrow \text { TECNOLOGIA DE PRODUÇÃO } \\
\text { PRECÁRIA } \\
\rightarrow \text { PRODUTORES CARENTES DE } \\
\text { INFRA-ESTRUTURA }\end{array}$ \\
\hline $\begin{array}{l}\text { MERCADO DAS FIBRAS } \\
\text { NATURAIS }\end{array}$ & $\begin{array}{l}\rightarrow \text { DOMINIO TÊXTIL } \\
\rightarrow \text { VARIEDADE DE CATEGORIAS } \\
\text { EPRODUTOS } \\
\rightarrow \text { NOVAS TECNOLOGIAS } \\
\rightarrow \text { ALCANCE DE NOVOS NICHOS }\end{array}$ & $\begin{array}{l}\rightarrow \text { CONCORRÊNCIA } \\
\text { CONSOLIDADA NO MERCADO } \\
\rightarrow \text { PROPRIEDADES } \\
\text { TECNOLOGICAS INVIȦVEIS } \\
\rightarrow \text { ALTO CUSTO PARA } \\
\text { PRODUÇÃO E ADAPTAÇÃO }\end{array}$ \\
\hline MEIO AMBIENTE & $\begin{array}{l}\rightarrow \text { ASPECTO SUSTENTÁVEL } \\
\rightarrow \text { ASPECTO ECOLÓGICO } \\
\rightarrow \text { VALOR NATURALEM } \\
\text { EVIDÊNCIA }\end{array}$ & $\begin{array}{l}\rightarrow \text { IMPACTO AMBIENTAL } \\
\rightarrow \text { AUSÊNCIA DE } \\
\text { PLANEJAMENTO À REPOSIÇÃO } \\
\text { DE MATÉRIAS-PRIMAS }\end{array}$ \\
\hline NORMATIVAS & $\begin{array}{l}\rightarrow \text { QUALIDADE DO MATERIAL } \\
\rightarrow \text { PROCESSO DE } \\
\text { TRANSFORMAÇÃO } \\
\rightarrow \text { CONFORTO } \\
\rightarrow \text { USABILIDADE } \\
\rightarrow \text { MANEO } \\
\rightarrow \text { DURABILIDADE }\end{array}$ & $\begin{array}{l}\rightarrow \text { MATERIAL INADEQUADO ÀS } \\
\text { NORMAS DE PADRÕES E/OU } \\
\text { CERTIFICAÇÃO }\end{array}$ \\
\hline $\begin{array}{l}\text { DESIGN: PROCESSOSE } \\
\text { PRODUTOS }\end{array}$ & $\begin{array}{l}\rightarrow \text { FERRAMENTA ESTRATÉGICA } \\
\text { DE AÇÃO E INOVAÇÃO } \\
\rightarrow \text { SINAUZADOR DE } \\
\text { OPORTUNIDADES } \\
\rightarrow \text { SISTEMATIZADOR DE } \\
\text { INFORMAÇÕES } \\
\rightarrow \text { VALOR AGREGADO }\end{array}$ & $\begin{array}{l}\rightarrow \text { AUSÊNCIA DE } \\
\text { CONHECIMENTOS SOBREO } \\
\text { MATERIAL; } \\
\rightarrow \text { NECESSIDADE DE } \\
\text { PADRONIZAÇÃO DO MATERIALE } \\
\text { PROCESSO DE } \\
\text { TRANSFORMAÇÃO. }\end{array}$ \\
\hline
\end{tabular}

A4_Figura 6. Opiniões consideradas pelos Especialistas de áreas correlacionadas ao tema estudado.

Apurando as opiniões apresentadas pelos dois grupos distintos de profissionais. Foi construído um cenário de identificação das oportunidades e limitações do 
Estudio de la prospección del uso de la fibra de tucumã-i (Astrocaryum acaule) para el desarrollo de productos semi-industriales

estudo, centrado somente nos fatores macros que contemplam os diagnósticos posicionados pelos profissionais consultados.

Para tanto, como ferramenta auxiliar, foi utilizado o método SWOT que ajudou a estruturar a matriz desse estudo (Figura 7) conforme: ambiente interno - forças e fraquezas; e ambiente externo - oportunidades e ameaças.

\begin{tabular}{|c|c|}
\hline PONTOS FORTES & PONTOS FRACOS \\
\hline $\begin{array}{l}\text { - Matéria-prima natural; } \\
\text { - Produção sustentável; } \\
\text { - Fonte de emprego e renda; } \\
\text { - Recurso natural comaspecto para a } \\
\text { inovação; } \\
\text { - Material disponível e de grande } \\
\text { procura à fabricação artesanal } \\
\text { Amazônicos. }\end{array}$ & $\begin{array}{l}\text { - Registros científicos insuficientes; } \\
\text { - Uso e manuseio semi-industrial e/ou } \\
\text { industrial desconhecidos; } \\
\text { - Tecnologias de produção e } \\
\text { transformação precárias; } \\
\text { - Material sem normas para uso e } \\
\text { padronização; } \\
\text { - Manuseada apenas pelas comunidades } \\
\text { produtoras. }\end{array}$ \\
\hline OPORTUNIDADES & AMEAÇAS \\
\hline $\begin{array}{l}\text { - O valor atribuído aos materiais naturais } \\
\text { e com denominação de origem; } \\
\text { - Tecnologias modernas ao processo de } \\
\text { transformação de matérias-primas; } \\
\text { - Beneficios Social/Ambiental/Econômico; } \\
\text { - Variedade de produtos e categorias no } \\
\text { mercado de fibras naturais; } \\
\text { - Design como ferramenta estratégica } \\
\text { para a transformação da fibra, qualidade } \\
\text { dos processos e alcance de novos } \\
\text { mercados. }\end{array}$ & $\begin{array}{l}\text { - Consumo de energia; } \\
\text { - Impacto ambiental; } \\
\text { - Características tecnológicas sem } \\
\text { experimentos no processo semi-industrial } \\
\text { e/ou industrial; } \\
\text { - Dificuldade em logística na Amazônia; } \\
\text { - Concorrência comfibras já consolidadas } \\
\text { no mercado }\end{array}$ \\
\hline
\end{tabular}

A4_Figura 7. Análise SWOT para identificar as oportunidades e limitações do estudo.

Considerando o processo de transformação da fibra e a sistematização para o registro das informações: o ambiente interno, apresentou como aspectos favoráveis a contextualização socioambiental e tecnológica relacionados ao objeto estudado por se tratar de: uma matéria-prima natural produzida de forma sustentável, com capacidade de gerar emprego e renda às suas 
comunidades produtoras, possuir características inovadoras e; ser um recurso disponível e com demanda comercial para a sua área de localização.

Como deficiências: a falta de um conhecimento técnico mais aprofundado e de publicações mais relevantes quanto ao uso, às tecnologias, às normativas e ao desenvolvimento de produtos por processo semi-industrial;

Conforme o posicionamento de mercado: o ambiente externo retrata como oportunas os seguintes fatores - considerados estratégicos: uma matéria-prima natural com denominação de origem, a disponibilidade de tecnologias modernas para auxiliar no seu processo de transformação, o desenvolvimento socioambiental e econômico para a sua região, a possibilidade da criação de novos produtos para a sua aplicação e a gestão do design para a viabilização dos processos, serviços e produtos.

Como aspectos ameaçadores ao estudo e ao aproveitamento destas oportunidades, a matriz sinaliza: o consumo de energia, o impacto ambiental, a falta de experimentos técnicos semi-industriais com a fibra, a dificuldade de logística e a concorrência com artigos similares já consolidados no mercado das fibras naturais para a fabricação de produtos.

Após a organização das informações na matriz SWOT, foi realizado um cruzamento entre os dados gerados, os quais foram codificados. A técnica ajudou a definir as variáveis mais importantes para dar prosseguir com o estudo e ter uma idéia sobre os possíveis aspectos que poderão dificultar o alcance dos objetivos planejados, para esse primeiro momento da investigação proposta.

A figura 8 apresenta a prática do cruzamento das informações realizada. Em seguida, os esclarecimentos sobre os aspectos associados aos pontos considerados: fracos, fortes, de oportunidades e de ameaças para o processo de transformação semi-industrial do objeto estudado. 


\begin{tabular}{|c|c|c|c|c|c|c|c|c|c|c|c|}
\hline • & $\frac{⿱}{\frac{m}{x}}$ & $\frac{\vec{a}}{\underline{x}}$ & $\frac{\pi}{x}$ & $\frac{\pi}{\frac{\pi}{x}}$ & $\frac{\pi}{\frac{\pi}{x}}$ & - & $\frac{\pi}{x}$ & $\frac{\pi}{x}$ & $\frac{\pi}{\frac{\pi}{m}}$ & $\frac{\tilde{d}}{\vec{d}}$ & $\frac{\| x}{\frac{\pi}{m}}$ \\
\hline & 芯 & $\tilde{\check{\Xi}}$ & $\vec{d}$ & I̊̃ & 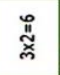 & - & $\stackrel{\pi}{\dddot{x}}$ & 范 & 总 & $\dot{\vec{z}}$ & 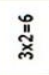 \\
\hline & 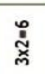 & 芩 & $\stackrel{\vec{z}}{\tilde{x}}$ & 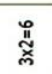 & 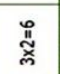 & . & $\underset{\check{z}}{\tilde{Z}}$ & 获 & 总 & $\dot{\vec{x}}$ & 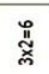 \\
\hline & 㞔 & $\underset{\tilde{n}}{\tilde{\Xi}}$ & : & i & ig & & $\underset{\pi}{\stackrel{\pi}{*}}$ & $\begin{array}{l}\stackrel{0}{0} \\
\text { : }\end{array}$ & 递 & :ٌ & : \\
\hline & : & 哭 & : & "x & g. & . & $\underset{\pi}{\pi}$ & 总 & 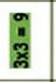 & ஜ̊ํํ & : \\
\hline & 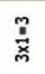 & $\underset{\mathbb{d}}{\vec{d}}$ & $\frac{\pi}{x}$ & $\frac{\pi}{\frac{\pi}{x}}$ & $\frac{\pi}{\frac{\pi}{x}}$ & & $\frac{\pi}{x}$ & $\frac{\pi}{x}$ & $\frac{\pi}{\frac{\pi}{x}}$ & $\frac{\tilde{z}}{\vec{d}}$ & $\frac{\pi}{\frac{\pi}{x}}$ \\
\hline & 㞔 & $\underset{\widetilde{\Xi}}{\tilde{\Xi}}$ & 总 & II & gi & & $\underset{\pi}{\stackrel{\pi}{*}}$ & 苋 & g. & ֻั. & g \\
\hline & 苂 & ฐ̃ & $\vec{z}$ & ֻू. & 总 & 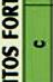 & $\tilde{\Xi}$ & 范 & 总 & $\dot{\nexists}$ & 胥 \\
\hline & 总 & $\underset{\dddot{\Xi}}{\tilde{\Xi}}$ & : & in & ig & 5 & $\underset{\mathbb{Z}}{\stackrel{\pi}{*}}$ & 苋 & g: & ஓ̊. & ב \\
\hline & 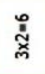 & $\underset{\cong}{\cong}$ & $\stackrel{d}{\vec{x}}$ & ֻू๊ & 胥 & & $\dddot{\pi}$ & 范 & 总 & $\overrightarrow{\dot{z}}$ & ָू. \\
\hline & $0^{\circ}$ & 0 & $\circ$ & 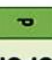 & $\bullet$ & & ${ }^{\circ}$ & 0 & $\circ$ & $\circ$ & - \\
\hline
\end{tabular}

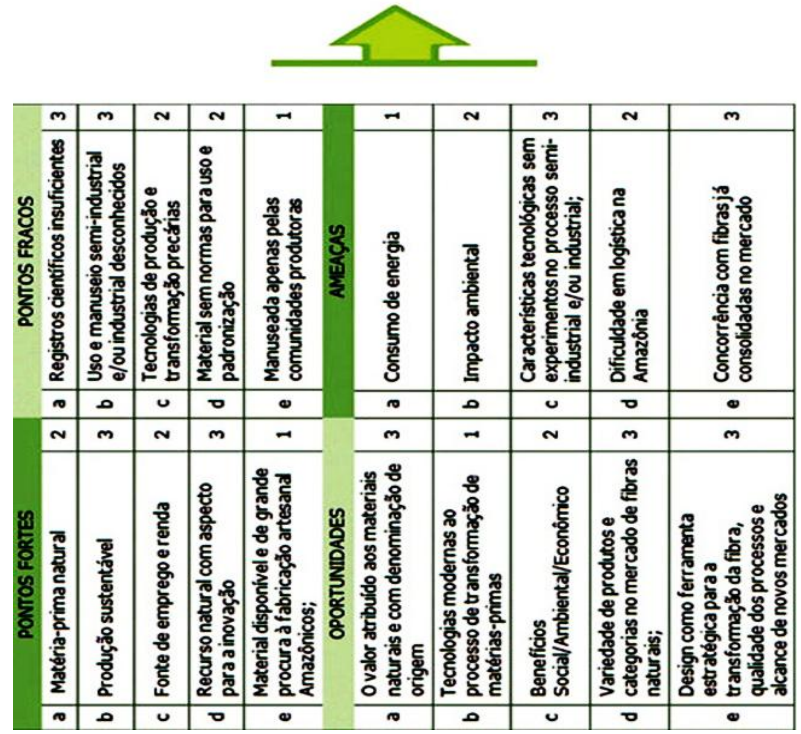

A4_Figura 8. Codificação e cruzamento das informações estruturadas a partir da matriz SWOT. 
Para o processo de transformação semi-industrial da fibra - os resultados mostraram que dentre os fatores pesquisados, os mais relevantes são: a produção sustentável de um recurso natural com aspectos favoráveis à inovação. 0 aspecto inovador destacado atribui às variedades de produtos e/ou categoria de uso que poderão ser originados a partir do objeto de estudo. 0 fortalecimento disso poderá encontrar em um estudo de mercado as possibilidades para essa aplicação.

Outros destaques seguem para: os valores e a denominação de origem atribuída aos materiais naturais; as possibilidades de aplicação das fibras naturais em uma grande variedade de produtos e segmentos e; o design, como ferramenta estratégica, para sistematizar as informações, e gestionar o processo de adaptação semi-industrial da fibra, registrando os valores que deverão ser considerados e embutidos no produto final (Tabela 4).

A4_Tabela 4. Identificação das oportunidades para o estudo

\begin{tabular}{ll}
\hline Pontos Fortes & \multicolumn{1}{c}{ Oportunidades } \\
\hline $\begin{array}{l}\text { - Produção } \\
\text { Sustentável; }\end{array}$ & $\rightarrow$ Valores atribuídos aos materiais naturais e com \\
& denominação de origem; \\
& $\rightarrow$ Variedade de produtos e categorias no mercado de \\
- Recurso natural & fibras naturais; \\
com aspecto para a & $\rightarrow$ Design como ferramenta estratégica para a \\
inovação. & $\begin{array}{l}\text { transformação da fibra, qualidade dos processos e } \\
\text { alcance de novos mercados. }\end{array}$
\end{tabular}

As limitações, retratadas como aspectos fracos, apontam: a ausência de registros científicos, fator que inclui o desconhecimento do uso e adaptação da fibra por processo semi-industrial.

As ameaças interligadas às fraquezas alertam que a falta de informações pertinentes ao objeto em estudo pode deixar a desejar nos quesitos referentes: às características tecnológicas insuficientes ao processo semiindustrial e/ou industrial e, ainda, à concorrência com fibras já consolidadas no mercado podem deixar a fibra de tucumã-i em desvantagem quanto a sua utilização em produtos. (Tabela 5)

\section{A4_Tabela 5. Identificação das limitações para o estudo}

\begin{tabular}{ll}
\hline Pontos Fracos & \multicolumn{2}{c}{ Ameaças } \\
\hline - Registros científicos insuficientes; & $\rightarrow$ Características tecnológicas sem \\
& experimentos no processo semi- \\
\hline
\end{tabular}


Estudio de la prospección del uso de la fibra de tucumã-i (Astrocaryum acaule) para el desarrollo de productos semi-industriales

industrial e/ou industrial;

- Uso e manuseio semi-industrial e/ou $\rightarrow$ Concorrência com fibras já industrial desconhecidos.

consolidadas no mercado

Em vista dos pontos fracos e ameaças, cabe à organização das informações, a ser estruturada por um método sistematizado e retroalimentar, orientar para a elaboração e implantação dos planos, programas e projetos, tendo em vista incrementar as fortalezas e eliminar - ou pelo menos minimizar - as debilidades identificadas nessa fase da pesquisa.

\section{Considerações Finais}

Este artigo apresentou uma análise de opiniões, fornecidas por 2 grupos de profissionais distintos, referentes ao uso da fibra natural amazônica de tucumã-i (Astrocaryum acaule) para a gestão e desenvolvimento de produtos semi-industriais. A investigação teve como auxílio para a identificação das oportunidades e limitações sobre o tema proposto a técnica qualitativa SWOT, que ordenou os diagnósticos considerados por cada grupo.

Foram observados que: o grupo composto por designers de produtos atribuiu como fatores predominantes ao estudo, os aspectos sociais, tecnológicos, econômicos, ambientais e científicos que, baseando-se por eles, a essência da fibra deverá ser trabalhada. Para cada um desses aspectos foram determinadas as vantagens e desvantagens em função da realidade apresentada sobre o objeto de estudo. Os profissionais de design ainda reforçam que a fibra necessita ser avaliada através de um processo de transformação, registrando cada etapa dessa adaptação para comparação, se existente, do desempenho analisado com relação ao processo artesanal, habitual, exercido por ela.

0 grupo representado pelos profissionais de áreas correlatas à investigação acredita que adaptar a fibra de modo a contribuir com a sua evolução do estágio artesanal ao semi-industrial poderá ser um marco para o ramo científico, uma vez que a espécie analisada não dispõe de muitos registros técnicos e experimentais. 0 que precisa ser providenciado com 0 apoio de uma ferramenta sistêmica que auxilie na estruturação das informações para um planejamento das ações mais eficaz à gestão e uso de novos recursos naturais ao mercado de produtos desenvolvidos com fibras vegetais que, além do domínio têxtil também apresenta uma grande variedade de categorias para uso oferecido. Sob este aspecto, os profissionais de Engenharia Florestal e Ambiental, Engenharia Têxtil, Engenharia de Produção, Engenharia Química, Economia de Mercado e Gestão Produtos ainda destacam a possibilidade do 
alcance de novos mercados e da disponibilidade de novas tecnológicas que poderão qualificar ainda mais as propriedades de uso da matéria-prima, tendo o design como uma ferramenta-chave para a elaboração estratégica, tomadas de decisões, ações e atribuição de todos esses valores para um melhor conhecimento, adaptação e utilização da fibra amazônica de tucumã-i (Astrocaryum acaule) em produtos semi-industriais.

Portanto, para o alcance de novos mercados faz-se necessário um estudo de opinião que possa ajudar a averiguar o grau de aceitação do uso semiindustrial da fibra e identificar os atributos do design a serem considerados para o desenvolvimento de novos produtos - conforme o contexto observado.

\section{Direcionamento para futuras investigações}

As informações apresentadas por esse artigo justificam as oportunidades e limitações diagnosticadas sobre o uso da fibra amazônica de tucumã-i (Astrocaryum acaule) para a gestão e desenvolvimento de produtos semiindustriais.

Os próximos passos atribuídos a essa investigação poderão contemplar um estudo de opiniões, por parte dos consumidores, uma análise das suas propriedades tecnológicas com relação a outros produtos similares já consolidadas no mercado, a experimentação tecnológica por processo semiindustrial da fibra e um estudo sistêmico das informações produzidas ao longo desta investigação.

O referido estudo é importante para registro da evolução da fibra - do processo artesanal ao semi-industrial, visando o progresso das atividades realizadas pelas suas comunidades produtoras, assim como, incentivando a outras áreas de conhecimento como: as ciências econômicas, sociais, culturais, florestais, dentre outras, uma participação maior, junto aos projetos de design, na construção da história desse recurso natural, contribuindo para a sua melhor atuação no desenvolvimento de produtos.

\section{Referências}

ABNT - Associação Brasileira de Normas Técnicas. Material têxtil: Determinação da resistência da costura em materiais têxteis confeccionados ou não - NBR 13374/1995. São Paulo: ABNT, 1995.

. Ensaios de Proficiência por Comparações Interlaboratoriais ABNT: 43-1, 1999. São Paulo: ABNT, 1999.

- Material têxtil: determinação da resistência à tração e alongamento de tecidos planos (tira). (Especifica o método para determinação 
da resistência à tração e alongamento de tecidos plano pelo método tira). NBR11912. Rio de Janeiro: 2001.

ASTM - Annual Book of ASTM Standart. Vol. 04.10 - Wood, ASTM 1413-76, Pennsylvania: 1984.

Athias, Renato. As Relações entre Hupdë-Maku e Tukano. A Origem das Desigualdades (tradução da Tese), 1990.

Barreto, Pirõ Dihio Otacila Lemos. A produção da fibra de tucum como alternativa econômica dos povos indígenas do Alto Rio Negro. Dissertação apresentada ao Programa de Pós-Graduação em Sociedade e Cultura da Amazônia da Universidade Federal do Amazonas, como requisito parcial para obtenção do título de Mestre em Sociedade e Cultura da Amazônia. Manaus, 2007. Disponível em:< www.ppgsca.ufam.edu.br/ dissertacao.html> Acesso em: 19 mai. 2011.

Cano, Wilson. Introdução à Economia: uma abordagem crítica. 2 ed. São Paulo: UNESP, 1998.

COPANT - Comissão Panamericana de Normas Técnicas. Cabo e fio de compensação e/ou extensão - Tolerâncias e identificação - NBR 13774, 1997.

Dincer, O. Strategy Management and Organization Policy, Beta Publication, Istanbul, 2004.

Gil, A.C. Como elaborar projetos de pesquisa. 4.ed. São Paulo: Atlas. 176p, 2002.

Kangas, J; Kurtila, M; Kajanus, M; Kangas, A. Evaluating the management strategies of a forestland estate-the S-O-S approach. Journal of Environmental Management 69, 349-358, 2003.

Kotler, P. Marketing Management: Analysis, Planning, Implementation and Control, Prentice- Hall, New Jersey, 1998.

Maciel, K. M. F. Estudo da Viabilidade Técnica da Fibra de Tucumã-i (Astrocaryum acaule) para Produção de Tecido a ser utilizado na Indústria de Confecções. Dissertação apresentada ao Programa de Pós-Graduação em Ciências Florestais e Ambientais da Universidade Federal do Amazonas, 2007. Disponível em:<http://www.ppgcifa.ufam.edu.br/dissertacao.html> Acesso em: 05 mai. 2008.

Marinelli A. L, Monteiro M.R, Ambrósio J.D and Branciforti M.C, Kobayashi M, Nobre AD. Desenvolvimento de compósitos poliméricos com fibras vegetais naturais da biodiversidade: uma contribuição para a sustentabilidade amazônica. Polímeros Ciência e Tecnologia. 18(2):92-99, 2008. 
Menezes, M. R, Pinheiro, R, Guazzell,A. C. e Martins, F. Cadeia produtiva das fibras vegetais extrativistas no estado do Amazonas. Governo do Estado do Amazonas - Manaus: SDS. Série Técnica. Meio Ambiente e Desenvolvimento Sustentável, 4.32p.; il., 2005.

Miranda, Ires Paula de Andrade. Frutos e Palmeiras da Amazônia. Ministério da Ciência e Tecnologia (MCT). Instituto Nacional de Pesquisas da Amazônia (INPA). Manaus - Amazonas - Brasil, 2001.

Miranda, I. P. A.; Rabelo, A. Guia de Identificação das palmeiras de Porto. Trombetas/PA. Ed. UFAM, INPA, Manaus, 2008. 364p.

Pletsch, M. Compostos naturais biologicamente ativos. Biotecnologia, Ciência e Desenvolvimento, Brasília, v. 1, n. 4, p. 12-15, 1998.

Santos, Aurelina Viana dos. Fibras vegetais para artesanato: Técnicas de produção de fibras de Arumã, Cipó Ambé e Tucumã. Amazonas: Fundação Vitória Amazônica (FVA), 2002.

Shrestha, R.K., Alavalapati, J.R.R., Kalmbacher, R.S. Exploring the potential for silvopasture adoption in south-central Florida: An application of SWOT-AHP method. Agricultural Systems, 81 (3): 185-199, 2004.

Schwartzman, S. Mercado para produtos extrativistas da Amazônia brasileira. In ARNT, A. R. O destino da floresta. Reservas extrativistas e desenvolvimento sustentável na Amazônia. Rio de Janeiro: Relume Dumará, 2004.

Souza, Hermes Moreira de. et al. Palmeiras brasileiras e exóticas cultivadas. Nova Odessa. São Paulo: Instituto Platarum, 2004.

Tassinari, Antonella Maria Imperatriz. Sociedades Indígenas: Introdução ao tema da diversidade cultural. In: SILVA, Aracy Lopes da e Luis Donisete Benzi Grupioni (Org.). A Temática indígena na escola: novos subsídios para professores de 1 e 2 graus. Brasília, MEC/MARI/Unesco, 1995.

Trochim, W. M. The Research Methods Knowledge Base, 2nd Edition, 2002. Disponível em: <http://trochim.human.cornell.edu/kb/index.htm> Acesso em: 15 out. 2010

Ulgen, H. et al. Strategic Management, Literatur Publication, Istanbul, 2004. 



\subsection{Artículo 5 - Análisis de la apreciación de los consumidores sobre el uso semi-industrial de la fibra vegetal amazónica de tucumã-i (Astrocaryum acaule) para el desarrollo de productos: Un estudio de mercado}

Esta producción científica ha sido realizada con la intención de analizar el posicionamiento de los consumidores potenciales sobre el uso semi-industrial del objeto de investigación para el desarrollo de productos (Publicación en portugués). El artículo corresponde al sub-objetivo 1 del objetivo 2 de la tesis (Pags.67, 68,69 y 70).

Revista: INGEPRO - Inovação, Gestão e Produção Indexada en: Associação Brasileira de Engenharia de Produção Instituto Brasileiro de Informação em Ciência e Tecnologia (IBICT - SEER) Portal para periódicos de livre acesso na Internet - LivRe!

PKP - Open Archives Harvester (Canadá)

DOAJ - Directory of Open Access Journals (Europe)

ISSN: 1984-6193

Enviado: 24.Agosto.11 | Aceptado: 30.Agosto.11 | Publicado: Septiembre.11

Cita: Pacheco, K. M. M.; Ortuño, B. H.; Miranda, I. P. A.; Nascimento, C. C.; Vicente, B. A. (2011). Análise da apreciação de consumidores sobre o uso semi-industrial da fibra vegetal amazônica de tucumã-i (Astrocaryum acaule) para o desenvolvimento de produtos: Um estudo de mercado. Revista INGEPRO - Inovação, Gestão e Produção, Universidade Federal de Santa Maria - UFSM. Rio Grande do Sul/Brasil, 3 (9): 44-51.

Análise da apreciação de consumidores sobre o uso semi-industrial da fibra vegetal amazônica de tucumã-i (Astrocaryum acaule) para o desenvolvimento de produtos: Um estudo de mercado

Karla Mazarelo Maciel Pacheco <karlamazarelo@hotmail.com>

Bernabé Hernandis Ortuño <bhernand@degi.upv.es>

Ires Paula de Andrade Miranda <ires@inpa.gov.br>

Claudete Catanhede do Nascimento <catanhed@inpa.gov.br>

Begoña Agudo Vicente <bagudo405p@cv.gva.es>

Resumo: Este artigo descreve uma sondagem de opiniões e idéias fornecidas, por 408 pessoas, com respeito à utilização semi-industrial de uma fibra natural amazônica para a fabricação de produtos. 0 estudo foi desenvolvido a partir de um levantamento bibliográfico, aplicação de questionário e análise dos dados por meio de frequências, nível de significância e cálculo de medias. Os resultados apresentados identificaram: o perfil do consumidor, os níveis de 
apreciação, consumo e razão do uso de produtos desenvolvidos com fibras vegetais; o posicionamento sobre a inserção de novas matérias-primas no mercado; o grau de aceitação da fibra vegetal de tucumã-i (Astrocaryum acaule) para o uso semi-industrial em produtos e os aspectos considerados relevantes para esse processo. Como conclusão, apesar dos elevados números de aprovação para o tema proposto, o público entrevistado ainda ressaltou que a matéria-prima necessita de uma atenção maior no momento da sua adaptação tecnológica, de modo a não comprometer os seus valores intrínsecos. A qualidade do material deverá ser o fator primordial a ser contemplado para esse processo, de forma à favorecer tanto para sua inserção no mercado quanto para o seu uso semi-industrial na fabricação de produtos e, com isso, oferecer benefícios aos seus futuros consumidores.

Palavras-chave: Estudo de Opinião; Fibra Vegetal Amazônica; Produto SemiIndustrial.

Analysis of the appreciation of consumers about the use of semi-industrial plant fiber Amazon tucuma-i (Astrocaryum acaule) for product development: A market study

Abstract: This article describes opinions and ideas provided by 408 people in a survey, with respect to the semi-industrial use of an Amazon natural fiber for the products manufacture. The study was developed from the literature review, a questionnaire application and data analysis in terms of frequencies, level of significance and calculation of averages. The results presented were: the consumer profile, the levels of discretion, consumption and use of products developed from natural fibers. As well the consumer position on the inclusion of new raw materials market, the degree of acceptance of the tucumã-i fiber (Astrocaryum acaule) for semi-industrial use of the products and the relevant aspects to this process. In conclusion, despite his high approval of the proposed theme, the public has also directed his interest toward technological adaptation of the raw material, in order not to compromise their intrinsic values. The material quality should be the main factor considered in this process, in order to facilitate both their market access and its use in the manufacturing of semi-industrial products. In this way it could provide benefits to future consumers.

Keywords: Study of Opinion; Amazon Fiber Plant, Semi-Industrial Product.

\section{Introdução}

A identificação de oportunidades é uma etapa permanente no processo de desenvolvimento de novos produtos. Ela representa a busca sistemática de 
informações que permitem a organização competitiva para a comercialização de produtos ou serviços. Assim, tanto um quanto o outro, pode dispor de uma grande probabilidade de sucesso se satisfazer, com benefícios, as necessidades expressas pelo mercado (Cooper, 1993).

Estudar as influências e as características do comportamento do consumidor, a fim de obter condições de um planejamento mais eficaz das ações para a concepção de propostas adequadas, de uso e de desenvolvimento de novos produtos, torna-se indispensável para um bom posicionamento no mercado, uma vez que a sondagem de opiniões baseia-se na idéia de que os seus resultados contêm a expressão da vontade popular e representa uma maneira efetiva de conhecer o que as pessoas pensam, contribuindo para uma investigação mais séria e eficaz sobre a metodologia do desenvolvimento de produto, que possa reduzir riscos e intervalos para a sua utilização (Champagne, 1998).

Neste contexto, o presente estudo descreve uma análise do posicionamento dos consumidores sobre o uso semi-industrial da fibra vegetal amazônica de tucumã-i (Astrocaryum acaule) para o desenvolvimento de novos produtos, razão pela qual se encontra centralizado nos seguintes objetivos:

- Identificar o perfil dos consumidores;

- Observar os níveis de apreciação, consumo e razão do uso de produtos concebidos a partir das fibras vegetais;

- Conferir o número de aprovação à inserção de novas fibras vegetais no mercado;

- Verificar o grau de aceitação para o uso semi-industrial da fibra de tucumã-i (Astrocaryum acaule) para o desenvolvimento de novos produtos;

- Identificar os aspectos considerados relevantes ao processo;

\section{Fibras vegetais e novos produtos}

As fibras vegetais, por serem abundantes, de baixo impacto ambiental e oferecerem propriedades tecnológicas adequadas às aplicações na indústria, estão se tornando alternativas atrativas do ponto de vista econômico e sustentável, o que vem aumentando através dos avanços nas pesquisas orientadas a sua utilização (Guimarães, 2010).

Para Aguiar Neto (1996), o campo de emprego das fibras vegetais é bastante amplo, abrangendo aplicações clássicas na indústria têxtil com a confecção de novos produtos, sobretudo, para a produção de tecidos naturais com composições variadas, enfatizando a reutilização e a reciclagem de materiais e participando do movimento de conscientização ao meio ambiente. Outra 
Estudio de la prospección del uso de la fibra de tucumã-i (Astrocaryum acaule) para el desarrollo de productos semi-industriales

forma de emprego é o desenvolvimento de peças para acabamento interno de veículos, apresentando propriedades mecânicas, térmicas e acústicas bastante relevantes (Marinelli, Monteiro, Ambrósio, Brancifort, Kobayashi, \& Nobre, 2008). Fibras como: a juta, o sisal, o coco, o rami, o cânhamo, a fibra de madeira, o bagaço de cana e várias outras, são exemplos de recursos vegetais que têm sido utilizados como matérias-primas para compor materiais novos e apresentando-se como grandes potenciais comerciais (Bledzki \& Gassan, 1999). 0 crescente interesse pelo conhecimento sobre as estruturas das fibras vegetais e suas propriedades, as quais auxiliam na produção de novos produtos e de novas aplicações, mostra-se cada vez mais em evidência tanto para o âmbito científico como para o campo mercadológico (Mendes, 1992).

A busca por informações e aspectos que possam contribuir para o desenvolvimento de produtos, são características desejadas pelo mercado consumidor que impulsiona os processos de investigação para analisar e trabalhar em todos os possíveis setores, como por exemplo: na identificação de novas fibras, na produção de fios, na tecelagem, nos acabamentos, nos equipamentos e, etc. Tudo isso, formando parte de um processo de tomada de decisão complexo e interativo com vários estágios e filtros.

Portanto, é preciso estar ciente que: a velocidade, a eficiência e a qualidade do trabalho é que determinará a competitividade do novo produto, assim como, é imprescindível ter o conhecimento necessário sobre a matéria-prima a ser empregada durante todo o prodecimento (Takahashi \& Takahashi, 2007).

\subsection{Os benefícios identificados na fibra de tucumã-i (Astrocaryum acaule)}

A busca por novas matérias-primas naturais é um incentivo que vem partindo da indústria, da ciência e de alguns países em desenvolvimento, com o intuito de desenvolver novos produtos que apresentem boa qualidade, funcionalidade, conforto, aspectos ecos-sustentáveis e que venham a atender às necessidades de uso e de aplicação para o mercado.

Partindo desse princípio, a fibra de tucumã-i (Astrocaryum acaule) está sendo apontada como uma boa opção para o desenvolvimento de novos produtos, por se tratar de um recurso vegetal proveniente de palmeira amazônica (Figura 01) com produção sustentável, realizada por comunidades indígenas e caboclas localizadas no Alto Rio Negro - estado do Amazonas, região norte do Brasil (Souza, 2004). 

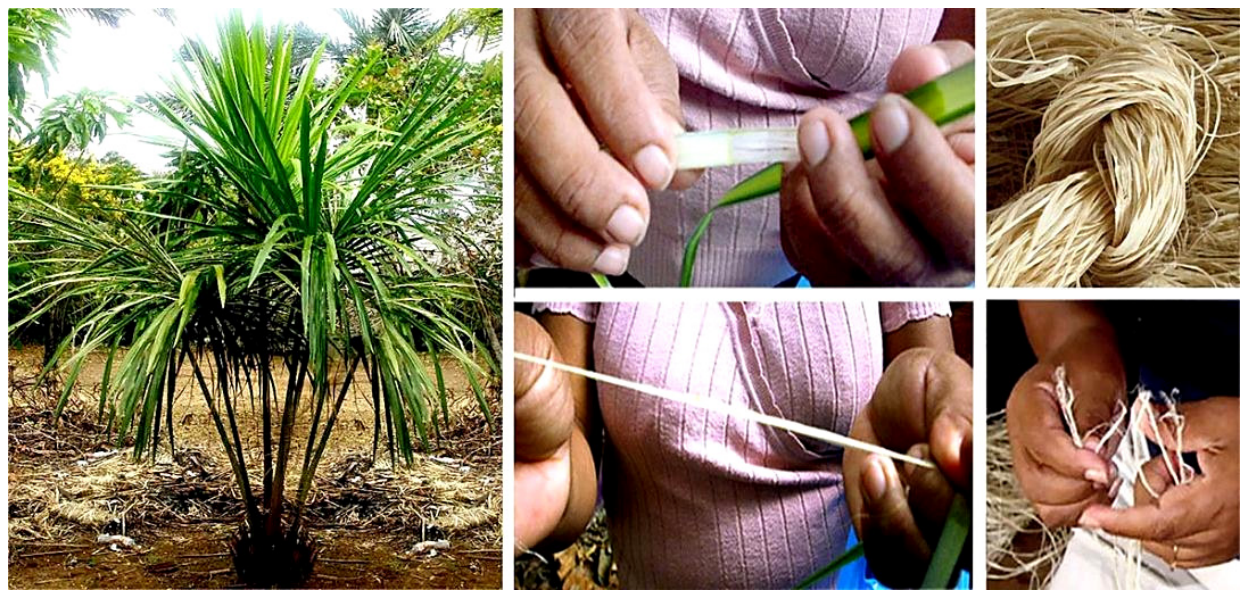

A5_Figura 1. Palmeira de tucumã-i (Astrocaryum acaule) e a sua área de localização no estado do Amazonas.

A qualidade da matéria-prima, os aspectos socioculturais e a demanda de mercado são fatores considerados positivos e estratégicos à fibra, uma vez que têm chamado a atenção de turistas, ONGs (Organizações NãoGovernamentais), Institutos de Investigações Tecnológicas e Empresas do ramo industrial (Menezes, Pinheiro, Guazzell, \& Martins, 2005).

Grande parte da potencialidade econômica da matéria-prima encontra-se nas folhas, com a extração de fibras de alta resistência, utilizadas para o desenvolvimento de produtos artesanais (Miranda, 2001).

A fibra de tucumã-i (Astrocaryum acaule) também conhecida como tucum, é um fio resistente, podendo ser utilizado de várias maneiras de acordo com a necessidade econômica. Além da produção de fios, a fibra ainda viabiliza a confecção de tecidos (Figura 2), dos quais são fabricados produtos como: redes, bolsas, esteiras, toalhas de mesa, descansos para pratos, tapetes, capas, cortinas, mantas, chapéus, acessórios e, etc (Maciel, 2007). 

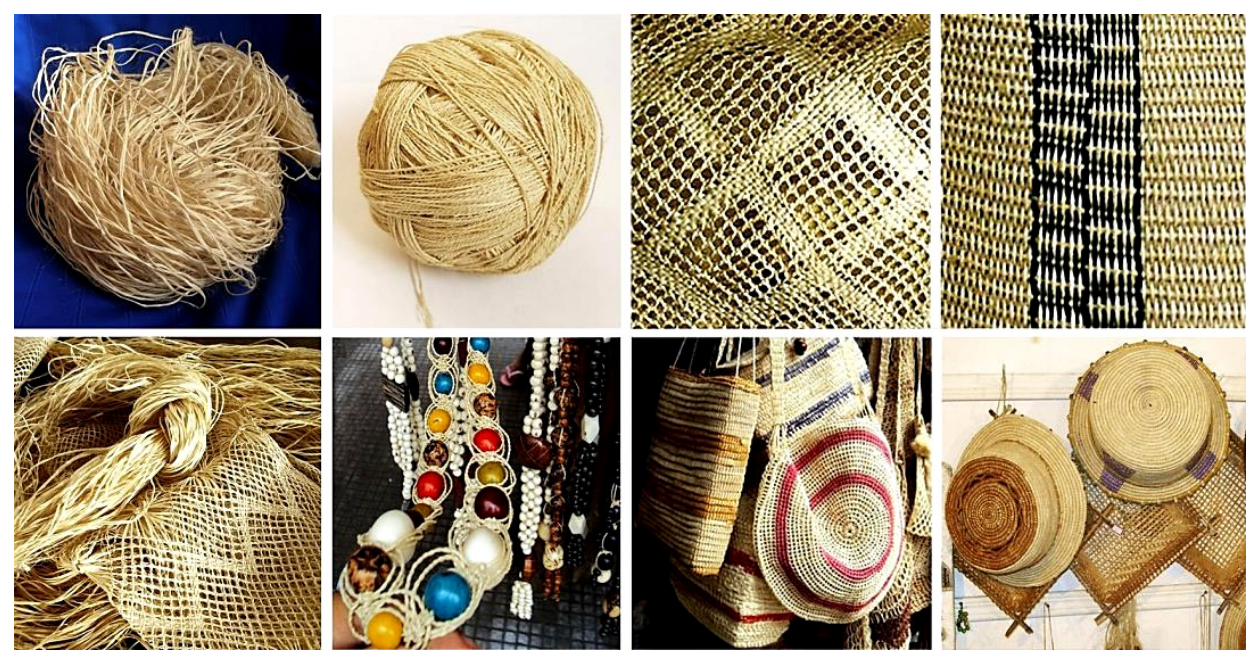

A5_Figura 2. Fibra, fio, tecidos e alguns produtos de tucumã-i (Astrocaryum acaule).

Sua estrutura vegetal apresenta propriedades tecnológicas compatíveis à produção têxtil (Tabela 1), com aspecto ecológico, uma vez que é biodegradável e sua obtenção e produção não demandam processos químicos de alto custo ambiental (Maciel, 2008).

A5_Tabela 1. Propriedades tecnológicas da fibra de tucumã-i (Astrocaryum acaule) compatíveis à produção têxtil

\begin{tabular}{|c|c|c|}
\hline Características & Itens & Dados \\
\hline \multirow{3}{*}{ Organolépticas } & Cheiro e gosto & $\rightarrow$ indistintos \\
\hline & Aparência & $\rightarrow$ brilho natural e tom amarelado \\
\hline & Textura & $\begin{array}{l}\rightarrow \text { lisa, macia e alinhada em direção às } \\
\text { pontas }\end{array}$ \\
\hline \multirow{2}{*}{ Físicas } & Densidade & $\begin{array}{l}\rightarrow \text { satisfatória com resultado igual a } 1.49 \\
\mathrm{~g} / \mathrm{cm}^{3}\end{array}$ \\
\hline & $\begin{array}{l}\text { Teor de } \\
\text { umidade }\end{array}$ & $\begin{array}{l}\rightarrow \text { padrão desejável com variação entre } \\
11,82 \% \text { e } 11,59 \%\end{array}$ \\
\hline Químicas & Toxidade & $\rightarrow$ índice nulo para reação tóxica \\
\hline Mecânicas & Resistência & $\begin{array}{l}\rightarrow \text { resistente a lavagem a seco ou a base de } \\
\text { água e sabão }\end{array}$ \\
\hline
\end{tabular}




$\begin{array}{ll} & \left.\rightarrow \text { resistente ao calor (máximo a } 200^{\circ} \mathrm{C}\right) \\ & \rightarrow \text { resistente à tração com variação em } \\ & \text { média de } 18 \mathrm{~kg} / \mathrm{cm} 2 \\ \text { Elasticidade } & \rightarrow \text { boa elasticidade, não apresenta casos de } \\ & \text { rompimentos bruscos } \\ \text { Flexibilidade } & \rightarrow \text { boa flexibilidade em testes de manuseio } \\ & \text { e desdobramento da fibra }\end{array}$

Fonte: Adaptado de Maciel (2007)

De acordo com Maciel (2008), esses dados foram comparados com outros produtos similares, conforme os parâmetros referentes às legislações cabíveis à produção têxtil estabelecido pelo Instituto de Pesos e Medidas de São Paulo (IPEM/SP), a fibra vegetal amazônica apresentou aspectos tecnológicos compatíveis à produção de tecidos naturais, inclusive, com valores próximos aos identificados na fibra de algodão e, ainda, destacou-se com um número de informações significativas quanto aos critérios relacionados à: cor, cheiro, gosto, textura, teor de umidade e toxidade, quando comparada ao sisal e à juta.

Apesar das vantagens, é compreensível que para a fibra formar parte da relação das matérias-primas vegetais, devidamente preparadas ao uso, processo de fabricação e comercialização de produtos - sobretudo têxtil, se faz necessário desenvolver um estudo que possa aprimorar tais benefícios, canalizando-os em prol de torná-la um produto de grande diferencial para o mercado.

Um estudo que identifique, compreenda e sistematize informações, para auxiliar na evolução do vegetal - considerando os princípios artesanais e empíricos observados em seu universo, poderá reunir e construir dados científicos que justifiquem o seu processo de adaptação ao uso e fabricação de novos produtos a um contexto mais elevado - nesse caso o semi-industrial, podendo validar a inovação e o diferencial por ela oferecidos.

\subsection{Processos de gestão e fabricação de produtos adaptados à tecnologia semi-industrial}

Quando a sondagem de opiniões retrata o interesse sobre o uso ou a concepção de um novo produto para o mercado, podemos perceber que as necessidades e exigências dos consumidores são grandes, uma vez que, a satisfação do cliente é derivada da proximidade entre as expectativas do comprador e o desempenho percebido do produto (Kotler, 2005).

Um produto bem planejado e eficiente compreende a adequada relação entre os processos de gestão e fabricação, coerentemente, adaptados às tecnologias 
Estudio de la prospección del uso de la fibra de tucumã-i (Astrocaryum acaule) para el desarrollo de productos semi-industriales

com estratégia de operações claras, abrangentes e de caráter ecosustentável. Todos esses, de modo a fazer parte de uma ação (processo) que recebe uma entrada (input), transforma (agregando valor) e gera uma saída (output), onde tanto o produto quanto o serviço possui valores agregados, com a finalidade de atender às expectativas do cliente (Harrington, 1993).

Faria (1992), ressalta que transformar os insumos em produtos é uma função da tecnologia, que deve ser compreendida como o conjunto de conhecimentos aplicados a um determinado tipo de atividade e não apenas às máquinas. Essa atividade contempla a troca de conhecimento técnico (transferências de tecnologia), utilizado no desenvolvimento de novos produtos ou processos, entre os indivíduos ou as organizações envolvidas, sendo ou podendo estar incorporado em equipamentos de produção ou em produtos manufaturados (Mt. Auburn Associates, 1995).

Segundo Lopes \& Bezerra (2008), é nesse contexto que a gestão, participa como é um fator base para a melhoria contínua das tecnologias produtivas, que amplia os níveis de eficiência, reduz as perdas e maximiza os lucros, possibilitando medir o desempenho do processo através de indicadores e verificando a evolução gerada pelas melhorias. Exercer atividades, cuja gestão e a tecnologia estão focadas na fabricação de produtos e/ou na prestação de serviços, implica trabalhar com um processo de negócios (Gonçalves, 2000).

Diante disso, promover um produto com características artesanais - mas com aspectos tecnológicos favoráveis para o uso têxtil, a um nível de qualidade mais elevado e que satisfaça as expectativas dos consumidores sem comprometer a sua essência vegetal, a identidade cultural e o conhecimento dos indivíduos que trabalham com a matéria-prima, requer uma atenção maior quanto ao emprego da tecnologia adequada.

Para tanto, sugere-se o processo semi-industrial como uma ponte entre os conhecimentos artesanais e industriais que possa contribuir para a evolução do recurso vegetal em estudo, de modo a levá-lo a um posicionamento significativo dentro do mercado, aprimorando as suas etapas de produção com o apoio de ferramentas e métodos não rudimentares como moldes e instrumentos, qualificando sua estrutura e acabamento final, como forma de estabelecer uma padronização propícia a uma linha de gestão e de fabricação para novos produtos.

\section{Procedimentos Metodológicos}

A pesquisa é de caráter descritivo, exploratório e explicativo utilizando técnicas quantitativas e qualitativas baseadas em pesquisa bibliográfica e documental (Gil, 2002). 
Para identificar o perfil dos consumidores e o seu posicionamento quanto ao uso semi-industrial da fibra vegetal amazônica de tucumã-i (Astrocaryum acaule) para o desenvolvimento de novos produtos, foram coletados dados a partir da aplicação de um questionário, construído em blocos temáticos obedecendo a uma ordem lógica na elaboração das perguntas, cujo roteiro contém perguntas abertas (respostas livres), fechadas (duas opções), e de múltipla escolha (fechada com uma série de respostas possíveis), apresentando um total de 33 questões, elaboradas a partir de temas relevantes apontados na literatura e da necessidade da obtenção e construção de informações para o tema proposto.

A seleção dos entrevistados foi aleatória, buscando cobrir os potenciais consumidores em termos de produtos a base de fibras naturais vegetais, assim a aplicação do questionário foi realizada via internet e teve como princípio técnico o uso do conceito "bola de neve" evidenciada por Bailey (1992), o qual sugere estabelecer alguns contatos iniciais na comunidade de interesse e esses contatos passam a indicar outros e assim em diante, de forma a construir redes de informantes. A técnica proporcionou uma interação efetiva entre os informantes e a pesquisa.

O procedimento foi realizado num prazo de dois meses, considerando o tempo para aplicação do questionário, a tabulação das informações por meio de suporte computacional, o armazenamento das questões e suas respostas em um banco de dados e para a análise dos resultados, sendo iniciado no mês de agosto de 2010. A amostra foi composta por 408 entrevistados (273 mulheres e 135 homens), sendo a maioria de nacionalidade brasileira e pertencente à cidade de Manaus, com idades variando de 20 a 73 anos.

Portanto, para a presente publicação, que é parte de um estudo de tese de doutorado, foram explorados os resultados de sete questões do documento aplicado com os consumidores sobre o uso semi-industrial da fibra de tucumã-i (Astrocaryum acaule) para a fabricação de produtos, em consonância com os objetivos do artigo e observando os seguintes aspectos: 1. Perfil dos consumidores; 2. Apreciação das fibras naturais vegetais para fabricação de produtos; 3. Consumo de produtos feitos com fibras vegetais; 4. Razão atribuída ao uso de produtos desenvolvidos com fibras vegetais; 5. Aprovação da inserção de novas fibras vegetais no mercado de produtos; 6. Aceitação da fibra de tucumã-i (Astrocaryum acaule) para o uso semi-industrial em produtos; 7. Variáveis consideradas importantes para o uso semi-industrial da fibra tucumã-i (Astrocaryum acaule) em produtos.

Os dados quantitativos foram organizados e analisados a partir da distribuição de freqüência, tabelas de contingencia - verificando o nível de significância 
das variáveis estudadas, através do teste Qui-quadrado $=X 2 \rightarrow(\mathrm{p} \leq 0,05)$, e cálculo de médias.

\section{Análise dos Resultados}

\subsection{Perfil dos consumidores}

A amostra com 408 entrevistados apresentou como nacionalidade dominante, a brasileira ( $n=395 ; 96,8 \%$ ) e teve a cidade de Manaus, capital do Amazonas, como a localidade com o maior número de participantes $(n=324 ; 79,4 \%)$. 0 público feminino foi dominante $(n=273 ; 66,9 \%)$, enquanto que a representatividade masculina foi menor $(n=135 ; 33,1 \%)$.

A elevada participação feminina se dá em função do Brasil possuir 3,9 milhões de mulheres a mais que homens e a cidade de Manaus apresentar um número maior de habitantes do sexo feminino $(n=922,2 ; 51,18 \%)$ quando comparado ao número de habitantes do sexo masculino $(n=879,7 ; 48,8 \%)$, de acordo com os dados do IBGE (2010). A faixa etária identificada no universo amostral varia de 20 a 73 anos.

No entanto, foram os consumidores de 24 a 29 anos de idade que representaram a grande maioria dos consultados $(n=120 ; 29,4 \%)$. 0 nível de escolaridade teve maior concentração na categoria de diplomados e pósgraduados ( $n=130 ; 31,94 \%)$. Quanto à renda familiar, foi observado que $77,9 \%$ $(n=318)$ apresenta um ingresso mensal de mais de 5 salários-mínimos (SM). No que se refere ao estado civil, prevaleceram as pessoas solteiras $(n=261 ; 64 \%)$, seguidas dos consumidores casados ( $n=125 ; 30,6 \%$ ).

A situação ocupacional mostrou-se dividida em três grandes grupos distintos: empresários $(n=125 ; 30,6 \%)$, profissionais do design $(n=117 ; 28,7)$ e, por fim, estudantes $(n=73 ; 17,9 \%)$.

\subsection{Apreciação do uso das fibras naturais vegetais para a fabricação de produtos}

Quando questionados sobre o uso das fibras naturais vegetais para a fabricação de produtos, os entrevistados apresentaram um nível de apreciação bem alto e através deste posicionamento foi possível observar melhor o perfil desse tipo de consumidor (Tabela 2). 


\section{A5_Tabela 2. Nível de apreciação do uso das fibras vegetais para o desenvolvimento de produtos}

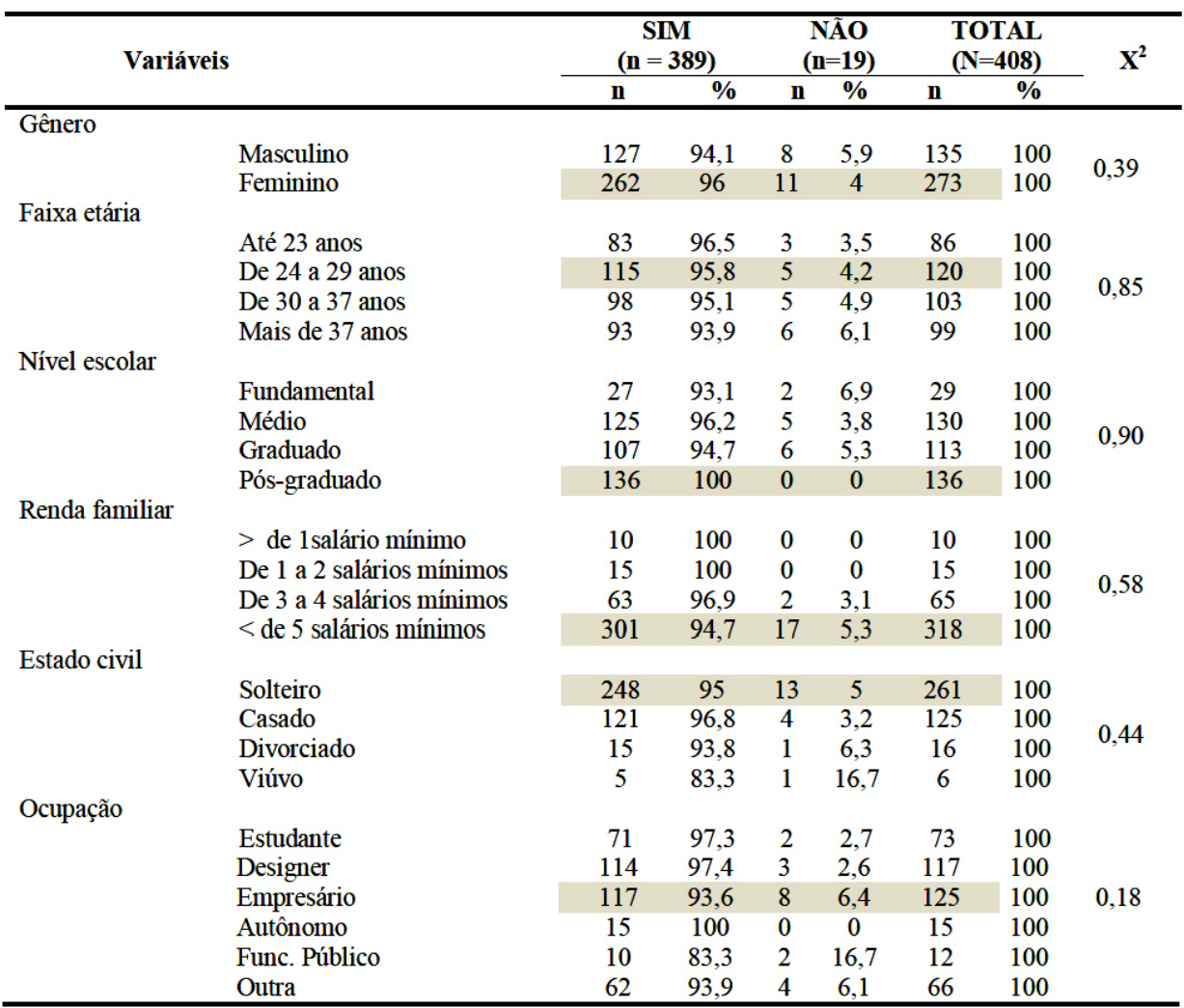

Fonte: Autores

Em relação ao item questionado, o público feminino mostrou-se predominante $(n=262 ; 96 \%)$. Os consumidores com idade de 24 a 29 anos foram os que mais demonstraram apreciam 0 uso das fibras naturais vegetais para 0 desenvolvimento de produtos ( $n=115 ; 95,8 \%)$.

Os entrevistados com pós-graduação representaram o nível de escolaridade com maior número de apreciação e com porcentagem total em relação ao número de seus integrantes $(n=136 ; 100 \%)$. A renda familiar identificada foi superior a cinco salários mínimos ( $\mathrm{n}=301 ; 94,7 \%)$.

Quanto ao estado civil dos consumidores, os solteiros foram a maioria $(n=248$; 95\%) e como ocupação profissional, os empresários foram os mais favoráveis $(\mathrm{n}=117 ; 93,6 \%)$ ao uso das fibras vegetais para o desenvolvimento de produtos. Com respeito às variáveis observadas, sobre a questão avaliada, não há um 
nível de significância estatística $\rightarrow X 2 \rightarrow(p \leq 0,05)$, ou seja, a apreciação do uso das fibras vegetais para a fabricação de produtos não se diferenciou segundo o sexo, faixa etária, nível de escolaridade, renda familiar, estado civil ou ocupação, na amostra estudada.

\subsection{Consumo de produtos desenvolvidos com as fibras vegetais}

A maior parte dos consumidores, além de apreciar o uso das fibras vegetais em produtos, também demonstrou - com um número bastante alto de participantes, que consume esse tipo de produto (Tabela 3).

A5_Tabela 3. Nível de consumo de produtos desenvolvidos com fibras vegetais

\begin{tabular}{lcc}
\hline Opinião & Quantidade & Percentual \\
\hline Sim & 331 & $81,1 \%$ \\
Não & 77 & $18,9 \%$ \\
Total & 408 & $100 \%$ \\
\hline
\end{tabular}

Fonte: Autores

No universo amostral analisado, o consumo de produtos desenvolvidos a partir do uso das fibras vegetais pelos consumidores é bem elevado $(n=331 ; 81,1 \%)$. Foi observado que apenas $18,9 \%$ dos entrevistados não utilizam produtos com essa característica específica.

\subsection{Razão e valor atribuído ao uso de produtos desenvolvidos com as fibras vegetais}

A justificativa, pelo alto consumo de produtos desenvolvidos com as fibras vegetais, é atribuída aos vários tipos de artigos produzidos a partir dessas matérias-primas (Tabela 4).

A5_Tabela 4. Razão atribuída ao uso de produtos feitos com as fibras vegetais

\begin{tabular}{lcc}
\hline Motivo & Quantidade & Percentual \\
\hline Preço & 37 & $9,1 \%$ \\
Variedade & 286 & $70,1 \%$ \\
Textura & 10 & $2,5 \%$ \\
Não é interessante & 41 & $10 \%$ \\
Outras & 34 & $8,3 \%$ \\
Total & 408 & $100 \%$ \\
\hline
\end{tabular}

Fonte: Autores 
Os entrevistados consideraram o fator 'variedade' $(n=286 ; 70,1 \%)$ um elemento diferencial e ao mesmo tempo estimulante para o consumo de produtos nesse segmento. Segundo eles, a quantidade de itens e as inúmeras formas de aplicação das fibras vegetais oferecidas no mercado, se constituem num leque de alternativas que desperta o interesse dos consumidores.

Com esse posicionamento sobre o consumo e a razão, os participantes afirmaram acreditar que o uso desse tipo de produto possui um valor extremamente significativo (Tabela 5).

A5_Tabela 5. Valoração atribuída ao uso de produtos feitos com as fibras vegetais

\begin{tabular}{lcc}
\hline Valor & Quantidade & Percentual \\
\hline Pouco importante & 11 & $2,7 \%$ \\
Importante & 89 & $21,8 \%$ \\
Muito importante & 116 & $28,4 \%$ \\
Bastante importante & 192 & $47,1 \%$ \\
Total & 408 & $100 \%$ \\
\hline
\end{tabular}

Fonte: Autores

De acordo com a amostra analisada, a maior parte dos entrevistados $(n=192$; $47,1 \%$ ) consideraram ser 'bastante importante' 0 uso de produtos desenvolvidos com as fibras vegetais.

O grau de importância atribuído corresponde não somente ao fator 'variedade', mas também se justifica pelo fato dos produtos fabricados com as matérias-primas naturais vegetais apresentarem baixo custo tecnológico, ser eco-eficientes, diferenciados, inovadores, resistente e ainda possuírem a capacidade de oferecer conforto e qualidade aos seus consumidores.

\subsection{Aprovação da inserção de novas fibras vegetais no mercado de produtos}

Os níveis de aceitação do uso das fibras vegetais para o desenvolvimento de produtos e de consumo desses produtos deixaram bem claro o posicionamento positivo dos entrevistados. Da mesma forma, os participantes demonstraram estar de acordo com a inserção de novas matérias-primas para uso no mercado de produtos (Tabela 6). 
Estudio de la prospección del uso de la fibra de tucumã-i (Astrocaryum acaule) para el desarrollo de productos semi-industriales

A5_Tabela 6. Razão atribuída ao uso de produtos feitos com as fibras vegetais

\begin{tabular}{lcc}
\hline Opinião & Quantidade & Percentual \\
\hline Sim & 405 & $99,3 \%$ \\
Não & 3 & $0,7 \%$ \\
Total & 408 & $100 \%$ \\
\hline
\end{tabular}

Fonte: Autores

Segundo o universo amostral, o índice de aprovação apresentou um número bem elevado por parte dos consumidores consultados ( $n=405 ; 99,3 \%$ ).

Os entrevistados acreditam que novas fibras vegetais para o mercado de produtos podem oferecer boas e mais vantagens para o seu processo produtivo; para o alcance de benefícios socio-econômicos - como geração de emprego e renda; para o aprimoramento tecnológico, para o lançamento de novas categorias de uso e fabricação de novos produtos.

4.6 Aceitação do uso semi-industrial da fibra natural amazônica de tucumã-i (Astrocaryum acaule) para a fabricação de produtos

0 grau de aceitação sobre o uso semi-industrial do objeto de estudo proposto foi bastante elevado. 0 perfil dos consumidores, identificado em um primeiro momento - durante o questionamento sobre o nível de apreciação do uso das fibras vegetais para o desenvolvimento de produtos, permaneceu o mesmo.

No entanto, os números de aprovação demonstrados para este quesito foram maiores (Tabela 7), devido os participante terem considerado alguns dos aspectos importantes já identificados na fibra em estudo, como: a presença de características tecnológicas propícias à fabricação de produtos, a prática tradicional e reconhecida no uso artesanal, o forte valor da denominação de origem - matéria-prima amazônica e as novas possibilidades para aplicação, nas mais variadas categorias de produtos, e para o alcance de novos mercados. 
A5_Tabela 7. Nível de aceitação do uso das fibras vegetais para o desenvolvimento de produtos

\begin{tabular}{|c|c|c|c|c|c|c|c|c|}
\hline \multirow{2}{*}{\multicolumn{2}{|c|}{ Variáveis }} & \multirow{2}{*}{\multicolumn{2}{|c|}{$\begin{array}{c}\text { SIM } \\
(n=406)\end{array}$}} & \multirow{2}{*}{\multicolumn{2}{|c|}{$\begin{array}{l}\text { NÃO } \\
(\mathbf{n}=2)\end{array}$}} & \multirow{2}{*}{\multicolumn{2}{|c|}{$\begin{array}{l}\text { TOTAL } \\
(\mathrm{N}=408)\end{array}$}} & \multirow[t]{2}{*}{$\mathbf{X}^{2}$} \\
\hline & & & & & & & & \\
\hline \multirow{2}{*}{\multicolumn{9}{|c|}{ Gênero }} \\
\hline & & & & & & & & \\
\hline & Masculino & 135 & 100 & 0 & 0 & 135 & 100 & \multirow{2}{*}{0,31} \\
\hline \multicolumn{2}{|l|}{ Faixa etária } & 271 & 99,3 & 2 & 0,7 & 273 & 100 & \\
\hline & Até 23 anos & 85 & 98,8 & 1 & 1,2 & 86 & 100 & \multirow{4}{*}{0,55} \\
\hline & De 24 a 29 anos & 119 & 99,2 & 1 & 0,8 & 120 & 100 & \\
\hline & De 30 a 37 anos & 103 & 100 & 0 & 0 & 103 & 100 & \\
\hline & Mais de 37 anos & 99 & 100 & 0 & 0 & 99 & 100 & \\
\hline \multicolumn{9}{|l|}{ Nível escolar } \\
\hline & Fundamental & 29 & 100 & 0 & 0 & 29 & 100 & \multirow{4}{*}{0,84} \\
\hline & Médio & 129 & 99,2 & 1 & 0,8 & 130 & 100 & \\
\hline & Graduado & 112 & 99,1 & 1 & 0,9 & 113 & 100 & \\
\hline & Pós-graduado & 136 & 100 & 0 & 0 & 136 & 100 & \\
\hline \multicolumn{9}{|l|}{ Renda familiar } \\
\hline & $>$ de 1salário mínimo & 10 & 100 & 0 & 0 & 10 & 100 & \multirow{4}{*}{0,90} \\
\hline & De 1 a 2 salários mínimos & 15 & 100 & 0 & 0 & 15 & 100 & \\
\hline & De 3 a 4 salários mínimos & 65 & 100 & 0 & 0 & 65 & 100 & \\
\hline & $<$ de 5 salários mínimos & 316 & 99,4 & 2 & 0,6 & 318 & 100 & \\
\hline \multicolumn{9}{|l|}{ Estado civil } \\
\hline & Solteiro & 259 & 99,2 & 2 & 0,8 & 261 & 100 & \multirow{4}{*}{0,76} \\
\hline & Casado & 125 & 100 & 0 & 0 & 125 & 100 & \\
\hline & Divorciado & 16 & 100 & 0 & 0 & 16 & 100 & \\
\hline & Viúvo & 6 & 100 & 0 & 0 & 6 & 100 & \\
\hline \multicolumn{9}{|l|}{ Ocupação } \\
\hline & Estudante & 73 & 100 & 0 & 0 & 73 & 100 & \multirow{6}{*}{0,72} \\
\hline & Designer & 116 & 99,1 & 1 & 0,9 & 117 & 100 & \\
\hline & Empresário & 125 & 100 & 0 & 0 & 125 & 100 & \\
\hline & Autônomo & 15 & 100 & 0 & 0 & 15 & 100 & \\
\hline & Func. Público & 12 & 100 & 0 & 0 & 12 & 100 & \\
\hline & Outra & 65 & 98,5 & 1 & 1,5 & 66 & 100 & \\
\hline
\end{tabular}

Fonte: Autores

Portanto, analisando o posicionamento dos consumidores para este quesito, foi observado que: a representatividade feminina continuou como maioria $(\mathrm{n}=271 ; 93, \%)$. Todavia, o número de participação masculina apresentou um acréscimo e com uma porcentagem total de aprovação $(n=135 ; 100 \%)$ da fibra de tucumã-i (Astrocaryum acaule) para o uso semi-industrial em produtos. A faixa etária de 24 a 29 anos, considerada a maior dentro do universo amostral, também apresentou acréscimos em números de participação $(n=119 ; 99,2 \%)$, da mesma forma os consumidores que possuem pós-graduação $(n=136 ; 100 \%)$, eles fizeram parte do nível de escolaridade com maior número de participantes e com porcentagem de aceitação total para o questionamento feito. A renda familiar identificada foi superior a cinco salários mínimos $(n=316 ; 99,4 \%)$. O estado civil com maior destaque foi composto pelos consumidores solteiros $(n=259 ; 99,2 \%)$. Os empresários demonstraram ser o 
grupo com maior aprovação sobre o tema proposto $(n=125 ; 100 \%)$, inclusive com uma porcentagem total de aceitação, em números de participantes representados. De acordo com o quesito analisado, as variáveis observadas não apresentaram um nível de significância estatística $\rightarrow X 2 \rightarrow(p \leq 0,05)$, ou seja, a aceitação do uso semi-industrial da fibra natural amazônica de tucumã-i (Astrocaryum acaule) para a fabricação de produtos, não se diferenciou segundo o sexo, faixa etária, nível de escolaridade, renda familiar, estado civil ou ocupação, na amostra estudada.

\subsection{Aspectos considerados importantes para o uso semi-industrial da fibra de tucumã-i (Astrocaryum acaule) em produtos.}

Os participantes também opinaram sobre quais fatores devem ser considerados indispensáveis para o processo e a utilização semi-industrial da fibra (Tabela 8). Segundo eles, é preciso que a matéria-prima ofereça vantagens relacionadas à essência do objeto, às propriedades físicas e mecânicas e ao meio ambiente.

A5_Tabela 8. Aspectos considerados importantes para o uso semi-industrial do objeto de estudo

\begin{tabular}{lr}
\hline Aspectos & Total (Médias) \\
\hline Qualidade do material & 3,38 \\
Resistência & 3,31 \\
Aspecto biodegradável & 3,24 \\
Conforto & 3,23 \\
Durabilidade & 3,13 \\
Outras & 3,10 \\
\hline
\end{tabular}

Fonte: Autores

Sendo assim, os entrevistados consideraram como 'muito importantes' todas os aspectos apresentados (médias > 3) . No entanto, numa escala de 1 a 4 onde 1 significa 'pouco importante' e 4 'bastante importante', o fator 'qualidade do material' foi o mais relevante e deve ser o elemento prioritário a ser respeitado $(m=3,38)$, sendo reforçado pelos fatores de 'resistência' $(m=3,31)$ e 'biodegradável' $(m=3,24)$. Para o universo amostral, um estudo focado sobre tais aspectos poderá preparar melhor a fibra para o seu correto uso semi-industrial, garantindo a fabricação de produtos diferenciados e apropriados para essa segmentação de mercado e ainda oferecendo benefícios aos seus consumidores. 


\section{Considerações Finais}

Este artigo apresentou uma sondagem de opiniões sobre o uso semi-industrial da fibra vegetal amazônica de tucumã-i (Astrocaryum acaule) para o desenvolvimento de produtos. 0 universo amostral foi composto por consumidores de produtos fabricados com fibras vegetais. A partir de dados bibliográficos e outras investigações iniciais foi possível desenvolver e aplicar um questionário para verificar o grau de aceitação dos participantes sobre o tema abordado. A técnica aplicada auxiliou no processo de identificação do perfil dos consumidores e a análise das opiniões considerou uma alta aceitação da fibra de tucumã-i (Astrocaryum acaule) como uma nova opção de matéria-prima vegetal a ser utilizada no mercado de produtos - não somente artesanais.

De acordo com as informações identificadas, o público alvo para usufruir os produtos semi-industriais a serem fabricados a partir desse recurso natural, poderá ser: mulheres solteiras com faixa etária entre 24 e 29 anos, de nível superior completo, recebendo mais de 5 salários mínimos e com a ocupação profissional focada para empresas. Para esse tipo de consumidor, que demonstrou ser a maioria, os produtos confeccionados a partir das fibras vegetais, além de serem considerados muito importante por apresentarem eco-eficiência e aspectos biodegradáveis, também oferecem uma grande variedade de artigos, que podem contemplar desde os acessórios até os itens para decoração.

Especificamente à fibra de tucumã-i (Astrocaryum acaule), o público entrevistado ressalta que a matéria-prima necessita de um preparo tecnológico que reforce os seus valores intrínsecos e garanta a qualidade do material de modo a favorecer tanto a sua inserção quanto o seu uso no mercado dos produtos semi-industriais e, ainda, de forma à beneficiar os seus futuros consumidores.

\section{Referências}

AGUIAR NETO, P. P. Fibras têxteis. v. 1. Rio de Janeiro: SENAI-CETIQT, 1996.

BAILEY, K. D. Methods of Social Research. McMillan. Nova York, EEUU. 553pp., 1992.

BLEDZKI, A. K. \& GASSAN, J. Composites reinforced with cellulose based fibres.Progress in Polymer, Science Elsevier Sci., v.24, p.221-272, 1999.

CHAMPAGNE, Patrick. Formar opinião: o novo jogo político. Petrópolis: Vozes, 1998. 
Estudio de la prospección del uso de la fibra de tucumã-i (Astrocaryum acaule) para el desarrollo de productos semi-industriales

COOPER, R. G. Winnig at New Products. Addison-Wesley Publishing Company, 1993.

FARIA, J. H. Tecnologia e Processo de Trabalho. Curitiba: UFPR, 1992

GONÇALVES, J. E. L. As Empresas São Grandes Coleções de Processos. RAE Revista de Administração de Empresas. , v. 40, n.1, p. 6-19, Jan./mar. 2000.

GUIMARÃES, M. et al. Caracterização anatômica da fibra de bambu (Bambusa vulgaris) visando sua utilização em compósitos poliméricos. Revista Iberoamericana de Polímeros 11(7), 442-456 SLAP, 2010.

HARRINGTON, H. J. Aperfeiçoando Processos Empresariais. São Paulo: Makron Books, 1993.

INSTITUTO BRASILEIRO DE GEOGRAFIA E ESTATÍSTICA. Dados do censo Demográfico no ano de 2010.

KOTLER, PHILIP. Marketing essencial: conceitos, estratégias e casos. 2 ed. São Paulo: Prentice Hall, 2005.

LOPES, MARCO AURÉLIO B. et al. Gestão de processos: fatores que influenciam o sucesso na sua implantação. XXVIII Encontro Nacional de Engenharia de Produção. Rio de Janeiro, 2008.

MACIEL, K. M. F. Estudo da Viabilidade Técnica da Fibra de Tucumã-i (Astrocaryum acaule) para Produção de Tecido a ser utilizado na Indústria de Confecções. Dissertação (Mestrado em Ciências Florestais e Ambientais). Universidade Federal do Amazonas - UFAM, Manaus -Amazonas, 2007.

MACIEL, K. M. F. Technical Viability of Tucumã-i Fibre (Astrocaryum acaule) for Production in Textile Industry. ECOWOOD 2008, 3 rd International Conference \& Exhibition on Environmentally-compatible forest products. Univerdidade Fernado Pessoa. Oporto, Portugal, 2008.

MARINELLI, ALESSANDRA L. et al. Desenvolvimento de Compósitos Poliméricos com Fibras Vegetais Naturais da Biodiversidade: Uma Contribuição para a Sustentabilidade Amazônica.Polímeros: Ciência e Tecnologia, vol. 18, n² 2, p. 92-99, 2008.

MENDES, T. M. F. F. Propriedades de resistência à tração e ao impacto de compósitos poliéster sisal - Um estudo comparativo. Dissertação de mestrado, UFRN, 123p., Natal, 1992.

MENEZES, M. R. et al. Cadeia produtiva das fibras vegetais extrativistas no estado do Amazonas. Governo do Estado do Amazonas - Manaus: SDS. Série Técnica. Meio Ambiente e Desenvolvimento Sustentável, 4.32p.; il., 2005. 
MIRANDA, IRES PAULA DE ANDRADE. Frutos e Palmeiras da Amazônia. Ministério da Ciência e Tecnologia (MCT). Instituto Nacional de Pesquisas da Amazônia (INPA). Manaus - Amazonas - Brasil, 2001.

MT. AUBURN ASSOCIATES. Technology Transfer to Small Manufactures: A Literature Review. Relatório final. Somerville, 1995.

SOUZA, HERMES MOREIRA DE. et al. Palmeiras brasileiras e exóticas cultivadas. Nova Odessa. São Paulo: Instituto Platarum, 2004.

TAKAHASHI, S. \& TAKAHASHI, V. P. Gestão de inovação de produtos: estratégia, processo, organização e conhecimento. Rio de Janeiro: Editora Campus, 2007. 



\subsection{Artículo 6 - Fibra vegetal amazónica de tucumã-i (Astrocaryum acaule) para la aplicación textil: Un análisis de opiniones}

Esta producción científica ha sido realizada con la intención de obtener informaciones sobre qué tipo de categoría de uso y de producto son considerados interesantes por los consumidores para la aplicación semiindustrial de la fibra (Publicación en portugués). El artículo corresponde al sub-objetivo 2 del objetivo 2 de la tesis (Pags.67, 68,69 y 70).

Revista: ACTA AGRONÓMICA Indexada: PUBLINDEX | Factor de Impacto: 0.034

ISSN: $0120-2812$

Enviado: 22.0ctubre.11 | En evaluación

Cita: Pacheco, K. M. M.; Vicente, B. A.; Pacheco, A. S.; Ortuño, B. H.; Paixão-Barradas, S. (XXXX). Fibra vegetal amazônica de tucumã-i (Astrocaryum acaule) para a aplicação têxtil: Uma análise de opiniões. Revista Acta Agronómica. Universidad Nacional de Colombia. Palmira - Colombia.

Fibra vegetal amazônica de tucumã-i (Astrocaryum acaule) para a aplicação têxtil: Uma análise de opiniões

Amazon's vegetal fiber of tucumã-i (Astrocaryum acaule) for textile applications: An opinions analysis's.

Karla Mazarelo Maciel Pacheco', Begoña Agudo Vicente ${ }^{2}$, Almir de Souza Pacheco $^{2}$, Bernabé Hernandis Ortuño ${ }^{2}$, Susana Paixão-Barradas ${ }^{2}$

${ }^{1}$ Departamento de Design e Expressão Gráfica (DEG), Faculdade de Tecnologia (FT), Universidade Federal do Amazonas (UFAM). Av. General Rodrigo Octávio Jordão Ramos, 3000, Campus Universitário, Coroado I. CEP: 69077-000. Manaus (AM), Brasil.

${ }^{2}$ Departamento de Ingeniería Gráfica. Universitat Politècnica de València (UPV). Camino de Vera, s/n. CP: 46022. Valencia, España.

Autor para correspondência: karlamazarelo@hotmail.com

\section{Resumo}

Este trabalho descreve uma análise de opinião de consumidores com respeito ao uso da fibra vegetal amazônica de tucumã-i (Astrocaryum acaule) para a sua aplicação semi-industrial têxtil. A pesquisa buscou saber quais dos segmentos de mercado: vestuário, acessório, decoração, têxtil para o lar e automóvel seria a mais apropriada ao tema. A partir da categoria escolhida, verificou-se o tipo de produto a ser desenvolvido e as características 
Estudio de la prospección del uso de la fibra de tucumã-i (Astrocaryum acaule) para el desarrollo de productos semi-industriales

tecnológicas que este deve oferecer como vantagens aos seus futuros consumidores. Foi aplicado um questionário e os dados analisados através de freqüências, nível de significância e cálculo de médias. Como resultados, o vestuário foi considerado a melhor forma para comunicar e divulgar as tendências e os novos recursos naturais em potencial ao uso comercial; a blusa foi assinalada como um produto estratégico para o bom posicionamento da matéria-prima no mercado e; a textura, a resistência, a toxidade e a durabilidade da fibra foram as características consideradas vantajosas à composição do produto final. Por fim, para o sucesso do uso semi-industrial têxtil da fibra, é importante observar os valores intrínsecos da matéria-prima, de forma a garantir a qualidade do produto e favorecer o diferencial e a inovação por ela proporcionados.

Palavras-chave: Fibra natural, Uso Semi-industrial, Desenvolvimento de Produto, Apreciação do Consumidor.

Abstract

This paper describes an opinion's consumer analysis about using of the Amazon vegetal fiber of tucumã-i (Astrocaryum acaule) for its textile semi-industrial application. The research sought to know which market segments: apparel, accessories, decor, textiles for the home and automobiles would be more appropriate to the subject. From the category chosen, it was identified the type of product being developed, as well as the technological features that should offer some advantages to future consumers. A questionnaire was applied and the data analyzed using frequencies, level of significance and calculation of averages. As a result, the clothing was considered the best way to communicate and disseminate trends and new natural resources potential for commercial use; the blouse was noted as a strategic product for the better raw material positioning in the market and, the texture, resistance, toxicity and durability of the fiber characteristics were considered advantageous to the final product composition. Finally, for successful of the textile semiindustrial application of this fibre, is very important to note the intrinsic values of the raw material, to ensure product quality and foster the differential and the innovation offered by it.

Keywords: Natural fibre, Semi-industrial use, Product development, Consumer appreciation.

\section{Introdução}

De acordo com Oashi (1998), os recursos naturais vegetais são considerados muito vantajosos para o mercado de produtos e ainda podem ser mais valorizados, uma vez que o avanço tecnológico tem mostrado que o uso das fibras naturais já não pode ficar limitado apenas às aplicações tradicionais. 0 
motivo se dá em função de apresentarem baixa densidade, serem renováveis, biodegradáveis, recicláveis e menos abrasivas aos equipamentos de processamento quando comparadas com outros recursos, o que thes permite competir com alguns materiais fósseis e industrializados (Leão, 1997). Sob esses aspectos e com o intuito de divulgar mais as pesquisas e trabalhos realizados com as matérias-primas da Amazônia brasileira, o artigo trabalha com informações sobre a fibra vegetal de tucumã-i (Astrocaryum acaule), uma espécie proveniente de palmeira nativa bastante utilizada para a confecção de produtos artesanais (Souza, 2004) e que segundo Miranda (2001), apresenta grande potencialidade econômica centrada nas folhas, de modo a proporcionar fibras de alta resistência (Figura 01).
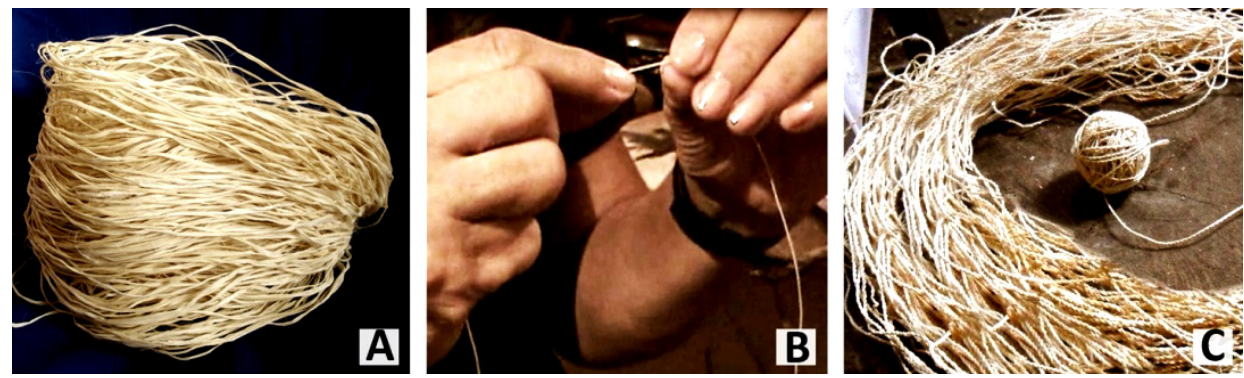

A6_Figura 1. A - Fibra de tucumã-i (Astrocaryum acaule) in natura; B transformada em fio e; $\mathrm{C}$ - em forma de novelo e linhas.

A palmeira usada para a produção da fibra ocorre, em grande parte, na região do Alto Rio Negro, estado do Amazonas (norte do Brasil), onde a coleta extrativa, voltada para o uso e consumo, é autossustentada e não predatória, sendo realizada por comunidades indígenas e caboclas, as quais são consideradas como as maiores conhecedoras e consumidoras da matéria-prima (Maciel K. M., 2008). A qualidade da matéria-prima, os aspectos socioculturais, a demanda de mercado e os resultados das suas aplicações em produtos vêm chamando a atenção de turistas, ONGs (Organizações NãoGovernamentais) e empresas. Outros fatores importantes também estão sendo atribuídos à fibra de tucumã-i (Astrocaryum acaule) de modo a torná-la mais competitiva à gestão e fabricação de produtos semi-industriais, proporcionando assim o alcance de novos mercados (Pacheco, 2011a). A vantagem de ser uma matéria-prima natural, produzida de forma sustentável, gerando emprego e renda para as suas comunidades produtoras, possuir características inovadoras e, mostrar-se disponível e em abundância para atender às limitações dadas à confecção de produtos ecologicamente 
Estudio de la prospección del uso de la fibra de tucumã-i (Astrocaryum acaule) para el desarrollo de productos semi-industriales

corretos, faz do objeto de estudo um recurso em potencial para a realização de novos experimentos, o que implica no seu possível emprego semi-industrial uma vez que possui propriedades tecnológicas compatíveis para tal e ainda apresenta uma grande facilidade e variedade para a aplicação em produtos (Figura 02).
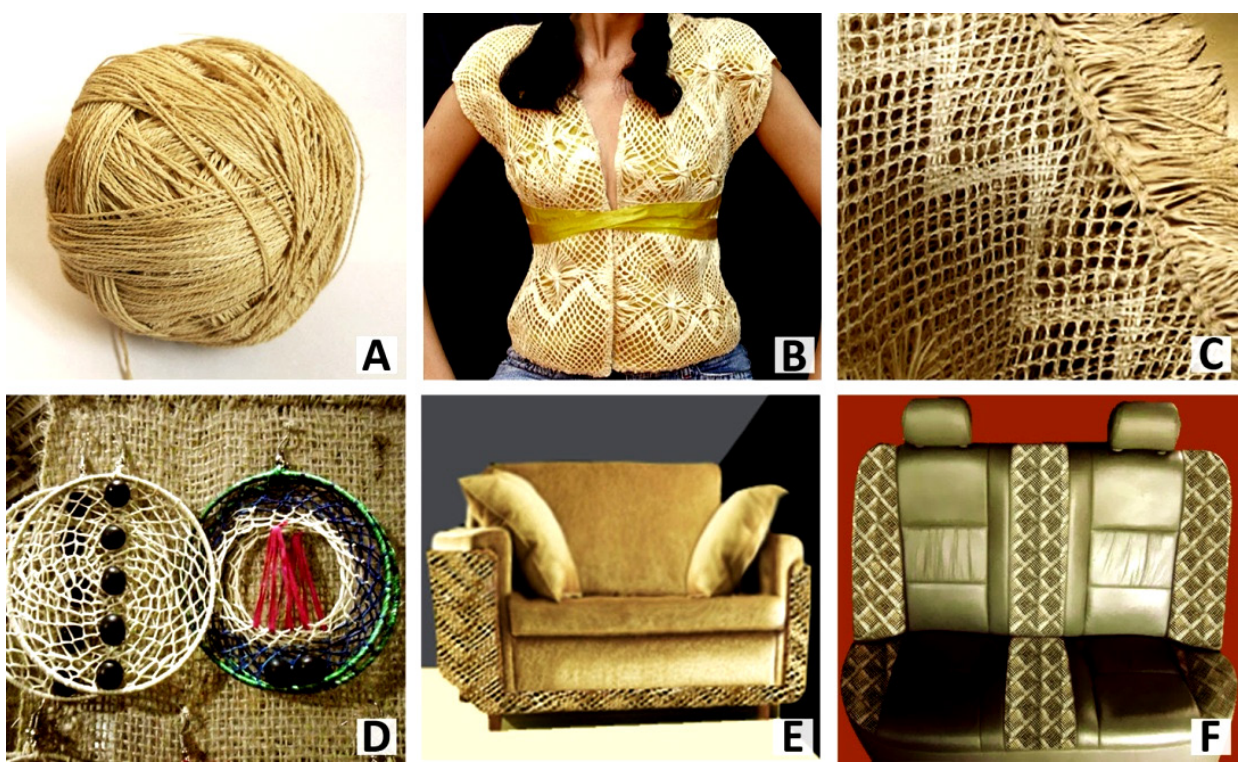

A6_Figura 2. A - Fibra de tucumã-i (Astrocaryum acaule) processada em fios para o desenvolvimento de produtos; $B$ - Fibra aplicada em vestuário $C$ - Fibra aplicada em tecido decorativa; D - Fibra aplicada em acessórios; E - Fibra simulada para aplicação em têxteis para estofamento de veículos.

$\mathrm{Na}$ busca de relacionar essas informações juntamente a um estudo de mercado, o qual se concentra no anseio e nas opiniões dos consumidores, tendo em vista contribuírem para a continuidade da investigação sobre a metodologia do desenvolvimento de produto, a partir da aplicação semiindustrial da fibra de tucumã-i (Astrocaryum acaule), que possa reduzir riscos e intervalos para a sua utilização, o presente estudo contempla os seguintes objetivos:

- Observar dentre os segmentos de mercado: vestuário, acessório, decoração, têxtil para o lar e automóvel, é o mais apropriado à aplicação semi-industrial têxtil da fibra vegetal amazônica de tucumã-i (Astrocaryum acaule);

- Verificar que tipo de produto, de acordo com a categoria escolhida pelos consumidores, pode ser desenvolvido para o tema proposto; 
- Analisar quais as características tecnológicas que o produto final deve oferecer como vantagens para o mercado e para os seus futuros consumidores;

- Relacionar o perfil dos consumidores com o segmento têxtil indicado (categoria de uso).

\section{Material e método}

o estudo é de caráter descritivo e explicativo utilizando técnicas quantitativas e qualitativas baseadas em pesquisa bibliográfica e documental (Gil, 2002). Os dados foram coletados dados a partir da aplicação de um questionário, cujo roteiro apresentou perguntas abertas (respostas livres), fechadas (duas opções), e de múltipla escolha (fechada com uma série de respostas possíveis), constituído por um total de 33 questões. A seleção dos entrevistados foi aleatória, buscando cobrir os potenciais consumidores em termos de produtos a base de fibras naturais vegetais, assim o questionário foi disponibilizado e preenchido via internet e teve como princípio técnico o uso do conceito "bola de neve", evidenciado por Bailey (1992), o qual sugere estabelecer alguns contatos iniciais na comunidade de interesse e esses contatos passam a indicar outros e assim em diante, de forma a construir redes de informantes. A técnica proporcionou uma interação efetiva entre os informantes e a pesquisa. O prazo para a obtenção das informações foi de, aproximadamente, dois meses (agosto a outubro de 2010), incluindo a tabulação das informações por meio de suporte computacional, o armazenamento das questões e suas respostas em um banco de dados. 0 universo amostral foi composto por 408 entrevistados (273 mulheres e 135 homens), de nacionalidade brasileira e pertencente à cidade de Manaus, com idades variando de 20 a 73 anos. Para a presente publicação, que é parte de um estudo de tese de doutorado, foram analisados os resultados de dez questões do documento aplicado com os consumidores, todas em consonância com os objetivos do trabalho e observando os seguintes aspectos: 1. Categoria de uso; 2. Tipo de produto; 3. Características tecnológicas e; 4. Perfil dos consumidores. Os dados quantitativos foram organizados e analisados a partir da distribuição de freqüência; tabelas de contingencia, verificando o nível de significância em função de $X 2 \rightarrow(p \leq 0,05)$; e cálculo de médias.

\section{Resultados e discussões}

\subsection{Categorias de uso (Segmento de mercado)}

Quando questionados sobre a categoria de uso ideal para o emprego semiindustrial têxtil da fibra de tucumã-i (Astrocaryum acaule), os consumidores 
Estudio de la prospección del uso de la fibra de tucumã-i (Astrocaryum acaule) para el desarrollo de productos semi-industriales

acreditam que a fibra possua características inovadoras e capacitadas para o uso em variados segmentos de mercado, sobretudo de vestuário (Tabela 1).

A6_Tabela 1. Categoria Selecionada Pelos Entrevistados

\begin{tabular}{l|ll}
\hline Categoria de uso & Frequência & Porcentagem \\
\hline Vestuário & 149 & $36,5 \%$ \\
Decorativo & 99 & $24,3 \%$ \\
Acessório & 89 & $21,8 \%$ \\
Têxtil lar & 54 & $13,2 \%$ \\
Automóvel & 17 & $4,2 \%$ \\
TOTAL & 408 & $100 \%$ \\
\hline
\end{tabular}

Fonte: Autores

A maior parte dos entrevistados ( $n=149 ; 36,5 \%$ ) elegeram o vestuário por ser uma forma de melhor representar os elementos simbólicos, semânticos, estéticos e significativos da fibra, e também por se trata uma interface que relaciona o corpo humano e o meio natural e cultural, proporcionando múltiplas finalidades, onde através de uma estrutura bem projetada - por conceito, material e técnicas que possam representar a idéia - poderá divulgar informações que destaquem os atributos identificados no objeto em estudo.

\subsection{Tipo de produto}

Em relação ao tipo de produto a ser desenvolvido, de acordo com a categoria de uso selecionada, os consumidores nomearam a blusa (Tabela 2 ).

A6_Tabela 2. Produto escolhido para a aplicação semi-industrial da fibra de tucumã-i (Astrocaryum Acaule)

\begin{tabular}{l|ll}
\hline Tipo de produto & Frequiência & Porcentagem \\
\hline Blusa & 141 & $34,6 \%$ \\
Sapato & 80 & $19,6 \%$ \\
Calça & 73 & $17,9 \%$ \\
Saia & 71 & $17,4 \%$ \\
Roupa praia & 43 & $10,5 \%$ \\
TOTAL & 408 & $100 \%$ \\
\hline
\end{tabular}

Fonte: Autores

Todos os itens pertencentes à categoria de vestuário foram bem aceitos pelo universo amostral. Entretanto, grande parte dos entrevistados $(n=141$; $34,6 \%$ ) optou pela blusa por se tratar de um elemento com maiores possibilidades para aplicações criativas, diferenciadas, inovadoras e, inclusive, para o processo de divulgação dos valores intrínsecos identificados 
na fibra de tucumã-i (Astrocaryum acaule) e para o bom posicionamento desta no mercado.

\subsection{Características tecnológicas para a fabricação do produto}

Os consumidores definiram, de acordo com as variáveis analisadas: vestuário e blusa, as principais características tecnologias a serem consideradas para o processo de aplicação semi-industrial da fibra. Tais propriedades foram avaliadas como positivas por apresentarem a media $\geq 3$, numa escala de 1 a 4 - onde 1 significa 'pouco importante' e 4 'bastante importante' (Tabelas 03, 04 e 05).

A6_Tabela 3. Características organolépticas denominadas pelos consumidores

\begin{tabular}{|c|c|c|c|c|c|c|c|c|c|c|c|c|}
\hline \multirow{3}{*}{ VARIÁVEIS } & \multicolumn{12}{|c|}{ CARACTERÍSTICAS TECNOLÓGICAS - ORGANOLÉPTICAS } \\
\hline & \multicolumn{2}{|c|}{ Suavidade } & \multicolumn{2}{|c|}{ Textura } & \multicolumn{2}{|c|}{ Aparência } & \multicolumn{2}{|c|}{ Brilho } & \multicolumn{2}{|c|}{ Cor } & \multicolumn{2}{|c|}{ Cheiro } \\
\hline & $\mathrm{m}$ & $\mathrm{X}^{2}$ & $\mathrm{~m}$ & $\mathrm{X}^{2}$ & $\mathrm{~m}$ & $\mathrm{X}^{2}$ & $\mathrm{~m}$ & $\mathrm{X}^{2}$ & $\mathrm{~m}$ & $\mathrm{X}^{2}$ & $\mathrm{~m}$ & $\mathrm{X}^{2}$ \\
\hline \multicolumn{13}{|l|}{ Vestuário } \\
\hline Blusa & 3.12 & 0,485 & 3.23 & $0,005^{* *}$ & 3,07 & 0,004 & 3,01 & 0,236 & 3,10 & 0,092 & 3,00 & 0,565 \\
\hline
\end{tabular}

${ }^{* *}$ Altamente significativo $(p<0,01)$. Fonte: Autores

Com respeito às características organolépticas, os entrevistados determinaram a 'textura' como o aspeto primordial a ser evidenciado no processo $(m=3,23 ; \mathrm{X} 2=0,004)$, por ser um dos atributos visuais mais atrativo e interessante na composição da fibra de tucumã-i (Astrocaryum acaule), além de prevalecer na percepção do material e poder revelar ao indivíduo a função da sua superfície através do bom emprego das tramas que irão fortalecer a estrutura do produto final. A variável também demonstrou um nível estatístico altamente significativo a $(p<0,01)$.

A6_Tabela 4. Características mecânicas denominadas pelos consumidores

\begin{tabular}{|c|c|c|c|c|c|c|c|c|c|c|c|c|}
\hline \multirow{3}{*}{ VARIÁVEIS } & \multicolumn{12}{|c|}{ CARACTERÍSTICAS TECNOLÓGICAS - MECANICAS } \\
\hline & \multicolumn{2}{|c|}{ Resistência } & \multicolumn{2}{|c|}{ Elasticidade } & \multicolumn{2}{|c|}{ Espessura } & \multicolumn{2}{|c|}{ Ruptura } & \multicolumn{2}{|c|}{ Lavar } & \multicolumn{2}{|c|}{ Secar } \\
\hline & $\mathrm{m}$ & $\mathrm{X}^{2}$ & $\mathrm{~m}$ & $\mathrm{X}^{2}$ & $\mathrm{~m}$ & $\mathrm{X}^{2}$ & $\mathrm{~m}$ & $\mathrm{X}^{2}$ & $\mathrm{~m}$ & $\mathrm{X}^{2}$ & $\mathrm{~m}$ & $\mathrm{X}^{2}$ \\
\hline \multicolumn{13}{|l|}{ Vestuário } \\
\hline Blusa & 3.41 & 0,079 ns & 3.18 & 0,779 & 3,16 & 0,202 & 3,35 & 0,416 & 3,21 & 0,044 & 3,24 & 0,023 \\
\hline
\end{tabular}

ns - Não significativo $(p>0,05)$. Fonte: Autores

No que se refere às características mecânicas, a 'resistência' foi o componente considerado como o mais importante $(\mathrm{m}=3,41 ; \mathrm{X} 2=0,079)$, que deve ser avaliado junto às etapas de adaptação dos fios, formação das tramas e produção do tecido que servirá de estrutura para o desenvolvimento do produto final, e ser constatado que apresenta vantagens em relação à tração, 
Estudio de la prospección del uso de la fibra de tucumã-i (Astrocaryum acaule) para el desarrollo de productos semi-industriales

ao calor, ao tempo, ao desgaste, à corrosão, à torção, aos tipos de tecnologias semi-industriais - a serem utilizadas durante a adequação da fibra em produto, entre outros.

No entanto, em relação ao nível estatístico, a variável não demonstrou ser significante por apresentar $(\mathrm{p}>0,05)$.

A6_Tabela 5. Características físico-químicas denominadas pelos consumidores

\begin{tabular}{rcccc}
\hline VARIÁvEIS & \multicolumn{2}{c}{$\begin{array}{c}\text { CARACTERÍSTICAS TECNOLÓGICAS - FISICO/QUÍMICAS } \\
\text { Umidade }\end{array}$} & \multicolumn{2}{c}{ Toxidade } \\
\cline { 2 - 5 } & $\mathrm{m}$ & $\mathrm{X}^{2}$ & $\mathrm{~m}$ & $\mathrm{X}^{2}$ \\
\cline { 1 - 4 } $\begin{array}{r}\text { Vestuário } \\
\text { Blusa }\end{array}$ & 3,01 & 0,004 & 3,33 & $0,080^{\mathrm{ns}}$ \\
\hline
\end{tabular}

ns - Não significativo $(p>0,05)$. Fonte: Autores

Em relação às características físico-químicas os consumidores apontaram a toxidade como um aspecto 'muito importante' a ser observado na fibra $(m=3,33 ; X 2=0,080)$, principalmente, por se tratar de uma estrutura que estará em contato com o corpo do usuário, quando transformada em vestuário.

Nesse caso, é fundamental que a fibra passe por uma sequência de experimentos químicos e físicos que possam diagnosticar a ausência de elementos tóxicos em sua composição evitando, assim, danos futuros ao uso da matéria-prima em artigos relacionados à segmentação escolhida. Todavia, a toxidade não apresentou um nível de significância estatística compatível a $(p \leq 0,05)$.

\subsection{Aspectos tecnológico para a certificação do produto}

Quanto aos critérios de certificação, os consumidores consideraram todos os itens relacionados como 'muito importantes' (com média $\geq 3$ ) numa escala de 1 a 4 - onde 1 significa 'pouco importante' e 4 'bastante importante'.

Todavia, os aspectos de: 'durabilidade', 'biodegradável', 'conforto' e, mais uma vez, 'resistência', foram os que obtiveram maiores valorações (Tabela 6).

A6_Tabela 6. Aspectos tecnológicos e de certificação do produto considerados pelos consumidores

\begin{tabular}{l|l}
\hline Aspectos & Total (Médias) \\
\hline
\end{tabular}




\begin{tabular}{l|l}
\hline Conforto & 3,33 \\
Segurança & 3,14 \\
Durabilidade & 3,36 \\
Qualidade do material & 3,24 \\
Denominação de origem & 3,16 \\
Biodegradável & 3,34 \\
Ecológico & 3,11 \\
Reciclável & 3,00 \\
Resistência & 3,32 \\
\hline
\end{tabular}

Fonte: Autores

A 'durabilidade' foi o aspecto com maior valor $(m=3,36)$ em relação aos demais critérios observados, por ser considerado um fator diretamente relacionado ao planejamento e à fabricação dos produtos que necessitam ser sustentáveis, rentáveis e atrativos para os produtores e consumidores, apresentando como diferencial o prolongamento da vida útil desses produtos, diminuindo a renovação, preservando a matéria-prima, limitando os impactos sobre o meio ambiente e tornando-se mais competitivo no mercado.

\subsection{Perfis dos consumidores quanto à categoria de uso escolhida}

De acordo com o universo amostral analisado em função da categoria de uso, para o vestuário, o número de opiniões passou a concentrar 149 dos 408 indivíduos consultados (Tabela 7). 
Estudio de la prospección del uso de la fibra de tucumã-i (Astrocaryum acaule) para el desarrollo de productos semi-industriales

A6_Tabela 7. Perfil dos consumidores em relação à categoria de uso

\begin{tabular}{|c|c|c|c|c|c|c|c|c|c|c|c|c|}
\hline \multirow[t]{3}{*}{ VARIÁVEIS } & \multicolumn{12}{|c|}{ CATEGORIAS DE USO } \\
\hline & \multicolumn{2}{|c|}{ Vestuário } & \multicolumn{2}{|c|}{ Decorativo } & \multicolumn{4}{|c|}{ Acessório Têxtil lar } & \multicolumn{2}{|c|}{ Automóvel } & \multicolumn{2}{|c|}{ TOTAL } \\
\hline & $\mathrm{n}$ & $\%$ & $\mathrm{n}$ & $\%$ & $\mathrm{n}$ & $\%$ & $\mathrm{n}$ & $\%$ & $\mathrm{n}$ & $\%$ & $\mathrm{n}$ & $\%$ \\
\hline \multicolumn{13}{|l|}{ Gênero $\left(X^{2}=0,060\right)^{\text {ns }}$} \\
\hline Masculino & 49 & $32,9 \%$ & 34 & $34,3 \%$ & 25 & $28,1 \%$ & 16 & $29,6 \%$ & 11 & $64,7 \%$ & 135 & $33,1 \%$ \\
\hline Feminino & 100 & $67,1 \%$ & 65 & $65,7 \%$ & 64 & $71,9 \%$ & 38 & $70,4 \%$ & 6 & $35,3 \%$ & 273 & $66,9 \%$ \\
\hline Total & 149 & $100 \%$ & 99 & $100 \%$ & 89 & $100 \%$ & 54 & $100 \%$ & 17 & $100 \%$ & 408 & $100 \%$ \\
\hline \multicolumn{13}{|l|}{ Idade $\left(X^{2}=0,416\right)^{n s}$} \\
\hline até 23 anos & 29 & $19,5 \%$ & 19 & $19,2 \%$ & 22 & $24,7 \%$ & 12 & $22,2 \%$ & 4 & $23,5 \%$ & 86 & $21,1 \%$ \\
\hline De 24 a 29 anos & 45 & $30,2 \%$ & 25 & $25,3 \%$ & 30 & $33,7 \%$ & 14 & $25,9 \%$ & 6 & $35,3 \%$ & 120 & $29,4 \%$ \\
\hline De 30 a 37 anos & 47 & $31,5 \%$ & 22 & $22,2 \%$ & 18 & $20,2 \%$ & 13 & $24,1 \%$ & 3 & $17,6 \%$ & 103 & $25,2 \%$ \\
\hline$>37$ anos & 28 & $18,8 \%$ & 33 & $33,3 \%$ & 19 & $21,3 \%$ & 15 & $27,8 \%$ & 4 & $23,5 \%$ & 99 & $24,3 \%$ \\
\hline Total & 149 & $100 \%$ & 99 & $100 \%$ & 89 & $100 \%$ & 54 & $100 \%$ & $1 \overline{7}$ & $100 \%$ & 408 & $100 \%$ \\
\hline \multicolumn{13}{|l|}{ Est. civil $\left(\mathrm{X}^{2}=0,858\right)^{\mathrm{ns}}$} \\
\hline Solteiro (a) & 97 & $65,1 \%$ & 60 & $60,6 \%$ & 62 & $69,7 \%$ & 30 & $55,6 \%$ & 12 & $70,6 \%$ & 261 & $64 \%$ \\
\hline Casado (a) & 46 & $30,9 \%$ & 31 & $31,3 \%$ & 23 & $25,8 \%$ & 20 & $37 \%$ & 5 & $29,4 \%$ & 125 & $30,6 \%$ \\
\hline Divorciado (a) & 5 & $3,4 \%$ & 5 & $5,1 \%$ & 3 & $3,4 \%$ & 3 & $5,6 \%$ & 0 & $0 \%$ & 16 & $3,9 \%$ \\
\hline Viúvo (a) & 1 & $0,7 \%$ & 3 & $3 \%$ & 1 & $1,1 \%$ & 1 & $1,9 \%$ & 0 & $0 \%$ & 6 & $1,5 \%$ \\
\hline Total & 149 & $100 \%$ & 99 & $100 \%$ & 89 & $100 \%$ & 54 & $100 \%$ & 17 & $100 \%$ & 408 & $100 \%$ \\
\hline \multicolumn{13}{|c|}{ Escolaridade $\left(X^{2}=0,364\right)^{n s}$} \\
\hline Ens. Fundament. & 10 & $6,7 \%$ & 9 & $9,1 \%$ & 7 & $7,9 \%$ & 3 & $5,6 \%$ & 0 & $0 \%$ & 29 & $7,1 \%$ \\
\hline Ens. Médio & 47 & $31,5 \%$ & 23 & $23,2 \%$ & 37 & $41,6 \%$ & 17 & $31,5 \%$ & 6 & $35,6 \%$ & 130 & $31,9 \%$ \\
\hline Graduação & 38 & $25,5 \%$ & 27 & $27,3 \%$ & 27 & $30,3 \%$ & 15 & $27,8 \%$ & 6 & $35,3 \%$ & 113 & $27,7 \%$ \\
\hline Pós-graduação & 54 & $36,3 \%$ & 40 & $40,4 \%$ & 18 & $20,2 \%$ & 19 & $35,1 \%$ & 5 & $29,1 \%$ & 136 & $33,3 \%$ \\
\hline Total & 149 & $100 \%$ & 99 & $100 \%$ & 89 & $100 \%$ & 54 & $100 \%$ & $1 \frac{\underline{7}}{77}$ & $100 \%$ & 408 & $100 \%$ \\
\hline \multicolumn{13}{|c|}{ Ocupação $\left(X^{2}=0,342\right)^{\text {ns }}$} \\
\hline Estudante & 30 & $20,1 \%$ & 11 & $11,1 \%$ & 20 & $22,5 \%$ & 9 & $16,7 \%$ & 3 & $17,6 \%$ & 73 & $17,9 \%$ \\
\hline Designer & 46 & $30,9 \%$ & 28 & $28,3 \%$ & 19 & $21,3 \%$ & 18 & $33,3 \%$ & 6 & $35,3 \%$ & 117 & $28,7 \%$ \\
\hline sário & 36 & $24,2 \%$ & 37 & $37,4 \%$ & 34 & $38,2 \%$ & 15 & $27,8 \%$ & 3 & $17,6 \%$ & 125 & $30,6 \%$ \\
\hline Autônomo & 12 & $8 \%$ & 6 & $6 \%$ & 5 & $5,6 \%$ & 3 & $5,5 \%$ & 1 & $6 \%$ & 27 & $6,6 \%$ \\
\hline Outra & 25 & $16,8 \%$ & 17 & $17,2 \%$ & 11 & $12,4 \%$ & 9 & $16,7 \%$ & 4 & $23,5 \%$ & 66 & $16,2 \%$ \\
\hline Total & 149 & $100 \%$ & 99 & $100 \%$ & 89 & $100 \%$ & 54 & $100 \%$ & 17 & $100 \%$ & 408 & $100 \%$ \\
\hline \multicolumn{13}{|c|}{ Proventos $\left(X^{2}=0,245\right)^{\mathrm{ns}}$} \\
\hline < 1 salário & 6 & $4 \%$ & 0 & $\%$ & 3 & $3,4 \%$ & 1 & $1,9 \%$ & 0 & $0 \%$ & 10 & $2,5 \%$ \\
\hline De 1 a 2 salários & 8 & $5,4 \%$ & 2 & $\%$ & 3 & $3,4 \%$ & 2 & $3,7 \%$ & 0 & $0 \%$ & 15 & $3,7 \%$ \\
\hline De 3 a 4 salários & 23 & $15,4 \%$ & 15 & $\%$ & 20 & $22,5 \%$ & 7 & $13 \%$ & 0 & $0 \%$ & 65 & $15,9 \%$ \\
\hline > 5 salários & 112 & $75,2 \%$ & 82 & $\%$ & 63 & $70,8 \%$ & 44 & $81,5 \%$ & 17 & $100 \%$ & 318 & $77,9 \%$ \\
\hline Total & 149 & $100 \%$ & 99 & $100 \%$ & 89 & $100 \%$ & 54 & $100 \%$ & 17 & $100 \%$ & 408 & $100 \%$ \\
\hline
\end{tabular}

ns - Não significativo $(p>0,05)$. Fonte: Autores

Neste contexto, o público feminino foi maioritário $(n=100 ; 67,1 \%)$, quando comparado à representatividade masculina, que foi menor $(n=49 ; 32,9 \%)$. A elevada participação feminina se dá em função do Brasil possuir 3,9 milhões de mulheres a mais que homens e a cidade de Manaus apresentar um número maior de habitantes do sexo feminino $(n=922,2 ; 51,18 \%)$ quando comparado ao número de habitantes do sexo masculino $(n=879,7 ; 48,8 \%)$, de acordo com Pacheco et al (2011b). A faixa etária de 30 a 37 anos apresentou um número maior ( $n=47 ; 31,5 \%$ ) de entrevistado em relação aos demais grupos etários identificados. No entanto, os consumidores de 24 a 29 anos também se 
mostraram fortes na composição da amostra. Em relação ao estado civil, os solteiros compõem a maior parte dos indivíduos entrevistados ( $n=97 ; 65,1 \%$ ), e em seguida estão os casados $(n=46 ; 30,9 \%)$. O nível escolar dos participantes apresentou um número significativo representado por aqueles que possuem pós-graduação $(n=54 ; 36,3 \%)$, e um pouco mais atrás destes estavam os consumidores com a formação no ensino médico completa $(n=47$; $31,5 \%)$. A ocupação profissional teve como ênfase os designers $(n=46 ; 30,9 \%)$, e em seguida as opiniões fornecidas por empresários $(n=36 ; 24,2 \%)$. $E$, por último, a renda familiar identificada mostrou-se superior a cinco salários mínimos ( $\mathrm{n}=112 ; 75,2 \%)$.Conforme as variáveis observadas, não existe um nível de significância estatística bastante relevante a $(\mathrm{p} \leq 0,05)$, ou seja, o perfil dos consumidores em relação à categoria escolhida não demonstrou alguma diferencia segundo o gênero, a idade, o estado civil, a escolaridade, a ocupação ou proventos, na amostra estudada.

\section{Conclusão}

Este artigo apresentou uma análise das opiniões sobre a aplicação semiindustrial têxtil da fibra vegetal amazônica de tucumã-i (Astrocaryum acaule). Os consumidores consideraram que a fibra possui características inovadoras e capacitadas para o uso nos mais variados tipos de segmentações do mercado, sobretudo têxtil, atribuindo ao vestuário o maior número aceitação, por se tratar de um veículo de comunicação capaz de divulgar os novos recursos naturais em potencial para o uso comercial e, à blusa um produto com grandes possibilidades para aplicações criativas, diferenciadas, inovadoras e estratégicas para o alcance de um bom posicionamento da matéria-prima no mercado.

Dos aspectos tecnológicos apresentados o público optou: pela textura, por ser um dos aspectos visuais da fibra que mais chama e se tratar da superfície que formará parte da construção das tramas do vestuário; a resistência, como fator essencial para o emprego semi-industrial da fibra na constituição do produto final, uma vez que está diretamente relacionado à estrutura dos materiais; a toxidade como elemento a ser averiguado de modo à aplicação da fibra em produtos para fins comerciais e; a durabilidade como aspecto de certificação para auxiliar na preservação na matéria-prima e minimizar os impactos causados ao meio ambiente.

O estudo evidencia que os valores intrínsecos da fibra em paralelo a potencialização de suas características tecnológicas devem garantir a qualidade do produto final, favorecendo o diferencial $e$ a inovação proporcionados por ela, para o alcance de novos mercados e o benefício de seus futuros consumidores. 
Estudio de la prospección del uso de la fibra de tucumã-i (Astrocaryum acaule) para el desarrollo de productos semi-industriales

\section{Referências}

1. Bailey, K. D. 1992. Methods of Social Research. McMillan. Nova York, EEUU. 553p.

2. Gil, A.C. 2002. Como elaborar projetos de pesquisa. 4.ed. São Paulo: Atlas. 176p.

3. Leão, A. L. 1997. Viabilidade técnica da produção de compósitos nãoestruturais à base de lignocelulósicos. Tese (Livre Docência em Recursos Naturais Renováveis). Universidade Estadual Paulista - UNESP. Botucatu - SP.

4. AUTOR. 2008. Estudo da viabilidade técnica da fibra do tucumã-i (Astrocaryum acaule) para a produção têxtil. XXVIII Encontro Nacional de Engenharia de Produção (ENEGEP). Rio de Janeiro - RJ. Disponível em: http://www.abepro.org.br/biblioteca/enegep2008_TN_STO_077_540_10943.p df [Revisão data: 12 de março de 2009].

5. Miranda, I .P. A. 2001. Frutos e Palmeiras da Amazônia. Ministério da Ciência e Tecnologia (MCT). Instituto Nacional de Pesquisas da Amazônia (INPA). Manaus - AM.

6. Oashi, M. C. G. 1998. Estudo da cadeia produtiva como subsídio da pesquisa e desenvolvimento do agronegócio do sisal na Paraíba. Tese (Doutorado de Engenharia de Produção). Universidade Federal de Santa Catarina - UFSC. Florianópolis - SC.

7. AUTOR. 2011a. Oportunidades e limitações do uso da fibra natural de tucumã-i (Astrocaryum acaule) para a gestão e desenvolvimento de produtos semi-industriais. Anais do $8^{\circ}$ Congresso Brasileiro de Gestão de Desenvolvimento de Produto (CBGDP). UFRGS/FEEng. Porto Alegre - RS. Disponível em: http://www.ufrgs.br/cbgdp2011/downloads/9230.pdf [Revisão data: 06 de outubro de 2011].

8. AUTOR. 2011b. Análise da apreciação de consumidores sobre o uso semiindustrial da fibra vegetal amazônica de tucumã-i (Astrocaryum acaule) para o desenvolvimento de produtos: Um estudo de mercado. Revista INGEPRO Inovação, Gestão e Produção Setembro de 2011, vol. 03, no. 09. Disponível em: http://ingepro.com.br/ [Revisão data: 02 de outubro de 2011].

9. Souza, H. M. D. et al. 2004. Palmeiras brasileiras e exóticas cultivadas. Nova Odessa. São Paulo: Instituto Platarum. São Paulo - SP. 


\subsection{Artículo 7 - Atributos necesarios a la fabricación de productos semi-industriales a partir del uso de la fibra natural amazónica de tucumã-i (Astrocaryum acaule): Una segmentación de mercado}

Esta producción científica ha sido realizada con la intención de segmentar el mercado y obtener informaciones sobre los atributos considerados necesarios, por los consumidores potenciales, para la fabricación de productos semiindustriales a partir de la fibra natural en estudio (Publicación en portugués). El artículo corresponde al sub-objetivo 3 del objetivo 2 de la tesis (Pags.67, 68,69 y 70 ).

Revista: GESTÃO \& PRODUÇÃO

Indexada: SciELO - Scientific Electronic Library Online

Factor de Impacto: 0.1485

ISSN: 0104-530X

Enviado: 24.Noviembre.11 | En evaluación

Cita: Pacheco, K. M. M.; Vicente, B. A.; Ortuño, B. H.; Paixão-Barradas, S.; Pacheco, A. S.; Castro. D. F. (XXXX). Atributos necessários à fabricação de produtos semi-industriais a partir do uso da fibra natural amazônica de tucumã-i (Astrocaryum acaule): Uma segmentação de mercado. Revista Gestão \& Produção. Universidade de São Carlos - UFSCar. São Carlos/São Paulo - Brasil.

Atributos necessários à fabricação de produtos semi-industriais a partir do uso da fibra natural amazônica de tucumã-i (Astrocaryum acaule): Uma segmentação de mercado

Karla Mazarelo Maciel Pacheco ${ }^{1}$, Begoña Agudo Vicente ${ }^{2}$, Bernabé Hernandis Ortuño ${ }^{2}$, Susana Paixão-Barradas ${ }^{2}$, Almir de Souza Pacheco ${ }^{2}$ e Daniel Ferreira de Castro ${ }^{1}$

${ }^{1}$ Universidade Federal do Amazonas (UFAM). Av. General Rodrigo Octávio Jordão Ramos, 3000, Campus Universitário, Coroado I. CEP: 69077-000. Manaus (AM), Brasil.

${ }^{2}$ Universitat Politècnica de València (UPV). Camino de Vera, s/n. CP: 46022.

Valencia, España. E-mails: karlamazarelo@hotmail.com; bego.agudo.vicente@gmail.com; bhernand@degi.upv.es;

supaipe@upvnet.upv.es; almirdesigner@gmail.com; dan.mao@hotmail.com

Resumo: Este artigo apresenta os atributos considerados necessários à fabricação de produtos semi-industriais, a partir do uso da fibra vegetal amazônica de tucumã-i (Astrocaryum acaule). Os dados foram obtidos por 
Estudio de la prospección del uso de la fibra de tucumã-i (Astrocaryum acaule) para el desarrollo de productos semi-industriales

meio da aplicação de questionário e analisados através do estudo de aglomeração hierárquica, cálculo de medias, frequências, nível de significância e classificação do perfil dos consumidores. Dos resultados alcançados, a técnica de agrupamento baseada no método Ward, gerou até 6 grupos de consumidores distintos, dos quais foi escolhida a aglomeração com 4 grupos, sendo cada um deles classificado conforme o perfil dos consumidores. 0 grupo identificado como 'com interesse' ajudou a definir a segmentação de mercado, por apresentar o maior número de participantes (219 indivíduos) com homogeneidade de opiniões, mostrando-se favorável ao uso das fibras vegetais para o desenvolvimento de produtos, avaliando cada um dos atributos para o design do produto bem acima da média e determinando como aspectos fundamentais: o acabamento, a durabilidade e a inovação. Como conclusão, aqueles pertencentes ao grupo 'com interesse', foram nomeados o público alvo a usufruir do produto desta investigação, justificando que as principais razões para o consumo são: o diferencial, o preço, a variedade, os aspectos eco sustentáveis e naturais a serem oferecidos para o benefício dos consumidores e para a conquista de novos mercados.

Palavras-chaves: Fibra Natural; Atributos do design; Desenvolvimento de produto; Estudo do consumidor.

\section{Introdução}

A análise de mercados ou de consumidores obriga a considerar um grande número de informações de modo a encontrar os melhores atributos que produzam um nível de resposta desejada, classificando e agrupando os dados. Sendo assim, a coleta de informações do mercado é essencial para garantir a adequação do produto em desenvolvimento às necessidades dos consumidores e/ou potenciais consumidores (Motta, Mattar, Barreto, \& Teixeira, 2007).

Identificar oportunidades é uma etapa permanente no processo de desenvolvimento de novos produtos e representa a busca sistemática de "pistas" que possam permitir a sua organização e oferecer uma boa probabilidade de sucesso para o seu uso comercial (Lima Junior, Carneiro, Medeiros, Romano, \& Sousa, 2010). Neste contexto, a competitividade é caracterizada por um processo interativo de descobertas, no qual novos conhecimentos são produzidos (Vasconcelos \& Cyrino, 2000) e permeia praticamente em todos os setores onde as necessidades e desejos dos consumidores formam a base para a concepção, a qualidade, o desempenho e a inovação desses novos produtos cuja diferenciação é uma estratégia mercadológica e que pode ser atingida através de fatores como: a aparência visual, a origem, a qualidade, a durabilidade, a funcionalidade, o estilo, os 
tipos de serviços oferecidos, o atendimento ao cliente, a competência, a credibilidade, entre outros (Castro \& Neves, 2003).

Sobre esses aspectos e para o designer, mesmo que não seja de sua responsabilidade, é útil se conhecer a mecânica da pesquisa de mercado e, com ela, as informações resultantes da investigação para melhor definição das estratégias que deverão ser adotadas ao design do produto (Torres, Cavalcante, \& Almeida, 2011).

Diante disso, este trabalho visa observar o uso semi-industrial da fibra de tucumã-i (Astrocaryum acaule) para o desenvolvimento de produtos, de modo a construir e sistematizar informações pertinentes com base na opinião de consumidores, relatando as ideias e as sugestões para a melhor utilização da matéria-prima e, sobretudo, para saber que tipos de atributos devem ser necessários à concepção, gestão e fabricação dos produtos. Para tanto, uma análise de agrupamento (cluster) poderá orientar às tomadas de decisões que o designer deverá considerar para a execução do tema proposto, tornando-se assim o ponto-chave do estudo, que também contempla os seguintes objetivos:

Classificar os dados coletados em grupos relativamente homogêneos com base no conjunto de variáveis consideradas (atributos para o design de produto);

Identificar os atributos avaliados como os mais importantes à fabricação de produtos semi-industriais a partir do uso da fibra natural de tucumã-i (Astrocaryum acaule);

Contribuir para a segmentação do mercado, de acordo com as vantagens e benefícios esperados na compra do produto final conforme opinião dos grupos de consumidores estudados;

\section{0 objeto de estudo}

A palmeira amazônica do gênero Astrocaryum da espécie acaule vem sendo apontada como uma grande fornecedora de fibras naturais para a produção artesanal e têxtil (Souza, 2004). Suas folhas apresentam um grande potencial econômico com a extração de fibras de alta resistência, utilizadas para o desenvolvimento de produtos (Miranda, 2001). Sua produção é sustentável e valoriza o vegetal desde o momento de seu cultivo, passando pelo processo de adaptação das fibras em fios, que a partir daí é definida a função para a qual será destinada e/ou aplicada (Santos, 2002).

A fibra de tucumã-i ou tucum (Figura 01) como também é conhecida, está localizado em grande parte no alto Rio Negro/Estado do Amazonas/região norte do Brasil, onde é produzida pelas comunidades indígenas e caboclas, 
Estudio de la prospección del uso de la fibra de tucumã-i (Astrocaryum acaule) para el desarrollo de productos semi-industriales

consideradas como as maiores conhecedoras e consumidoras da matéria-prima (Maciel, 2008).
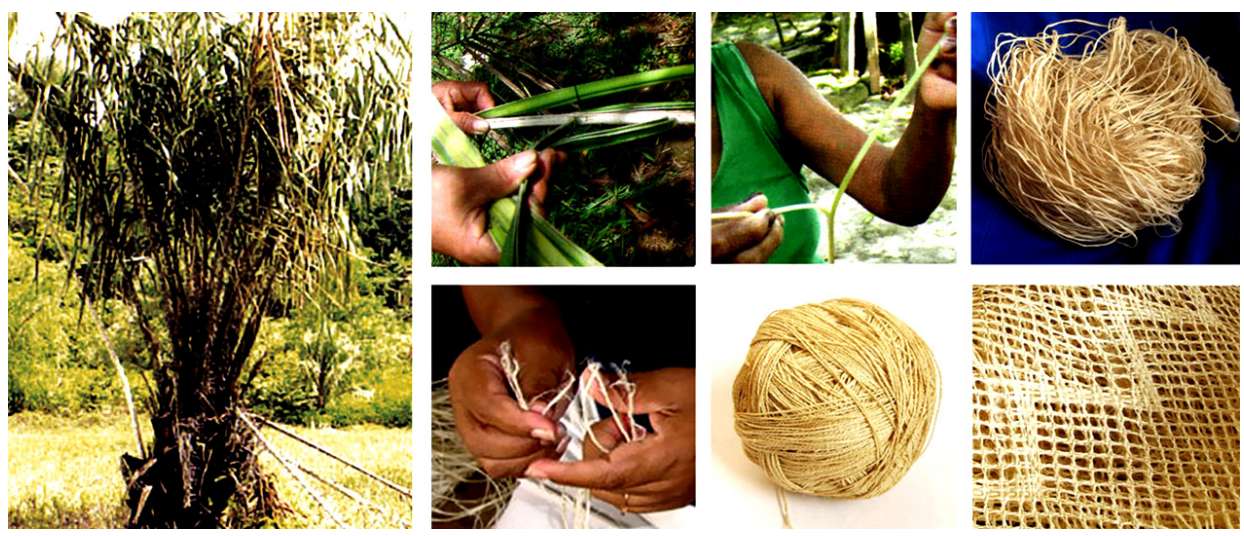

A7_Figura 1. Palmeira amazônica Astrocaryum acaule e a sua fibra adaptada à fabricação de produto (tecido). Fonte: dos Autores.

A comercialização é feita através da compra e venda da fibra no seu estado in natura, ou já transformada em produtos artesanais (Figura 02), em centros comerciais, feiras e eventos culturais, tendo como principais mercados para o consumo: a capital do estado do Amazonas (Manaus), alguns estados brasileiros e países da Américas do Norte, América do Sul e da Europa (Pacheco, Ortuño, Miranda, Nascimento, \& Pacheco, 2011).
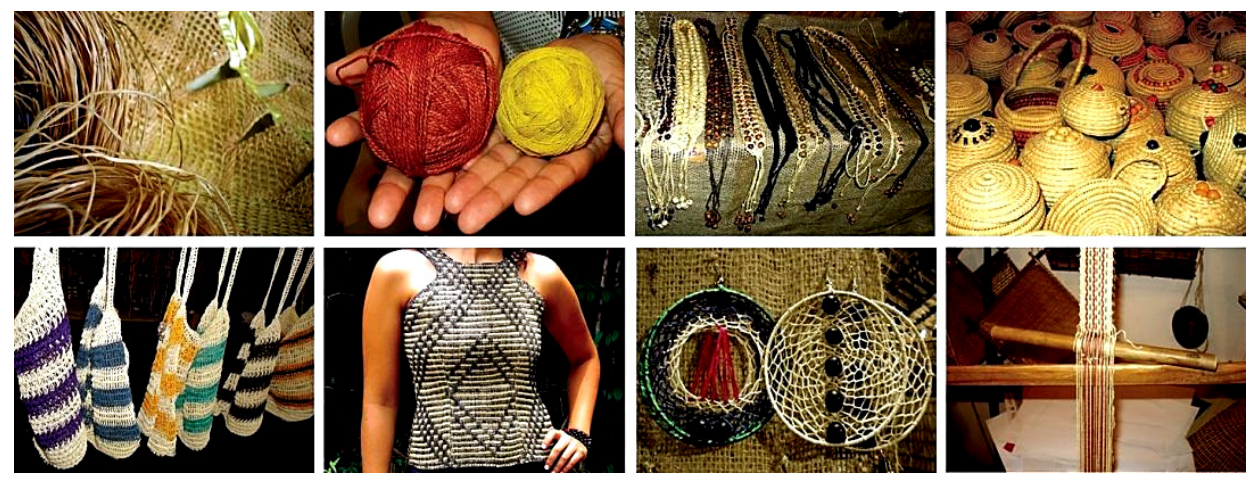

A7_Figura 2. Alguns produtos desenvolvidos e comercializados com a fibra de tucumã-i (Astrocaryum acaule). Fonte: dos Autores. 
A vantagem de ser uma matéria-prima natural, produzida de forma sustentável, gerando emprego e renda para as suas comunidades produtoras, possuir características inovadoras e, mostrar-se disponível e em abundância para atender às limitações dadas à confecção de produtos ecologicamente corretos, faz do objeto de estudo um recurso em potencial para a realização de novos experimentos (Pacheco, 2011a). Existem algumas investigações, relacionadas ao uso da fibra de tucumã-i (Astrocaryum acaule) para o desenvolvimento de produtos, afirmando que a mesma apresenta, em sua estrutura vegetal, propriedades tecnológicas compatíveis à fabricação têxtil (Maciel, 2008), favorecendo os aspectos ecológicos e biodegradáveis, principalmente por seus processos de obtenção e produção não demandarem artifícios químicos nocivos e de alto impacto ambiental.

Sobre o mesmo tema, publicações feitas com base na opinião de profissionais de design, afirmam que além dos aspectos tecnológicos e das características intrínsecas a serem valorizados na fibra, outros fatores importantes como: os tipos de processos a serem empregados, tanto para o uso semi-industrial da fibra quanto para a transferência de tecnologia, também devem ser analisados (Pacheco, 2011b).

O mesmo raciocínio é também compartilhado por especialistas de áreas relacionadas ao tema, e ainda enfatizam a precisão de um estudo de mercado que, segundo eles, deve identificar o nível de apreciação da fibra para a aplicação semi-industrial, nas possíveis categorias de uso, atributos e tipos de produtos a serem desenvolvidos, e ainda orientando na construção sistêmica das informações em prol de uma boa gestão e o emprego devido de novos recursos naturais no mercado (Pacheco, 2011c).

Sobre tais orientações e conforme investigação preliminar realizada com alguns consumidores de produtos fabricados com fibras vegetais, apesar dos elevados números de aprovação da fibra de tucumã-i (Astrocaryum acaule) para o uso semi-industrial em produtos, o público ressaltou que a matériaprima necessita de uma atenção maior no momento da sua adaptação tecnológica e concepção do produto final, de modo a valorizar a qualidade do material, favorecer o alcance de novos mercados e oferecer benefícios aos seus futuros consumidores (Pacheco, 2011d).

Assim sendo, como próximo passo e com o intuito de fortalecer os registros científicos realizados até o momento sobre o objeto de estudo, torna-se importante segmentar o mercado, escolhendo um grupo de consumidores com necessidades homogêneas, para o qual a concepção e a fabricação semiindutrial dos produtos feitos a partir da fibra de tucumã-i (Astrocayum acaule), sejam trabalhadas mediante os fatores, as vantagens e os benefícios identificados e que afetam nas decisões de compra desses consumidores. 
Estudio de la prospección del uso de la fibra de tucumã-i (Astrocaryum acaule) para el desarrollo de productos semi-industriales

\section{Materiais e métodos}

A pesquisa é de caráter descritivo, exploratório e explicativo utilizando técnicas quantitativas e qualitativas baseadas em pesquisa bibliográfica e documental (Gil, 2002) Os dados foram coletados dados a partir da aplicação de um questionário, cujo roteiro apresentou perguntas abertas (respostas livres), fechadas (duas opções), e de múltipla escolha (fechada com uma série de respostas possíveis), constituído por um total de 33 questões.

A seleção dos entrevistados foi aleatória, buscando cobrir os potenciais consumidores em termos de produtos a base de fibras naturais vegetais, assim o questionário foi disponibilizado e preenchido via internet e teve como princípio técnico o uso do conceito "bola de neve", evidenciado por Bailey (1992), o qual sugere estabelecer alguns contatos iniciais na comunidade de interesse e esses contatos passam a indicar outros e assim em diante, de forma a construir redes de informantes. A técnica proporcionou uma interação efetiva entre os informantes e a pesquisa.

As informações foram obtidas no período de, aproximadamente, dois meses (agosto a outubro de 2010), incluindo a tabulação dos dados por meio de suporte computacional, sendo as questões e suas respostas armazenadas em um banco de dados. A amostra foi composta por 408 entrevistados brasileiros (273 mulheres e 135 homens), em sua maioria pertencente à cidade de Manaus e com idades variando de 20 a 73 anos.

Para a presente publicação, que é parte de um estudo de tese de doutorado, foram analisados os resultados de dez questões do documento aplicado aos consumidores, todas em consonância com os objetivos do trabalho e observando os seguintes aspectos: 1 . Atributos para o design do produto, onde foram relacionados os aspectos de forma, função e ergonomia e; 2 . Perfil dos consumidores, classificando os participantes quanto a: gênero, idade, estado civil, renda mensal, escolaridade e ocupação.

Os dados quantitativos foram organizados e analisados a partir: da técnica de aglomeração hierárquica, interligando os indivíduos por suas associações, produzindo um dendrograma onde as amostras semelhantes, segundo as variáveis escolhidas, são agrupadas entre si e a suposição básica de sua interpretação é quanto menor a distância entre os pontos, maior a semelhança entre as amostras (Moita Neto \& Moita, 1998).

Para reforçar a aplicação do método, a estratificação dos dados foi feita pela análise de cluster com a aplicação do algoritmo de agrupamento denominado Ward que se trata de é um método de agrupamento de dados que forma grupos de maneira a atingir sempre o menor erro interno entre os vetores que compõem cada grupo e o vetor médio do grupo. Isto equivale a buscar o 
mínimo desvio padrão entre os dados de cada grupo (Dutra, Sperandio, \& Coelho, 2003). Além do agrupamento homogêneo e de conglomerados, também foram feitas: distribuição de frequiência, cálculo de médias e tabelas de contingência com o nível de significância em função de $a \leq 0,1$.

\section{Resultados}

\subsection{Aglomeração hierárquica dos grupos de consumidores}

Para definir a segmentação de mercado em função das opiniões dos consumidores através da análise cluster, foi realizado um estudo de aglomeração hierárquica onde os indivíduos foram interligados a grupos por suas associações. Um histórico das informações foi produzido por um dendrograma, onde os dados semelhantes foram agrupados entre si de acordo com as variáveis estudadas.

O método Ward foi aplicado para a formação de grupos homogêneos e para calcular as médias de todas as variáveis, assim como, a distância euclidiana quadrática através da soma dos quadrados das diferenças de cada objeto da aglomeração formada.

Foram combinados os dois aglomerados que apresentaram menor aumento na soma global dos quadrados dentro dos agrupamentos e as distâncias entre os últimos estágios de combinação foram calculadas observando que as mesmas foram maiores nas últimas seis etapas formando, dessa maneira, até seis grupos distintos (Tabela 1).

A7_Tabela 1. Aglomeração hierárquica formada com até de seis grupos distintos

\begin{tabular}{crrcrccccccr}
\hline \multicolumn{1}{c}{ Ward 1 } & \multicolumn{4}{c}{ Ward 2 } & \multicolumn{4}{c}{ Ward 3 } & \multicolumn{3}{c}{ Ward 4 } \\
\hline Grupos & Freq. & \% & Grupos & Freq. & \% & Grupos & Freq. & \% & Grupos & Freq. & \% \\
\hline 1 & 97 & 23, & 1 & 219 & 53,7 & 1 & 219 & 53,7 & 1 & 219 & 53,7 \\
2 & 122 & 29,9 & 2 & 33 & 8,1 & 2 & 33 & 8,1 & 2 & 33 & 8,1 \\
3 & 33 & 8,1 & 3 & 108 & 26,5 & 3 & 116 & 28,4 & 3 & 156 & 38,2 \\
4 & 108 & 26,5 & 4 & 40 & 9,8 & 4 & 40 & 9,8 & - & - & - \\
5 & 40 & 9,8 & 5 & 8 & 2 & - & - & - & - & - & - \\
6 & 8 & 2 & - & - & - & - & - & - & - & - & - \\
Total & 408 & 100 & Total & 408 & 100 & Total & 408 & 100 & Total & 408 & 100 \\
\hline
\end{tabular}

Fonte: Dados da pesquisa.

A partir dos seis grupos distintos formados, foi escolhida a aglomeração com quatro grupos (Tabela 2) por ser considerada como a mais interessante, uma vez que em sua composição o grupo de 33 indivíduos apresenta inflexibilidade para compor outros agrupamentos, ocorrendo o mesmo com o grupo composto por 40 consumidores. 
A7_Tabela 2. Amostra Selecionada

\begin{tabular}{crr}
\hline \multicolumn{3}{c}{ AMOSTRA SELECIONADA } \\
Ward 3 \\
\hline Grupos & Freqüência & $\%$ \\
\hline 1 & 219 & $53,7 \%$ \\
2 & 33 & $8,1 \%$ \\
3 & 116 & $28,4 \%$ \\
4 & 40 & $9,8 \%$ \\
Total & 408 & $100 \%$ \\
\hline
\end{tabular}

Fonte: Dados da pesquisa.

Analisando a formação de cada grupo que compõe a amostra escolhida, foi detectado que o grupo 1 apresentou o maior número de participantes $(n=219$; $53,7 \%$ ), seguido pelo grupo 3 que também demonstrou ter bastante consumidores ( $n=116 ; 28,4 \%$ ). No entanto, o grupo 2 foi composto pelo menor número de entrevistados $(n=33 ; 8,1 \%)$, assim como a composição do grupo 4 $(n=40 ; 9,8 \%)$.

Contudo, a proximidade observada, com respeito à quantidade de pessoas que representam tanto os grupos 1 e 3 quanto os grupos 2 e 4, possibilitaram visualizar o posicionamento do universo amostral de forma clara e precisa em relação aos atributos considerados necessários à fabricação de produtos semiindustriais a partir do uso da fibra natural de tucumã-i (Astrocaryum acaule).

\subsection{Atributos para o design de produto segundo o grupo de consumidores selecionados}

Após a seleção da amostra, com quatro grupos distintos de consumidores, foram observadas as opiniões desses em relação aos atributos considerados importantes para o design do produto. A princípio foram analisadas as médias atribuídas aos aspectos formais (Tabela 3 ). 
A7_Tabela 3. Posicionamento da amostra em relação aos atributos formais do produto

\begin{tabular}{c|lcccccc}
\hline \multirow{2}{*}{ DESIGN } & \multirow{2}{*}{ VARIÁVEIS } & \multicolumn{4}{c}{ AMOSTRA ESTUDADA } & \multirow{2}{*}{ Total } \\
\cline { 3 - 6 } & & Grupo 1 & Grupo 2 & Grupo 3 & Grupo 4 & Grupo/Média \\
\hline \multirow{3}{*}{} & Estilo & 3,53 & Média & Média & Média & \\
& Cor & 3,34 & 1,58 & 2,84 & 3,20 & 3,14 \\
& Textura & 3,56 & 1,64 & 3,04 & 3,20 & 3,06 \\
& Tendência & 2,91 & 2,61 & 2,15 & 2,78 & 3,22 \\
\cline { 2 - 5 } & Harmonia & 3,55 & 1,70 & 3,09 & 2,90 & 3,65 \\
& Elegância & 3,57 & 1,58 & 3,14 & 3,08 & 3,24 \\
& Acabamento & 3,87 & 1,24 & 3,78 & 2,63 & 3,51 \\
& Originalidade & 3,77 & 1,58 & 3,47 & 3,03 & $\mathbf{3 , 4 3}$ \\
\hline
\end{tabular}

Fonte: Dados da pesquisa.

Segundo o posicionamento do universo amostral e numa escala de 1 a 4 - onde 1 significa 'pouco importante' e 4 'bastante importante, o grupo 1 foi o que valorou cada um dos atributos formais bem a cima da media e ainda, destacou com maior valoração o fator 'acabamento' ( $m=3,77)$.

Ao contrario do grupo 1, o grupo 2 apresentou uma avaliação abaixo da média, inclusive discordando do grupo anterior com respeito ao quesito 'acabamento' que recebeu a menor pontuação $(m=1,24)$, o mesmo grupo considerou a 'tendência' como o aspecto mais importante $(m=2,61)$.

0 grupo 3 demonstrou uma apreciação maior pelos atributos: 'acabamento' $(m=3,47)$, 'originalidade' $(m=3,47)$, 'elegância' $(m=3,14)$ e 'harmonia' $(m=3,09)$ e mesmo tendo considerado a 'tendência' como um aspecto formal importante para o produto, foi o quesito que recebeu a menor valoração $(m=2,15)$.

0 grupo 4 foi favorável às características relacionadas a: 'originalidade' $(m=3,03)$, 'elegância' $(m=3,08)$, 'cor' $(m=3,10)$, ponderando como aspectos mais importantes o 'estilo' e a 'textura' (ambos com $m=3,20$ ) e valorando com uma pontuação menor o 'acabamento' $(m=2,63)$.

No geral, o valor total de médias atribuídas pelo grupo amostral para cada aspecto formal avaliado apontou como o mais interessante a 'originalidade' (média total $=3,43$ ), deixando com a menor pontuação a 'tendência' $(m=2,65)$. 
Estudio de la prospección del uso de la fibra de tucumã-i (Astrocaryum acaule) para el desarrollo de productos semi-industriales

A7_Tabela 4. Posicionamento da amostra em relação aos atributos funcionais do produto

\begin{tabular}{|c|c|c|c|c|c|c|}
\hline \multirow{3}{*}{ DESIGN } & \multirow{3}{*}{ VARIÁVEIS } & \multicolumn{4}{|c|}{ AMOSTRA ESTUDADA } & \multirow{3}{*}{$\begin{array}{c}\text { Total } \\
\text { Grupo/Média }\end{array}$} \\
\hline & & Grupo 1 & Grupo 2 & Grupo 3 & Grupo 4 & \\
\hline & & Média & Média & Média & Média & \\
\hline \multirow{6}{*}{ 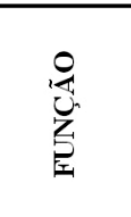 } & Tecnologia & $\overline{3,44}$ & 1,85 & 3,09 & 2,80 & 3,15 \\
\hline & Durabilidade & 3,83 & 1,30 & 3,59 & 2,68 & 3,45 \\
\hline & Multifuncional & 3,63 & 1,85 & 3,06 & 2,70 & 3,23 \\
\hline & Adaptabilidade & 3,50 & 2,09 & 2,77 & 2,98 & 3,13 \\
\hline & Sustentável & 3,76 & 1,64 & 3,08 & 2,93 & 3,31 \\
\hline & Transformação & 3,34 & 2,55 & 2,32 & 3,33 & 2,99 \\
\hline
\end{tabular}

Fonte: Dados da pesquisa.

Quanto aos aspectos funcionais do produto, mais uma vez o grupo 1 foi favorável à aplicação de todas as variáveis apresentadas, atribuindo médias bem altas, sobretudo ao aspecto de 'durabilidade' que recebeu a maior valoração $(m=3,83)$.

A pontuação menor deste grupo foi dada ao fator de 'transformação' $(m=3,34)$ e, ainda assim, continuou sendo um dos quesitos mais importantes. 0 grupo 2 também seguiu valorando abaixo das médias e discordando da opinião dada pelo grupo 1 , que avaliou com a menor pontuação o item 'durabilidade' $(m=1,30)$ e considerou importante a 'transformação' $(m=2,55)$.

0 grupo 3 avaliou como 'muito importante' os fatores: 'multifuncional' $(m=3,06)$, 'sustentável' $(m=3,08)$, 'tecnologia' $(m=3,09)$ e, de maneira especial, a 'durabilidade' $(m=3,59)$, o que tornou o posicionamento deste grupo compatível ao grupo 1 que também conferiu um valor menor ao item 'transformação' $(m=2,32)$.

0 grupo 4 apresentou uma avaliação superior às médias atribuídas pelo grupo 2. No entanto, assim como o grupo 2, também assinalou como 'muito importante' o fator 'transformação' $(m=3,33)$ que recebeu a maior pontuação em relação às demais variáveis e mesmo sendo considerada 'importante', a 'durabilidade' foi o componente que apresentou a menor valoração $(m=2,68)$ por esse grupo.

Observando o total das médias atribuídas aos aspectos funcionais do produto, a 'durabilidade' demonstrou ter a maior preferência e ser a característica mais importante $(m=3,49)$, enquanto que a 'transformação', ainda que 'importante', foi o quesito que apresentou o menor valor conferido $(m=2,99)$. 
A7_Tabela 5. Posicionamento da amostra em relação aos atributos ergonômicos do produto

\begin{tabular}{|c|c|c|c|c|c|c|}
\hline \multirow{3}{*}{ DESIGN } & \multirow{3}{*}{ VARIÁVEIS } & \multicolumn{4}{|c|}{ AMOSTRA ESTUDADA } & \multirow{3}{*}{$\begin{array}{c}\text { Total } \\
\text { Grupo/Média }\end{array}$} \\
\hline & & Grupo 1 & Grupo 2 & Grupo 3 & Grupo 4 & \\
\hline & & Média & Média & Média & Média & \\
\hline \multirow{6}{*}{ 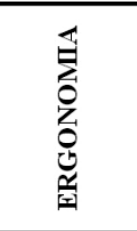 } & Manejo & 3,68 & 1,39 & 3,71 & 2,48 & 3,38 \\
\hline & Denomina/Origem & 3,67 & 2,00 & 2,48 & 2,95 & 3,13 \\
\hline & Tradição & 3,13 & 2,30 & 2,31 & 2,85 & 2,80 \\
\hline & Modernidade & 3,39 & 2,09 & 2,81 & 3,00 & 3,08 \\
\hline & Inovação & 3,76 & 1,55 & 3,39 & 2,58 & 3,36 \\
\hline & Variedade & 3,72 & 2,12 & 3,09 & 2,95 & 3,34 \\
\hline
\end{tabular}

Fonte: Dados da pesquisa.

Conforme as opiniões da amostra em relação aos atributos ergonômicos do produto, o grupo 1 continuou a avaliar as variáveis bem a cima das médias, considerando todas como 'muito importante', principalmente o aspecto de 'inovação' $(m=3,76)$.

0 grupo 2 considerou a 'tradição' $(m=2,30)$ como o componente primordial à ergonomia do produto final e, ao contrário do primeiro grupo, atribuiu ao item 'inovação' o menor valor $(m=1,55)$. Para o grupo 3 , a 'variedade' $(m=3,09)$, a 'inovação' $(m=3,39)$ e, sobretudo, o 'manejo' $(m=3,71)$ são vitais à fabricação de um produto ergonômico e, apesar de avaliado como 'importante', a 'tradição' foi o último fator posicionado pelo grupo $(m=2,31)$.

0 grupo 4 considerou todos os atributos importantes, mas optou como 'muito importante' o item 'modernidade' $(m=3,00)$ e ponderou com valor menor o 'manejo' $(m=3,71)$. Assim sendo, na distribuição do valor total das médias para cada variável analisada pelos quatro grupos distintos, o 'manejo' apresentou a maior valoração $(m=3,38)$ e a 'tradição' recebeu a menor pontuação $(m=2,80)$.

Ao analisar o posicionamento dos consumidores, em relação aos atributos do design de produto, foram observadas as características que identificam e diferenciam os quatro grupos que compõem o universo amostral, onde o grupo 1 avaliou todas as variáveis muito acima da média, enquanto que o grupo 2 posicionou-se totalmente ao contrário, valorando todos os atributos abaixo da média.

Desta forma, os grupos 1 e 2 foram considerados antagônicos entre si, sendo o que um valoriza o outro considera menos importante. Assim mesmo, o grupo 2 avalia dentro das suas variáveis, como menos considerada a que melhor média ha tido em nível geral por todos os demais grupos. 
Estudio de la prospección del uso de la fibra de tucumã-i (Astrocaryum acaule) para el desarrollo de productos semi-industriales

Outra questão ressaltada foi que o grupo 1 apresentou-se como o mais numeroso $(n=219 ; 53,7 \%)$ em relação ao grupo $2(n=33 ; 8,1 \%)$ sendo, portanto, selecionado como a fonte de opinião mais interessante a ser considerada para este estudo. A partir disso, o grupo 1 passou a ser identificado como 'com interesse' e o grupo 2 como 'desinteressados'.

Com respeito aos grupos 3 e 4, os mesmos não demonstraram estar definidos pelos resultados a nível geral, a não ser pelas suas tendências referenciadas aos diferentes atributos estudados e dispostos da seguinte forma: grupo $3 \rightarrow$ maior valoração atribuída a: 'acabamento' $(m=3,78)$, 'manejo' $(m=3,71)$, 'durabilidade' $(m=3,59)$, originalidade' $(m=3,47)$, 'inovação' $(m=3,39)$, 'elegância' $(m=3,14)$, 'harmonia' $(m=3,09)$, 'tecnologia' $(m=3,09)$, 'variedade' $(m=3,09)$, 'sustentável' $(m=3,08)$, 'multifuncional' $(m=3,06)$ e 'textura' $(m=3,04)$.

De acordo com a apreciação demonstrada por esse grupo, o mesmo revelou ter uma personalidade com características mais contemporâneas e voltadas à atualidade, sendo, portanto denominado como o grupo dos consumidores 'modernos' e; em relação ao grupo $4 \rightarrow$ maior valoração atribuída a: 'transformação' $(m=3,33)$, 'estilo' $(m=3,20)$, 'textura' $(m=3,20)$, 'cor' $(m=3,10)$, 'elegância' $(m=3,08)$, 'originalidade' $(m=3,03)$, 'adaptabilidade' $(m=2,98)$, 'denominação de origem' $(m=2,95)$, 'variedade' $(m=2,95)$ 'sustentável' $(m=2,93)$, 'harmonia' $(m=2,90)$ e 'tradição' $(m=2,85)$. As preferências evidenciadas por esse grupo revelaram um comportamento mais clássico e com tendências ao conservadorismo, sendo assim identificado como o grupo dos consumidores 'tradicionais'.

Diante do diagnóstico realizado com os grupos 3 e 4, foi registrado que o grupo 3 mostrou-se mais numeroso $(n=116 ; 28,4 \%)$ que o grupo $4(n=40 ; 9,8 \%)$, passando a ser selecionado, como o mais conveniente à pesquisa, assim como o grupo 1. Assim, o grupo 'com interesse' e o grupo 'modernos' decidiram as diferenças existentes entre os grupos principais formados pela amostra.

\subsection{Perfil dos consumidores}

Uma vez bem definidos os conglomerados, o estudo procedeu com a observação de outros aspectos (Tabela 6) e, para tal, foram realizados os contrates de hipóteses mediante a prova do qui-quadrado de Pearson para a hipótese nula de independência, na qual foi considerado rejeitar a hipótese nula a um nível de significância em função de $\alpha \leq 0,1$. 
A7_Tabela 6. Perfil do grupo de consumidores em função das variáveis de classificação

\begin{tabular}{|c|c|c|c|c|c|c|c|c|c|c|}
\hline \multirow{3}{*}{ VARIÁVEIS } & \multicolumn{10}{|c|}{ AMOSTRA ESTUDADA } \\
\hline & \multicolumn{2}{|c|}{$\begin{array}{c}\text { Grupo } 1 \\
\text { 'c/interesse' }\end{array}$} & \multicolumn{2}{|c|}{$\begin{array}{c}\text { Grupo } 2 \\
\text { 'desinteressados' }\end{array}$} & \multicolumn{2}{|c|}{$\begin{array}{l}\text { Grupo } 3 \\
\text { 'modernos' }\end{array}$} & \multicolumn{2}{|c|}{$\begin{array}{c}\text { Grupo } 4 \\
\text { 'tradicionais' }\end{array}$} & \multicolumn{2}{|c|}{ Total } \\
\hline & n & $\%$ & $\mathbf{n}$ & $\%$ & n & $\%$ & $\mathbf{n}$ & $\%$ & n & $\%$ \\
\hline \multicolumn{11}{|l|}{ Gênero - $(\alpha=0,293)$} \\
\hline Masculino & 66 & $30,1 \%$ & 13 & $39,4 \%$ & 45 & $38,8 \%$ & 11 & $27,5 \%$ & 135 & $33,1 \%$ \\
\hline Feminino & 153 & $69,9 \%$ & 20 & $60,6 \%$ & 71 & $61,2 \%$ & 29 & $72,5 \%$ & 273 & $66,9 \%$ \\
\hline Total & 219 & $100 \%$ & 33 & $100 \%$ & 116 & $100 \%$ & 40 & $100 \%$ & 408 & $100 \%$ \\
\hline \multicolumn{11}{|l|}{ Idade - $(\alpha=0,00)$} \\
\hline até 23 anos & 32 & $14,6 \%$ & 7 & $21,2 \%$ & 39 & $33,6 \%$ & 8 & $20 \%$ & 86 & $21,1 \%$ \\
\hline De 24 a 29 anos & 66 & $30,1 \%$ & 5 & $15,2 \%$ & 38 & $32,8 \%$ & 11 & $27,5 \%$ & 120 & $29,4 \%$ \\
\hline De 30 a 37 anos & 51 & $23,3 \%$ & 14 & $42,4 \%$ & 27 & $23,3 \%$ & 11 & $27,5 \%$ & 103 & $25,2 \%$ \\
\hline$>37$ anos & 70 & $32 \%$ & 7 & $21,2 \%$ & 12 & $10,3 \%$ & 10 & $25 \%$ & 99 & $24,3 \%$ \\
\hline Total & 219 & $100 \%$ & 33 & $100 \%$ & 116 & $100 \%$ & 40 & $100 \%$ & 408 & $100 \%$ \\
\hline \multicolumn{11}{|c|}{ Estado Civil - $(\alpha=0,411)$} \\
\hline Solteiro & 130 & $59,4 \%$ & 20 & $60,6 \%$ & 84 & $72,4 \%$ & 27 & $67,5 \%$ & 261 & $64 \%$ \\
\hline Casado & 74 & $33,8 \%$ & 10 & $30,3 \%$ & 30 & $25,9 \%$ & 11 & $27,5 \%$ & 125 & $30,6 \%$ \\
\hline Divorciado & 11 & $5 \%$ & 2 & $6,1 \%$ & 2 & $1,7 \%$ & 1 & $2,5 \%$ & 16 & $3,9 \%$ \\
\hline Viúvo & 4 & $1,8 \%$ & 1 & $3 \%$ & 0 & $0 \%$ & 1 & $2,5 \%$ & 6 & $1,5 \%$ \\
\hline Total & 219 & $100 \%$ & 33 & $100 \%$ & 116 & $100 \%$ & 40 & $100 \%$ & 408 & $100 \%$ \\
\hline \multicolumn{11}{|c|}{ Escolaridade $-(\alpha=0,081)$} \\
\hline Ens. Fundamental & 15 & $6,8 \%$ & 1 & $3 \%$ & 5 & $4,3 \%$ & 8 & $20 \%$ & 29 & $7,1 \%$ \\
\hline Ens. Médio & 64 & $29,2 \%$ & 10 & $30,3 \%$ & 48 & $41,4 \%$ & 8 & $20 \%$ & 130 & $31,9 \%$ \\
\hline Graduação & 69 & $31,6 \%$ & 10 & $30,3 \%$ & 30 & $25,9 \%$ & 12 & $30 \%$ & 121 & $29,6 \%$ \\
\hline Pós-graduação & 71 & $32,4 \%$ & 12 & $36,4 \%$ & 33 & $28,4 \%$ & 12 & $30 \%$ & 128 & $31,4 \%$ \\
\hline Total & 219 & $100 \%$ & 33 & $100 \%$ & 116 & $100 \%$ & 40 & $100 \%$ & 408 & $100 \%$ \\
\hline \multicolumn{11}{|c|}{ Ocupação - $(\alpha=0,179)$} \\
\hline Estudante & 30 & $13,7 \%$ & 5 & $15,2 \%$ & 30 & $25,9 \%$ & 8 & $20 \%$ & 73 & $17,9 \%$ \\
\hline Designer & 71 & $32,4 \%$ & 8 & $24,2 \%$ & 32 & $27,6 \%$ & 6 & $15 \%$ & 117 & $28,7 \%$ \\
\hline Empresário & 69 & $31,5 \%$ & 9 & $27,3 \%$ & 34 & $29,3 \%$ & 13 & $32,5 \%$ & 125 & $30,6 \%$ \\
\hline Autônomo & 10 & $4,6 \%$ & 0 & $0 \%$ & 3 & $2,6 \%$ & 2 & $5 \%$ & 15 & $3,7 \%$ \\
\hline Func. Publico & 5 & $2,3 \%$ & 2 & $6,1 \%$ & 3 & $2,6 \%$ & 2 & $5 \%$ & 12 & $2,9 \%$ \\
\hline Outra & 34 & $15,5 \%$ & 9 & $27,3 \%$ & 14 & $12,1 \%$ & 9 & $22,5 \%$ & 66 & $16,2 \%$ \\
\hline Total & 219 & $100 \%$ & 33 & $100 \%$ & 116 & $100 \%$ & 40 & $100 \%$ & 408 & $100 \%$ \\
\hline \multicolumn{11}{|c|}{ Proventos - $(\alpha=0,515)$} \\
\hline$<1$ salário & 5 & $2,3 \%$ & 0 & $0 \%$ & 2 & $1,7 \%$ & 3 & $7,5 \%$ & 10 & $2,5 \%$ \\
\hline De 1 a 2 salários & 7 & $3,2 \%$ & 1 & $3 \%$ & 6 & $5,2 \%$ & 1 & $2,5 \%$ & 15 & $3,7 \%$ \\
\hline De 3 a 4 salários & 36 & $16,4 \%$ & 4 & $12,1 \%$ & 21 & $18,1 \%$ & 4 & $10 \%$ & 65 & $15,9 \%$ \\
\hline > 5 salários & 171 & $78,1 \%$ & 28 & $84,8 \%$ & 87 & $75 \%$ & 32 & $80 \%$ & 318 & $77,9 \%$ \\
\hline Total & 219 & $100 \%$ & 33 & $100 \%$ & 116 & $100 \%$ & 40 & $100 \%$ & 408 & $100 \%$ \\
\hline
\end{tabular}

Fonte: Dados da pesquisa.

De acordo com as variáveis de classificação analisadas nos 4 grupos selecionados, o público feminino foi maioritário $(n=273 ; 66,9 \%)$. A faixa etária dominante foi representada por indivíduos de 24 a 29 anos (n =120; 29,4\%). Em relação ao estado civil, os solteiros demonstraram ser a maioria $(n=261$; 64\%). Quanto à escolaridade, aqueles com o nível médio completo evidenciaram ser o maior grupo $(n=130 ; 31,9 \%)$.

No quesito ocupação profissional, a ênfase foi dada aos consumidores empresários $(n=125 ; 30,6 \%)$. $E$, por último, a renda familiar indicou ser superior a cinco salários mínimos $(n=318 ; 77,9 \%)$. Neste contexto, foi 
Estudio de la prospección del uso de la fibra de tucumã-i (Astrocaryum acaule) para el desarrollo de productos semi-industriales

observado que o universo amostral apresentou-se independente em relação aos itens: gênero, estado civil, ocupação e renda familiar. Contudo, ao rejeitar a independência dos membros do grupo, com respeito à idade e a escolaridade, foi identificado que em ambos os itens o nível estatístico mostrou-se altamente significativo a $(a<0,1)$.

Sendo assim, foi ressaltada uma relação muito interessante entre os gostos dos consumidores, independentemente, das demais variáveis que os caracterizam (Tabelas 7 e 8).

A7_Tabela 7. Perfil do grupo de consumidores em relação à idade

\begin{tabular}{|c|c|c|c|c|c|c|c|c|c|c|}
\hline \multirow{3}{*}{$\begin{array}{l}\text { AMOSTRA } \\
\text { ESTUDADA }\end{array}$} & \multicolumn{8}{|c|}{ Idade } & & \\
\hline & \multicolumn{2}{|c|}{ até 23} & \multicolumn{2}{|c|}{ de 24 a 29} & \multicolumn{2}{|c|}{ de 30 a 37} & \multicolumn{2}{|c|}{ maiores de 37} & \multicolumn{2}{|c|}{ Total } \\
\hline & $\mathrm{n}$ & $\%$ & $\mathrm{n}$ & $\%$ & $\mathrm{n}$ & $\%$ & $\mathrm{n}$ & $\%$ & $\mathrm{n}$ & $\%$ \\
\hline \multicolumn{11}{|l|}{ grupos } \\
\hline 'com interesse' & 32 & $14,6 \%$ & 66 & $30,1 \%$ & 51 & $23,3 \%$ & 70 & $32,0 \%$ & 219 & $100,0 \%$ \\
\hline 'desinteressados' & 7 & $21,2 \%$ & 5 & $15,2 \%$ & 14 & $42,4 \%$ & 7 & $21,2 \%$ & 33 & $100,0 \%$ \\
\hline 'modernos' & 39 & $33,6 \%$ & 38 & $32,8 \%$ & 27 & $23,3 \%$ & 12 & $10,3 \%$ & 116 & $100,0 \%$ \\
\hline 'tradicionais' & 8 & $20,0 \%$ & 11 & $27,5 \%$ & 11 & $27,5 \%$ & 10 & $25,0 \%$ & 40 & $100,0 \%$ \\
\hline Total & 86 & $21,1 \%$ & 120 & $29,4 \%$ & 103 & $25,2 \%$ & 99 & $24,3 \%$ & 408 & $100,0 \%$ \\
\hline \multicolumn{5}{|c|}{ Qui-quadrado de Pearson 31,200(a) } & gl 9 & & \multicolumn{4}{|c|}{ Sig. Assintótica (bilateral) $0,000^{*}$} \\
\hline
\end{tabular}

Fonte: Dados da pesquisa.

Na relação observada, quanto ao gosto dos consumidores em função da idade, foi averiguado que o grupo de 'modernos' é composto por jovens com até 23 anos, enquanto o grupo 'com interesse' é determinado por pessoas maiores de 37 anos, o grupo de "desinteressados" representa os consumidores com idade entre 30 e 37 anos e os 'tradicionais' compõem uma faixa etária ampla de 24 a 37 anos.

\section{A7_Tabela 8. Perfil do grupo de consumidores em relação à escolaridade}

\begin{tabular}{|c|c|c|c|c|c|c|c|c|c|c|}
\hline \multicolumn{11}{|c|}{ Escolaridade } \\
\hline \multirow{2}{*}{$\begin{array}{l}\text { AMOSTRA } \\
\text { ESTUDADA }\end{array}$} & \multicolumn{2}{|c|}{ Ens.Fund. } & \multicolumn{2}{|c|}{ Ens. Médio } & \multicolumn{2}{|c|}{ Graduação } & \multicolumn{2}{|c|}{ Pós-graduação } & \multicolumn{2}{|c|}{ Total } \\
\hline & $\mathrm{n}$ & $\%$ & $\mathrm{n}$ & $\%$ & $\mathrm{n}$ & $\%$ & $\mathrm{n}$ & $\%$ & $\mathrm{n}$ & $\%$ \\
\hline \multicolumn{11}{|l|}{ grupos } \\
\hline 'com interesse' & 15 & $6,8 \%$ & 64 & $29,2 \%$ & 69 & $31,6 \%$ & 71 & $32,4 \%$ & 219 & $100,0 \%$ \\
\hline 'desinteressados' & 1 & $3,0 \%$ & 10 & $30,3 \%$ & 10 & $30,3 \%$ & 12 & $36,4 \%$ & 33 & $100,0 \%$ \\
\hline 'modernos' & 5 & $4,3 \%$ & 48 & $41,4 \%$ & 30 & $25,9 \%$ & 33 & $28,4 \%$ & 116 & $100,0 \%$ \\
\hline 'tradicionais' & 8 & $20,0 \%$ & 8 & $20,0 \%$ & 12 & $30,0 \%$ & 12 & $30,0 \%$ & 40 & $100,0 \%$ \\
\hline Total & 29 & $7,1 \%$ & 130 & $31,9 \%$ & 121 & $29,6 \%$ & 128 & $31,4 \%$ & 408 & $100,0 \%$ \\
\hline \multicolumn{5}{|c|}{ Qui-quadrado de Pearson 19,322(a) } & \multicolumn{2}{|c|}{ gl 12} & \multicolumn{4}{|c|}{ Sig. Assintótica (bilateral) $0,081^{*}$} \\
\hline
\end{tabular}

*Altamente significativo $(\alpha<0,1)$. Fonte: Dados da pesquisa. 
Analisando a mesma relação em função da escolaridade identificada na amostra, foi detectado que o grupo de 'modernos' é formado por consumidores com ensino médico completo, enquanto que os demais grupos possuem nível superior: 'tradicionais' (graduação e/ou pós-graduação), 'desinteressados' (pós-graduação) e 'com interesse' (pós-graduação). Após conferir os dados de classificação da amostra, foi necessário verificar qual grupo ou grupos deve ser o público-alvo mais apropriado para o estudo proposto. Para tanto, foi identificado o posicionamento dos consumidores em relação: ao uso das fibras vegetais para a fabricação de produtos; ao grau de satisfação quanto à oferta desses produtos no mercado e ao consumo desses tipos de produtos (Tabelas 9, 10 e 11). As variáveis foram identificadas através de uma apreciação de independência entre a valorização da amostra em relação aos membros que compõem cada um dos quatro grupos distintos.

A7_Tabela 9. Apreciação do uso de fibras vegetais para o desenvolvimento de produtos

\begin{tabular}{|c|c|c|c|c|c|c|}
\hline \multicolumn{2}{|l|}{ Variável } & \multicolumn{4}{|c|}{ AMOSTRA ESTUDADA (Grupos) } & \multirow{3}{*}{$\begin{array}{l}\text { Total } \\
100,0 \%\end{array}$} \\
\hline & & com interesse & \multirow{2}{*}{$\begin{array}{r}\text { desinteresados } \\
7,5 \%\end{array}$} & \multirow{2}{*}{$\begin{array}{r}\text { modernos } \\
27,8 \%\end{array}$} & \multirow{2}{*}{$\begin{array}{r}\text { tradicionais } \\
9,8 \%\end{array}$} & \\
\hline $\begin{array}{l}\text { Apreciação / fibras } \\
\text { vegetais para produtos }\end{array}$ & Sim & $55,0 \%$ & & & & \\
\hline & Não & $26,3 \%$ & $21,1 \%$ & $42,1 \%$ & $10,5 \%$ & $100,0 \%$ \\
\hline Qui-quadrado de Pe & on 8,2 & 42(a) & gl 3 & Sig. assi & tótica (bilater & $0,041^{*}$ \\
\hline
\end{tabular}

*Altamente significativo $(\alpha<0,1)$. Fonte: Dados da pesquisa.

Em relação ao uso de fibras vegetais para o desenvolvimento de produtos, o grupo 'com interesse' evidenciou ser, maioritariamente, a favor, enquanto que o grupo dos 'modernos' ratificou ser, expressivamente, contra. Os 'desinteressados' e 'tradicionais', apesar de ser minoria na amostra analisada, também não demonstraram ser partidários à referida questão.

A7_Tabela 10. Grau de satisfação dos produtos desenvolvimento com fibras vegetais

\begin{tabular}{|c|c|c|c|c|c|c|}
\hline \multirow{2}{*}{\multicolumn{2}{|c|}{ Variável }} & \multicolumn{4}{|c|}{ AMOSTRA ESTUDADA (Grupos) } & \multirow{3}{*}{$\begin{array}{c}\text { Total } \\
100,0 \%\end{array}$} \\
\hline & & \multirow{2}{*}{$\begin{array}{r}\text { com interesse } \\
599 \%\end{array}$} & \multirow{2}{*}{$\begin{array}{r}\text { desinteressados } \\
7,2 \%\end{array}$} & \multirow{2}{*}{$\begin{array}{r}\text { modernos } \\
22,8 \%\end{array}$} & \multirow{2}{*}{$\begin{array}{r}\text { tradicionais } \\
10,1 \%\end{array}$} & \\
\hline $\begin{array}{l}\text { Grau de satisfação } \\
\text { dos produtos }\end{array}$ & Sim & & & & & \\
\hline & Não & $45,0 \%$ & $9,4 \%$ & $36,3 \%$ & $9,4 \%$ & $100,0 \%$ \\
\hline Qui-quadrado de 1 & n 11,0 & $8(a)$ & g13 & Sig. assi & tótica (bilater & 1) $0,011^{*}$ \\
\hline
\end{tabular}


Estudio de la prospección del uso de la fibra de tucumã-i (Astrocaryum acaule) para el desarrollo de productos semi-industriales

Quanto ao grau de satisfação referente aos produtos fabricados com fibras vegetais, o grupo 'com interesse' confirmou estar bem satisfeito com os artigos oferecidos no mercado, enquanto que o grupo dos 'modernos' admitiu não estar muito contente com esses tipos de produtos, da mesma opinião compartilharam os grupos dos 'desinteressados' e 'tradicionais'.

A7_Tabela 11. Consumo de produtos desenvolvimento com fibras vegetais

\begin{tabular}{lrrrrrrr}
\hline \multirow{2}{*}{ Variável } & \multicolumn{5}{c}{ AMOSTRA ESTUDADA (Grupos) } & \multirow{2}{*}{ Total } \\
\cline { 2 - 7 } & & com interesse & desinteressados & modernos & tradicionais & \\
\hline $\begin{array}{l}\text { Consumo de produtos } \\
\text { feitos c/fibras vegetais }\end{array}$ & Sim & $57,7 \%$ & $6,9 \%$ & $87,2 \%$ & $10,6 \%$ & $100,0 \%$ \\
& Não & $36,4 \%$ & $13,0 \%$ & $44,2 \%$ & $6,5 \%$ & $100,0 \%$ \\
\hline Qui-quadrado de Pearson $17,431(a)$ & & gl 3 & & Sig. assintótica (bilateral) $0,001^{*}$ \\
\hline
\end{tabular}

*Altamente significativo $(\alpha<0,1)$. Fonte: Dados da pesquisa

Com respeito ao consumo de produtos fabricados com fibras vegetais, o grupo dos 'modernos' surpreendeu ao confirmar de forma bem representativa que, apesar de não apreciar e não está satisfeito com esses tipos de produtos no comércio, aprova o consumo dos mesmos no mercado.

0 grupo 'com interesse' seguiu opinando como favorável, assim como o grupo dos 'tradicionais' e o grupo dos 'desinteressados' foi o único a consagrar de forma negativa a questão avaliada. Diante das variáveis analisadas, foi observado que nos três casos o resultado, além de ser muito significativo estatisticamente, é também similar, uma vez que em todos eles o grupo que possui a maior quantidade de consumidores demonstrou: ser favorável ao uso das fibras vegetais para o desenvolvimento de produtos, estar satisfeito com esse tipo de oferta para o mercado e, principalmente, estar apto para consumi-lo.

Logo, aqueles do grupo 'com interesse' são os maiores consumidores do produto em estudo. Neste caso, o estudo determinou concentrar seus esforços em consumidores pertencentes ao primeiro grupo, realçando as características mais valorizadas por eles e realizando um esboço de quais seriam as razões para usar os referidos produtos (Tabela 12). 
A7_Tabela 12. Razões para consumir produtos desenvolvimento com fibras vegetais

\begin{tabular}{|c|c|c|c|c|c|c|}
\hline \multicolumn{2}{|c|}{ Variáveis } & \multicolumn{4}{|c|}{ AMOSTRA ESTUDADA (Grupos) } & \multirow{3}{*}{$\begin{array}{l}\text { Total } \\
100,0 \%\end{array}$} \\
\hline & & \multirow{2}{*}{$\begin{array}{r}\text { com interesse } \\
64,9 \%\end{array}$} & \multirow{2}{*}{$\begin{array}{r}\text { desinteressados } \\
10,8 \%\end{array}$} & \multirow{2}{*}{$\begin{array}{r}\text { modernos } \\
18,9 \%\end{array}$} & \multirow{2}{*}{$\begin{array}{r}\text { tradicionais } \\
5,4 \%\end{array}$} & \\
\hline Razão do uso & Preço & & & & & \\
\hline & Variedade & $59,6 \%$ & $5,2 \%$ & $26,1 \%$ & $9,1 \%$ & $100,0 \%$ \\
\hline & Textura & $40,0 \%$ & $30,0 \%$ & $20,0 \%$ & $10,0 \%$ & $100,0 \%$ \\
\hline & Beleza & $33,3 \%$ & $5,6 \%$ & $22,2 \%$ & $38,9 \%$ & $100,0 \%$ \\
\hline & Estética & $50,0 \%$ & $0,0 \%$ & $37,5 \%$ & $12,5 \%$ & $100,0 \%$ \\
\hline & Diferencial & $75,0 \%$ & $0,0 \%$ & $12,5 \%$ & $12,5 \%$ & $100,0 \%$ \\
\hline & Aspecto natural & $56,3 \%$ & $12,5 \%$ & $31,3 \%$ & $0,0 \%$ & $100,0 \%$ \\
\hline & Ecost & $58,3 \%$ & $25,0 \%$ & $16,7 \%$ & $0,0 \%$ & $100,0 \%$ \\
\hline & No es interesante & $27,8 \%$ & $19,4 \%$ & $44,4 \%$ & $8,3 \%$ & $100,0 \%$ \\
\hline & Outras & $36,4 \%$ & $3,0 \%$ & $48,5 \%$ & $12,1 \%$ & $100,0 \%$ \\
\hline & Total & $53,7 \%$ & $8,1 \%$ & $28,4 \%$ & $9,8 \%$ & $100,0 \%$ \\
\hline Qui-quadrad & Pearson 63,758(a) & & g1 27 & Sig. assin & ótica (bilatera & $0,000^{*}$ \\
\hline
\end{tabular}

*Altamente significativo $(a<0,1)$. Fonte: Dados da pesquisa

De acordo com o grupo 'com interesse', as principais razões do uso de produtos feitos com fibras vegetais estão: no 'diferencial' oferecido por elas; no 'preço', também relacionado ao baixo custo de produção; na 'variedade' dos produtos oferecidos no mercado; nos aspectos 'eco sustentáveis' com os princípios voltados para o meio ambiente e, sobretudo; nas características 'naturais' do produto, podendo ser recicláveis, biodegradáveis, ter boas propriedades tecnológicas e vantagens em relação a outros tipos de materiais. Nesse caso, as variáveis analisadas apresentaram um nível estatístico altamente significativo $(\alpha<0,1)$.

\section{Considerações Finais}

Este artigo apresentou os atributos necessários ao design de produto, a ser fabricado a partir do uso semi-industrial da fibra vegetal amazônica de tucumã-i (Astrocaryum acaule). A partir de um estudo de aglomeração com 408 indivíduos entrevistados sobre o tema proposto, foram gerados até 6 grupos distintos de consumidores, dos quais foi selecionada uma aglomeração com 4 grupos distintos que de acordo com seus gostos e opiniões foram identificados como: grupo 1 - 'com interesse', grupo 2 - 'desinteressados', grupo 3 - 'modernos' e grupo 4 - 'tradicionais'.

Apesar da homogeneidade proporcionada pelos 4 grupos analisados, o grupo 'com interesse' foi o que apresentou maior número de participantes (219 indivíduos) e avaliou cada um dos atributos bem acima da média, já o grupo dos 'desinteressados' apresentou uma avaliação abaixo da média e os grupos dos 'modernos' e dos 'tradicionais' não demonstraram estar definidos pelos 
Estudio de la prospección del uso de la fibra de tucumã-i (Astrocaryum acaule) para el desarrollo de productos semi-industriales

resultados a nível geral e sim pelas suas tendências referenciadas aos diferentes atributos estudados.

Portanto, a partir dessas informações e através de uma apreciação de independência entre a valorização da amostra em relação aos membros que compõem cada um dos quatro grupos distintos, foi determinado que o grupo 'com interesse' seria a principal fonte de opinião a ser contrastada com os dados fornecidos pelos outros grupos. Em função do destacado posicionamento do grupo 'com interesse' em relação aos demais grupos, foi confirmado que aqueles indivíduos que o compõem são os maiores consumidores do produto da investigação, enquanto que os grupos formados pelos 'desinteressados' e 'tradicionais' não ofereceram demanda.

Ainda que o grupo dos 'modernos' tenha concordado expressivamente com o consumo das fibras naturais para o desenvolvimento de produtos e, por conseguinte, com a venda destes no comércio, mostrou-se incoerente ao confirmar a sua insatisfação e desaprovação do uso de matérias-primas vegetais para tal finalidade enquanto que, desde o princípio do estudo, o grupo 'com interesse' demonstrou com satisfação e empenho, em todos os atributos avaliados, ser favorável ao uso das fibras vegetais para a fabricação de produtos, ser consumidor habitual e estar satisfeito com esse tipo de produto oferecido no mercado.

As informações identificadas, sobre o perfil de consumidores pertencentes ao grupo 'com interesse', assinalam como público alvo para usufruir os produtos semi-industriais a serem fabricados a partir da fibra em questão: as mulheres, maiores de 37 anos e de nível superior completo. Para esse tipo de consumidoras, que demonstraram ser a maioria, os produtos confeccionados a partir das fibras vegetais, sobretudo a fibra de tucumã-i (Astrocaryum acaule), devem evidenciar no processo de fabricação e no produto final: o 'acabamento', a 'durabilidade' e a 'inovação', de modo a garantir a qualidade do material e, ainda, ressaltam que as principais razões a motivarem o consumo desse tipo de produto, certamente estão relacionadas a fatores como: o 'diferencial', o 'preço', a 'variedade', os aspectos 'ecossustentáveis' e 'naturais' a serem oferecidos para o benefício dos seus consumidores e, consequentemente, o alcance de novos mercados.

\section{Referências}

BAILEY, K. D. Methods of Social Research. McMillan. Nova York, EEUU. 553p., 1992

DUTRA, R. M. O.; SPERANDIO, M.; COELHO, J. O Método Ward de Agrupamento de Dados e sua Aplicação em associação com os Mapas Auto-Organizáveis de Kohonen. Universidade Federal de Santa Catarina (UFSC),2003. 
GIL, A.C. Como elaborar projetos de pesquisa. 4. ed. São Paulo: Atlas. 176p., 2002.

LIMA JUNIOR, F. A.; CARNEIRO, J. D. S.; MEDEIROS, N. J.; ROMANO, L. M.; SOUSA, A. B. Matriz de oportunidades: Aplicação no desenvolvimento de produtos lácteos. XIX Congresso de Pós-graduação da UFLA. Lavras - MG. 2010. Disponível em: < http://www.sbpcnet.org.br/livro/lavras/listatodos_apg.htm> Acesso em: 15 de outubro de 2011.

MACIEL, K. M. F. Estudo da viabilidade técnica da fibra do tucumã-i (Astrocaryum acaule) para a produção têxtil. XXVIII Encontro Nacional de Engenharia de Produção (ENEGEP). Rio de Janeiro - RJ. Disponível em: <http://www.abepro.org.br/biblioteca/enegep2008_TN_STO_077_540_10943. pdf> Acesso em: 12 de março de 2009.

MOITA NETO, J. M., MOITA, G. C. Uma introdução à análise exploratória de dados multivariados. Química Nova, São Paulo - SP, v.21, n.4, p.467-469, 1998.

MOTTA, S. L. S.; MATTAR, F. N.; BARRETO, I. F.; TEIXEIRA, L. F. Processo de desenvolvimento e lançamento de novos produtos em pequena empresa: Um estudo de caso. Revista de Administração USP - R.Adm., São Paulo, v.42, n.3, p.373-383, jul./ago./set. 2007.

NEVES, M.; CASTRO. Marketing e estratégia em agronegócios e alimentos. São Paulo:Editora Atlas, São Paulo/SP, 2003.

PACHECO, K. M. M.; ORTUÑO, B. H.; MIRANDA, I. P. A.; NASCIMENTO, C. C.; PACHECO, A. S. Oportunidades e limitações do uso da fibra natural de tucumã-i (Astrocaryum acaule) para a gestão e desenvolvimento de produtos semi-industriais. Anais do $8^{\circ}$ Congresso Brasileiro de Gestão de Desenvolvimento de Produto (CBGDP). UFRGS/FEEng. Porto Alegre - RS. 2011a.

PACHECO, K. M. M.; ORTUÑO, B. H.; MIRANDA, I. P. A. Análise do posicionamento do design quanto ao uso semi-industrial da fibra amazônica de tucumã-i (Astrocaryum acaule) para a fabricação de produtos. $1^{\circ}$ Congresso de Design UEM - $5^{\text {a }}$ Semana de Design UEM - Design brasileiro: cultura ou influência?. Universidade Estadual de Maringá - UEM. Campus Regional de Cianorte - Paraná, 2011b.

PACHECO, K. M. M.; ORTUÑO, B. H.; PACHECO, A. S. Análise do posicionamento de especialistas sobre o uso da fibra natural amazônica de tucumã-i (Astrocaryum acaule) para o desenvolvimento de produtos semiindustriais. Anais do III Simpósio Brasileiro de Design Sustentável (III SBDS) - 
Proceedings of the 3rd International Symposium on Sustainable Design (ISSD). Editora Universitária UFPE. Pernambuco - RE, 2011c.

PACHECO, K. M. M.; ORTUÑO, B. H.; MIRANDA, I. P. A.; NASCIMENTO, C. C.; VICENTE, B. A. Análise da apreciação de consumidores sobre o uso semiindustrial da fibra vegetal amazônica de tucumã-i (Astrocaryum acaule) para o desenvolvimento de produtos: Um estudo de mercado. Revista INGEPRO Inovação, Gestão e Produção, Set. vol. 03, nº. 09, (p.44-51), 2011d.

TORRES, P.; CAVALCANTE, A.; ALMEIDA, R. Pesquisa de mercado como base para o design de calçados femininos - Marketing como fonte de informação para projeto de design. VI Congresso Internacional de Pesquisa em Design (CIPED). CIAUD - Centro de Investigação em Arquitetura, Urbanismo e Design da FA-UTL. Lisboa/ Portugal, 2011.

VASCONCELOS, F. C. \& CYRINO, A. B. Vantagem Competitiva: os modelos teóricos atuais e a convergência entre estratégia e teoria organizacional. RAE - Revista de Administração de Empresas, Out. /Dez, v. 40, n. 4, p. 20-37, São Paulo, 2000. 


\subsection{Artículo 8 - La importancia del diseño sistémico para la competitividad de la fibra natural Amazónica de tucumã-i (Astrocaryum acaule) en el desarrollo semi-industrial de productos: Un estudio de caso para la categoría del vestuario}

Esta producción científica ha sido realizada con la intención de analizar la competitividad del objeto de estudio para su aplicación semi-industrial en el desarrollo de productos, en este caso para la categoría del vestuario, a través del modelo de diseño concurrente (Publicación en español). El artículo corresponde al objetivo 3 de la tesis (Pags.67, 68,69 y 70).

Congreso: $2^{\circ}$ Congreso Internacional de Diseño e Innovación.

ISBN: 978-84-936165-1-9

Enviado: 07.0ctubre.11 | Aceptado: 02.Noviembre.11 | Publicado: Abril.12

Cita: Pacheco, K. M. M.; Ortuño, B. H.; Paixão-Barradas, S.; Pacheco, A. S. (2012). La importancia del diseño sistémico para la competitividad de la fibra natural Amazónica de tucumã-i (Astrocaryum acaule) en el desarrollo semiindustrial de productos: Un estudio de caso para la categoría del vestuario. $2^{\circ}$ Congreso Internacional de Diseño e Innovación. Escuela Superior de Diseño ESDi. Universitat Ramon Llull - URL. Sabadell/ Barcelona - España.

La importancia del diseño sistémico para la competitividad de la fibra natural Amazónica de tucumã-i (Astrocaryum acaule) en el desarrollo semi-industrial de productos: Un estudio de caso para la categoría del vestuario

Karla Mazarelo Maciel Pacheco ${ }^{1}$, Bernabé Hernandis Ortuño ${ }^{2}$, Almir de Souza Pacheco $^{2}$ e Susana Paixão-Barradas ${ }^{2}$

${ }^{1}$ Universidade Federal do Amazonas/UFAM, Manaus-AM, Brasil (karlamazarelo@hotmail.com)

${ }^{2}$ Universitat Politècnica de València/UPV, Valencia, España

\section{Abstract}

In today's global markets seek to be different and offer new ideas, conditions and guarantees of satisfaction to their consumers, so it is essential to design an innovative and competitive factor for a new generation of products and services based on new values and new qualities. It calls for a systemic approach that links all phases of the life cycle of the product / service, and yet, considers the benefits and harmful effects of input and output variables may cause. In this context, the design is no longer a mere instrument of creation / project to be a potential mechanism for management that acts to draw valuable and integrate the system, with the main focus for the 
strategic design vision whose level of decision lies in what to do. So, you must set and achieve objectives and goals for the formation and implementation of products and / or services proposed, offering innovative features and competitive advantage, its progress and acceptance in the market. In order to match that information to market products developed from natural fibers, the research focuses on a raw material of plant origin, from the Brazilian Amazon, where there is a great biological diversity level which is considered as material significance in scientific and foray into bioindustry. In his valuable list of plant fibers, has the tucumã-i fiber (Astrocaryum acaule) characterized by their sustainable production, adaptability to different types of products and their usability for textile production. This case study describes an analysis of the application of Amazon vegetable fiber tucumã-i (Astrocaryum acaule) in the semi-industrial development of clothing, and uses concurrent design model as qualitative tool to observe the necessary information in product design, according to the formal, functional and ergonomic object under study. The results were considered: the intrinsic values of the fiber should be observed for best semiindustrial use, of all the stages necessary to the process of making the costumes, stages of spinning and textiles have been considered as the main, the attributes ergonomic have indicated that the wires, generated from the fiber, need to be better adapted to the textile process, the structure presented by the systemic model gives a good overview of the stages of product made and allowed the identification of some factors related to the competitiveness as the ease and variety of fiber applications in products, the acceptance of fiber for semi-industrial use in the market and innovation is clearly represented by the final product. As a conclusion, the organization of data for product development, through a systemic approach may make the approach more effective actions, encouraging the production and management of new resources and new products, making them more competitive reach new markets.

Keywords: Natural Amazon fiber, Concurrent design model, Product design, Semi-industrial process, Case study.

\section{Introducción}

El concepto de "competitividad sistémica" constituye un marco de referencia para los países tanto industrializados como en desarrollo y la capacidad competitiva exige un elevado contenido de organización, interacción y gestión por parte de los grupos de actores, que deben procurar una gestión sistémica que abarque, este caso, el producto generado en su conjunto (Klaus, Wolfgang, Dirk, \& Jörg, 1996). El trabajo de diseño en la transformación de materias primas en productos y bienes de consumo es el vínculo entre el 
conocimiento y la producción. Dirige las tendencias de consumo de la sociedad, incluyendo la función del producto bajo los aspectos tecnológicos, económicos y socioculturales, sobre todo, compete al diseño agilizar el proceso de producción, mejorando la eficiencia, mediante el empleo de métodos científicos (Teixeira, Candido, \& Abreu, 2001).

Con el avance de las tecnologías y las crecientes formas de utilización de los recursos naturales en productos, los estudios con materiales más específicos son desarrollados para evaluar su prospección para un uso comercial más amplio. La demanda para ese tipo de producto, relacionado con actividades tradicionales y cuya fabricación sea compatible con un desarrollo económico sostenible a largo plazo, tiene una tendencia creciente en los países desarrollados y en desarrollo desde hace algunos años (Moral Pajares \& Rodriguez Cohard, 2000) y es razonable esperar que ésta experimente aún mayores aumentos, sobre los productos desarrollados con fibras naturales.

En este contexto, es interesante construir la información teniendo como base una metodología sistémica que vincule todas las fases del ciclo de vida del producto/servicio, analizando el entorno externo, considerando los beneficios y efectos perjudiciales que las variables de entrada y salida puedan causar, ofreciendo en el diseño un instrumento simple de creación/proyecto, de carácter estratégico y competitivo para ser un mecanismo potencial de gestión que actúa de forma valiosa para dibujar e integrar el sistema. Esas informaciones se convierten en los aspectos principales observados de este artículo, para el cual se proponen los siguientes objetivos:

- Analizar la posibilidad del uso semi-industrial de la fibra de tucumã-i (Astrocaryum acaule) para el desarrollo de productos a partir de un estudio sobre su aplicación artesanal en la confección de un vestuario;

- Utilizar el modelo de diseño concurrente, como herramienta cualitativa, para la estructuración de la información referente al sistema de estudio;

- Observar los variables necesarios al diseño de producto, según los aspectos formales, funcionales y ergonómicos;

- Identificar los factores relacionados con la competitividad del producto final ofrecido en el mercado.

2. El diseño en la generación de nuevos productos a partir del uso de las fibras naturales

La generación de nuevos productos/conceptos de diseño se ajusta a la realidad circundante respondiendo de manera adecuada a la disponibilidad de los recursos materiales y a las capacidades tecnológicas del lugar para la transformación de los mismos (Nahir \& Barrera, 2010). La etapa de desarrollo 
Estudio de la prospección del uso de la fibra de tucumã-i (Astrocaryum acaule) para el desarrollo de productos semi-industriales

del concepto y sus procedimientos en el uso de la materia prima son primordiales, una vez que éstos definen el carácter del producto, siendo una descripción concisa de cómo el producto podría ir a encontrar las necesidades, deseos, motivaciones y expectativas de los interesados potenciales (seguimiento del mercado/tipo de consumidor) y generar una experiencia de uso satisfactoria (Desmet, 2006).

En este caso, se torna importante aplicar a éstos nociones de innovación y valores más competitivos al alcance de nuevos mercados, donde el diseño estratégico podrá orientar en los posibles caminos de acción, comprender los problemas, verificar las oportunidades y limitaciones (Miguel Fernández, 2005)promoviendo la reconversión de la base tecnológica de uso de las fibras naturales para facilitar y calificar el desarrollo de nuevos productos, maximizando beneficios, ofreciendo mayor control de la misma, mejoras de acabados, de procesos y tornando los materiales más eficaces.

Con el propósito de corresponder esa información al mercado de productos desarrollados con fibras naturales, la investigación se enfoca en una materia prima de origen vegetal, proveniente de la Amazonia brasileña, en la que se presenta una gran diversidad a nivel biológico la cual es considerada como material de significancia en los estudios científicos y de incursión en la bioindustria. En su valioso listado de las fibras vegetales está la fibra de tucumã-i (Astrocaryum acaule) caracterizada por su producción sostenible, su adaptabilidad a diferentes tipologías de productos y su viabilidad de uso para la producción textil.

\section{La fibra vegetal amazónica de tucumã-i (Astrocaryum acaule)}

Las materias primas de uso artesanal en las últimas décadas están asumiendo un papel importante puesto que la aplicación de las propiedades naturales de las fibras posibilita mejoras en la calidad de vida, a partir de soluciones a problemas cotidianos (Ariza \& Dorado, 2009), y cada vez más están siendo utilizadas para el desarrollo de productos más competitivos y con aspectos de innovación.

Así siendo, la variedad de flora tropical de la Amazonia brasileña y el conocimiento popular del uso de las fibras vegetales, sugiere la posibilidad de transformación de estas materias primas en plantas cultivadas para el desarrollo de productos con denominación de origen, que pueden tornarse expresiones sociales, culturales, medioambientales, tecnológicas y económicas para la región.

Con base a este principio, la fibra natural amazónica de tucumã-i (Astrocaryum acaule), es considerada como uno de los recursos más empleados en la cadena de productos artesanales (Souza, 2004). La fibra, 
también conocida como tucum (Figura 1), está localizado en gran parte en el Alto Rio Negro - región norte de Brasil, y se destaca por presentar variables favorables al desarrollo de productos textiles (Maciel, 2008).
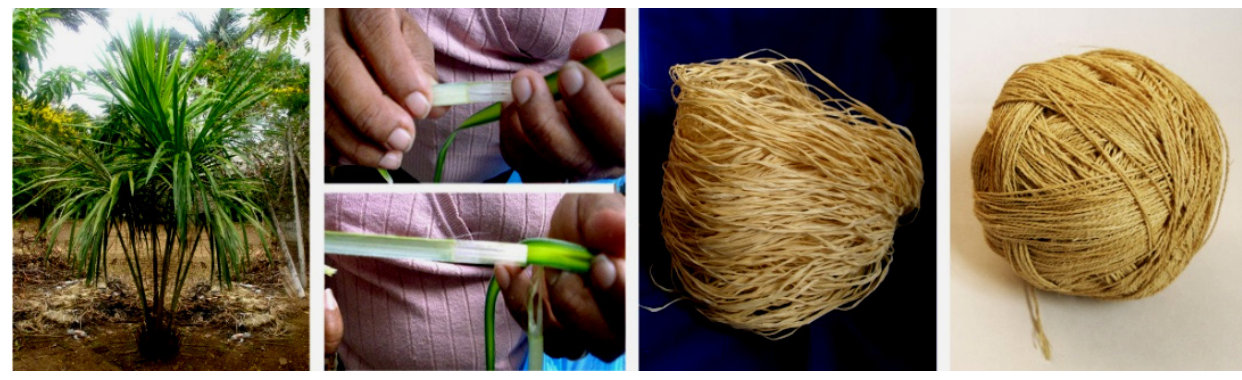

A8_Figura 1. Fibra de tucumã-i (Astrocaryum acaule).

La fibra por presentar aspectos de sostenibilidad, adaptabilidad en diferentes tipologías de productos (Figura 2), generación de empleo y renta a las comunidades productoras y poseer características tecnológicas innovadoras, la fibra demuestra su abundante disponibilidad para atender las limitaciones impuestas a la elaboración de productos ecológicamente correctos, tornando como un recurso natural con potencial para la práctica de nuevos experimentos.
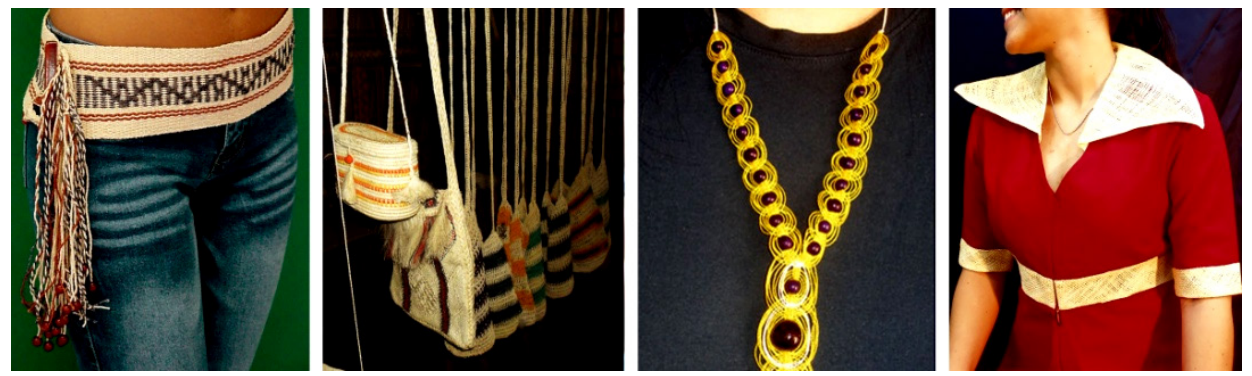

A8_Figura 2. Ejemplos de productos desarrollados con la fibra.

Además de los aspectos tecnológicos y de las características intrínsecas a ser valoradas en la fibra, hay otros factores considerados importantes como: la transferencia de conocimiento y los tipos de procesos a ser empleados para el uso de la fibra amazónica de tucumã-i (Astrocaryum acaule) en el desarrollo de nuevos productos (Pacheco et al., 2011a).

De acuerdo con la consulta previa con 15 expertos, el posicionamiento presentado por ellos ha sido unánime en cuanto a la aceptación de la fibra 
Estudio de la prospección del uso de la fibra de tucumã-i (Astrocaryum acaule) para el desarrollo de productos semi-industriales

como un nuevo recurso vegetal a ser inserido en el mercado de productos desarrollados con fibras naturales. En correspondencia al proceso de transformación y adaptación semi-industrial de la fibra en estudio, los expertos creen es una posibilidad para hacerla más eficiente y competitiva para el uso en nuevas categorías y tipologías de productos y, aún, para alcanzar nuevos mercados (Pacheco et al, 2011b).

Sobre el nivel de apreciación del uso de la fibra para el desarrollo de productos semi-industriales por parte de los consumidores (408 individuos entrevistados en Brasil), ha diagnosticado que la mayoría de los consultados mujeres, solteras, con edad variando entre 24 y más de 37 años, todas con pos-grado, ingreso mensual superior a cinco salarios mínimos y ocupación profesional dirigida a actuación en empresas y/o en la área del diseño presentó interés en consumir artículos referente a esta temática (Pacheco et al, 2011c) y que, según este público, la categoría de uso ideal para la aplicación de la fibra sería el vestuario, por tratarse de un vehículo de comunicación capaz de divulgar nuevos recursos naturales con un potencial para o uso comercial, sobre todo si confeccionado en forma de blusa, un tipo de producto creativo y estratégico para la obtención de una buena colocación para la materia prima en el mercado deseado.

En este contexto, el artículo se enfoca en la aplicación del modelo de diseño concurrente, para sistematizar y evaluar esas informaciones identificadas en estudios anteriores, principalmente a partir de una experiencia con la fibra de tucumã-i (Astrocaryum acaule) en el desarrollo de prendas de vestir específicamente blusas) teniendo en cuenta el conocimiento artesanal como la parte técnica industrial sobre coste y costura.

4. Modelo de Diseño Concurrente - Sistematización de datos para el desarrollo de vestuario a partir de uso semi-industrial de la fibra amazónica de tucumã-i (Astrocaryum acaule)

El origen del proceso semi-industrial se entiende a través de referencias hechas por los cambios en los medios de fabricación de los productos, en los cuales el diseño aparece vinculado a la diferenciación y a la optimización del desarrollo y de la manufactura, en serie, de los artículos a ser ofrecidos en el mercado, con el intuito de tornarlos más estratégicos y competitivos.

Así, el diseño empieza a hacer parte de un proceso de transición que puede orientar en los cambios de un producto artesanal para un nivel industrial ó lo más acerca de eso (semi-industrial), considerando el grado reproductibilidad de un objeto y la calidad del proyecto, principalmente en relación a su excusión (Cunha de Castro, 2009). Sobre este aspecto, el proceso de fabricación puede disponer de utilización de moldes, máquinas y 
equipamientos de reproducción, así como, de la colaboración de personas conocedoras del proceso (Mascêne, 2010) para calificar y ofrecer mejorías a la gestión, desarrollo, fabricación y comercialización del producto final.

Con respecto a este estudio, el modelo de diseño concurrente (figura 3) tornase una herramienta de apoyo para el uso da la materia prima investigada, analizando y trabajando mejor los aspectos funcionales, formales, ergonómicos y tecnológicos, de modo a evaluar su posibilidad de adaptación al uso semi-industrial, teniendo como base las variables identificadas como necesarias a este proceso y buscando alcanzar como resultado un producto tangible de diseño que sea interactivo, eficaz y trabajado a través de un proceso constante que vuelve al problema, lo analiza nuevamente y sintetiza soluciones (Swann, 2002).

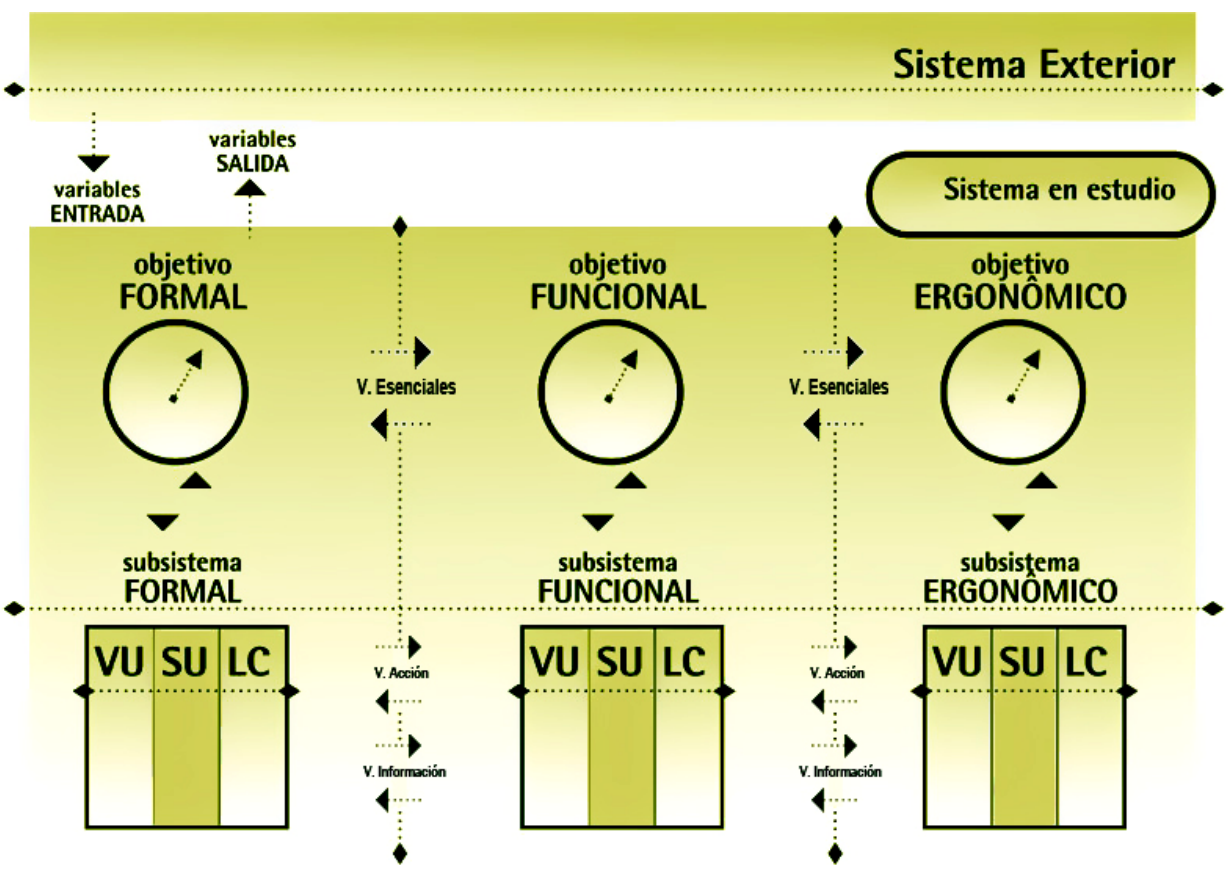

A8_Figura 3. Modelo de diseño concurrente.

El uso de este modelo sistémico específico se justifica por la posibilidad de examinar las variables necesarias para el diseño, de manera a dar vida, dinámica y actualizar a través de la retroalimentación de las informaciones y, consecuentemente, del feedback de todas las partes que componen el 
Estudio de la prospección del uso de la fibra de tucumã-i (Astrocaryum acaule) para el desarrollo de productos semi-industriales

modelo, en el cual las variables se tornan responsables por analizar, comprobar y mantener todo el sistema activo y controlado (Hernandis, 2003).

Por lo tanto, este apartado se expone el modelo a través del cual se gestionaron datos, informaciones y conocimientos durante el desarrollo de la actividad. Es oportuno destacar, que dado el alcance del trabajo, dicho proceso se centró básicamente en la definición de los componentes del sistema exterior, de las variables de entrada y el establecimiento de los objetivos correspondientes a los subsistemas funcional, ergonómico y formal, que auxiliaron en los apuntes considerados importantes para la identificación de los factores relacionados a la competitividad del uso semi-industrial de la fibra para el desarrollo del vestuario y, por fin, de la presentación del producto final.

\section{Material y método}

La investigación fue estructurada con base en la sistematización de informaciones referentes a un estudio de caso realizado a partir de la aplicación de la fibra vegetal amazónica de tucumã-i (Astrocaryum acaule) en el desarrollo semi-industrial de una prenda de vestuario (blusa).

Para el análisis de los datos, ha sido aplicado el modelo de diseño concurrente como una herramienta cualitativa y el registros de las informaciones ha sido realizado de modo exploratorio, descriptivo y explicativo en un marco teórico que proporcionó el enfoque conceptual sobre el tema propuesto (Gil, 2002).

La técnica cualitativa aplicada, auxilió en la identificación y observación de las variables necesarias al diseño de producto, según los aspectos formales, funcionales y ergonómicos del objeto en estudio. Además la estructura ofrecida por el modelo sistémico de diseño ha facilitado visualizar las etapas del producto confeccionado, permitiendo un mejor diagnóstico sobre los factores relativos a la competitividad de la fibra para actuación en el mercado y, consecuentemente, su prospección para el uso semi-industrial a partir del resultado obtenido a través del producto generado en el estudio de caso.

\section{Resultados y Discusión}

El desarrollo de la blusa de tucumã-i (Astrocaryum acaule) comprendió algunas etapas que se presentaran centradas en aspectos artesanales e industriales como: proceso de hilatura (artesanal), proceso de tejeduría (artesanal), patrón de corte (industrial), costura (industrial) y pruebas de uso con el producto final (Figura 4). 

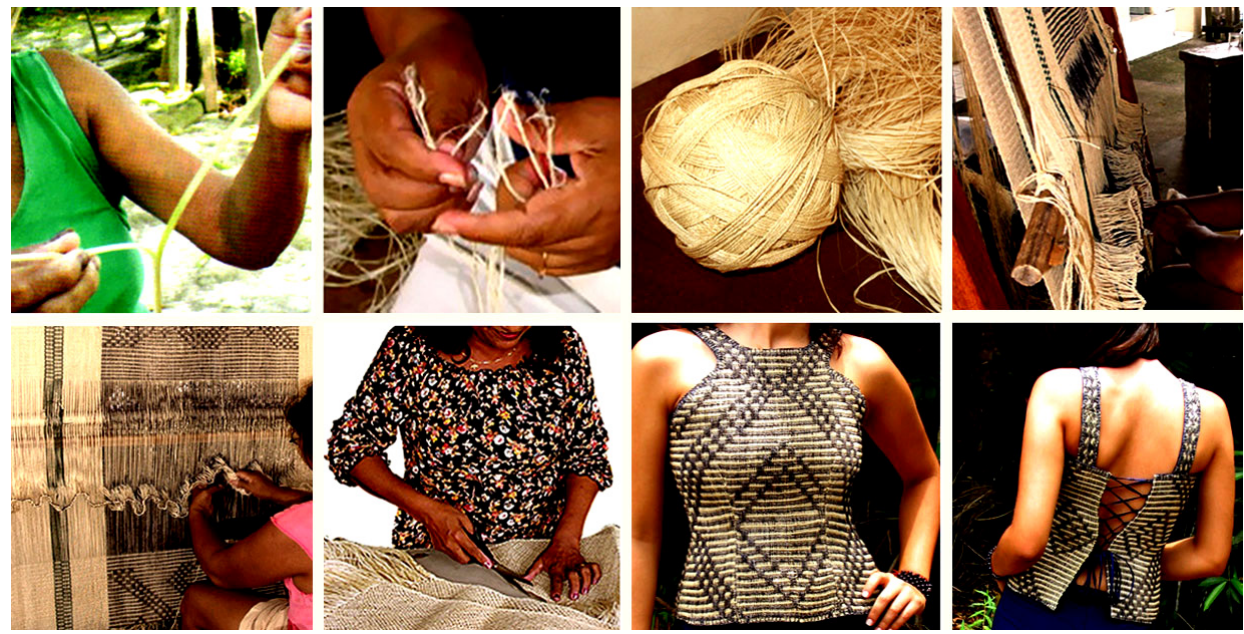

A8_Figura 4. Fases observadas en la confección de la blusa (Sistema de estudio).

De acuerdo con los análisis realizados para cada una de esas etapas:

- El proceso de hilatura $\rightarrow$ Inicialmente por ser un procedimiento aún desarrollado de forma artesanal, debido tratarse de una fibra sin muchos experimentos tecnológicos más avanzados, el proceso de hilatura necesita estandarizar los hilos cuanto a los aspectos de dimensión, de espesor, de textura y de proporción, para beneficiar la confección del tejido que sirve de estructura para la construcción de la blusa y, sobre todo, por tratarse del principal material a ser utilizado para tal finalidad.

La necesidad de mejorar el elemento hilo, también está relacionada al factor peso y, consecuentemente, para la disposición final del producto. Por lo tanto, es importante intentar viabilizar tal proceso de forma a no comprometer los valores intrínsecos de la materia prima, como por ejemplo la utilización de una maquinaria, no muy industrial y tampoco solamente artesanal, pero que pueda controlar los aspectos identificados como necesarios. En este caso, se considera importante un estudio ergonómico para suplir tal necesidad.

- El proceso de tejeduría $\rightarrow$ Aunque presente, como resultado final, un tejido natural resistente, durable y con aspectos visuales atractivos - que da énfasis a las tradiciones culturales de las comunidades productoras de la fibra, esta etapa por depender de los efectos alcanzados en la formación de los hilos, también necesita ser estandarizada en cuanto al espesor del hilo, la geometría y la textura. El uso de un telar mecánico, podrá trabajar las dimensiones de los hilos para el desarrollo del tejido final, proporcionando 
mayor igualdad y acabado a la estructura de la malla. Siendo así reiterativa la importancia del factor ergonómico.

- Patrón de corte y costura $\rightarrow$ El proceso de adaptación de la fibra natural a la forma de tejido y este al molde de la blusa proyectada, ha sido aplicado en uniformidad con las normativas establecidas por la ABNT - NBR 13374/1995, observando los aspectos técnicos de corte y costura de los materiales textiles.

- Experimentos de uso con el producto final (blusa) $\rightarrow$ A pesar de las inconformidades encontradas en las fases de hilatura y tejidos (consideradas como las etapas principales para el desarrollo del producto deseado), el producto final ha presentado muchos aspectos positivos como: apreciación y aprobación bastante significativa por parte del consumidor, principalmente por la facilidad y la variedad de aplicaciones de la fibra en productos textiles y la innovación claramente representada por esta como producto final.

Con base en este análisis, se construyó el modelo de diseño concurrente (Figura 5), para sistematizar los datos y proponer mejoras a los aspectos considerados importantes a la adaptación de la fibra de tucumã-i (Astrocaryum acaule) para el uso semi-industrial y, igualmente, para el desarrollo de un producto textil, como es el caso de una prenda de vestuario (blusa). 


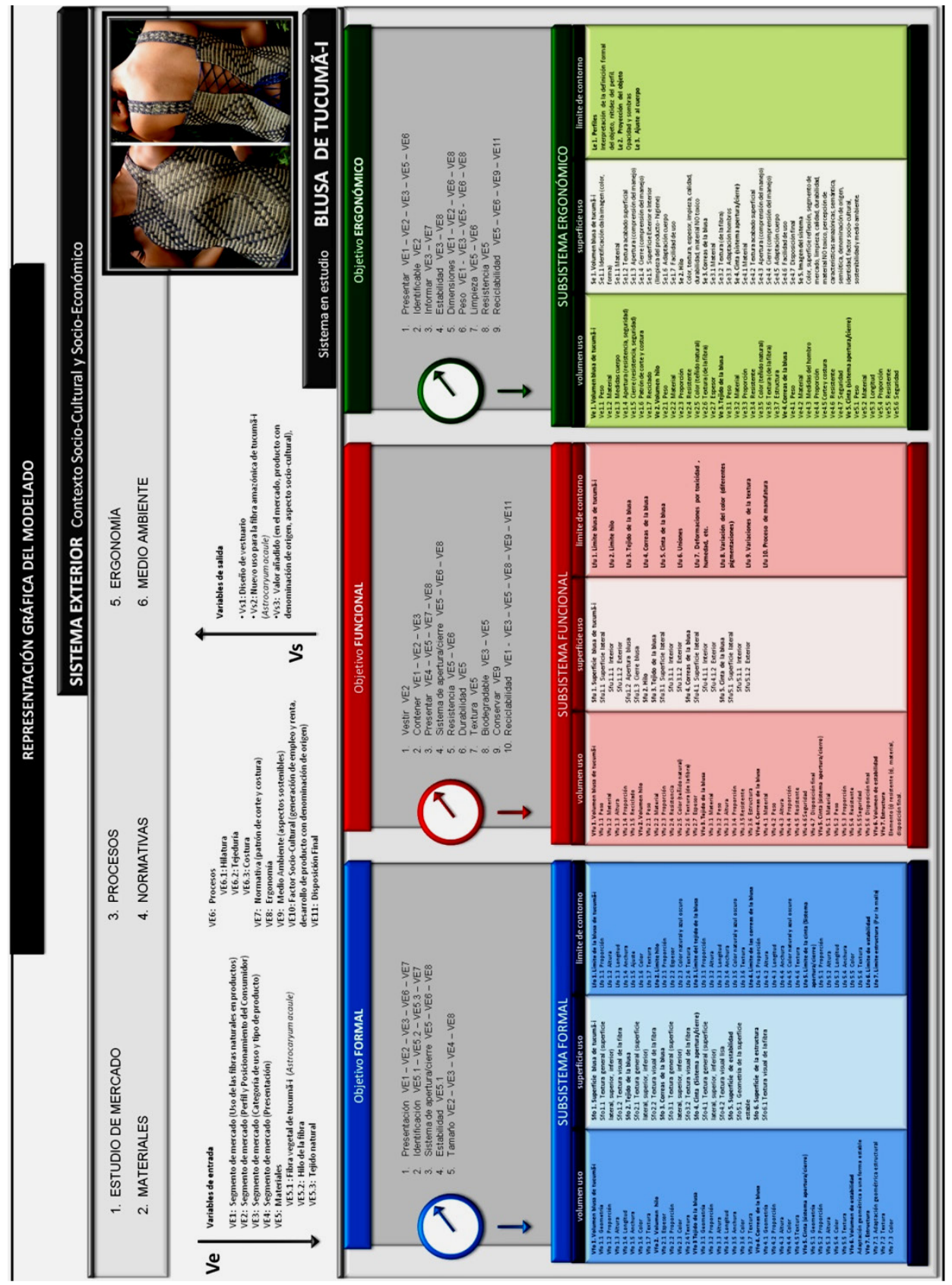

A8_Figura 5. Modelo de diseño concurrente aplicado al tema en estudio. 
En el sistema exterior del modelo buscó relacionar los contextos socio-cultural y socio-económico, estableciendo como parámetros factores de referencia: el estudio del mercado, los tipos de materiales, los procesos para adaptación y fabricación de productos, las normativas, la ergonomía y el medio ambiente. De acuerdo con cada uno de los parámetros establecidos como referencia (variables del sistema exterior), fueron determinadas las variables de entrada para auxiliar el sistema de estudio, conteniendo así las siguientes informaciones:

Ve1: Segmento de mercado (Uso de las fibras naturales en productos); Ve2: Segmento de mercado (Perfil y Posicionamiento del Consumidor); Ve3: Segmento de mercado (Categoría de uso y tipo de producto);

Ve4: Segmento de mercado (Presentación);

Ve5: Materiales (Ve5.1: Fibra vegetal de tucumã-i (Astrocaryum acaule)

Ve5.2: Hilo de la fibra / Ve5.3: Tejido natural)

Ve6: Procesos (Ve6.1: Hilatura/ Ve6.2: Tejeduría/ Ve6.3: Costura)

Ve7: Normativa (patrón de corte y costura);

Ve8: Ergonomía;

Ve9: Medio Ambiente (aspectos sostenibles);

Ve10: Factor Socio-Cultural (generación de empleo y renta, desarrollo de producto con denominación de origen);

Ve11: Disposición Final

Una vez determinadas y comprendidas las variables de entrada, el sistema de estudio estructura conforma las fases tomadas como necesarias para el desarrollado de la blusa de tucumã-i (Astrocaryum acaule). Los datos identificados en el análisis anterior pasaron a relacionarse con las informaciones establecidas para el sistema exterior y, como, variables de entrada.

Ese procedimiento ayudó en la formulación de los objetivos, a ser contemplados por el sistema de estudio de acuerdo con los aspectos funcionales, ergonómicos y formales del diseño de producto, factores estos que podrán preparar el producto final para una actuación más competitiva en el mercado.

De forma a contemplar las informaciones analizadas sobre el uso de la fibra para el desarrollo semi-industrial de productos - en este caso vestuario, consideradas importantes para la formación del modelo sistémico y para la generación de un producto final innovador y más competitivo al mercado, fueron formulados los siguientes objetivos:

- Objetivo formal se centró en $\rightarrow 1$. Presentar el segmento de mercado (uso de las fibras naturales en productos/ perfil y posicionamiento del consumidor/ 
categoría de uso y tipo de producto), procesos y normativas; 2. Identificar materiales (fibra en estudio/ hilo y tejido natural a ser producido antes de la confección del producto final); normativa (patrón de corte y costura); 3. Trabajar el sistema de apertura/cierre de la blusa (materiales/procesos/ergonomía); 4. Verificar la estabilidad de la fibra estudiada; 5. Observar el tamaño en función del segmento de mercado y de la ergonomía.

- Objetivo funcional se direccionó en $\rightarrow 1$. Elaborar un producto que tenga como finalidad el vestir, de acuerdo con qué piensa y necesita el consumidor; 2. Contener informaciones referentes al segmento de mercado (uso de las fibras naturales en productos/ perfil y posicionamiento del consumidor/ categoría de uso y tipo de producto); 3. Presentar segmento de mercado, materiales, normativas y ergonomía; 4. Trabajar el sistema de apertura/cierre en función (materiales/ procesos/ ergonomía); 5. Presentar resistencia de materiales y procesos; 6. Presentar durabilidad en los materiales utilizados; 7. Presentar textura en los materiales; 8. Generar un producto biodegradable de acuerdo con la categoría de uso y los materiales aplicados; 9. Conservar el medio ambiente resaltando los aspectos sostenibles en el producto generado; 10 . Ofrecer un producto reciclable de acuerdo con los criterios adoptados en el mercado de fibras naturales, categoría de uso, materiales, ergonomía, medio ambiente y factores socio-culturales.

- Objetivo ergonómico se constituyó en $\rightarrow 1$. Presentar el segmento de mercado (uso de las fibras naturales en productos/ perfil y posicionamiento del consumidor/ categoría de uso y tipo de producto), materiales y procesos; 2. Trabajar el producto de acuerdo con el perfil identificado en el consumidor; 3. Informar la categoría de uso, tipo de producto, patrón de corte y costura; 4. Generar estabilidad entre la categoría de uso, el tipo de producto y los aspectos ergonómicos para la confección del producto final; 5. Trabajar las dimensiones conforme el segmento de mercado (uso de las fibras naturales en productos/ perfil y posicionamiento del consumidor), procesos y ergonomía; 6. Verificar el peso del producto en función del segmento de mercado (uso de las fibras naturales en productos/ perfil y posicionamiento del consumidor), materiales, procesos y ergonomía; 7. Primar pela limpieza del producto en relación al tipo de material y proceso utilizado para su confección; 8. Presentar resistencia de materiales; 9. Ser reciclable en función de los materiales, procesos, medio ambiente y disposición final.

Con base en los objetivos, los subsistemas del modelo fueron estructurados para trabajar los siguientes elementos de composición del producto: blusa, hilo, tejido, correas de la blusa, sistema de apertura y cierre de la blusa, estabilidad y estructura. Los ítems fueron evaluados conforme el volumen de 
Estudio de la prospección del uso de la fibra de tucumã-i (Astrocaryum acaule) para el desarrollo de productos semi-industriales

uso, superficie de uso y límite de contorno, pertenecen a cada uno de los subsistemas formales, funcionales y ergonómicos, siendo especificados seguir:

Subsistema formal: volumen de uso $\rightarrow$ trabajar: geometría, proporción, altura, longitud, anchura, color y textura; superficie de uso $\rightarrow$ trabajar: textura y geometría en función de las superficies lateral, superior e inferior; límite de contorno $\rightarrow$ trabajar: proporción, altura, longitud, anchura, color y textura.

- Subsistema funcional: volumen de uso $\rightarrow$ trabajar: peso, material, altura, longitud, anchura, proporción, resistencia, seguridad, estructura y disposición final; superficie de uso $\rightarrow$ trabajar: superficies (lateral, superior e inferior); límite de contorno $\rightarrow$ trabajar: límites de contorno para cada uno de los puntos indicados, así como para ítems relacionados a los mecanismos de uniones, deformaciones generadas por la humedad, variación del color atribuida por la aplicación de las diferente pigmentaciones naturales, variaciones de texturas, etc.

- Subsistema ergonómico: volumen de uso $\rightarrow$ trabajar: peso, material, altura, longitud, anchura, proporción, resistencia, seguridad, estructura y disposición final; superficie de uso $\rightarrow$ trabajar: identificación de la imagen, material, textura, sistema de apertura y cierre, adaptación al cuerpo, facilidad de uso, color, disposición final; límite de contorno $\rightarrow$ trabajar perfiles, proyección del objeto y ajuste al cuerpo.

La estructura final del modelo sistémico permitió una buena visión de las etapas para el desarrollo del producto e identificó algunos factores relativos a la competitividad como: la facilidad y la variedad de aplicaciones de la fibra en productos, la innovación claramente representada por esta como producto final, tornándose una materia prima favorable al uso semi-industrial.

\section{Conclusiones}

El presente modelo facilita la estructuración y la organización sistémica de informaciones consideradas importante para el desarrollo de productos, sobre todo que utilicen materias primas naturales, de forma a vincular todas las fases del su ciclo de vida, orientando en los posibles caminos de acción, comprendiendo los problemas y señalando las oportunidades y las limitaciones para su viabilidad tecnológica y comercial.

Basado en éstos aspectos, el uso de la fibra de tucumã-i (Astrocaryum acaule) para el desarrollo de producto por proceso semi-industrial, puede obtener a través del uso del modelo un planteamiento de acciones más eficaces, favoreciendo a los elementos que necesitan más atención a un proceso de 
transición tecnológica (del estado artesanal al semi-industrial), de modo a vislumbrar las etapas de uso de los recursos naturales y, consecuentemente, de gestión, desarrollo y fabricación de productos más competitivos para el alcance de nuevos mercados y beneficio de los consumidores potenciales.

\section{Referencias}

ABNT - Associação Brasileira de Normas Técnicas. Material têxtil: Determinação da resistência da costura em materiais têxteis confeccionados ou não - NBR 13374/1995.

Ariza, Raquel y Dorado, Cecília. (2009). Diseño Sustentable: Oportunidades de agregar valor a la cadena lanera. In: Diseño en Palermo. IV Encuentro Latinoamericano de Diseño. Actas de Diseño. Facultad de Diseño y Comunicación.

Cunha, M. L. A. C. (2009). Entre arte e indústria: o artesanato em suas articulações com o design. Revista Espaço Acadêmico, v. 9, n. 102. 2009.

Desmet, Pieter. (2006). Inspire \& Desire. Departamento de Diseño Industrial. Delft University of Technology.

Filgueiras, A. (2008). A importância de fibras e fios no design de têxteis destinados à prática desportiva. Estudos em Design. PUC-Rio/Brasil.

Gil, A.C. (2002). Como elaborar projetos de pesquisa. 4.edição. São Paulo: Atlas.

Hernandis, B. (2003). Tesis Doctoral: Desarrollo de una metodología sistémica para el diseño de productos industriales. Universidad Politécnica de Valencia, España.

Klaus, E.; Wolfgang, H.; Dirk, M.; Jörg, M. S. (1996). Competitividad sistémica: Nuevo desafío a las empresas y a la política. Revista de la CEPAL, Santiago, número 59 , páginas $39-52$.

Maciel, Karla Mazarelo Ferreira. (2008). Technical Viability of Tucumã-i Fibre (Astrocaryum acaule) for Production in Textile Industry. In: Ecowood 2008, 3rd International Conference \& Exhibition on Environmentally-compatible forest products. Universidade Fernando Pessoa. Oporto, Portugal

Mascêne, Durcelice Cândida. (2010). Termo de referência: atuação do Sistema SEBRAE no artesanato. Brasília: SEBRAE, Brasil. 
Miguel Fernández, E. de (2005), Introducción a la gestión (Management), València, Universidad Politècnica de Valencia.

Moral Pajares, E. y Rodriguez Cohard, J.C. (2000). La competitividad internacional de la industria de madera, mimbre y muebles de madera de Jaén. Boletín del Instituto de Estudios Giennenses, número 176, páginas 1149. 1171.

Pacheco, K. M. M. et al. (2011a). Oportunidades e limitações do uso da fibra natural de tucumã-i (Astrocaryum acaule) para a gestão e desenvolvimento de produtos semi-industriais. In: Anais do $8^{\circ}$ Congresso Brasileiro de Gestão de Desenvolvimento de Produto (CBGDP). UFRGS/FEEng. Porto Alegre.

Pacheco, K. M. M. et al. (2011b). Análise do posicionamento de especialistas sobre o uso da fibra natural amazônica de tucumã-i (Astrocaryum acaule) para o desenvolvimento de produtos semi-industriais. In: Anais do III Simpósio Brasileiro de Design Sustentável (III SBDS) - Proceedings of the 3rd International Symposium on Sustainable Design (ISSD). Editora Universitária UFPE. Pernambuco.

Pacheco, K. M. M. et al. (2011c). Análise da apreciação de consumidores sobre o uso semi-industrial da fibra vegetal amazônica de ucumã-i (Astrocaryum acaule) para o desenvolvimento de produtos: Um estudo de mercado. Revista INGEPRO - Inovação, Gestão e Produção, 3 (9): 44-51.

Souza, Hermes Moreira de. et al. (2004). Palmeiras brasileiras e exóticas cultivadas. Nova Odessa. São Paulo: Instituto Platarum.

Swann, Cal (2002). Action Research and the Practice of Design. Design Issues. Weatherhead School of Management - Case Western Reserve University, Cleveland - Ohio, 18 (2): 49- 61.

Teixeira, J. A; Candido, G.A \& Abreu, A.F. (2001). A Utilização dos Materiais no Design e a Competitividade da Indústria Moveleira da Região Metropolitana de Curitiba: um estudo de caso. Revista Produção -Scielo Brasil, São Paulo, 11 (1): 27-41.

Yaffa Nahir, Ivette Gomez Barrera. (2010). Nuevos conceptos para el diseño y la artesanía locales. Revista Grafías Disciplinares de la Universidad Católica Popular del Risaralda, Colombia, 12 (1): 50 - 55. 


\subsection{Artículo 9 - Variables esenciales y aspectos del diseño considerados importantes al uso y beneficio de la fibra natural amazónica de tucumã-i (Astrocaryum acaule) para su aplicación textil}

Esta producción científica ha sido realizada con la intención de identificar, a través del modelo de diseño concurrente, las variables esenciales y cuál de los aspectos de diseño deben ser considerados importante al beneficio y mejor competitividad del objeto de estudio para su aplicación textil (Publicación en portugués). El artículo corresponde al objetivo 3 de la tesis (Pags.67, 68,69 y 70).

Conferencia: II Conferência Internacional de Design, Engenharia e Gestão para a inovação.

\section{ISBN 978-972-752-117-3}

Enviado: 30.Mayo.12 | Aceptado: 20.Julio.12 | Publicado: Octubre.12

Cita: Pacheco, K. M. M.; Ortuño, B. H.; Pacheco, A. S.; Paixão-Barradas, S. (2012). Variáveis essenciais e aspectos do design considerados importantes ao uso e beneficiamento da fibra natural amazônica de tucumã-i (Astrocaryum acaule) para aplicação têxtil. II Conferência Internacional de Design, Engenharia e Gestão para a inovação - IDEMi : Projeto Centrado no Usuário. Florianópolis, SC, Brasil, 21-23, Outubro, 2012.

Variáveis essenciais e aspectos do design considerados importantes ao uso e beneficiamento da fibra natural amazônica de tucumã-i (Astrocaryum acaule) para aplicação têxtil

Karla Mazarelo Maciel Pachecoํㅜㄹ Bernabé Hernandez Ortuño², Almir de Souza Pacheco $^{2}$, Susana Paixão-Barradas ${ }^{2}$

1 Universidade Federal do Amazonas - UFAM, karlmazarelo@hotmail.com

2 Universitat Politècnica de València - UPV, bhernand@degi.upv.es

${ }^{2}$ Universitat Politècnica de València - UPV, almirdesigner@gmail.com

${ }^{2}$ Universitat Politècnica de València - UPV, supaipe@upvnet.upv.es

\section{Abstract:}

The paper presents an analysis about the using of the natural Amazonian fibre of tucuma-i (Astrocaryum acaule) in the development of clothing in order to adapt it (eventually) to a semi-industrial process. The research used the design competition model, proposed by Hernandis (2003), to sort the data 
Estudio de la prospección del uso de la fibra de tucumã-i (Astrocaryum acaule) para el desarrollo de productos semi-industriales

obtained in previous studies using bibliographic records and application of techniques such as: focus groups, in-depth interview and a questionnaire to consumers and, thereby, identify the key variables of study system. Among the results, ergonomics was considered the most important design aspect for the process of fibre beneficiation, particularly to assist in the standardization of elements of the final product (yarn and fabric), which enables the use of new technologies to improvement of the processes of spinning and weaving; the structure of the applied method enabled the visualization of the steps of the product manufacturing (clearly), corroborating for planning of actions and management of the natural resource studied to development of new and/or various textiles products, more competitive in order to reach new markets and potential consumer satisfaction.

Palavras chave: fibra natural; aspectos do design; design de produto, modelo sistêmico e produto têxtil.

\section{Introdução}

O design está desenvolvendo, cada vez mais, a sua atuação em muitas áreas do conhecimento (Marques, 2010), das quais se pode destacar o uso de recursos naturais para o desenvolvimento de novos produtos. 0 sucesso de novos produtos, no entanto, necessita de um planejamento que esteja diretamente ligado a conceitos e características que despertem uma atitude diferente no consumidor em relação a ele (Christensen, Brown, Markides \& Geroski, 2005). Sendo assim, a análise de produtos, mercados e público-alvo obrigam a considerar um grande número de informações de modo a encontrar os melhores atributos que produzam um nível de resposta desejada, classificando e agrupando os dados. A coleta e a sistematização desses elementos são essenciais para garantir a adequação do produto final às necessidades dos consumidores em potencial, tornando-o mais competitivo para atuar no mercado almejado (Motta, Mattar, Barreto, \& Teixeira, 2007). Neste contexto, o uso de recursos naturais na fabricação de produtos é considerado muito vantajoso para o mercado e ainda podem ser mais valorizados, uma vez que o avanço tecnológico tem mostrado que o uso das fibras naturais já não pode ficar limitado apenas às aplicações tradicionais (Oashi, 1998). Sobre esses aspectos, a fibra vegetal amazônica de tucumã-i (Astrocaryum acaule) vem se destacando na região norte do Brasil pela sua resistência, ausência de componentes tóxicos, possibilidade de aplicação têxtil e capacidade de gerar uma grande variedade de produtos ( $\mathrm{K}$. Pacheco, Ortuño, Miranda, Nascimento \& A. Pacheco, 2011). Experimentos realizados com esta matéria-prima contemplam a confecção de peças de vestuários como: blusas, corseletes, tops, cintos e etc., todas idealizadas conforme os 
aspectos intrínsecos existentes na fibra. Os processos tecnológicos utilizados nos ensaios são de natureza artesanal e de conhecimento tradicional indígena, apresentando apenas como diferencial: a assistência técnica do Design de produto e as informações básicas sobre corte, costura e tecelagem fornecidas e exemplificadas por uma profissional têxtil, vinculada a uma empresa de pequeno porte (Maciel, Nascimento, \& Lucas Filho, 2007). Uma análise sobre a aplicação da fibra de tucumã-i (Astrocaryum acaule) no desenvolvimento de vestuário busca identificar os aspectos do design considerados mais importantes neste contexto e, com isto, tentar beneficiar a matéria-prima para uma posterior aplicação semi-industrial, sobretudo na confecção de artigos do segmento têxtil, razão pela qual a investigação encontra-se centralizada nos seguintes objetivos:

- Identificar as variáveis essenciais para a atuação do design no sistema de estudo, segundo os aspectos formais, funcionais e ergonômicos;

- Identificar qual aspecto do design (forma, função e ergonomia) deve ser enfatizado para o benefício do objeto de estudo e melhor competitividade do produto final.

\section{Materiais e métodos}

A pesquisa foi estruturada com base na sistematização de informações obtidas, em um primeiro momento, através de registros bibliográficos (Maciel, 2007) e aplicações de técnicas como focus group (Pacheco, Ortuño \& Miranda, 2011), entrevista em profundidade (K. Pacheco, Ortuño \& A. Pacheco, 2011) e questionário ao consumidor (Pacheco, Ortuño, Miranda, Nascimento \& Vicente, 2011). Em seguida, foram somadas às observações realizadas a partir de um estudo de caso sobre a aplicação da fibra vegetal amazônica tucumã-i (Astrocaryum acaule) no desenvolvimento de um vestuário (blusa). Para análise dos dados, foi aplicado o modelo de design concorrente proposto por Hernandis (2003), como uma ferramenta qualitativa. A técnica aplicada objetivou registrar e ordenar as informações dentro de um quadro de estudo, de modo exploratório, descritivo e explicativo, proporcionando assim uma abordagem conceitual sobre o tema proposto (Gil, 2002), e ainda, auxiliando na identificação e observação das variáveis essenciais para o design de produto, conforme os atributos: formal, funcional e ergonômico. Além disso, a estrutura oferecida pelo modelo sistêmico tem proporcionado uma boa visibilidade aos projetos voltados à fabricação de produtos, o que permite um melhor diagnóstico dos fatores relacionados à competitividade da fibra de tucumã-i (Astrocaryum acaule) para o seu desempenho no mercado e, ainda, um diagnóstico preliminar para o seu uso semi-industrial, considerando como base inicial o produto final gerado através do experimento analisado. 
Estudio de la prospección del uso de la fibra de tucumã-i (Astrocaryum acaule) para el desarrollo de productos semi-industriales

\section{Resultados obtidos}

Conforme os dados bibliográficos levantados, foi diagnosticado que a fibra de tucumã-i (Astrocaryum acaule) é um recurso natural vegetal da Amazônia brasileira, pouco explorado e conhecido, caracterizando-se por sua produção sustentável e pela possibilidade de gerar diversos tipos de produtos: têxteis, utensílios domésticos e/ou decorativos. A matéria-prima não apresenta maiores informações quanto a sua aplicação em produtos mediante o uso de processos de fabricação avançados de caráter industrial ou semi-industrial. Os subsídios existentes descrevem somente práticas desenvolvidas de forma empírica e artesanal. Com base nessa informação, foram iniciados (há pouco tempo) alguns estudos com o intuito de verificar a possibilidade de aplicação semi-industrial da fibra de tucumã-i (Astrocaryum acaule) para o desenvolvimento de produtos. A princípio, uma sondagem de opinião realizada com designers de produtos, através da técnica focus group, e outra atividade praticada com especialistas de áreas relacionadas ao tema por entrevista em profundidade apresentaram um parecer bastante positivo, ressaltando com prioridade os aspectos tecnológicos e de transformação existentes na fibra e, ainda, a necessidade de saber a opinião dos potenciais consumidores deste produto, para um melhor processo de adaptação e direcionamento da referida matéria-prima no mercado (Figura 1).

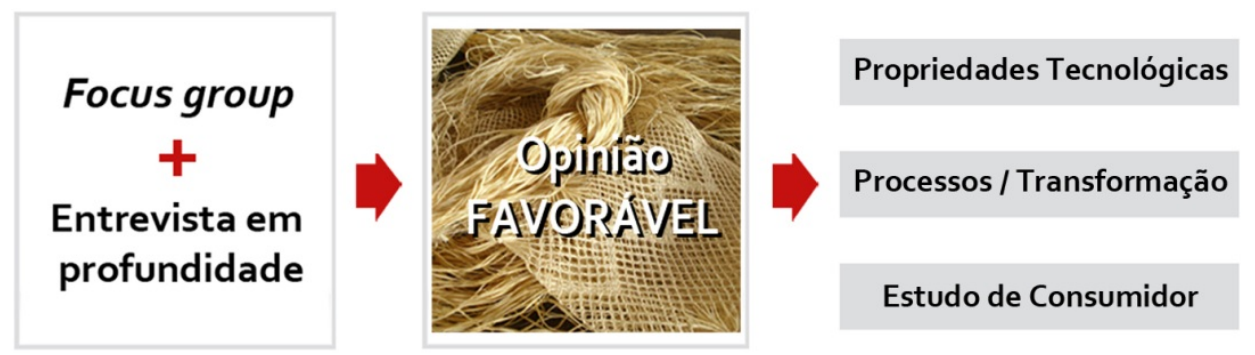

A9_Figura 1. Resultado da sondagem de opiniões feita com designers de produto e especialistas de áreas relacionadas ao tema de estudo.

A pesquisa de opinião realizada com 408 consumidores apresentou um alto nível de consumo de produtos confeccionados com fibras naturais, sendo justificado pela grande variedade de fibras e tipos de produtos oferecidos no mercado. 0 coeficiente de apreciação, desses consumidores, com relação ao uso e inserção de novas fibras vegetais para o desenvolvimento e comercialização de produtos foi considerado bastante significativo, principalmente quando questionados a respeito da fibra de tucumã-i (Astrocaryum acaule) e a sua possibilidade de aplicação semi-industrial. 
Mediante os quesitos apresentados aos consumidores, a resposta (Figura 2) foi extremamente positiva em relação ao número de participantes envolvidos.

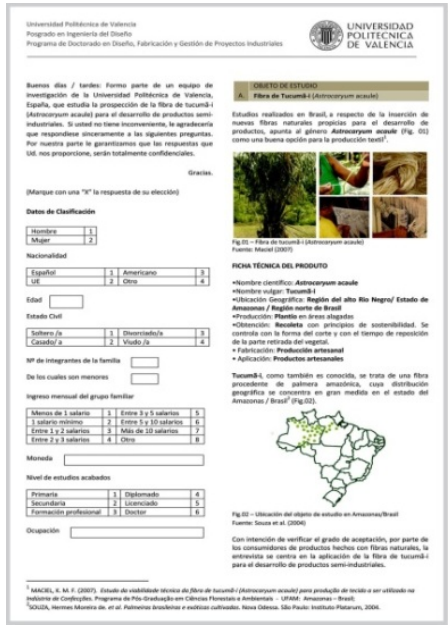

\section{Pesquisa de opinião | Consumidor}

\section{Nível de consumo PRODUTOS FIBRAS NATURAIS Frequência \\ 331 \\ $81,1 \%$ \\ Motivo do consumo VARIEDADE FIBRAS/PRODUTOS \\ Frequência \\ 286 \\ $70,1 \%$}

Nível de apreciação USO DE NOVAS FIBRAS VEGETAIS

\begin{tabular}{|lr|}
\hline Frequência & $\%$ \\
\hline 405 & $99,3 \%$
\end{tabular}

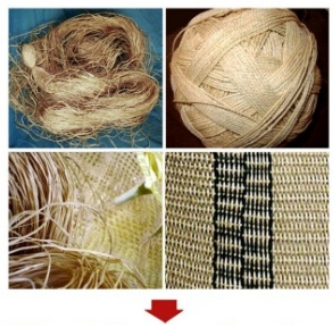

Nível de aceitação TUCUMÄ-I/PROD. SEMI-INDUSTRIAL

\begin{tabular}{|lr}
\hline Frequência & $\%$ \\
\hline 406 & $99,5 \%$ \\
\hline
\end{tabular}

A9_Figura 2. Pesquisa de opinião realizada com os consumidores.

Ainda com base nos dados apresentados pelos consumidores, observou-se que a categoria de uso e o tipo de produto, mais votados, para a aplicação semiindustrial da fibra foram os de segmento têxtil, destacando o setor do vestuário e, dentro deste, a confecção de blusas (Figura 3).

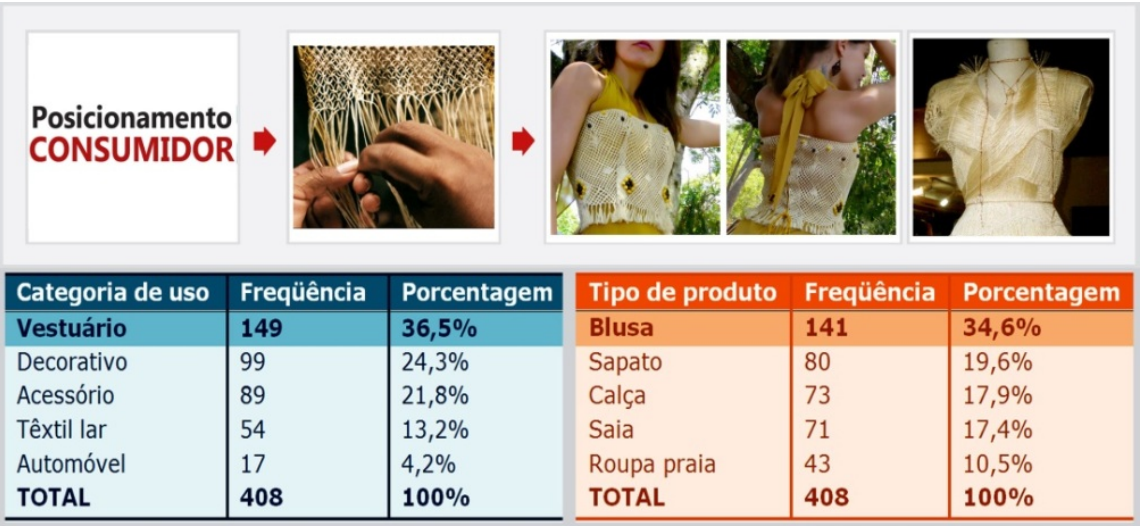

A9_Figura 3. Opinião do consumidor: categoria de uso e tipo de produto.

Tomando por base a categoria de uso e o tipo de produto assinalado pelos consumidores, os dados coletados, nessa primeira etapa da pesquisa, foram 
Estudio de la prospección del uso de la fibra de tucumã-i (Astrocaryum acaule) para el desarrollo de productos semi-industriales

relacionados com um experimento realizado por Maciel (2007), que retrata a confecção de peças de vestuários utilizando a fibra de tucumã-i (Astrocaryum acaule). Todas as informações foram ponderadas e inseridas na estrutura oferecida pelo modelo de design concorrente para proceder com a análise sobre o uso da fibra para o segmento têxtil e identificar as variáveis necessárias ao sistema de estudo em função dos aspectos do design do produto. Neste contexto, a análise teve como sistema de referência a confecção de uma blusa e todos os procedimentos e materiais utilizados para o desenvolvimento do produto final (Figura 4).

\section{OBJETO DE ESTUDO}

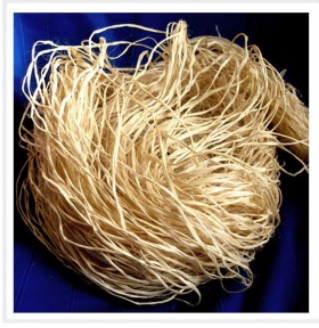

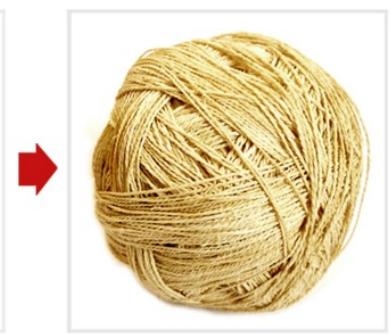

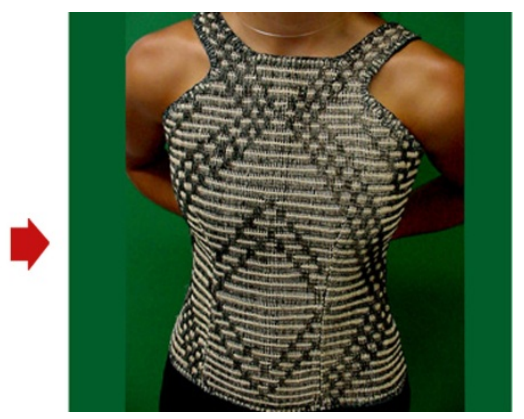

A9_Figura 4. Objeto de análise - blusa de tucumã-i (Astrocaryum acaule).

Os materiais, técnicas e etapas utilizadas para o processo de confecção da blusa de tucumã-i (Astrocaryum acaule) apresentaram um conhecimento puramente artesanal, salvo as fases de:

- Geração de alternativas propostas para a confecção da blusa, realizada por um designer;

- Tecelagem corte e costura que foram embasadas na NBR 13374/1995 da ABNT (Associação Brasileira de Normas técnicas) e trabalhadas por uma profissional têxtil.

Os procedimentos tradicionais utilizados não permitiram uma padronização de alguns aspectos necessários à confecção do produto final, apesar da fibra apresentar propriedades tecnológicas compatíveis à prática realizada e oferecer, no seu conjunto, a fabricação de um produto natural, inovador e com grandes vantagens competitivas.

A principal limitação identificada durante o experimento foi à falta de padronização nos processos de fiação da fibra e confecção do tecido (Figura 5) que, em ambos os casos, necessitam de uma uniformidade nos fios e na construção das tramas do tecido no que concerne a aspectos de proporção, 
tamanho, espessura, textura, peso, etc., em beneficio do desenvolvimento do produto final (blusa).
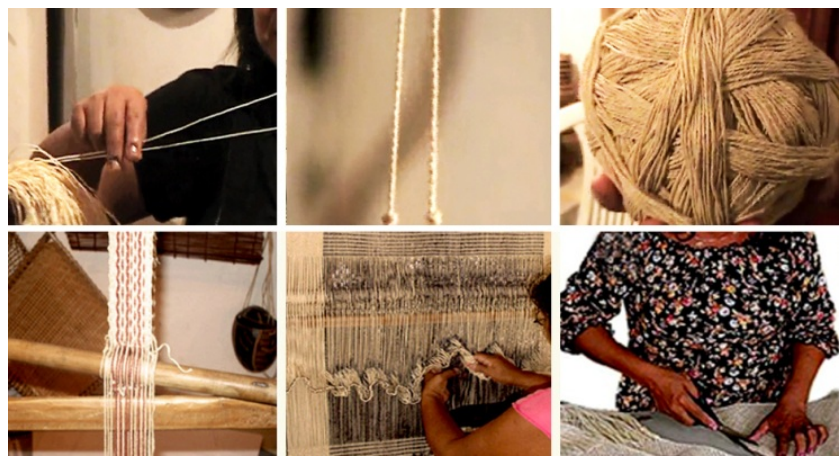

A9_Figura 5. Etapas de fiação e confecção de tecido.

Mediante as observações e os objetivos propostos, foi iniciada a sistematização das informações no modelo de design concorrente, no qual o sistema exterior foi composto por oito itens principais: estudo de mercado, materiais, processos, normas técnicas, ergonomia, meio ambiente, fator sociocultural e tecnologia. No próximo passo, foram determinadas as variáveis de entrada (Figura 6) do sistema de estudo.

SISTEMA EXTERIOR
1. Estudo de Mercado
2. Materiais
3. Processos
4. Normas Técnicas
5. Ergonomia
6. Meio Ambiente
7. Fator Sociocultural
8. Tecnologia

\section{A9_Figura 6. Sistema exterior e variável de entrada do sistema.}


Estudio de la prospección del uso de la fibra de tucumã-i (Astrocaryum acaule) para el desarrollo de productos semi-industriales

Em seguida, foram elaborados os objetivos de estudo do sistema (Figura 7), vinculados a cada uma das variáveis de entradas e aos aspectos do design com relação à forma, função e ergonomia do produto.

\section{Objetivo FORMAL}

Apresentar Ve1 | Ve2 | Ve3 | Ve4

Ve5 | Ve6 | Ve 7 | Ve8

Compreender Ve2 | Ve2.1 | Ve2.2

Beneficiar Ve1.1 | Ve2 | Ve6 | Ve7

Relacionar Ve1 | Ve2 | Ve3 | Ve5

Padronizar Ve1.2|Ve2.1|Ve5.1

\section{Objetivo FUNCIONAL}

Vestir Ve1.1

Conter Ve1 | Ve2 | Ve2.2

Apresentar Ve3 | Ve4 | Ve5

Facilitar sistema de fecho $\mathrm{Ve} 2|\mathrm{Ve} 3| \mathrm{Ve} 5$

Oferecer resistência Ve2 | Ve3

Propor durabilidade $\mathrm{Ve} 2$

Ser biodegradável Ve1.2

Considerar Ve6

\title{
Objetivo ERGONÔMICO
}

\author{
Apresentar Ve1 | Ve2 | Ve3 | Ve4 \\ Identificar Ve1.1 \\ Informar Ve1.2 | Ve4 \\ Propor estabilidade Ve1.2 | Ve5 \\ Dimensionar Ve1.1 | Ve3 | Ve5 \\ Diminuir peso $\mathrm{Ve} 1.2$ | Ve2 |Ve3 | Ve5 \\ Oferecer limpeza $\mathrm{Ve} 2$ |Ve3 \\ Ser reciclável Ve2 |Ve3 | Ve6
}

A9_Figura 7. Objetivos do sistema de estudo.

Após a definição dos objetivos foram trabalhados os subsistemas de estudo, que buscaram a melhor forma de utilização e adaptação dos elementos de composição do produto (estrutura da blusa, fio, tecido, alças, fecho e etc.), avaliando os aspectos de volume de uso, superfície de uso e limite de contorno, pertencentes a cada um dos atributos: formal, funcional e ergonômico que compõem o modelo aplicado (Figura 8). 


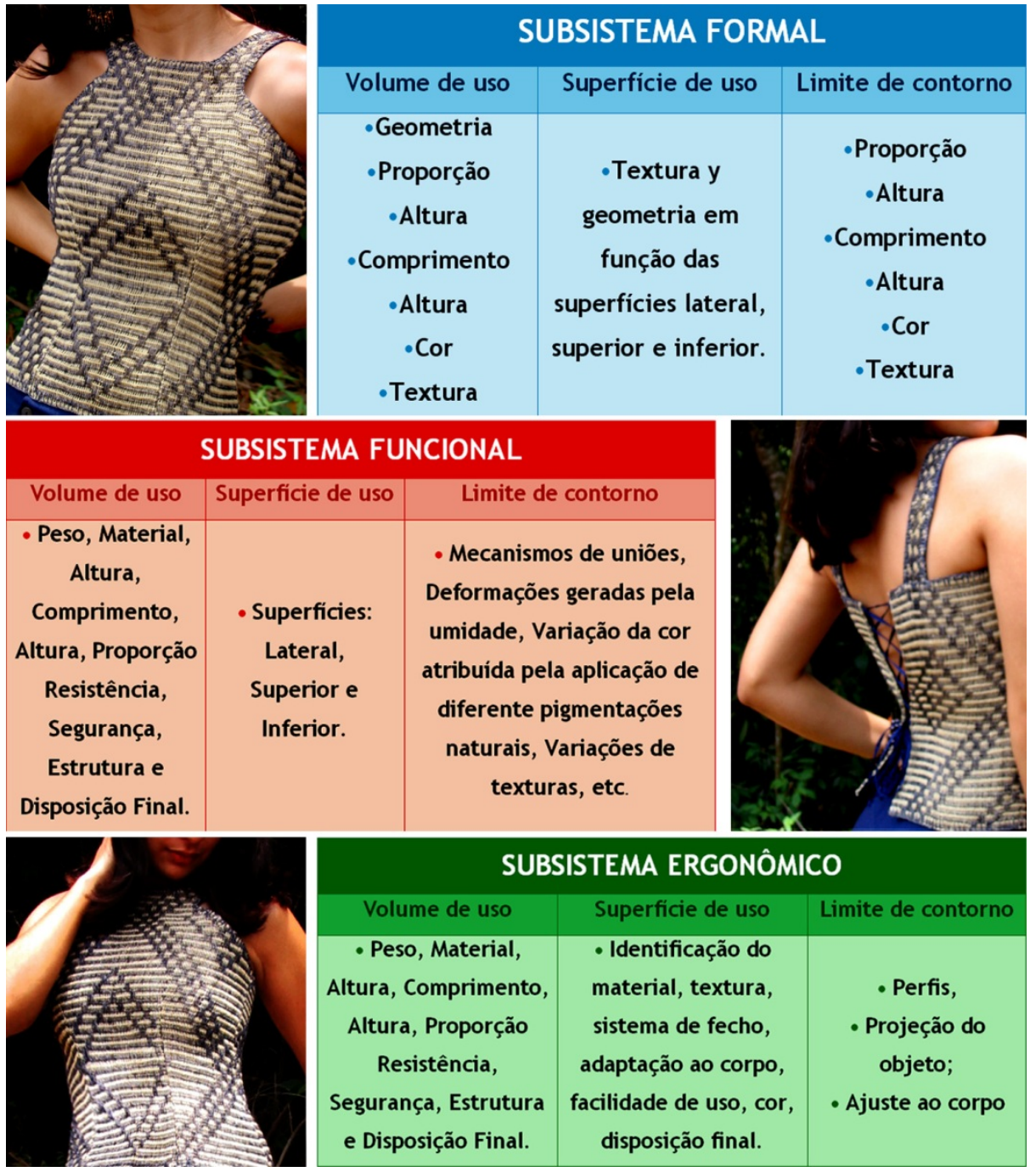

A9_Figura 8. Subsistemas formal, funcional e ergonómico.

Com a determinação dos componentes e elementos dos subsistemas (sistemas fundamentais de estudo), mais uma vez foi realizada uma análise direcionada aos objetivos globais pertencentes a cada um dos sistemas fundamentais, verificando e delimitando a tarefa a ser exercida por eles, em função da composição do produto final. Nesta etapa, também foram observadas as variáveis de ação e informação (Figura 09), onde a primeira delineou o 
caminho para a atuação do design em relação ao sistema de estudo e a segunda apresentou os resultados alcançados com as variáveis de ação.
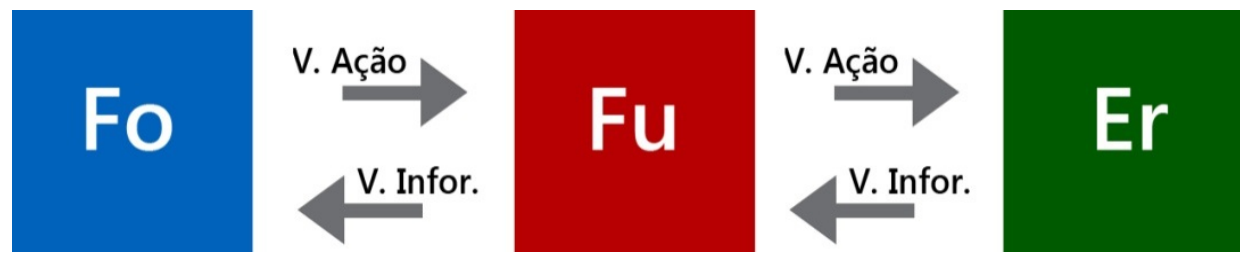

A9_Figura 9. Processo de atuação das variáveis de ação e informação nos sistemas fundamentais do estudo.

Relacionando as variáveis de ação a cada um dos subsistemas estudados, as orientações dadas ao design, como fatores prioritários, foram:

VaFu-Er: Solucionar os aspectos técnicos pendentes nos elementos: fio e tecido; Qualificar os processos de fiação e tecelagem da blusa; Trabalhar as medidas antropométricas do produto; Valorizar os aspectos intrínsecos da fibra; Considerar a preferência dada ao tipo de produto escolhido pelo consumidor; Seguir normas técnicas para padronização de materiais têxteis.

VaFu-Fo: Valorizar a estrutura do material; Evidenciar a textura da matériaprima utilizada para o produto; Explorar as variações de cores disponíveis nos processos de pigmentação natural realizado com a fibra; Propor novas alternativas à composição visual do produto final; Verificar as tendências de mercado (cores, formas, texturas) oferecidas ao consumidor e relacioná-las às informações contextualizadas neste sistema de estudo.

VaEr-Fu: Padronizar os elementos gerados a partir dos processos de fiação e tecelagem da fibra (fio e tecido); Facilitar o uso do produto; Propor resistência, segurança e durabilidade à blusa.

VaEr-Fo: Trabalhar os aspectos antropométricos em função do tipo de produto escolhido pelo público-alvo (ajuste ao corpo); Otimizar os elementos de composição do produto: alças, fecho, material, textura, etc., Trabalhar os aspecto de peso, comprimento, proporção, altura, largura e entre outros.

Como variáveis de informação, foram assinalados os possíveis benefícios ao produto final:

- Maior valorização da fibra (aspecto natural e sociocultural, origem, produção, propriedades tecnológicas, uso, etc.);

- Beneficiamento e melhor utilização da matéria-prima para a sua aplicação têxtil; 
- Possibilidades de gerar novos e variados tipos de produtos a partir da fibra beneficiada;

- Matéria-prima com critérios de padronização para o desenvolvimento de produtos têxteis;

- Uso de novas tecnologias em função da qualificação dos processos de confecção de produtos a base da matéria-prima estudada;

- Registro de novas informações sobre o uso da fibra de tucumã-i (Astrocaryum acaule) para a fabricação de vestuário;

- Design como fator estratégico para o alcance de novos mercados;

- Geração e oferta de produtos mais competitivos e com aspecto de inovação;

- Benefício social, econômico e ao meio ambiente (produto com aspecto sustentável);

A partir dessas informações foram identificadas as variáveis essenciais ao sistema de estudo que deverão atuar diretamente sobre os objetivos e as fases que competem à ação do design (Figura 10) para melhor adaptação e uso da fibra de tucumã-i (Astrocaryum acaule) na confecção de vestuário e segmento têxtil.

\begin{tabular}{|c|c|}
\hline \multicolumn{2}{|l|}{ VARIÁVEIS ESSENCIAIS } \\
\hline \multicolumn{2}{|l|}{ MATERIAL $\vee$ FIBRA DE TUCUMÄ-I (Astrocaryum acaule) } \\
\hline Aspectos tecnológicos favoráveis ao uso têxtil & + \\
\hline Variedade de aplicação em produtos & * \\
\hline Aspectos de inovação e de competitividade & 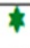 \\
\hline Produçãosustentável & 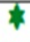 \\
\hline Produtonatural & $\downarrow$ \\
\hline \multicolumn{2}{|l|}{ ESTUDO DE MERCADO } \\
\hline Aprovação dos consumidoresem potencial & + \\
\hline Preferência por uma categoria de uso & + \\
\hline Preferência por um tipo de produto & 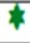 \\
\hline
\end{tabular}

\begin{tabular}{|c|c|}
\hline DS & \\
\hline Possibilidades de transformação e adaptação têxtil & $\pitchfork$ \\
\hline Possibilidades de aplicacôestêxteis & 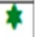 \\
\hline Possibilidade de adaptação às tecnologias mais avançadas & 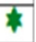 \\
\hline NORMASTÉCNICAS & \\
\hline Produto enquadrado às normastécnicasp/mateniaistêxtes & 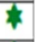 \\
\hline Produto embasado nas normastécnicasp/cortee costura & 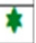 \\
\hline ERGONOMIA & \\
\hline Produto com padronização de fios & $\star$ \\
\hline Produto com padronização de tecidos & 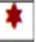 \\
\hline Produto/Usuário & 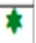 \\
\hline Produto/Acabamento & 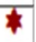 \\
\hline Produto/Sistemade uso & † \\
\hline
\end{tabular}

A9_Figura 10. Variáveis essenciais do sistema.

Das variáveis essenciais relacionadas, mais uma vez, foi identificado que os aspectos de padronização da fibra tornam-se primordiais ao produto final, assim como o "acabamento" que está diretamente relacionado com a unificação dos elementos de composição da blusa. 


\section{Conclusão}

A análise sobre a aplicação da fibra de tucumã-i (Astrocaryum acaule) no desenvolvimento de vestuário objetivou identificar as limitações existentes no experimento realizado com a matéria-prima para a confecção de uma blusa e, a partir dela, propor melhoras às etapas que necessitam de maior atenção para a fabricação do produto final de forma a oferecer um artigo têxtil inovador, diferenciado e competitivo. Através do modelo de design concorrente proposto por Hernandis (2003), foi possível organizar os dados levantados sobre a matéria-prima, opinião de mercado e demais aspectos relacionados ao tema e ter uma visão ampla do sistema de estudo. A ferramenta utilizada apontou as informações necessárias ao design do produto, considerando os aspectos formais, funcionais e ergonômicos. Com isso, sinalizou que a ergonomia deve ser o principal atributo a ser trabalhado no design do objeto analisado, sobretudo no que concerne à padronização da fibra e dos elementos gerados (fio e tecido) através dos processos de fiação e tecelagem relacionados à sua aplicação têxtil. Os benefícios originados a partir dessas melhoras facilitarão o planejamento das ações, tornando-as mais eficazes e favorecendo a gestão do uso da fibra de tucumã-i (Astrocaryum acaule) para o desenvolvimento de novos e/ou variados artigos têxteis, assim como poderão orientar a inserção de tecnologias mais avançadas ao processo, como o método semi-industrial, por exemplo, vislumbrando a fabricação de produtos diferenciados e mais competitivos para o alcance de novos mercados e satisfação dos consumidores em potencial.

\section{Referências}

Christensen, C.; Brown, J. D.; Markides, C.; Geroski, P. O crescimento pela Inovação: como crescer de forma sustentada e reinventar o sucesso. Rio de Janeiro: ELSEVIER: Campus, 336p, il. Tradução de: Innovator's solution. 2003.

Hernandis, B. Desarrollo de una metodología sistémica para el diseño de productos industriales. Tesis Doctoral (Doctorado en Ingeniería Industrial) Universidad Politécnica de Valencia, 2003.

Maciel, K. M. F. Estudo da Viabilidade Técnica da Fibra de Tucumã-i (Astrocaryum acaule) para Produção de Tecido a ser utilizado na Indústria de Confecções. Dissertação apresentada ao Programa de Pós-Graduação em Ciências Florestais e Ambientais da Universidade Federal do Amazonas ,2007.

Maciel, K. M. F.; Nascimento, C. C.; \& Lucas Filho, F. C. (2007). Fibra de tucumã-i (Astrocaryum acaule) como matéria-prima para o design têxtil: um estudo da viabilidade técnica. In: Congresso Internacional de Pesquisa em Design, 4., 2007, Rio de Janeiro. Anais do $4^{\circ}$ Congresso Internacional de 
Pesquisa em Design. Rio de Janeiro: CCJF, 2007. 1 CD-ROM. ISBN: 85-8928903-6

Marques, Carolina de Oliveira. O ensino e o mercado de trabalho na área de design. Dissertação apresentada ao Programa de Pós-graduação em Design da Faculdade de Arquitetura, Artes e Comunicação da Universidade Estadual Paulista "Júlio de Mesquita Filho", 2010.

Pacheco, K. M. M.; Ortuño, B. H.; Miranda, I. P. A. (2011). Análise do posicionamento do design quanto ao uso semi-industrial da fibra amazônica de tucumã-i (Astrocaryum acaule) para a fabricação de produtos. $1^{\circ}$ Congresso de Design UEM - $5^{a}$ Semana de Design UEM - Design brasileiro: cultura ou influência? - Universidade Estadual de Maringá - UEM. Campus Regional de Cianorte - Paraná/ Brasil. ISSN: 2237-0862.

Pacheco, K. M. M.; Ortuño, B. H.; Miranda, I. P. A.; Nascimento, C. C.; Pacheco, A. S., (2011). Oportunidades e limitações do uso da fibra natural de tucumã-i (Astrocaryum acaule) para a gestão e desenvolvimento de produtos semi-industriais. In: $8^{\circ}$ Congresso Brasileiro de Gestão de Desenvolvimento de Produto (CBGDP), 8., 2011. Anais do $8^{\circ}$ Congresso Brasileiro de Gestão de Desenvolvimento de Produto (CBGDP). UFRGS/FEEng. Porto Alegre - RS/ Brasil. ISBN:85-88085-47-3 (Livro Congresso).

Pacheco, K. M. M.; Ortuño, B. H.; Miranda, I. P. A.; Nascimento, C. C.; Vicente, B. A. (2011). Análise da apreciação de consumidores sobre o uso semi-industrial da fibra vegetal amazônica de tucumã-i (Astrocaryum acaule) para o desenvolvimento de produtos: Um estudo de mercado. Revista INGEPRO - Inovação, Gestão e Produção, Universidade Federal de Santa Maria - UFSM. Rio Grande do Sul/Brasil, 3 (9): 44-51. ISSN: 1984-6193

Pacheco, K. M. M.; Ortuño, B. H.; Pacheco, A. S. (2011). Análise do posicionamento de especialistas sobre o uso da fibra natural amazônica de tucumã-i (Astrocaryum acaule) para o desenvolvimento de produtos semiindustriais. Anais do III Simpósio Brasileiro de Design Sustentável (III SBDS) Proceedings of the 3rd International Symposium on Sustainable Design (ISSD). Editora Universitária - UFPE. Pernambuco - RE/Brasil. ISBN: 978.85.7315.949-3 



\subsection{Artículo 10 - Viabilidad técnica de la fibra de tucumã-i (Astrocaryum acaule) para la producción textil}

Esta producción científica ha sido desarrollada con la intención de verificar la viabilidad técnica del objeto de estudio para su aplicación en el segmento textil (Publicación en inglés). La publicación corresponde a las contribuciones sobre el tema de estudio de la tesis (Pags.67, 68,69 y 70).

Congreso: $6^{\text {th }}$ Ecodesign Symposium: The future of your products!

Enviado: 20.0ctubre.09 | Aceptado: 31.0ctubre.09 | Publicado: Noviembre. 09

Cita: Pacheco, K. M. M.; Pacheco, K. M. M.; Ortuño, B. H.; Pacheco, A. S. (2009). Technical viability of tucumã-i (Astrocaryum acaule) for textile production. $6^{\text {th }}$ Ecodesign Symposium: The future of your products! Involvement of the users, from product birth to its second life. The embarcadère - Lyon/Francia.

Technical viability of tucumã-i (Astrocaryum acaule) for textile production

Karla Mazarelo Maciel Pachecoํㅜㄹ Bernabé Hernandez Ortuño², Almir de Souza Pacheco ${ }^{1}$

1 PhD student of Industrial Design /Polytechnic University of Valencia- UPV

2 PhD in Industrial Design / Polytechnic University of Valencia- UPV

*e-mail: bhernandis@degi.upv.es

Keywords: Design, Technology, Natural fiber, Textile production Introduction

The study shows a technique viability of tucumã-i fiber (Astrocaryum acaule), an amazonian palm fiber grown in an ecologically correct, for the textile production. Design, technology, environmental and forestry sciences were unified for knowledge in valuation of this raw material, to enable a conception of a new product for the insert on industrial textile market.

Materials and methods

The study was based in the theoretical and practical aspects of the forest products and technology of the management of the design, qualified in the textile sector, methods, application forms and status that guide the process and the comprehension of the changes of paradigm (Tripodi, Fellin, \& H., 1975). Technological evaluations of the samples of the i-tucumã fibers were in accordance to ASTM (Annual Standard Materials Trade) (1984), COPANT 
(Commission of Pan American Standards) (1997) and ABNT (Brazilian Association of Technical Norms) $(1995,1999)$. The experiments with the samples were made more than once in laboratories (Figure 1).
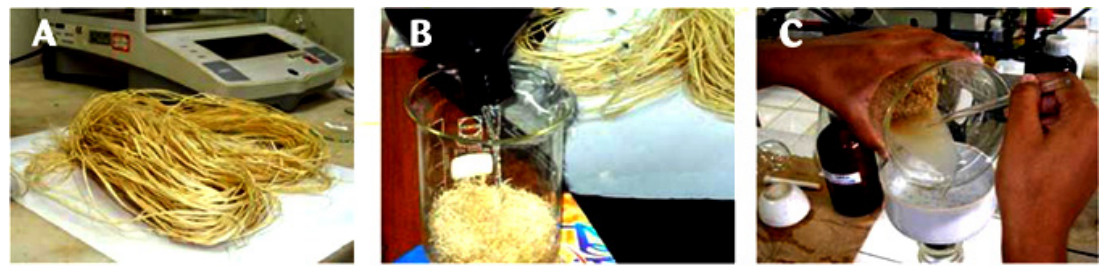

A10_Figure 1. A, B e C - Technology assessment of tucumã-i fiber (Source: author's archives).

In the experimental design was made an approach quantitative, descriptive, exploratory and experimental) realized together native artisan, forest production and chemistry engineer professionals and potential users. After collecting the fiber extracted from the ecologically palm, and the experiments conducted on samples, the fiber was adapted for the craft's manufacture of a fabric (Figure 2).
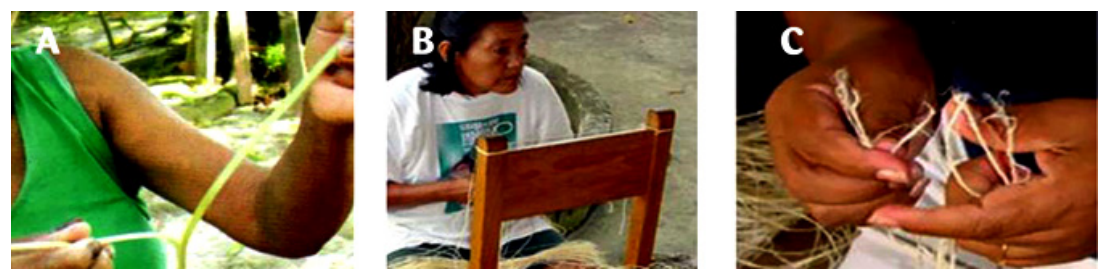

A10_Figure 2. A, B e C - Adaptation of the tucumã-i fiber for cords (Source: author's archives).

After the obtaining of the fabric the next step was developing a prototype, allying creativity and technical knowledge like: ergonomic, functional and esthetic production of the product (lida, 1992). For such outlines were produced drawings (sketches.) for showing a textile product (feminine clothes) suitable to Amazonian tropical climate, emphasizing some concepts of the design (Figure 3 ). The final process was carried out by a dressmaker. 

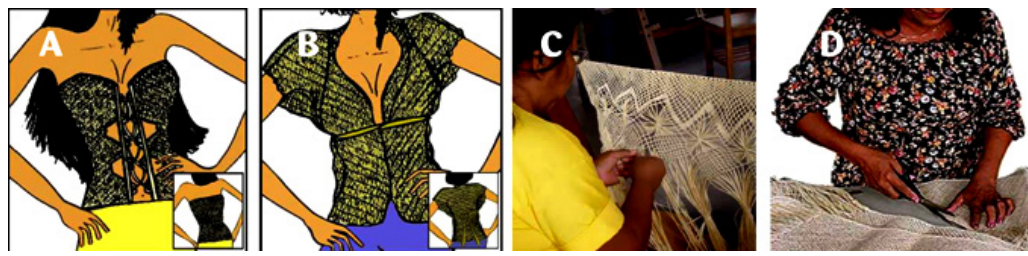

A10_Figure 3. A, B - Design of the prototypes; C, D - Production and finishing of the fabric of tucumã-i (Source: author's archives).

\section{Results}

The fiber of the tucumã-i (Astrocaryum acaule) gave positive response to the evaluations done in its physical, chemistry and organoleptics properties taking into consideration its gender, species, origin, usefulness and vegetable formation. (Figure 4).

\begin{tabular}{|c|c|c|c|c|c|c|c|c|c|c|c|c|c|c|}
\hline \multicolumn{15}{|c|}{ Technological Properties Identified in the fiber TUCUMA-I } \\
\hline $\begin{array}{c}\text { Longth of } \\
\text { fiber }\end{array}$ & $\begin{array}{l}\text { Softor } \\
\text { fiber }\end{array}$ & $\begin{array}{l}\text { Fibor } \\
\text { space }\end{array}$ & Color & \begin{tabular}{|l|} 
Bright and \\
appearance
\end{tabular} & Burst test & $\begin{array}{c}\text { Rosistanco } \\
\text { to dry }\end{array}$ & \begin{tabular}{|l|} 
Molsture \\
resistance
\end{tabular} & \begin{tabular}{|c|} 
Elasticity \\
resistance
\end{tabular} & \begin{tabular}{|c|}
$\begin{array}{c}\text { Rosistance } \\
\text { to boiling }\end{array}$ \\
\end{tabular} & Washing & Density & \begin{tabular}{|c|} 
Bohavior \\
in the heat \\
\end{tabular} & Toxicity & $\begin{array}{l}\text { Stability } \\
\text { of form }\end{array}$ \\
\hline $\begin{array}{l}\text { Up to } \\
100 \mathrm{~cm}\end{array}$ & $\begin{array}{l}\text { From } 0.07 \\
\text { to } 0.6 \mathrm{~mm}\end{array}$ & $\begin{array}{l}\text { Solt and } \\
\text { smooth }\end{array}$ & $\begin{array}{c}\text { Yollow with } \\
\text { as silly } \\
\text { sheen }\end{array}$ & $\begin{array}{l}\text { Soh and } \\
\text { smooth }\end{array}$ & $\begin{array}{c}\text { Good } \\
\text { resistance }\end{array}$ & $\begin{array}{l}\text { Robust and } \\
\text { oasy to diy }\end{array}$ & $\begin{array}{l}\text { Absorption } \\
\text { of } 11.82 \% \\
\text { to } 11.5 \% \% \\
\text { moisture }\end{array}$ & $\begin{array}{l}\text { Good } \\
\text { elestielity }\end{array}$ & $\begin{array}{l}\text { Rosistant } \\
\text { to bolling }\end{array}$ & $\begin{array}{l}\text { Woy good. } \\
\text { can be } \\
\text { mashed math } \\
\text { soap and } \\
\text { motiter of } \\
\text { bo dry }\end{array}$ & $\begin{array}{l}\text { Good, with } \\
1.51 \mathrm{~g} / \mathrm{cm} \text { ' }\end{array}$ & 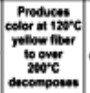 & $\begin{array}{c}\text { No toxic } \\
\text { components }\end{array}$ & $\begin{array}{l}\text { Loss } \\
\text { than } \\
\text { cottion }\end{array}$ \\
\hline
\end{tabular}

A10_Figure 4. Properties identified in the tucumã-i fiber (Source: Adapted from MACIEL, 2007).

The resource presented favorable conditions in its use for making of natural cloth that proved your technical viability for the textile production (Figure 5).
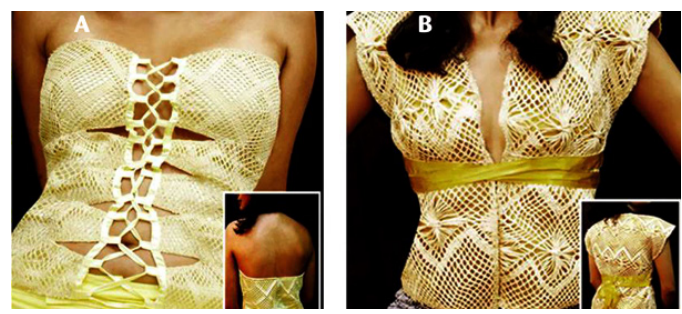

A10_Figure 5. A e B - Clothes made with the tucumã-i fiber (Source: author's archives).

\section{Conclusions}

The raw material of tucumã-i presented aspects related to the elasticity as waviness, thickness, resistance and coloring; it was demonstrated a good 
flexibility at handling and unfolding of the fiber without abrupt rigged of the structure; physical aspect plain, smooth and alignment towards the end; appearance with natural brilliance; the structure of the washing, boiling resistance, bleaching and dyeing was ensured; free of toxic substances; ergonomic analysis contributed a better adaptation of the products to the users as handling and proper wear; scientific and technical viability with the textile production chain. Therefore, an alternative for improving the productivity or the profitability of the cultivation to made up of to select palms with economic, ecological and sustainable potential as proposal of preservation and rational exploration.

\section{References}

ABNT - Associação Brasileira de Normas Técnicas. Material têxtil: Determinação da resistência da costura em materiais têxteis confeccionados ou não - NBR 13374/1995.

Associação Brasileira de Normas Técnicas. Ensaios de Proficiência por Comparações Interlaboratoriais - ABNT: 43-1/1999.

ASTM (Annual Standard Trade Materials). 04.10 - Wood, ASTM 1413-76, Pennsylvania, 1984.

COPANT - Comissión Panamericana de Normas Técnicas. Cabo e fio de compensação e/ou extensão - Tolerâncias e identificação - NBR 13774:1997.

IIDA I. Ergonomia, projetos e produção. São Paulo: Edgar Blücher Ltda, 1992.

MACIEL, Karla Mazarelo Ferreira. Estudo da Viabilidade Técnica da Fibra de Tucumã-i (Astrocaryum acaule) para Produção de Tecido a ser utilizado na Indústria de Confecções. Dissertação apresentada ao Programa de PósGraduação em Ciências Florestais e Ambientais da Universidade Federal do Amazonas no ano de 2007. Disponível em: http://www.ppgcifa.ufam.edu.br/dissertacao.html. Acesso em: 24 mai. 2008.

MATOS FJA. Introdução à fitoquímica experimental. Fortaleza, Editora UFCE,128p, 1988.

MIRANDA I. P. A, RABELO A, BUENO CR, BARBOSA EM, RIBEIRO MNS. Frutos de Palmeiras da Amazônia. Manaus, MCT/INPA, 120p, 2001.

SANTOS, F. A. O Design como diferencial competitivo. Santa Catarina: Editora da Univale, 2000.

TRIPODI T, FELLIN P, MEYER H. Análise da Pesquisa Social. Rio de Janeiro Francisco Alves Editora S.A. , 1975. 


\subsection{Artículo 11 - Procedimientos para la obtención de tintes vegetales de la Amazonía para su aplicación en productos industriales}

Esta producción científica ha sido desarrollada con el intuito de obtener informaciones sobre las herramientas y técnicas utilizadas por las comunidades productoras indígenas Tukano, para la fabricación de tintes naturales vegetales, el proceso de aplicación en las fibras naturales amazónicas y, por siguiente, su viabilidad de producción para el uso industrial (Publicación en inglés). La publicación corresponde a las contribuciones sobre el tema de estudio de la tesis (Pags.67, 68,69 y 70).

Congreso: ECOWOOD 2010 - 4th International Conference on EnvironmentallyCompatible Forest Products

ISBN: 978-989-643-016-0

Enviado: 23.Agosto.10 | Aceptado: 30.Agosto.10 | Publicado: Septiembre.10

Cita: Pacheco, K. M. M.; Ortuño, B. H.; Pacheco, A. S.; Catanhede, C. N.; Varejão, M. J. C. (2010). Procedures for obtaining vegetable dyes of Amazon for application in industrial products. In: ECOWOOD 2010 - 4th International Conference on Environmentally-Compatible Forest Products. Abstract Book 4th International Conference on Environmentally-Compatible Forest Products. Universidade Fernando Pessoa, Porto/Portugal.

Procedures for obtaining vegetable dyes of Amazon for application in industrial products

Karla Mazarelo Maciel Pacheco

MSc. at Forestry and Environmental/Amazonas Federal University - UFAM

* karlamazarelo@hotmail.com

Bernabé Hernandis Ortuño

Doctor at Industrial Engineering/Polytechnic University of Valencia - UPV

Almir de Souza Pacheco

Design Specialist/Amazonas Federal University - UFAM

Claudete Catanhede Nascimento

Doctor at Forest Sciences/National Institute for Amazonian Research - INPA

Maria de Jesus Coutinho Varejão

Doctor at Ecology/National Institute for Amazonian Reseach - INPA

Introduction

The study was structured in theoretical and practical aspects of the process of production of dyes and natural dyeing, according to the craftsmanship of Indian ethnicity Tukano - including its methods and forms of production and 
application of vegetable dyes. The proposal of this research is a contribution for the design engineering, especially, for the development industrial products by models simple systems. Therefore, such work tries to do a bridge between the craft and scientific aspects, from the perspective of design engineering, including tools and materials used in the formation of vegetable dyes, as well as the production of knowledge for the benefit of the projection new products for the industrial sector.

Key Words: Natural dyes, Amazon vegetables, Design, Technology, Industrial Product.

\section{Materials and Methods}

The study was based on methods and tools classified as:

- The nature - basic and applied research or technology;

- The goal: exploratory, descriptive and explanatory research;

- The technical procedures - literature search, documented data, experimental research and case study (Gil, 2002).

Such reference gave subsidies that reinforce the search for knowledge of the training culture of natural vegetable dyes for their use in future products to be developed by design engineering.

During the research on methods and tools used for production of vegetable dye, we observed some techniques practiced by the Tukano indigenous group. The plants used by Indians Tukano for the formation of natural dyes were selected according to source, cultivation and collection.

These factors contribute to the proper removal of any species of their habitat, which favors the adequate replacement of the plant to the environment sustainably. The selected vegetables were: Annatto (Bixa orellana); Jenipapo (Genipa Americana U.S); Crajirú (Arrabidaea chica) and Mangarataia (Zingiber officinale).

The urucum's dye (Figure 1) was obtained from its seeds, which are located in closed capsules of the plant. The seeds are separated in a container with water and kneaded until the exit in full color. After being crushed, the seeds are mixed with a natural solution, a kind of oil made with roots and vegetable fat, which when diluted create a reddish color. 

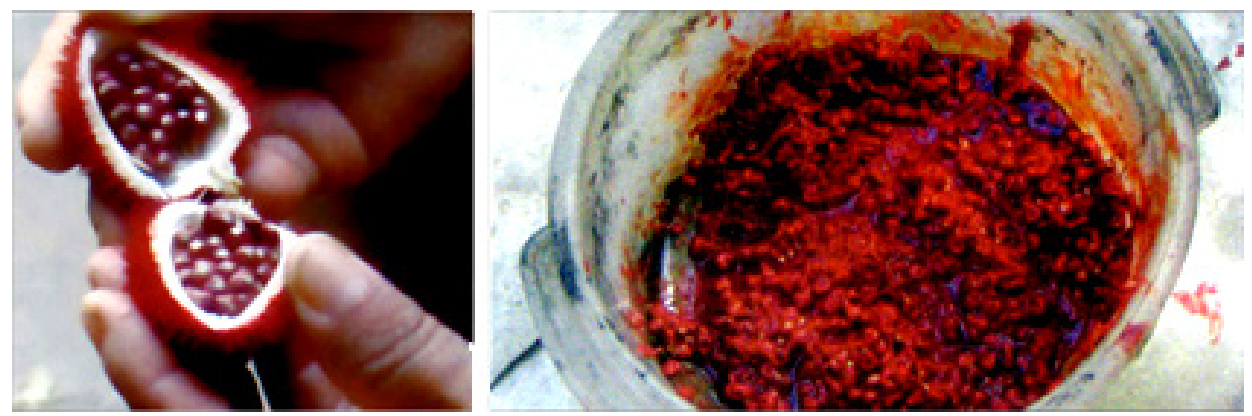

A11_Figure 1. Seeds of urucum in their natural state and then diluted and mixed with a natural oil. (Source: SANTOS, 2002).

The crajiru's dye was obtained by boiling the leaves, which were harvested at the mature phase. It was put in a pan and mixed with a little water, and brought to the fire for an hour. The color obtained was a tone purple and red, depending on the species harvested. The procedure was also adapted to the leaves of mangarataia which produce the yellow color.The application of dyes involved the participation of some natural fibers such as arumã and tucumã. These fibers are grown by Tukano indigenous artisans and they're used to demonstrate the process of applying dyes produced sustainably and naturally.

To dye arumã fiber (Figure 2) with urucum dye, the Tukano indigenous artisans used the paint by hand. The dye was applicated in the fiber until to be well fixed in the material. For a darker color to stay, it was repeated the same action three times in the same fiber.
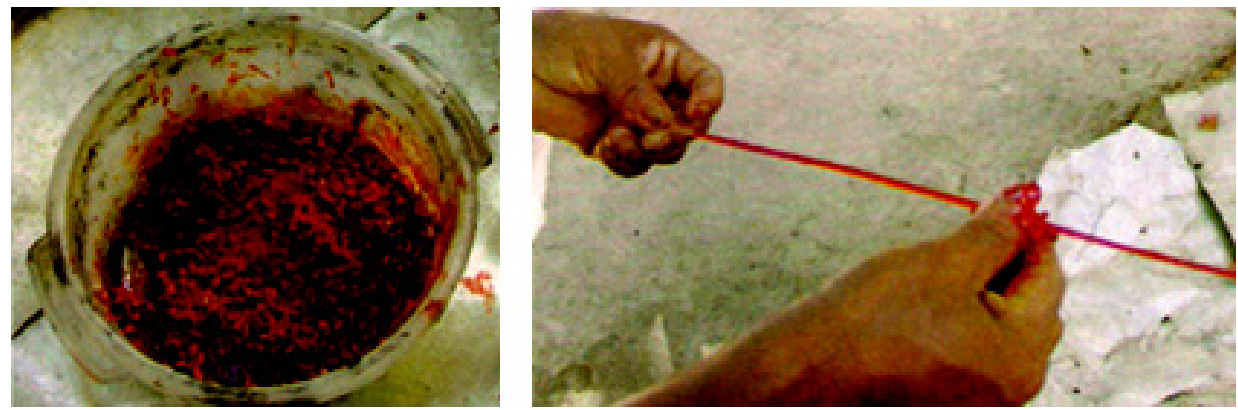

A11_Figure 2. Urucum's natural dye application in the arumã fiber. (Source: SANTOS, 2002).

To dye tucumã fiber with crajiru's dye (Figure 3), tukano women boiled together the crajiru's sheets with the tucumã fiber. They do the harvest the 
Estudio de la prospección del uso de la fibra de tucumã-i (Astrocaryum acaule) para el desarrollo de productos semi-industriales

leaves to mince them. After being well mixed, the leaves are dipped in a pan with water and brought to the fire for about thirty minutes.
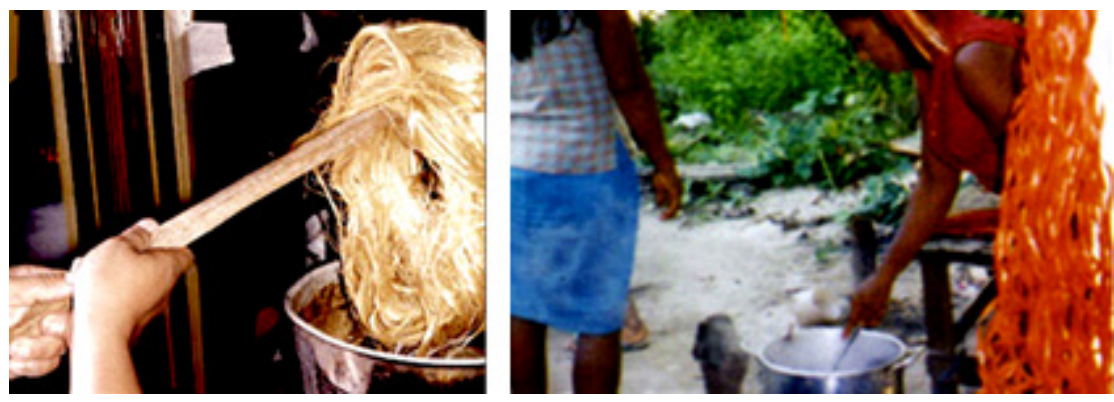

A11_Figure 3. Tucumã fiber boiled with the crajiru's leaves and getting the red tinge. (Source: SANTOS, 2002).

\section{Results}

Since this is a simple systematic model, whose goal is to obtain production of natural dyes, some criteria were needed to final product quality, such as the right choice of vegetables, a good knowledge about the species, notions about collecting and environmental restoration of the raw material. During the production and application of dyes, we observed that the treatment given to plants favored the dissolution of the color inks resistant and durable, with concentrated pigments rather than dispersed on the techniques of hand painting and boiling. In the colors obtained (Figure 4), it was realized that the higher the amount of leaves or fruit of plants involved in the formation of dye greater its tone.

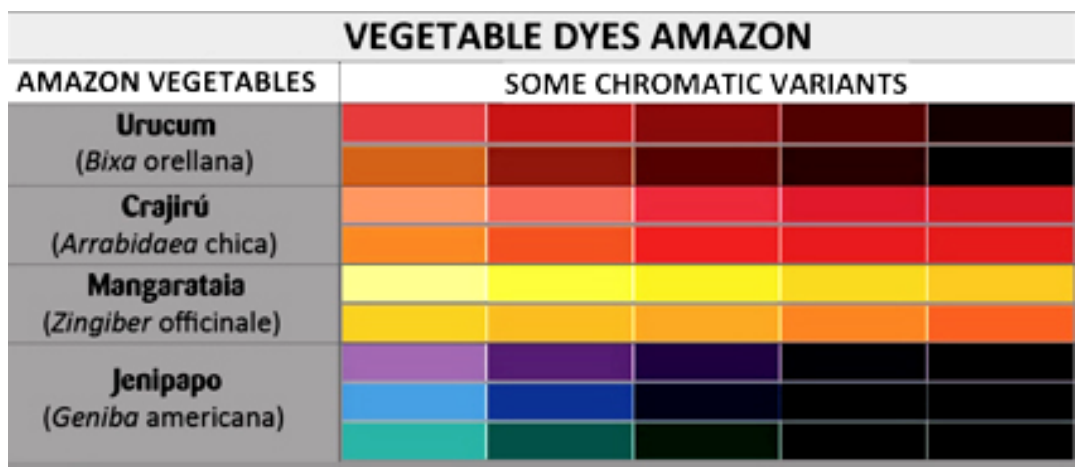

A11_Figure 4. Colors obtained by vegetable dyes of Amazon. (Source: authors file). 
The vegetable dyes generated for making textile pieces (Figure 5), passed the craft technique for transforming ideas into product design.

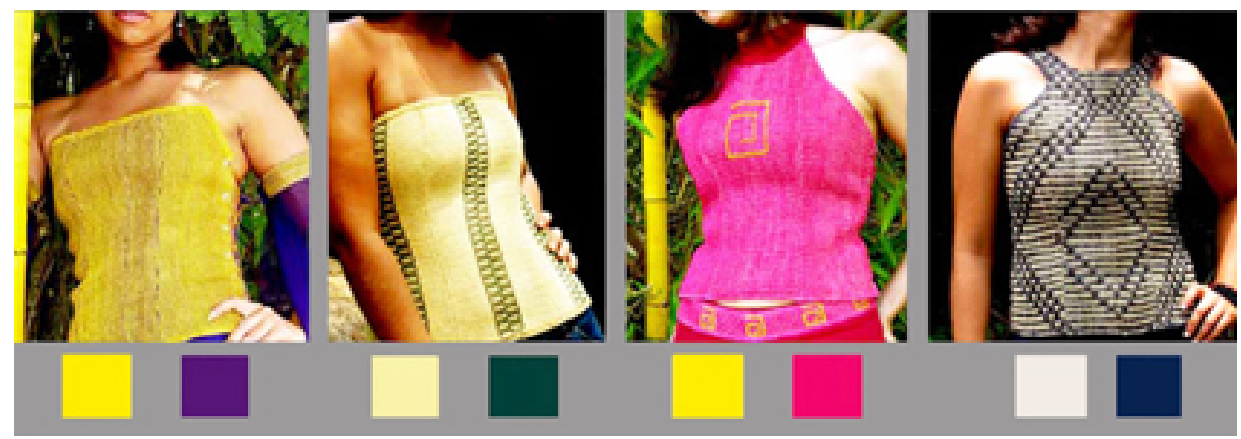

A11_Figure 5. Textile pieces manufactured with tucumã fiber and dyed with vegetable dyes Amazon. (Source: authors' file).

For the development of the textile pieces it was necesary the training of vegetable dyes for their application. The dyeing process also had a positive effect on fiber structure of tucumã, material used for the manufacture of clothing, by the technique (boiling) and quantity (three) of times that it was painted.

Finally, we highlight the contribution of design in the search for production models for the application of new materials and processes into product design, especially those who might use them refused Amazon's natural.

\section{References}

ARAÚJO, M. E. M (2005). Corantes naturais para têxteis da Antiguidade aos tempos modernos. Conservar Património, 2-4, 39-51.

BONSIEPE, Gui (1983). A Tecnologia da tecnologia. São Paulo: Edgard Blucher.

DEO, H. T., \& DESAI, B. K (1999). Dyeing of cotton and jute with tea as a natural dye. Journal of the Society of Dyers and Colourists, 7, 224-227.

FACHIN, Odília. (2001). Fundamentos de metodologia. 3 ed. São Paulo: Saraiva.

GIL, Antonio Carlos. (2002). Como elaborar projetos de pesquisa. 4. ed. São Paulo: Atlas.

JOTHI, D (2008). Extraction of Natural Dyes from African Marigold Flower (Tagetes Ereecta L) For Textile Coloration. Autex Research Journal, 49, 1-5. 
Estudio de la prospección del uso de la fibra de tucumã-i (Astrocaryum acaule) para el desarrollo de productos semi-industriales

MACZ-POP, G.A. et al. (2006) Natural occurrence of free anthocyanin aglycones in beans. (Phaseolus vulgaris L.). Food Chemistry. 94 (3), P.448

STRINGHETA, P.C (2007). Usos e aplicações de corantes naturais. Seminário sobre corantes artificiais e naturais em alimentos. ITAL - Campinas.

SANTOS, A.V. (2002). Fibras vegetais para artesanato: Técnicas de produção de fibras de Arumã, Cipó Ambé e Tucumã. Fundação Vitória Amazônica. Manaus Amazonas. 
3.12. Artículo 12 - Diseño mediante el uso de materiales naturales: análisis de los atributos esenciales al desarrollo de nuevos productos

Esta producción científica ha sido desarrollada con la intención de buscar informaciones sobre como orientar y adaptar el uso de materiales naturales, identificando, en particular, los atributos esenciales para el desarrollo de nuevos productos, de acuerdo con la opinión de expertos (Publicación en inglés). La publicación corresponde a las contribuciones sobre el tema de estudio de la tesis (Pags.67, 68,69 y 70).

Congreso: $6^{\circ} \mathrm{CIPED}$ - Congresso Internacional de Pesquisa em Design

ISSN: 2175-0289 | Código: 15040836

Enviado: 15.Abril.11 | Aceptado: 15.Mayo.11 | Publicado: Octubre.11

Cita: Paixão-Barradas, S.; Pacheco, K. M. M.; Ortuño, B. H. (2011). Design using natural materials: Essential attributes analysis for development of new products. Congresso Internacional de Pesquisa em Design (CIPED), v. 6, p. 194-198. Congresso Internacional de Pesquisa em Design. Lisboa-Portugal.

Design using natural materials: Essential attributes analysis for development of new products

Susana PAIXÃO-BARRADAS, 1 Karla PACHECO,2 Bernabé ORTUÑO 1

1 Ingeniería del Diseño de la Universidad Politecnica de Valencia ETSDI/UPV/Espanha | 2 Departamento de Design da Universidade Federal do Amazonas - DEG/UFAM / Brasil

supaipe@upvnet.upv.es,karlamazarelo@hotmail.com,bhernandis@degi.upv.es

\section{Abstract}

This paper seeks to target and tailor the use of natural materials, identifying in particular, the essential attributes to development of new products. In this sense, we describe two case studies - Natural Stone and Fiber considering the opinion of experts, supported the themes addressed on issues priority. The results consider parameters that are grouped to form, function and ergonomics design concluding that the relevant information is subject to the material, technology, process and sustainability.

\section{Keywords}

Product Design and Design's Attributes of Natural Material 


\section{Introduction}

The new products success requires a plan that is directly linked to concepts and features that arouse the user a different attitude towards him. [Clayton03]. It's in the multidisciplinary, also existing in the design performance, that project-oriented activity improves the formal, functional and ergonomic aspects of the object studied. Understanding these abilities facilitates to designer a better planning of steps to research a product. They are applied with variable use, and may determine the construction requirements of the object, in order to supply the needs identified [Bernabé03]. The stone and fiber, for being raw materials of natural origin, combine the unique traditions of each country and with international technical and technological references. At the global consumer market there is room for all these approaches, it is important that each country or operator of a community of these materials, knows how to sell their products, focusing on aspects such as the identity, quality, satisfaction, alternatives for reducing production costs and improved environmental protection [Rosane08]. Therefore, an analysis of the idea of designing new products - by using natural materials, considering the essential attributes of this process becomes the starting point this paper, where the following objectives are proposed:

- Identify the design's attributes in common, existing studies in two cases;

- Observe the consideration of experts in relation to the identified attributes;

- Placing these attributes according to the concepts: Form - Function Ergonomics;

- Identify the dominant attributes for the development of new products.

\section{Materials and methods}

The study presents a qualitative approach for the purposes of exploratory and descriptive research. The structure includes a content research literature and public documents, ratified in two specific case studies - related to the processes of innovation and strategy [Robert01]. Data were collected from references that discuss the issue and previous studies, by applying expert interviews - structured by a questionnaire with questions about the design aspects. For these objectives were selected for this research - intentionally, two case studies. Each study is directed to a specific natural product, namely: Case Study 1 (Natural Stone) and Case Study 2 (Natural Fiber). For the implementation of this proposal, we identified the attributes required for 
participation in the information organization that will help the designing process and developing new products by using natural materials.

\subsection{Case Studies}

\subsubsection{Case Study $1 \rightarrow$ Natural Stone}

Natural stone (Figure 1) is a material widely used since the beginning of humanity. Its application and functionality is amply justified by its technical characteristics, which have been tried for centuries. The natural stone application focuses mainly on technical aspects, namely the cost, viability and production feasibility, function and maintenance.
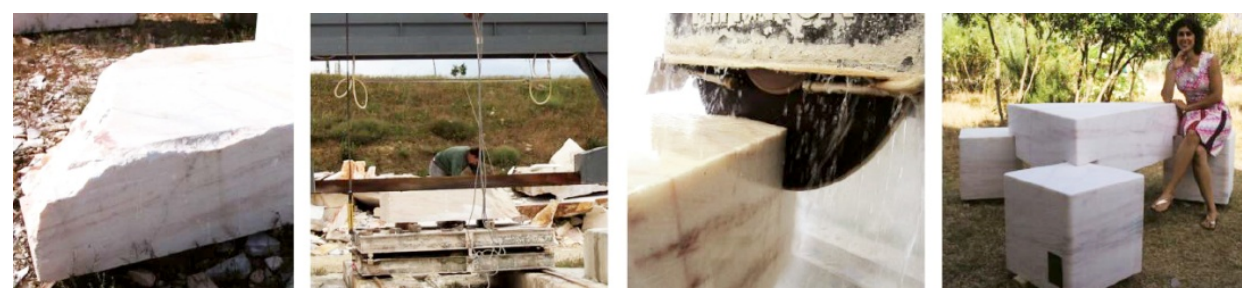

A12_Figure 1. Natural Stone, processed into products.

However, there are other aspects, such as the interaction and usability of the material that influence the human being [CEAC01]. The current scientific and technical knowledge allows us to understand the rock also from another perspective, not only as a natural material, green and beautiful, but also as a source of wealth for economic and social development of many communities [António06].

\subsection{Case Study $2 \rightarrow$ Natural Fiber}

Natural fibers are classified by their origin, such as: cellulose - plants (Figure 2), protein (animal), and minerals. Its field of employment is quite broad, ranging from the textile industry for use as reinforcement in polymer matrices and, among other applications.
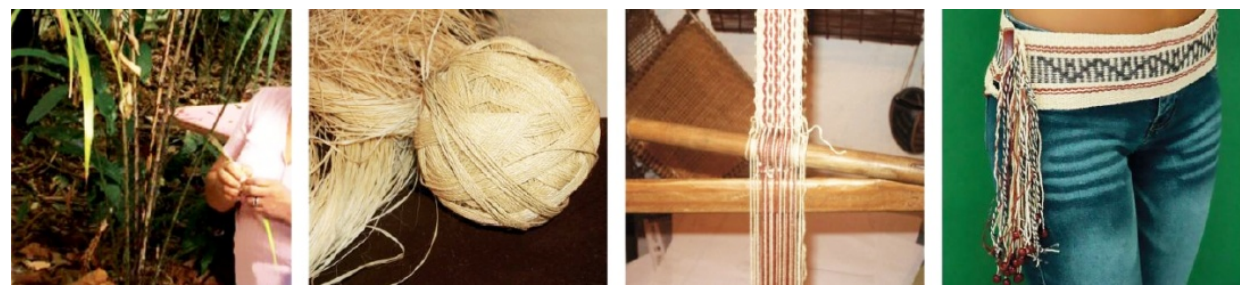

A12_Figure 2. Natural fiber, processed into handcraft product. 
It's very important for the economic development and vital for the livelihoods and food security of millions of small farmers. Considering product development natural fiber has important advantages like: low cost, high toughness, good mechanical and thermal properties, reduced wear of machines, ease of separation, and biodegradability, among others aspects considered very positive [James06]. From a structured questionnaire that was distributed to 11 experts, of each subject area, were identified and selected attributes in common. Then, were evidenced the aspects that, according to experts, represent the most important values in each study, and finally, grouped conform design aspects considered relevant for product development.

\section{Results}

Table 1 shows the aspects that were considered by experts in each case, Stone and Natural Fiber. The information identified in $(J)$ represent the most relevant to the study, and therefore represented with $(X)$ the minor.

\section{A12_Table 1. Illustrative Table - Attributes / Case Studies}

\begin{tabular}{|c|c|c|c|}
\hline & Parameters joint study & Case 1: Stone & Case 1: Fiber \\
\hline \multirow{7}{*}{ 톤 } & Brightness & $x$ & $x$ \\
\hline & Uniqueness & $X$ & J \\
\hline & Composition & J & $x$ \\
\hline & Color & 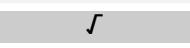 & $\tau$ \\
\hline & Aesthetics & $r$ & 2 \\
\hline & Texture & 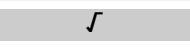 & $\tau$ \\
\hline & Finishing & $x$ & s \\
\hline \multirow{11}{*}{ 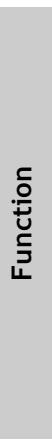 } & Friendly & 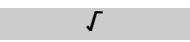 & 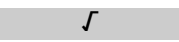 \\
\hline & Knowledge of the material & 2 & 2 \\
\hline & Skilled labor & 2 & 2 \\
\hline & Price & $x$ & $\mathrm{x}$ \\
\hline & Transformation process & $\tau$ & 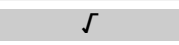 \\
\hline & Technological properties & 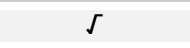 & $\tau$ \\
\hline & Quality & $x$ & s \\
\hline & Recycled & $x$ & $\mathrm{x}$ \\
\hline & Resistance & $\tau$ & $\tau$ \\
\hline & Sustainability & 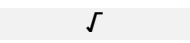 & 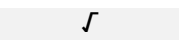 \\
\hline & Humidity & $\mathrm{X}$ & S \\
\hline \multirow{6}{*}{ 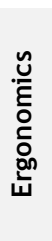 } & Perception by sight & 2 & 2 \\
\hline & Perception by touch & 2 & $\tau$ \\
\hline & Weight & 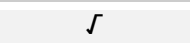 & r \\
\hline & Toxicity & $x$ & s \\
\hline & Symbolic value & 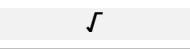 & 2 \\
\hline & Volume & $x$ & $x$ \\
\hline
\end{tabular}


We can observe that the least valued aspects in common, were: Form $\rightarrow$ Brightness; Function $\rightarrow$ Price and Recycled; Ergonomics $\rightarrow$ Volume. While the attributes in common, most valued were: Form $\rightarrow$ Color, texture and aesthetics; Function $\rightarrow$ Friendly, Knowledge of the material, Skilled labor, Transformation Process, Technology properties, Strength and Sustainability; Ergonomics $\rightarrow$ Perception by sight, Perception by touch, Weight and Symbolic value.

\section{Conclusion}

The information presented in this paper justifies diagnosed opportunities and limitations on the use of natural materials for the development of new products, according to two case studies analyzed. Attributes considered as non-priority, like the Price, are irrelevant when you compare it to the Symbolic value of the natural material (like: Color, Aesthetics, Texture...). Investigations in this area point out that the benefits of using natural materials issues point to the healthy, sustainable, alternative technology, sense of responsibility, in this context, the study also considers as priority issues in the materials analyzed: Friendly, Resistance, Technology properties, Process transformation, Sustainability.

\section{References}

[CEAC01] CEAC. Materiales de construcción. Nueva enciclopedia del encargado de obras, 2. Barcelona, ESP: CEAC. 2001.

[Clayton03] Christensen, Clayton M.; Brown, J. D.; Markides, C.; GEROSKI, P. $O$ crescimento pela Inovação: como crescer de forma sustentada e reinventar o sucesso. Rio de Janeiro: ELSEVIER: Campus, 336p, il. Tradução de: Innovator's solution. 2003.

[Peter02] Drucker, Peter Ferdinand. Inovação e espírito empreendedor (entrepreneurship): práticas e princípios. São Paulo: Pioneira Thompson, 2002.

[Bernabé03] Ortuño, Bernabé H. Desarrollo de una metodología sistémica para el diseño de productos industriales. Tesis Doctoral (Doctorado en Ingeniería Industrial) - Universidad Politécnica de Valencia, 2003.

[James06] Holberry, James and Houston D. Natural Fiber-Reinforced Polymer Composites in Automotive Applications, Journal of Materials 58, 11, Nov 2006.

[Rosane08] Martins, Rosane F. F.; Merino, E. A gestão de design como estratégia organizacional (1 $1^{\text {a }}$. Ed.). Londrina, BRS: Universidade Estadual de Londrina. 2008. 
Estudio de la prospección del uso de la fibra de tucumã-i (Astrocaryum acaule) para el desarrollo de productos semi-industriales

[António06] Pinto, António. C. R., Alho, A. A., Moura, A. A. C. A., Henriques, A. M. E., Carvalho, C. I. P., Ramos, J. M. F. et al. Manual da Pedra Natural para a arquitectura (1 ${ }^{\mathrm{a}}$. Ed.). Lisboa: Direcção Geral de Geologia e Energia. 2006.

[Robert01] Yin, Robert K. Estudo de caso: planejamento e métodos. Tradução Daniel Grassi. 2.ed. Porto Alegre: Bookman, 2001 


\subsection{Capítulo de libro - La enseñanza del diseño en la utilización de los recursos naturales para la aplicación en productos industriales}

Esta producción científica ha sido desarrollada con la intención de orientar el los procesos de investigación y uso de los recursos naturales para el desarrollo de productos industriales, a través de la óptica de la enseñanza del diseño. La publicación corresponde a las contribuciones sobre el tema de estudio de la tesis (Pags.67, 68,69 y 70).

Publicación: LIBRO DE ENSEÑANZA EN DISEÑO

ISBSN: XXXXXXXXXXXX (ya solicitado/en proceso de obtención)

Enviado: 22.Deciembre.10 | Aceptado: 02.Deciembre.11

Publicado: Deciembre.12 (Predicción)

Karla Mazarelo Maciel Pacheco| Almir de Souza Pacheco| Bernabé Hernandis

0 ensino do design na utilização de recursos naturais para aplicação em produtos industriais

\section{Resumo}

Este capítulo aborda a importância do processo de investigação e utilização dos recursos naturais para o desenvolvimento de produtos industriais sob a ótica do ensino do design. Os autores consideram importante fazer uma confluência de conhecimentos que possam envolver: a concepção e o desenvolvimento de projeto; o estudo do recurso natural a ser utilizado; a análise do sistema exterior (relacionando mercado, processos e meio ambiente), as tecnologias disponíveis e os tipos de produtos a serem industrializados. A proposta sugere ao design uma forma de engrandecer e fortificar o seu ensino através de informações que são pertinentes à formação do designer, um profissional que hoje se encontra em meio as atividades mais solicitadas à projeção de produtos, sobretudo, referentes as temáticas voltadas para os aspectos de sustentabilidade, de meio ambiente e de ecologia.

\section{Introdução}

O design está desenvolvendo, cada vez mais, a sua atuação em muitas áreas do conhecimento. Entre elas, destaca-se o setor dos recursos naturais, amparado pelos conceitos de sustentabilidade e ecologia. Os aspectos sociais, culturais e econômicos também participam desse contexto. Eles também são considerados variáveis de estudo, para o desenvolvimento de novos produtos.

Para Christensen; Brown; Markides; Geroski (2005), o sucesso de novos produtos necessita de um planejamento esteja diretamente ligado a conceitos 
Estudio de la prospección del uso de la fibra de tucumã-i (Astrocaryum acaule) para el desarrollo de productos semi-industriales

e características que despertem uma atitude diferente no consumidor em relação a ele.

Lojacomo \& Zaccai (2004), afirma que o resultado do processo de design (PRODUTO), deve impor uma solução cultural de fácil assimilação, comunicar o seu uso, ser formalmente atraente, e ter um processo de fabricação simples. Assim, a investigação torna-se é a bússola para a prática da atividade projetual, na qual são aplicados conceitos, tecnologias, materiais e métodos para a obtenção de informações que irão ajudar na construção da ideia e formação do objeto a ser introduzido no mercado industrial.

Miguel Fernandez (2005) enfatiza que é durante a investigação que o design participa como um elemento estratégico à orientação dos possíveis caminhos de ação para compreender bem os problemas e as oportunidades a serem abordadas, verificando o grau de utilização desses recursos naturais para a fabricação de produtos e o alcance de novos mercados.

Sendo assim, com base nos ensinamentos do design e observando as oportunidades de mercado, uma análise sobre a utilização dos recursos naturais para a concepção e planejamento de novos produtos, considerando as variáveis essenciais para esse processo, tornam-se o ponto de partida para esse capitulo, onde são propostos os seguintes objetivos:

- Apresentar os conceitos-técnicos da formação profissional do designer para atuação no desenvolvimento de produtos naturais;

- Indicar as etapas necessárias ao processo de investigação dos recursos naturais para formação de produtos;

- Relacionar a atividade do design com o estudo dos recursos naturais, uso das tecnologias e o conhecimento de mercado para o planejamento de produtos industriais;

\section{Aspectos técnico-científicos da formação do design}

Segundo Freire (2009), o design, desde a sua origem, esteve vinculado ao sistema de produção industrial. Mas, com a evolução dos tempos essa atividade ampliou a sua forma de atuação que, além do planejamento para o desenvolvimento de produtos, passou a ser vista como uma ferramenta auxiliar na projeção dos processos e dos sistemas que fundamentam as experiências, as estratégias e as filosofias do projeto, até os detalhes finais dos resultados (Moritz, 2005). Tornou-se ainda, uma interação entre três elementos-chaves: contexto, pessoas e produtos (figura 1). 


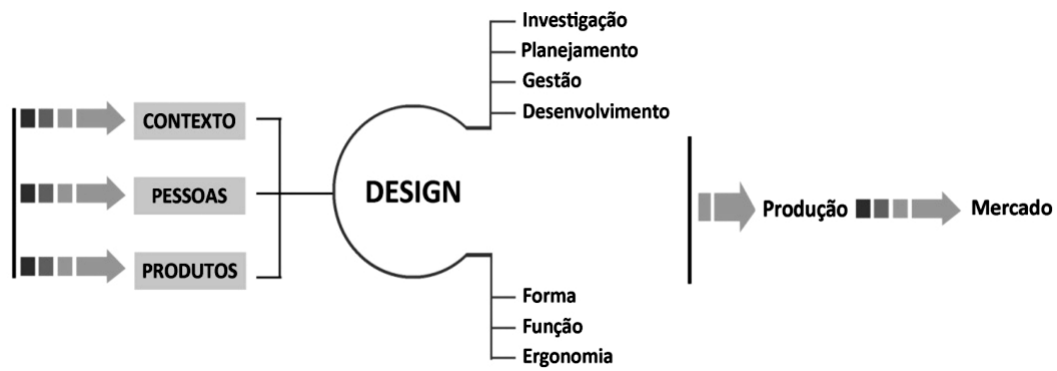

Cap_Lib_Figura 1. Interação da atividade projetual em relação a: contexto, pessoas e produtos. Fonte: autores.

A interação do design sob tais vertentes não pode ser totalmente compreendida fora das realidades sociais, econômicas, políticas, culturais e tecnológicas que levam à sua concepção e realização. É com base nessas referências que será capaz de transmitir os argumentos de mercado, ser responsável por redescobrir e inventar experiências autênticas que poderão estar inseridas no universo do consumo (Kurtgozu, 2003).

Sob esse aspecto, Löbach (2001), destaca que dos projetos mais requisitados para a aplicação dos conceitos-técnicos do design, está à adaptação de produtos obsoletos às condições atuais. A gestão do conhecimento deve ser um dos principais conceitos do design a ser aplicado nesse processo. É por meio dela que, o design ao trabalhar na formação do produto, irá buscar um fator de inovação. Tanto o design quanto a inovação são processos que lidam com criatividade, trabalham com tecnologia, inventam, descobrem, desenvolvem experimentos e são interdisciplinares em função do mercado (Puerto, 1999). É na multidisciplinaridade, existente também na atuação do design, que a atividade projetual planeja a melhoria dos aspectos formais, funcionais, ergonômicos do objeto estudado. Tais critérios são trabalhados para que os produtos tenham qualidade, conforto, identidade e segurança, atendendo as expectativas do consumidor e do comércio. A compreensão dessas habilidades facilita ao designer um melhor planejamento das etapas para investigação de um produto. Elas serão aplicadas com variáveis de uso, e podem determinar os requisitos de construção do objeto, objetivando suprir as necessidades identificadas.

Hernandis (2003), explica que o aspecto formal, estrutura do produto, além de satisfazer as exigências estéticas, preocupa-se também com os volumes de uso (limite geométrico tridimensional que cumpre um objetivo específico: formal, funcional ou ergonômico), com as superfícies de uso (limita os volumes, desagrupa os objetivos, os conceitos e a identificação) e com os 
Estudio de la prospección del uso de la fibra de tucumã-i (Astrocaryum acaule) para el desarrollo de productos semi-industriales

limites de contorno (lugar geométrico que limita a superfície ou o volume, a partir da qual deixam de serem importantes as considerações conceituais, identificadas como forma, função ou ergonomia.

Para Langenbach (2008), o aspecto funcional do produto é a parte técnica de como esse será utilizado pelo homem. É no design prático do objeto, que se estabelece como essa usabilidade poderá ser feita da melhor maneira possível pelo seu usuário. Nessa fase, as considerações são associadas aos materiais, às tecnologias, aos mecanismos, às operações e à funcionalidade necessária ao seu correto desempenho. 0 aspecto ergonômico é uma tecnologia apoiada por dados científicos, o design de produto é um processo de criar novos e aperfeiçoados produtos para o uso de pessoas e sucesso comercial do produto (Soares, 1998). O objetivo ergonômico é adaptar os aspectos formais e funcionais ao usuário, estudar as relações entre o usuário e o produto para uma melhor adaptação possível. Esse três princípios básicos, para a prática da atividade projetual, ajudam o design a ser um fator estratégico para o produto. Em outras palavras, o design estratégico mais uma vez vai estar focado na inovação, complementando a forma, a função e a ergonomia, agregando valor e competitividade ao produto. Nesse contexto, o design atua diretamente na percepção de valor do produto (Lemos, 2006). 0 valor pode ser incorporado ao produto tanto pelos aspectos conceituais do design quanto pelos atributos de inovação que a ele são agregados. Esse valor dos produtos é medido pela satisfação do consumidor que vai desfrutar com o seu uso. A qualidade de valor aplicada ao produto acelera o crescimento empresarial e rapidamente evoluir em quantidade e qualidade com os recursos que a empresa poderá investir em novos projetos (Kuhn, 1993).

\section{Métodos para investigação do design no campo dos recursos naturais}

No campo da metodologia, muitos autores estabelecem as etapas para a pesquisa científica. $\mathrm{Na}$ área do design, existem estudiosos como: Bonfim (1995), (Munari (1983), Bonsiepe (1984), Baxter (1998), Asimov (1962), Alexander (1964) e, entre outros, que orientam a como compor esse processo de investigação. Os métodos e técnicas são muitos. Mas, é do designer a responsabilidade de identificar o método e/ou técnica específica a serem adotados para o desenvolvimento projetual, uma vez que, cada projeto requer uma situação diferente. Assim, o design utiliza o método para obter uma solução. Ele considera as características e processos pelos quais o produto deverá passar para atender com êxito às funções pré-determinadas. As técnicas são utilizadas pelo designer, de acordo com suas necessidades e características do projeto, para auxiliar nas etapas de desenvolvimento do produto. Analisando as descrições metodológicas registradas pelos investigadores, anteriormente citados, percebe-se que a maioria deles afirma 
ser a necessidade, o ponto inicial ao processo de investigação do design. É a partir dessa necessidade, que surgem às etapas compatíveis à prática da pesquisa, como: definição do problema; valores do sistema; síntese do sistema; análise do sistema; seleção do melhor sistema e planejamento da ação. Nesse caso, entende-se por sistema, a proposta de produto onde o designer deve elaborar metas a serem atingidas em cada etapa do seu desenvolvimento (Roosemburg \& Eekels, 1996).

A necessidade de se especificar metas, requisitos e restrições do projeto, e a montagem de um cronograma de execução dessas etapas, fazem da aplicação da metodologia um instrumento guia ou um roteiro de ações. Assim, o resultado dessa aplicação se define como o caminho mais seguro no desenvolvimento de um produto (Abramovitz \& Rebello, 2002).Para existir produto, transforma-se material. Se nenhum material estiver disponível para converter um produto em uma entidade tangível, ele irá permanecer como um conceito, uma idéia, ou talvez um desenho (Evbuomwan, Sivaloganathan, \& Jebb, 1995). A compreensão do produto está relacionada com o estabelecimento de um modelo conceitual apropriado (figura 2).

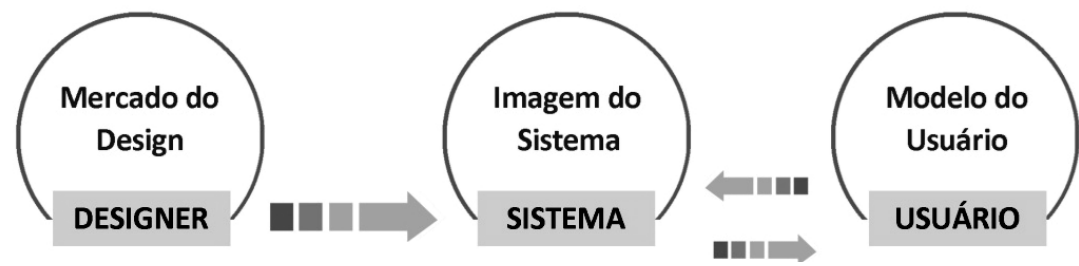

Cap_Lib_Figura 2. Modelo conceitual para a concepção de produto pelo processo de investigação do design. Fonte: Adaptado de Norman (2002).

Segundo Norman (2002), a imagem concebida pelo designer (Modelo do Design) é o primeiro passo, em seguida vem à imagem da pessoa que usa o produto e, por fim, do que se trata o produto e como funciona (Modelo do Usuário). Quando o produto é derivado de um recurso natural, a investigação possui uma atenção redobrada. Os recursos naturais envolvem aspectos naturais e, com isso, atingem os âmbitos ambientais, ecológicos e, muitas vezes, sociais, culturais e econômicos. Nesse caso, a principal função do designer deverá ser a compreensão de algo que seja possível tecnicamente/tecnologicamente ao que é ecologicamente necessário para fazer surgir novas propostas que sejam apreciáveis à utilização dos recursos naturais ao desenvolvimento de novos produtos. Uma das tarefas para o desenvolvimento de novos produtos é a de projetar o seu ciclo de vida. 0 ciclo de vida refere-se às trocas (in put e out put) entre o ambiente e o 
Estudio de la prospección del uso de la fibra de tucumã-i (Astrocaryum acaule) para el desarrollo de productos semi-industriales

conjunto dos processos que seguem o nascimento, vida e a morte de um produto. Considera-se o produto desde a retirada dos recursos necessários para a produção dos materiais que o constituem até o último tratamento desses materiais após o uso do produto (Manzini \& Vezzoli, 2005). A partir disso, o processo de investigação do design estrutura-se em um estudo sistêmico, onde faz uma inter-relação com vários conceitos projetual, tecnológico, social, ambiental, ecológico, econômico e, entre outros. E aos poucos vai identificando a necessidade e problema da pesquisa e, determinando os objetivos, análises e diagnósticos do sistema estudado (PRODUTO).As fases que determinam o processo de investigação do design para um sistema de estudo com recursos naturais, podem apresentar a seguinte seqüência: Proposta, Desenvolvimento, Projeção, Produção e Consumo (figura 3), conforme adaptações feitas com base em algumas referências projetuais.

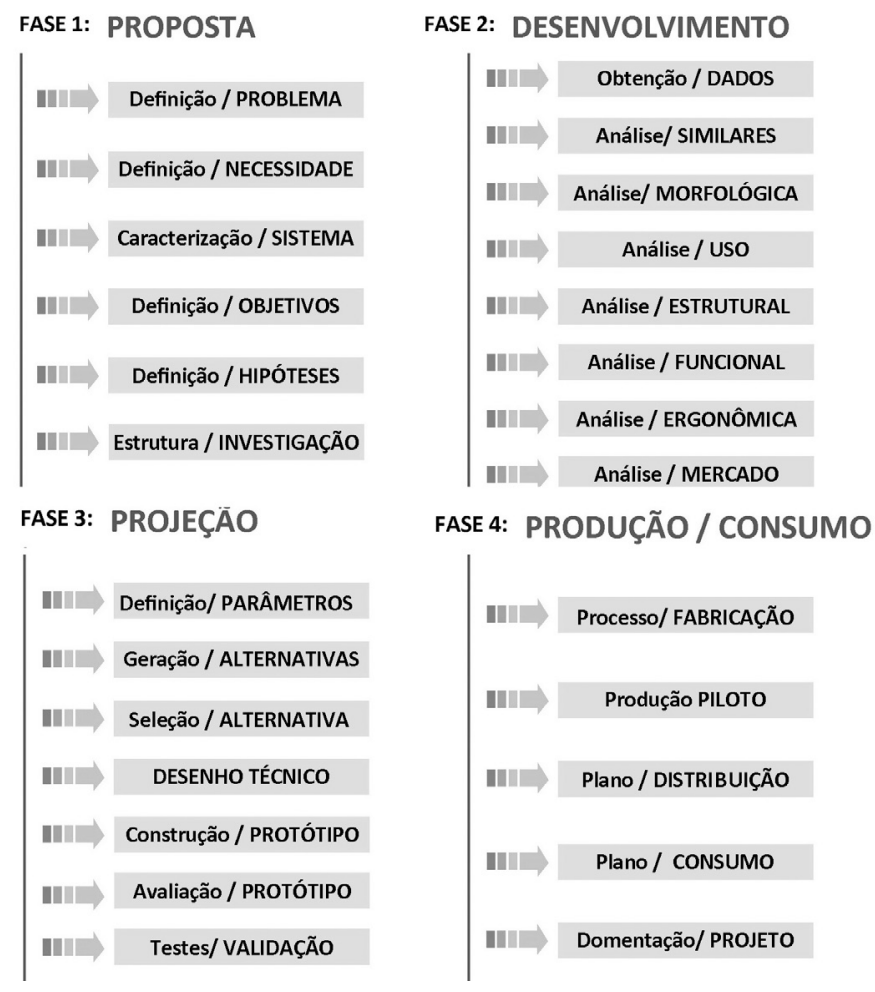

Cap_Lib_Figura 3. Fases da investigação do design para um sistema de estudo, focado em recursos naturais. Fonte: Adaptado de Bonsiepe (1984), Bonfim (1995), Munari (1983) e Asimov (1962). 
Projetar um produto significa também explorar, descrever, explicar, sintetizar, planejar e documentar uma idéia através da investigação. Nesse contexto, o uso dos recursos naturais pode abranger uma pesquisa com diversas atividades que surgem desde a necessidade e podem se estende ao plano de consumo do produto que irá suprir tal necessidade. Assim como a investigação busca o conhecimento sobre o que é e como a matéria-prima poderá ser utilizada, esse mesmo conhecimento vai operar no processo de transformação dessa matéria-prima em um novo produto.

\section{Design, recursos naturais, tecnologia e mercado}

Um dos focos de pesquisa com maior potencial, nos últimos tempos, é o dos produtos feitos com recursos naturais. Todas as suas etapas de construção estão voltadas ao consumidor final e para isso, saber projetar é fazer uma interseção entre produto, ser humano e mercado.

Quando se relaciona design e tecnologia, percebe-se que há uma presença forte do conhecimento técnico e científico, uma vez que, tanto um quanto o outro, trabalham com ferramentas, processos e materiais.

Para que o conhecimento, de ambos, possa trabalhar em função de um recurso natural, a ser inserido no mercado, precisa transformar a matériaprima em um novo produto, conhecer suas características tecnológicas, agregar novos valores, oferecer qualidade, processos de produção ou montagem mais simples para a sua formulação, propor operações práticas, ecológicas e sustentáveis, analisar os aspectos necessários a sua comercialização e entre outros fatores.

A atividade de desenvolver produtos, muitas vezes envolve uma sequência de esforços técnicos- científicos e necessita gerar maior segurança para buscar a otimização de fatores como rapidez, qualidade e custo (Cheng, 1995). As ideias de novos produtos, a partir do uso dos recursos naturais, podem surgir de muitas fontes: consumidores, cientistas, empresas, governos, mercado, etc. No entanto, são as técnicas de criatividade, informações mercadológicas e técnicas de escolha entre ideias que podem aperfeiçoar os resultados alcançados (Kotler, 1994).

Sob esse aspecto, é aconselhável que o designer e essas fontes articulem a respeito dos objetivos da sustentabilidade e ecologia durante a aplicação da metodologia projetual, para que os processos produtivos, as inovações e as tecnologias sejam adequados ao uso dos recursos naturais. Assim, o desafio das atividades do designer é grande: inovar as tecnologias e os processos, mantendo o real valor do produto desejado pelo usuário. 
Estudio de la prospección del uso de la fibra de tucumã-i (Astrocaryum acaule) para el desarrollo de productos semi-industriales

Preparar o recurso natural com 0 auxílio da tecnologia para o desenvolvimento de um novo produto faz da interferência do design no processo de investigação, um diferencial estratégico ao alcance de novas oportunidades de mercado para esse produto.

\section{Considerações Finais}

0 ensino de design tem direcionado o conhecimento-técnico-científico sobre a prática da atividade projetual para atuar no planejamento e desenvolvimento de produtos que possam utilizar os mais variados tipos de matérias-primas, como os recursos naturais.

Planejar um produto, com base nos princípios estruturais, funcionais, ergonômicos, ambientais, ecológicos, de gestãode e de produção e comercialização dos recursos naturais, é abrange todas as variáveis que possam influenciar na agregação de valores e,consequentemente, no aumento da competitividade desse produto no mercado.

Identificar o problema em função da necessidade, estruturar os objetivos a serem alcançados e definir o sitema de estudo, para a concepção de um novo produto utilizando recursos naturais, são as primeiras ações para a investigação em design. 0 desenvolvimento, a projeção do produto, fabricção, experimentos, validação e consumo, são etapas sequenciais desse processo.

O sistema a ser estudado deve identificar também as variáveis necessárias à formação do novo produto. Ter noção do universo de informações que giram em torno dos recursos naturais e as suas possibilidades de uso. Saber processar as etapas que caberão ao design, à fabricação, à gestão e ao desenvolvimento industrial ou semi-industrial da matéria-prima, até que esteja adequada às normas e padrões estabelecidos ao mercado de produtos naturais e, ao perfil e necessidade do consumidor final.

Portanto, compreende-se que a utilização dos recursos naturais para o desenvolvimento de produtos industriais, pode estar caracterizada da seguinte forma: o design investiga e conceitua a idéia (novo produto), o recurso natural é a matéria-prima a ser transformada em novo produto, a tecnologia possibilita a transformação do recurso natural (matéria-prima) em um novo produto e o mercado/indústria oferece, ao consumidor, a oportunidade de ter acesso ao novo produto (ideia conceitual do design).

Referencias:

ABRAMOVITZ, J.; REBELLO, L. H. B. - Metodologia do Projeto - Rio de Janeiro, UniverCidade / NPD, apostila de aula, 2002. 
ALEXANDER, Christopher. Notes on the Synthesis of Form. Cambridge, Massachusetts: Harvard University Press, 1964.

ASIMOV, Morris. Introduction to Design. Prentice-Hall, New Jersey. 1962.

BAXTER, M. - Projeto de Produto - Guia Prático para o Desenvolvimento de Novos Produtos - São Paulo, Editora Edgar Blücher, 1998.

BOMFIM, G. A. - Metodologia para o Desenvolvimento de Projetos - João Pessoa, Editora Universitária/UFPB, 1995.

BONSIEPE, G. - Metodologia Experimental: Desenho Industrial - Brasília, CNPq / Coordenação Editorial, 1984.

CHENG e outros. QFD: Planejamento da Qualidade. Belo Horizonte: Fundação Christiano Ottoni, 1995.

CHRISTENSEN, C.; BROWN, J. D.; MARKIDES, C.; GEROSKI, P. O crescimento pela Inovação: como crescer de forma sustentada e reinventar o sucesso. Rio de Janeiro: ELSEVIER: Campus, 336p, il. Tradução de: Innovator's solution. 2003.

EVBUOMWAN, N. F. O.; SIVALOGANATHAN, S.; JEBB, A. Concurrent Materials and Manufacturing Process Selection in Design Function Deployment. Concurrent Engineering: Research and Applications, 3, p. 135-144, 1995.

FREIRE, K. Reflections upon the experience design concept. Strategic Design Research Journal, 2(1):37-44 jan/jun. 2009.

HERNANDIS, B. Desarrollo de una metodología sistémica para el diseño de productos industriales. Tesis Doctoral (Doctorado en Ingeniería Industrial) Universidad Politécnica de Valencia, 2003.

KOTLER, P. Administração de marketing: análise, implementação e controle. 4. ed. São Paulo: Atlas, 1994.

KUHN, Robert Lawrence, "Generating Creative and Innovation in large Bureaucracies, Quorum Books, 1993.

KURTGOZU, A. From function to emotion: a critical essay on the History of design arguments. The Design Journal, 6(2):45-49. 2003.

LANGENBACH, Marcos Lins. Além do apenas Funcional - Inovação Social e Design de Serviços na Realidade Brasileira. Dissertação (Mestrado em Ciências em Engenharia de Produção) - Universidade Federal do Rio de Janeiro. Rio de Janeiro, 2008.

LEMOS, Roselie de Faria. A inserção do design nas indústrias de utensílios domésticos dos estados de Santa Catarina e Rio Grande do Sul. Dissertação 
(Mestrado em Administração), Programa de Pós Graduação em Administração e Negócios, Universidade Regional de Blumenau-FURB, 2006.

LÖBACH, Bernd. Design industrial: bases para a configuração dos produtos industriais. São Paulo: Edgard Blucher, 2001.

LOJACOMO, G.; ZACCAI, G. Um novo modelo de negócio. HSM Management, São Paulo, n.47, nov./dez. 2004.

MANZINI, E.; VEZZOLI, C. O desenvolvimento de produtos sustentáveis: os requisitos ambientais dos produtos industriais. São Paulo: Editora da Universidade de São Paulo, 2005.

MIGUEL FERNÁNDEZ, Enrique de. Introducción a la Gestión (Management). Universidad Politécnica de Valencia. 2005.

MORITZ, S. Service Design: pratical acess to an envolving field. Londres, KISD, 245 p. 2005.

MUNARI, Bruno. Das coisas nascem coisas. Apontamentos por uma metodologia projetual. Barcelona: Editorial Gustavo Gili, 1983

NORMAN, D. A.. The Design of everyday things. New York: Basic Books, 2002.

PUERTO, Henry.B. Design e Inovação tecnológica. Coletâneas de idéias para construir um discurso. Salvador: Ed. IEL - FIEB, 1999.

SOARES, M.M. Segurança do Produto: Reduzindo acidentes através do Design. (ABERGO, Rio de Janeiro, 1998.

ROOSEMBURG, N.; EEKELS, N. - Product Design: Fundamentals and Methods West Sussex, UK, Wiley, 1996.

\section{Autora principal}

Karla Mazarelo Maciel Pacheco (karlamazarelo@hotmail.com), Designer Industrial, Especialista em Marketing Empresarial e Mestre em Ciências Florestais e Ambientais pela Universidade Federal do Amazonas (UFAM) e Doutoranda em Design, Fabricação e Gestão de Projetos Industriais pela Universidade Politécnica de Valência (UPV/Espanha). Professora titular da UFAM, pelo Departamento de Design \& Expressão Gráfica, com experiência em Desenho Industrial, Comunicação Visual Gráfica, Gestão de Projetos em Design, Pesquisa e Inovação Tecnológica e Recursos Naturais Ambientais da Amazônia aplicados ao desenvolvimento de produtos. 


\section{Colaboradores}

Bernabé Hernandis Ortuño (bhernandis@degi.upv.es), Doutor em Engenharia Industrial pela Universidade Politécnica de Valência (UPV / Espanha). Professor em Design Industrial e Diretor do Programa de Doutorado em Design, Produção e Gestão de Projetos Industriais da Universidade Politécnica de Valência (UPV / Espanha). Tem experiência na área de Desenho Industrial com ênfase em Método Concorrente, Design Concorrente, Design Sistêmico, Modelo de Design e Desenvolvimento de Projetos Industriais.

Almir de Souza Pacheco (almirdesigner@gmail.com), Designer Industrial e Especialista em Design, Propaganda e Marketing pela Universidade Federal do Amazonas (UFAM). Doutorando em Design, Fabricação e Gestão de Projetos Industriais pela Universidade Politécnica de Valência (UPV/Espanha). Professor e Pesquisador em Design Gráfico com ênfase nas áreas de Identidade Visual, Tipografia, Desenvolvimento e Gestão de Projetos Gráficos Industriais e Metodologia do Projeto. 

3.14. Proyecto de innovación tecnológica - Intervención del diseño en el proceso de beneficio de la fibra natural de tucumã-i (Astrocaryum acaule) para el desarrollo de productos - Proyecto elaborado para el Nucleó de Innovación Tecnológica (NIT) de la Universidad Federal de Amazonas - UFAM / Manaus - Amazonas Brasil.

Este proyecto ha sido desarrollado y sometido a la apreciación del comité evaluador de la Pro-Rectoría y Nucleó de Innovación Tecnológica - PRONIT, vinculado a Universidad Federal de Amazonas - UFAM/Brasil con el apoyo del Ministerio de la Ciencia y Tecnología -MCT/ República Federativa de Brasil Gobierno Federal. El proyecto corresponde a las contribuciones sobre el tema de estudio de la tesis (Pags.67, 68,69 y 70).

Enviado: 29.0ctubre.11|Aceptado:15.Deciembre.11|Início: $2^{\circ}$ semestre del año de 2012

\section{ROTEIRO DE PROJETO}

Intervenção do design no processo de beneficiamento da fibra natural de tucumã-i (Astrocaryum acaule) para o desenvolvimento de produtos

Coordenação:

Prof $^{a}$ Karla Mazarelo Maciel Pacheco / DEG - FT - UFAM

Prof. Daniel Ferreira de Castro / FT - UFAM

karlamazarelo@hotmail.com e dan.mao@hotmail.com

\section{Introdução}

A identificação de oportunidades é uma etapa permanente no processo de desenvolvimento de novos produtos. Ela representa a busca sistemática de informações que permitem a organização competitiva para a comercialização de produtos ou serviços na qual, tanto um quanto o outro, pode dispor de uma grande probabilidade de sucesso, com benefícios, as necessidades expressas pelo mercado (COOPER, 1993).

Sob esse aspecto, as fibras vegetais da Amazônia brasileira, biodiversidade considerada como o maior potencial natural do mundo contemporâneo, vem servindo de material para estudos científicos e insumos às bioindústrias, por serem abundantes, apresentarem baixo custo, pouco impacto ambiental e oferecerem propriedades tecnológicas adequadas para aplicações nos mais variados tipos de produtos e serviços (GUIMARÃES et al., 2010), cujos os resultados constituem fontes importantes de renda às populações florestais e 
Estudio de la prospección del uso de la fibra de tucumã-i (Astrocaryum acaule) para el desarrollo de productos semi-industriales

para o desenvolvimento econômico de alguns dos estados dessa região, tornando-se um motivo à reforçar as iniciativas de fortalecer e ampliar os mercados para novos produtos (SCHWARTZMAN, 2004).

Com base nessas informações e de acordo com os princípios que regem as pesquisas voltadas ao setor florestal, que tem relevância estratégica para fomentar o desenvolvimento sustentável na Amazônia através da Ciência e Tecnologia, a presente proposta busca aplicar o design como elemento estratégico no processo de beneficiamento da fibra natural de tucumã-i (Astrocaryum acaule) para o desenvolvimento de produtos.

Entre as metas estabelecidas pelo projeto estão: gerar e organizar informações através de um modelo de Design Sistêmico (HERNANDIS, 2003) de modo a analisar os sistemas:

- Exterior - aspectos que envolvem o universo das fibras vegetais para o uso comercial;

- De estudo - atributos formais, funcionais e ergonômicos para o design do produto, como auxílio às etapas necessárias para a troca de conhecimento e transição do processo tecnológico a serem empregado, visando a competitividade e inovação tecnológica do produto final para o alcance novos mercados.

O trabalho conta com o apoio técnico-científico multidisciplinar de uma equipe composta por professores-investigadores do Curso de Design da Universidade Federal do Amazonas - DEG/UFAM, pesquisadores em botânica e produtos florestais do Instituto Nacional de Pesquisas da Amazônia - INPA e especialistas em áreas afins, e vislumbra fortalecer parcerias com universidades internacionais, como a Universidade Politécnica de Valência UPV, na Espanha - através da Escola Técnica Superior de Engenharia do Design - ETSID e o Centro de Investigação em Gestão e Engenharia de Produção CIGIP, que participam da formação profissional de membros da equipe para atuação em projetos de Design e Engenharia de Produção, focados ao uso de recursos naturais para a gestão e fabricação de produtos, de modo a valorizar e prezar pelos aspectos socio-culturais, econômicos e eco sustentáveis.

\section{Objetivos (Geral e Específicos)}

\subsection{Objetivo Geral}

Aplicar o design como elemento estratégico no processo de beneficiamento da fibra natural de tucumã-i (Astrocaryum acaule) para o desenvolvimento de produtos. 


\subsection{Objetivos Específicos}

- Coletar informações inerentes ao processo de produção, aspectos socioculturais, eco sustentáveis, econômicos e tecnológicos da fibra e suas formas de utilização em produtos;

- Analisar normas técnicas, critérios de certificação e o posicionamento do mercado sobre o uso da fibra de tucumã-i (Astrocaryum acaule) para o desenvolvimento de produtos;

- Identificar técnicas e/ou métodos para aprimorar o processo de beneficiamento da fibra natural de tucumã-i (Astrocaryum acaule) no que concerne a fabricação e desenvolvimento de produtos;

- Organizar as informações obtidas através do modelo de design sistêmico, observando os aspectos formais, funcionais e ergonômicos da fibra para o desenvolvimento e fabricação de produtos;

- Verificar as categorias e tipos de produtos a serem desenvolvidos a partir do beneficiamento da fibra;

- Apresentar os resultados do estudo através de um manual de orientações sobre o beneficiamento e aplicação da fibra natural de tucumã-i (Astrocaryum acaule) para o desenvolvimento e fabricação de produtos.

\section{Justificativa}

As fibras naturais tem sido o foco principal de muitos pesquisadores nos últimos anos, uma vez que a busca por novos materiais se apresenta como uma oportunidade única de encontrar soluções alternativas e inovadoras às áreas ainda não exploradas. 0 que significa avançar em direção ao sucesso, conquistando posições dominantes e promissoras (REIS NETO,2003).

0 interesse por esses tipos de matérias-primas se dá em função de apresentarem baixa densidade, alto módulo específico, serem menos abrasivas aos equipamentos de processamento, quando comparadas com outros recursos - pois são renováveis, biodegradáveis e recicláveis, o que thes permite competir com outros materiais fósseis e industrializados (LEÃO, 1997). Esses aspectos são considerados vantajosos ao mercado de produtos e ainda podem ser mais valorizados, uma vez que o avanço tecnológico tem mostrado que o uso de fibras naturais já não pode ficar limitado apenas às aplicações tradicionais (OASHI,1998).

Neste contexto, busca-se atribuir uma atenção especial às fibras naturais vegetais da Amazônia brasileira, sobretudo as que são utilizadas pelas comunidades produtoras da região do Alto Rio Negro para o trabalho artesanal, por apresentarem variedade de espécies nativas e serem empregadas através do conhecimento popular, sugerindo a possibilidade de 
Estudio de la prospección del uso de la fibra de tucumã-i (Astrocaryum acaule) para el desarrollo de productos semi-industriales

sua transformação em plantas cultiváveis para o desenvolvimento de produtos, com expressão sociocultural, tecnológica e eco sustentável, para o benefício das comunidades produtoras, do mercado e de seus potenciais consumidores.

No entanto, entende-se que a produção e o consumo são bastante diferenciados no tempo e no espaço, devido existir uma difícil compreensão, por parte das comunidades, em atender certa ou até necessária adequação entre as exigências do mercado regional e as características tradicionais valorizadas pelas unidades produtoras (CANO, 1998).

Tal realidade corresponde a desafios e superação, em busca de inovações e qualidade dos produtos para a concorrência, sem temer dificuldades ou fracassos, relacionando sua produção nas operações econômicas, na organização, na comercialização e na gestão necessária ao funcionamento de seu empreendimento (BARRETO, 2007).

O desenvolvimento de novos produtos competitivos não é uma tarefa fácil, em função da exigência do mercado e do esforço contínuo de renovação para aqueles que se acostumou a produzir, os mesmos produto durante anos e que precisam oferecê-los como novos e criativos (TASSINARI, 1995).

Portanto, sintetizar informações à tomada de decisões, solucionar problemas e querer cada vez mais dados relevantes para determinados fins, beneficiando o uso de novos materiais à fabricação dos produtos, à melhoria dos serviços e à mudança de um sistema mais eficaz na produção desses materiais possibilita criar produtos de sucesso, uma vez, que podem ser tão importantes (se não mais) para investir no projeto do processo de concepção, assim como na concepção do próprio produto (BUXTON, 2007). Assim sendo, o projeto justifica-se através dos seguintes aspectos:

\section{Social}

Introduzir as fibras vegetais amazônicas, com potencial para o uso comercial, no mercado, de modo a orientar as suas formas de aplicação e desenvolvimento de produtos, sistematizando suas etapas de uso e/ou aplicação poderá agregando um maior valor à utilidade das fibras, de forma a respeitar sua essência e oferecer mais qualidade aos produtos desenvolvidos a partir dela e, ainda, considerar a implementação de alguns atributo importantes em sua formação, como: o fator da denominação de origem, dos aspectos eco sustentáveis, da possibilidade de geração de renda e emprego às comunidades produtoras, da divulgação da cultural, da beleza, da identidade e dos valores locais. 


\section{Tecnológico}

Tratando-se de matérias-primas vegetais, precisamente irão oferecem aspectos tecnológicos plausíveis ao desenvolvimento de produtos por serem naturais e apresentarem baixo custo, alta resistência, boas propriedades físicas, mecânicas e térmicas, redução no desgaste de máquinas, facilidade de separação, durabilidade sem degradação e estrutura para reutilização e/ou pós-uso. Outra questão, considerada significante para esse item, é a possibilidade de transformar os insumos em produtos e contemplar a troca de conhecimento técnico (transferências de tecnologia) entre os indivíduos envolvidos no projeto, para o desenvolvimento de novos produtos - a partir da evolução do processo artesanal para o semi-industrial e/ou industrial se for o caso, sendo incorporado aos equipamentos de produção ou em produtos manufaturados.

\section{Econômico}

Assim como a maioria dos recursos extrativistas no Brasil, a produção e o processo de adaptação das fibras vegetais amazônicas (a serem identificadas por este projeto) para o desenvolvimento de produtos são de grande importância econômica, de subsistência e de segurança alimentaria para as comunidades produtoras, sobretudo aquelas que se encontram nas regiões mais isoladas do estado do Amazonas.

Sobre esse aspecto, o conhecimento adequado sobre o uso e a essência das fibras poderá fazer destas um produto bastante promissor, de forma a estimular, cada vez mais, o cultivo, qualificando os processos para adaptação, promovendo a transferência de conhecimento e principalmente, gerando renda e emprego para as famílias e produtores agrícolas locados naquela região e estado, e ainda contribuir para que haja mais estudos sobre o uso e preparo para torná-las cada vez más auto-suficientes em prol do alcance de novos mercados.

\section{Ambiental}

Ao optar pelo uso de fibras vegetais amazônicas para o desenvolvimento de produtos, sugere-se utilizar matérias-primas renováveis por excelência e que ao final de seu ciclo de vida devam se tornar $100 \%$ biodegradável. Portanto, o processo de obtenção necessita envolver todo um cuidado que vai desde a escolha, passando pela extração e finalizando com o corte, tendo por base a reposição natural do vegetal num período máximo de 3 a 6 meses - tornandose uma ação que não prejudica o meio ambiente e compartilha com os princípios que enfocam as preocupações globais. Assim sendo, o projeto pretende compreender e adequar a essência das matérias-primas, juntamente com os seus aspectos produtivos, aos processos de gestão e fabricação, ambos 
Estudio de la prospección del uso de la fibra de tucumã-i (Astrocaryum acaule) para el desarrollo de productos semi-industriales

coerentemente adaptados às tecnologias com estratégia de operações claras, abrangentes e de caráter eco-sustentável.

\section{Científico}

0 estudo também busca promover e registrar informações que contemplem grande parte dos aspectos intrínsecos a serem identificados nas matériasprimas a serem identificadas, de modo a contribuir para a sua evolução, gestão e uso para a fabricação de produtos.

E como ferramenta de apoio para essa produção documental, o design poderá participar como elemento de sistematização das informações, assim como elemento-chave para a elaboração estratégica, tomadas de decisões, ações e atribuição de valores para um melhor conhecimento, adaptação e utilização de fibras vegetais no que se refere ao tema proposto. Nesse contexto, a investigação poderá promover registros inéditos e inovadores para o campo científico, facilitando estudos futuros sobre o referido assunto.

\section{Metodologia}

O estudo apresenta uma combinação de dados qualitativos e quantitativos, ambos de caráter exploratório, descritivo e explicativo num marco teórico que proporciona o enfoque conceitual sobre o tema proposto (GIL, 2002). Os aspectos da investigação qualitativa servirão para obter as percepções de alguns profissionais sobre questões e fatos sociais sobre o status atual do fenômeno estudado e /ou para descrever a natureza das condições existentes em uma situação (TROCHIM, 2000).

Para a análise dos fatos, sob o ponto de vista empírico e confrontá-lo a uma visão teórica e científica a respeito dos dados coletados da realidade, o trabalho apresenta um modelo operativo, para uma primeira etapa da pesquisa, com coleta de dados procedida por pesquisas bibliográficas e documentais, ratificadas a estudos de caso específicos, correlacionados aos processos de inovação e de estratégia (YIN, 2001).

As técnicas utilizadas para coleta de dados, identificação das oportunidades e possibilidades de solução para os problemas detectados, são compostas por: grupo focal e entrevista em profundidade (MARCONI \& LAKATOS, 2006), onde a primeira possui o intuito de obter as percepções de um grupo de pessoas, neste caso as equipes envolvidas no projeto, sobre questões, fatos sociais e status atual do objeto de estudo, gerando idéias, comentários e a produção de insights (KRUEGER \& CASEY, 2000) e a segunda, explora o posicionamento e as perspectivas de especialistas de áreas correlatas ao tema, de forma não estruturada e direta para obter informações, a partir de cada participante, de forma individual (MALHOTRA, 2006). 0 estudo utiliza também o método de 
análise de SWOT para verificar as opiniões existentes entre o grupo focal e os participantes da entrevista em profundidade.

A técnica auxilia na identificação das oportunidades e possibilidades de solução para os problemas detectados, possibilitando a categorização dos fatores como sendo internos (pontos fortes e fracos) e externos (oportunidades e ameaças) em relação a uma determinada decisão, e como tal permite a comparação das oportunidades e ameaças com as fraquezas e pontos fortes do produto (SHRESTHA; ALAVALAPATI \& KALMBACHER, 2004).

Os dados quantitativos, produzidos pela investigação, permitem examinar as informações coletadas de maneira científica e de forma mais especificamente numérica, gerando medidas precisas e confiáveis, permitindo uma análise estatística que avalie a importância, gravidade, risco e tendência de agravos e ameaças. Tratam, ainda, das probabilidades, associações significantes e importantes param se conhecer a realidade da temática proposta (CODATO; NAKAMA, 2006).

A organização e apreciação das informações partem da distribuição de frequências, do cálculo de médias e da análise de variância de um fator em relação aos componentes principais.

Por fim, a aplicação do modelo de design concorrente que se justifica pela possibilidade de avaliar as variáveis necessárias ao projeto, através da análise de aspectos formais, funcionais e ergonômicos dos objetos em estudo e, a partir dessas informações, obter os parâmetros referenciais para a gestão, desenvolvimento e fabricação de produtos (HERNANDIS, 2003).

A ferramenta (Figura 1) observa a distinção e a relação que se estabelece entre o sistema de estudo, de referência, que é o sistema de trabalho, os produtos que se pretende desenvolver, e o sistema exterior, que é o contexto onde este está inserido e, ainda, completa o processo de adaptação aos novos métodos utilizados para gerar produtos, incorporando a possibilidade de utilização das técnicas de prototipagem (AGUAYO, 2002). 


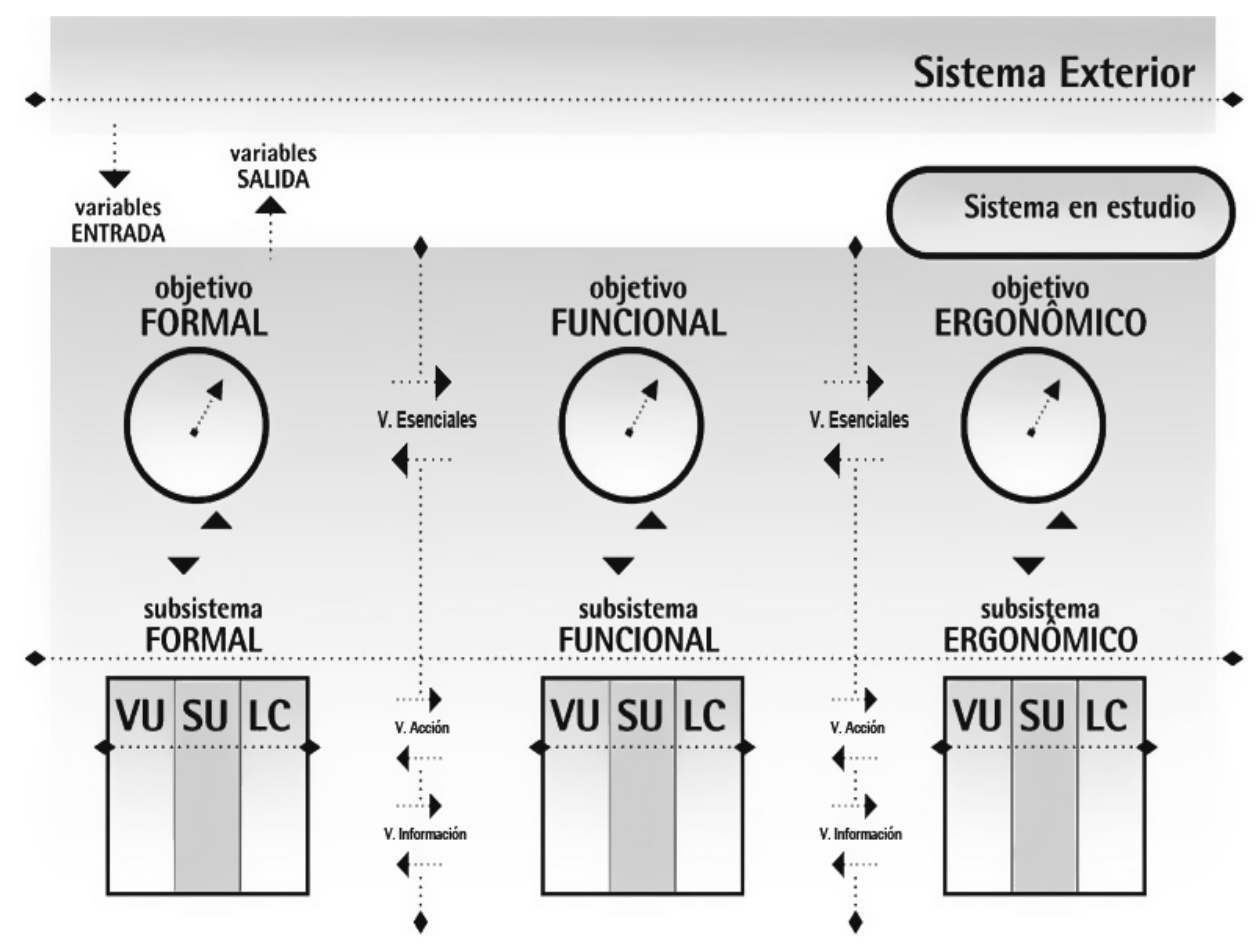

PIT_Figura 1. Representação gráfica do modelo de Design Concorrente (HERNANDIS, 2003).

O referido modelo de design concorrente busca dar vida, dinâmica e atualizar, através da retroalimentação das informações e, consequentemente, do feedback de todas as partes do sistema, no qual as variáveis tornam-se responsáveis por analisar, comprovar e manter todo o sistema ativo e controlado (HERNANDIS, 2003).

Assim sendo, e conforme os demais métodos e materiais utilizados, o projeto delimita-se mediante as seguintes etapas para execução das ações (Quadro 1): 
Quadro 1. Ações a serem realizadas pelo projeto

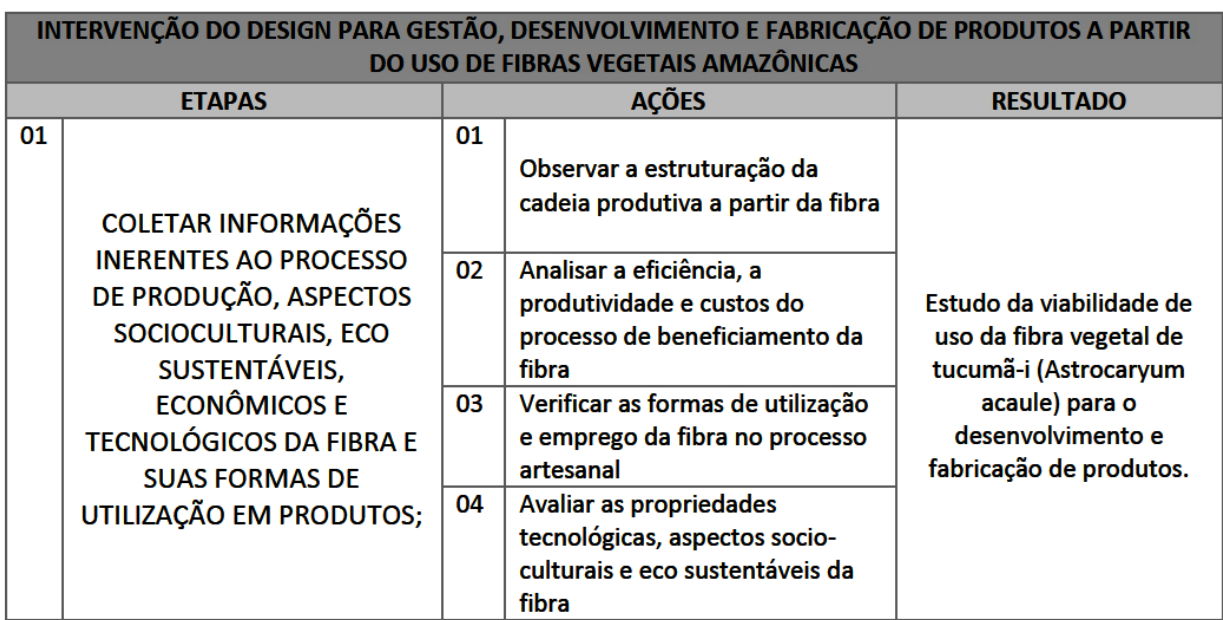

\begin{tabular}{|c|c|c|c|c|}
\hline \multirow{4}{*}{02} & \multirow{4}{*}{$\begin{array}{l}\text { ANALISAR NORMAS } \\
\text { TÉCNICAS, CRITÉRIOS DE } \\
\text { CERTIFICAÇÃO E O } \\
\text { POSICIONAMENTO DO } \\
\text { MERCADO QUANTO AO USO } \\
\text { DA FIBRA DE TUCUMÃ-I } \\
\text { (Astrocaryum acaule) PARA } \\
\text { O DESENVOLVIMENTO DE } \\
\text { PRODUTOS; }\end{array}$} & 01 & $\begin{array}{l}\text { Verificar normas técnicas e } \\
\text { critérios para fabricação dos } \\
\text { produtos. }\end{array}$ & \multirow{4}{*}{$\begin{array}{l}\text { Estabelecer critérios para } \\
\text { a aplicação da fibra de } \\
\text { acordo com o } \\
\text { posicionamento do } \\
\text { mercado, normas técnicas } \\
\text { e critérios para } \\
\text { certificação e } \\
\text { desenvolvimento de } \\
\text { produtos }\end{array}$} \\
\hline & & 02 & $\begin{array}{l}\text { Identificar consumidores em } \\
\text { potencial }\end{array}$ & \\
\hline & & 03 & $\begin{array}{l}\text { Ponderar o nível de apreciação } \\
\text { dos consumidores quanto ao } \\
\text { uso de fibras vegetais } \\
\text { amazônicas para fabricação de } \\
\text { produtos }\end{array}$ & \\
\hline & & 04 & $\begin{array}{l}\text { Identificar as categorias de uso e } \\
\text { tipos de produtos que podem } \\
\text { ser desenvolvidos a partir da } \\
\text { fibra }\end{array}$ & \\
\hline
\end{tabular}

\begin{tabular}{|c|c|c|c|c|}
\hline \multirow[t]{3}{*}{03} & \multirow{3}{*}{$\begin{array}{c}\text { IDENTIFICAR TÉCNICAS E/OU } \\
\text { MÉTODOS PARA } \\
\text { APRIMORAR O PROCESSO } \\
\text { DE BENEFICIAMENTO DA } \\
\text { FIBRA NATURAL DE } \\
\text { TUCUMÃ-I (Astrocaryum } \\
\text { acaule) NO QUE CONCERNE } \\
\text { A FABRICAÇÃO E } \\
\text { DESENVOLVIMENTO DE } \\
\text { PRODUTOS; }\end{array}$} & 01 & $\begin{array}{l}\text { Identificar técnicas e métodos, } \\
\text { utilizados no mercado, para o } \\
\text { beneficiamento de fibras } \\
\text { vegetais. }\end{array}$ & \multirow{3}{*}{$\begin{array}{l}\text { Propor técnicas e métodos } \\
\text { para o beneficiamento da } \\
\text { fibra de tucumã-i } \\
\text { (Astrocaryum acaule) }\end{array}$} \\
\hline & & 02 & $\begin{array}{l}\text { Identificar equipamentos } \\
\text { aplicados no processo de } \\
\text { beneficiamento de fibras } \\
\text { vegetais. }\end{array}$ & \\
\hline & & 03 & $\begin{array}{l}\text { Avaliar as técnicas, métodos e } \\
\text { equipamentos mais adequados } \\
\text { ao beneficiamento da fibra de } \\
\text { tucumã-i (Astrocaryum acaule) }\end{array}$ & \\
\hline
\end{tabular}


Estudio de la prospección del uso de la fibra de tucumã-i (Astrocaryum acaule) para el desarrollo de productos semi-industriales

\begin{tabular}{|c|c|c|c|c|}
\hline \multirow[t]{4}{*}{04} & \multirow{4}{*}{$\begin{array}{c}\text { ORGANIZAR AS } \\
\text { INFORMAÇÕES OBTIDAS } \\
\text { ATRAVÉS DO MODELO DE } \\
\text { DESIGN SISTÊMICO, } \\
\text { OBSERVANDO OS ASPECTOS } \\
\text { FORMAIS, FUNCIONAIS E } \\
\text { ERGONÔMICOS DA FIBRA } \\
\text { PARA O DESENVOLVIMENTO } \\
\text { E FABRICAÇÃO DE } \\
\text { PRODUTOS; }\end{array}$} & 01 & $\begin{array}{l}\text { Alimentar o modelo sistêmico } \\
\text { de design de produto com as } \\
\text { informações obtidas por meio } \\
\text { dos objetivos } 1,2 \text { e } 3 \text {. }\end{array}$ & \multirow{4}{*}{$\begin{array}{l}\text { Apresentar as variáveis de } \\
\text { saída resultantes da } \\
\text { aplicação do modelo de } \\
\text { design de produto }\end{array}$} \\
\hline & & 02 & $\begin{array}{l}\text { Estabelecer as variáveis de } \\
\text { entrada para o sistema de } \\
\text { beneficiamento da fibra }\end{array}$ & \\
\hline & & 03 & $\begin{array}{l}\text { Propor os objetivos funcionais, } \\
\text { ergonômicos e formais para o } \\
\text { sistema em estudo }\end{array}$ & \\
\hline & & 04 & $\begin{array}{l}\text { Indicar os subsistemas dos } \\
\text { objetivos funcionais, } \\
\text { ergonômicos e formais }\end{array}$ & \\
\hline
\end{tabular}

\begin{tabular}{|c|c|c|c|c|}
\hline \multirow[t]{2}{*}{05} & \multirow{2}{*}{$\begin{array}{l}\text { VERIFICAR AS CATEGORIAS E } \\
\text { TIPOS DE PRODUTOS A } \\
\text { SEREM DESENVOLVIDOS A } \\
\text { PARTIR DO } \\
\text { BENEFICIAMENTO } \\
\text { DA FIBRA; }\end{array}$} & 01 & $\begin{array}{l}\text { Definir produtos a serem } \\
\text { desenvolvidos a partir do } \\
\text { beneficiamento da fibra de } \\
\text { tucumã-i (Astrocaryum acaule) }\end{array}$ & \multirow{2}{*}{$\begin{array}{l}\text { Apresentar propostas de } \\
\text { modelos virtuais dos } \\
\text { produtos para análise dos } \\
\text { aspectos de design e } \\
\text { possibilidade de } \\
\text { desenvolvimento de } \\
\text { protótipos }\end{array}$} \\
\hline & & 02 & $\begin{array}{l}\text { Estabelecer requisitos e } \\
\text { parâmetros para o design de } \\
\text { produtos. }\end{array}$ & \\
\hline
\end{tabular}

\begin{tabular}{|c|c|c|c|c|}
\hline 06 & $\begin{array}{c}\text { APRESENTAR OS } \\
\text { RESULTADOS DO ESTUDO }\end{array}$ & 01 & $\begin{array}{l}\text { Estruturar por etapas as } \\
\text { informações e materiais } \\
\text { produzidos pelo estudo }\end{array}$ & $\begin{array}{c}\text { Produção gráfica do } \\
\text { manual de orientações } \\
\text { sobre o beneficiamento e }\end{array}$ \\
\hline & $\begin{array}{l}\text { ATRAVÉS DE UM MANUAL } \\
\text { DE ORIENTAÇÕES SOBRE O }\end{array}$ & 02 & $\begin{array}{l}\text { Desenvolver o projeto gráfico do } \\
\text { manual de orientações }\end{array}$ & \multirow{2}{*}{$\begin{array}{c}\text { aplicação da fibra natural } \\
\text { de tucumã-i (Astrocaryum } \\
\text { acaule) para o } \\
\text { desenvolvimento e } \\
\text { fabricação de produtos }\end{array}$} \\
\hline & $\begin{array}{c}\text { BENEFICIAMENTO E } \\
\text { APLICAÇÃO DA FIBRA } \\
\text { NATURAL DE TUCUMÃ-I } \\
\text { (Astrocaryum acaule) PARA } \\
\text { O DESENVOLVIMENTO E } \\
\text { FABRICAÇÃO DE PRODUTOS. }\end{array}$ & 03 & $\begin{array}{l}\text { Apresentar um protótipo } \\
\text { impresso do manual de } \\
\text { orientação elaborado. }\end{array}$ & \\
\hline
\end{tabular}

\section{Equipe técnica}

A equipe que compõe o projeto (Quadro 2), é formada por profissionais de área correlacionadas ao tema, com experiência e publicações voltadas a estudos com recursos naturais, mercado e design. Estão também vinculados a grandes instituições de ensino superior, pesquisa e tecnologia. Como: Departamento de Design \& Expressão Gráfica da Universidade Federal do Amazonas (DEG/UFAM) / Departamento de Economia Universidade Federal do Amazonas (FES/ UFAM) / Faculdade de Tecnologia da Universidade Federal do Amazonas (FT/UFAM) / Laboratório de Pesquisas em Palmeiras do Instituto Nacional de Pesquisas da Amazônia (LABPALM/INPA) / Instituto Nacional Ciência e Tecnologia de Madeiras da Amazônia do Instituto Nacional de Pesquisas da Amazônia (INCT/INPA) / Escuela Técnica Superior de Ingeniería 
del Diseño de la Universitat Politècnica de València (ETSID/ UPV/ESPAÑA) / Centro de Investigación en Gestión e Ingeniería de Producción de la Universitat Politècnica de València (CIGIP/ UPV/ESPAÑA).

Quadro 2. Equipe técnica do projeto

\begin{tabular}{|c|c|c|c|c|}
\hline N. & Nome & Formação & Lotação & Atribuições/Projeto \\
\hline 01 & $\begin{array}{l}\text { Karla Mazarelo Maciel } \\
\text { Pacheco }\end{array}$ & $\begin{array}{l}\text { Doutoranda - Design, Fabricação } \\
\text { e Gestão de projetos industriais }\end{array}$ & DEG/UFAM & Coordenação \\
\hline 02 & Daniel Ferreira de Castro & $\begin{array}{l}\text { Doutoranda - Engenharia de } \\
\text { Produção }\end{array}$ & FT/UFAM & Vice coordenação \\
\hline 03 & Sheila Cordeiro Mota & $\begin{array}{l}\text { Mestrado - Engenharia de } \\
\text { Produção }\end{array}$ & DEG/UFAM & Gerente operacional \\
\hline 04 & $\begin{array}{l}\text { Valdenei de Melo } \\
\text { Parente }\end{array}$ & Doutoranda-Economia & FES/UFAM & $\begin{array}{l}\text { Estudo de mercado e } \\
\text { viabilidade econômica }\end{array}$ \\
\hline 05 & $\begin{array}{l}\text { Ires Paula de Andrade } \\
\text { Miranda }\end{array}$ & $\begin{array}{l}\text { Doutora - Ciências Biológicas } \\
\text { (Botânica) }\end{array}$ & LABPALM/INPA & $\begin{array}{l}\text { Identificação e } \\
\text { Catalogação das } \\
\text { espécies vegetais }\end{array}$ \\
\hline 06 & $\begin{array}{l}\text { Edelcílio Marques } \\
\text { Barbosa }\end{array}$ & $\begin{array}{l}\text { Doutora - Ciências Biológicas } \\
\text { (Botânica) }\end{array}$ & LABPALM/INPA & $\begin{array}{l}\text { Identificação e } \\
\text { Catalogação das } \\
\text { espécies vegetais }\end{array}$ \\
\hline 07 & $\begin{array}{l}\text { Claudete Catanhede do } \\
\text { Nascimento }\end{array}$ & $\begin{array}{l}\text { Doutora - Ciências Biológicas } \\
\text { (Botânica) }\end{array}$ & INCT/INPA & $\begin{array}{l}\text { Propriedades } \\
\text { tecnológicas }\end{array}$ \\
\hline 08 & $\begin{array}{l}\text { Bernabé Hernandis } \\
\text { Ortuño }\end{array}$ & Doutor em Engenharia Industrial & ETSID/UPV & $\begin{array}{l}\text { Estudo da aplicação } \\
\text { do Modelo de Design } \\
\text { Concorrente }\end{array}$ \\
\hline 09 & Eduardo Vicens Salort & Doutor em Engenharia Industrial & CIGIP/UPV & $\begin{array}{l}\text { Processo de } \\
\text { beneficiamento do } \\
\text { produto }\end{array}$ \\
\hline 10 & Susana Paixão-Barrada & $\begin{array}{l}\text { Doutoranda - Design, Fabricação } \\
\text { e Gestão de projetos industriais }\end{array}$ & ETSID/UPV & $\begin{array}{l}\text { Estudo da aplicação } \\
\text { do Modelo de Design } \\
\text { Concorrente }\end{array}$ \\
\hline 11 & Almir de Souza Pacheco & $\begin{array}{l}\text { Doutorando - Design, Fabricação } \\
\text { e Gestão de projetos industriais }\end{array}$ & ETSID/UPV & $\begin{array}{l}\text { Desenvolvimento e } \\
\text { produção gráfica do } \\
\text { manual }\end{array}$ \\
\hline 12 & $\begin{array}{l}\text { Andrea Lúcia Medina } \\
\text { Gómez }\end{array}$ & $\begin{array}{l}\text { Doutoranda - Design, Fabricação } \\
\text { e Gestão de projetos industriais }\end{array}$ & ETSID/UPV & $\begin{array}{l}\text { Estudo de Mercado/ } \\
\text { Design de Produtos }\end{array}$ \\
\hline 13 & $\begin{array}{l}\text { John Jairo Cardozo } \\
\text { Vásquez }\end{array}$ & $\begin{array}{l}\text { Doutoranda - Design, Fabricação } \\
\text { e Gestão de projetos industriais }\end{array}$ & ETSID/UPV & $\begin{array}{l}\text { Estudo Eco } \\
\text { sustentável /Design } \\
\text { de Produtos }\end{array}$ \\
\hline 14 & $\begin{array}{l}\text { Nélida Yaneth Ramírez } \\
\text { Triana }\end{array}$ & $\begin{array}{l}\text { Doutoranda - Design, Fabricação } \\
\text { e Gestão de projetos industriais }\end{array}$ & ETSID/UPV & $\begin{array}{l}\text { Estudo Eco } \\
\text { sustentável /Design } \\
\text { de Produtos }\end{array}$ \\
\hline 15 & $\begin{array}{l}\text { José Rafael González } \\
\text { Díaz }\end{array}$ & $\begin{array}{l}\text { Doutoranda - Design, Fabricação } \\
\text { e Gestão de projetos industriais }\end{array}$ & ETSID/UPV & $\begin{array}{l}\text { Estudo de Mercado/ } \\
\text { Design de Produtos }\end{array}$ \\
\hline 16 & 10 (dez) a definir & $\begin{array}{l}\text { Acadêmicos de curso de } \\
\text { graduação em áreas afins }\end{array}$ & UFAM & a definir \\
\hline
\end{tabular}


Estudio de la prospección del uso de la fibra de tucumã-i (Astrocaryum acaule) para el desarrollo de productos semi-industriales

\section{Cronograma}

Quadro 3. Cronograma provisório do projeto

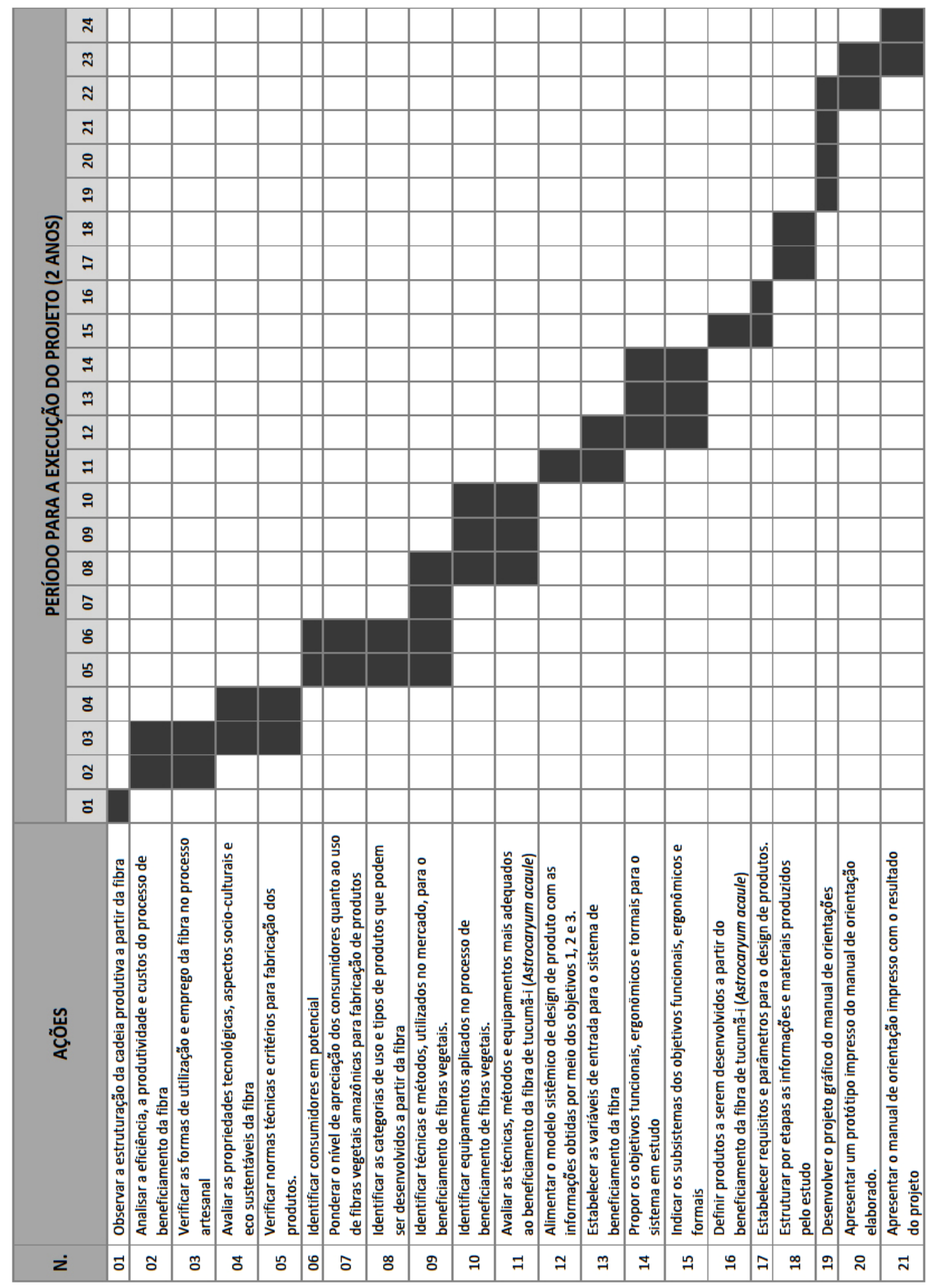


7. Orçamento: Equipamentos, materiais, despesas com a equipe (DIÁRIAS, PASSAGENS E BOLSAS) com todas as descrições detalhadas. Planilha de Material e Serviços.

\section{Quadro 4. Planilha de material e serviço}

\begin{tabular}{|l|l|l|c|c|c|}
\hline Item & \multicolumn{1}{|c|}{ Descrição } & Unidade & Custo Unitário (R\$) & Quantidade & Custo Total (R\$) \\
\hline 1 & $\begin{array}{l}\text { Material de consumo (material de } \\
\text { expediente, suprimento de informática, } \\
\text { etc.) }\end{array}$ & Lote & 500,00 & 24 & $12.000,00$ \\
\hline 2 & $\begin{array}{l}\text { Serviços prestados pessoa física } \\
\text { (serviços técnicos especializados de } \\
\text { nível superior) }\end{array}$ & Serviço & $4.000,00$ & 36 & $144.000,00$ \\
\hline 3 & $\begin{array}{l}\text { Serviços prestados pessoa física } \\
\text { (serviços prestados de manutenção e } \\
\text { suporte.) }\end{array}$ & Serviço & $1.000,00$ & 12 & $12.000,00$ \\
\hline 4 & $\begin{array}{l}\text { Transporte de pesquisadores (taxi, } \\
\text { moto taxi, ônibus, automóvel particular, } \\
\text { barco) (Pessoa Física ou Jurídica) }\end{array}$ & Serviço & 350,00 & 40 & $14.000,00$ \\
\hline 5 & $\begin{array}{l}\text { Combustível automóvel, motocicleta e } \\
\text { barco (Pessoa Jurídica) }\end{array}$ & Litro & 2,89 & 5000 & $14.450,00$ \\
\hline 6 & $\begin{array}{l}\text { Taxas de participação em Cursos e } \\
\text { Eventos técnicos científicos (Pessoa } \\
\text { Jurídica) }\end{array}$ & Taxa & 700,00 & 20 & $14.000,00$ \\
\hline 7 & $\begin{array}{l}\text { Seguro de vida de pesquisadores e } \\
\text { bolsistas }\end{array}$ & Serviço & 120,00 & 300 & $36.000,00$ \\
\hline 8 & $\begin{array}{l}\text { Serviço de manutenção de } \\
\text { equipamentos e instalações (Pessoa } \\
\text { Jurídica) }\end{array}$ & Serviço & $2.000,00$ & 10 & $20.000,00$ \\
\hline 9 & Livros e periódicos & Unidade & 150,00 & 45 & $6.750,00$ \\
\hline 10 & Serviços gráficos (Pessoa Jurídica) & Serviço & $12.000,00$ & 02 & $24.000,00$ \\
\hline & \multicolumn{1}{|c|}{ Total em Material e Serviços } & & $297.200,00$ \\
\hline
\end{tabular}

Quadro 5. Planilha de equipamento

\begin{tabular}{|l|l|c|c|c|c|}
\hline Item & \multicolumn{1}{|c|}{ Descrição } & Unidade & Custo Unitário (R\$) & Quantidade & Custo Total (R\$) \\
\hline 11 & $\begin{array}{l}\text { Notebook HP Compaq Presario CQ42- } \\
\text { 213br,Intel Celeron T3300, 3GB } \\
\text { memória, HD 320, câmera }\end{array}$ & $-2.500,00$ & 09 & $22.500,00$ \\
\hline 12 & $\begin{array}{l}\text { Impressora monocromática } \\
\text { Multifuncional HP Laserjet M1132 Laser }\end{array}$ & - & 935,00 & 01 & 935,00 \\
\hline 13 & Impressora Deskjet A3 - HP & - & $1.600,00$ & 01 & $1.600,00$ \\
\hline 14 & $\begin{array}{l}\text { Impressora Multifuncional Jato de Tinta } \\
\text { Colorida Deskejet 3050 c / Wireless } \\
\text { CH383C HP }\end{array}$ & - & 241,53 & 01 & 241,53 \\
\hline 15 & $\begin{array}{l}\text { Máquina fotográfica NIKON D5000, } \\
\text { lente 18-55 mm + lente 55-200 mm. }\end{array}$ & - & $1.700,00$ & 01 & $1.700,00$ \\
\hline 16 & $\begin{array}{l}\text { Projetor multimídia - definição 1024 x } \\
780 \text { pixels, brilho 2.200 ANSI }\end{array}$ & - & $2.000,00$ & 01 & $2.000,00$ \\
\hline \multicolumn{5}{|c|}{ Total em Equipamentos } \\
\hline
\end{tabular}


Estudio de la prospección del uso de la fibra de tucumã-i (Astrocaryum acaule) para el desarrollo de productos semi-industriales

Quadro 6. Planilha de diárias

\begin{tabular}{|l|l|l|r|r|r|}
\hline Item & \multicolumn{1}{|c|}{ Descrição } & Unidade & $\begin{array}{c}\text { Custo Unitário } \\
\text { (R\$) }\end{array}$ & $\begin{array}{c}\text { Quantid } \\
\text { ade }\end{array}$ & $\begin{array}{c}\text { Custo Total } \\
\text { (R\$) }\end{array}$ \\
\hline 17 & Diárias Nacionais & Unitário & 310,00 & 60 & $18.600,00$ \\
\hline 18 & Diárias Internacionais & Unitário & 460,00 & 40 & $18.400,00$ \\
\hline \multicolumn{4}{|c|}{ Total em Diárias } \\
\hline
\end{tabular}

Quadro 7. Planilha de passagens

\begin{tabular}{|l|l|l|r|c|r|}
\hline Item & \multicolumn{1}{|c|}{ Descrição } & Unidade & Custo Unitário (R\$) & Quantidade & Custo Total (R\$) \\
\hline 19 & $\begin{array}{l}\text { Passagem aérea } \\
\text { nacional }\end{array}$ & Bilhete & $1.700,00$ & 20 & $34.000,00$ \\
\hline 20 & $\begin{array}{l}\text { Passagem aérea } \\
\text { internacional }\end{array}$ & Bilhete & $4.500,00$ & 8 & $36.000,00$ \\
\hline \multicolumn{7}{|c|}{ Total em Passagens } \\
\hline
\end{tabular}

Quadro 8. Planilha de bolsas

\begin{tabular}{|l|l|c|c|c|c|}
\hline Item & Modelo de bolsa & Número de bolsistas & $\begin{array}{c}\text { Número de } \\
\text { meses }\end{array}$ & Valor unitário & Total \\
\hline 21 & Iniciação Científica & 10 & 24 & 500,00 & $120.000,00$ \\
\hline 22 & Mestre & 03 & 24 & $1.900,00$ & $136.800,00$ \\
\hline 23 & Doutor & 02 & 24 & $2.100,00$ & $100.800,00$ \\
\hline \multicolumn{4}{|c|}{ Total em Bolsa } \\
\hline
\end{tabular}

Total Geral (24 mêses):

R\$

790.776,56

\section{Referencias}

Aguayo, F. Metodología del diseño industrial: un enfoque desde la ingeniería concurrente. Ed Ra-Ma, Madrid, 2002.

Barreto, P. D. O. L. A produção da fibra de tucum como alternativa econômica dos povos indígenas do Alto Rio Negro. Dissertação (Mestrado em Sociedade e Cultura da Amazônia). Universidade Federal do Amazonas - UFAM, Manaus AM, 2007.

Buxton, B. Sketching user experience - Getting the design right and the right design. San Francisco: Morgan Kaufman, 2007. 
Cano, W. Introdução à Economia: uma abordagem crítica. 2 ed. UNESP: São Paulo, 1998.

Cooper, R. G. Winnig at New Products. Addison-Wesley Publishing Company, 1993.

Gil, Antonio Carlos. Como Elaborar Projetos de Pesquisa. Metodologia da Pesquisa. 4.ed. São Paulo: Atlas, 2002.

Guimarães, M. et al. Caracterização anatômica da fibra de bambu (Bambusa vulgaris) visando sua utilização em compósitos poliméricos. Revista Iberoamericana de Polímeros 11(7), 442-456 SLAP, 2010.

Hernandis, B. Desarrollo de una metodología sistémica para el diseño de productos Industriales -Tesis Doctoral, Universidad Politécnica de Valencia, 2003.

Krueger, R. A. \& Casey, M. A. Focus Groups. A Practical Guide for Applied Research. 3rd ed. Thousand Oaks, CA: Sage Publications, 2000.

Leão, A. L. Viabilidade técnica da produção de compósitos não-estruturais à base de lignocelulósicos. Tese (Livre Docência em Recursos Naturais Renováveis). Universidade Estadual Paulista - UNESP. Botucatu - SP, 1997.

Malhotra, Naresh K. Pesquisa de marketing. $4^{\mathrm{a} e d}$. Porto Alegre: Bookman, RS, 2006.

Marconi, M. A.; Lakatos, E. M. Fundamentos de metodologia cientifica. 6.ed. São Paulo: Atlas, 2006.

Oashi, M. C. G. Estudo da cadeia produtiva como subsídio da pesquisa e desenvolvimento do agronegócio do sisal na Paraíba. Tese (Doutorado de Engenharia de Produção). Universidade Federal de Santa Catarina - UFSC. Florianópolis - SC, 1998.

Reis Neto, O. P. R. Fundamentos para a viabilização econômica da utilização de matérias-primas de fontes renováveis na fabricação de bens de consumo. Dissertação de Mestrado de Engenharia Mecânica. Universidade Estadual de Campinas - UEC, Faculdade de Engenharia Mecânica. Campinas - SP, 2003.

Schwartzman, S. Mercado para produtos extrativistas da Amazônia brasileira. In ARNT, A. R. O destino da floresta. Reservas extrativistas e desenvolvimento sustentável na Amazônia. Relume Dumará, Rio de Janeiro - RJ, 2004.

Shrestha, R.K., Alavalapati, J.R.R., Kalmbacher, R.S. Exploring the Potential for Silvopasture Adoption in. South-Central Florida: an Application of SWOTAHP Method. Agricultural Systems 81, pp.185-199, 2004. 
Estudio de la prospección del uso de la fibra de tucumã-i (Astrocaryum acaule) para el desarrollo de productos semi-industriales

Tassinari, A. M. I. Sociedades Indígenas: Introdução ao tema da diversidade cultural. A Temática indígena na escola: novos subsídios para professores de 1 e 2 graus. MEC/MARI/UNESCO, Brasília - DF, 1995.

Trochim, W. M. The research methods knowledge base. 2nd Edition. Cincinnati, OH: Atomic Dog Publishing, 2000.

Yin, Robert K. Estudo de caso: planejamento e métodos. Tradução Daniel Grassi. 2.ed. Porto Alegre: Bookman, 2001. 
Capítulo 4 - Discusión final 



\section{Discusión final}

\subsection{Resultados generales}

Los resultados son acordes con los objetivos establecidos en la tesis respondiendo de este modo a las investigaciones presentadas en respuesta a las hipótesis planteadas. La siguiente información corresponde a los resultados esenciales de la investigación, presentados en forma resumida y ordenados conforme a las actividades planeadas en función del cumplimento de cada uno de los objetivos del estudio.

Con respecto a las OPORTUNIDADES Y LIMITACIONES DEL TEMA EN ESTUDIO y el POSICIONAMIENTO DE LOS ESPECIALISTAS EN DISEÑO (Artículo 1), la investigación, analiza algunos aspectos claves como: las propiedades tecnológicas, el proceso de transformación y el estudio de mercado, para un mejor direccionamiento y desarrollo del estudio (Figura 14).

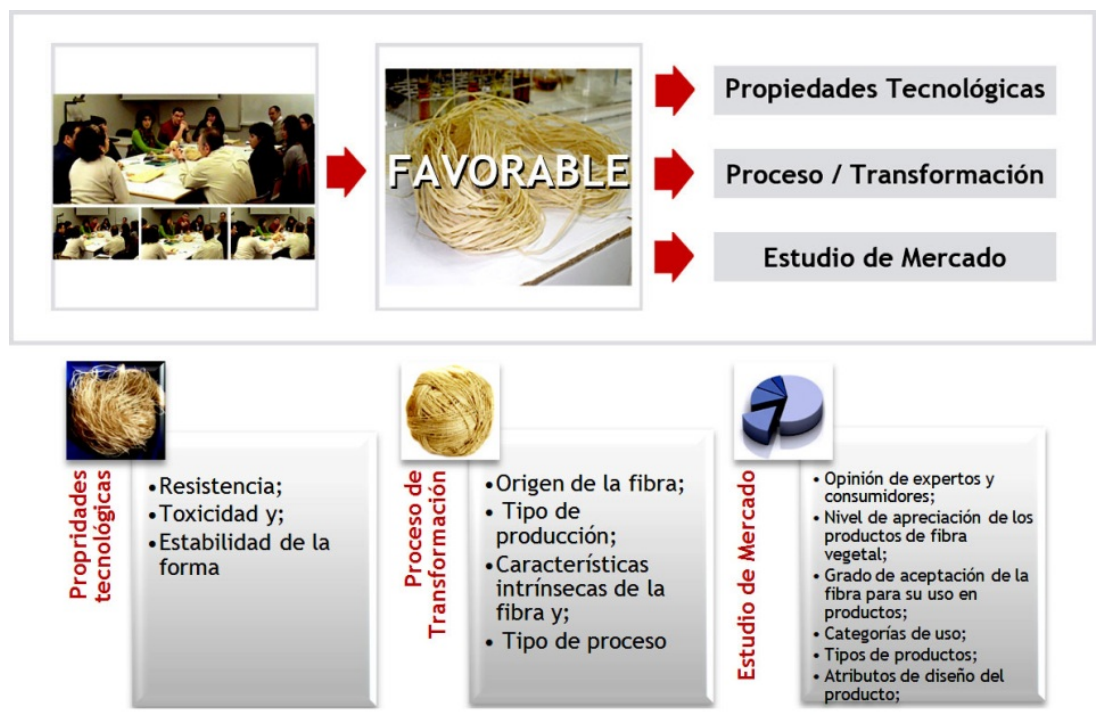

Figura 14. Posicionamiento de los especialistas de diseño. Fuente: de la autora (2012).

Según los profesionales de diseño, es primordial identificar y observar las propiedades tecnológicas presentadas por la fibra, sobre todo en lo referente a los aspectos relativos a resistencia, toxicidad y estabilidad con respecto a la forma de la fibra. 
El proceso de transformación de la fibra ha sido otro factor apuntado por los diseñadores como significativo, principalmente debido a la necesidad de conocer el origen de la materia prima, los aspectos productivos, las características intrínsecas de esta, así como aquellos aspectos relativos a la cuestión socio-ambiental que involucra al objeto estudiado y a las informaciones necesarias a tener en cuenta para futuras transferencias de tecnología.

También, el estudio de mercado se ha mostrado como una herramienta básica para la obtención de información con respecto a lo qué piensan los expertos y los consumidores en cuanto a: los productos desarrollados con fibras vegetales, el uso de fibra tucumã-i (Astrocaryum acaule), la categoría de uso, así como los tipos de productos y atributos del diseño para la aplicación del objeto de estudio en este contexto.

En cuanto al POSICIONAMIENTO DE LOS EXPERTOS (artículo 2), la respuesta también ha sido positiva al proceso de transformación y adaptación semiindustrial de la fibra, por tratarse de una posibilidad para revalorizar la fibra haciéndola más eficiente y competitiva.

Los entrevistados se mostraron de acuerdo con los diseñadores en cuanto a considerar como aspectos prioritarios para el desarrollo de tema en estudio: las propiedades tecnológicas, el proceso de transformación y el estudio de mercado.

Sin embargo, también se han apuntado otros factores como relevantes a considerar: los criterios de certificación, el registro de datos y la sistematización de informaciones (Figura 15).

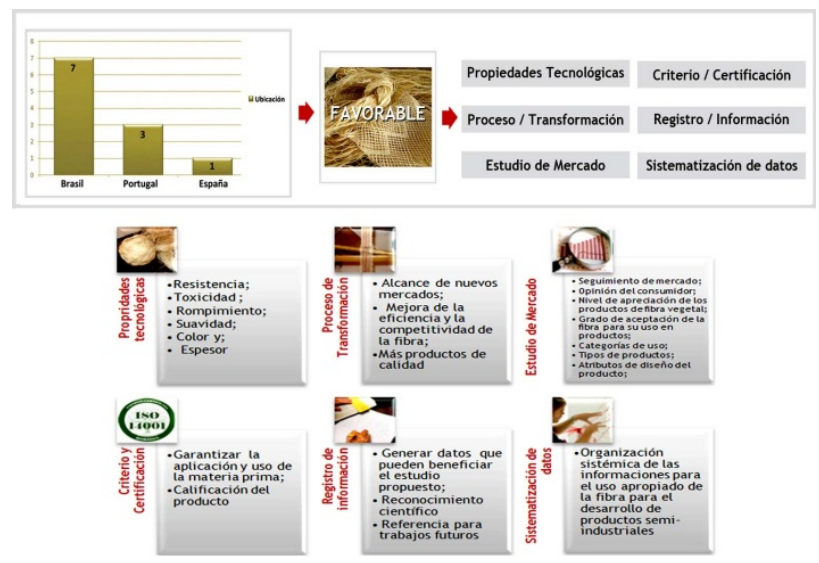

Figura 15. Posicionamiento de los expertos. Fuente: de la autora (2012). 
Según los profesionales consultados, las características tecnológicas y los criterios para certificación son importantes para garantizar una buena aplicación de la fibra en cualquier categoría de producto, ya que según los expertos es a través de estos aspectos y su consideración la manera en que se cumplen los atributos demandados de los materiales naturales necesarios para la fabricación de productos.

Con respecto al proceso de transformación de la materia prima es fundamental analizarlo en función de los valores intrínsecos de la fibra y del tipo de técnica a ser empleada en este contexto, observando también los factores socio-ambientales que involucran al objeto de estudio.

De este modo la fibra podrá alcanzar nuevos mercados, mejorar su eficiencia, competitividad y ofrecer productos con más calidad. Otra información esencial para la investigación ha sido el estudio de mercado con objeto de identificar los consumidores potenciales y su posicionamiento con respecto a la propuesta de la investigación a saber: categorías de uso, tipo de productos y atributos necesarios para el diseño del producto.

Con objeto de entender mejor los aspectos considerados y necesarios en el estudio, los expertos sugieren la realización de un registro de toda la información recogida a lo largo de la investigación. El objetivo de este procedimiento es importante para el campo científico, y además, sirve para organizar los datos en un contexto sistémico de modo que observe la transición de un producto de naturaleza artesanal para su adaptación semiindustrial. En este contexto, los entrevistados creen que el diseño puede participar como elemento clave para la sistematización de la información, facilitando la toma de decisiones para la obtención de resultados satisfactorios a lo largo del estudio.

Al analizar las OPINIONES EXPRESADAS POR DOS GRUPOS DISTINTOS: DISEÑADORES Y LOS EXPERTOS (Artículos 1, 2 y 3), fueron identificadas las oportunidades y limitaciones del estudio, dónde los factores considerados relevantes para la transformación de la fibra, y consecuentemente su uso para el desarrollo de productos semi-industriales son: el hecho de ser una materia prima natural y renovable; el ser una fibra producida de manera sostenible; ser una fuente para generación de empleo y renta; poseer aspectos de innovación - sobre todo por su aplicabilidad en una variedad de tipologías de productos y tener una buena receptividad en el mercado de productos artesanales.

Estos aspectos hacen viable: ventajas centradas en el valor atribuido a los materiales naturales y con denominación de origen; al uso de tecnologías modernas y viables al tipo de transformación sugerida; a los beneficios 
Estudio de la prospección del uso de la fibra de tucumã-i (Astrocaryum acaule) para el desarrollo de productos semi-industriales

sociales, culturales y económicos que la propuesta puede ofrecer; a la existencia de más variedades de productos, nuevas categorías para el uso de la fibra en el mercado; al registro de datos y al alcance de nuevos mercados a través de la influencia del diseño como herramienta estratégica para la obtención del objetivo general del estudio.

Sin embargo el análisis DAFO (Figura 16) realizado respecto al posicionamiento de los diseñadores y expertos (Artículo 4),también apuntó algunos aspectos considerados negativos en el estudio, como son: la insuficiencia de datos científicos con respecto al uso y manejo de la fibra en el proceso industrial o semi-industrial; el uso de tecnologías precarias para la transformación de la fibra en producto; una actividad realizada solamente por las comunidades productoras, y la ausencia de estandarización para el desarrollo de productos. Además de la consideración de estos factores existe la preocupación con respecto a cuestiones como el consumo de energía, el impacto ambiental, la dificultad de logística en la Amazonía y la competencia con las fibras tradicionalmente consolidadas en el mercado.

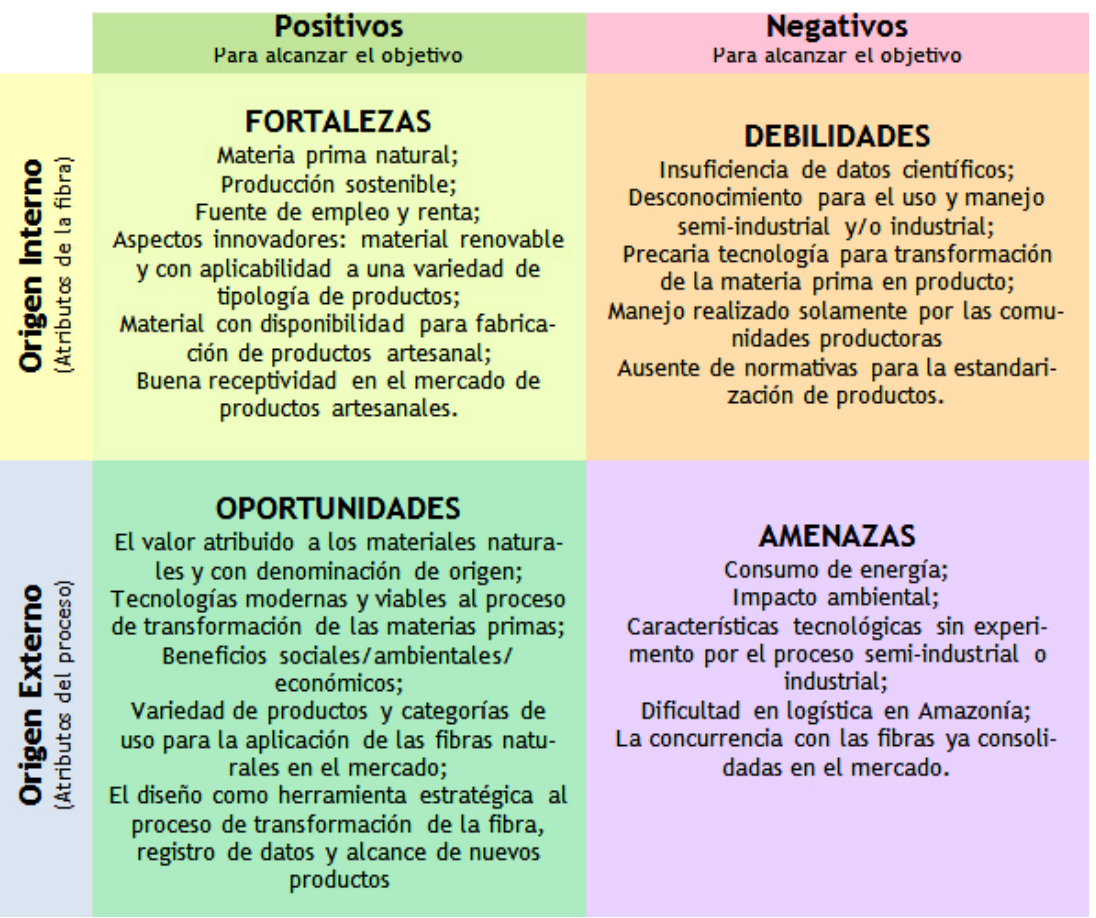

Figura 16. Oportunidades y limitaciones del estudio. Fuente: de la autora (2012). 
Frente a las debilidades y amenazas identificadas, los grupos propusieron la realización de un estudio de mercado, para identificar los consumidores potenciales y saber qué opinan sobre el uso de la fibra de tucumã-i (Astrocaryum acaule) para el desarrollo de productos semi-industriales.

Otra aportación considerada muy importante para la investigación se refiere a la oportunidad de mantener un registro sistémico de todas las informaciones generadas, sobre todo durante en la etapa de transformación y aplicación de la fibra para su conversión en un producto artesanal con objeto de obtener una posterior evaluación de cada una de las etapas.

De esta manera y según los profesionales consultados, tales procedimientos podrán mejorar aún más las fortalezas y eliminar - o al menos minimizar - los puntos débiles descritos en esta fase de la investigación, de modo que se pueda beneficiar la evolución de la materia prima - desde su procesado artesanal al semi-industrial, implicando por tanto una aportación al campo científico y una referencia para futuras aplicaciones en este sentido.

Por tanto, el cumplimiento de las consideraciones aportadas en el estudio por los grupos de expertos y profesionales, así como tener en cuenta los datos obtenidos a partir del ESTUDIO DE MERCADO Y DEL CONSUMIDOR, garantiza el cumplimiento (Figura 17) de la propuesta del estudio.

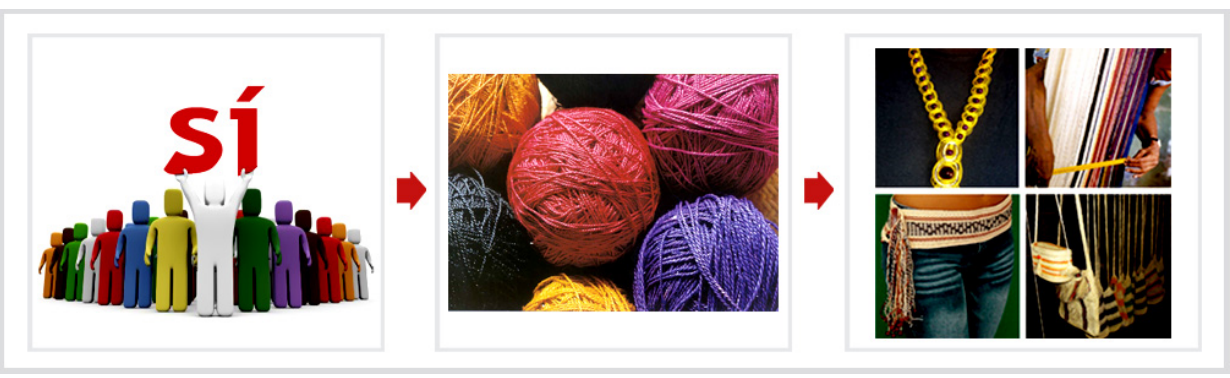

Figura 17. Posicionamiento de mercado. Fuente: de la autora (2012).

De acuerdo con los 408 individuos encuestados - en territorio brasileño esencialmente en la ciudad de Manaus/Amazonas, ubicación primordial del objeto de la investigación y población donde se localiza la mayor participación de los encuestados - el nivel de consumo de productos desarrollados con fibras vegetales se evidenció como elevado ( $n=331 ; 81,1 \%)$, principalmente debido a la existencia de una gran variedad de productos en oferta $(n=286 ; 70,1 \%)$ y de diversas tipologías de productos confeccionados con este tipo de materia prima. 
Estudio de la prospección del uso de la fibra de tucumã-i (Astrocaryum acaule) para el desarrollo de productos semi-industriales

Cuando se pregunta a los encuestados sobre cuál es el precio que estarían dispuestos a pagar por un producto hecho con fibra vegetal, los encuestados contestaron que el factor precio no es determinante al considerar la existencia de otros aspectos que aportan múltiples beneficios al consumir esta categoría de artículos, demostrando por tanto su disposición a pagar casi cualquier importe.

En cuanto a la inserción de nuevas fibras vegetales en el mercado, para la fabricación de productos, los consumidores presentaron una buena receptividad $(n=405 ; 99,3 \%)$ y en relación al GRADO DE ACEPTACIÓN para el uso de la fibra amazónica de tucumã-i (Astrocaryum acaule) en productos (Artículo 5), especialmente realizada por proceso semi-industrial, la aceptación ha sido considerable $(n=406 ; 99,5 \%)$, principalmente por parte del público femenino $(n=406 ; 99,5 \%)$.

Con respecto a las CATEGORÍAS DE USO Y TIPO DE PRODUCTO para el procesado semi-industrial de la fibra (Artículo 6), los consumidores eligieron principalmente vestuario y dentro de esta tipología en particular la blusa (Figura 18).

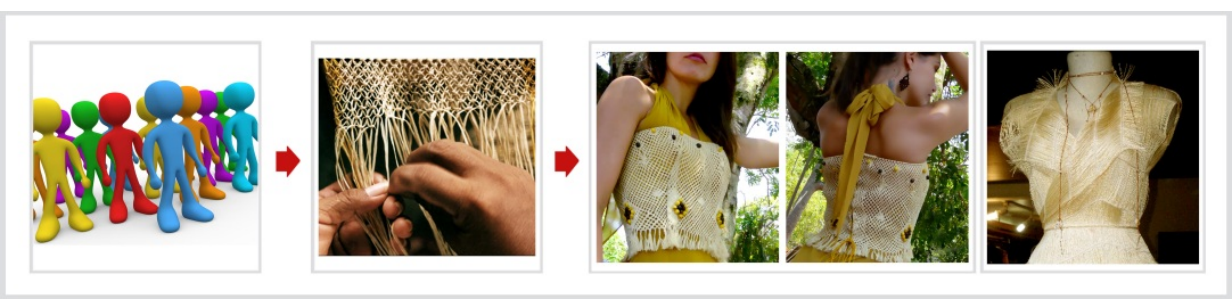

Figura 18. Categoria de uso y tipo de producto elegidos por los consumidores. Fuente: de la autora (2012).

Los consumidores consideraron que la fibra posee características innovadoras y está capacitada para su utilización en los más variados tipos de productos y segmentos del mercado, principalmente en el campo de actuación textil. Con respecto al posicionamiento del público, el vestuario fue la categoría de uso mas valorada ( $n=149 ; 36,5 \%)$.

Los encuestados opinan que el vestuario es un vehículo de comunicación ideal para la divulgación de nuevos recursos naturales, y en función de esto, señalaron la blusa $(n=141 ; 34,6 \%)$ como un producto prometedor y con grandes posibilidades para aplicaciones creativas, innovadoras y estratégicas que seguramente ayudarán a promover el uso de la materia prima en el mercado. 
El público también evidenció, en esta etapa de la investigación, los valores intrínsecos de la fibra que, en paralelo a las posibilidades que ofrecen sus características tecnológicas, deben garantizar la calidad del producto final, favoreciendo la diferencia en la innovación proporcionadas por ésta, sobre todo al alcance de nuevos mercados $y$ en beneficio de sus futuros consumidores.

Considerando estas opiniones y a partir de los resultados obtenidos mediante un estudio de agrupamientos a partir de una encuesta cuya muestra representativa fue de 408 individuos se identificó: la SEGMENTACIÓN DE MERCADO Y LOS ATRIBUTOS NECESÁRIOS AL DISEÑO DEL PRODUCTO (Artículo 7). En esta etapa fueron detectados hasta 6 grupos distintos de consumidores, y se optó por la conformación de 4 grupos diferentes (Figura 19).

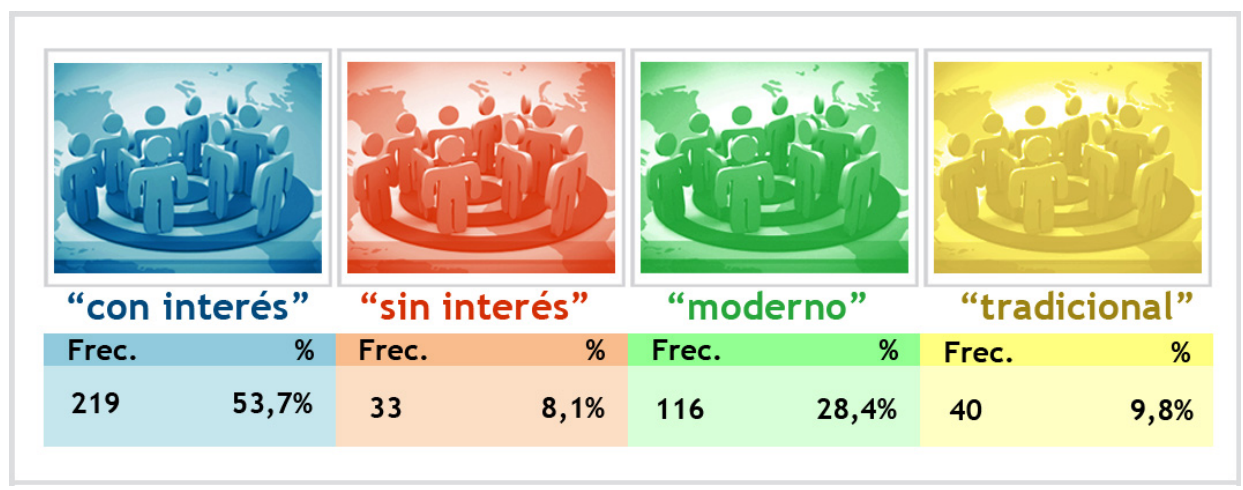

Figura 19. Grupos caracterizados. Fuente: de la autora (2012).

Conforme a los gustos y opiniones de los consumidores que componían la muestra, su agrupación se caracterizó para cada uno de los grupos definiendo cada uno con la siguiente denominación: grupo 1 - "con interés"; grupo 2 "sin interés"; grupo 3 - "moderno" y grupo 4 - "tradicional".

A pesar de la homogeneidad que ofrece los cuatro grupos analizados, el grupo "con interés" fue el que presentó mayor número de participantes (219 individuos) y evaluó cada uno de los atributos por encima del promedio; el grupo "sin interés", presentó una evaluación por debajo de la media.

Los otros grupos "tradicional" y "moderno" no se mostraron definidos por medio de los resultados presentados sino por las tendencias demostradas con respecto a los diferentes atributos estudiados. Por tanto, a partir de esta información y mediante el reconocimiento de la independencia entre la valoración de la muestra, en relación a los miembros que componen cada uno de los cuatro grupos diferentes, se determinó que el grupo "con interés" sería 
Estudio de la prospección del uso de la fibra de tucumã-i (Astrocaryum acaule) para el desarrollo de productos semi-industriales

la principal fuente de opinión que contrasta con los datos proporcionados por otros grupos.

Debido a la posición prominente del grupo "con interés" en relación a los otros grupos, se confirmó que los individuos que lo componen son los mayores consumidores del producto objeto de la investigación, mientras que los grupos denominados como "sin interés" y "tradicionales" no presentaban ninguna demanda. Aunque el grupo denominado como "moderno" manifiesta expresamente su acuerdo con el consumo de fibras naturales, y por tanto el desarrollo de productos y su venta comercial, el grupo "con interés" ha evidenciado su satisfacción con respecto a estos productos e interés con respecto a todos los atributos evaluados, siendo un claro indicador para el mercado, en cuanto al interés que puede existir en la utilización de fibras vegetales para la fabricación de productos, siendo un potencial cliente habitual satisfecho con este tipo de productos.

La información analizada en el perfil del consumidor al que pertenece el grupo denominado "con interés", los evidencia como público principal (SEGMENTO DE MERCADO) a la hora de disfrutar de los productos semiindustriales que se fabrican a partir de la fibra en estudio, siendo el grupo de las mujeres mayores de 37 años y graduadas en universidad su principales futuras clientes. Estas consumidoras, mostraron un mayoritario interés en los productos a base de fibras vegetales, sobre todo con respecto al uso de la fibra tucumã-i (Astrocaryum acaule), debiendo presentar estos productos ATRIBUTOS DEL DISEÑO (Figura 20) que se puedan valorar desde todos el contexto investigado, siendo importante la concepción y promoción de un producto con aspectos y ventajas concebidas desde los denominados aspectos naturales.

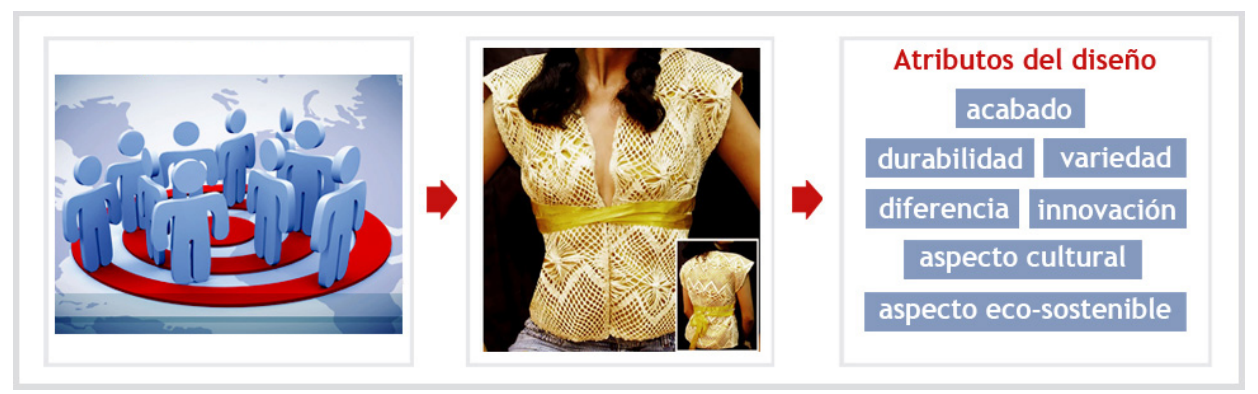

Figura 20. Atributos del diseño señalados. Fuente: de la autora (2012).

De acuerdo con la segmentación de mercado y teniendo en cuenta el proceso de gestión del diseño, desarrollo y fabricación de un producto realizado en 
fibra de tucumã-i (Astrocaryum acaule), los atributos del diseño detectados como necesarios en el diseño final fueron: el 'acabado', la 'durabilidad' y la 'innovación', con objeto de asegurar la calidad del material y su novedad.

Como justificación y motivación del consumo de dichos productos, el grupo denominado "con interés" en la segmentación, afirma que los factores como: la "diferencia", la "variedad" y los aspectos "eco-sostenibles y naturales deben ser los tipos de beneficios ofrecidos para los consumidores considerándose como una ventaja potencial para el alcance de nuevos mercados.

$\mathrm{Si}$ tenemos en cuenta las orientaciones expresadas por los grupos de diseñadores y de expertos, se realizó un ANÁLISIS DE LA POSIBILIDAD DEL USO DE LA FIBRA DE TUCUMÃ-I (Astrocaryum acaule) PARA EL DESARROLLO DE PRODUCTOS SEMI-INDUSTRIALES (Artículo 8), mediante el estudio de un caso, en el que la materia prima fibra de fue tucumã-i utilizada por artesanos para la confección de prendas de vestir. Durante este procedimiento y de acuerdo con cada etapa de la elaboración del producto (blusa), fueron identificados los siguientes aspectos:

- El proceso de hilatura necesita estandarizar los hilos en cuanto a los aspectos: dimensión, espesor, textura y proporción, con objeto de facilitar la confección del tejido que sirve de estructura para la construcción de la blusa. La necesidad de mejorar el elemento hilo, también está relacionada con el factor peso, siendo una ventaja evidente para el usuario en relación al el uso y disfrute del producto;

- El tejido natural generado a partir del proceso de tejeduría, además presentar resistencia, durabilidad y una composición visual atractiva con énfasis a las tradiciones culturales de las comunidades productoras de la fibra, también necesita ser estandarizado sobre todo en relación al espesor del hilo, la geometría y la textura;

- El proceso de adaptación de la fibra natural a la forma de tejido y este al molde de la blusa proyectada, ha sido aplicado en uniformidad con las normativas establecidas por la ABNT - NBR 13374/1995, observando los aspectos técnicos de corte y costura de los materiales textiles;

- El producto final presentó muchos aspectos positivos como: aceptación y aprobación por parte del consumidor, principalmente en cuanto a la facilidad y la variedad de aplicaciones de la fibra en productos textiles y a la innovación que su uso supone para el desarrollo de nuevos productos.

Considerando la información observada, se aplicó el modelo de diseño concurrente para evaluar y sistematizar los datos generados y proponer una mejor adaptación de los aspectos detectados como atributos significativos, 
Estudio de la prospección del uso de la fibra de tucumã-i (Astrocaryum acaule) para el desarrollo de productos semi-industriales

considerados importantes para el uso semi-industrial de la fibra de tucumã-i (Astrocaryum acaule) en productos textiles - en este caso específico para la confección de una blusa. Por tanto siguiendo la descripción e implementación del modelo de diseño concurrente, se consideraron como variables de entrada del sistema exterior (Figura 21): el segmento de mercado; los materiales; el hilo de la fibra; el tejido natural; los procesos; la normativa; la ergonomía; el medio ambiente; el factor socio-cultural y; la disposición final del producto.

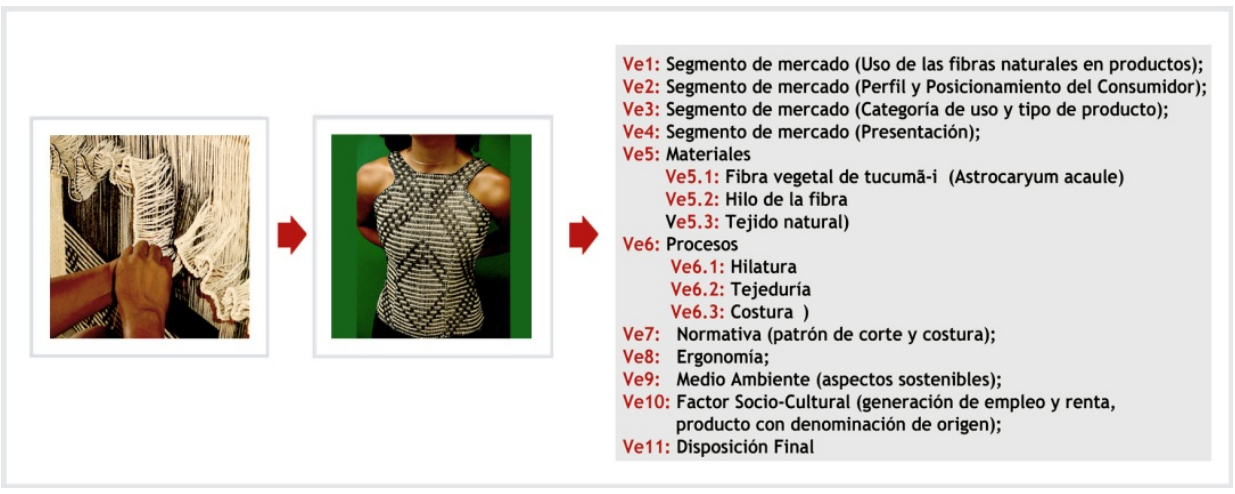

Figura 21. Informaciones del sistema exterior. Fuente: de la autora (2012).

A partir de las variables de entrada y conforme las características de los datos identificados fueron considerados los objetivos (Figura 22) referentes a los aspectos: formal, funcional y ergonómico del sistema, con la intención de generar un producto final innovador y más competitivo en el mercado, calificando la materia prima y ofreciendo los atributos solicitados por los consumidores potenciales.

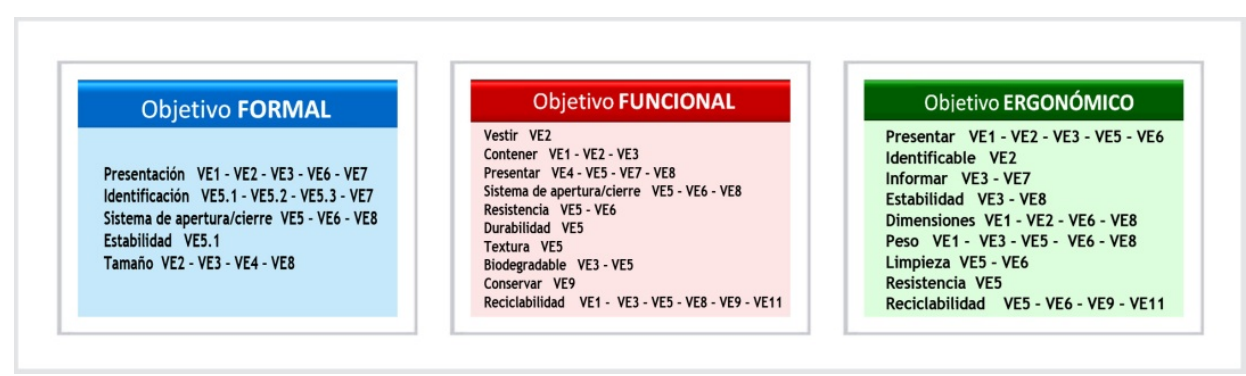

Figura 22. Objetivos del sistema en estudio. Fuente: de la autora (2012). 
Una vez establecidos los objetivos del sistema en estudio, el siguiente paso fue proponer la mejor utilización y adaptación de los elementos de composición del producto, o sea: blusa, hilo, tejido, correas de la blusa, sistema de apertura y cierre de la blusa, estabilidad y estructura. Por tanto, estos componentes fueron evaluados de acuerdo con el volumen de uso, superficie de uso y límite de contorno, pertenecientes a cada uno de los subsistemas formal, funcional y ergonómico (Figura 23).

\begin{tabular}{|c|c|c|}
\hline \multicolumn{3}{|c|}{ SUBSISTEMA FORMAL } \\
\hline Volumen de uso & Superficie de uso & Límite de contorno \\
\hline -Geometría & & -Proporción \\
-Proporción & -Textura y & -Altura \\
-Altura & geometria en & -Longitud \\
-Longitud & $\begin{array}{c}\text { función de las } \\
\text {-Anchura }\end{array}$ & $\begin{array}{l}\text { superficies lateral, } \\
\text {-Anchura }\end{array}$ \\
-Color & superior e inferior & -Color \\
\hline Textura & & -Textura \\
\hline
\end{tabular}
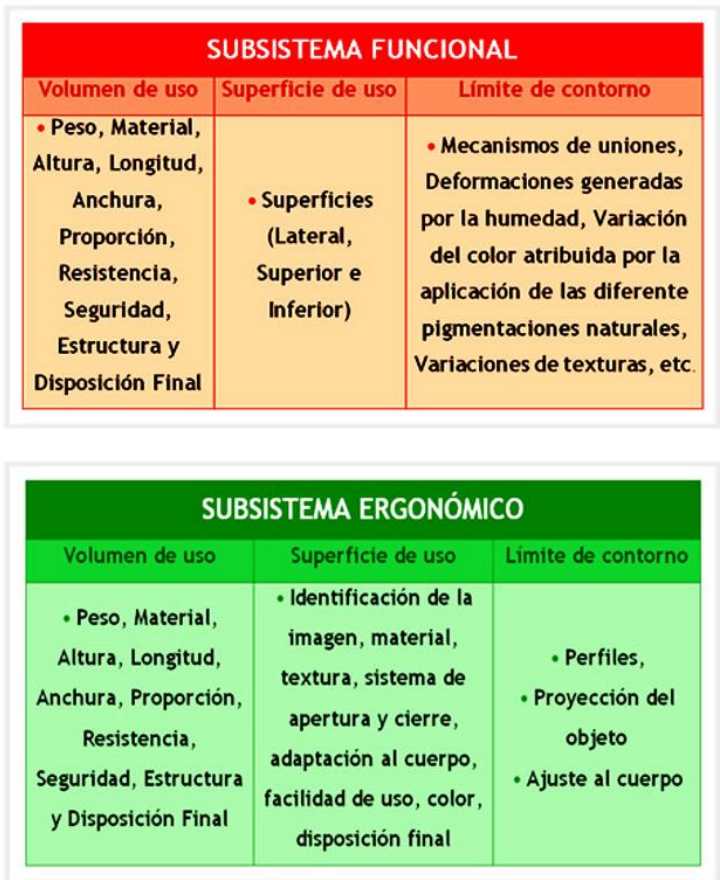

Figura 23. Subsistemas del sistema de estudio. Fuente: de la autora (2012). 
Del estudio de los subsistemas fundamentales: formal, funcional $y$ ergonómico, se analizaron los componentes y fueron una vez más observados mediante la aplicación sistémica ofrecida por el modelo de diseño concurrente obteniendo de este modo una amplia visión de todas las fases necesarias la preparación y utilización de la fibra en el desarrollo de un producto textil.

Como resultado, el modelo facilitó la estructuración y la organización sistémica de la información con objeto de vincular todas las fases necesarias para la fabricación del producto final, aportando soluciones para suplir las dificultades identificadas en el sistema en estudio (diseño de producto).

Mediante el uso de la aplicación del modelo de diseño concurrente, también se pudo Identificar las VARIABLES ESENCIALES Y LOS ASPECTOS DEL DISEÑO CONSIDERADOS IMPORTANTES AL USO Y BENEFICIO DE LA FIBRA NATURAL AMAZÓNICA DE TUCUMÃ-I (Astrocaryum acaule) PARA SU APLICACIÓN TEXTIL (Artículo 9) a través de un análisis direccionado a los objetivos generales que pertenecen a cada uno de los sistemas fundamentales. En esta etapa se verificó las variables de acción y de información (Figura 24), donde el primero grupo (variables de acción) describe el camino para el rendimiento del diseño de producto y el según grupo (variables de información) vislumbra a los posibles resultados a se obtener a partir de las variables de acción.
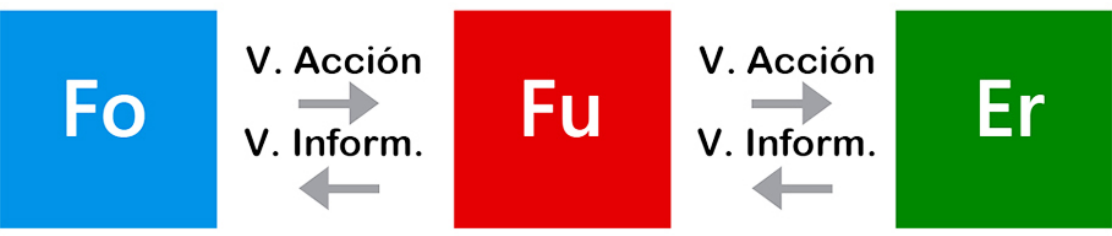

Figura 24. Representación del proceso de interacción de las variables de acción y de información en el sistema de estudio. Fuente: Hernandis (2003).

Como variables de acción, fueron registradas las siguientes observaciones conforme las situaciones presentadas por cada subsistema de estudio:

VaFu-Er (Variables de acción $\rightarrow$ Función - Ergonomia)

* Solucionar los aspectos técnicos identificados como débiles en los elementos: hilo y tejido;

* Cualificar los procesos de hilatura y tejeduría de la blusa; 
* Trabajar las medidas antropométricas para la fabricación final del producto;

* Valorar los aspectos intrínsecos de la fibra (caracteristicas tecnológicas, sociocultural, sotenible, de origen, etc.);

* Considerar la categoria de uso y el tipo de producto elegidos por el consumidor;

* Considerar los aspectos para normalización de materiales textiles.

VaFu-Fo (Variables de acción $\rightarrow$ Función - Forma)

* Valorar la estructura del material;

* Evidenciar la textura de la materia prima utilizada para el producto;

* Explotar la disponibilidad de colores ofrecida por los procesos de pigmentación natural realizado con la fibra;

* Proponer nuevas alternativas para la composición visual del producto final;

* Verificar las tendencias ofrecidas por el mercado (colores, formas, texturas) y relaciónalas a las informaciones contextualizadas en el sistema de estudio.

VaEr-Fu (Variables de acción $\rightarrow$ Ergonomia - Función)

* Estandarizar a los elementos generados a partir de los procesos de hilatura y tejeduría de la fibra (hilo y tejido);

* Facilitar el uso del producto;

* Proponer una estructura con más resistencia, seguridad y durabilidad para la blusa - como una de las ventajas ofrecida por el producto final.

VaEr-Fo (Variables de acción $\rightarrow$ Ergonomia - Forma)

* Apropiar los aspectos antropométricos con relación al tipo de producto elegido por el consumidor (ajuste a cuerpo);

* Optimizar los elementos de composición del producto: sistema de apertura y cierre, material, textura, etc.;

* Trabajar los aspectos de peso, longitud, proporción, altura, anchura y entre otros, del producto desarrollado.

Con respecto a las variables de información, fueron señaladas como los posibles beneficios para el producto final: 
* Mayor valorización de la fibra (aspectos natural y sociocultural, producción sostenible, propiedades tecnológicas, categoría de uso, tipología de productos, denominación de origen, etc.);

* Mejor utilización de la materia prima para a su aplicación textil;

* Posibilidades de generar nuevas y variadas tipologías de productos a partir da fibra beneficiada;

* Materia prima con criterios de estandarización para el desarrollo de productos textiles;

* Uso de nuevas tecnologías a favor de la calificación de los procesos de confección de productos a partir de la materia prima estudiada;

* Registro de nuevas informaciones sobre el uso de la fibra de tucumã-i (Astrocaryum acaule) para la fabricación de vestuario;

* Diseño como factor estratégico para el alcance de nuevos mercados;

* Generación y oferta de productos más competitivos y con aspecto de innovación;

* Beneficio social, económico y ambiental (producto con aspecto sostenible);

De acuerdo con el proceso de interacción realizado entre las variables de acción y las variables de información, se identificó que para la obtención de los resultados apuntados anteriormente, se torna necesario considerar como variables esenciales al sistema de estudio:

- Materia prima $\rightarrow$ Fibra de tucumã-i (Astrocaryum acaule), donde se destaca como y/o con:

* Producto natural;

* Producción sostenible;

* Aspectos de innovación y de competitividad;

* Propiedades tecnológicas favorables para la producción textil;

- Variedad de aplicación en productos

- Estudio de Mercado $\rightarrow$ donde se evidencia:

* Grado de aceptación de la matéria prima por parte de los consumidores em potencial;

* Categoría de uso más señalada por los consumidores; 
* Tipo de producto elegido por los consumidores.

- Procesos $\rightarrow$ que enseñala:

* Posibilidades de transformación y adaptación de la materia prima para su utilización textil;

* Posibilidades de nuevas aplicaciones textiles;

* Posibilidades de ajustes a tecnologías más avanzadas.

- Estandarización $\rightarrow$ que especifica:

* Producto con las normas técnicas para la fabricación de materiales textiles;

* Normalización para corte, costura y confección textil.

- Ergonomía $\rightarrow$ que relaciona materia prima/proceso/producto/usuario:

* Producto con patrones para la producción de hilos (mejora del proceso de hilatura de la fibra);

* Producto con patrones para la fabricación de tejidos (calificación del proceso de tejeduría de la fibra);

* Producto apropiado al perfil del consumidor

* Producto con resistencia, durabilidad y mejor acabado para el uso y alcance de nuevos mercados.

* Producto con registros de informaciones para su gestión, fabricación y uso (Sistematización de datos).

Con base en las informaciones referenciadas a cada una de las variables esenciales identificadas, se observó que la ergonomía es el ítem que más necesita de mayor atención, principalmente cuando relacionado a los subsistemas de estudio. Éste topico, atribuye al diseño el reto de intentar solucionar los problemas identificados de modo a orientar los caminos más adecuados para la confección de un producto final innovador, competitivo y de acuerdo con qué opina y espera el consumidor en potencial.

Por lo tanto, el desafío también implica buscar nuevos medios tecnológicos que faciliten el proceso ergonómico del produto y a partir de los cuales se sugiere - en primera instancia, el experimento de una maquinaria mecánica (tear mecánico) con objeto de trabajar adecuadamente las dimensiones de los hilos; facilitar las tareas de individuos involucrados en los procesos de hilatura y tejeduría de la fibra (practicadas mediante el conocimento y uso de 
Estudio de la prospección del uso de la fibra de tucumã-i (Astrocaryum acaule) para el desarrollo de productos semi-industriales

herramientas artesanales) y; proporcionar mayor calidad y acabado a la estructura de la fibra en cuanto producto final.

Para respaldar éste intento, sin comprometer los valores intrínsecos de la materia prima, es importante tener en cuenta los aspectos competitivos detectados mediante el uso del modelo de diseño concurrente, como: la facilidad y la variedad de aplicaciones de la fibra en productos, la aceptación de la fibra para el uso semi-industrial en el mercado y la innovación claramente representada en cuanto al resultado obtenido en el producto final. De esta forma, el modelo puede confirmar que las opiniones vertidas por los diseñadores, expertos y consumidores consultados, se han considerado como necesarias para un uso más eficiente y coherente de la fibra investigada.

Además, fueron exploradas diversas informaciones en paralelo, con objeto de confrontar los resultados obtenidos con respecto al objetivo principal propuesto en este estudio que pretendía valorar el uso de la fibra de tucumã-i y contribuir con su investigación al conocimiento y registro de esta información en el campo científico.

Por tanto, de acuerdo con algunos aspectos observados en algunas fases de ejecución de la tesis, se necesitó recabar información sobre: la viabilidad técnica de la fibra de tucumã-i (Astrocaryum acaule) (Artículo 10); los tintes vegetales amazónicos aplicados en productos (Artículo 11); el diseño mediante el uso de materiales naturales (artículo 12); la enseñanza del diseño para la utilización de los recursos naturales en productos (Capítulo de libro) y, por fin, realizar una propuesta de proyecto para ser implementada en el estado de Amazonas/Brasil, a través de la Universidad Federal de Amazonas UFAM (Proyecto aprobado por NIT/UFAM-Brasil), teniendo como objetivo principal: la intervención del diseño en el proceso de beneficio de la fibra natural de tucumã-i (Astrocaryum acaule) para el desarrollo de productos.

El proceso de implementación de esta propuesta tiene como referencia principal, los resultados obtenidos en los diferentes artículos que conforman el compendio por artículos de la presente tesis. Por tanto podemos decir que los resultados alcanzados presentaron respuestas bastante positivas, una vez que los datos recolectados, los estudios: de opiniones, de mercado, de caso y de otras informaciones paralelas, generaron contenidos clasificados como innovadores e inéditos, al involucrar un recurso natural nuevo para su explotación. Los datos generados seguramente podrán servir de referencia para futuras líneas de investigación y orientar nuevas estrategias sostenibles para el uso coherente de la fibra de tucumã-i (Astrocaryum acaule) en su aplicación en la generación de productos. 


\subsection{Conclusiones generales}

El estudio basado en la prospección del uso de la fibra de tucumã-i (Astrocaryum acaule) para el desarrollo de productos semi-industriales, proporcionó un viaje al universo de las fibras naturales utilizadas para la fabricación de productos, según los objetivos planteados en esta investigación, ha posibilitado conocer la información pertinente a las etapas de: producción, recolección, preparación, tipo de proceso, transformación, procedimientos para trabajar los hilos y tejidos, formas de aplicación y análisis sobre la variedad de tipologías de productos susceptibles de ser producidos en este contexto. Con respecto a la materia prima estudiada, nos ha permitido observar de qué manera un recurso natural, manejado actualmente por técnicas artesanales, pero con características innovadoras y potencial para el uso comercial - sobre todo para actuación al segmento textil, puede ser adaptado a una tecnología más avanzada, de modo que pueda ofrecer ventajas demostrables para su aplicación en productos y no afecte a los valores intrínsecos pertenecientes a su formación natural.

En el devenir de la investigación, gran parte de la información fue generada con objeto de obtener respuestas sobre la prospección del uso de la fibra de tucumã-i (Astrocaryum acaule) para el desarrollo de productos semiindustriales. Entre los datos obtenidos están las opiniones de diseñadores y expertos; un estudio de mercado, dirigido a la identificación de los consumidores potenciales $y$, consecuentemente, su opinión e interés con respecto al tema abordado; un estudio de un caso, realizado sobre la aplicación artesanal de la fibra durante la confección de un producto textil, evaluado mediante la aplicación del modelo de diseño concurrente con intención de verificar las diversas posibilidades con respecto al uso de la fibra para el desarrollo de productos semi-industriales y; la producción de datos complementarios (contribuciones) para la valoración y registro científico del tema estudiado.

Por lo tanto en respuesta a la problemática identificada, a los objetivos e hipótesis planteados, de acuerdo con los resultados obtenidos:

- La fibra de tucumã-i (Astrocaryum acaule) puede, seguramente, ser utilizada para el desarrollo de cualquier producto, sea éste doméstico, decorativo o textil (información comprobada a través de datos bibliográficos, publicaciones y consulta a diseñadores, expertos y consumidores).

- El grado de aceptación de esta fibra para el desarrollo de productos es significativo con $99,5 \%$ de aprobación.

- La clase de producto más apropiada, indicada por los consumidores con un $36,5 \%$, ha sido el vestuario. 
Estudio de la prospección del uso de la fibra de tucumã-i (Astrocaryum acaule) para el desarrollo de productos semi-industriales

- Y cualquier tipo de producto del segmento textil puede ser desarrollado a partir del uso de la fibra, principalmente en la categoría de vestuario. De acuerdo con el posicionamiento de los consumidores, la mayoría (34,6\%) del público objetivo consultado ha sido favorable a la confección de blusas;

- Los aspectos tecnológicos considerados más importantes con respecto al proceso de transformación de la fibra en un producto semi-industrial son: la resistencia, el refuerzo para no romper los hilos producidos a partir de la materia prima, la ausencia de elementos tóxicos, el color, el espesor y la suavidad de la fibra;

- La mejor adaptación de la fibra para su aplicación en productos semiindustriales compete a tres aspectos básicos: conocer su esencia natural (propiedades tecnológicas, factor socio-cultural y sostenible), comprender todas las fases de su proceso productivo y los procesos utilizados para confección de productos a partir de ésta materia prima.

- El implemento de un proceso semi-industrial para el uso de la fibra de tucumã-i (Astrocaryum acaule) en el desarrollo de productos no afectará a los aspectos culturales y tradicionales de las comunidades productoras involucradas en este contexto, pues el estudio comprobó que la transferencia del conocimiento se trata de un de los puntos de apoyo principales para el beneficio y valoración de la materia prima en estudio, de modo a tórnala un producto innovador y competitivo para el alcance de nuevos mercados. Además, la intención de la investigación no es alterar el saber tradicional de las personas que manejan la fibra (que, a través de esto, poseen un papel esencial al avance del estudio) y sí verificar los posibles caminos que pueden proponer mejoras (con base en la realidad de su ambiente y demás procesos productivos artesanales operados para el uso de la materia prima para la fabricación de productos) en favor de la obtención de una técnica más sofisticada que pueda integrar nuevos elementos, calificar cada vez más a los servicios y productos desarrollados por las comunidades locales y, así, divulgar su identidad cultural.

- El estudio determinó que el uso de la fibra de tucumã-i (Astrocaryum acaule) para el desarrollo de productos por proceso semi-industrial, se hace necesario trabajar los siguientes aspectos:

* Optimizar los procesos de hilatura y tejeduría;

* Identificar una tecnología más apropiada y evolucionada para la optimización y normalización de los procesos de hilatura y tejeduría de la fibra que, consecuentemente, ofrescan beneficios a la materia prima empleada y más calidad al producto final; 
* Relacionar la técnica semi-industrial (cuando elegida) y el producto final desarrollado a partir de èsta, a las posibles formas de protección establecidas por la legislación brasileña de la Propiedad Intelectual, que protege y respalda a las indicaciones geográficas (IG),indicaciones de procedencia (IP) y la denominación de origen (DO) de los productos o servicios con características naturales y humanas.

Por ende al mejorar la evolución de un proceso con una importante representación social, todos los demás componentes del sistema estarán siendo favorecidos: las comunidades productoras, los consumidores en potenciales y el mercado, según se observó al realizar el análisis mediante la aplicación del modelo de diseño concurrente. Cada aspecto que ha sido mejorado, es una nueva información que podrá ser retroalimentada en el todo sistema, aportando de este modo resultados más satisfactorios en el producto final resultante.

\subsection{Futuras líneas de investigación}

El trabajo desarrollado en esta tesis por compendio de publicaciones y los resultados obtenidos, dan lugar a un amplio abanico de posibles trabajos planteados como futuras líneas de investigación. A continuación se destacan algunas de ellas:

- Identificación de técnicas y/o métodos para la mejora de la fibra en lo que concierne a la fabricación y desarrollo de productos.

- Desarrollo de tecnologías para la conservación de fibras y productos.

- Optimización del proceso de hilatura y tejeduría para el beneficio de la aplicación de la fibra en productos.

- Realización de estudios económicos y análisis de costes para el posicionamiento de la fibra en el mercado (proceso tecnológico $\mathrm{x}$ precio del producto).

- Propuesta de gestión de negocios y gestión de la optimización de la fibra para aplicación de nuevos productos y alcance de nuevos mercados.

- Mejora de la formación en gestión y comercialización conjunta de las comunidades para los productos.

- Preparación del plan de gestión para el desarrollo de productos semiindustriales a partir de la fibra, una vez que ha sido tecnológicamente mejorada. 
Estudio de la prospección del uso de la fibra de tucumã-i (Astrocaryum acaule) para el desarrollo de productos semi-industriales

- Cartografía más detallada sobre las ubicaciones de las comunidades productoras de la fibra y la creación de bases de datos.

- Sistematización de datos sobre el proceso de desarrollo de productos a partir de la fibra optimizada que posibilita la implementación del modelo de formulación por objetivos para la gestión del diseño en las empresas (ambiente de las comunidades productoras). 


\section{Anexos}

Documentos acreditativos y utilizados en esta investigación 



\section{Anexos}

\subsection{Anexo I: Cuestionarios utilizados - Cuestionario para expertos}

Universidad Politécnica de Valencia

Posgrado en Ingenieria del Diseño

Programa de Doctorado en Diseño, Fabricación y Gestión de Proyectos Industriales

Buenos dias / tardes: Formo parte de un equipo de investigación de la Universidad Politécnica de Valencia, España, que estudia la prospección de la fibra de tucumã(Astrocaryum acaule) para el desarrollo de productos semiindustriales. Si usted no tiene inconveniente, le agradecería que respondiese sinceramente a las siguientes preguntas. Por nuestra parte le garantizamos que las respuestas que Ud. nos proporcione, serán totalmente confidenciales.

Gracias.

(Marque con una " $\mathrm{X}$ " la respuesta de su elección

1.- Ubicación (* Poner el nombre de la ciudad donde vive):

\begin{tabular}{|l|l|}
\hline España & 1 \\
\hline Brasil & 2 \\
\hline Unión Europea & 3 \\
\hline América & 4 \\
\hline Otras & 5 \\
\hline
\end{tabular}

- Ciudad:

2.- Carrera Profesional en:

\begin{tabular}{|l|l|}
\hline Textil & 1 \\
\hline Diseño & 2 \\
\hline Medio Ambiente & 3 \\
\hline Ing. Forestal & 4 \\
\hline Otras & 5 \\
\hline
\end{tabular}

3.- Tipo de empresa donde trabaja:

\begin{tabular}{|l|l|}
\hline Inst. Investigación & 1 \\
\hline Textil & 2 \\
\hline Textil Hogar & 3 \\
\hline Diseño & 4 \\
\hline Diseño y fabricación & 5 \\
\hline Otras & 6 \\
\hline
\end{tabular}

4.- Caracteristicas de la empresa:

\begin{tabular}{|l|l|l|l|}
\hline Estudio de las fibras & 1 & Fabricación y tienda & 4 \\
\hline Fabricación & 2 & Estudio de diseño & 5 \\
\hline Tienda & 3 & Otras & 6 \\
\hline
\end{tabular}

Otras:

OBJETO DE ESTUDIO

A. Fibra de Tucumă-i (Astrocaryum acaule)

La fibra vegetal amazónica de Tucumã-i (Astrocaryum acaule) presenta aspectos tecnológicos, sostenibles y de transformación compatibles a la fabricación de productos ${ }^{2}$. Pero, con base en los procesos artesanales.
Con intención de verificar el grado de aceptación, por parte de los expertos actuantes en el área de fibras naturales, diseño, fabricación y gestión de productos. La entrevista se centraliza en la aplicación de la fibra de tucumã-i para el desarrollo de productos a través de un proceso industrial o semindustrial.

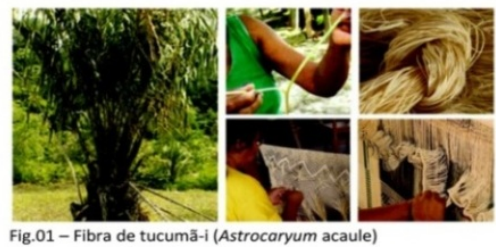

Fig.01 - Fibra de tucumã-i (Astrocaryum acaule)

Fuente: Maciel (2007)

\section{FICHA TÉCNICA DEL PRODUTO}

-Nombre cientifico: Astrocaryum acaule

- Nombre vulgar: Tucumã-i

- Ubicación Geográfica: Región del alto Rio Negro/ Estado de Amazonas / Región norte de Brasil

- Producción: Plantío en áreas alagadas

- Obtención: Recoleta con principios de sostenibilidad. Se controla con la forma del corte y con el tiempo de reposición de la parte retirada del vegetal.

- Fabricación: Producción artesanal

- Aplicación: Productos artesanales

B. FIBRAS NATURALES

Fibras vegetales aplicadas en el mercado de productos

5.- ¿Aprecia Ud. el uso de las fibras vegetales para la fabricación de productos?

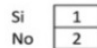

6. - ¿Está Ud. satisfecho con los productos desarrollados con las fibras vegetales ofrecidos en el mercado?

7.- ¿Qué valor atribuye Ud. a esos productos? Señale de 1 a 4 el grado de importancia que tienen para Ud. (1= poco importante, $4=$ muy importante):

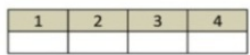

${ }^{1}$ Maciel, K. M. F. (2007). Estudo da viabilidade técnica da fibra de tucumā-i (Astrocaryum acaule) para produção de tecido a ser utilizado na Indústria de Confeç̧őes, Programa de Pós-Graduaçăo em Ciências Florestais e Ambientais - UFAM: Manaus, Amazonas - Brasil 
Estudio de la prospección del uso de la fibra de tucumã-i (Astrocaryum acaule) para el desarrollo de productos semi-industriales

8.-¿Qué valores asocia Ud. a un producto de cualidad desarrollado con fibras vegetales? Señale de 1 a 4 el grado de importancia que tienen para Ud. $(1=$ poco importante, $4=$ muy importante):

\begin{tabular}{|l|l|l|l|l|}
\hline Elegancia & 1 & 2 & 3 & 4 \\
\hline Lugar de origen de la fibra & 1 & 2 & 3 & 4 \\
\hline Tradición & 1 & 2 & 3 & 4 \\
\hline Modernidad & 1 & 2 & 3 & 4 \\
\hline Innovación & 1 & 2 & 3 & 4 \\
\hline Variedad & 1 & 2 & 3 & 4 \\
\hline
\end{tabular}

9.- De las fibras vegetales. ¿Cuáles cree Ud. son las más indicadas para la aplicación en los productos? Marcar hasta 3 opciones. Marcar con $\underline{x}$ la razón principal y con $\underline{Q}$ las siguientes.

\begin{tabular}{|l|l|l|l|}
\hline Algodón & & Sisal & \\
\hline Lino & & Bambú & \\
\hline Ramio & & Coco & \\
\hline Yute & & Otras (especificar) & \\
\hline
\end{tabular}

Otras:

10.- ¿Por qué razón?

\begin{tabular}{|l|l|l|l|}
\hline Por la variedad & 1 & $\begin{array}{l}\text { Por la disponibilidad en } \\
\text { el mercado }\end{array}$ & 4 \\
\hline $\begin{array}{l}\text { Por la practicidad } \\
\text { de fabricación }\end{array}$ & 2 & $\begin{array}{l}\text { Por los aspectos } \\
\text { sociales y sostenibles }\end{array}$ & 5 \\
\hline Por la cualidad & 3 & Otras (especificar) & 6 \\
\hline
\end{tabular}

Otras:

11.- ¿Qué opinión tiene Ud. al respecto de la utilización de las fibras vegetales (coco, sisal, yute e bambú) para la fabricación de productos? Marcar hasta 2 opciones. Marcar con $\underline{X}$ la razón principal y con $\underline{Q}$ las siguientes.

\begin{tabular}{|l|l|l|l|}
\hline Una buena opción & & Un proceso caro & \\
\hline No muy convencional & & Innovador & \\
\hline Depende del producto & & Otras & \\
\hline
\end{tabular}

Otras:

12.- ¿Cree Ud. es posible el proceso de transformación de la fibra de tucumã-i (producto artesanal) en producto industrial o semindustrial?

$$
\begin{array}{l|l|}
\text { Si } & 1 \\
\text { No } & \\
&
\end{array}
$$

C. FIBRA DE TUCUMĀ-I DE LA AMAZÓNIA Una propuesta para aplicación en productos di segmento industrial o semindustrial

13.- ¿Aprueba Ud. la inserción de nuevas fibras vegetales para su actuación en el mercado de productos?

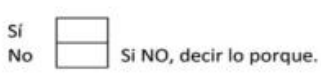

Porque:
14.- ¿Aceptaría Ud. la utilización de una fibra de palmera Amazónica tucumã-i (Astrocaryum acaule) para el desarrollo de productos?

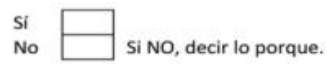

Porque:

15. ¿Cree Ud. en el proceso de transformación de la fibra de tucumã-i (Astrocaryum acaule) para su aplicación en producto industrial o semindustrial?

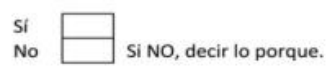

Porque:

16. ¿Cuáles cree Ud. deberán ser las variables consideradas en el proceso de transformación de la fibra de tucumã-i? hasta 3 opciones. Marcar con $\underline{X}$ la razón principal y con $\underline{0}$ las siguientes.

\begin{tabular}{|l|l|l|l|}
\hline Origen de la fibra & & Tipo de proceso & \\
\hline Tipo de producción & & Tipo de maquinaria & \\
\hline $\begin{array}{l}\text { Caracteristicas } \\
\text { intrínsecas / fibra }\end{array}$ & $\begin{array}{l}\text { Requerimiento/ de } \\
\text { uso }\end{array}$ & \\
\hline Normativas & & Otros (especificar) & \\
\hline
\end{tabular}

Otras:

17.- Del proceso de transformación. Indique las posibles ventajas que la fibra de tucumã-i podrá ofrecer a los productos. Marcar hasta 3 opciones. Marcar con X la razón principal y con 으 las siguientes.

\begin{tabular}{|l|l|l|l|}
\hline $\begin{array}{l}\text { Más calidad al } \\
\text { producto final }\end{array}$ & $\begin{array}{l}\text { Más eficiencia y } \\
\text { competitividad d de }\end{array}$ & \\
\hline $\begin{array}{l}\text { Aumento de } \\
\text { producción }\end{array}$ & $\begin{array}{l}\text { Mayor control de } \\
\text { proceso }\end{array}$ & \\
\hline Reducción de costos & $\begin{array}{l}\text { Alcance a nuevos } \\
\text { mercados }\end{array}$ & \\
\hline Nuevas tecnologías & & Otras (especificar) & \\
\hline
\end{tabular}

Otras:

E. PRODUCTOS CON LA FIBRA DE TUCUMĀ-I Posibles productos para la aplicación de la fibra

18.- De los productos para la aplicación de la fibra de tucumă-i. ¿Cuáles cree Ud. son las categorías más viables? Marcar con $\underline{X}$

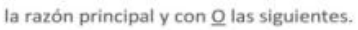

\begin{tabular}{|l|l|l|l|}
\hline Accesorio & & Hogar & \\
\hline Decorativo & & Otros (especificar) & \\
\hline
\end{tabular}

Otros: 
19.- Del segmento de accesorios. Marcar con $\underline{x}$ la razón principal y con $\mathrm{O}$ las siguientes.

\begin{tabular}{|l|l|l|l|}
\hline Pulseras & & Bolsas & \\
\hline Collares & & Cintos & \\
\hline Sombreros & & Otros (especificar) & \\
\hline
\end{tabular}

Otros:

20.- A respecto del segmento para hogar. Marcar con $\underline{x}$ la razón principal y con $\mathrm{O}$ las siguientes.

\begin{tabular}{|l|l|l|l|}
\hline Cama & Alacena & \\
\hline Mesa & & Cocina & \\
\hline Baño & & Otros (especificar) & \\
\hline
\end{tabular}

Otros:

21. Cuanto al segmento decorativo. Marcar con $\underline{x}$ la razón principal y con Q las siguientes.

\begin{tabular}{|l|l|l|l|}
\hline Cortinas & Pufs & \\
\hline Mantas & & Fundas/sofá & \\
\hline Almohadas & & Alfombras & \\
\hline Colchas & & Otros (especificar) & \\
\hline
\end{tabular}

Otros:

\section{DISENOO DEL PRODUCTO}

F. Forma / Función / Ergonomia

22.- De los aspectos formales de diseño del producto. ¿Cuá cree Ud. podrá ser más evidenciado en los productos desarrollados con la fibra de tucumã-i? Señale de 1 a 4 el grado de importancia que tienen para Ud. ( $1=$ poco importante, $4=$ muy importante):

\begin{tabular}{|l|l|l|l|l|}
\hline Grado de importancia & 1 & 2 & 3 & 4 \\
\hline Estilo & & & & \\
\hline Color & & & & \\
\hline Textura & & & & \\
\hline Tendencias & & & & \\
\hline Armonia de las formas & & & & \\
\hline Acabado & & & & \\
\hline Originalidad & & & & \\
\hline
\end{tabular}

\section{PROPIEDADES TECNOLOGICAS}

Caracteristicas ofrecidas por la fibra de tucumã-i

23. - ¿Cuáles cree Ud. deben ser las características tecnológicas más importantes para la aplicación de la fibra de tucumã-i al desarrollo de productos? Marcar hasta 5 opciones. Marcar con $\underline{X}$ la razón principal y con 으 las siguientes.

\begin{tabular}{|l|l|l|l|}
\hline Suavidad & & Textura/ Brillo & \\
\hline Resistencia & & Lavabilidad & \\
\hline Elasticidad & & Apariencia & \\
\hline Toxicidad & & Espesor & \\
\hline Ruptura & & Estabilidad de la forma & \\
\hline Color & & Otras (especificar) & \\
\hline
\end{tabular}

Otras:
24.- De los criterios de certificación. ¿Cuáles cree Ud. serán los más observados, por el consumidor, en el momento de compra del producto desarrollado con la fibra de tucumã-i? Marcar hasta 3 opciones. Marcar con $\underline{x}$ la razón principal y con $\underline{\text { OQ }}$ las siguientes.

\begin{tabular}{|l|l|l|l|}
\hline Confort & & Biodegradable & \\
\hline Seguridad & & Ecológico & \\
\hline Durabilidad & & Resistencia & \\
\hline Cualidad del material & & Otros (especificar) & \\
\hline
\end{tabular}

Otros:

25- ¿Qué valoración le otorgaría a los aspectos funcionales? Señale de 1 a 4 el grado de importancia que tienen para Ud. (1= poco importante, $4=$ muy importante):

\begin{tabular}{|l|l|l|l|l|}
\hline Grado de importancia & 1 & 2 & 3 & 4 \\
\hline Tecnologia & & & & \\
\hline Durabilidad & & & & \\
\hline Multifuncionalidad & & & & \\
\hline Adaptabilidad & & & & \\
\hline Transformabilidad & & & & \\
\hline Manejabilidad & & & & \\
\hline Usabilidad & & & & \\
\hline
\end{tabular}

26 - Cuanto a los aspectos ergonómicos. ¿Cuál cree Ud. podrá ser el más importante? Señale de 1 a 4 el grado de importancia que tienen para Ud. ( $1=$ poco importante, $4=$ muy importante):

\begin{tabular}{|l|l|l|l|l|}
\hline Grado de importancia & 1 & 2 & 3 & 4 \\
\hline Confort & & & & \\
\hline Seguridad & & & & \\
\hline Material & & & & \\
\hline Atributos del usuario & & & & \\
\hline $\begin{array}{l}\text { Atributos de los sistemas de } \\
\text { gestión y los controles }\end{array}$ & & & & \\
\hline Caracteristicas del usuario & & & & \\
\hline Conceptos Proyectual & & & & \\
\hline
\end{tabular}

MUCHAS GRACIAS POR SU COLABORACIÓN.

Datos del entrevistado (opcional)

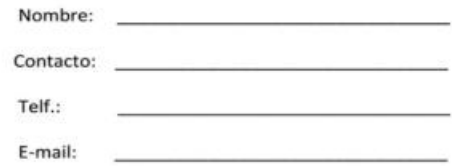

Investigador Principal: Karla Mazarelo Maciel Pacheco Centro o Departamento: Departamento de Ingeniería Gráfica Edificio: ETSID Teléfono: 963879055 (79055 Correo electrónico: karmapac@upvnet.upv.es

Móvil: 638435869 Valencia a 15 de Marzo de 2011 


\subsection{Anexo II: Cuestionarios utilizados - Cuestionario para Consumidor}

Buenos días / tardes: Formo parte de un equipo de investigación de la Universidad Politécnica de Valencia, España, que estudia la prospección de la fibra de tucumã-i (Astrocaryum acaule) para el desarrollo de productos semiindustriales. Si usted no tiene inconveniente, le agradecería que respondiese sinceramente a las siguientes preguntas. Por nuestra parte le garantizamos que las respuestas que Ud. nos proporcione, serán totalmente confidenciales.

Gracias.

(Marque con una " $\mathrm{X}$ " la respuesta de su elección)

Datos de Clasificación

\begin{tabular}{|l|l|}
\hline Hombre & 1 \\
\hline Mujer & 2 \\
\hline
\end{tabular}

Nacionalidad

\begin{tabular}{|l|l|l|l|}
\hline Español & 1 & Americano & 3 \\
\hline UE & 2 & Otro & 4 \\
\hline
\end{tabular}
Edad Estado Civil
\begin{tabular}{|l|l|l|l|}
\hline Soltero/a & 1 & Divorciado/a & 3 \\
\hline Casado/a & 2 & Viudo /a & 4 \\
\hline
\end{tabular}

№ de integrantes de la familia

De los cuales son menores

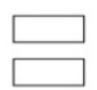

Ingreso mensual del grupo familiar

\begin{tabular}{|l|l|l|l|}
\hline Menos de 1 salario & 1 & Entre 3 y 5 salarios & 5 \\
\hline 1 salario mínimo & 2 & Entre 5 y 10 salarios & 6 \\
\hline Entre 1 y 2 salarios & 3 & Más de 10 salarios & 7 \\
\hline Entre 2 y 3 salarios & 4 & Otro & 8 \\
\hline
\end{tabular}

Moneda

Nivel de estudios acabados

\begin{tabular}{|l|l|l|l|}
\hline Primaria & 1 & Diplomado & 4 \\
\hline Secundaria & 2 & Licenciado & 5 \\
\hline Formación profesional & 3 & Doctor & 6 \\
\hline
\end{tabular}

Ocupación

\section{OBJETO DE ESTUDIO}

A. Fibra de Tucumã-i (Astrocaryum acaule)

Estudios realizados en Brasil, a respecto de la inserción de nuevas fibras naturales propicias para el desarrollo de productos, apunta al género Astrocaryum acaule (Fig. 01) como una buena opción para la producción textil ${ }^{1}$.

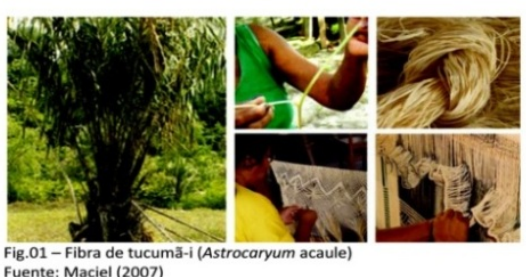

Fuente: Maciel (2007)

\section{FICHA TÉCNICA DEL PRODUTO}

-Nombre cientifico: Astrocaryum acaule

-Nombre vulgar: Tucumã-i

- Ubicación Geográfica: Región del alto Rio Negro/ Estado de Amazonas / Región norte de Brasil

- Producción: Plantío en áreas alagadas

- Obtención: Recoleta con principios de sostenibilidad. Se controla con la forma del corte y con el tiempo de reposición de la parte retirada del vegetal.

- Fabricación: Producción artesanal

- Aplicación: Productos artesanales

Tucumã-i, como también es conocida, se trata de una fibra procedente de palmera amazónica, cuya distribución geográfica se concentra en gran medida en el estado del Amazonas / Brasil ${ }^{2}$ (Fig.02)

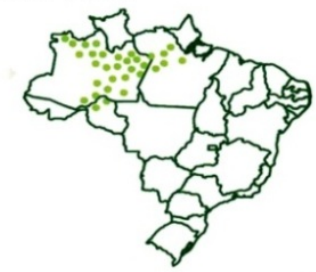

Fig.02 - Ubicación del objeto de estudio en Amazonas/Brasil Fuente: Souza et al. (2004)

Con intención de verificar el grado de aceptación, por parte de los consumidores de productos hechos con fibras naturales, la entrevista se centra en la aplicación de la fibra de tucumã-i para el desarrollo de productos semi-industriales.

\footnotetext{
${ }^{1}$ MACIEL, K. M. F. (2007). Estudo da viabilidade técnica da fibra de tucumãa-i (Astrocaryum acaule) para produção de tecido a ser utilizado no Indústria de Confeç̧ões. Programa de Pós-Graduaçăo em Ciências Florestais e Ambientais - UFAM: Amazonas - Brasil;

${ }^{2}$ SOUZA, Hermes Moreira de. et al. Palmeiras brasileiras e exóticas cultivadas. Nova Odessa. São Paulo: Instituto Platarum, 2004.
} 


\section{B. FIBRAS NATURALES}

Fibras vegetales aplicadas en el mercado de productos

1.- ¿Aprecia Ud. el uso de las fibras vegetales para la fabricación de productos?

$$
\begin{array}{l|l|}
\text { Si } & 1 \\
\text { No } & 2 \\
\hline
\end{array}
$$

2.- ¿Consume usted productos hechos con fibras naturales vegetales?

$$
\begin{array}{l|l|}
\text { Si } & 1 \\
& 2 \\
\hline
\end{array}
$$

3.- ¿Por qué razón?

\begin{tabular}{|l|l|l|l|}
\hline Por el precio & 1 & No es interesante & 3 \\
\hline Por la variedad & 2 & Otra & 4 \\
\hline
\end{tabular}

Otra:

4.- ¿Está Ud. satisfecho con los productos de fibras vegetales ofrecidos en el mercado?

$$
\begin{array}{l|l|}
\text { Si } & 1 \\
& \\
&
\end{array}
$$

5- ¿Qué valoración le otorgaría a los productos para texti hogar desarrollados con las fibras naturales vegetales? Señale de 1 a 4 el grado de importancia que tienen para Ud. (1= poco importante, $4=$ muy importante):

\begin{tabular}{|l|l|l|l|}
\hline 1 & 2 & 3 & 4 \\
\hline
\end{tabular}

6.- De las fibras vegetales. ¿Cuáles cree Ud. son las más indicadas para la aplicación en productos decorativos? Marcar hasta 3 opciones. Marcar en 1 la razón principal y en 2 las siguientes.

\begin{tabular}{|l|l|l|}
\hline Algodón & 1 & 2 \\
\hline Lino & 1 & 2 \\
\hline Ramio & 1 & 2 \\
\hline Yute & 1 & 2 \\
\hline Sisal & 1 & 2 \\
\hline Otra & 1 & 2 \\
\hline
\end{tabular}

Otra:

\section{7.- ¿Por qué razón?}

\begin{tabular}{|l|l|l|l|}
\hline Por el precio & 1 & Por ser accesible & 3 \\
\hline Por la calidad & 2 & Otra & 4 \\
\hline
\end{tabular}

Otra:

8.- ¿Aprobaría Ud. la inserción de nuevas fibras naturales vegetales en el mercado de productos textiles:

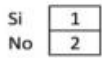
segmento industrial o semindustrial

9.- ¿Aprobaría Ud. el uso de la fibra natural amazónica de tucumã-i (Astrocaryum acaule) para el desarrollo de productos:

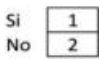

10.- LAprobaría Ud. el desarrollo de productos a partir de la fibra natural amazónica de tucumã-i (Astrocaryum acaule) por proceso semi-industrial:

$$
\begin{array}{l|l|}
\text { Si } & 1 \\
\hline \text { No } & 2 \\
\hline
\end{array}
$$

11.- ¿Estaría Ud. dispuesto a divulgar los valores de denominación de origen de la fibra de tucumă-i (Astrocaryum acaule), de acuerdo con los productos semi-industriales desarrollados a partir de ella:

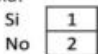

\section{PROPIEDADES TECNOLOGICAS}

Caracteristicas ofrecidas por la fibra de tucumã-i

12.- ¿Cuáles cree Ud. deben ser las características tecnológicas más importantes para la aplicación de la fibra de tucumã-i a desarrollo de productos? Marcar hasta 5 opciones. Marcar en 1 la razón principal y en 2 las siguientes.

\begin{tabular}{|l|l|l|}
\hline Suavidad & $\mathbf{1}$ & $\mathbf{2}$ \\
\hline Resistencia & 1 & $\mathbf{2}$ \\
\hline Elasticidad & 1 & 2 \\
\hline Humedad & 1 & 2 \\
\hline Espesor & 1 & 2 \\
\hline Toxicidad & 1 & $\mathbf{2}$ \\
\hline Ruptura & 1 & 2 \\
\hline Textura & 1 & 2 \\
\hline Ruptura & 1 & 2 \\
\hline Lavabilidad & 1 & 2 \\
\hline Apariencia & 1 & 2 \\
\hline Brillo & 1 & 2 \\
\hline Color & 1 & 2 \\
\hline Olor & 1 & 2 \\
\hline Otras & 1 & 2 \\
\hline
\end{tabular}

Otras:

13.- De los criterios de certificación. ¿Cuáles cree Ud. serán los más observados, por el consumidor, en el momento de compra del producto desarrollado con la fibra de tucumã-i? Marcar hasta 3 opciones. Marcar con $\underline{X}$ la razón principal y con $\underline{0}$ las siguientes.

\begin{tabular}{|l|c|l|c|}
\hline Confort & 1 & Biodegradable & 5 \\
\hline Seguridad & 2 & Ecológico & 6 \\
\hline Durabilidad & 3 & Resistencia & 7 \\
\hline Calidad del material & 4 & Otros (especificar) & 8 \\
\hline
\end{tabular}

Otros: 
Estudio de la prospección del uso de la fibra de tucumã-i (Astrocaryum acaule) para el desarrollo de productos semi-industriales

PRODUCTOS CON LA FIBRA DE TUCUMĀ-I

Posibles productos para la aplicación de la fibra

14.- De los productos para la aplicación semi-industrial de la fibra de tucumă-i. ¿Cuáles cree Ud. son las categorías más viables? Marcar hasta 2 opciones. Marcar con $\underline{X}$ la razón principal y con $\underline{0}$ la siguiente.

\begin{tabular}{|l|l|l|l|}
\hline Vestuario & 1 & Decorativo & 4 \\
\hline Accesorio & 2 & Automóvil & 5 \\
\hline Textil Hogar & 3 & Otros (especificar) & 6 \\
\hline
\end{tabular}

Otros:

15.- Del segmento Vestuario. ¿Cuáles cree Ud. podrán ser las opciones más viables para la aplicación de la fibra de tucumā-i (Astrocaryum acaule) Marcar hasta 3 opciones. Marcar en 1 la razón principal y en 2 las siguientes.

\begin{tabular}{|l|l|l|}
\hline Camisa/ Blusa & 1 & 2 \\
\hline Pollera & 1 & 2 \\
\hline Pantalón & 1 & 2 \\
\hline Zapato & 1 & 2 \\
\hline Ropa/Playa & 1 & 2 \\
\hline Otra & 1 & 2 \\
\hline
\end{tabular}

Otra:

16.- Del segmento Accesorios. ¿Cuáles cree Ud. podrán ser las opciones más viables para la aplicación de la fibra de tucumã-i (Astrocaryum acaule) Marcar hasta 3 opciones. Marcar en 1 la razón principal y en 2 las siguientes.

\begin{tabular}{|l|l|l|}
\hline Pulseras & 1 & 2 \\
\hline Collares & 1 & 2 \\
\hline Sombreros & 1 & 2 \\
\hline Bolsos & 1 & 2 \\
\hline Cinturones & 1 & 2 \\
\hline Otra & 1 & 2 \\
\hline
\end{tabular}

Otra:

17.- Del segmento Textil Hogar. ¿Cuáles cree Ud. podrán ser las opciones más viables para la aplicación de la fibra de tucumã-i (Astrocaryum acaule) Marcar hasta 3 opciones. Marcar en 1 la razón principal y en 2 las siguientes.

\begin{tabular}{|l|l|l|}
\hline Cama & 1 & 2 \\
\hline Mesa & 1 & 2 \\
\hline Baño & 1 & 2 \\
\hline Alacena & 1 & 2 \\
\hline Cocina & 1 & 2 \\
\hline Otra & 1 & 2 \\
\hline
\end{tabular}

Otra:
18.- Del segmento Decorativo. ¿Cuáles cree Ud. podrán ser las opciones más viables para la aplicación de la fibra de tucumã(Astrocaryum acaule) Marcar hasta 3 opciones. Marcar en 1 la razón principal y en 2 las siguientes.

\begin{tabular}{|l|l|l|}
\hline Cortinas & 1 & 2 \\
\hline Mantas & 1 & 2 \\
\hline Alfombras & 1 & 2 \\
\hline Pufs & 1 & 2 \\
\hline Fundas/Sofá & 1 & 2 \\
\hline Otra & 1 & 2 \\
\hline
\end{tabular}

Otra:

19.- Del segmento Automóvil. ¿Cuáles cree Ud. podrán ser las opciones más viables para la aplicación de la fibra de tucumã-i (Astrocaryum acaule) Marcar hasta 3 opciones. Marcar en 1 la razón principal y en 2 las siguientes.

\begin{tabular}{|l|l|l|}
\hline Asiento & 1 & 2 \\
\hline Moqueta & 1 & 2 \\
\hline Forro/techo & 1 & 2 \\
\hline Cubierta/volante & 1 & 2 \\
\hline Alfombras & 1 & 2 \\
\hline Otra & 1 & 2 \\
\hline
\end{tabular}

Otra:

DISEÑO DE PRODUCTO

F. Forma / Función / Ergonomia

20.- ¿Qué valoración le otorgaría a los aspectos formales del diseño de producto? Señale de 1 a 4 el grado de importancia que tienen para Ud. ( $1=$ poco importante, $4=$ muy importante):

\begin{tabular}{|l|l|l|l|l|}
\hline \multirow{2}{*}{ Aspectos Formales } & \multicolumn{5}{|c|}{ Grado de importancia } \\
\cline { 2 - 5 } & 1 & 2 & 3 & 4 \\
\hline Estilo & & & & \\
\hline Color & & & & \\
\hline Textura & & & & \\
\hline Tendencia & & & & \\
\hline Armonia de las formas & & & & \\
\hline Acabado & & & & \\
\hline Originalidad & & & & \\
\hline
\end{tabular}

21- ¿Qué valoración le otorgaria a los aspectos funcionales? Señale de 1 a 4 el grado de importancia que tienen para Ud. (1= poco importante, $4=$ muy importante):

\begin{tabular}{|l|c|c|c|c|}
\hline \multirow{2}{*}{ Aspectos Funcionales } & \multicolumn{4}{|c|}{ Grado de importancia } \\
\cline { 2 - 5 } & 1 & 2 & 3 & 4 \\
\hline Tecnologia & & & & \\
\hline Durabilidad & & & & \\
\hline Multifuncionalidad & & & & \\
\hline Adaptabilidad & & & & \\
\hline Transformabilidad & & & & \\
\hline Manejabilidad & & & & \\
\hline Usabilidad & & & & \\
\hline
\end{tabular}


22- ¿Qué valoración le otorgaría a los aspectos ergonómicos del diseño de producto? Señale de 1 a 4 el grado de importancia que tienen para Ud. (1= poco importante, $4=$ muy importante):

\begin{tabular}{|l|l|l|l|l|}
\hline \multirow{2}{*}{ Aspectos Ergonómicos } & \multicolumn{4}{|c|}{ Grado de importancia } \\
\cline { 2 - 5 } & 1 & 2 & 3 & 4 \\
\hline Confort & & & & \\
\hline Seguridad & & & & \\
\hline Material & & & & \\
\hline Atributos del usuario & & & & \\
\hline Sistemas de gestión y controles & & & & \\
\hline Caracteristicas del usuario & & & & \\
\hline Conceptos Proyectual & & & & \\
\hline
\end{tabular}

23- De los siguientes valores atribuidos a los productos. ¿Cuáles cree Ud. son los más relevantes? Señale de 1 a 4 el grado de importancia que tienen para Ud. (1= poco importante, $4=$ muy importante):

\begin{tabular}{|l|c|c|c|c|}
\hline \multirow{2}{*}{ Aspectos do Producto } & \multicolumn{5}{|c|}{ Grado de importancia } \\
\cline { 2 - 5 } & 1 & 2 & 3 & 4 \\
\hline Elegancia & & & & \\
\hline Denominación de origen & & & & \\
\hline Tradición & & & & \\
\hline Modernidad & & & & \\
\hline Innovación & & & & \\
\hline Variedad & & & & \\
\hline
\end{tabular}

24.- Como parámetro de producto. ¿Cuáles de las siguientes fibras vegetales cree Ud. es la más indicada como modelo de referencia a ser seguido para la aplicación del objeto de estudio al desarrollo de producto semi-industrial? Marcar hasta 2 opciones. Marcar con $\underline{X}$ la razón principal y con $\underline{\underline{O}}$ las siguientes.

\begin{tabular}{|l|l|l|l|}
\hline Algodón & 1 & Sisal & 5 \\
\hline Lino & 2 & Bambú & 6 \\
\hline Ramio & 3 & Coco & 7 \\
\hline Yute & 4 & Otro (especificar) & 8 \\
\hline
\end{tabular}

Otro:

\section{MUCHAS GRACIAS POR SU COLABORACIÓN.}

Investigador Principal: Karla Mazarelo Maciel Pacheco Centro o Departamento: Departamento de Ingeniería Gráfica Edificio: ETSID Teléfono: 963879055 (79055) Correo electrónico: karmapac@upvnet.upv.es Móvil: 638435869 Valencia a 15 de Marzo de 2011 


\subsection{Anexo III: Consentimientos Informativos - expertos}

\section{CONSENTIMIENTO INFORMADO - EXPERTOS}

Como estudiante del Programa de doctorado en Diseño, Fabricación y Gestión de proyectos industriales de la Universidad Politécnica de Valencia (UPV, España) y dentro del ámbito de mi proyecto de tesis que pretende abarcar el estudio de "La prospección de la fibra natural amazónica de tucumã-i (Astrocaryum acaule) para el desarrollo de productos semi-industriales" contacto a profesionales de diseño y expertos que trabajan con recursos naturales, para identificar los valores de la fibra de tucumã-i (Astrocaryum acaule) al desarrollo de nuevos productos - a través de estudios de casos.

A partir de una entrevista en profundidad con diseñadores y especialistas relacionados al tema del estudio propuesto, se pretende: entender que piensan estos profesionales sobre la Fibra Natural de Tucumã-i (Astrocaryum acaule), así como relacionar sus ventajas y desventajas, como medio de establecer la estructura de la investigación y contribución a los estudios futuros. Se pretende verificar el grado de aceptación del objeto de estudio para el desarrollo de productos semi-industriales, así como observar y responder sobre cuáles son las variables consideradas más importantes a la categoría de uso y tipo de producto para su aplicación. Este estudio requiere llenar un cuestionario, el cual contiene 24 preguntas. Le tomará contestarlo aproximadamente 15 a 20 minutos. Se pretende hacer una toma de datos, con la finalidad de comparar y crear conclusiones que sean importantes para el desarrollo de nuevos productos con este recurso natural. Se pretende utilizar estos datos en la divulgación del trabajo, dentro del ámbito académico y científico - en conferencias y revistas de prestigio cientifico, dentro del sector.

La participación de los expertos es estrictamente voluntaria. El proceso no conlleva ningún riesgo, ni recibe ningún beneficio y será estrictamente confidencial. LOS DATOS PERSONALES DE LOS PARTICIPANTES NO SERÁN UTILIZADOS en ningún informe cuando los resultados de la investigación sean publicados. La INVESTIGADORA y el DIRECTOR DE LA INVESTIGACIÓN de tesis SE COMPROMETEN A: 1- Salvaguardar la confidencialidad de los datos personales en todas las presentaciones de resultados que produzca ; 2 - No entregar los datos personales a terceros, y ; 3- Eliminar los datos personales registrados en el programa utilizado para evaluar el grado de aceptación de los participantes con relación al objeto estudiado - al final del proyecto de tesis.

Los participantes fueran seleccionados a través de criterios basados en indices de investigación, innovación y diseño, recolectados por currículos, estudio bibliográfico, noticias de prensa, participación en ferias, etc. Se pretende abarcar 2 a 5 estudios de caso centrados, especialmente, en: Brasil, Portugal y España. Si tiene alguna pregunta sobre esta investigación, podrá contactar con la investigadora principal: Karla Mazarelo Maciel Pacheco (karmapac@upvnet.upv.es) o con el director de la investigación: Dr. Bernabé Hernandis Ortuño (bhernand@dig.upv.es).

Les agradecemos que, si está de acuerdo con el procedimiento descrito arriba, pulse sobre el siguiente enlace como forma prestar su consentimiento en colaborar en esta investigación.

(UINK ENCUESTA)

IMUCHISIMAS GRACIAS POR COMPRENSIÓN Y COLABORACIÓN!!! 


\section{CONSENTIMIENTO INFORMADO \\ CONSUMIDORES DE PRODUCTOS HECHOS CON FIBRAS NATURALES}

Como estudiante del Programa de doctorado en Diseño, Fabricación y Gestión de proyectos industriales de la Universidad Politécnica de Valencia (UPV, España) y dentro del ámbito de mi proyecto de tesis que pretende abarcar el estudio de "La prospección de la fibra natural amazónica de tucumã-i (Astrocaryum acaule) para el desarrollo de productos semi-industriales" contacto a consumidores de productos desarrollados con fibras naturales, para verificar el grado de aceptación de la fibra de tucumã-i (Astrocaryum acaule) para el desarrollo de nuevos productos por el proceso semiindustrial - a través de estudio de caso.

A partir de una encuesta a consumidor se pretende saber que piensan los usuarios de productos hechos con fibras naturales sobre la fibra de tucumã-i (Astrocaryum acaule) como una opción para el desarrollo de nuevos productos - sobre todo por proceso semi-industrial, asi como observar y responder sobre cuáles son las variables consideradas más importantes a la categoría de uso y tipo de producto para su aplicación; saber qué aprecian sobre los productos desarrollados con fibras naturales; qué conocen sobre las tendencias de estos productos, las ofertas, los aspectos formales, funcionales y ergonómicos del material y, cómo se puede a través de esta investigación diagnosticar la aplicación semi-industrial del objeto estudio, de acuerdo con las variables observadas en el modelo de diseño concurrente para producto.

Este estudio requiere llenar un cuestionario, el cual contiene 22 preguntas. Le tomará contestarlo aproximadamente 15 a 20 minutos. Se pretende hacer una toma de datos, con la finalidad de comparar y crear conclusiones que sean importantes para el desarrollo de nuevos productos con este recurso natural. Se pretende utilizar estos datos en la divulgación del trabajo, dentro del ámbito académico y científico - en conferencias y revistas de prestigio científico, dentro del sector.

La participación de los consumidores es estrictamente voluntaria. El proceso no conlleva ningún riesgo, ni recibe ningún beneficio y será estrictamente confidencial. LOS DATOS PERSONALES DE LOS PARTICIPANTES NO SERÁN UTIUZADOS en ningún informe cuando los resultados de la investigación sean publicados. La INVESTIGADORA y el DIRECTOR DE LA INVESTIGACIÓN de tesis SE COMPROMETEN A: 1- Salvaguardar la confidencialidad de los datos personales en todas las presentaciones de resultados que produzca ; 2- No entregar los datos personales a terceros, y ; 3- Eliminar los datos personales registrados en el programa utilizado para evaluar el grado de aceptación de los participantes con relación al objeto estudiado - al final del proyecto de tesis.

El procedimiento será aplicado con $\mathbf{4 0 0}$ personas - apreciadoras de productos desarrollados con fibras naturales, ubicadas en Brasil - más especificamente en el estado de Amazonas (Región Norte del pais). Los resultados serán ponderados en función a las provincias y/o distritos que conforman el estudio. Para el conjunto de la muestra, se pretende que el margen de error sea inferior a $5 \%$ para un nivel de confianza del $90 \%$, bajo el supuesto de máxima indeterminación ( $p=q=0,5$ ). 
Estudio de la prospección del uso de la fibra de tucumã-i (Astrocaryum acaule) para el desarrollo de productos semi-industriales

UNIVERSIDAD

POLITECNICA

DE VALENCIA

\begin{abstract}
Si tiene alguna pregunta sobre esta investigación, podrá contactar con la investigadora principal: Karla Mazarelo Maciel Pacheco (karmapac@upvnet.upv.es) o con el director de la investigación: Dr. Bernabé Hernandis Ortuño (bhernand@dig.upv.es).

Les agradecemos que, sí está de acuerdo con el procedimiento descrito arriba, pulse sobre el siguiente enlace como forma prestar su consentimiento en colaborar en esta investigación.

(LINK ENCUESTA)

IMUCHISIMAS GRACIAS POR COMPRENSIÓN Y COLABORACIÓNII!
\end{abstract}




\subsection{Anexo IV: Consentimientos Informativos - consumidor}

\section{TÉRMINO DE COMPROMISO}

Como miembros integrantes del Programa de doctorado en Diseño, Fabricación y Gestión de proyectos industriales de la Universidad Politécnica de Valencia (UPV, España) y dentro del ámbito de un proyecto de tesis que pretende abarcar el estudio de "La prospección de la fibra natural amazónica de tucumã-i (Astrocaryum acaule) para el desarrollo de productos semi-industriales" donde se pretende contactar a profesionales de diseño y expertos que trabajan con recursos naturales, para identificar los valores de la fibra de tucumã-i (Astrocaryum acaule) para el desarrollo de nuevos productos - a través de estudios de casos $\mathrm{y}$, a consumidores de productos desarrollados con fibras naturales, para verificar el grado de aceptación de la fibra de tucumã-i (Astrocaryum acaule) para el mismo principio. Se considera que:

Los procedimientos para la investigación deben, igualmente, ser realizados conforme a los principios de la competencia leal, tal como son generalmente comprendidos y aceptados - según estándares técnicos de alto nivel en estricta conformidad con las disposiciones del Código Internacional de la Asociación Europea de Estudios de Opinión y Mercado (ESOMAR9 de 1976), en cuanto a la protección de su privacidad. Por lo tanto, se pretende para esta investigación:

- Trabajar mediante el anonimato de los entrevistados cumpliendo la norma del artículo 2 del Código de ética que enfatiza el siguiente $\rightarrow$ Ninguna información que pueda servir para identificar a las personas entrevistadas, sea directa o indirectamente, debe ser divulgada a nadie, a excepción del personal de investigación perteneciente a la organización del investigador que necesita de esta información para la realización y el control de las entrevistas, tratamiento de los datos, etc.

- Considerar los derechos de los entrevistados, conforme artículo $6 \rightarrow$ Todas las precauciones razonables deben ser tomadas a fin de asegurarse que la persona entrevistada y sus familiares no sufrirán ninguna incomodidad o molestia a consecuencia de la entrevista. La persona entrevistada debe estar informada del objeto de la encuesta cuando, por no estarlo, se arriesga a facilitar informaciones que podrian perjudicarlo.

- Presentar los resultados de un estudio, de acuerdo con el artículo $33 \rightarrow \mathrm{El}$ investigador debe hacer una clara distinción entre los resultados propiamente dichos y la interpretación de los mismos, asi como de sus recomendaciones - sea en forma de informe escrito, de exposición oral, o en cualquier otra forma.

- Cancelar o borrar los datos (implica el bloqueo y la posterior eliminación de los datos) cuando termine la finalidad para la que han sido recabados.

Así siendo, la participación de los profesionales de diseño, expertos y consumidores es estrictamente voluntaria. El proceso no conlleva ningún riesgo, nỉ recibe ningún beneficio y será estrictamente confidencial. LOS DATOS PERSONALES DE ESTOS PARTICIPANTES NO SERÁN UTIUZADOS en ningún informe cuando los resultados de la investigación sean publicados. 
Estudio de la prospección del uso de la fibra de tucumã-i (Astrocaryum acaule) para el desarrollo de productos semi-industriales

La investigadora y el director de la investigación de tesis se comprometen a:

1- Salvaguardar la confidencialidad de los datos personales en todas las presentaciones de resultados que produzca ;

2- No entregar los datos personales a terceros, y ;

3- Eliminar los datos personales registrados en el programa utilizado para evaluar el grado de aceptación de los participantes con relación al objeto estudiado - al final del proyecto de tesis.

Si tiene alguna pregunta sobre esta investigación, podrá contactar con la investigadora principal: Karla Mazarelo Maciel Pacheco (karmapac@upvnet.upv.es) o con el director de la investigación: Dr. Bernabé Hernandis Ortuño (bhernand@dig.upv.es).

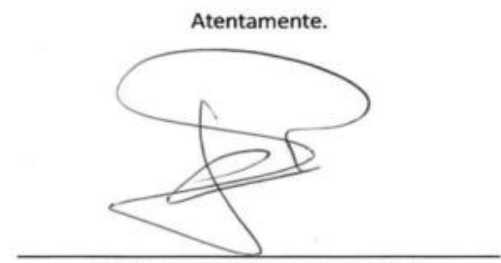

BERNABÉ HERNANDIS ORTUÑO

Director de investigación

Programa de doctorado en Diseño - ETSDI

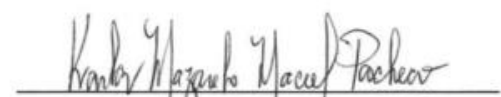

KARLA MAZARELO MACIEL PACHECO

Investigadora

Programa de doctorado en Diseño - ETSDI 
Anexos

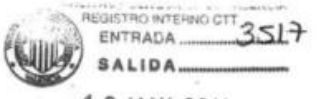

13 MAY 2011

nomвre: Bernabé Hernandis Cofbuño. D.N.L. $\quad 19460767$

QXe se aporta escrito en ol que re especificau convideraciones idse las encuesters realidadas por tarla Ma savelo defaydo cont fancia de que los dabos 10 o riran vtolviados para la investigación y revar havabss todas los dabos jue d mpiguen una idact ficaciou porsopat. Bite rodrmonte re procedrá al spirado se todos las datos perionales en calguier coso.

DOCUMENTACIÓN OUE ADJUNTA

- Carta coma promileo.

- Con rentirm eytro in forvala - expertos.

- Con un timiento informado consu widores.

valencia, 13 de Mayo de 2011.

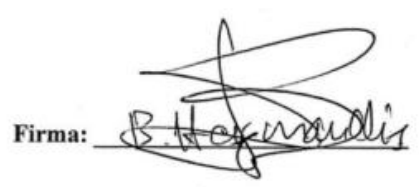

341 


\subsection{Anexo V: Informaciones a los expertos}

\section{Fwd: ENTREVISTA A ESPECIALISTAS}

De: Karla Mazarelo Maciel Pacheco (karmapac@etsid.upv.es)

Enviada: quinta-feira, 15 de julho de 2010 14:45:45

Para: karlamazarelo@hotmail.com

1 anexo

ENTREVISTA A EXPERTOS_EM PORTUGUES.dOCX (263,8 KB)

-..-- Mensaje reenviado de Karla Mazarelo Maciel Pacheco <karmapacletsid.upv.es〉

Fecha: Thu, 15 Jul $2010 \quad 16: 44: 55+0200$

De: Karla Mazarelo Maciel Pacheco <karmapaceetsid.upv,es>

Responder-A: Karla Mazarelo Maciel Pacheco <karmapac@etsid.upv.es>

Asunto: ENTREVISTA A ESPECIALISTAS

Para: daferde3eposgrado.upv.es, hinayanalegmail.com, josi@det.uminho.pt,

merinoecce.ufsc.br, merinoedeps.ufsc.br, eadmerinoegmail.com,

claudete@ufam.edu.br, sheila.motaegmail.com, valparente@ufam.edu.br,

evcgaldamez@uem.br, varejaolinpa.gov.br, catanhedeinpa.gov.br,

pesquisaflora.sede日ibama.gov.br, PGonzagaecetiqt.senai.br,

marcuslimafam. sebrae.com.br

\section{Prezados Senhores:}

- Daniel Castro - (Eng. de Produção / Universidade Politécnica de Valencia -UpV); -Maria José Abreu - (Engenharia Têxtil - Universidade do Minho) :

- Hinayana Silva - (Design Textil e Moda - Universidade do Minho);

-Eugenio Merino - (Design / Universidade Federal de Santa Catarina - UFSC);

- Claudete Barbosa - (Design / Universidade Federal do Amazonas - UFAM) :

- Sheila Mota - (Design / Universidade Federal do Amazonas - UFAM);

- Valdenei Parente - (Economia / Universidade Federal do Amazonas - UFAM) :

-Edwin Cardoza - (Eng. de Produçăo / Universidade Estadual de Maringá - UEM);

- Maria de Jesus Varejão - (Eng. Florestal /Instituto Nacional de Pesquisas da Amazónia - INPA);

- Claudete Catanhede - (Quimica Florestal / Instituto Nacional de Pesquisas da Amazônia - INPA):

- Claudia Mello - (Comércio Internacional de Espécies da Flora e Fauna Selvagens - IBAMA) :

-Paulo Roberto Gonzaga - (Gerênoia Confecção Industrial /SENAI-CETIQT);

- Marcus Lima - ( Consultoria Design / SBBRAE-AM).

Solicito a sua atenção e cooperação para responder a um questionário destinado a especialistas nas seguintes áreas de atuação: têxtil, produção, design,

economia, comercio, gestão, florestal e ambiental.

O intuito dessa entrevista é formalizar uma das etapas da minha tese doutoral realizada na Universidade Politécnica de Valencia - UPV (Espanha).

Essa pesquisa está focada no Estudo da aplicaçåo da fibra natural amazônica de tucumă-1 (Astrocaryum acaule) para o desenvolvimento de produtos.

Conto com a valoroza opinia a dos Senhores e disponho-me a responder qualquer dúvida com relaçăo ao referido trabalho.

Atenciosamente.

Karla Mazarelo Maciel Pacheco

Univeraidad Politecnica de Valencia

Posgrado en Ingenieria del Diseflo

Prograna de Doctorado en Disefo, Fabricación y Gestión de Proyectos Industrialea

..... Fin del mensaje reenviado ...... 


\section{Expertos participantes}

\begin{tabular}{|c|c|c|c|}
\hline Nome & Telefone & E-mail & Instituiçāo \\
\hline Clara Guimar & (351) 964864232 & guimarães.clara@gmail.com & Universidade de Minho \\
\hline Claudete Bart & $(92) 81951195$ & \multirow{3}{*}{$\begin{array}{l}\text { b_claudete@hotmail.com } \\
\text { daferde3@posgrado.upv.es } \\
\text { evcgaldamez@uem.br }\end{array}$} & UFAM \\
\hline Daneil Castro & (034) 625835922 & & UPV \\
\hline Edwin Cardoz & $+55(44) 3011-5820$ & & UEM - Universidade Estadual de Maringá - Depa \\
\hline Eugenio Meri & 554837216403 & merino@deps.ufsc.br & UFSC \\
\hline Claudete Cata & $(092) 36433273 / 36$ & catanhed@inpa.gov.br & $\begin{array}{l}\text { INPA/Coordenação de Pesquisas em Silvicultura } \\
\text { Tropical - CPST }\end{array}$ \\
\hline Maria de Jesy & $+55923643-3070$ & varejao@inpa.gov.br & Inst. Nacional de Pesquisas da Amazônia INPA \\
\hline Fernando Rib & 351912782374 & fernandomoc@hotmail.com & Universidade de Minho \\
\hline Hinayana Pint & 351915859737 & hinayana1@gmail.com & Universidade de Minho \\
\hline Sheila Cordeir & (92) 88415774 & sheimota@yahoo.com.br & UFAM \\
\hline VALDENEI DE & 34963202256 & valparente@ufam.edu.br & UFAM \\
\hline
\end{tabular}




\section{Fwd: Re: ENTREVISTA A ESPECIALISTAS}

De: Karla Mazarelo Maciel Pacheco (karmapac@etsid.upv.es)

Enviada: quarta-feira, 17 de novembro de 2010 21:22:48

Para: karlamazarelo@hotmail.com

3 anexos

unnamed (2,3 KB) , unnamed (2,6 KB) , ENTREVISTA A EXPERTOS_EM PORTUGUES vm.docx (265,0 KB)

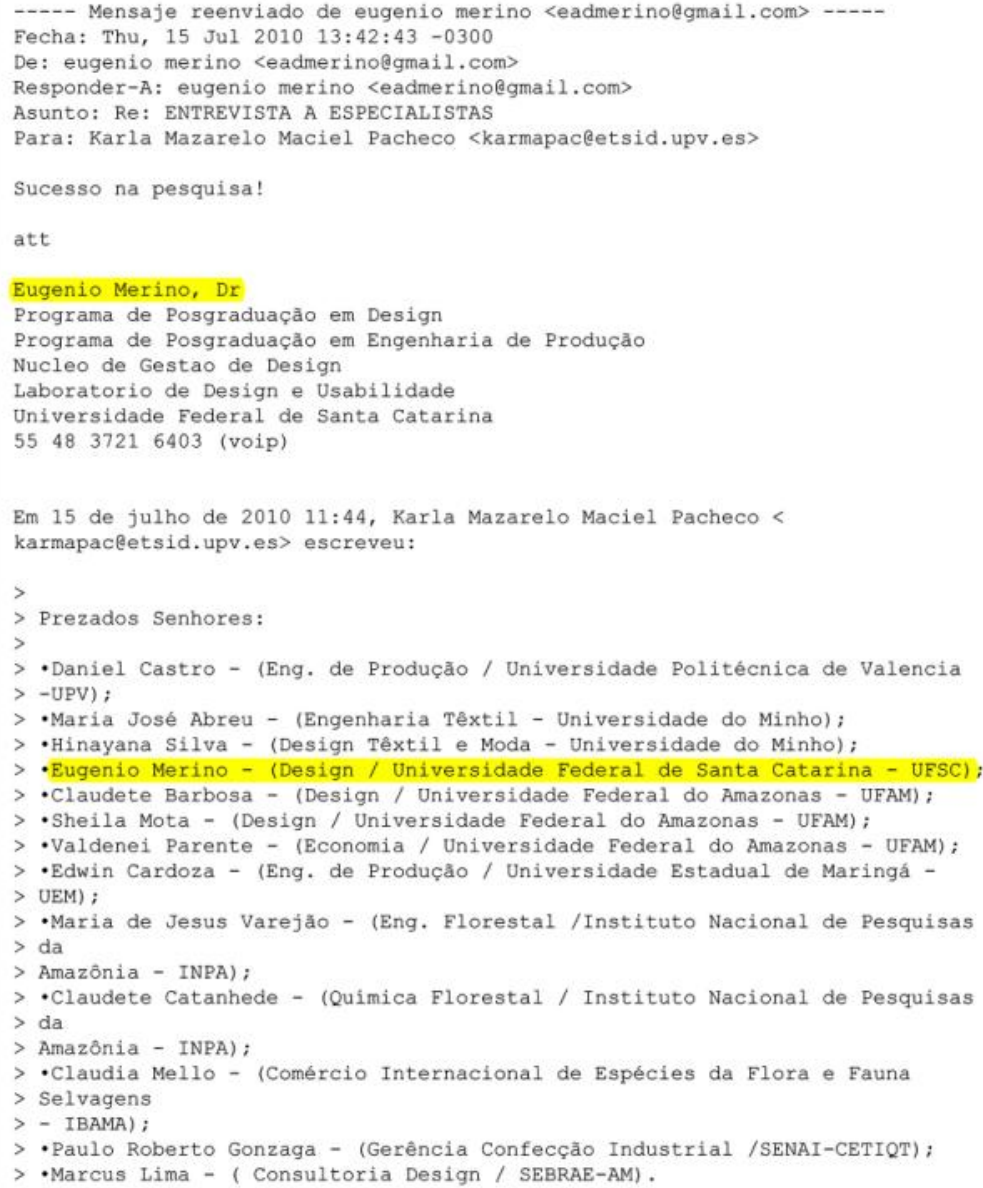




\section{Fwd: ENTREVISTA A ESPECIALISTAS}

De: Karla Mazarelo Maciel Pacheco (karmapac@etsid.upv.es)

Enviada: quarta-feira, 17 de novembro de 2010 21:28:22

Para: karlamazarelo@hotmail.com

1 anexo

ENTREVISTA A EXPERTOS_EM PORTUGUES.docx $(265,0 \mathrm{~KB})$

Fecha: Sun, 18 Jul 2010 13:28:03 -0300 (BRT)

De: Edwin Cardoza 〈evcgaldamezeuem.br>

Responder-A: Edwin Cardoza <evcgaldamezeuem.br>

Asunto: ENTREVISTA A ESPECIALISTAS

Para: karmapacetsid.upv.es

Prezada Karla,

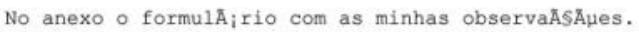

Sucesso no seu projeto.

Obrigado.

Edwin Cardoza

Prezados Senhores:

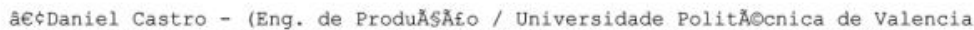
-UPV); åŁcMaria JosĀO Abreu - (Engenharia TÃa xtil - Universidade do Minho); ąఢHinayana Silva - (Design TÃxtil e Moda - Universidade do Minho); ącEugenio Merino - (Design / Universidade Federal de Santa Catarina - UFSC) ; a€cClaudete Barbosa - (Design / Universidade Federal do Amazonas - UFAM); a€cSheila Mota - (Design / Universidade Federal do Amazonas - UFAM); a€ఢValdenei Parente - (Economia / Universidade Federal do Amazonas - UFAM);

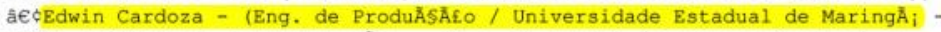
UEM); â€cMaria de Jesus VarejĄo - (Eng. Florestal /Instituto Nacional de

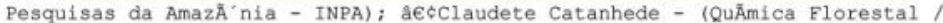
Instituto Nacional de Pesquisas da AmazÁnia - INPA); åçClaudia Mello (ComÅ̈rcio Internacional de EspÅđecies da Flora e Fauna Selvagens - IBAMA);

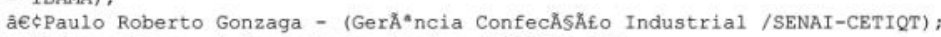
a€ $\$$ Marcus Lima - (Consultoria Design / SEBRAE-AM).

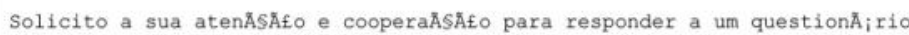

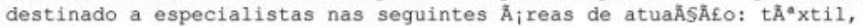
produ§̊§̊̊, design, economia, comercio, gestÅo, florestal e ambiental.

O intuito dessa entrevista $\AA_{\odot}$ formalizar uma das etapas da minha tese doutoral realizada na Universidade PolitÅcnica de Valencia - UPV (Espanha).

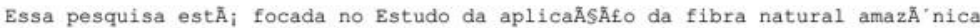
de tucumÃ -1 (Astrocaryum acaule) para o desenvolvimento de produtos.

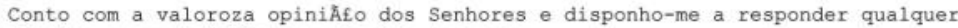

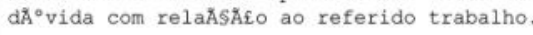




\section{FW: Entrevista}

De: Claudete Nascimento (ccatanhede@hotmail.com)

Enviada: sexta-feira, 6 de agosto de 2010 13:43:37

Para: Karla Mazarelo (karlamazarelo@hotmail.com); mirella.sou@gmail.com

1 anexo

Entrevista Karla.doc (386,0 KB)

From: ccatanhede@hotmail.com

To: karlamazarelo@hotmail.com

Subject: FW: Entrevista

Date: Mon, 26 Jul 2010 01:33:14 +0000

> Date: Sun, 25 Jul 2010 12:34:04 -0400

> Subject: Entrevista

> From: catanhed@inpa.gov.br

> To: karmapac@etsid.upv.es

>CC: bhernand@degi.upv.es

$>$

$>$

$>$ Prezados,

$>$

> Primeiramente gostaria de agradecer por estar participando desta

> entrevista dada importância da pesquisa a ser desenvolvida. No

> momento,envio o formulário preenchido.

$>$

$>$ Atenciosamente,

$>$

$>$ Claudete Catanhede do Nascimento, Dra.

$>$ Pesquisadora Titular

> Instituto Nacional de Pesquisas da Amazônia - INPA

$>$ Coordenação de Pesquisas em Silvicultura Tropical - CPST

Hotmail: Trusted email with Microsoft's powerful SPAM protection. Sign up now. 


\title{
Fwd: RE: ENTREVISTA A ESPECIALISTAS
}

\author{
De: Karla Mazarelo Maciel Pacheco (karmapac@etsid.upv.es) \\ Enviada: quarta-feira, 17 de novembro de 2010 21:21:17 \\ Para: karlamazarelo@hotmail.com \\ 3 anexos \\ unnamed (5,3 KB) , unnamed (6,1 KB) , ENTREVISTA_A_EXPERTOS_EM_PORTUGUES[1].doc (394,5 \\ $\mathrm{KB})$
}

\author{
-..-- Mensaje reenviado de Fernando Ribeiro oliveira <fernandomocehotmail.com> \\ -n-- \\ Fecha: Fri, 16 Ju1 2010 09:11:09 +0000 \\ De: Fernando Ribeiro oliveira <fernandomocehotma1l.com> \\ Responder-A: Fernando Ribeiro Oliveira <fernandomocehotmail.com> \\ Asunto: RE: ENTREVISTA A ESPECIALISTAS \\ Para: karmapacøetsid.upv.es
}

Prezada Karla Mazzarelo, primeiramente gostaria de parabenizá-la pelo estudo. Penso que será um trabalho muito interessante e me parece que esta fibra possui um grande potencial a ser explorado. Entretando, se possivel, gostaria de tirar algumas dúvidas. Como se dá o processo de obtenção das fibras? É por exemplo como o linho, ou Sisal? Consegue-se uma boa homogeneidade no comprimento $e$ titulo das fibras? O processo de fiaçăo è realizado em máquinas convencionais? São obtidos fios com boa qualidade nos parămetros uniformidade, pontos grossos, pontos finos, neps etc? A resistência do fio é boa?

Vocês já tentaram a utilizaçăo desta fibra em teares com alta produtividade, ou apenas através de artesãos (teares manuais)?

Com relação ao tingimento, que classe de corante normalmente utilizam? Consegue-se boa solidez à lavagem, à luz e a fricçâo?

Essas são algumas questões que penso ser importantes para se conseguir a aplicaçăo deste tipo de fibra na cadeia têxtil.

Atualmente trabalho na Universidade do Minho em Portugal, fiz o mestrado aqui atualmente faço o doutorado, minha área de atuaçăo é activação superficial de materiais têxtil através do tratamento plasmático DBD (Double Barrier Discharge).

Espero poder ter ajudado no teu trabalho e caso necessite de algo mais é só dizer.

Um grande abraço,

Fernando

$>$ Date: Thu, 15 Jul 2010 19:33:32 +0200

$>$ From: karmapaceetsid.upv.es

$>$ To: heriberoliverehotmail.com; fernandomochhotmail.com; 


\section{Fwd: Re: ENTREVISTA A ESPECIALISTAS}

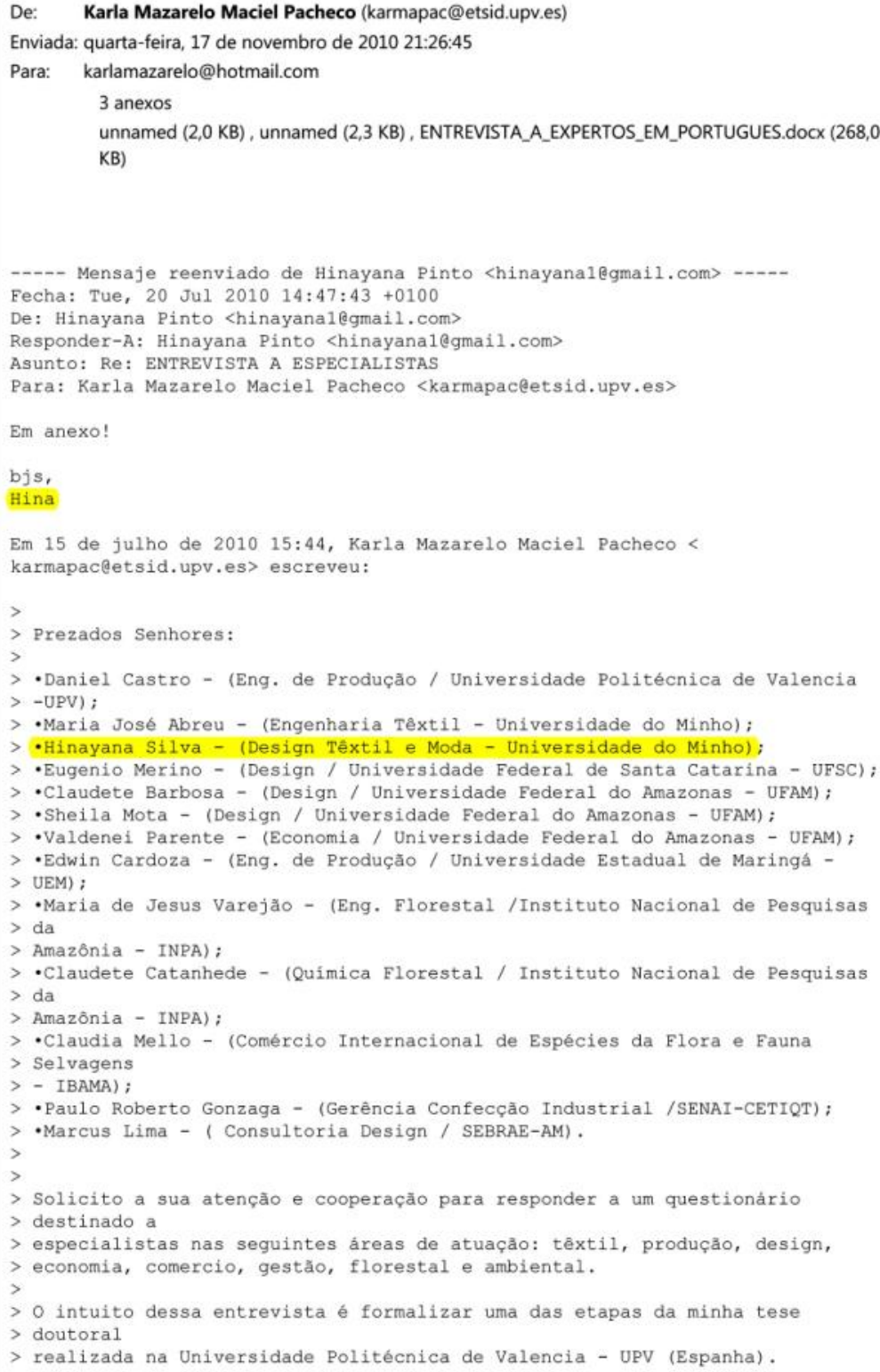




\section{Fwd: Re: ENTREVISTA A ESPECIALISTAS}

De: Karla Mazarelo Maciel Pacheco (karmapac@etsid.upv.es)

Enviada: quarta-feira, 17 de novembro de 2010 21:23:29

Para: karlamazarelo@hotmail.com

3 anexos

unnamed (3,7 KB) , unnamed (4,8 KB) , ENTREVISTA A EXPERTOS_EM PORTUGUES[1].docx (264,5

KB)

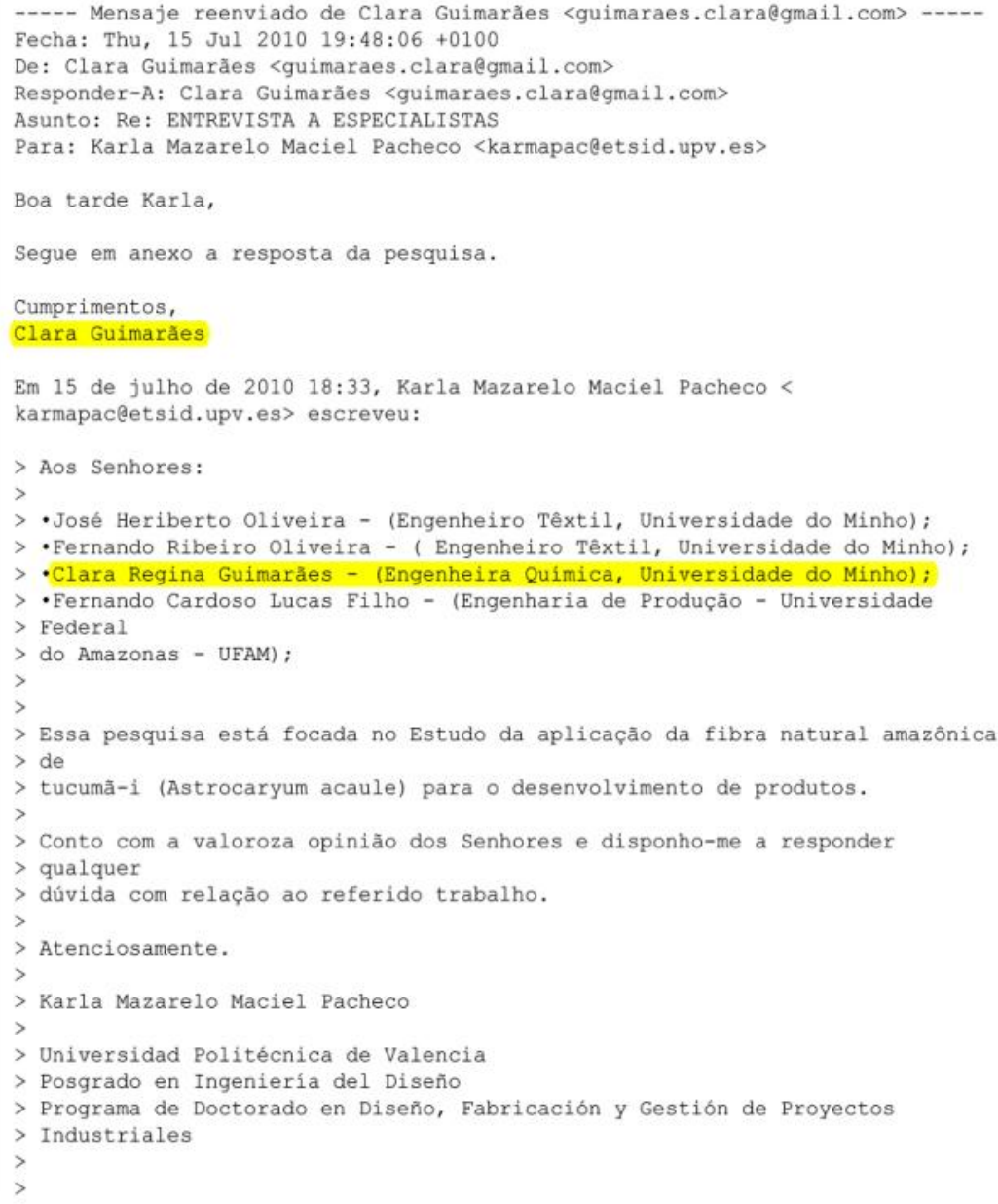


Estudio de la prospección del uso de la fibra de tucumã-i (Astrocaryum acaule) para el desarrollo de productos semi-industriales

\section{questionário}

De: Valdenei de Melo Parente (valparente@hotmail.com)

Enviada: quinta-feira, 22 de julho de 2010 15:56:08

Para: karlamazarelo@hotmail.com

1 anexo

ENTREVISTA_A_EXPERTOS_EM_PORTUGUES[1].doc $(386,0 \mathrm{~KB})$

Olá Karla

Ai vai o questionário. Espero que possa ter contribuido de alguma forma.

Besitos,

Val

LEVE SEU MESSENGER PARA ONDE VOCÊ ESTIVER PELO SEU CELULAR. CLIQUE E VEJA COMO FAZER 


\subsection{Anexo VI: Informaciones a los consumidores}

\section{Questionário - Grau de aceitação da fibra de TUCUMÃ-I para aplicação em produtos}

De: Karla Mazarelo (karlamazarelo@hotmail.com)

Enviada: domingo, 18 de julho de 2010 09:11:05

Para: Karla Mazarelo UPV (karmapac@etsid.upv.es)

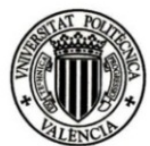

UNIVERSITAT

POLITĖCNICA

DE VALÈNCIA

Bom dia / tarde. Esse questionário faz parte de uma investigcação científica desenvolvida por uma docente do curso de Desenho Industrial da Universidade Federal do Amazonas - UFAM, em parceria com o Programa de doutorado em Desenho, Fabricação e Gestão de Produtos Industriais da Universidade Politécnica de Valencia UPV/Espanha, que estuda a aplicação da fibra natural amazônica de tucumã-i (Astrocaryum acaule) para o desenvolvimento de produtos.

Se não for incoveniente, agradeceríamos que respondesse as seguintes perguntas. Da nossa parte Ihe garantimos que as respostas, que nos proporcionar, serão totalmente confidenciais.

Obrigada.

OBJETO ESTUDADO: Fibra de Tucumã-i (Astrocaryum acaule)

A fibra vegetal amazônica de Tucumã-i (Astrocaryum acaule) apresenta aspectos tecnológicos, sustentáveis e de transformação compativeis ao desenvolvimento de produtos[1].

No entanto, a sua utilização é direcionada à fabricação artesanal.

Com o intuito de verificar o grau de aceitação, por parte dos consumidores de produtos feitos com fibras naturais

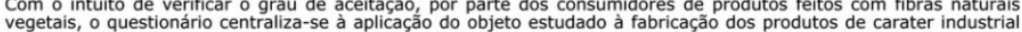
vegetais, o questionar
ou semi-industrial.

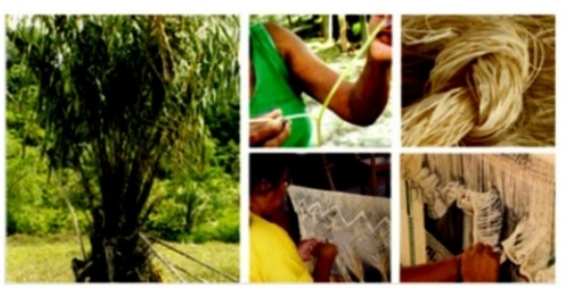

Fig.01 - Fibra de tucumă-i (Astrocaryum acaule)

Fonte: Maciel (2007)

FICHA TÉCNICA DO PRODUTO

-Nome cientifico: Astrocaryum acaule

-Nome vulga: Tucumă-i

- Localizaçăo Geográfica: Alto Rio Negro/ Amazonas

-Processo de produçăo: Plantio em áreas alagadas 
Estudio de la prospección del uso de la fibra de tucumã-i (Astrocaryum acaule) para el desarrollo de productos semi-industriales

-Processo de obtenção: Coleta e preparo com base nos principios da sustentabilidade, preocupando-se com o tipo de corte e o tempo de reposiçăo da parte retirado do vetegal.

•Utilizaçăo: Produção artesanal

- Caracteristicas tecnológicas identificadas e comprovadas, cientificamente, para aplicaçăo em produtos: Organoléptica (cor, cheiro e textura) quimica (toxidade), fisica (umidade e densidade) e mecânica (resistência à traçăo/ calor/ lavagem).

Para facilitar a avaliação da fibra de tucumã-i e conhecer as fibras similares analisadas nessa investigação. Segue o quadro ilustrativo das fibras naturais vegetais.

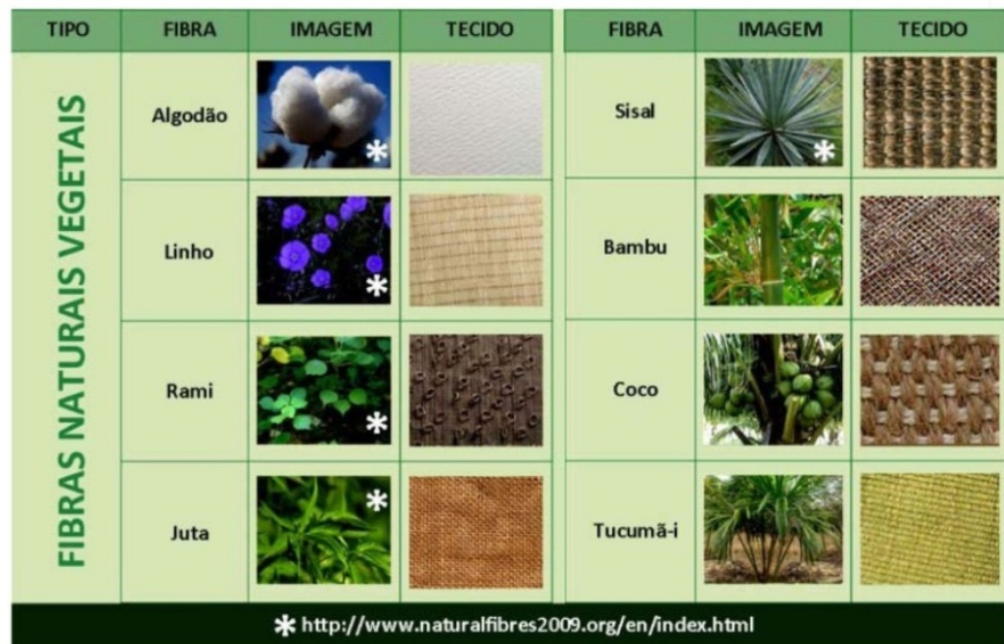

Fonte: a autora.

[1] Maciel, K. M. F. (2007). Estudo da viabilidade técnica da fibra de tucumd-i (Astrocaryum acaule) para produçöo de tecido a ser utilizado na Indüstria de Confeç̧⿸丆es. Programa de Pós-Graduaçăo em Ciéncias Florestais e Ambientais - UFAM: Manaus, Amazonas - Brasil

Para responder ao questionário clique no link e quando concluído em submit

https://spreadsheets.google.com

Iviewform?formkey = diHNESUXOTW5Ic3JVZkxvemhUT083VIE6MQ

MUITO OBRIGADA PELA SUA COLABORAÇÃO.

Pesquisadora:

Profa MSc. Karla Mazarelo M. Pacheco - UFAM

karlamazarelo@hotmail.com

Orientador:

Profo Dr. Bernabé Hernandis Ortuño - UPV 


\subsection{Anexo VII: Aceptación publicaciones}

\section{$1^{\circ}$ CONGRESSO DE DESIGN UEM design brasileiro: cultura ou influência?}

Cianorte, 31 de Agosto de 2011.

Gostariamos de parabenizá-lo pela aprovação de seu trabalho para publicação nos anais do 12 Congresso de Design UEM e apresentação durante o evento, a ser realizado no campus da UEM em Cianorte-PR.

As sessões técnicas de apresentação dos trabalhos ocorrerão exclusivamente na sexta-feira, das $14 \mathrm{~h} 00$ às $17 \mathrm{~h} 30$, em salas organizadas por temas. O horário exato da apresentação, bem como a que sala temática pertencerá o trabalho serão informados na semana anterior ao evento.

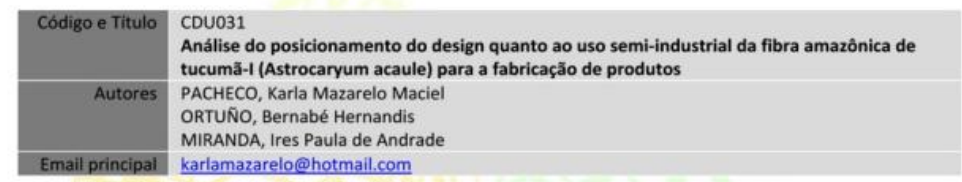

Informamos que a notificação aos co-autores é de sua responsabilidade e lembramos que, para que o artigo seja publicado nos anais do evento, é imprescindível efetuar inscrição como articulista de um dos autores até o prazo máximo de 5 de setembro de 2011.

Após a realização do pagamento, o articulista deverá encaminhar o comprovante, bem como o boleto gerado para o email congressouemdesign@gmail.com, mencionando o(s) código(s) e nome(s) do(s) trabalho(s) por extenso. Vale ressaltar que todos os trabalhos que tiverem um dos autores inscritos (conforme normas para inscrição) serão publicados nos anais, independente da apresentação no evento ou participação dos articulistas.

Aos que forem apresentar o trabalho, favor confirmar presença até 9 de setembro de 2011 para que possamos viabilizar a programação de apresentação dos trabalhos. Os arquivos da apresentação em extensão PPT ou PDF deverão ser encaminhados até o dia 14 de setembro de 2011, impreterivelmente.

Mais uma vez, agradecemos sua participação e o esperamos em Cianorte entre os dias 19 e 25 de Setembro de 2011 para o 1 을 Congresso de Design UEM e 5a Semana de Design UEM.

Atenciosamente,

Comissão Organizadora

Universidade Estadual de Maringá

Cianorte - Paraná - 2011 


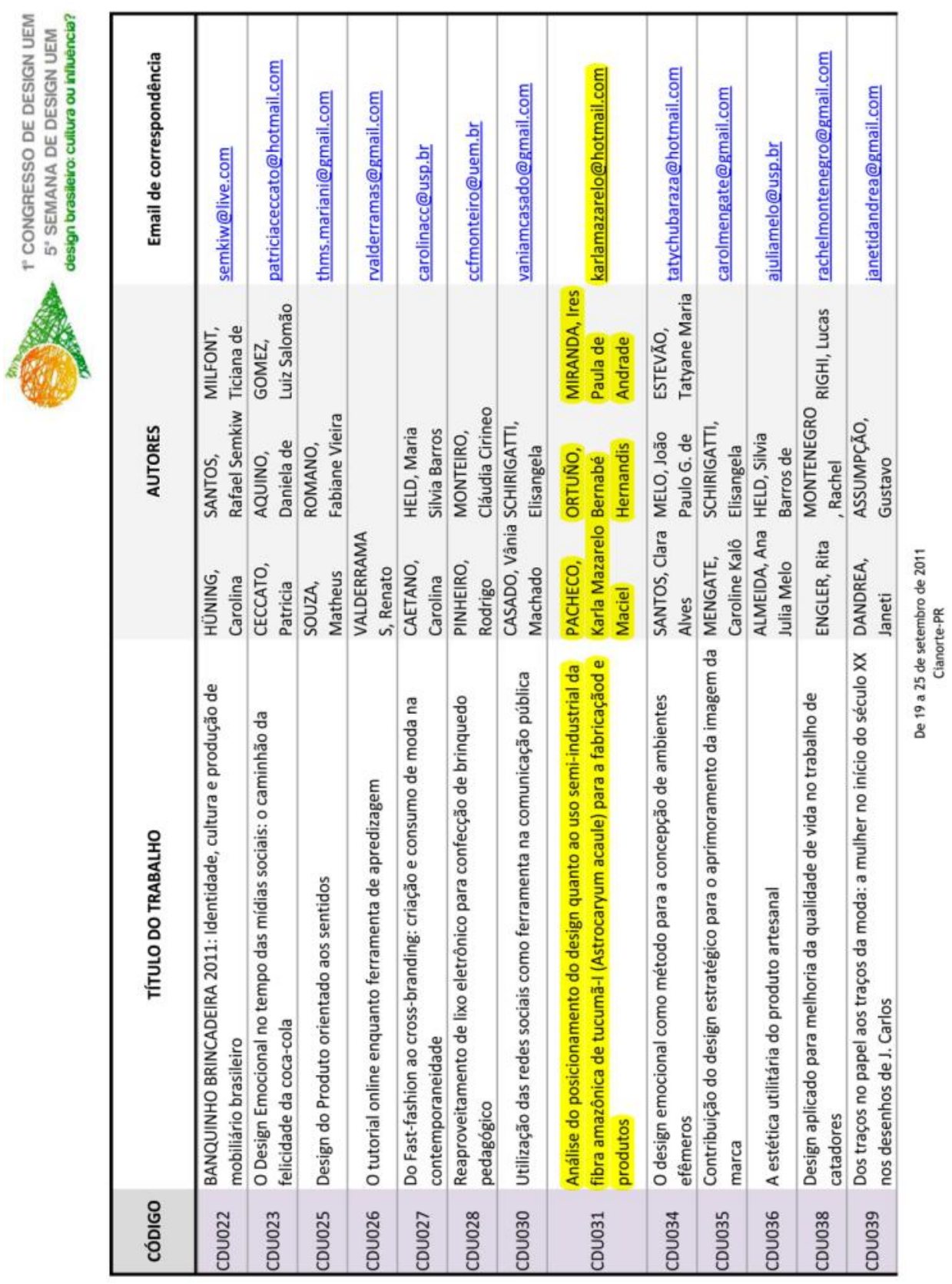




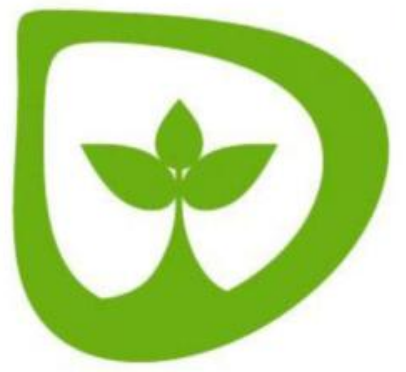

\title{
International Symposium on Sustainable Design
}

Simpósio Brasileiro de Design Sustentável

\author{
2011 \\ Recife | Brasil
}

ACCEPTED PAPERS

Artigos Aceitos

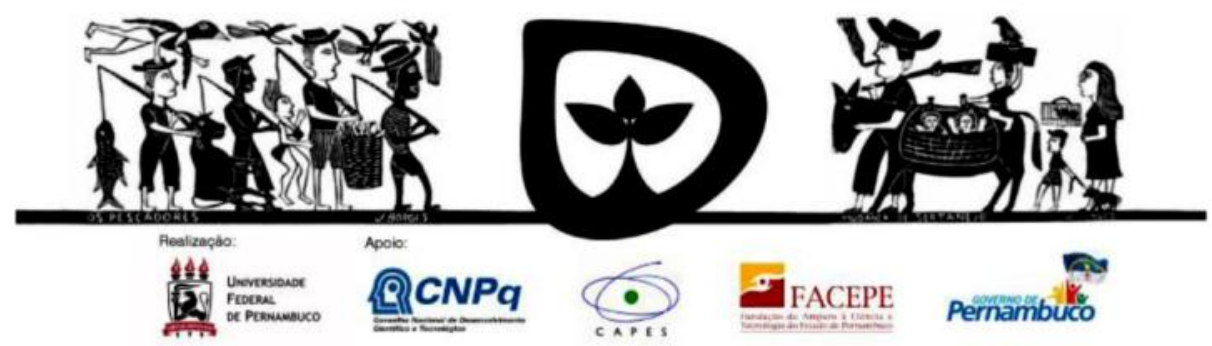


Estudio de la prospección del uso de la fibra de tucumã-i (Astrocaryum acaule) para el desarrollo de productos semi-industriales

International Symposium on Sustainable Design

Simobicio Brasibio de Design Suttentibol

2011

\begin{tabular}{|c|c|c|c|}
\hline SBDS0030 & $\begin{array}{l}\text { Intervençães de Design } \\
\text { Participativo em Grupos Artesanais } \\
\text { no Nordeste do Brasil }\end{array}$ & $\begin{array}{l}\text { GUIMARĀES, Luiz Eduardo Cid } \\
\text { DANTAS, Leiliam Cruz } \\
\text { PEREIRA, Tamyris Luana Pedroza } \\
\text { CAMPOS, Yasmin Mariani de Moura e } \\
\text { Campos }\end{array}$ & UFCG \\
\hline SBDS0032 & $\begin{array}{l}\text { Gabinetes de Eletrodomésticos } \\
\text { "Linha Branca" em Compósito de } \\
\text { Madeira Platico? Isto è Possivel? }\end{array}$ & VERONEZE, Sônia & UFPR \\
\hline SBDS0037 & $\begin{array}{l}\text { Capacitação tecnológica, Inovação } \\
\text { e Lapidação de Materiais } \\
\text { Descartados dos corpos } \\
\text { pegmatiticos aplicados a } \\
\text { Acessórios e Artesanato Mineral }\end{array}$ & $\begin{array}{l}\text { TEIXEIRA, Bernadete } \\
\text { CANAAN, Raquel } \\
\text { GUERRA, Mara Lucia }\end{array}$ & UEMG \\
\hline SBDS0043 & $\begin{array}{l}\text { Design e sustentabilidade: a moda } \\
\text { como outra possibilidade de } \\
\text { conscientização }\end{array}$ & $\begin{array}{l}\text { MARCHI, Salette Mafalda } \\
\text { BECKER, Monique Rorato } \\
\text { ARONIS, Jéssica Nakaema }\end{array}$ & $\begin{array}{l}\text { Centro } \\
\text { Universitário } \\
\text { Franciscano } \\
\text { UNIFRA }\end{array}$ \\
\hline SBDS0044 & $\begin{array}{l}\text { A Energia Solar no Agreste } \\
\text { Pernambucano: é possivel de se } \\
\text { implementar em um campus } \\
\text { universitário federal? }\end{array}$ & $\begin{array}{l}\text { VIEIRA, DjuriTafnes } \\
\text { ROCHA, Mariana Thamiris Silva } \\
\text { MENDONÇA, Renata de Sá } \\
\text { MACHADO, Francisco Oliveira }\end{array}$ & UFPE \\
\hline SBDS0045 & $\begin{array}{l}\text { Comunicar com o Design do } \\
\text { Terceiro Mundo }\end{array}$ & $\begin{array}{l}\text { APARO, Ermanno } \\
\text { SOARES, Liliana }\end{array}$ & $\begin{array}{l}\text { Polytechnic } \\
\text { Institute of Viana } \\
\text { do Castelo } \\
\text { University of } \\
\text { Lisbon }\end{array}$ \\
\hline SBDS0049 & $\begin{array}{l}\text { A inserção de materiais } \\
\text { alternativos, de origem natural e } \\
\text { sintética, no design de joias }\end{array}$ & $\begin{array}{l}\text { CAVA, Thiago } \\
\text { AIEX, Viviane }\end{array}$ & UFPR \\
\hline SBDS0053 & $\begin{array}{l}\text { Metodologia de design de serviços } \\
\text { aplicado ao desenvolvimento de } \\
\text { redes comunitárias }\end{array}$ & QUADROS, Rodrigo & UFBA \\
\hline SBDS0055 & $\begin{array}{l}\text { Análise sobre o posicionamento do } \\
\text { uso da fibra natural amazônica } \\
\text { tucumã-i (Astrocaryum acaule) } \\
\text { para o desenvolvimento de } \\
\text { produtos semi-industriais }\end{array}$ & $\begin{array}{l}\text { PACHECO, Karla Mazarelo } \\
\text { HERNANDIS, Bernabé } \\
\text { PACHECO, Almir }\end{array}$ & $\begin{array}{l}\text { UFAM } \\
\text { Universidad } \\
\text { Politécnica de } \\
\text { Valencia- UPV }\end{array}$ \\
\hline SBDS0057 & $\begin{array}{l}\text { Desenvolvimento de compósito } \\
\text { produzido com resina natural e } \\
\text { fibra da semente de açai (Euterpe } \\
\text { precatória). }\end{array}$ & $\begin{array}{l}\text { QUIRINO, Magnólia } \\
\text { VASCONCELOS, Raimundo }\end{array}$ & UFAM \\
\hline
\end{tabular}




\section{ICOnCFacto}

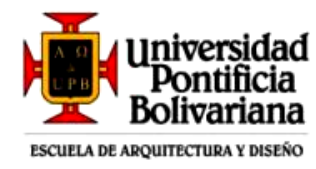

Medellín, 10 de Enero de 2012

Como editor y director la revista ICONOFACTO indexada en categoría "C" de PUBLINDEX, certifico que el artículo "Atributos del diseño para el proceso de transformación y uso de la fibra natural amazónica de tucumã-i (Astrocaryum acaule) en el desarrollo de productos semi-industriales" de la profesora Karla Mazarelo Maciel Pacheco, fue evaluado favorablemente por el árbitro externo y aprobado para el Volumen $8 \mathrm{~N}^{\circ} 9$ de Junio diciembre de 2011 . Dicho texto se encuentra en este momento en proceso de diseño y saldrá impreso a principios del año 2012.

Atentamente,

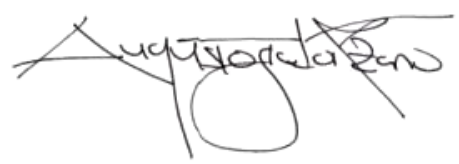

Augusto Solórzano

Director ICONOFACTO

Revista de la Escuela de Arquitectura y Diseño U.P.B 
Estudio de la prospección del uso de la fibra de tucumã-i (Astrocaryum acaule) para el desarrollo de productos semi-industriales

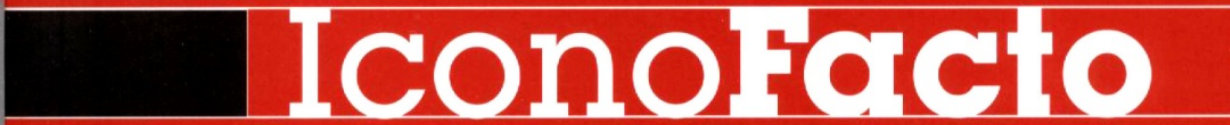

REVISTA DE LA ESCUELA DE ARQUITECTURA Y DISEÑO · Volumen 7, número 9 


\section{Contenido}

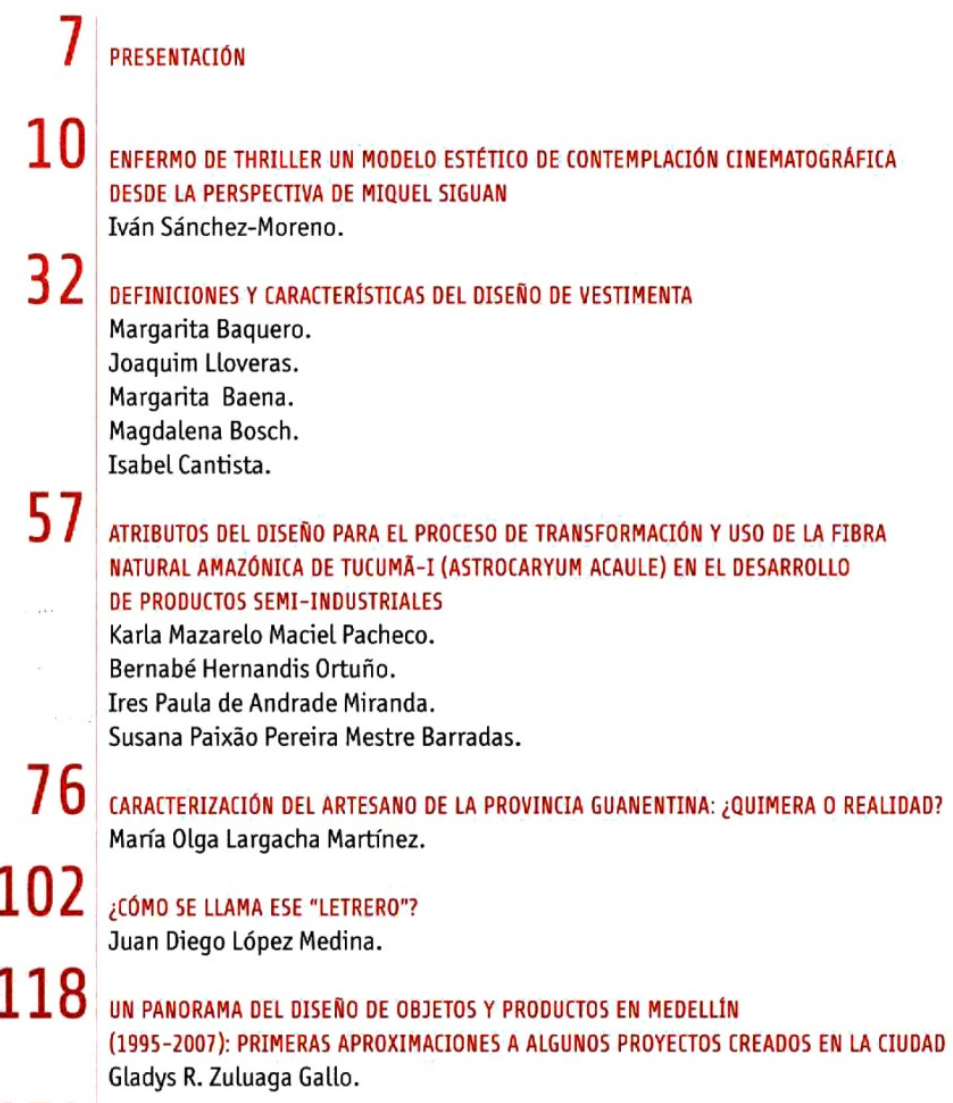


Estudio de la prospección del uso de la fibra de tucumã-i (Astrocaryum acaule) para el desarrollo de productos semi-industriales

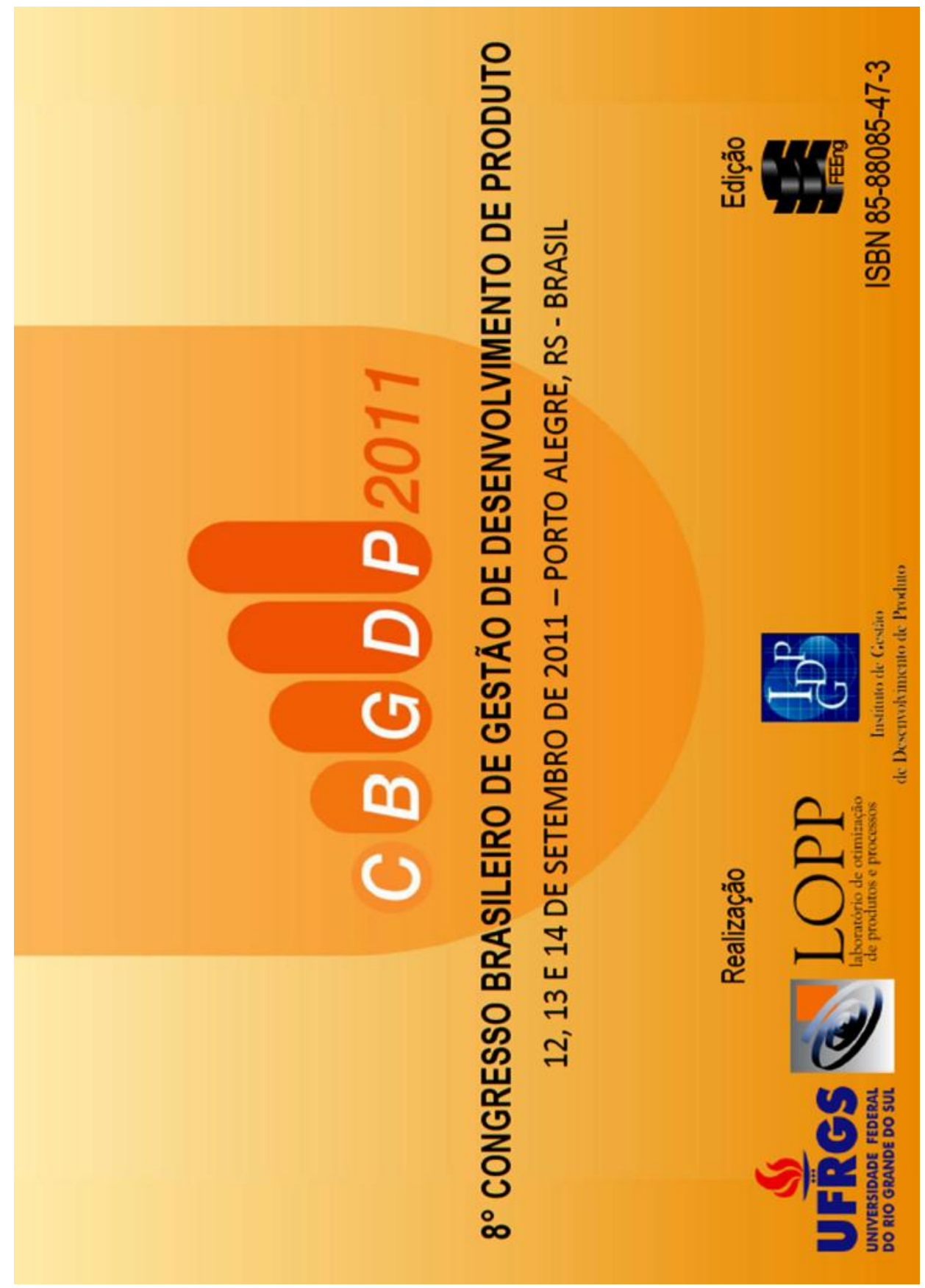




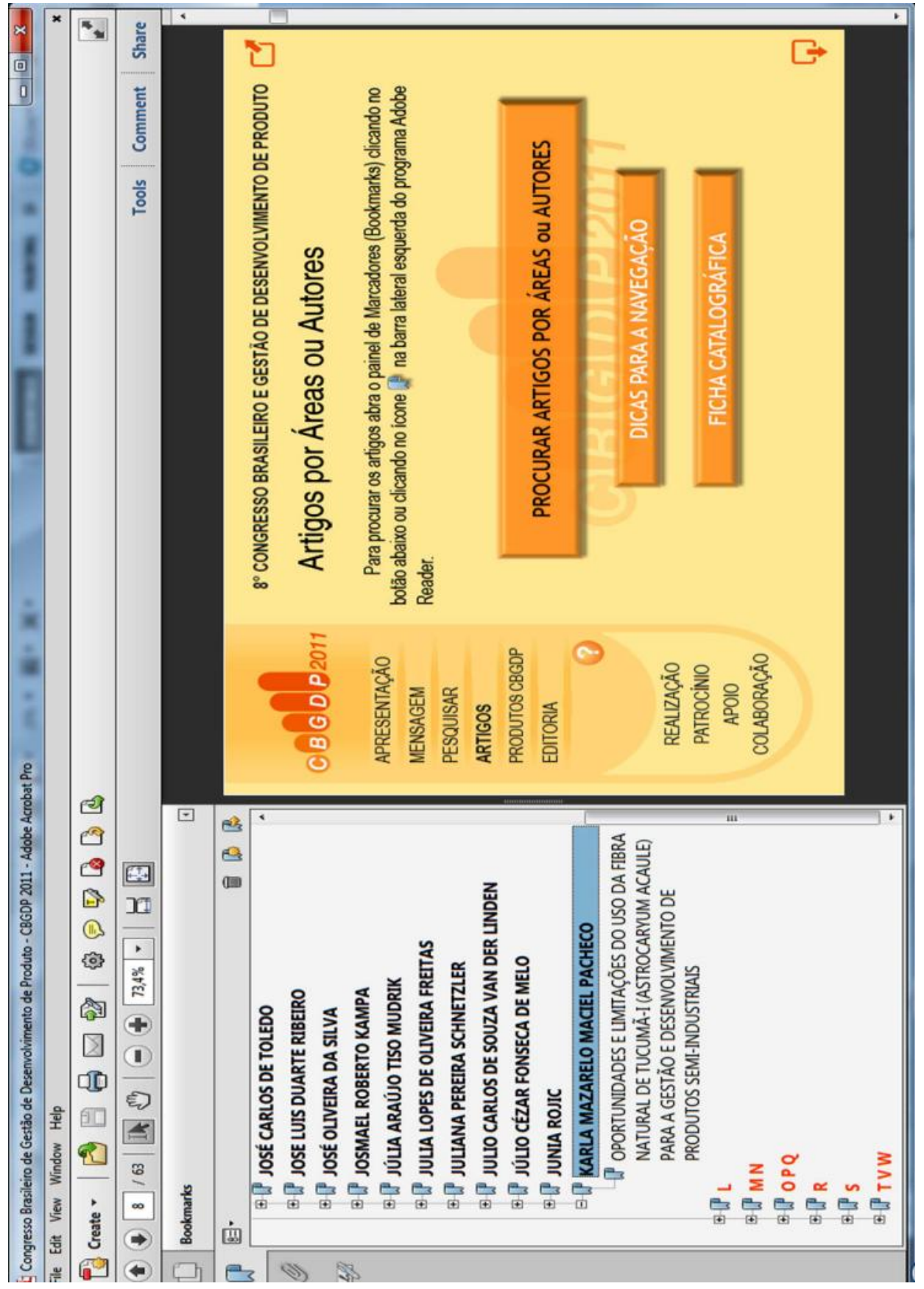


Estudio de la prospección del uso de la fibra de tucumã-i (Astrocaryum acaule) para el desarrollo de productos semi-industriales

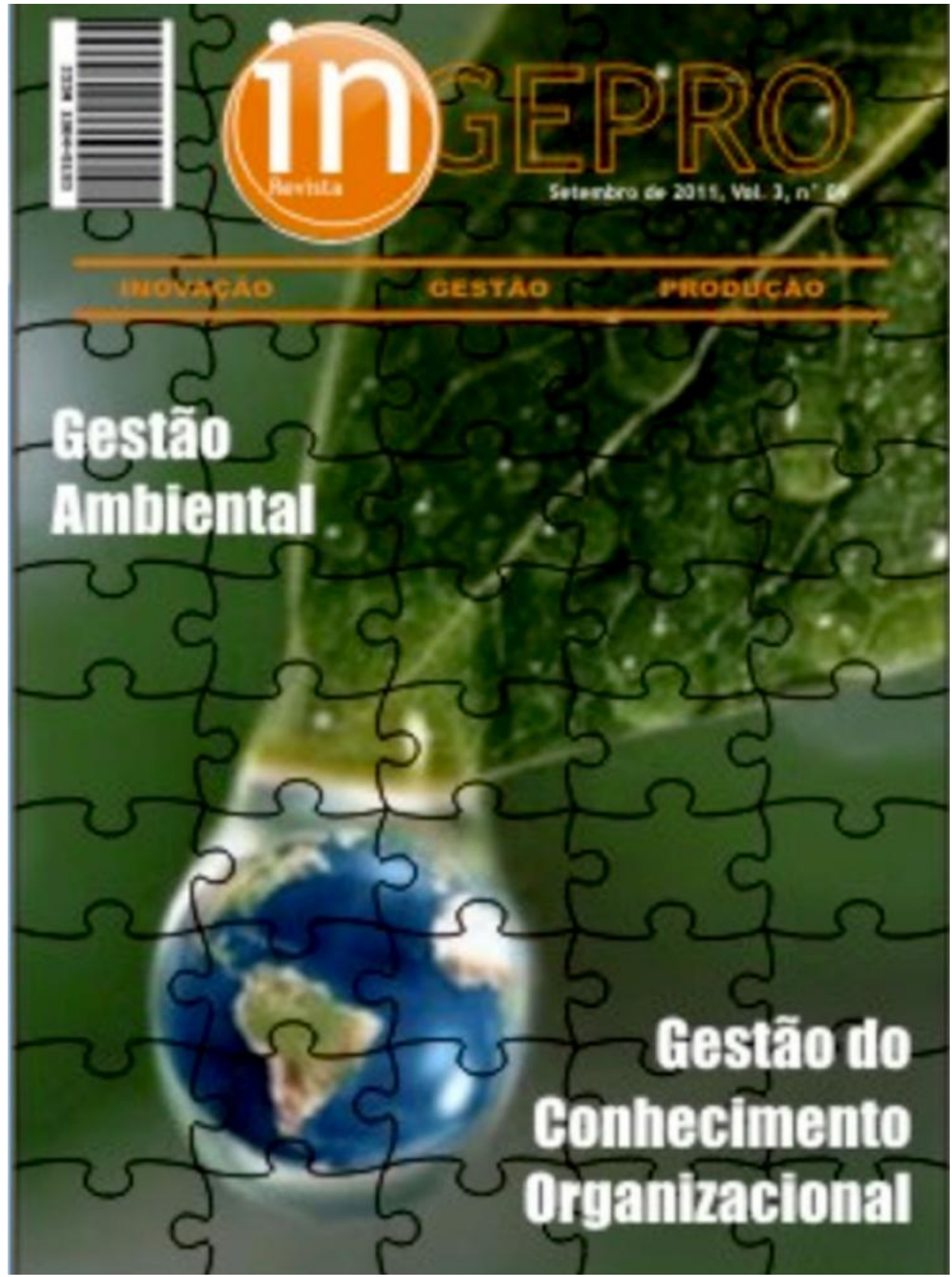




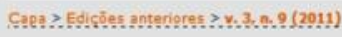

v. 3 , n. 9 (2011)

REVISTA INGEPRO - Setembro de 2011

\section{Sumário}

\section{Artigos}

Ueilizacio de indicaderes da qualidade parn análise de eficiència dos processes de transeorte rodoviário de cargas

Enio Fernandes Rodrigues, Alexandre Formigoni, Ivan Pérsio de Arruda Campos, Rosalina Leal

Proieto de Cadeia de Suprimentos e Alinhamento Dinaimicos Proposta de um

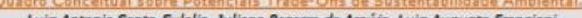
Luis Antonio Santa-Eulalia, Juliano Bezerra de Araujjo, Luis Augusto Franciosi, Rodrigo Cambiaghi Azevedo, Carlos Frederico Bremer

Sistema de cestrolo ambiental e educacilo ambientali um ertude de caso em uma smpresa do Polo Industrial de Manaus - PTM a partir da percepcalo de seus Solntorrodore:

Patricia Auxiliadora Ribeiro de França, Geraldo Vieira da Costa

Anälise da agreciaciöo de consumidores sobre o uso semi-industrial da fibra vegetal amazônica de tucumà-i (Astrocarvum acaule) para o desenvolvimento de rodutos: Um estudo de mercade

Sra. Karla Mazarelo Maciel Pacheco, Or. Bemabé Hernandis Ortuño, Ora. Ires Paula de Andrade Miranda, Dra. Claudecte Catanhede do Nascimento, Sra. Begaña Agudo Vicente

CARACTERISTICAS DA INOVACÃOI UMA REVISÃO DELITERATURA Simone Sartoni

(ब) 1

Este trabalho está licenciado sob uma Licenca Creative Commens Attribution 3.0 .
Conteúdo Da Revista

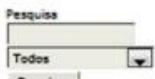

Peavis

Prowar

- Jar taleba

: Dercitiar

然

$001-013$

20e

Login

014-026

BOE

Acesso

Alufle de vitims

027-038

$039-051$

[A: $A$ [DA

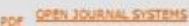

$052-064$

\section{Informações}

: Paratitom

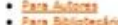




\section{Fwd: Notificación de aceptación}

De: Karla Mazarelo Maciel Pacheco (karmapac@etsid.upv.es)

Enviada: segunda-feira, 28 de novembro de 2011 15:00:32

Para: supaipe@upvnet.upv.es; bhernand@degi.upv.es; almirdesigner@gmail.com

Cc: karlamazarelo@hotmail.com

3 anexos

unnamed (1,0 KB) , unnamed (1,3 KB) , G_guia_para_el_formato_de_las_ponencias.doc $(903,0 \mathrm{~KB})$

-.-- Mensaje reenviado de Congrés de Disseny i Innovació ESDi <congres@esdi.es> -10-

Fecha: Mon, 28 Nov 2011 15:28:42+0100

De: Congrés de Disseny i Innovació ESDi <congreslesdi.es>

Responder-A: Congrés de Disseny i Innovació ESDi <congres@esdi.es>

Asunto: Notificación de aceptación

Para: Karla Mazarelo Maciel Pacheco <karmapac@etsid.upv.es>

Buenos días,

En primer lugar, le pedimos disculpas por el retraso con que 10 informamos, que se ha debido a la gran cantidad de propuestas que hemos recibido.

Le comunico que su propuesta de ponencia ha sido aceptada para participar

al $2^{\circ}$ Congreso Internacional de Diseño e Innovación de Cataluña (CIDIC).

Para poder incluir un número más grande de propuestas, el comité

organizador ha decidido que habrá tres modalidades de trabajos: con

presentación oral de 20 minutos, en formato de póster o únicamente la

públicación del artículo en la página web de la Escuela Superior de Diseño, ESDi. Las dos primeras modalidades también incluyen la publicación del

articulo. Bien pronto le notificaremos en cuál de las tres modalidades se incluye su propuesta.

El plazo de entrega de los articulos enteros se ha ampliado hasta el 13 de febrero de 2012. En el documento adjunto encontrará las caracteristicas formales que tiene que cumplir.

Atentamente,

Gemma Gómez

Secretaria del CIDIC

-..-- Fin del mensaje reenviado -..--

> Date: Mon, 28 Nov 2011 14:21:30+0100 


\author{
CERTIFICADO DE PRESENTACIÓN DE PONENCIA \\ EN EL $2^{\circ}$ CONGRESO INTERNACIONAL DE DISEÑO \\ E INNOVACION DE CATALUÑA
}

Dr. Llorenç Guilera Agüera, en calidad de Director de la Escuela Superior de Diseño
ESDI -centro adscrito a la Universidad Ramon Llull- y director del Comité Organizador
del $2^{\circ}$ Congreso Internacional de Diseño e Innovación de Cataluña, CIDIC, y en del $2^{\circ}$ Congreso Internacional de Diseño e Innova
nombre de Uli Marchsteiner, presidente del mismo,

CERTIFICA QUE:

La ponencia "La importancia del diseño sistémico para la competitividad de la fibra natural Amazónica de tucumã-i (Astrocaryum acaule) en el desarrollo semi-industrial de productos: Un estudio de caso para la categoría del vestuario" presentada por Karla Mazarelo Maciel Pacheco ha sido presentada en una de las sesiones temáticas del Congreso que ha tenido lugar durante los días 25,26 y 27 de abril de 2012 en el campus de la ESDi.

Sabadell, a 8 de mayo de 2012

Firmado:

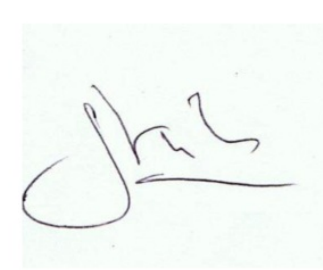

Dr. Llorenç Guilera Agüera

Llorenç Guilera i Agüera

direccio@esdi.es

Marqués de Comillas 81-83

08202 Sabadell - Barcelona, España

Tel. (+34) 937274819 Ext. 42 - Fax. (+34) 937263369

http://www.esdi.es 
Estudio de la prospección del uso de la fibra de tucumã-i (Astrocaryum acaule) para el desarrollo de productos semi-industriales

\section{Your IDEMi 2012 paper 103307}

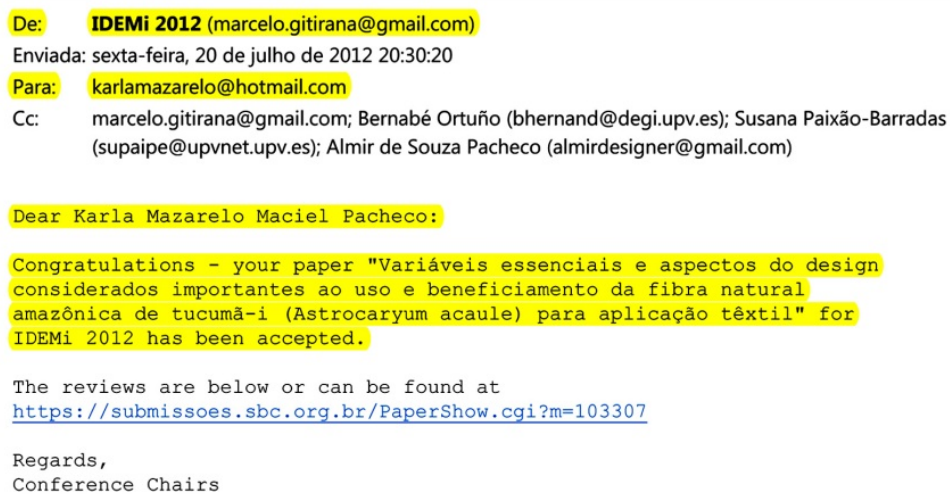




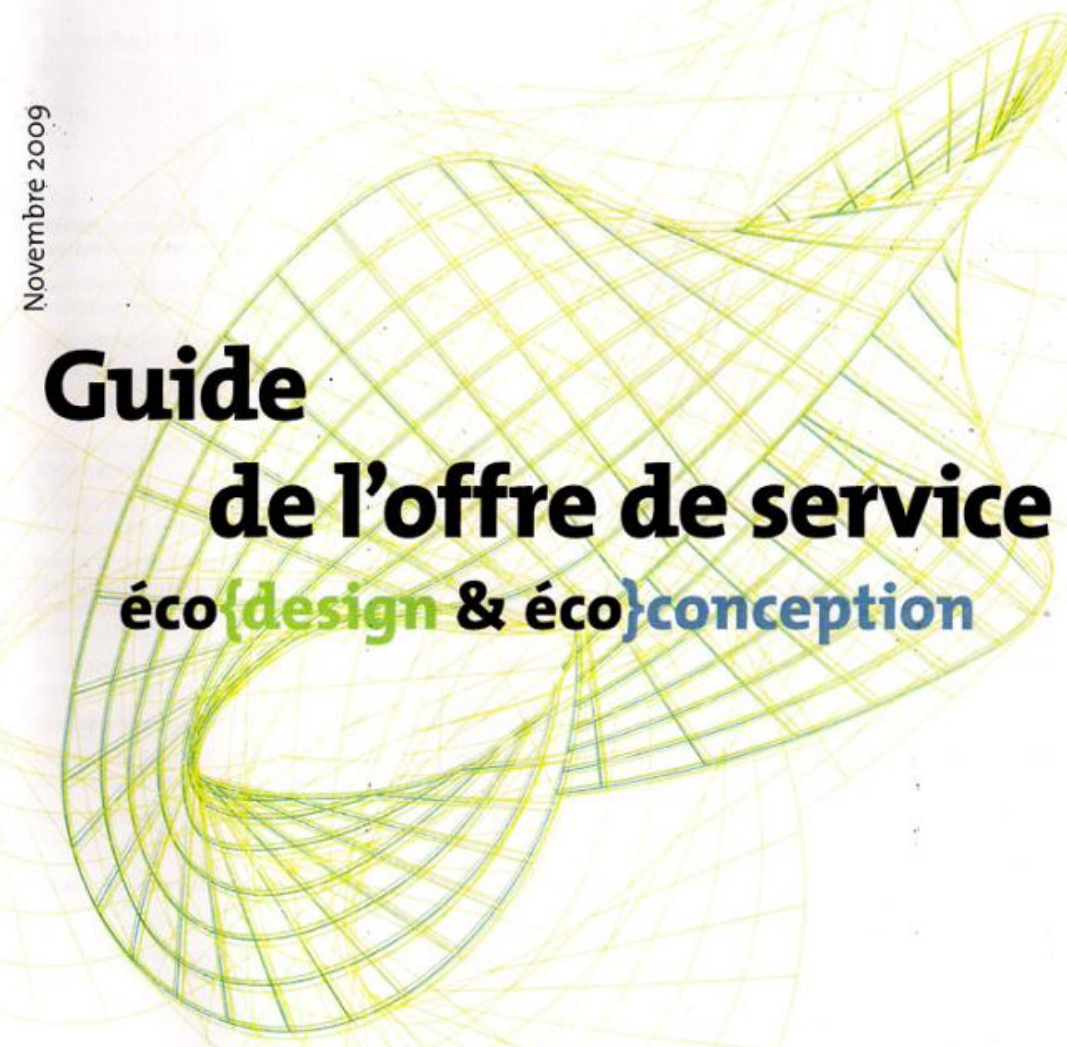

AR D 
Estudio de la prospección del uso de la fibra de tucumã-i (Astrocaryum acaule) para el desarrollo de productos semi-industriales

Ce document a été réalisé avec le concours du Rhône-Alpes Automotive Cluster qui co-organisait la journée technique «Eco-conception et Matériaux :

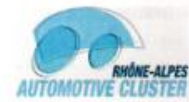
Quels enjeux pour la filière automobile? du 26 novembre 2009 .

\section{AR, D., I ' Rhônetlpes}




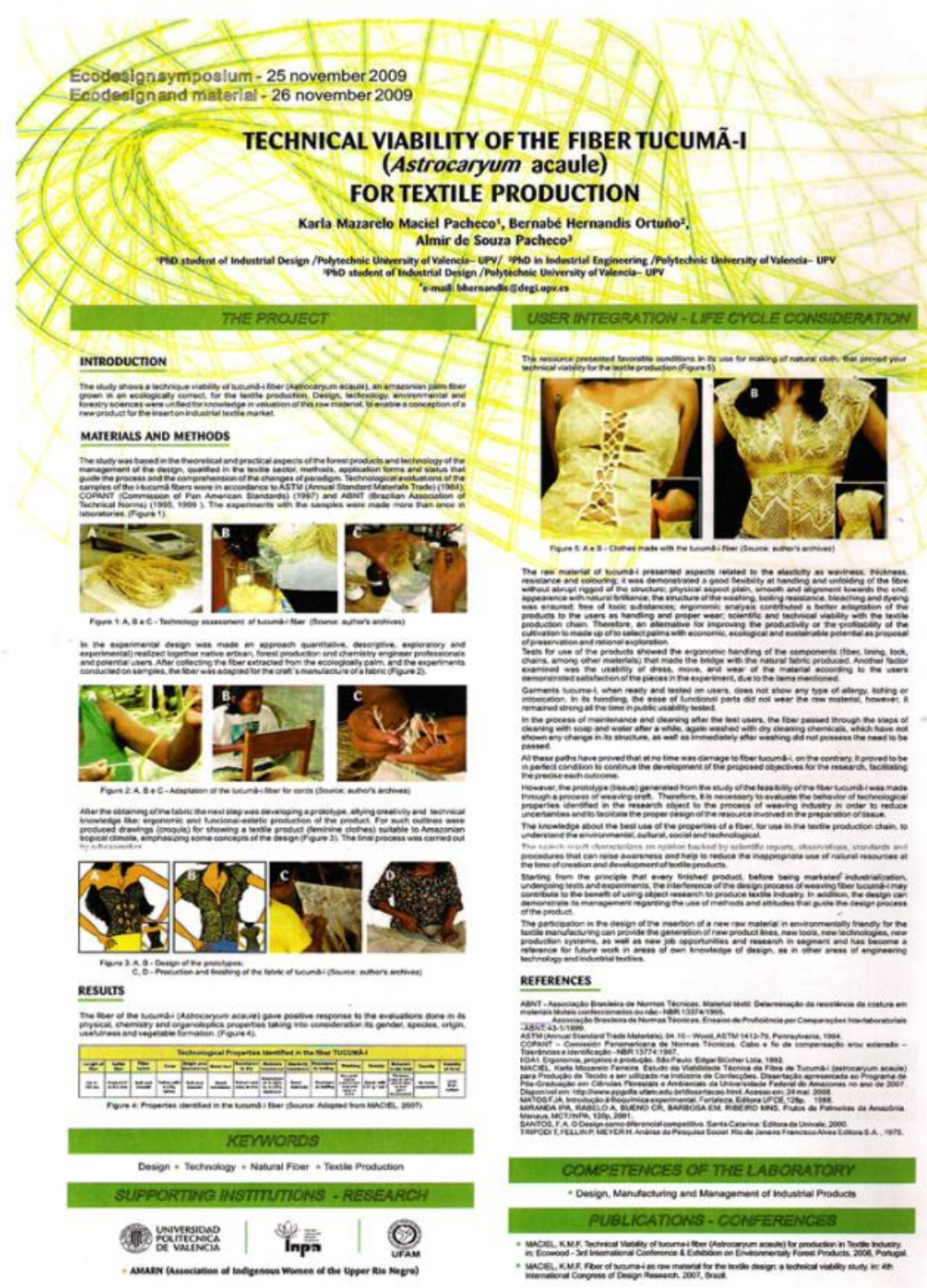

$34\{$ guide de l'offre de service éco-design \& éco-conception 
Estudio de la prospección del uso de la fibra de tucumã-i (Astrocaryum acaule) para el desarrollo de productos semi-industriales

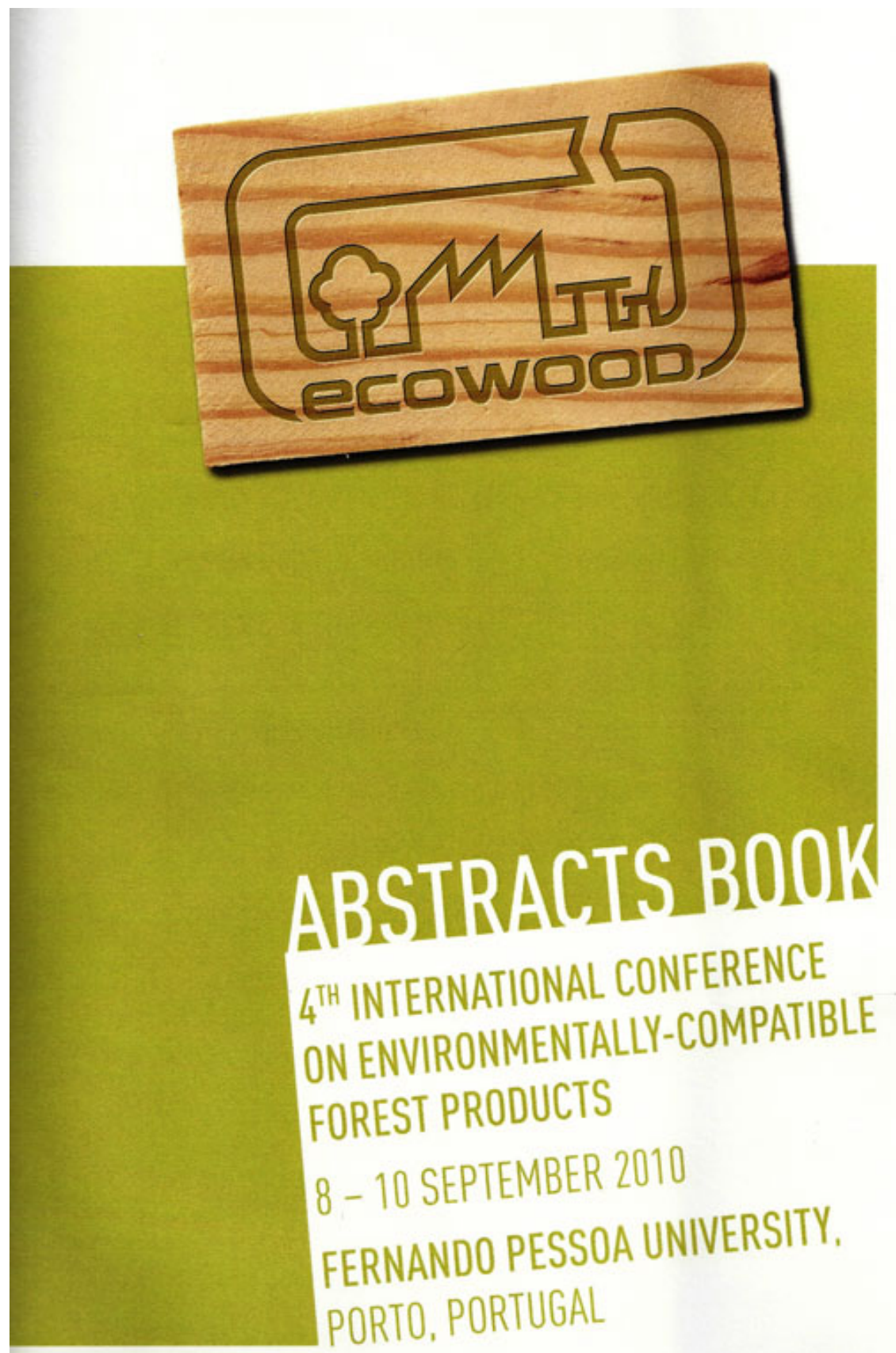




\section{ORGANIZING COMMISSION:}

\section{Alzira Dinis}

\section{Ana Fonseca}

\section{Fernando Caldeira (coordinator)}

\section{Nelson Barros}

\section{SCIENTIFIC COMMITTEE:}

Ana Fonseca: Research Center on Global Changes, Energy, Environment and Bioengineering [CIAGEB], Fernando Pessoa University (UFP), Portugal

Fernando Caldeira: CIAGEB - UFP [coordinator]

José Vicente Ferreira: Department of Wood Engineering. Technology School, Polytechnic Institute of Viseu, Portugal.

Lina Nunes: LNEC - National Laboratory of Civil Engineering. Timber Group, Lisbon, Portugal.

Mark Irle: PRES UNAM, Laboratoire Matériaux

Composites Bois, Ecole Supérieure du Bois, Nantes, France

Marko Petric: Department of Wood Science and Technology, Biotechnical Faculty, University of Ljubljana, Slovenia

Nelson Barros: CIAGEB - UFP

Roger Rowel: Forest Products Laboratory, USDA, Madison and University of Wisconsin, USA
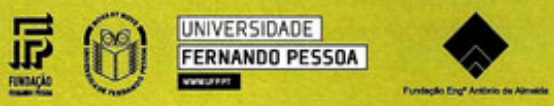
Estudio de la prospección del uso de la fibra de tucumã-i (Astrocaryum acaule) para el desarrollo de productos semi-industriales
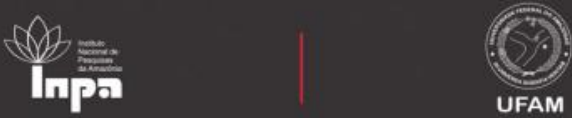

\section{Procedures for obtaining} vegetable dyes of Amazon for application in industrial products

Karla Mararelo Maciel Pacheco:

MSc at Forestry and Envirommental/Amaronas Federd Unversity - UFA

tartamazareloephotmailcom

Bernabé Hernandis Ortuho

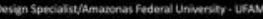

Claudete Catanhede Nascimento

ia de Jesus Coutinho Varej:

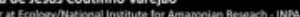

AMARN (Indigenous Women Assodiation of Black Rewer High)

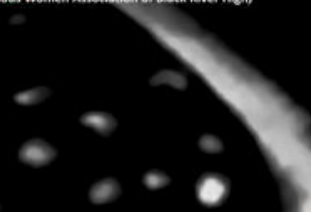

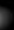

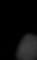
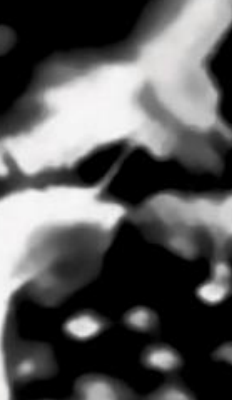

8
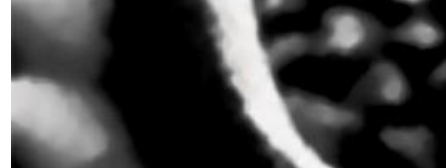

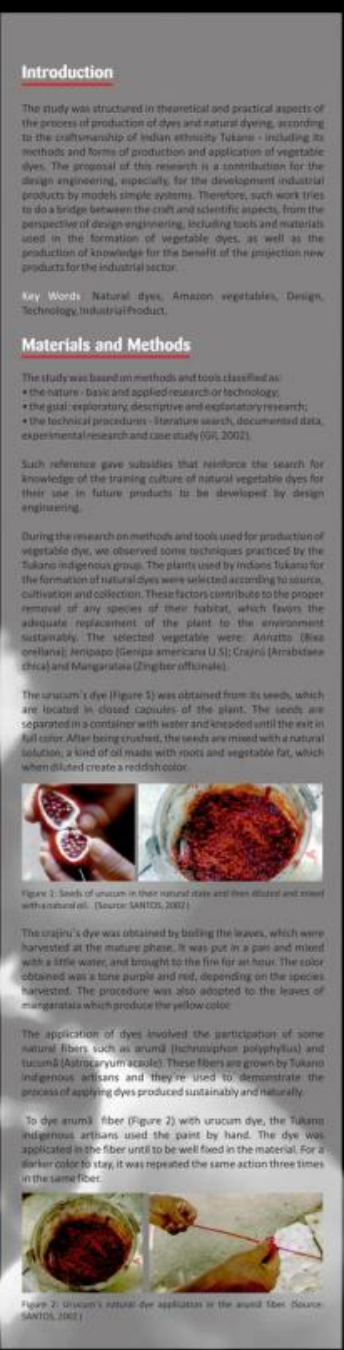



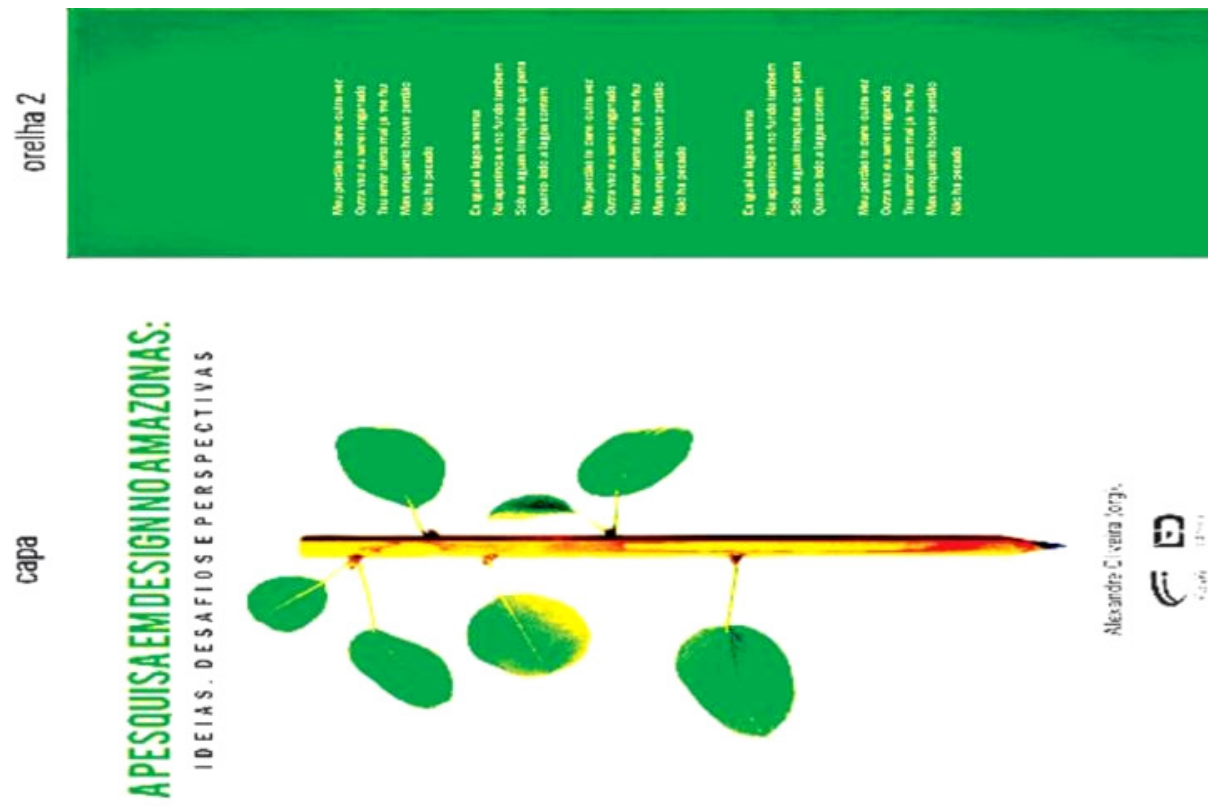

응
등

I

(i)

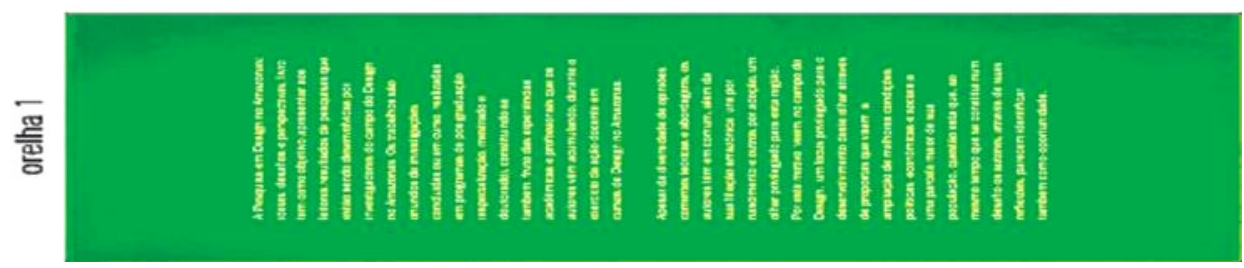


Estudio de la prospección del uso de la fibra de tucumã-i (Astrocaryum acaule) para el desarrollo de productos semi-industriales

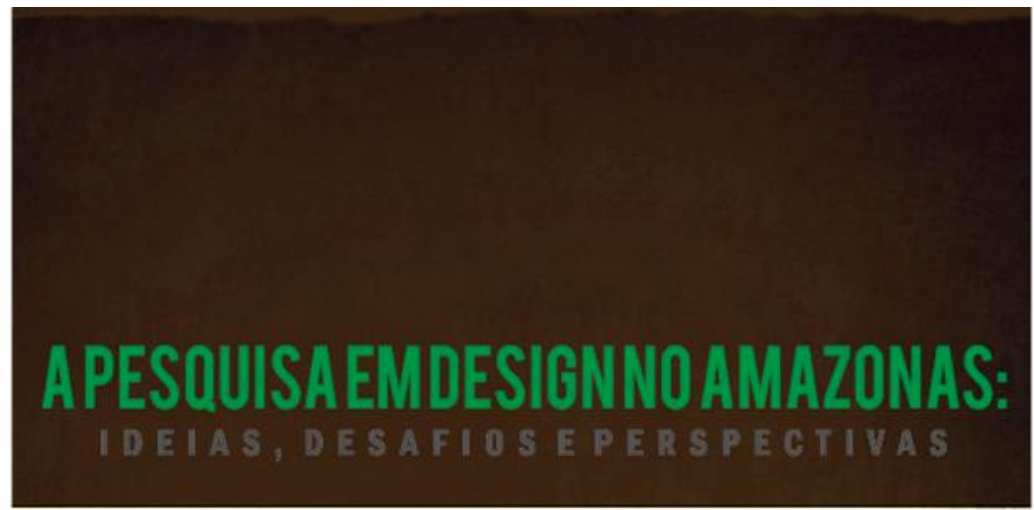

ALEXANDRE DE OLIVEIRA (ORGANIZAÇÄO)

ALMIR DESOUZAPACHECO

ANNY VENÂNCIO

BERNABÉ HERNANDIS ORTUÑO

BRUNNAROCHA ANCHIETA

CATARINA SOUZA

HINAYANAPINTO RASIIVA

KARLA MAZARELO MACIEL PACHECO

MARIAEVANYDONASCIMENTO

NARLE TEIXEIRA

RITA MARIA DESOUZA COUTO

SHEILACORDEIROMOTA 


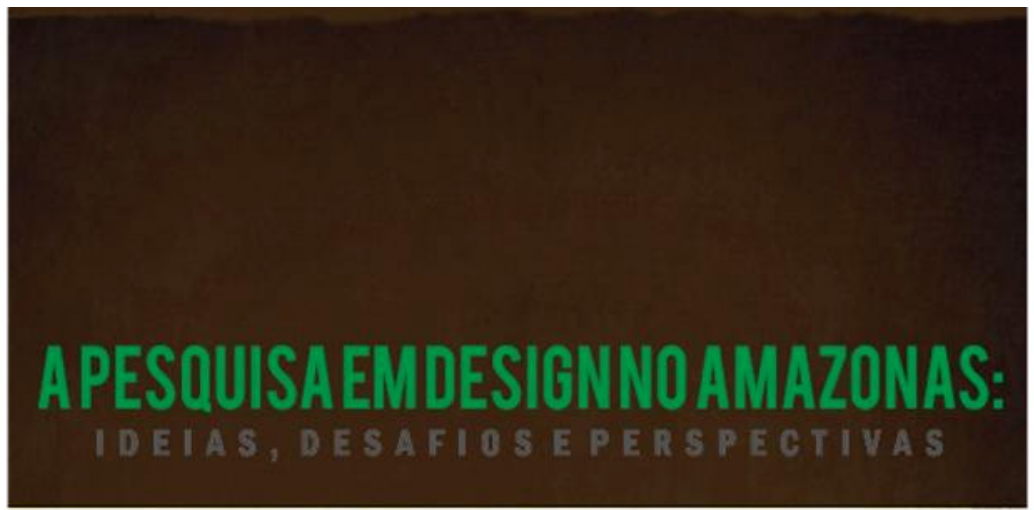

\title{
0 ensino do Design na utilização de recursos naturais para aplicação em produtos industriais
}

\author{
Karla Mazarelo Maciel Pacheco \\ Bernabé Hernandis Ortuño \\ Almir de Souza Pacheco
}

Esse capitulo aborda a importância do processo de investigação e utilização dos recursos naturais para o desenvolvimento de produtos industriais sob a ótica do ensino do design. Para tanto, os autores consideram importante fazer uma mescla de conhecimentos que possam envolver: o desenvolvimento de projeto, o estudo do recurso natural a ser utilizado, a análise do sistema exterior (mercado/meio ambiente), as tecnologias disponiveis e os tipos de produtos a serem industrializados. Essa proposta, traz ao design uma forma de engrandecer e fortificar o seu ensino através de informações que são pertinentes à formação do designer, um profissional, que hoje se encontra no meio dos mais solicitados para a projeção de produtos com temáticas voltadas ao meio ambiente e à ecologia. 
Estudio de la prospección del uso de la fibra de tucumã-i (Astrocaryum acaule) para el desarrollo de productos semi-industriales

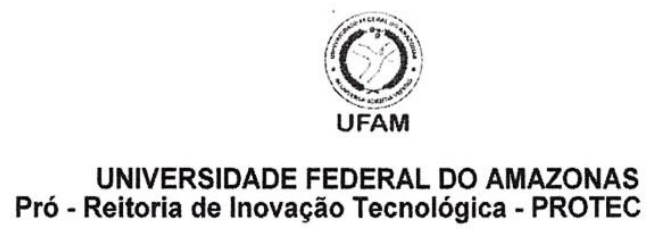

UNIVERSIDADE FEDERAL DO AMAZONAS

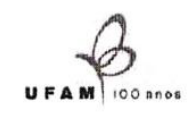

\section{DECLARAÇ Ã O}

Declaramos para os devido fins que a Profa. Karla Mazarelo Maciel Pacheco submeteu o projeto intitulado "Intervenção do design no processo de beneficiamento da fibra natural de tucumã-i (Astrocaryum acaule) para $\circ$ desenvolvimento de produtos" o qual foi aprovado no Programa de Expansão e Sustentabilidade do Parque Científico e Tecnológico para Inclusão Social da Universidade Federal do Amazonas e encontra-se em processo de apreciação do órgão financiador.

Manaus, 21 de dezembro de 2011.

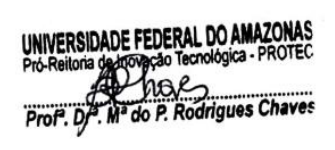




\subsection{Anexo VIII: Justificante de la aprobación del Comité Ética}

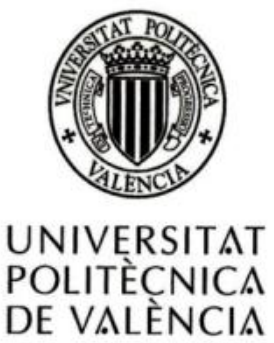

AMPARO CHIRALT BOIX, PRESIDENTA DEL COMITÉ DE ÉTICA EN INVESTIGACIÓN DE LA UNIVERSIDAD POLITÉCNICA DE VALENCIA

HACE CONSTAR: que el Comité de Ética en Investigación de esta universidad, en sesión celebrada el 19 de abril de 2011, tras evaluar el proyecto de investigación "Estudio de la prospección de la fibra natural de tucuma-i (Astrocaryum acaule) para el desarrollo de productos semi-industriales" cuya investigadora principal es la Dra. Karla Mazarelo Maciel Pacheco, ha decidido informarlo favorablemente.

Valencia, a 19 de abril de 2011

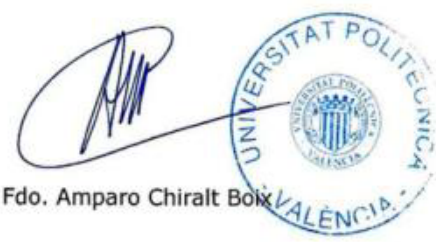




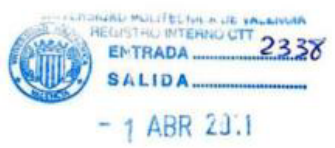

\title{
Comité de Ética en Investigación de la Universidad Politécnica de Valencia
}

\section{Solicitud de evaluación de proyecto de Investigación con implicaciones éticas o de bioseguridad.}

\begin{abstract}
- Este documento deberá remitirse, debidamente cumplimentado, junto con la documentación completa del Proyecto a la secretaría del Comité (Sección de Ayudas Públicas del CTT) y al correo electrónico (comite.etica @upv.es).

- Para que la autorización del Comité de Ética en Investigación pueda remitirse junto con la solicitud del proyecto, dicho documento deberá enviarse a la secretaría del Comité al menos una semana antes de la finalización del plazo de presentación de proyectos, con el fin de que se pueda revisar su contenido. Si no dispone de la autorización del Comité en el momento de presentar la solicitud, podrá enviarlo con posterioridad, pero será un requisito para la aprobación del proyecto.

- En aquellos proyectos en los que las muestras o tejidos humanos procedan de un Hospital o de un Banco de Tejidos, se deberá aportar la certificación del Comité de Ética de dicha institución, en la que se autorice su utilización en el proyecto solicitado.
\end{abstract}

Indicar si la propuesta contempla alguno de los siguientes aspectos que puedan tener implicaciones éticas o relativas a la bioseguridad: ( $L a$ contestación afirmativa a alguna de estos supuestos conlleva completar el epigrafe correspondiente.)
A. Experimentación clínica con seres humanos
B. Utilización de células troncales embrionarias humanas, o líneas
derivadas de ellas, procedentes de preembriones sobrantes
$\square \quad$ Q
C. Utilización de tejidos o muestras biológicas de origen humano
D. Uso de datos personales.
E. Experimentación animal.
F. Utilización de agentes biológicos de riesgo para la salud humana, animal o para las plantas.
G. Uso de organismos modificados genéticamente (OMGs)
H. Liberación de OMGs

Si No

Proyecto: Estudio de la prospección de la fibra natural de tucumã-i (Astrocaryum acaule) para el desarrollo de productos semi-industriales

\section{Datos del Investigador Principal:}

Nombre y Apellidos: Karla Mazarelo Maciel Pacheco

Centro o Departamento: Departamento de Ingeniería Gráfica

Edificio: ETSID Teléfono: 963879055 (79055)

Correo electrónico:

karmapac@upvnet.upv.es 


\subsection{Anexo IX: Carta de aceptación de los autores}

\section{UNIVERSITAT MODELO DE ACEPTACIÓN DE LOS COAUTORES POLITÈCNICA DE VALÈNCIA \\ (Doctores y no Doctores)}

Dr. BERNABÉ HERNANDIS ORTUÑO, con el DNI/Passaport nº $19460767 \mathrm{~F}$ nacido/a el 24/01/1955 y con domicilio en Valencia, calle Plaza Santa Urzula, núm. 3, puerta 7, código postal 46001, ciudad y país Valencia, España, telefono 660766751 ,e-mail bhernand@degi.upv.es

\section{MANIFIESTO QUE}

I Como COAUTOR NO DOCTOR, estoy informado/a que el/la señor/a KARLA MAZARELO MACIEL PACHECO quiere solicitar la autorització a la Comisión de Doctorado de la Universitat Politècnica de València para la presentación de su tesis doctoral en forma de compendio de publicaciones y que hago la renuncia como coautor a la presentación de los trabajos como parte de otra tesis doctoral

II. Com a COAUTOR DOCTOR, estoy informado/a que el/la señor/a

quiere solicitar la autorització a la Comisión de Doctorado de la Universitat Politècnica de València para la presentación de su tesis doctoral en forma de compendio de publicaciones

$\mathrm{Y}$, a este efecto

\section{HAGO CONSTAR}

Que acepto que se utilicen el/los trabajo/s:

- PACHECO, K. M. M.; ORTUÑO, B. H.; MIRANDA, I. P. A. Análise do posicionamento do design quanto ao uso semi-industrial da fibra amazônica de tucumã-i (Astrocaryum acaule) para a fabricação de

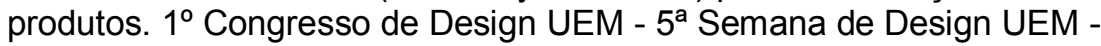
Design brasileiro: cultura ou influência?. Universidade Estadual de Maringá - UEM. Campus Regional de Cianorte - Paraná, 2011b. ISSN: 2237-0862 
Estudio de la prospección del uso de la fibra de tucumã-i (Astrocaryum acaule) para el desarrollo de productos semi-industriales

- PACHECO, K. M. M.; ORTUÑO, B. H.; PACHECO, A. S. Análise do posicionamento de especialistas sobre o uso da fibra natural amazônica de tucumã-i (Astrocaryum acaule) para o desenvolvimento de produtos semi-industriais. Anais do III Simpósio Brasileiro de DesignSustentável (III SBDS) - Proceedings of the 3rd International Symposium on Sustainable Design (ISSD). Editora Universitária UFPE. Pernambuco - RE, 2011. ISBN: 978.85.7315.949-3

- PACHECO, K. M. M.; ORTUÑO, B. H.; MIRANDA, I. P. A.; NASCIMENTO, C. C.; PACHECO, A. S. Oportunidades e limitações do uso da fibra natural de tucumã-i (Astrocaryum acaule) para a gestão e desenvolvimento de produtos semi-industriais. Anais do $8^{\circ}$ Congresso Brasileiro de Gestão de Desenvolvimento de Produto (CBGDP). UFRGS/FEEng. Porto Alegre - RS. 2011. ISBN:978-85-88085-46-6 (Resumo) e ISBN:85-88085-47-3 (Artigo Completo).

- PACHECO, K. M. M.; ORTUÑO, B. H.; MIRANDA, I. P. A.; NASCIMENTO, C. C.; VICENTE, B. A. Análise da apreciação de consumidores sobre o uso semi-industrial da fibra vegetal amazônica de tucumã-i (Astrocaryum acaule) para o desenvolvimento de produtos: Um estudo de mercado. Revista INGEPRO - Inovação, Gestão e Produção, Set. vol. 03, nº. 09, (p.44-51) - Universidade Federal de Santa Maria - UFSM. Santa Maria- RS, 2011. ISSN: 1984-6193.

- PACHECO, K. M. M.; ORTUÑO, B. H.; MIRANDA, I. P. A.; PAIXÃOBARRADAS, S. Atributos del diseño para el proceso de transformación y uso de la fibra natural amazónica de tucumã-i (Astrocaryum acaule) en el desarrollo de productos semi-industriales. Revista Icono Facto Revista de la Escuela de Arquitectura y Diseño. Universidad Pontificia Bolivariana. Volumen 7, número 8, Medellín - Colombia, Diciembre. 2011. ISSN: $1900-2785$

- PACHECO, K. M. M.; ORTUÑO, B. H.; PAIXÃO-BARRADAS, S.; PACHECO, A. S. La importancia del diseño sistémico para la competitividad de la fibra natural Amazónica de tucumã-i (Astrocaryum acaule) en el desarrollo semi-industrial de productos: Un estudio de caso para la categoría del vestuario. $2^{\circ}$ Congreso Internacional de Diseño e Innovación. Escuela Superior de Diseño ESDi. Universitat Ramon Llull - URL. Sabadell/ Barcelona - España, 2012. ISBN: 978-84936165-1-9 ¿?

- PACHECO, K. M. M.; VICENTE, B. A.; PACHECO, A. S.; ORTUÑo, B. H.; PAIXÃO-BARRADAS, S. Fibra vegetal amazônica de tucumã-i (Astrocaryum acaule) para a aplicação têxtil: Uma análise de opiniões. Revista Acta Agronómica. Universidad Nacional de Colombia. Palmira - Colombia. ISSN: 0120-2812, JCR - 0.034 
- $\quad$ PACHECO, K. M. M.; VICENTE, B. A.; ORTUÑO, B. H..; PAIXÃOBARRADAS, S.; PACHECO, A. S.; CASTRO. D. F. Atributos necessários à fabricação de produtos semi-industriais a partir do uso da fibra natural amazônica de tucumã-i (Astrocaryum acaule): Uma segmentação de mercado. Revista Gestão \& Produção. Universidade de São Carlos - UFSCar. São Carlos/São Paulo - Brasil. ISSN: 0104530X, JCR - 0.1485

\section{Firma}

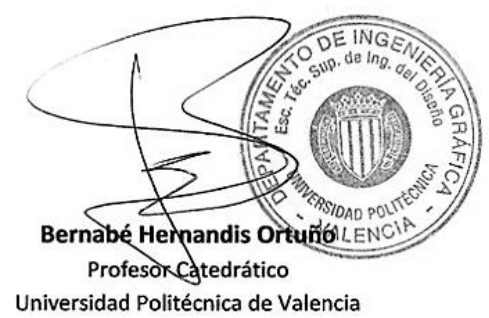

Bernabe Hernandis Ortuño

Valencia, 23 de Enero de 2012 



\section{MODELO DE ACEPTACIÓN DE LOS COAUTORES} (Doctores y no Doctores)

BEGOÑA AGUDO VICENTE, con el DNI/Passaport n $n^{\circ} 19999405 \mathrm{P}$ nacido/a el 25/12/1968 y con domicilio y con domicilio en Valencia,calle Plaza Santa Urzula, núm. 3, puerta 7,código postal 46001, ciudad y país Valencia, España, telefono 652038221,e-mail bagudo405p@cv.gva.es.

\section{MANIFIESTO QUE}

I Como COAUTOR NO DOCTOR, estoy informado/a que el/la señor/a KARLA MAZARELO MACIEL PACHECO quiere solicitar la autorització a la Comisión de Doctorado de la Universitat Politècnica de València para la presentación de su tesis doctoral en forma de compendio de publicaciones y que hago la renuncia como coautor a la presentación de los trabajos como parte de otra tesis doctoral

II. Com a COAUTOR DOCTOR, estoy informado/a que el/la señor/a

quiere solicitar la autorització a la Comisión de Doctorado de la Universitat Politècnica de València para la presentación de su tesis doctoral en forma de compendio de publicaciones

\section{$\mathrm{Y}$, a este efecto}

\section{HAGO CONSTAR}

- PACHECO, K. M. M.; ORTUÑO, B. H.; MIRANDA, I. P. A.; NASCIMENTO, C. C.; VICENTE, B. A. Análise da apreciação de consumidores sobre o uso semi-industrial da fibra vegetal amazônica de tucumã-i (Astrocaryum acaule) para o desenvolvimento de produtos: Um estudo de mercado. Revista INGEPRO - Inovação, Gestão e Produção, Set. vol. 03, nº. 09, (p.44-51) - Universidade Federal de Santa Maria - UFSM. Santa Maria- RS, 2011. ISSN: 1984-6193.

- PACHECO, K. M. M.; VICENTE, B. A.; PACHECO, A. S.; ORTUÑO, B. H.; PAIXÃO-BARRADAS, S. Fibra vegetal amazônica de tucumã-i (Astrocaryum acaule) para a aplicação têxtil: Uma análise de opiniões. Revista Acta Agronómica. Universidad Nacional de Colombia. Palmira - Colombia. ISSN: 0120-2812, JCR - 0.034 
- PACHECO, K. M. M.; VICENTE, B. A.; ORTUÑO, B. H.; PAIXÃOBARRADAS, S.; PACHECO, A. S.; CASTRO. D. F. Atributos necessários à fabricação de produtos semi-industriais a partir do uso da fibra natural amazônica de tucumã-i (Astrocaryum acaule): Uma segmentação de mercado. Revista Gestão \& Produção. Universidade de São Carlos - UFSCar. São Carlos/São Paulo - Brasil. ISSN: 0104530X, JCR -0.1485

Firma

Begoña Agudo Vicente

Valencia, 23 de Enero de 2012 


\section{MODELO DE ACEPTACIÓN DE LOS COAUTORES (Doctores y no Doctores)}

SUSANA PAIXÃO PEREIRA MESTRE BARRADAS, con el DNI/Passaport $n^{\circ}$ 11315039 nacido/a el 12/08/1978 y con domicilio en la Avd. Blasco Ibañéz, núm. 149, piso 3 y puerta 17,código postal 46022, ciudad y país, Valencia/España. telefono (0034) 600763080,e-mail supaipe@upvnet.upv.es

\section{MANIFIESTO QUE}

I Como COAUTOR NO DOCTOR, estoy informado/a que el/la señor/a KARLA MAZARELO MACIEL PACHECO quiere solicitar la autorització a la Comisión de Doctorado de la Universitat Politècnica de València para la presentación de su tesis doctoral en forma de compendio de publicaciones y que hago la renuncia como coautor a la presentación de los trabajos como parte de otra tesis doctoral

II. Com a COAUTOR DOCTOR, estoy informado/a que el/la señor/a

quiere solicitar la autorització a la Comisión de Doctorado de la Universitat Politècnica de València para la presentación de su tesis doctoral en forma de compendio de publicaciones

\section{$Y$, a este efecto}

\section{HAGO CONSTAR}

Que acepto que se utilicen el/los trabajo/s:

- $\quad$ PACHECO, K. M. M.; ORTUÑO, B. H.; MIRANDA, I. P. A.; PAIXÃO-

BARRADAS, S. Atributos del diseño para el proceso de transformación y uso de la fibra natural amazónica de tucumã-i (Astrocaryum acaule) en el desarrollo de productos semi-industriales. Revista Icono Facto Revista de la Escuela de Arquitectura y Diseño. Universidad Pontificia Bolivariana. Volumen 7, número 8, Medellín - Colombia, Diciembre. 2011. ISSN: 1900-2785

- $\quad$ PACHECO, K. M. M.; ORTUÑO, B. H.; PAIXÃO-BARRADAS, S.;

PACHECO, A. S. La importancia del diseño sistémico para la competitividad de la fibra natural Amazónica de tucumã-i (Astrocaryum acaule) en el desarrollo semi-industrial de productos: Un estudio 
decaso para la categoría del vestuario. $2^{\circ}$ Congreso Internacional de Diseño e Innovación. Escuela Superior de Diseño ESDi. Universitat Ramon Llull - URL. Sabadell/ Barcelona - España, 2012. ISBN: 978-84936165-1-9

- PACHECO, K. M. M.; VICENTE, B. A.; PACHECO, A. S.; ORTUÑO, B. H.; PAIXÃO-BARRADAS, S. Fibra vegetal amazônica de tucumã-i (Astrocaryum acaule) para a aplicação têxtil: Uma análise de opiniões. Revista Acta Agronómica. Universidad Nacional de Colombia. Palmira - Colombia. ISSN: 0120-2812, JCR - 0.034

- PACHECO, K. M. M.; VICENTE, B. A.; ORTUÑO, B. H.; PAIXÃOBARRADAS, S.; PACHECO, A. S.; CASTRO. D. F. Atributos necessários à fabricação de produtos semi-industriais a partir do uso da fibra natural amazônica de tucumã-i (Astrocaryum acaule): Uma segmentação de mercado. Revista Gestão \& Produção. Universidade de São Carlos - UFSCar. São Carlos/São Paulo - Brasil. ISSN: 0104$530 X$, JCR -0.1485

Firma

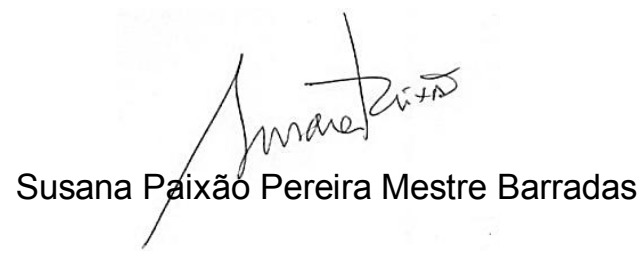

Valencia, 23 de Enero de 2012 


\section{MODELO DE ACEPTACIÓN DE LOS COAUTORES} (Doctores y no Doctores)

ALMIR DE SOUZA PACHECO, con el DNI/Passaport no Y0539977 C nacido/a el 12/03/196 y con domicilio en Valencia, calle Del Poeta Mas y Ros, núm. 42, puerta 10, código postal 46022, ciudad y país Valencia, España, telefono 638541531 ,e-mail almirdesigner@gmail.com,

\section{MANIFIESTO QUE}

I Como COAUTOR NO DOCTOR, estoy informado/a que el/la señor/a KARLA MAZARELO MACIEL PACHECO quiere solicitar la autorització a la Comisión de Doctorado de la Universitat Politècnica de València para la presentación de su tesis doctoral en forma de compendio de publicaciones y que hago la renuncia como coautor a la presentación de los trabajos como parte de otra tesis doctoral

II. Com a COAUTOR DOCTOR, estoy informado/a que el/la señor/a quiere solicitar la autorització a la Comisión de Doctorado de la Universitat Politècnica de València para la presentación de su tesis doctoral en forma de compendio de publicaciones

$\mathrm{Y}$, a este efecto

\section{HAGO CONSTAR}

Que acepto que se utilicen el/los trabajo/s:

- PACHECO, K. M. M.; ORTUÑO, B. H.; PACHeCo, A. S. Análise do posicionamento de especialistas sobre o uso da fibra natural amazônica de tucumã-i (Astrocaryum acaule) para o desenvolvimento de produtos semiindustriais. Anais do III Simpósio Brasileiro de Design Sustentável (III SBDS) - Proceedings of the 3rd International Symposium on Sustainable Design (ISSD). Editora Universitária - UFPE. Pernambuco - RE, 2011. ISBN: 978.85.7315.949-3

- PACHECO, K. M. M.; ORTUÑO, B. H.; MIRANDA, I. P. A.; NASCIMENTO, C. C.; PACHECO, A. S. Oportunidades e limitações do 
uso da fibra natural de tucumã-i (Astrocaryum acaule) para a gestão e desenvolvimento de produtos semi-industriais. Anais do $8^{\circ}$ Congresso Brasileiro de Gestão de Desenvolvimento de Produto (CBGDP). UFRGS/FEEng. Porto Alegre - RS. 2011. ISBN:978-85-88085-46-6 (Resumo) e ISBN:85-88085-47-3 (Artigo Completo).

- PACHECO, K. M. M.; ORTUÑO, B. H.; PAIXÃO-BARRADAS, S.; PACHECO, A. S. La importancia del diseño sistémico para la competitividad de la fibra natural Amazónica de tucumã-i (Astrocaryum acaule) en el desarrollo semi-industrial de productos: Un estudio de caso para la categoría del vestuario. $2^{\circ}$ Congreso Internacional de Diseño e Innovación. Escuela Superior de Diseño ESDi. Universitat Ramon Llull - URL. Sabadell/ Barcelona - España, 2012. ISBN: 978-84936165-1-9.

- PACHECO, K. M. M.; VICENTE, B. A.; PACHECo, A. S.; ORTUÑO, B. H.; PAIXÃO-BARRADAS, S. Fibra vegetal amazônica de tucumã-i (Astrocaryum acaule) para a aplicação têxtil: Uma análise de opiniões. Revista Acta Agronómica. Universidad Nacional de Colombia. Palmira - Colombia. ISSN: 0120-2812, JCR - 0.034

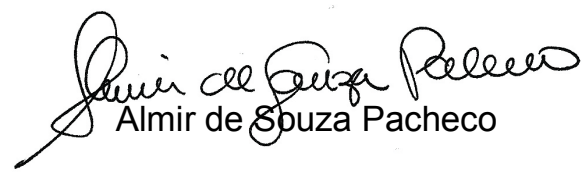

Valencia, 23 de Enero de 2012 


\section{MODELO DE ACEPTACIÓN DE LOS COAUTORES} (Doctores y no Doctores)

Dra. CLAUDETE CATANHEDE DO NASCIMENTO, con el CPF $n^{\circ}$ 160.446.142-04 y con dirección institucional: Av. André Araújo, núm. 2936 Aleixo. código postal 69060-001, ciudad y país Manaus-Amazonas, Brasil, telefono 005592 3643-3659,e-mail: catanhed@inpa.gov.br

\section{MANIFIESTO QUE}

I Como COAUTOR NO DOCTOR, estoy informado/a que el/la señor/a KARLA MAZARELO MACIEL PACHECO quiere solicitar la autorització a la Comisión de Doctorado de la Universitat Politècnica de València para la presentación de su tesis doctoral en forma de compendio de publicaciones y que hago la renuncia como coautor a la presentación de los trabajos como parte de otra tesis doctoral

II. Com a COAUTOR DOCTOR, estoy informado/a que el/la señor/a

quiere solicitar la autorització a la Comisión de Doctorado de la Universitat Politècnica de València para la presentación de su tesis doctoral en forma de compendio de publicaciones

\section{$Y$, a este efecto}

\section{HAGO CONSTAR}

Que acepto que se utilicen el/los trabajo/s:

- $\quad$ PACHECO, K. M. M.; ORTUÑO, B. H.; MIRANDA, I. P. A.;

NASCIMENTO, C. C.; PACHECO, A. S. Oportunidades e limitações do uso da fibra natural de tucumã-i (Astrocaryum acaule) para a gestão e desenvolvimento de produtos semi-industriais. Anais do $8^{\circ}$ Congresso Brasileiro de Gestão de Desenvolvimento de Produto (CBGDP).

UFRGS/FEEng. Porto Alegre - RS. 2011. ISBN:978-85-88085-46-6 (Resumo) e ISBN:85-88085-47-3 (Artigo Completo).

- $\quad$ PACHECO, K. M. M.; ORTUÑO, B. H.; MIRANDA, I. P. A.; NASCIMENTO, C. C.; VICENTE, B. A. Análise da apreciação de consumidores sobre o uso semi-industrial da fibra vegetal amazônica de tucumã-i (Astrocaryum acaule) para o desenvolvimento de produtos: 
Estudio de la prospección del uso de la fibra de tucumã-i (Astrocaryum acaule) para el desarrollo de productos semi-industriales

Um estudo de mercado. Revista INGEPRO - Inovação, Gestão e Produção, Set. vol. 03, n. 09, (p.44-51) - Universidade Federal de Santa Maria - UFSM. Santa Maria- RS, 2011. ISSN: 1984-6193.

Firma

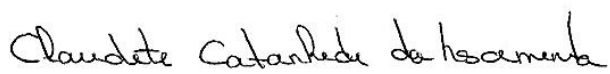

Claudete Catanhede do Nacimento

Valencia, 23 de Enero de 2012 


\section{MODELO DE ACEPTACIÓN DE LOS COAUTORES} (Doctores y no Doctores)

Dra. IRES PAULA DE ANDRADE MIRANDA, con el CPF nº 027.130.392-15 y con dirección institucional: Av. André Araújo, núm. 2936 - Aleixo. código postal 69060-001, ciudad y país Manaus-Amazonas, Brasil, telefono 005592 36433108 ,e-mail: ires@inpa.gov.br

\section{MANIFIESTO QUE}

I Como COAUTOR NO DOCTOR, estoy informado/a que el/la señor/a KARLA MAZARELO MACIEL PACHECO quiere solicitar la autorització a la Comisión de Doctorado de la Universitat Politècnica de València para la presentación de su tesis doctoral en forma de compendio de publicaciones y que hago la renuncia como coautor a la presentación de los trabajos como parte de otra tesis doctoral

II. Com a COAUTOR DOCTOR, estoy informado/a que el/la señor/a

quiere solicitar la autorització a la Comisión de Doctorado de la Universitat Politècnica de València para la presentación de su tesis doctoral en forma de compendio de publicaciones

\section{$Y$, a este efecto}

\section{HAGO CONSTAR}

Que acepto que se utilicen el/los trabajo/s:

- $\quad$ PACHECO, K. M. M.; ORTUÑO, B. H.; MIRANDA, I. P. A. Análise do posicionamento do design quanto ao uso semi-industrial da fibra amazônica de tucumã-i (Astrocaryum acaule) para a fabricação de

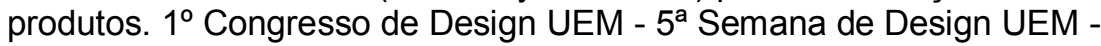
Design brasileiro: cultura ou influência?. Universidade Estadual de Maringá - UEM. Campus Regional de Cianorte - Paraná, 2011b. ISSN: 2237-0862

- $\quad$ PACHECO, K. M. M.; ORTUÑO, B. H.; MIRANDA, I. P. A.;

NASCIMENTO, C. C.; PACHECO, A. S. Oportunidades e limitações do uso da fibra natural de tucumã-i (Astrocaryum acaule) para a gestão e desenvolvimento de produtos semi-industriais. Anais do $8^{\circ}$ Congresso 
Brasileiro de Gestão de Desenvolvimento de Produto (CBGDP).

UFRGS/FEEng. Porto Alegre - RS. 2011. ISBN:978-85-88085-46-6 (Resumo) e ISBN:85-88085-47-3 (Artigo Completo).

- PACHECO, K. M. M.; ORTUÑO, B. H.; MIRANDA, I. P. A.; NASCIMENTO, C. C.; VICENTE, B. A. Análise da apreciação de consumidores sobre o uso semi-industrial da fibra vegetal amazônica de tucumã-i (Astrocaryum acaule) para o desenvolvimento de produtos: Um estudo de mercado. Revista INGEPRO - Inovação, Gestão e Produção, Set. vol. 03, n. 09, (p.44-51) - Universidade Federal de Santa Maria - UFSM. Santa Maria- RS, 2011. ISSN: 1984-6193.

- PACHECO, K. M. M.; ORTUÑO, B. H.; MIRANDA, I. P. A.; PAIXÃOBARRADAS, S. Atributos del diseño para el proceso de transformación y uso de la fibra natural amazónica de tucumã-i (Astrocaryum acaule) en el desarrollo de productos semi-industriales. Revista Icono Facto Revista de la Escuela de Arquitectura y Diseño. Universidad Pontificia Bolivariana. Volumen 7, número 8, Medellín - Colombia, Diciembre. 2011. ISSN: $1900-2785$

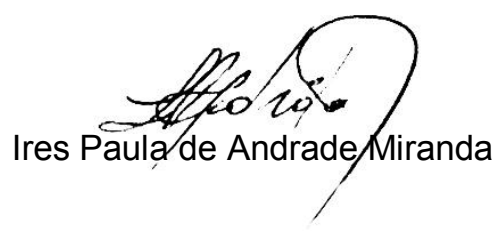

Valencia, 23 de Enero de 2012 